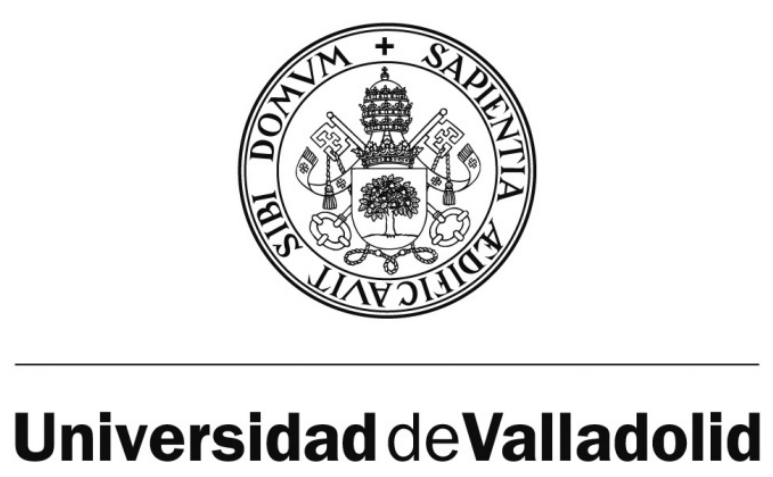

ESCUELA TÉCNICA SUPERIOR DE INGENIERIAS AGRARIAS

DEPARTAMENTO DE PRODUCCIÓN VEGETAL Y RECURSOS FORESTALES

TESIS DOCTORAL:

\title{
UTILIZACIÓN DE MEDIDAS DE FLUORESCENCIA DE LA CLOROFILA PARA MONITORIZAR EL ESTADO NUTRICIONAL Y ESTIMAR EL POTENCIAL ENOLÓGICO EN VIÑEDOS AFECTADOS POR CLOROSIS FÉRRICA
}

\author{
Presentada por Álvaro Catalina Tomás para optar \\ al grado de doctor por la Universidad de Valladolid
}

Dirigida por: Pedro Martín Peña y María Rosa González García 



\section{ÍNDICE GENERAL}

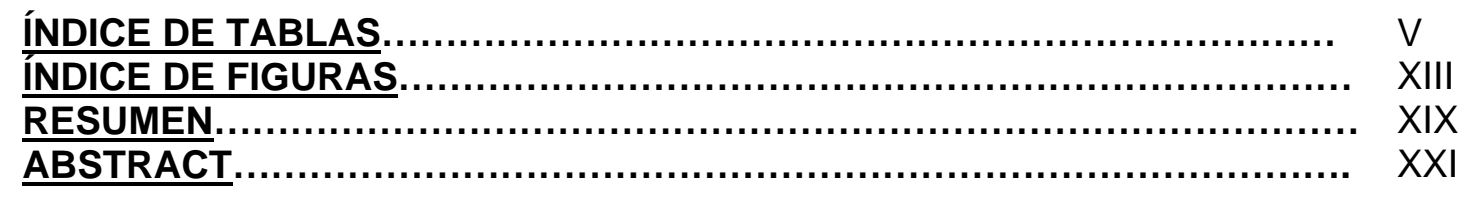

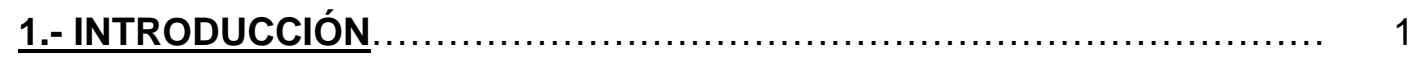

1.1.- La nutrición mineral del viñedo; impacto en el comportamiento agronómico y en la calidad de la uva.

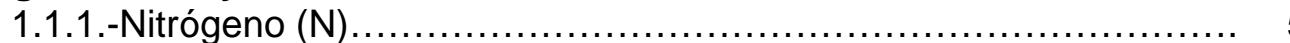

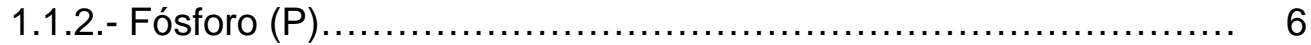

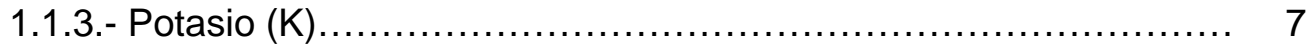

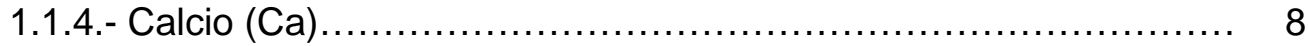

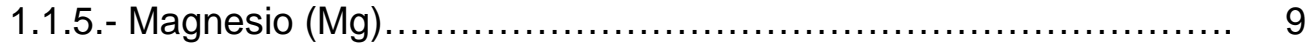

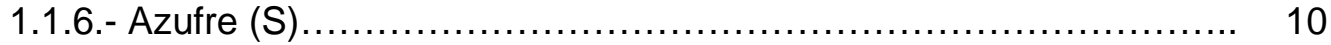

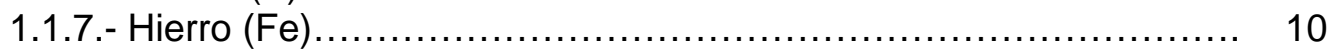

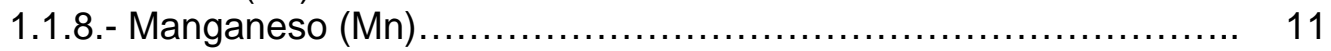

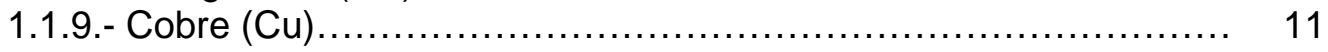

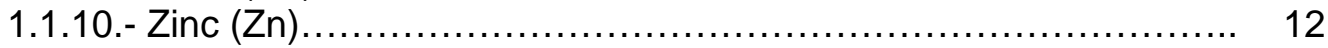

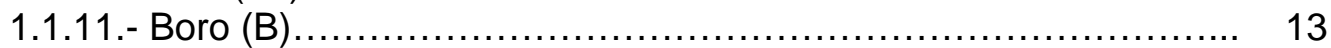

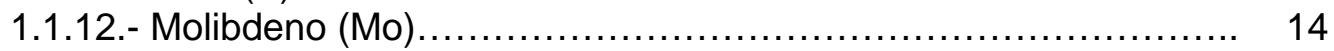

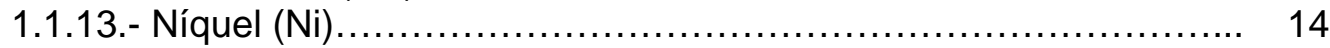

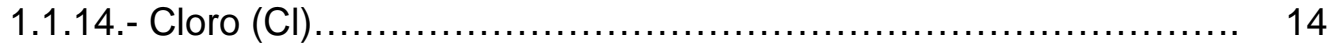

1.2.- Problemática nutricional del viñedo en suelos calizos ............... 16

1.2.1.- Propiedades físicas............................................ 17

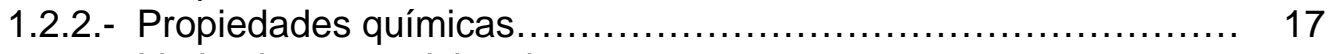

1.2.3.- Limitaciones nutricionales ................................. 19

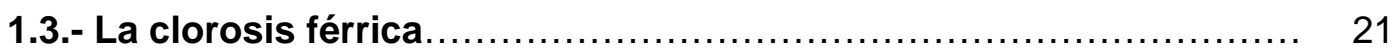

1.3.1.- Síntomas de la clorosis férrica ................................. 21

1.3.2.- El hierro en el sistema suelo-planta............................... 22

1.3.2.1.- El hierro en el suelo..................................... 22

1.3.2.2.- Asimilación del hierro por la planta.......................... 24

1.3.2.3.- Respuesta de las plantas a la deficiencia de hierro........... 25

1.3.2.4.- Transporte del hierro en la planta............................. 29

1.3.2.5.- Funciones del hierro en la planta.......................... 30

1.3.3.- Propiedades del suelo que influyen en la clorosis férrica........... 32

1.3.3.1.- Formas de hierro en el suelo................................ 32

1.3.3.2.- $\mathrm{pH}$ del suelo............................................ 33

1.3.3.3.- Carbonatos e ión bicarbonato............................... 34

1.3.3.4.- Presencia de sustancias complejantes: materia orgánica y actividad microbiana............................................. 35

1.3.3.5.- Interacción del hierro con otros elementos................... 36

1.3.3.6.- Otros factores................................................. 41

1.3.4.- Efecto de la clorosis férrica en la planta......................... 42

1.3.4.1.- Pigmentos foliares........................................ 42

1.3.4.2.- Aparato fotosintético ...................................... 43 
1.3.4.3.- Vigor, rendimiento y calidad de la uva....................... 44

1.3.5.- Métodos de diagnostico de la clorosis férrica...................... 46

1.3.6.- Prevención y métodos de corrección............................. 47

1.4.- Parámetros de fluorescencia clorofílica. Aplicaciones para la detección y seguimiento de situaciones de estrés nutricional.......... 51

1.4.1.- El efecto Kautsky............................................. 52

1.4.2.- Parámetros de la fluorescencia.................................... 53

1.4.3.- Fuentes de error............................................... 55

1.4.4.- Medida de la eficiencia fotosintética a través de la fluorescencia clorofílica............................................................. 56

1.4.5.- Detección de estrés nutricional mediante parámetros de fluorescencia...................................................... 58

1.4.6.- Aplicaciones en viticultura de precisión........................... 59

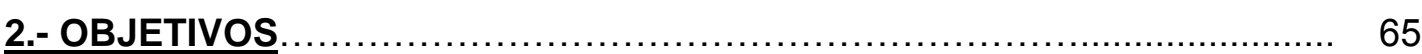

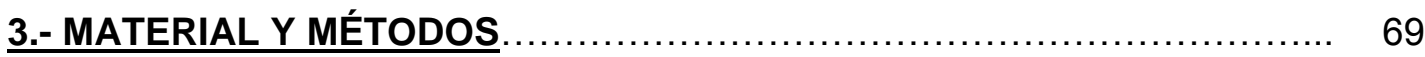

3.1.- Diseño experimental.............................................. 69

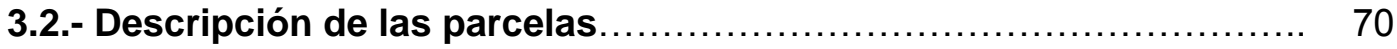

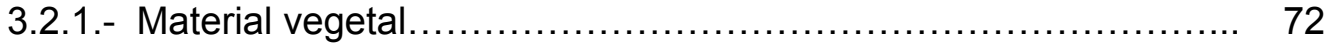

3.2.2.- Características edáficas...................................... 74

3.2.3.- Meteorología y seguimiento fenológico........................ 76

3.3.- Controles y Observaciones. ..................................... 80

3.3.1.- Contenido de elementos minerales en peciolos.................. 80

3.3.2.- Contenido de pigmentos foliares.............................. 81

3.3.2.1.- Determinación del nivel de clorofila foliar en campo........... 81

3.3.2.2.- Determinación de las clorofilas, carotenoides y antocianinas en el laboratorio.................................................. 82

3.3.3.- Asimilación neta y conductancia estomática....................... 84

3.3.4.- Medidas de la fluorescencia de la clorofila a nivel de hoja.......... 86

3.3.5.- Parámetros de vigor y desarrollo vegetativo........................ 88

3.3.6.- Rendimiento y sus componentes................................ 89

3.3.7.- Análisis físico-químicos de las bayas........................... 90

3.3.7.1.- Composición de los mostos.............................. 90

3.3.7.1.1.- Contenido en sólidos solubles (SST) ................... 91

3.3.7.1.2.- $\mathrm{pH}$ y acidez total (AT) ............................... 91

3.3.7.1.3.- Nitrógeno fácilmente asimilable (NFA)................. 92

3.3.7.1.4.- Índice de polifenoles totales (IPT) ...................... 92

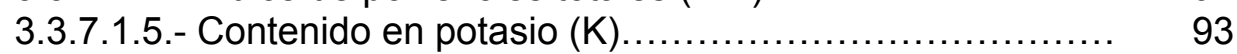

3.3.7.2.- Parámetros colorimétricos ................................. 93

3.3.7.3.- Madurez fenólica de la uva................................ 95

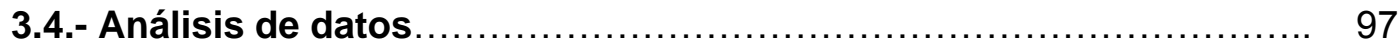

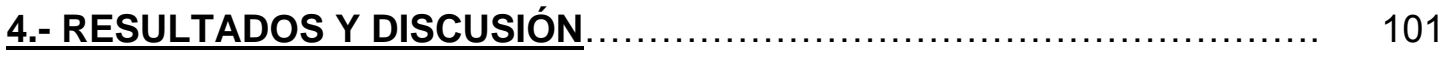

4.1.- Caracterización nutricional de las parcelas de estudio.............. 101

4.1.1.- Nutrientes minerales........................................ 105 
4.1.1.1.- Nitrógeno................................................. 105

4.1.1.2.- Fósforo..................................................... 105

4.1.1.3.- Potasio....................................................... 106

4.1.1.4.- Magnesio.................................................. 108

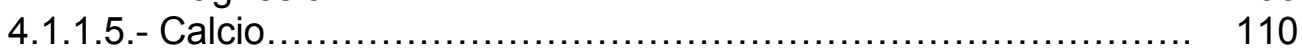

4.1.1.6.- Hierro.................................................... 111

4.1.1.7.- Cobre.................................................... 112

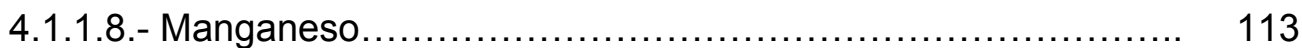

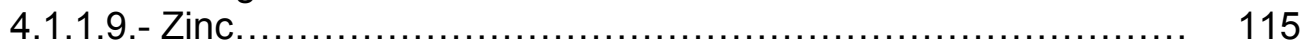

4.1.1.10.- Boro................................................... 116

4.1.2.- Relación entre las características físico-químicas del suelo y la composición mineral de los peciolos................................ 117

4.2.- Niveles foliares de clorofilas, carotenoides y antocianinas.......... 124

4.2.1.- Evolución estacional de los contenidos foliares de clorofila........ 124

4.2.2.- Relación entre el estado nutricional y los contenidos foliares de pigmentos.

4.2.3.- Diagnóstico de la clorosis férrica............................. 139

4.3.- Parámetros de eficiencia fotosintética............................. 142

4.3.1.- Relación entre el estado nutricional del viñedo y la asimilación neta, conductancia estomática y parámetros de la fluorescencia de la clorofila.

4.3.2.- Relación del contenido en pigmentos foliares del viñedo con la asimilación neta, conductancia estomática y los parámetros de fluorescencia de la clorofila.

4.3.3.- Influencia del estado nutricional de los viñedos sobre los parámetros de la fluorescencia de la clorofila foliar.

4.4.- Desarrollo vegetativo, rendimiento del viñedo y calidad de la uva...

4.4.1.- Efectos del estado nutricional del viñedo en los parámetros del vigor y rendimiento del viñedo.

4.4.1.1.- Parámetros de vigor.

4.4.2.- Efectos del estado nutricional del viñedo en la composición de la

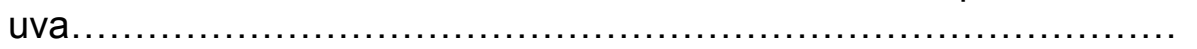

4.4.2.1.- Composición del mosto.

4.4.2.2.- Características cromáticas...................................

4.4.2.3.- Madurez fenólica de las bayas................................. 199

4.5.- Utilización de parámetros de fluorescencia de la clorofila para la estimación del vigor, rendimiento y del potencial enológico de viñedos con diferente estado nutricional.

4.5.1.- Parámetros de vigor.

4.5.2.- Parámetros de rendimiento.................................... 215

4.5.3.- Composición del mosto........................................ 221

4.5.4.- Características cromáticas del mosto............................ 227

4.5.5.- Madurez fenólica de las bayas................................ 230 



\section{ÍNDICE DE TABLAS}

Tabla 3.1. Localización, marcos de plantación y años de seguimiento de las subparcelas de viñedo

Tabla 3.2. Resumen de las principales características del patrón 110-Richter (Hidalgo, 1999).

Tabla 3.3. Parámetros físico-químicos determinados en los suelos, métodos de extracción y unidades de concentración empleados....

Tabla 3.4. Datos mensuales de temperatura media ( $T$ ), media de las máximas $(\mathrm{TM})$ y media de las mínimas $(\mathrm{Tm})$ en ${ }^{\circ} \mathrm{C}$ y precipitación $(P)$ en $\mathrm{mm}$, recogidos durante los tres años de estudio en la estación meteorológica de Valbuena de Duero (VA-07)..............

Tabla 3.5. Valores de evapotranspiración potencial (ETP) calculada por el método Penman-Monteith y de precipitación efectiva $(\mathrm{Pe})$, recogidos en la estación meteorológica de Valbuena de Duero (VA-07) para los tres años de estudio....

Tabla 3.6. Fechas de los estados fenológicos más destacados registradas en los tres años de ensayo.

Tabla 3.7. Niveles nutricionales de referencia de los peciolos en el estado fenológico de envero para el diagnóstico foliar del viñedo cv. Tempranillo en la Ribera del Duero (González y Martín, 2005)......

Tabla 3.8. $\quad$ Fechas de las medidas del contenido en clorofila realizadas de 9 a $12 \mathrm{~h}$

Tabla 3.9. Fechas de muestreo para las medidas del contenido de clorofilas, carotenoides y antocianinas foliares...

Tabla 3.10. Fechas de las medidas de las variables de intercambio de gases y fluorescencia de la clorofila....

Tabla 4.1. Características físico-químicas de los suelos de viñedo en el conjunto de las zonas de estudio.

Tabla 4.2. Interpretación de los niveles de las características físico-químicas de los suelos en el conjunto de zonas de estudio

Tabla 4.3. Valores de $\mathrm{F}$ de Fisher y nivel de significación del análisis de la varianza (ANOVA) de los contenidos peciolares de nutrientes en el envero en función de los años de estudio.

Tabla 4.4. Composición mineral de las muestras de tejido peciolar de vides tomadas en los viñedos estudiados en el estado fenológico de envero 
Tabla 4.5. Coeficiente de determinación $\left(R^{2}\right)$, nivel de significación y pendiente de la regresión del contenido en $\mathrm{P}, \mathrm{Mg}, \mathrm{Mn}$ y los ratios $\mathrm{Ca} / \mathrm{P}$ y Fe/Mn de los peciolos en el envero sobre el porcentaje de arcilla del suelo.

Tabla 4.6. Coeficiente de determinación $\left(R^{2}\right)$, nivel de significación y pendiente de la regresión de la composición mineral y los ratios $\mathrm{Ca} / \mathrm{P}, \mathrm{K} / \mathrm{Mg}, \mathrm{K} / \mathrm{Ca}, \mathrm{K} /(\mathrm{Ca}+\mathrm{Mg}), \mathrm{Ca} / \mathrm{Mg}$ y $\mathrm{Fe} / \mathrm{Mn}$ de los peciolos en el envero sobre el contenido en carbonatos totales del suelo.

Tabla 4.7. Coeficiente de determinación $\left(R^{2}\right)$, nivel de significación y pendiente de la regresión del contenido mineral del suelo sobre el contenido mineral de los peciolos en el envero para cada elemento entre sí mismo.

Tabla 4.8. Coeficiente de determinación (R2), nivel de significación y pendiente de la regresión del contenido de $\mathrm{K}$ y los ratios $\mathrm{K} / \mathrm{Mg}$, $\mathrm{K} / \mathrm{Ca}$ y $\mathrm{K} /(\mathrm{Ca}+\mathrm{Mg})$ en el suelo sobre el contenido en $\mathrm{P}, \mathrm{Ca}, \mathrm{Mg}(\%$ s.m.s.), $\mathrm{Fe}$ (mg.kg ${ }^{-1}$ s.m.s.) y los ratios $\mathrm{Ca} / \mathrm{P}$ y $\mathrm{P} / \mathrm{Fe}$ de los peciolos en el envero

Tabla 4.9. Coeficiente de determinación $\left(R^{2}\right)$, nivel de significación y pendiente de la regresión del contenido de $\mathrm{Mg}$ y $\mathrm{Mn}$ en los peciolos en el envero sobre el nivel de $\mathrm{Mg}, \mathrm{Mn}$ y los ratios $\mathrm{CT} / \mathrm{Mg}$, $\mathrm{CT} / \mathrm{Mn}$ y $\mathrm{Mg} / \mathrm{Mn}$ del suelo.

Tabla 4.10. Valores de la $\mathrm{F}$ de Fisher y el nivel de significación del análisis de la varianza (ANOVA) de los contenidos foliares de clorofila, antocianinas y carotenoides en cuajado y envero en función de los años de estudio

Tabla 4.11. Coeficiente de determinación $\left(R^{2}\right)$, nivel de significación y pendiente de la regresión de la concentración de los diferentes pigmentos foliares $\left(\mu \mathrm{g} \cdot \mathrm{cm}^{-2}\right)$, y relaciones entre ellos, sobre el contenido en arcilla en el suelo.

Tabla 4.12. Coeficiente de determinación $\left(R^{2}\right)$, nivel de significación y pendiente de la regresión de los carbonatos totales (\%) sobre el contenido de pigmentos foliares y sus ratios $\left(\mathrm{mg} \cdot \mathrm{cm}^{-2}\right)$...

Tabla 4.13. Coeficiente de determinación $\left(R^{2}\right)$, nivel de significación y pendiente de la regresión del contenido en $\mathrm{K}$ y los ratios $\mathrm{K} / \mathrm{Mg}$, $\mathrm{K} / \mathrm{Ca}$ y $\mathrm{K} /(\mathrm{Ca}+\mathrm{Mg})$ en el suelo sobre la concentración de pigmentos foliares $\left(\mu \mathrm{g} \cdot \mathrm{cm}^{-2}\right)$ y los ratios clorofila $(a+b) / c a r o t e n o i d e s$ y clorofila $a / c l o r o f i l a ~ b$ en el cuajado, envero y postvendimia en los tres años de estudio.

Tabla 4.14. Coeficiente de determinación $\left(R^{2}\right)$, nivel de significación y pendiente de la regresión del contenido en $\mathrm{K}$ y los ratios $\mathrm{K} / \mathrm{Mg}$, $\mathrm{K} / \mathrm{Ca}$ y $\mathrm{K} /(\mathrm{Ca}+\mathrm{Mg})$ en el los peciolos sobre la concentración de pigmentos foliares $\left(\mu \mathrm{g} \cdot \mathrm{cm}^{-2}\right)$ y los ratios clorofila

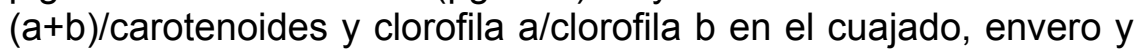
postvendimia en los tres años de estudio. 
Tabla 4.15. Coeficiente de determinación $\left(R^{2}\right)$, nivel de significación y pendiente de la regresión del contenido de $\mathrm{Mg}$ peciolar en el envero sobre la concentración de pigmentos foliares y sus ratios $\left(\mathrm{mg} \cdot \mathrm{cm}^{-2}\right)$

Tabla 4.16. Coeficiente de determinación $\left(R^{2}\right)$, nivel de significación y pendiente de la regresión del contenido de $\mathrm{Mn}$ en el suelo sobre el contenido de pigmentos foliares y sus ratios $\left(\mathrm{mg} \cdot \mathrm{cm}^{-2}\right) \ldots \ldots \ldots \ldots$

Tabla 4.17. Coeficiente de determinación $\left(R^{2}\right)$, nivel de significación y pendiente de la regresión del contenido de $\mathrm{Mn}$ peciolar en el envero sobre la concentración de pigmentos foliares y sus ratios $\left(\mathrm{mg} \cdot \mathrm{cm}^{-2}\right)$

Tabla 4.18. Coeficiente de determinación $\left(R^{2}\right)$, nivel de significación y pendiente de la regresión de la concentración de clorofila foliar $\left(\mathrm{mg} \cdot \mathrm{cm}^{-2}\right)$ sobre diferentes ratios entre contenidos peciolares de nutrientes.

Tabla 4.19. Valores de la $F$ de Fisher y el nivel de significación del análisis de la varianza (ANOVA) de la asimilación neta (An), conductancia estomática (gs) y los parámetros de fluorescencia de la clorofila en el cuajado y el envero en función de los años de estudio.

Tabla 4.20. Coeficiente de determinación $\left(R^{2}\right)$, nivel de significación y pendiente de la regresión de la asimilación neta $\left(\mu \mathrm{mol} \mathrm{CO}_{2} \cdot \mathrm{m}^{-2} \mathrm{~s}^{-1}\right)$ y la conductancia estomática $\left(\mathrm{mmol} \mathrm{H}_{2} \mathrm{O} \cdot \mathrm{m}^{-2} \mathrm{~s}^{-1}\right)$ medidas en cuajado y envero sobre el contenido en nutrientes de suelo y peciolos.

Tabla 4.21. Coeficiente de determinación $\left(R^{2}\right)$, nivel de significación y pendiente de la regresión de los parámetro de fluorescencia de la clorofila medidos en cuajado y envero sobre el contenido en arcilla del suelo (\%).

Tabla 4.22. Coeficiente de determinación $\left(R^{2}\right)$, nivel de significación y pendiente de la regresión de los parámetro de fluorescencia de la clorofila medidos en cuajado y envero sobre el contenido en carbonatos totales del suelo (\%).

Tabla 4.23. Coeficiente de determinación $\left(R^{2}\right)$, nivel de significación y pendiente de la regresión de los parámetro de fluorescencia de la clorofila medidos en cuajado y envero sobre el contenido de $\mathrm{K}$ en el suelo $\left(\mathrm{mg} \cdot \mathrm{kg}^{-1}\right)$.

Tabla 4.24. Coeficiente de determinación $\left(R^{2}\right)$, nivel de significación y pendiente de la regresión de los parámetro de fluorescencia de la clorofila medidos en cuajado y envero sobre el contenido de $\mathrm{Mg}$ en el suelo $\left(\mathrm{meq} \cdot 100 \mathrm{~g}^{-1}\right)$.

Tabla 4.25. Coeficiente de determinación $\left(R^{2}\right)$, nivel de significación y pendiente de la regresión de los parámetro de fluorescencia de la clorofila medidos en cuajado y envero sobre el contenido de $\mathrm{Mg}$ en los peciolos (\% s.m.s.). 
Tabla 4.26. Coeficiente de determinación $\left(R^{2}\right)$, nivel de significación y pendiente de la regresión de los parámetro de fluorescencia de la clorofila medidos en cuajado y envero sobre el contenido de $\mathrm{Mn}$ en el suelo $\left(\mathrm{mg} \cdot \mathrm{kg}^{-1}\right)$.

Tabla 4.27. Coeficiente de determinación $\left(R^{2}\right)$, nivel de significación y pendiente de la regresión de los parámetro de fluorescencia de la clorofila medidos en cuajado y envero sobre el contenido de $\mathrm{Mn}$

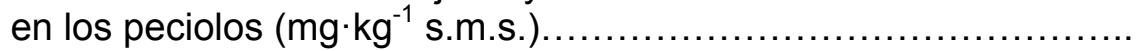

Tabla 4.28. Coeficiente de determinación $\left(R^{2}\right)$, nivel de significación y pendiente de la regresión de la asimilación neta $\left(\mu \mathrm{mol} \mathrm{CO}_{2} \cdot \mathrm{m}^{-2} \mathrm{~s}^{-1}\right)$ y la conductancia estomática $\left(\mathrm{mmol} \mathrm{H}_{2} \mathrm{O} \cdot \mathrm{m}^{-2} \mathrm{~s}^{-1}\right)$ medidas en cuajado y envero sobre el contenido en pigmentos de las hojas.

Tabla 4.29. Coeficiente de determinación $\left(R^{2}\right)$, nivel de significación y pendiente de la regresión de los parámetro de fluorescencia de la clorofila medidos en cuajado y envero sobre el contenido en clorofila a de las hojas $\left(\mu \mathrm{g} \cdot \mathrm{cm}^{-2}\right)$.....

Tabla 4.30. Coeficiente de determinación $\left(R^{2}\right)$, nivel de significación y pendiente de la regresión de los parámetro de fluorescencia de la clorofila medidos en cuajado y envero sobre el contenido en clorofila b de las hojas $\left(\mu \mathrm{g} \cdot \mathrm{cm}^{-2}\right)$......

Tabla 4.31. Coeficiente de determinación $\left(R^{2}\right)$, nivel de significación y pendiente de la regresión de los parámetro de fluorescencia de la clorofila medidos en cuajado y envero sobre el contenido en clorofila $\mathrm{a}+\mathrm{b}$ de las hojas $\left(\mu \mathrm{g} \cdot \mathrm{cm}^{-2}\right)$

Tabla 4.32. Coeficiente de determinación $\left(R^{2}\right)$, nivel de significación y pendiente de la regresión de los parámetro de fluorescencia de la clorofila medidos en cuajado y envero sobre el contenido en carotenoides de las hojas.

Tabla 4.33. Coeficiente de determinación $\left(R^{2}\right)$, nivel de significación y pendiente de la regresión de los parámetro de fluorescencia de la clorofila medidos en cuajado y envero sobre el contenido en antocianinas de las hojas $\left(\mu \mathrm{g} \cdot \mathrm{cm}^{-2}\right)$.

Tabla 4.34. Valores medios de diferentes parámetros de fluorescencia de la clorofila medidos en cuajado y envero en áreas de muestreo afectadas (C) y no afectadas (NC) por clorosis férrica.

Tabla 4.35. Valores de la $\mathrm{F}$ de Fisher y nivel de significación del análisis de la varianza (ANOVA) de los parámetros de vigor y rendimiento del viñedo en función de los años de estudio.

Tabla 4.36. Parámetros de superficie foliar, vigor y rendimiento en el conjunto de las zonas de viñedo en los tres años de seguimiento. 
Tabla 4.37. Valores de la $F$ de Fisher y nivel de significación del análisis factorial de la varianza (ANOVA) del peso de la madera de poda (PMP), el rendimiento (rto) y el índice de Ravaz (IR) en las áreas de estudio cloróticas (C) y no cloróticas (NC) y con distinto estado nutricional de $\mathrm{P}, \mathrm{K}, \mathrm{Mg}$ y $\mathrm{Cu}$.

Tabla 4.38. Coeficiente de determinación $\left(R^{2}\right)$, nivel de significación y pendiente de la regresión de los parámetros de vigor sobre el contenido mineral tanto en el suelo como en los peciolos en los tres años de estudio.

Tabla 4.39. Coeficiente de determinación $\left(R^{2}\right)$, nivel de significación y pendiente de la regresión del índice de área foliar y la superficie media de la hoja en cuajado y envero sobre el contenido mineral tanto en el suelo como en los peciolos en el envero en los tres años de estudio

Tabla 4.40. Valores medios de diferentes parámetros de vigor en áreas de muestreo afectadas (C) y no afectadas (NC) por clorosis férrica.

Tabla 4.41. Valores medios del índice de área foliar y superficie de la hoja en cuajado y envero para áreas de muestreo con diferente estado nutricional.

Tabla 4.42. Coeficiente de determinación $\left(R^{2}\right)$, nivel de significación y pendiente de la regresión de los parámetros de rendimiento sobre el contenido mineral tanto en el suelo como en los peciolos en los tres años de estudio.

Tabla 4.43. Valores medios del rendimiento, sus componentes y el índice de Ravaz en áreas de muestreo afectadas (C) y no afectadas (NC) por clorosis férrica

Tabla 4.44. Valores medios del rendimiento y sus componentes en áreas de muestreo con diferente estado nutricional

Tabla 4.45. Valores de la $\mathrm{F}$ de Fisher y nivel de significación del análisis de la varianza (ANOVA) de los parámetros físico-químicos del mosto en función de los años de estudio.

Tabla 4.46. Valores de los parámetros físico-químicos del mosto en el conjunto de las zonas de viñedo en los tres años de seguimiento.

Tabla 4.47. Coeficiente de determinación $\left(R^{2}\right)$, nivel de significación y pendiente de la regresión de los parámetros de composición del mosto sobre el contenido en arcilla, carbonatos totales (CT) y concentración de elementos minerales en el suelo.

Tabla 4.48. Coeficiente de determinación $\left(R^{2}\right)$, nivel de significación y pendiente de la regresión de los parámetros de composición del mosto sobre el contenido de nutrientes minerales en los peciolos. 
Tabla 4.49. Valores de la $F$ de Fisher y nivel de significación del análisis factorial de la varianza (ANOVA) de los parámetros físicoquímicos del mosto en función del nivel de afección de clorosis férrica $(\mathrm{CF})$ y el nivel nutricional de diversos nutrientes (nt), según diagnóstico realizado en los apartados 4.2.3. y 4.1 respectivamente.

Tabla 4.50. Valores medios de los parámetros físico-químicos del mosto en áreas de muestreo afectadas (C) y no afectadas (NC) por clorosis férrica.

Tabla 4.51. Coeficientes de correlación de Pearson ( $r$ ) entre el IPT y el contenido en SST con el rendimiento y sus componentes en los tres años de estudio.

Tabla 4.52. Valores medios de la composición del mosto para áreas de muestreo con diferente estado nutricional

Tabla 4.53. Coordenadas CIELAB e índice cromático de uvas tintas (Carreño et al., 1995) del mosto de vendimia en el conjunto de las zonas de estudio en los tres años de seguimiento.

Tabla 4.54. Coeficiente de determinación $\left(R^{2}\right)$, nivel de significación y pendiente de la regresión de las coordenadas CIELAB e índice cromático de uvas tintas (Carreño et al., 1995) del mosto de vendimia sobre el contenido en arcilla, carbonatos totales (CT) y concentración de elementos minerales en el suelo.

Tabla 4.55. Coeficiente de determinación $\left(R^{2}\right)$, nivel de significación y pendiente de la regresión de las coordenadas CIELAB e índice cromático de uvas tintas (Carreño et al., 1995) del mosto de vendimia sobre el contenido de nutrientes minerales en los peciolos.

Tabla 4.56. Valores medios de las coordenadas CIELAB e índice cromático de uvas tintas (Carreño et al., 1995) del mosto de vendimia en áreas de muestreo afectadas $(\mathrm{C})$ y no afectadas $(\mathrm{NC})$ por clorosis férrica....

Tabla 4.57. Valores medios de las coordenadas CIELAB e índice cromático de uvas tintas (Carreño et al., 1995) del mosto de vendimia para áreas de muestreo con diferente estado nutricional.

Tabla 4.58. Valores de parámetros de madurez fenólica de las bayas en el conjunto de las zonas de viñedo en los tres años de seguimiento.

Tabla 4.59. Coeficiente de determinación $\left(R^{2}\right)$, nivel de significación y pendiente de la regresión de los parámetros de madurez fenólica de las bayas sobre el contenido en arcilla, carbonatos totales (CT) y concentración de elementos minerales en el suelo. 
Tabla 4.60. Coeficiente de determinación $\left(R^{2}\right)$, nivel de significación y pendiente de la regresión de los parámetros de madurez fenólica de las bayas sobre el contenido de nutrientes minerales en los peciolos.

Tabla 4.61. Valores de la $F$ de Fisher y nivel de significación del análisis factorial de la varianza (ANOVA) de los parámetros de madurez fenólica de las bayas en función del nivel de afección de clorosis férrica (CF) y el nivel nutricional de diversos nutrientes (nt), según diagnóstico realizado en los apartados 4.2.3. y 4.1 respectivamente.

Tabla 4.62. Valores medios de la composición fenólica de las bayas en áreas de muestreo afectadas (C) y no afectadas (NC) por clorosis férrica.

Tabla 4.63. Valores medios de los parámetros de madurez fenólica de las bayas para áreas de muestreo con diferente estado nutricional

Tabla 4.64. Coeficiente de determinación $\left(R^{2}\right)$, nivel de significación y pendiente de la regresión de los parámetros de vigor sobre la clorofila foliar (Clo), las antocianinas foliares (Anth), la asimilación neta (An), la conductancia estomática (gs) y los parámetros de la fluorescencia de la clorofila en cuajado en los tres años de estudio.

Tabla 4.65. Coeficiente de determinación $\left(R^{2}\right)$, nivel de significación y pendiente de la regresión de los parámetros de vigor sobre la clorofila foliar (Clo), las antocianinas foliares (Anth), la asimilación neta (An), la conductancia estomática (gs) y los parámetros de la fluorescencia de la clorofila en envero en los tres años de estudio.

Tabla 4.66. Coeficiente de determinación $\left(R^{2}\right)$, nivel de significación y pendiente de la regresión de los parámetros de rendimiento sobre la clorofila foliar ( $\mathrm{Clo}$ ), las antocianinas foliares (Anth), la asimilación neta (An), la conductancia estomática (gs) y los parámetros de fluorescencia de la clorofila en cuajado en los tres años de estudio.

Tabla 4.67. Coeficiente de determinación $\left(R^{2}\right)$, nivel de significación y pendiente de la regresión de los parámetros de rendimiento sobre la clorofila foliar (Clo), las antocianinas foliares (Anth), la asimilación neta (An), la conductancia estomática (gs) y los parámetros de fluorescencia de la clorofila en envero en los tres años de estudio.

Tabla 4.68. Coeficiente de determinación $\left(R^{2}\right)$, nivel de significación y pendiente de la regresión de los parámetros físico-químicos de los mostos sobre la clorofila foliar (Clo), las antocianinas foliares (Anth), la asimilación neta (An), la conductancia estomática (gs) y los parámetro de fluorescencia de la clorofila medidos en cuajado en los tres años de estudio. 
Tabla 4.69. Coeficiente de determinación $\left(R^{2}\right)$, nivel de significación y pendiente de la regresión de los parámetros físico-químicos de los mostos sobre la clorofila foliar (Clo), las antocianinas foliares (Anth), la asimilación neta (An), la conductancia estomática (gs) y los parámetro de fluorescencia de la clorofila medidos en envero en los tres años de estudio.

Tabla 4.70. Coeficiente de determinación $\left(R^{2}\right)$, nivel de significación y pendiente de la regresión de los parámetros cromáticos del mosto sobre la clorofila foliar (Clo), las antocianinas foliares (Anth), la asimilación neta (An), la conductancia estomática (gs) y los parámetro de fluorescencia de la clorofila medidos en cuajado en los tres años de estudio.

Tabla 4.71. Coeficiente de determinación $\left(R^{2}\right)$, nivel de significación y pendiente de la regresión de los parámetros cromáticos del mosto sobre la clorofila foliar (Clo), las antocianinas foliares (Anth), la asimilación neta (An), la conductancia estomática (gs) y los parámetro de fluorescencia de la clorofila medidos en envero en los tres años de estudio

Tabla 4.72. Coeficiente de determinación $\left(R^{2}\right)$, nivel de significación y pendiente de la regresión de los parámetros de madurez fenólica de las bayas sobre la clorofila foliar (Clo), las antocianinas foliares (Anth), la asimilación neta (An), la conductancia estomática (gs) y los parámetro de fluorescencia de la clorofila medidos en cuajado en los tres años de estudio.

Tabla 4.73. Coeficiente de determinación $\left(R^{2}\right)$, nivel de significación y pendiente de la regresión de los parámetros de madurez fenólica de las bayas sobre la clorofila foliar (Clo), las antocianinas foliares (Anth), la asimilación neta (An), la conductancia estomática (gs) y los parámetro de fluorescencia de la clorofila medidos en envero en los tres años de estudio. 


\section{$\underline{\text { ÍNDICE DE FIGURAS }}$}

Figura 1.1 Hojas afectadas por clorosis férrica, a) tonalidades verde claro, que evolucionan a amarillento y los nervios permanecen verdes;

b) con aparición de manchas necróticas en los bordes.............. 22

Figura 1.2. Ciclo del hierro en el suelo (Adaptada de Schwertmann, 1991).... 24

Figura 1.3 Sistema estándar de reducción de hierro en las plantas (Buchanan et al. ,2000)......................................... 25

Figura 1.4. Modelos de respuesta de las plantas a la deficiencia de hierro. a) Estrategia I, b) Estrategia II y c) Estrategia combinada (Walker y Connolly, 2008).................................................. 2

Figura 1.5. Funciones del Fe en la planta (Álvarez-Fernández, 2000)......... 31

Figura 1.6. Solubilidad de las distintas especies de Fe...................... 33

Figura 1.7. Efecto $\mathrm{pH}$ sobre las especies $\mathrm{Fe}^{2+}$ y $\mathrm{Fe}(\mathrm{OH})^{+}$en comparación con las especies hidroxiladas de $\mathrm{Fe}(\mathrm{III})$ en equilibrio con el $\mathrm{Fe}$ del suelo (Lindsay y Schwab, 1982)

Figura 1.8. Generación de la fluorescencia de la clorofila en el fotosistema II (Guo y Tan, 2015)

Figura 1.9. Gráfica del análisis de la fluorescencia usando un sistema modulado (Baker y Rosenqvist, 2004)........................... 54

Figura 1.10. Curva de inducción de fluorescencia de clorofila a y su correspondencia con las reacciones de la cadena transportadora de electrones (González et al., 2008).

Figura 3.1. Aspecto de los viñedos en la zona de estudio. (Subzona 5)....... 70

Figura 3.2. Localización de Pesquera de Duero dentro de la D.O. Ribera del Duero.

Figura 3.3. Cepa de la variedad de uva tinta "Tempranillo".

Figura 3.4. Medidor portátil de clorofila CL-01 (HANSATECH INSTRUMENT Ltd., Norfolk, UK)....

Figura 3.5. Fundamento de actuación un analizador de gases por infrarrojo. (LI-Cor, 2003).

Figura 3.6. Realización de las medidas de fluorescencia de la clorofila en condiciones de oscuridad.

Figura 3.7. Coordenadas $\mathrm{CIEL}^{*} \mathrm{a}^{*} \mathrm{~b}$ representadas en un sistema tridimensional. (Cheftel y Cheftel, 1992). 
Figura 4.1. Distribución de las subparcelas en función de los contenidos de fósforo (\% s.m.s.) en el peciolo en las tres campañas de estudio, teniendo en cuenta los valores de referencia propuestos por González y Martín (2005).

Figura 4.2. Distribución de las subparcelas en función de los contenidos de potasio (\% s.m.s.) en el peciolo en las tres campañas de estudio, teniendo en cuenta los valores de referencia propuestos por González y Martín (2005).

Figura 4.3. Distribución de las subparcelas en función de los contenidos de magnesio (\% $\%$ s.m.s.) en el peciolo en las tres campañas de estudio, teniendo en cuenta los valores de referencia propuestos por González y Martín (2005).....

Figura 4.4. Distribución de las subparcelas en función de los contenidos de calcio (\% s.m.s.) en el peciolo en las tres campañas de estudio, teniendo en cuenta los valores de referencia propuestos por González y Martín (2005)

Figura 4.5. Distribución de las subparcelas en función de los contenidos de hierro (mg. $\mathrm{kg}^{-1}$ s.m.s.) en el peciolo en las tres campañas de estudio, teniendo en cuenta los valores de referencia propuestos por González y Martín (2005).

Figura 4.6. Distribución de las subparcelas en función de los contenidos de cobre (mg $\mathrm{kg}^{-1}$ s.m.s.) en el peciolo en las tres campañas de estudio, teniendo en cuenta los valores de referencia propuestos por González y Martín (2005).....

Figura 4.7. Distribución de las subparcelas en función de los contenidos de manganeso (mg $\cdot \mathrm{kg}^{-1} \mathrm{~s}$.m.s.) en el peciolo en las tres campañas de estudio, teniendo en cuenta los valores de referencia propuestos por González y Martín (2005).

Figura 4.8. Distribución de las subparcelas en función de los contenidos de zinc (mg. $\mathrm{kg}^{-1}$ s.m.s.) en el peciolo en las tres campañas de estudio, teniendo en cuenta los valores de referencia propuestos por González y Martín (2005).

Figura 4.9. Distribución de las subparcelas en función de los contenidos de boro (mg $\cdot \mathrm{kg}^{-1}$ s.m.s.) en el peciolo en las tres campañas de estudio, teniendo en cuenta los valores de referencia propuestos por González y Martín (2005).

Figura 4.10. Gráfico de dispersión del contenido de arcilla y el contenido de carbonatos totales en el suelo.

Figura 4.11. Gráfico de dispersión del contenido de $\mathrm{K}$ y el contenido de $\mathrm{Mg}$ en los peciolos recogidos en el envero.

Figura 4.12. Gráfico de dispersión del contenido de $\mathrm{Mg}$ y el contenido de $\mathrm{Mn}$ en los peciolos recogidos en el envero.

Figura 4.13. Seguimiento en el tiempo de la concentración de la clorofila foliar $\left(\mu \mathrm{g} \cdot \mathrm{cm}^{-2}\right)$ 
Figura 4.14. Evolución de la concentración de clorofila foliar a lo largo del ciclo vegetativo en función del contenido de carbonatos totales en el suelo (Yañez, 1989) en los tres años del estudio

Figura 4.15. Evolución de la concentración de clorofila foliar a lo largo del ciclo vegetativo en función del contenido de $\mathrm{K}$ en el suelo (Yañez, 1989) en los tres años del estudio.

Figura 4.16. Evolución de la concentración de clorofila foliar a lo largo del ciclo vegetativo en función del contenido de $\mathrm{Mg}$ en los peciolos en el estado fenológico de envero (González y Martín, 2005) en los tres años del estudio.

Figura 4.17. Evolución de la concentración de clorofila foliar a lo largo del ciclo vegetativo en función del contenido de $\mathrm{Mn}$ en el suelo (Yañez, 1989) en los tres años del estudio.

Figura 4.18. Evolución de la concentración de clorofila foliar a lo largo del ciclo vegetativo en función del contenido de $\mathrm{Mn}$ en los peciolos en el estado fenológico de envero (González y Martín, 2005) en los tres años del estudio.

Figura 4.19. Rendimiento en las áreas de estudio cloróticas (C) y no cloróticas (NC) con distinto nivel nutricional de Mg

Figura 4.20. Contenido en sólidos solubles totales del mosto en las áreas de estudio afectadas (C) y no afectadas por clorosis férrica (NC), en función del nivel nutricional de potasio.

Figura 4.21. Contenido en sólidos solubles totales del mosto en las áreas de estudio afectadas (C) y no afectadas por clorosis férrica (NC), en función del nivel nutricional de Magnesio.

Figura 4.22. Primer plano factorial del análisis de componentes principales realizado con los datos de los parámetros físico-químicos del mosto en el conjunto de las zonas de estudio en los tres años de seguimiento. Los círculos rojos representan las variables físicoquímicas de mosto y vino, los triángulos negros representan las áreas de muestreo no afectadas por clorosis férrica y los triángulos en blanco representan las áreas de muestreo con clorosis férrica.

Figura 4.23. Contenido en antocianos fácilmente extraíbles de la baya en las áreas de estudio afectadas (C) y no afectadas por clorosis férrica (NC), en función del nivel nutricional de cobre.

Figura 4.24. Primer plano factorial del análisis de componentes principales realizado con los datos de las variables de fluorescencia de la clorofila en el envero de los viñedos en el conjunto de las zonas de estudio en los tres años de seguimiento. Los círculos rojos representan los parámetros de fluorescencia de la clorofila en el envero, los triángulos negros representan las áreas de muestreo con alto crecimiento de madera de poda y los triángulos en blanco representan las áreas de muestreo con bajo crecimiento de madera de poda, utilizando la mediana como límite de peso. 
Figura 4.25. Primer plano factorial del análisis de componentes principales realizado con los datos de las variables de fluorescencia de la clorofila en el envero de los viñedos en el conjunto de las zonas de estudio en los tres años de seguimiento. Los círculos rojos representan los parámetros de fluorescencia de la clorofila en el envero, los triángulos negros representan las áreas de muestreo con alto rendimiento y los triángulos en blanco representan las áreas de muestreo con bajo rendimiento, utilizando la mediana como límite de peso.

Figura 4.26. Primer plano factorial del análisis de componentes principales realizado con los datos de las variables de fluorescencia de la clorofila en el envero de los viñedos en el conjunto de las zonas de estudio en los tres años de seguimiento. Los círculos rojos representan los parámetros de fluorescencia de la clorofila en el envero, los triángulos negros representan las áreas de muestreo con alto SST y los triángulos en blanco representan las áreas de muestreo con bajo SST, utilizando la mediana como límite de medida. 




\section{RESUMEN}

La fertilización es una técnica fundamental en la producción vitícola, porque de la nutrición mineral dependen múltiples aspectos del desarrollo de la vid, el vigor y rendimiento del viñedo y, en última instancia, la calidad de la uva y el vino. Para optimizar la fertilización es necesario disponer de métodos adecuados para el diagnóstico del estado nutricional, y para conocer el impacto que los niveles de cada nutriente tienen sobre las componentes de la expresión vegetativa en las condiciones ecofisiológicas concretas de cada viñedo.

La deficiencia de hierro ó clorosis férrica es uno de los principales estreses abióticos que afectan a los cultivos leñosos en la zona mediterránea. El hierro interviene en la síntesis de clorofila y su deficiencia modifica la estructura y la funcionalidad del aparato fotosintético, provocando pérdidas en el rendimiento y la calidad de la uva variables en función del nivel de carencia y de los efectos acumulativos que esta tiene sobre el vigor de las cepas año tras año. La deficiencia de hierro inducida en terrenos calizos por la presencia excesiva de carbonatos y bicarbonatos en el suelo, suele ir acompañada de desequilibrios en la nutrición de otros elementos que interfieren con el hierro y/o que presentan baja disponibilidad en ese tipo de suelos. El seguimiento de la clorosis férrica en campo se realiza fundamentalmente en base al contenido foliar en pigmentos. Es interesante desarrollar métodos alternativos a éste, que permitan monitorizar el nivel de deficiencia de hierro y otros nutrientes, para su aplicación en viticultura de precisión. Estos métodos podrían servir tanto para diseñar estrategias más eficientes para la corrección de carencias y realizar el abonado, como para elaborar mapas de rendimiento y calidad en viñedos afectados por clorosis férrica.

Las medidas de fluorescencia de la clorofila se vienen empleando cada vez más en los estudios de ecofisiología vegetal. Su relación con la eficiencia energética y el nivel de asimilación de $\mathrm{CO}_{2}$ en la fotosíntesis permite que los parámetros de fluorescencia puedan ser utilizados para valorar diferencias en la respuesta de las plantas a factores medioambientales y, por consiguiente, para la detección de estrés ambiental. Los avances en la investigación de estrés nutricional con estas técnicas son importantes en los últimos años.

El presente trabajo ha tenido tres objetivos: (1) estudiar las relaciones entre el estado nutricional del viñedo, los contenidos en pigmentos foliares de la vid y los parámetros de eficiencia fotosintética a nivel de hoja; 2) evaluar los efectos del estado nutricional sobre la expresión vegetativa de viñedos cv. Tempranillo cultivados en suelos calizos de la Denominación de Origen Ribera del Duero; y (3) valorar el potencial de las medidas de fluorescencia de la clorofila como herramienta para la detección de clorosis férrica y otras deficiencias nutricionales, y para estimar el potencial enológico del viñedo, para su aplicación en viticultura de precisión.

Para alcanzar los objetivos propuestos, se ha realizado un seguimiento de parámetros fisiológicos, agronómicos y de composición de la uva durante tres años (2009-2011) en un conjunto de 32 subparcelas de viñedo, afectadas y no afectadas de 
clorosis férrica. Las subparcelas, de $10 \times 10 \mathrm{~m}^{2}$ de superficie cada una corresponden a viñedos cv. Tempranillo cultivados en secano en Pesquera de Duero (Valladolid), al oeste de la Denominación de Origen "Ribera del Duero". El diagnóstico nutricional de las subparcelas se ha llevado a cabo mediante análisis de suelo al inicio de la investigación, y de la composición mineral de peciolos, recogidos en el envero durante las tres campañas. En cada subparcela se determinó el contenido en clorofila, carotenoides y antocianinas foliares, asimilación neta y conductancia estomática, y parámetros de fluorescencia de la clorofila en los estados fenológicos de cuajado y envero. Se controló el vigor, la superficie foliar, el rendimiento y sus componentes, y se analizó la composición del mosto de vendimia y sus características cromáticas, así como distintos parámetros de madurez fenólica de la uva. Las relaciones existentes entre contenidos foliares de pigmentos y parámetros de fluorescencia con las variables agronómicas y de calidad del viñedo se estudiaron mediante análisis de la varianza y métodos de regresión lineal.

Los suelos de los viñedos de la zona de estudio mostraron una elevada variabilidad en el porcentaje de arcilla, contenido en carbonatos totales y niveles de $P$, $\mathrm{K}, \mathrm{Mg}, \mathrm{Zn}$ y $\mathrm{Cu}$ asimilables. La composición mineral de los peciolos recogidos en envero también ha registrado una gran variación espacial para los mencionados nutrientes.

Los resultados confirman que los niveles peciolares de Fe no son válidos para el diagnóstico de la clorosis férrica. La deficiencia provoca una acumulación de Mn en los peciolos y una reducción de la concentración foliar de clorofilas, carotenoides y antocianinas, detectándose una mayor variabilidad espacial en el estado fenológico de cuajado que en el envero.

La clorosis férrica se ha traducido en un menor vigor y rendimiento del viñedo, dando mayores índices de polifenoles totales y contenidos en sólidos solubles en los mostos. En general, mayores niveles de nutrición de $\mathrm{K}$ y $\mathrm{Zn}$ en el área de estudio han tendido a incrementar el vigor y rendimiento, reduciendo los contenidos en azúcares y polifenoles de la uva, mientras que niveles crecientes de nutrición de $\mathrm{P}, \mathrm{Mg}$ y $\mathrm{Cu}$ han tenido el efecto contrario.

Las concentraciones foliares de pigmentos se han relacionado positivamente con la fluorescencia mínima y negativamente con la fluorescencia variable, la eficiencia fotoquímica del fotosistema II y del transporte aparente de electrones. Fo y $\mathrm{Fv} / \mathrm{Fm}$ se han correlacionado significativamente con los niveles de clorosis férrica y de nutrición de $\mathrm{K}, \mathrm{Mg}$ y $\mathrm{Mn}$. La ratio Fo/Fv ha sido especialmente sensible a los niveles nutricionales de $\mathrm{Mn}$. Los resultados muestran que tanto estos parámetros de fluorescencia monitorizados en cuajado y envero, como la concentración de antocianinas foliares en envero, podrían ser útiles para estimar el potencial productivo y cualitativo del viñedo en zonas afectadas por clorosis férrica, para su aplicación en viticultura de precisión. 


\section{ABSTRACT}

Fertilization is a fundamental technique in the vine production because many aspects of vine growth and development, affecting vigour and yield of vineyard and, ultimately, grape and wine quality. To optimize the fertilization, it is necessary to have appropriate methods for the diagnosis of nutritional status and to know the impact of the nutrient levels on agronomic performance in the specific ecophysiological conditions of each vineyard.

Iron deficiency, or iron chlorosis, is a major abiotic stresses affecting tree crops in Mediterranean area. Iron is involved in the chlorophyll synthesis and its deficiency produce changes in the structure and usefulness of photosynthetic apparatus, causing losses in yield and grape quality, variable depending on the deficiency level and the accumulative effects that this has on the vine vigour year to year. Iron deficiency is induced in calcareous zones by excessive presence of carbonates and bicarbonates in the soil, usually accompanied by imbalances for other nutrients which interact with iron and/or have low availability in such soils. Iron chlorosis is usually monitored in the field by leaf pigment content measurements. It is interesting to develop alternative methods to monitor the level of iron and other nutrient deficiencies, for applying in precision viticulture. These methods could be used both to design more effective strategies for the correction of deficiencies, and to develop yield and quality maps in vineyards affected by iron chlorosis.

Chlorophyll fluorescence measurements are being increasingly used in plant ecophysiology studies. Its relation to energy efficiency and $\mathrm{CO} 2$ assimilation level in the photosynthesis allows the fluorescence measurements can be used to asses differences in the plant responses to environmental factors and therefore, to detect environmental stresses. Advances in research on the nutritional stress with these techniques are important in recent years.

This investigation has three objectives: (1) to study the relationships between the nutritional status of vineyard, the leaf pigment contents and the photosynthetic efficiency parameters; 2) to evaluate the effects of nutritional status on the vegetative expression of the vineyard cv. Tempranillo grown in lime soils of D.O. Ribera del Duero; and (3) to assess the potential of the chlorophyll fluorescence measurements as a tool for the detection of iron chlorosis and other nutritional deficiencies, and to estimate the quality potential of vineyards, to be used in precision viticulture.

To get these aims, a monitoring of physiological, agronomic and grape composition was carried out during three years (2009-2011) in a group of 32 vineyard subzones, affected and unaffected by iron chlorosis. The subzones, of $10 \times 10 \mathrm{~m} 2$ of area each, correspond to cv. Tempranillo vineyards cultivated in rainfed conditions in Pesquera de Duero, west of the Designation of Origin "Ribera del Duero" (Spain). The nutritional diagnosis of the subzones was carried out by soil analysis at the beginning of the investigation, and the mineral composition analysis of petioles, collected at veraison during each season. In each subzone, leaf chlorophyll, carotenoid and anthocyanin contents, net assimilation, stomatal conductance and chlorophyll 
fluorescence parameters were monitorized at fruit set and veraison phenological stages. Vigour, leaf area, yield and yield components were determined, and the must composition and color characteristics, as well as various parameters of phenolic maturity of grape were analyzed at harvest. The relationships between leaf pigment content and fluorescence parameters with agronomic performance and quality variables were studied by analysis of variance and linear regression methods.

The vineyards soils of the study area showed a high variability on the clay content, total carbonate content and levels of assimilable P, K, Mg, $\mathrm{Zn}$ and $\mathrm{Cu}$. The mineral composition of the petioles collected at veraison has also recorded a large spatial variation for the above nutrients.

The results confirm that $\mathrm{Fe}$ petiole levels are not valid to iron chlorosis diagnosis. The deficiency causes an accumulation of $\mathrm{Mn}$ in petioles and a reduction of the leaf chlorophyll, carotenoid and anthocyanin concentration, detecting a greater spatial variability in fruit set than veraison data.

Iron chlorosis has resulted in a less vigour and yield of the vineyard, getting higher total polyphenol index and soluble solid content in musts. In general, higher $\mathrm{K}$ and $\mathrm{Zn}$ nutrition levels in the study area have tended to increase the vigour and yield, reducing sugar and polyphenol contents in grapes, while $\mathrm{P}, \mathrm{Mg}$ and $\mathrm{Cu}$ increasing levels have had the opposite effect.

The leaf pigment concentrations were positively related with minimum fluorescence and negatively with variable fluorescence, photochemical efficiency of photosystem II and electron transport ratio. Fo and $\mathrm{Fv} / \mathrm{Fm}$ has been related significantly with iron chlorosis and $\mathrm{K}, \mathrm{Mg}$ and $\mathrm{Mn}$ nutrition levels. Fo/Fv ratio has been particularly sensitive to nutritional levels of $\mathrm{Mn}$. The results show both these fluorescence parameters monitored at fruit set and veraison, as the foliar anthocyanin concentration at veraison, could be useful to estimate the productive and qualitative potential of the vineyards in areas affected by iron chlorosis, to be used in precision viticulture. 




\section{INTRODUCCIÓN}




$$
\text { • }
$$




\section{1.- INTRODUCCIÓN.}

El mercado vitivinícola actual exige, cada vez más, productos de máxima calidad. La calidad del vino es un concepto subjetivo, que puede estar definido por múltiples criterios. Este concepto está estrechamente relacionado con la demanda del mercado y con el valor comercial del producto.

La identificación y cuantificación de los componentes químicos del vino sirve como base para explicar sus características sensoriales, para evaluar su estabilidad, origen y autenticidad y, en consecuencia, su calidad comercial (Sáenz-Navajas et al., 2010a). La relación entre la evaluación sensorial y la composición química del vino es un punto crítico de investigación en enología (Escudero et al., 2007; Holt et al., 2008; Sáenz-Navajas et al., 2010b; Chira et al., 2011). Por otra parte, la relación entre la composición química del vino con la variedad o zona agroecológica de procedencia es un importante objeto de estudio en las investigaciones vitivinícolas, por su importancia en el marketing de los productos. Se intentan desarrollar metodologías capaces de verificar la autenticidad de los vinos (Hernández-Orte et al., 2002; Otteneder et al., 2004; Garde-Cerdán et al., 2009), y técnicas adecuadas para evaluar diferentes factores vitícolas (González-Neves et al., 2002; Ojeda et al., 2002; Guidoni et al., 2008) y enológicos (Sacchi et al., 2005; Comuzzo et al., 2006) que inciden sobre la calidad de los vinos.

La biosíntesis y acumulación de sustancias a lo largo del desarrollo de las uvas, depende tanto del genotipo de la planta como de otros factores del medio (condiciones edafoclimáticas fundamentalmente), y de las prácticas culturales realizadas en el viñedo. La influencia del "factor variedad" sobre la composición cualitativa y cuantitativa de la uva es evidente. Así, Núñez et al. (2004) y Otteneder et al. (2004) encontraron perfiles antociánicos característicos en distintas variedades de uva, mientras que otros autores mostraron amplias diferencias en el perfil de flavonoles entre cultivares (Mattivi et al., 2006; Castillo-Muñoz et al., 2007).

Las características físicas y químicas del suelo (composición nutricional, estructura, profundidad, textura...) pueden afectar a la calidad de la uva, debido a su incidencia directa sobre el crecimiento y desarrollo de las plantas. El principal impacto del tipo de suelo está muchas veces referido a la capacidad de retención de agua y a las condiciones limitantes en la disponibilidad de macro y micronutrientes, como por ejemplo pH extremos (Matus Picero, 2008). Algunos autores (Ojeda et al., 2002; Roby y Matthews, 2004; Castellarin et al., 2007) encontraron que en condiciones de restricción hídrica se observó un aumento del contenido de antocianinas y proantocianidinas en bayas, mientras que en otros estudios la restricción hídrica mostró un efecto bajo o nulo sobre la acumulación de estos compuestos (Kennedy et al., 2002). Según Downey et al. (2006), el efecto del déficit hídrico sobre la concentración de compuestos fenólicos estaría relacionado con la disminución del tamaño de la baya y la modificación de la relación peso de hollejo/peso de baya. Algunos autores consideran que los cambios en la estructura del hollejo serían tan 
responsables de este efecto como la incidencia directa sobre las rutas biosíntéticas de los compuesto fenólicos (Roby et al., 2004; Roby y Matthews, 2004). Para evaluar el impacto que tiene la disponibilidad de agua sobre la calidad de la uva es necesario considerar su influencia sobre procesos biológicos de la planta muy diversos, tales como el cierre/apertura estomática, fotosíntesis, acumulación de fotoasimilados, crecimiento vegetativo y desarrollo radicular, senescencia de tejidos, etc (Downey et al., 2006).

La influencia de las condiciones ambientales sobre la composición de las uvas ha sido ampliamente estudiada en diversas zonas vitivinícolas. La exposición a la luz solar y a la temperatura de hojas y racimos constituyen los factores más relevantes sobre la composición fenólica de las bayas (Haselgrove et al., 2000; Spayd et al., 2002; Downey et al., 2004). Las prácticas culturales que favorecen la exposición a la luz de los racimos incrementar la acumulación de polifenoles (Cortell y Kennedy, 2006), al promover la expresión de genes implicados en las rutas metabólicas de estos compuestos (Downey et al., 2004; Jeong et al., 2004).

Las prácticas agronómicas realizadas en el viñedo tienen como una de sus funciones principales controlar el equilibrio entre el crecimiento vegetativo y productivo de la vid para, en definitiva, lograr la calidad de la uva adecuada para el tipo de vino que se va a obtener. Entre las técnicas culturales que pueden modificar la composición de las bayas se encuentran, el sistema de conducción (Haselgrove et al., 2000), el tipo de poda (González-Neves et al., 2002), el aclareo de racimos (Guidoni et al., 2008; Valdés et al., 2009), las labores de poda en verde (desbrote, despunte, deshoje) (Poni et al., 2009), la fertilización mineral (Delgado et al., 2004) y el manejo del riego (Esteban et al., 2001; Ojeda et al., 2002), entre otros. Adicionalmente, la aplicación de prácticas culturales bajo sistemas convencionales, orgánicos o biodinámicos han mostrado cierta incidencia sobre la composición química de las bayas (Reeve et al., 2005; Vian et al., 2006).

Factores como la edad del viñedo (Reynolds et al., 2007) y la presencia de enfermedades criptogámicas (Amati et al., 1996) también pueden afectar la composición química de las uvas y los vinos. Finalmente, resulta esencial el grado de madurez de las uvas (hollejo, semilla y pulpa), que permitirá definir el momento oportuno de cosecha, con el mejor potencial de calidad, para producir el vino con las características buscadas.

Los procesos fisiológicos y metabólicos implicados en el crecimiento y la producción de fruto en la vid están influenciados por la disponibilidad macro y micronutrientes. La cuantificación de las necesidades nutricionales de la vid es fundamental para desarrollar programas de manejo de la fertilización eficaces (Robinson, 1995).

La disponibilidad de nutrientes minerales influye notablemente en el comportamiento agronómico del viñedo y afecta en gran medida a la composición de distintos tejidos de la uva. En diversos estudios se ha constatado que una disponibilidad excesiva de nitrógeno, o desequilibrada con el potasio, tiende a disminuir la concentración fenólica en los hollejos (Jackson y Lombard, 1993; Delgado et al., 2004). Según Downey et al. (2006), el mecanismo principal de esta disminución 
podría estar vinculado con el mayor vigor de las plantas sobrealimentadas de nitrógeno. Diversos autores han observado cambios cuantitativos en la composición fenólica de las bayas en vides manejadas con distintos niveles de vigor (Peña-Neira et al., 2004; Cortell et al., 2005). En muchos casos, además del efecto del vigor, existen cambios en la arquitectura del follaje, dando como resultado una modificación en la exposición solar de hojas y racimos (Coombe y McCarthy, 2000).

La optimización de la nutrición mineral ha de ser objetivo prioritario en el manejo en el viñedo, por lo que es necesario disponer de métodos adecuados de diagnóstico que nos permitan evaluar su estado. Así mismo, es esencial conocer la influencia del estado nutricional de la planta en la calidad del vino. Las diferencias que podemos observar en el estado nutricional se pueden atribuir, en gran parte, a distintos niveles de absorción radicular y acumulación en la planta, condicionados a su vez por la disponibilidad de nutrientes en el suelo. La correcta interpretación de los resultados de los análisis foliares ha de tener en cuenta factores como el suelo, la variedad, el portainjerto, el estado fisiológico, la carga de poda, la edad de la planta, la localización de la hoja en el sarmiento y el tejido muestreado (hoja o peciolo) y el momento del muestreo. El diagnóstico foliar requiere un estándar de referencia para condiciones ecológicas y tipo de cultivo concretos (Martín et al, 1999).

La viticultura de precisión engloba un conjunto de técnicas que se emplean para caracterizar la variabilidad espacial en campo de los factores de producción y calidad de la uva, con objeto de aplicar después métodos de manejo adecuados a cada subzona o subparcela consideradas. El desarrollo actual de la viticultura de precisión se ha visto impulsado por la puesta a punto de tecnologías diversas: Sistemas de posicionamiento global (GPS), sistemas de información geográfica (GIS), sensores y técnicas para captación de datos, sistemas de gestión de datos y soporte para toma de decisiones, tecnologías para aplicación variable de imputs $u$ operaciones.

Por su influencia en el comportamiento agronómico del viñedo y en la calidad de la uva la detección de estrés, tanto hídrico como nutricional, es un aspecto clave en viticultura de precisión. Esto es interesante no sólo para decidir las medidas de corrección a nivel espacial o temporal, sino que ha de ser considerado en la gestión integral del viñedo, para mejorar en rendimientos y en calidad de cosecha, y para un mantenimiento sostenible del medio ambiente (Gallé y Flexas, 2010). 


\section{1.- LA NUTRICIÓN MINERAL DEL VIÑEDO; IMPACTO EN EL COMPORTAMIENTO AGRONÓMICO Y EN LA CALIDAD DE LA UVA.}

Los nutrientes minerales son, junto con el agua, requisitos básicos para el crecimiento y el desarrollo de las plantas (Bergmann, 1992). La nutrición mineral es fundamental para la producción de uva, impactando sobre todos los aspectos de crecimiento de la vid, desarrollo y maduración de la baya y, en última instancia, en la composición del mosto y el vino. Buena parte de la influencia de la nutrición mineral sobre la composición de la baya es indirecta, a través de la alteración del crecimiento y el nivel de rendimiento de las plantas.

Catorce elementos minerales se consideran esenciales para un mayor crecimiento de las plantas; estos elementos incluyen 6 macronutrientes $(\mathrm{N}, \mathrm{P}, \mathrm{K}, \mathrm{Ca}$, $\mathrm{Mg}, \mathrm{S}$ ) y 8 oligoelementos ( $\mathrm{Fe}, \mathrm{Mn}, \mathrm{Zn}, \mathrm{Cu}, \mathrm{Cl}, \mathrm{B}, \mathrm{Mo}, \mathrm{Ni}$ ). Es vital conocer el papel fisiológico de cada elemento, así como los síntomas de deficiencia y los métodos para prevenir o curar los trastornos nutricionales. El análisis químico de la hoja y/o del pecíolo es una importante herramienta para evaluar el estado nutricional de la planta. Para que esta herramienta sea útil, se debe establecer una metodología óptima para llevar a cabo la toma de muestras, así como la concentración de referencia de cada elemento. En cualquier caso, la composición mineral de las hojas puede cambiar a dependiendo de la variedad y el portainjerto (Christensen, 1984; Peuke, 2009).

Durante el ciclo anual, la vid puede sufrir deficiencias minerales que afecten a la fisiología de la planta, debido a factores relacionados con el vigor de las plantas, las propiedades del suelo o las condiciones meteorológicas. Los estados carenciales pueden afectar a la composición química de la uva y al rendimiento de la vid, y pueden ser consecuencia de la deficiencia de uno o varios nutrientes a la vez (Pearson y Goheen, 1998). Los síntomas visibles proporcionan indicios sobre su presencia, pero sólo el análisis de suelo y hoja (limbo o pecíolo) pueden confirmar la existencia de carencias o desequilibrio de nutrientes.

Los suelos varían no solo en las cantidades de los nutrientes minerales (macro y microelementos), sino también en el grado de disponibilidad para las plantas. La capacidad de almacenamiento de nutrientes en el suelo y su disponibilidad son influenciados por la textura, el contenido de materia orgánica, la humedad y el pH del suelo (Keller, 2005). Estos parámetros pueden afectar a varios procesos químicos y bioquímicos que ocurren en el suelo: precipitación-disolución, adsorción-desorción, complejación-disociación y oxidación-reducción, que controlan la movilidad y la disponibilidad de nutrientes para la planta (He et al, 2005). Los nutrientes son absorbidos por la planta en forma de iones disueltos en la solución del suelo, lo que depende también del flujo de agua a través de la vía suelo-raíz-tallo (Keller, 2005).

Las deficiencias de nutrientes se producen cuando la planta no puede adquirir cantidades suficientes de nutrientes para cubrir sus necesidades. Por otro lado, un suministro excesivo de elementos, especialmente oligoelementos (por ejemplo, $\mathrm{Zn}, \mathrm{Cu}$ o Mn), resultan tóxicos para la planta (He et al., 2005). Los síntomas de deficiencias 
específicas pueden ser muy variados, aunque la decoloración (clorosis) de las hojas es el que se observa con mayor frecuencia. Muchas veces los síntomas de deficiencia y toxicidad pueden confundirse con daños por sequía, enfermedades, ataques de insectos...

Los síntomas de deficiencia de nutrientes con baja movilidad dentro de las plantas (como Fe y $\mathrm{Zn}$ ) aparecen al principio del ciclo y sobre todo en las hojas superiores más cercanas al ápice, mientras que en el caso de nutrientes más móviles (como $\mathrm{Mg}$ ) aparecen principalmente en las hojas basales totalmente expandidas (Marschner, 1995).

Existen muchos estudios (Conradie y Saayman, 1989b; Jackson y Lombard, 1993; Hilbert et al., 2003; Keller, 2005; Topalović et al., 2011), donde ha sido investigada la influencia del tipo de suelo, el clima o el cultivar sobre la calidad de la uva. Sin embargo son menos abundantes en la literatura estudios sobre correlaciones entre los niveles de nutrición mineral de las plantas y parámetros de composición de las uvas como el contenido de polifenoles.

\subsection{1.- Nitrógeno (N)}

El nitrato $\left(\mathrm{NO}_{3}{ }^{-}\right)$y el amonio $\left(\mathrm{NH}_{4}{ }^{+}\right)$son las principales formas de nitrógeno que son absorbidas por las plantas. La forma de nitrato presenta una disponibilidad más inmediata, pero se lixivia fácilmente fuera del perfil del suelo. El amonio se toma más lentamente y se transforma en nitrato a través del proceso microbiano de nitrificación. Cuando el $\mathrm{N}$ se aplica en cantidades insuficientes o excesivas puede causar efectos negativos en productividad de las plantas y en la calidad de los frutos (Keller, 2010).

El nitrógeno es un constituyente de la clorofila, proteínas, hormonas, ácidos nucléicos, lecitinas, vitaminas y alcaloides. Mejora el crecimiento vegetativo (vigor), el rendimiento, aunque puede retrasar la maduración de la uva y reducir su calidad cuando su disponibilidad es excesiva (Bavaresco et al., 2010b). En diversas investigaciones se ha registrado un aumento del crecimiento vegetativo y el rendimiento de los cultivos en respuesta a la aplicación de N (Ahlawat y Yamdagni, 1988a, 1988b; Keller et al., 1998; Bell y Robson, 1999; Conradie, 2001; Keller et al., 2001a; Zerihun y Treeby, 2002).

En las vides, los síntomas visuales de deficiencia de nitrógeno incluyen una coloración verde pálida a amarilla de las hojas. Las hojas más maduras suelen mostrar síntomas de deficiencia de $\mathrm{N}$ antes que las hojas más jóvenes (es muy móvil en la planta). El pecíolo y los tallos del raquis pueden volverse de color rosado o rojo. Los síntomas de exceso de $\mathrm{N}$ incluyen hojas de color verde oscuro, crecimiento excesivo y prolongado en el tiempo, aumento de la longitud de los entrenudos y del tamaño y grosor de la hoja (Pearson y Goheen, 1998).

La aplicación de $\mathrm{N}$ afecta al contenido de clorofila de las hojas. Keller et al. (2001b) mostraron un aumento en el contenido de clorofila y en la actividad fotosintética de las hojas como resultado de las aplicaciones de N. Keller et al. (1998) 
también informaron de un retraso en la senescencia de las hojas, como resultado de la aplicación de $\mathrm{N}$.

La aplicación de $\mathrm{N}$ también puede interactuar con otros nutrientes. Wolf et al. (1983) han estudiado estas interacciones con aplicaciones de $\mathrm{N}$ en cuatro concentraciones diferentes en cv. Seyvel Blanc. El análisis de los tejidos demostró que el incremento de la concentración de $\mathrm{N}$ aumenta los niveles de fósforo y de hierro, mientras que disminuye los niveles de magnesio y calcio.

Trabajos, como los de Jackson y Lombard (1993), Keller (2005), Topalović et al. (2011) muestran que el nitrógeno eleva los rendimientos y reduce los contenidos en sólidos solubles y antocianinas. La deficiencia de nitrógeno junto con la escasez de agua provoca un crecimiento reducido de las plantas y una estimulación de la biosíntesis de polifenoles de la uva (Hilbert et al., 2003; Castellarin et al., 2007). Es comúnmente aceptado, que aplicaciones moderadas de $\mathrm{N}$ aumentan los niveles de antocianinas, mientras que disminuyen el contenido de sólidos solubles (Ahalwat y Yamdagni, 1988b; Ruhl et al., 1992; Keller et al., 1998; Conradie, 2001; Delgado et al., 2004; Martín et al., 2004). Ruhl et al. (1992) evaluaron los efectos de la aplicación de $\mathrm{N}$ en la composición de la uva en distintas variedades cultivadas en diferentes regiones y observaron que la aplicación de $\mathrm{N}$ aumentaba significativamente el $\mathrm{pH}$ del mosto en todos los casos.

\subsection{2.- Fósforo (P)}

El fósforo es absorbido como ion fosfato monovalente $\left(\mathrm{H}_{2} \mathrm{PO}_{4}\right)$ y divalente $\left(\mathrm{HPO}_{4}{ }^{2-}\right)$. La disponibilidad del ión fosfato se ve afectada por el $\mathrm{pH}$ del suelo. Con un $\mathrm{pH}$ inferior a 7 se encuentra disponible en forma de fosfato monovalente, y a un pH por encima de 7 en forma de fosfato divalente. El ion monovalente es la forma preferente de absorber fósforo por las plantas (Salisbury y Ross, 1992).

EI P es un constituyente de la membrana celular, ácidos nucléicos, vitaminas, lecitinas, proteínas y ATP. Incrementa el crecimiento del ápice de los brotes y la raíz y de las hojas, y la concentración de aromas de la uva (Bavaresco et al., 2010b). El P es un elemento móvil en las plantas y es esencial para la fotosíntesis, la respiración y la regulación de muchos procesos metabólicos (Salisbury y Ross, 1992; Keller, 2010). Por otra parte, la fosforilación de las acuaporinas regula el transporte de agua a través de membranas: las acuaporinas fosforiladas están activas, es decir, abiertas (Maurel et al., 2008).

La deficiencia de $\mathrm{P}$ provoca una disminución del número y el tamaño de las hojas permaneciendo de un color verde oscuro grisáceo. Un bajo aporte de $\mathrm{P}$ limita la división celular, restringiendo la expansión de las hojas y el crecimiento de los brotes laterales (Chiera et al., 2002), e inhiben la diferenciación del racimo (Keller, 2010). La deficiencia severa de $\mathrm{P}$ puede provocar hojas de colores rojos debido a la producción de antocianinas a partir de azúcares acumulados que no se exportan desde las hojas (Lillo et al., 2008). 
Niveles excesivos de $\mathrm{P}$ provocan deficiencias de zinc y de hierro, ya que actúa como antagonista (Pearson y Goheen, 1998), reduciendo la cantidad absorbida de estos nutrientes. Además existen interacciones del $\mathrm{P}$ con otros nutrientes, así, Haeseler et al. (1980) mostraron una disminución de las concentraciones de zinc y calcio en el pecíolo con aplicaciones de P. Skinner y Matthews (1990) observaron que la aplicación de $\mathrm{P}$ aumentaba la traslocación de magnesio de las raíces a los brotes en vides deficientes en fósforo.

La deficiencia de fósforo reduce el rendimiento de las plantas. Skinner y Matthews (1989) informaron que la deficiencia afecta más al ciclo reproductivo que al crecimiento vegetativo, disminuyendo el número de bayas por racimo, el peso de la baya, peso del racimo y el número de racimos por planta. Haeseler et al. (1980) mostraron un aumento en el vigor, rendimiento, peso del racimo y fertilidad de las yemas como resultado de la aplicación de P. Los incrementos en vigor frente a controles sin tratar también han sido observados por Grant y Matthews (1996) como resultado de la aplicación de fósforo. Conradie y Saayman (1989b) observaron que el aporte de $\mathrm{P}$ induce una concentración significativamente mayor de acidez total frente a testigos sin abonar.

\subsection{3.- Potasio (K).}

El potasio es un activador de enzimas que son esenciales para la fotosíntesis y la respiración, así como de enzimas que producen almidón y proteínas (Bhandal y Malik, 1988). El $\mathrm{K}$ también está involucrado en la regulación del equilibrio osmótico de las células, así como la turgencia de las células oclusivas que determinan la apertura y cierre de los estomas (Salisbury y Ross, 1992). El aporte de potasio mejora el crecimiento de brotes, la resistencia a las enfermedades y a las heladas de invierno, la acumulación de azúcares y de almidón (en las bayas y en los órganos leñosos respectivamente), y favorece la resistencia al estrés hídrico (Bavaresco et al. 2010b).

Los síntomas de carencia en vid varían con la edad de la hoja; en las hojas jóvenes aparecen zonas decoloradas y manchas necróticas en el borde de las hojas cuyos bordes se pueden secar y enrollar. Las hojas más viejas pueden adquirir tonos violeta-marrón a marrón oscuro. Las deficiencias son más comunes en climas secos (Pearson y Goheen, 1998).

Son muchos los autores que han señalado que la aplicación de $\mathrm{K}$ aumenta la concentración del nutriente en el peciolo, el limbo de la hoja y la uva (Morris et al., 1980; Morris y Cawthon, 1982; Wolf et al., 1983; García et al., 1999; Poni et al., 2003; Delgado et al., 2004).

Las interacciones entre $\mathrm{K}$ y otros nutrientes han sido ampliamente estudias. El exceso de $\mathrm{K}^{+}$puede disminuir las concentraciones de $\mathrm{Mg}^{2+}$ y $\mathrm{Ca}^{2+}$ en la hoja e inducir deficiencia de Mg debido su antagonismo (Morris et al., 1980). Esto es particularmente pronunciado en vides jóvenes, especialmente en suelos arenosos con pH bajo (Gärtel, 1993). Morris y Cawthon (1982) mostraron una disminución en las concentraciones de Ca y $\mathrm{Mg}$ en los peciolos como resultado de la aplicación de sulfato potásico en el suelo en viñedos cv. Concord. Wolf et al. (1983) observaron en cv. Seyvel Blanc una 
reducción en los niveles de $\mathrm{N}$ y $\mathrm{Mg}$ en la hoja a concentraciones altas de abonado de $\mathrm{K}$ en el suelo; mientras que a concentraciones moderadas se observó un aumento del Ca. García et al. (1999) investigaron la interacción entre K y Ca y los efectos de sus relaciones en la nutrición de la vid cultivada en medio hidropónico y observaron un claro antagonismo entre los dos nutrientes. Morris et al. (1980) mostraron una reducción en la concentración de manganeso en los pecíolos como resultado de la aplicación de cloruro potásico en el suelo.

La aplicación de $\mathrm{K}$ da lugar a un incremento en el crecimiento de la vid, aumentando el peso de la madera de poda, la producción de materia seca y el grosor del tronco (Morris y Cawthon, 1982; Wolf et al., 1983; Conradie et al., 1989a). Smolarz y Mercik (1997) informaron de que la carencia de K mantenida durante mucho tiempo disminuye considerablemente el crecimiento de brotes. Además de una reducción en el crecimiento, la carencia de $\mathrm{K}$ provoca una disminución en el rendimiento de la vid (Smolarz y Mercik, 1997). Conradie y Saayman (1989a) mostraron un incremento significativo en el rendimiento con aplicaciones de K.

El potasio es el catión más abundante presente en la uva (Hradzina et al., 1984). Debido a su alta movilidad en el floema, se acumula principalmente en los tejidos del hollejo durante la maduración, como resultado de la retraslocación del ion desde las hojas adultas. El potasio neutraliza los ácidos orgánicos y desempeña un papel importante en el control de la acidez y el pH del mosto (Coombe, 1992; Poni et al., 2003). Ruhl (1989) observó que la concentración de $\mathrm{K}$ en los peciolos se relacionaba directamente con el $\mathrm{pH}$ del mosto, así, una alta concentración de $\mathrm{K}$ en el pecíolo puede resultar en un incremento de $\mathrm{pH}$ que puede traducirse en una pérdida de la calidad final del vino, especialmente en lo que se refiere a su estabilidad química y microbiológica (Jackson y Lombard, 1993). Morris et al. (1980), Morris y Cawthon (1982), Dundon et al. (1984), Conradie y Saayman (1989b), Brancadoro et al. (1994) y Delgado et al. (2004) han informado de una reducción en la acidez del mosto como resultado de la aportación de $\mathrm{K}$ al viñedo.

Los contenidos en sólidos solubles (Ahalwat y Yamdagni, 1988a), los niveles de madurez tecnológica (Morris et al., 1980) y la concentración de antocianinas en el mosto (Delgado et al., 2004) también están influenciados por la nutrición potásica. Ahalwat y Yamdagni (1988a) demostró que los sólidos solubles aumentaron con el aumento de las aplicaciones de K.

\subsection{4.- Calcio (Ca).}

El calcio es tomado por las plantas como ion divalente, que no puede ser absorbido y translocado por el floema. Los primeros síntomas de la deficiencia de calcio se producen en las partes jóvenes de la planta donde es imprescindible para los procesos de la división celular. Generalmente los síntomas incluyen deformaciones en los ápices de crecimiento (Salisbury y Ross, 1992). El Ca es un constituyente de la pared celular. Está implicado en la síntesis de proteínas y carbohidratos y en la transpiración (Bavaresco et al., 2010b). 
En vid, las deficiencias de $\mathrm{Ca}$ son poco frecuentes, pero pueden ocurrir en suelos muy ácidos, por debajo de $\mathrm{pH} 4,5$. Los síntomas de deficiencia en la hoja comienzan como un borde necrótico estrecho en el margen del limbo que se mueve paulatinamente hacia la unión con el pecíolo. También pueden aparecer manchas marrones oscuras de hasta $1 \mathrm{~mm}$ de diámetro en los entrenudos y marchitamiento y necrosis del racimo después del envero (Pearson y Goheen, 1998).

Existe una fuerte interacción del $\mathrm{Ca}$ con el $\mathrm{K}$ y el $\mathrm{Mg}$ que ha sido puesta de manifiesto por muchos autores (García et al., 1999; Morris y Cawthon, 1982; Morris et al., 1980; Wolf et al., 1983).

\subsection{5.- Magnesio (Mg).}

Al igual que el $\mathrm{Ca}$, las plantas toman el $\mathrm{Mg}$ como ión divalente. Por lo general, los síntomas de deficiencia se muestran como clorosis internervial en las hojas basales antes de la floración (Pearson y Goheen, 1998). El Mg es un componente esencial de la clorofila, así como para la capacidad funcional del ATP en muchas reacciones. También es responsable de la activación de muchas enzimas en la fotosíntesis, la respiración y la síntesis de ácidos nucléicos (Salisbury y Ross, 1992). El Mg aumenta la actividad enzimática de la fructosa-1 y 6- bis fosfatasa, causando un aumento de la síntesis de azúcar en la uva (Bybordi y Shabanov, 2010) e incrementa la translocación de las moléculas sintetizadas por la fotosíntesis de la hoja al fruto (Malakouti, 2006).

La deficiencia de Mg con frecuencia se puede observar en suelos arenosos en regiones de alta precipitación, suelos con mal drenaje, o suelos alcalinos (Marschner, 1995). La deficiencia de Mg puede ser inducida, incluso en suelos con niveles suficientes de $\mathrm{Mg}$, por altas concentraciones (antagonismo) de otros iones tales como $\mathrm{H}^{+}$( $\mathrm{pH}$ bajo), $\mathrm{K}^{+}$(aplicación excesiva de fertilizantes potásicos), $\mathrm{NH}_{4}{ }^{+}$(sulfato de amonio como fertilizante), $\mathrm{Ca}^{2+}, \mathrm{Mn}^{2+}$, e iones $\mathrm{Al}^{3+}$ en suelos con $\mathrm{pH} \leq 5$ (Bergmann, 1992).

Wolf et al. (1983) que investigaron el efecto del aporte de diferentes dosis de abonado magnésico en vides cv. Seyvel Blanc, mostrando que el crecimiento y la producción de materia seca aumentaban con el aporte de Mg. Májer (2004) observó que la aplicación de $\mathrm{Mg}$ en el suelo incrementaba el rendimiento de la vendimia, mientras que los tratamientos foliares no. Sin embargo, en otros trabajos se han detectado incrementos en el rendimiento y en el peso de la baya a través de la aplicación de pulverizaciones foliares de Mg (Usha y Singh, 2002).

Morris y Cawthon (1989), García et al. (1982) y Morris et al. (1980) han documentado que el aumento de la concentración de $\mathrm{K}$ en las dosis de abonado reduce la concentración de $\mathrm{Mg}$ en hojas y peciolos de la vid. Wolf et al. (1983) mostraron una disminución en la concentración de $\mathrm{K}$ en las hojas como resultado de aumentar la concentración de Mg en la solución de tratamiento, lo que indicaba que existía una fuerte interacción entre los dos elementos. Estos autores también observaron una interacción significativa entre $\mathrm{N}$ y $\mathrm{Mg}$. 
Ruhl et al. (1992) investigaron el efecto de la aplicación de Mg en la composición del mosto de distintas variedades de uva cultivadas en diferentes regiones sin observar ningún cambio en el $\mathrm{pH}$ del mosto en la mayoría de los casos. Májer (2004) tampoco encontró ningún cambio en la acidez como respuesta a la aplicación de Mg.

\subsection{6.- Azufre (S).}

El azufre es un constituyente esencial de los aminoácidos cisteína y metionina, de los lípidos, de metabolitos intermedios (acetil-CoA) en la generación de energía (ATP) y transporte de electrones, y de las moléculas que participan en la protección de los tejidos contra el estrés oxidativo (Kopriva, 2006). Los compuestos que contienen azufre son utilizados por las células para contrarrestar las formas reactivas del oxígeno cuya formación se ve favorecida por factores de estreses como la sequía, el frío, el calor, iluminación excesiva y el ataque de hongos (Noctor y Foyer, 1998). El sulfato $\left(\mathrm{SO}_{4}{ }^{2-}\right)$ se puede transportar por el xilema y el floema y se almacena temporalmente en las vacuolas.

La deficiencia de azufre puede dar lugar a un incremento en la susceptibilidad al ataque de patógenos. Los síntomas de deficiencia incluyen amarillamiento (clorosis) de las hojas jóvenes, formación de raíces laterales cerca del ápice radicular y disminución del crecimiento de los brotes, tal vez en respuesta a un aumento de la producción de auxinas (López-Bucio et al,. 2003; Schachtman y Shin, 2007). La aplicación de fungicidas antioidio a base de azufre en la vid contribuye prevenir la deficiencia del elemento (Cooper y Williams, 2004).

\subsection{7.- Hierro (Fe).}

El Fe es un constituyente de los citocromos y otras enzimas implicados en la fotosíntesis, la respiración y la reducción del nitrato (Bavaresco et al., 2010b). La deficiencia se denomina "clorosis férrica" o "clorosis caliza" porque en la mayoría de los casos está inducida por un exceso de caliza en el suelo (Pearson y Goheen, 1998). Debido a la baja movilidad del hierro dentro de la planta, los primeros síntomas de la carencia de Fe se aprecia en las hojas más jóvenes de la planta (del Campillo y Torrent, 1992) Dichas hojas toman una tonalidad que suele evolucionar a amarillenta si la clorosis persiste, pero permaneciendo verdes las zonas próximas a las nervaduras.

Hay muchos factores de tipo genético y ambiental que pueden afectar a la absorción de hierro y su utilización por parte de las plantas. La deficiencia de Fe es reconocida como uno de los principales estreses abióticos que afectan a los cultivos de frutales en suelos calcáreos de la zona mediterránea (Tagliavini y Rombolá, 2001). La clorosis férrica es muy frecuente en el viñedo (Bergmann, 1992; Fregoni, 1998) y conduce a reducciones importantes del rendimiento y pérdidas de calidad de la uva (Mengel, 1994; Bertamini et al., 2002). 
La deficiencia de Fe disminuye el crecimiento vegetativo, la eficiencia fotosintética, el área foliar y la acumulación de materia seca (Tagliavini y Rombolà, 2001; Pestana et al., 2003; Chen et al., 2004a; Bertamini y Nandunchezhian, 2005). La deficiencia de hierro también ocasiona una pobre calidad de los mostos, reduciendo el azúcar y la cantidad de antocianos acumulados en las bayas durante la maduración, e incrementando la acidez total. (Castino et al., 1987; Veilksar et al., 2005).

En muchas ocasiones, el contenido de hierro en las hojas cloróticas, expresado sobre materia seca, es similar o incluso superior al de las hojas verdes. El hecho, conocido como "paradoja de la clorosis férrica" (Römheld, 1997; Zaharieva y Römheld, 2000; Bavaresco et al., 1999), es consecuencia de una acumulación de hierro fisiológicamente inactivo en las hojas enfermas, así como de un menor desarrollo de estas hojas, lo que produce un efecto de concentración del elemento en los tejidos.

\subsection{8.- Manganeso (Mn)}

El Mn es tomado de la solución del suelo por las plantas en forma de catión divalente $\left(\mathrm{Mn}^{2+}\right)$. El $\mathrm{Mn}$ es importante en la fotosíntesis, en la fotólisis del agua y también como activador de muchas enzimas (Salisbury y Ross, 1992). El Mn está involucrado en el metabolismo de proteínas, en el metabolismo oxidativo, en la fotosíntesis y en la biosíntesis de hormonas. En la vid, el aporte de Mn incrementa la fertilidad de las yemas, el cuajado de los frutos y la lignificación de la madera, contribuyendo a mejorar la calidad del vino (Bavaresco et al., 2010b).

La deficiencia de Mn puede incrementar la sensibilidad de los tejidos al estrés oxidativo (Kochian et al., 2004). Los síntomas de deficiencia son en consecuencia más grave en las hojas expuestas al sol. Las hojas cloróticas en respuesta a la insuficiente disponibilidad de Mn aparecen por primera vez en la parte basal de los brotes, poco después de la brotación, con forma de mosaico. Más tarde, las hojas adquieren un color rojizo o color bronce. La deficiencia reduce el crecimiento de los órganos vegetativos y fructíferos, y retrasa la maduración de la uva (Keller, 2010). Por otro lado, las plantas pueden tomar mucho más $\mathrm{Mn}$ del que requieren, y este exceso puede ser extremadamente tóxico (Pittman, 2005). A pesar de sus propiedades antioxidantes a concentraciones normales, el exceso de $\mathrm{Mn}$ induce estrés oxidativo y resulta en síntomas tales como retraso del crecimiento, clorosis de las hojas y necrosis (Kochian et al., 2004). La absorción de Mn también puede verse aumentada en condiciones de deficiencia de Fe y Zn (Pittman, 2005).

\subsection{9.- Cobre $(\mathrm{Cu})$.}

El $\mathrm{Cu}$ puede ser absorbido por las plantas tanto en la forma de catión monovalente como divalente. La forma monovalente es absorbida solo en los suelos húmedos con disponibilidad de oxígeno limitada. El Cu es más abundante en las capas superficiales del suelo, y se combina con carbonatos, minerales de las arcillas, óxidos hidratados de Al, Fe y Mn y materia orgánica (Mengel y Kirby, 2001). El Cu es un elemento móvil en el floema que puede ser retraslocado desde las hojas viejas y 
los órganos vivaces hacia otras partes de la planta que lo demanden, aunque este reciclaje no parece ser muy eficiente para las hojas jóvenes que se ven más afectadas por la deficiencia de Cu que las hojas viejas (Marschner, 1995). Los síntomas de deficiencia incluyen la inhibición del crecimiento de las raíces; brotes raquíticos; hojas pequeñas, deformes, de color verde pálido y a menudo con márgenes rizados. La deficiencia acarrea una disminución de la producción de frutos debido a una polinización deficiente y a una menor viabilidad del embrión de la semilla (Marschner, 1995). En general, es raro encontrar deficiencia de Cu en el viñedo (Marschner, 1995), sobre todo en zonas donde se realizan habitualmente tratamientos cúpricos contra el mildiu.

Como componente de diferentes proteínas, tales como la plastocianina,

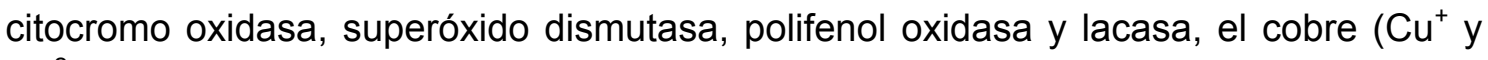
$\mathrm{Cu}^{2+}$ ) participa en la fotosíntesis y la transferencia de electrones en la cadena respiratoria, la lignificación, el metabolismo de la pared celular, la protección contra el estrés oxidativo (junto con el $\mathrm{Zn}$ ) y en la síntesis del cofactor de molibdeno, necesario para la actividad de algunas enzimas tales como la sulfito oxidasa, xantina oxidorreductasa, y aldehído oxidasa (Burkhead et al., 2009). El Cu interviene en la formación del polen, la fecundación, la lignificación de los tejidos y la defensa frente a las enfermedades (Bavaresco et al., 2010b).

\subsubsection{0.- Zinc (Zn).}

Las plantas toman el $\mathrm{Zn}$ del suelo como un catión divalente. La deficiencia tiene como resultado una reducción en el crecimiento de los tejidos jóvenes, pequeñas hojas y entrenudos (Srivastava y Singh, 2009). En las plantas, el Zn juega un papel clave como componente estructural o co-factor regulador de una amplia gama de enzimas en vías metabólicas importantes. Estas rutas forman parte del metabolismo de los hidratos de carbono (tanto en la fotosíntesis como en la conversión de los azúcares en almidón), proteínas, y auxinas, y están implicadas en el mantenimiento de la integridad de las membranas biológicas (Marschner, 1995; Aloway, 2004; Krämer y Clemens, 2006). El Zn mejora favorece el crecimiento de las plantas, incrementa la fertilidad de las yemas, el cuajado, la resistencia a la sequía y a las heladas, y mejora el bouquet del vino (Bavaresco et al., 2010b).

La movilidad del $\mathrm{Zn}$ dentro de las plantas es baja, pero es mayor que la del Fe. El Zn es relativamente inmóvil en el suelo, excepto cuando este tiene carácter ácido (Farago, 1994). La deficiencia de $\mathrm{Zn}$ ocurre comúnmente en suelos con valores de $\mathrm{pH}$ de 6,5 a 8,0. Pueden darse deficiencias en suelos arenosos, en suelos de $\mathrm{pH}$ alto, con alto contenido de $\mathrm{P}$, o en suelos erosionados que han perdido el horizonte superficial (Pearson y Goheen, 1998).

En vides, los síntomas de deficiencia pueden mostrar hojas de pequeño tamaño, con senos peciolares estrechos y dientes afilados, y las áreas internerviales pueden aparecer manchas de color verde claro a amarillo a modo de mosaico. Los síntomas más avanzados incluyen áreas cloróticas en las hojas que acaban necrosándose (Pearson y Goheen, 1998). 
Volschenk et al. (1996) examinaron los efectos de diferentes niveles nutricionales de $\mathrm{Zn}$ en el crecimiento de las vides desarrolladas sobre una solución nutritiva con diferentes concentraciones del elemento. El incremento del nivel de $\mathrm{Zn}$ resultó en un aumento de la producción de materia seca, actividad fotosintética y concentración de $\mathrm{Zn}$ en los órganos de la planta. Ashoori et al., (2013) también demostraron que el suministro de zinc promueve el crecimiento de las vides.

Muchos autores han informado que tratamientos de $\mathrm{Zn}$ aumentan el contenido de sólidos solubles totales en la uva (Mustafa et al., 1986; Singh, 2002), lo que tiene que ver, al menos en parte, con el aumento en la actividad enzimática de la fructosa-1 y 6- bis fosfatasa (Bybordi y Shabanov, 2010). Song et al., (2015) informaron que tratamientos foliares con $\mathrm{Zn}$ producian efectos positivos sobre la fotosíntesis y el desarrollo de la baya en la vid, principalmente a partir del envero, aumentaban la acumulación de sólidos solubles totales, fenoles totales, flavonoides, taninos y antocianinas, y disminuían la concentración de ácidos en el mosto.

\subsubsection{1.- Boro (B).}

El boro se absorbe como ácido bórico, y se transloca lentamente en la planta. La deficiencia provoca una disminución de la síntesis de ADN y ARN y de la división celular en los ápices de tallos y raíces. El B también es conocido por su participación en la elongación del tubo polínico (Salisbury y Ross, 1992). En la vid, el B mejora el desarrollo radicular, la síntesis de lignina, la integridad y funcionalidad de las membranas celulares, la germinación del polen y el crecimiento del tubo polínico, y la acumulación de azúcares en los frutos (Bavaresco et al., 2010b).

La absorción de $\mathrm{B}$ se ve favorecida por el riego, siendo las carencias más frecuentes en condiciones de secano. Por otro lado, una elevada precipitación o riego excesivo puede lixiviar el B especialmente en suelos arenosos (Pearson y Goheen, 1998).

En vides, los síntomas de deficiencia pueden comenzar en el inicio de la floración, en los zarcillos de los extremos de los brotes, que se tornan oscuros, con protuberancias nudosas y necróticas. Pueden darse deformaciones en los entrenudos, muerte de flores, aparecer pecíolos cortos y gruesos, en algunas ocasiones con lesiones longitudinales. Las raíces permanecen cortas y gruesas y forman nudosidades que pueden rajarse longitudinalmente (Pearson y Goheen, 1998).

Los síntomas de toxicidad por exceso de B afectan a las partes aéreas de la planta. Las hojas pueden ser severamente deformadas, con bordes necrosados en los bordes que progresan hacia el tejido internervial. En los ramos principales disminuye el crecimiento apical en favor de los brotes laterales (Pearson y Goheen 1998). Downtom y Hawker (1980) mostraron que una disponibilidad de B excesiva reduce la longitud de los brotes, la producción de materia seca de la planta y el peso de las raíces. 


\subsubsection{2.- Molibdeno (Mo).}

El molibdeno se encuentra disponible para las raíces de la vid en su mayoría como oxianión molibdato $\left(\mathrm{MoO}_{4}{ }^{2-}\right)$. Se requiere en muy pequeñas cantidades por la vid, principalmente como un cofactor que forma la parte activa de las proteínas llamadas molibdeno-enzimas (Schwarz y Mendel, 2006). La deficiencia de Mo trae como consecuencia la acumulación de nitrato debido a la reducción de la actividad de la nitrato reductasa y la falta de síntesis de aminoácidos (Keller, 2010). En consecuencia, los síntomas visuales de la carencia son similares a los de la deficiencia de $\mathrm{N}$ : reducción del crecimiento y del rendimiento de las plantas (Longbottom et al., 2005). La aldehído oxidasa es una molibdeno-enzima, implicada en la producción de auxinas y ABA (Schwarz y Mendel, 2006). La escasez en el aporte de Mo también puede resultar en una reducción del cuajado (Kaiser et al., 2005), y hojas de color verde pálido con márgenes necróticos. Aunque la deficiencia de Mo es infrecuente, puede ocurrir en suelos ácidos y suelos con alto contenido de $\mathrm{Fe}$, especialmente en climas fríos. La toxicidad debida a un exceso de Mo es aún más rara que la deficiencia, los síntomas pueden manifestarse con tonos púrpura en las hojas.

\subsubsection{3.- Níquel (Ni).}

Aunque muchas proteínas contienen $\mathrm{Ni}$, se sabe muy poco acerca de su función en las plantas. Varias enzimas son activadas por $\mathrm{Ni}$, como, la ureasa, implicada en el metabolismo del nitrógeno (Witte et al., 2005), la superóxido dismutasa, que desempeña un papel importante en la defensa contra el estrés oxidativo. La concentración de $\mathrm{Ni}$ en las uvas disminuye durante la maduración, aunque su cantidad total se mantiene constante después del envero (Rogiers et al., 2006). La deficiencia de níquel provoca una reducción del vigor de los brotes, hojas enanas, gruesas y con puntas ahuecadas, pérdida de la dominancia apical, y madera frágil debido a una mala lignificación.

\subsubsection{4.- Cloro (Cl).}

El cloro es absorbido por las plantas en forma de anión monovalente $\left(\mathrm{Cl}^{-}\right)$. La movilidad del $\mathrm{Cl}$ en el suelo es alta, sus sales son solubles y su concentración en la solución del suelo varía dentro de un amplio intervalo (Marschner, 1995). El Cl está involucrado en la fotolisis oxidativa del agua del PS II (reacción de Hill), El cloruro actúa en la estabilización del potencial de la membrana y está implicado en la turgencia y la regulación del $\mathrm{pH}$ de las células. El $\mathrm{Cl}$ es el anión inorgánico más abundante en las células vegetales y juega un papel cuantitativamente importante en el equilibrio iónico, y particularmente en la regulación de la apertura y cierre de los estomas Se requiere $\mathrm{Cl}^{-}$para la activación de al menos tres enzimas, que son la amilasa, la asparagina sintetasa y la ATPasa (Marschner, 1995). 
Los principales síntomas de la deficiencia de $\mathrm{Cl}$ son marchitamiento, reducción de la superficie de la hoja, y disminución del crecimiento. La carencia trae consigo una reducción de las tasas de división y crecimiento celular (Marschner, 1995). 


\section{2.- PROBLEMÁTICA NUTRICIONAL DEL VIÑEDO EN SUELOS CALIZOS.}

El exceso de calcio, en combinación con otras condiciones físico-químicas del suelo, origina en la viña una problemática nutricional específica.

Los suelos calcáreos cubren más del $30 \%$ de la superficie de la Tierra (Marschner, 1995) y se encuentran ampliamente distribuidos en las regiones áridas y semiáridas de la zona mediterránea. Se ha estimado que estos suelos comprenden más de un tercio de la superficie terrestre del planeta. Los suelos calcáreos son aquellos que contienen grandes cantidades de carbonato de calcio, que afectan claramente a sus propiedades físicas y químicas. El margen en el que el suelo podría ser considerado calcáreo ha sido discutido por muchos autores. Hilal et al. (1973) y Anter (1984) marcan el nivel en el $8 \%$ de carbonatos. Hagin y Tucker (1982) definen suelo calcáreo como aquel en que los niveles de $\mathrm{Ca}$ y $\mathrm{Mg}$ extraíbles exceden la capacidad de intercambio catiónico.

No hay que identificar suelos calcáreos con suelos alcalinos ( $\mathrm{pH}$ alto). Los suelos calcáreos contienen carbonatos de metales alcalinotérreos, calcio $\mathrm{Ca}$ y $\mathrm{Mg}, \mathrm{y}$ en un grado menor, carbonatos de los metales de transición como $\mathrm{Fe}$, Zn y Mn (Brown et al. 1978; Talibudeen 1981). La calcita y aragonita $\left(\mathrm{CaCO}_{3}\right)$, la dolomita $(\mathrm{CaMg}$ $\left.\left(\mathrm{CO}_{3}\right)_{2}\right)$, y la magnesita $\left(\mathrm{MgCO}_{3}\right)$ son los minerales que se encuentran en mayor proporción en los suelos calcáreos (Hunt, 1972; Brown et al 1978). Los carbonatos presentes en el suelo pueden ser primarios, originados a partir de materiales madre ricos en carbonatos, o bien secundarios, formados por re-precipitación parcial de los carbonatos disueltos. La alternancia frecuente de períodos húmedos y secos, y la existencia de una larga estación seca, no favorecen la lixiviación de los carbonatos en los suelos (Balba 1987; Brady y Weil, 1999).

La reactividad de los carbonatos puede ser una medida más útil que el contenido total de carbonatos en el suelo (Loeppert et al. 1994). Esta reactividad está relacionada con el tamaño de las partículas, la mineralogía, la morfología de la superficie, y el estado de agregación de los carbonatos con otros componentes del suelo (Hartwig y Loeppert 1991).

Los suelos calcáreos de la zona mediterránea favorecen la inmovilización de micronutrientes debido a la presencia de carbonatos, un $\mathrm{pH}$ alto, y condiciones climáticas de baja pluviometría y alta evapotranspiración. En tales condiciones, los patrones de biodisponibilidad de los micronutrientes son difíciles de predecir, siendo modulada por la acción de los carbonatos y las interacciones con otras fases reactivas del suelo tales como la materia orgánica (Martín-Calvarro et al., 2014). 


\subsection{1.- Propiedades físicas.}

Los carbonatos influyen tanto en la formación de horizontes de los suelos, como de los agregados estructurales. Las pobres propiedades físicas de muchos subsuelos calcáreos, por ejemplo alta densidad aparente y baja macroporosidad (Lewis, 1991), se pueden agravar con texturas finas y la acción de cementación de materiales calcáreos (Curran, 1999). Los suelos calcáreos pueden ser compactados o cementados en profundidad (Utzig y Herring, 1975), y pueden formar costras superficiales que pueden dificultar la brotación y el crecimiento de plántulas (Tinus, 1987; Marion et al., 1993). La compacidad de los suelos calcáreos puede tener efectos negativos sobre la penetración de las raíces, la infiltración de agua, y el intercambio de gases.

La tasa de agregación y su estabilidad está influenciada, entre otros factores, por el pH del suelo (Haynes y Naidu, 1998). La carga superficial negativa de las partículas de arcilla aumenta con el $\mathrm{pH}$, incrementando la repulsión de partículas; a menudo las partículas de arcilla floculan a valores altos de pH (Haynes y Naidu, 1998). Según Omara (1993), los efectos directos e indirectos sobre la estabilidad de los agregados dependen de la proporción de arcilla fina y gruesa y del contenido de $\mathrm{CaCO}_{3}$.

Seni y Marshed (1998) señalaron que el aumento del contenido en caliza activa incrementa la estabilidad de la estructura y consecuentemente, la conductividad hidráulica del suelo. Sin embargo, para Abdel-Mawgoud et al. (1998) la presencia de $\mathrm{CaCO}_{3}$ en la fracción de arcilla y limo tiende a disminuir la conductividad hidráulica.

La profundidad de enraizamiento es más superficial en los suelos mal drenados que en los bien drenados. Badibanga et al. (1992) estudiaron el crecimiento de las raíces en suelos calcáreos y ácidos, observando que en suelos calcáreos la masa total de las raíces era mayor, y la biomasa de las raíces secundarias menor que en suelos ácidos.

\subsection{2.- Propiedades químicas.}

Las condiciones químicas de los suelos calcáreos están dominadas por la presencia de $\mathrm{CaCO}_{3}$ (Loeppert, 1986). Los suelos calcáreos tienen el $100 \%$ de saturación de bases y el calcio es el catión dominante en el complejo de cambio y en la solución del suelo (Loeppert y Suárez, 1996). Los carbonatos se caracterizan por una solubilidad relativamente alta, reactividad y naturaleza alcalina; su disolución produce una concentración alta de $\mathrm{HCO}_{3}{ }^{-}$en la solución del suelo que mantiene el pH en un rango de 7,5 a 8,5. La reacción global para la disolución y re-precipitación de $\mathrm{CaCO}_{3}$ es:

$$
\mathrm{CaCO}_{3}+\mathrm{H}_{2} \mathrm{O} \rightarrow \mathrm{Ca}^{2+}+\mathrm{HCO}_{3}^{-}+\mathrm{OH}^{-}
$$


Los carbonatos de calcio y magnesio se encuentran entre los constituyentes del suelo menos estables, o más reactivos (Hunt, 1972). El pH en suelos calcáreos con iones de calcio libres oscila entre 8,2 a 8,4, mientras que en el caso de iones de magnesio el valor del $\mathrm{pH}$ es superior en 1,5 unidades.

El pH del suelo es una medida de la concentración de los iones hidrógeno $\left(\mathrm{H}^{+}\right)$ en la disolución del suelo (expresa por tanto, su grado de acidez o alcalinidad). Según los valores del $\mathrm{pH}$, se pueden considerar las siguientes categorías de suelos: muy ácidos $(\mathrm{pH}<5,5)$; ácidos ( $\mathrm{pH}$ comprendido entre 5,5-6,5); neutro ( $\mathrm{pH}$ entre 6,5-7,5); alcalinos ( $\mathrm{pH}$ entre $7,5-8,5)$ y muy alcalinos $(\mathrm{pH}>8,5)$.

El pH ejerce una gran influencia en las reacciones de adsorción/desorción y de disolución/precipitación que regulan la disponibilidad de nutrientes como el fósforo, hierro, cobre, zinc, manganeso y boro). El pH influye decisivamente en la descomposición de la materia orgánica, y por ello en la facilidad con la que pueden hacerse disponible para las plantas las formas orgánicas que contienen $\mathrm{N}, \mathrm{S}$ y $\mathrm{P}$. Considerando ambos aspectos, el intervalo de $\mathrm{pH}$ en que es máxima la disponibilidad de la mayoría de los nutrientes está entre 6 y 7 (Marschner, 1995). 2003):

El pH del suelo depende, fundamentalmente de tres factores (Parra et al.,

- La proporción de iones $\mathrm{Ca}^{2+}, \mathrm{Mg}^{2+}, \mathrm{K}^{+}$y $\mathrm{Na}^{+}$adsorbidos en los sitios de intercambio catiónico. Estos cationes actúan químicamente como bases (generan alcalinidad), por lo que se denominan bases de cambio. En consecuencia, cuanto mayor sea el porcentaje de dichos cationes en relación con la $\mathrm{CIC}$ (o porcentaje de saturación de bases, $\mathrm{PSB}$ ), mayor es el pH.

- La presencia de carbonato cálcico $\left(\mathrm{CaCO}_{3}\right)$. Bastan pequeñas cantidades, incluso menores del $1 \%$, para que el $\mathrm{pH}$ del suelo se sitúe entre 8 y 8,4 . En estas condiciones, la CIC del suelo está completamente saturada de bases $(\mathrm{PSB}=100 \%)$.

- La proporción del ión $\mathrm{Na}^{+}$adsorbido en los sitios de intercambio catiónico. Cuanto mayor es el porcentaje de sodio intercambiable (PSI) en relación con la $\mathrm{CIC}$, mayor es el $\mathrm{pH}$. En particular, los suelos con $\mathrm{PSI}>15 \%$ suelen tener $\mathrm{pH}>$ 8,5 , si no tienen exceso de bases solubles.

El PSB del suelo está muy condicionado por el contenido en $\mathrm{Ca}, \mathrm{Mg}, \mathrm{Na}$ y $\mathrm{K}$ del material originario (especialmente por el contenido en calcio), y por el clima, que determina la cantidad de agua capaz de atravesar el perfil, decalcificar el material de origen y lavar las bases. Muchos suelos vinícolas de la zona mediterránea se han desarrollado a partir de rocas y sedimentos que, o bien son calcáreos, o bien, aún sin serlo, presentan contenidos abundantes de calcio. La naturaleza de tales materiales originarios, junto con la escasez de precipitaciones propia del clima mediterráneo, han sido determinantes para que la mayoría de los suelos de vid mantengan una alta saturación de bases y un $\mathrm{pH}$ de ligeramente ácido a netamente alcalino (en el intervalo de 6,0-8,5), así como para que haya una especial abundancia de suelos calcáreos con pH en torno a 7,8-8,4 (Hidalgo, 1999). 


\subsection{3.- Limitaciones nutricionales.}

El exceso de calcio, en combinación con otras condiciones físico-químicas del suelo, origina en la viña una problemática nutricional específica.

Se requiere una mejora de la gestión nutricional para el cultivo exitoso en los suelos calcáreos. El manejo de la nutrición en suelos calcáreos difiere de la de suelos no calcáreos, debido al efecto del $\mathrm{pH}$ del suelo en la disponibilidad de nutrientes del suelo y las reacciones químicas que afectan a la pérdida o la fijación de casi todos los nutrientes. La presencia de $\mathrm{CaCO}_{3}$ afecta directa o indirectamente la química y la disponibilidad de nitrógeno, fósforo, magnesio, potasio, manganeso, zinc, cobre y hierro (Obreza et al., 1993; Marschner, 1995).

Los principales síntomas de una nutrición alterada en los suelos calcáreos son clorosis y crecimiento atrofiado. Esto se atribuye al elevado $\mathrm{pH}$ y a la reducción de la disponibilidad de nutrientes, ya que la toxicidad directa de iones bicarbonato $\left(\mathrm{HCO}^{3-}\right)$ en los sistemas fisiológicos y bioquímicos es mucho menos probable (Pearce et al., 1999).

El pH del suelo ejerce una gran influencia en la asimilación de elementos nutritivos, ya que facilita o dificulta su disolución y crea, a veces, antagonismos iónicos. El comportamiento de los distintos elementos nutritivos con relación al pH es el siguiente (Fuentes-Yagüe, 2000):

- Nitrógeno: Las sales amónicas y nítricas son solubles en todo el intervalo de $\mathrm{pH}$ que pueda presentar el suelo. La nitrificación tiene lugar con gran intensidad en intervalos comprendidos entre 6,5 y 8 . No obstante, los valores de $\mathrm{pH}$ alcalino que se encuentran en suelos calcáreos afectan la tasa de transformación del $\mathrm{N}$, que a su vez pueden influir en la eficiencia de uso del $\mathrm{N}$ por las plantas.

- Fósforo: Con pH igual a 6, disminuye el fósforo disponible, debido a que el hierro y el aluminio se encuentran muy solubilizados y provocan la formación de fosfatos insolubles. En el intervalo comprendido entre 6 y 7,5 ocurre la mejor utilización del fósforo. Con pH superior a 7,5 los aniones fosfato reaccionan con el Ca y el Mg para formar compuestos de fosfato de solubilidad limitada.

- Potasio: La solubilidad del potasio es alta en todo el intervalo de pH que pueda presentar el suelo. Cuando existe mucho calcio ( $\mathrm{pH}$ superior a 8) se crea un antagonismo iónico entre el calcio y el potasio, en donde el exceso de calcio impide la absorción de K. El K disponible se encuentra generalmente en un suministro adecuado en suelos calcáreos. Esto es debido a los altos niveles nativos de $\mathrm{K}$ intercambiable, que apenas se lixivian en las regiones de baja precipitación (Brady y Weil, 1999). La liberación de K no intercambiable es mayor para los suelos arcillosos, lo que indica que estos suelos tienen una mayor oferta a largo plazo de $\mathrm{K}$ disponible que los suelos de textura ligera (Havlin y Westfall, 1985).

- Calcio y magnesio: Estos elementos son muy asimilables con valores altos de $\mathrm{pH}$. Cuando este excede de 8,5 es casi segura la presencia de sodio, que 
sustituye al calcio y al magnesio en el complejo de cambio, precipitándose ambos como carbonatos insolubles.

Un desequilibrio entre iones $\mathrm{Mg}$, Ca y $\mathrm{K}$ disponibles para la planta puede acarrear deficiencias de $\mathrm{Mg}$ y/o $\mathrm{K}$ en los cultivos. En suelos calcáreos, la proporción de Ca de otros cationes intercambiables en general supera el $80 \%$, y una baja proporción de Mg intercambiable (menos del $4 \%$ ) puede conducir a la deficiencia de $\mathrm{Mg}$ en las plantas (Hagin y Tucker, 1982). Los altos niveles de $\mathrm{Ca}$ en suelos suprimen, en parte, la absorción de $\mathrm{Mg}$ y $\mathrm{K}$ por los cultivos, presumiblemente, a través de la competencia entre $\mathrm{Ca}$, $\mathrm{Mg}$ y $\mathrm{K}$ (Marschner, 1995). Por ejemplo, en la vid, el antagonismo K-Ca dificulta la absorción de K por la planta y resulta en la disminución de la concentración de $\mathrm{K}$ en las bayas, lo que lleva a los vinos más ácidos (García et al., 1999). Por lo tanto, los cultivos que crecen en suelos con alto contenido en $\mathrm{Ca}$ requieren a menudo niveles de fertilización por encima de los normales de $\mathrm{Mg}$ y $\mathrm{K}$ para una nutrición satisfactoria (Brady y Weil, 1999).

- Hierro, cobre y zinc: Estos elementos son muy solubles con pH inferior a 5,5. $\mathrm{El} \mathrm{pH}$ del suelo es el factor más importante que regula el suministro de $\mathrm{Fe}, \mathrm{Zn}$ y $\mathrm{Mn}$ en suelos calcáreos $\mathrm{A}$ medida que aumenta el $\mathrm{pH}$ del suelo disminuye su solubilidad, de tal forma que en suelo alcalino es muy escasa su absorción por las plantas. El hierro es considerablemente menos soluble que el $\mathrm{Zn}$ o $\mathrm{Mn}$ en suelos con un $\mathrm{pH}$ de 8 . Los suelos calcáreos pueden contener altos niveles de Fe total, pero en formas no disponible para las plantas. La deficiencia de Fe o clorosis férrica, es común en muchos cultivos. Las deficiencias de zinc y manganeso son claramente dependiente del $\mathrm{pH}$, y la concentración de ambos en la solución del suelo disminuye 100 veces por cada unidad de aumento en el pH (Lindsay, 1972). A niveles altos de $\mathrm{pH}$ se forman precipitados, tales como hidróxidos y carbonatos de $\mathrm{Zn}$.

- Cobre: La solubilidad del cobre es dependiente del pH y disminuye con el aumento del mismo. Sin embargo, los cambios apreciables en la solubilidad se producen en el intervalo de $\mathrm{pH}$ por debajo de 5 , y por encima de este valor la solubilidad no cambia mucho. La deficiencia de cobre se encuentra generalmente en suelos arenosos lixiviados (Hagin y Tucker, 1982).

- Boro: La solubilidad es máxima en el intervalo de pH comprendido entre 5 y 7. A partir de $\mathrm{pH} 8$ su solubilidad es insignificante. Existe una interacción entre la disponibilidad de $\mathrm{B}$ y la presencia de iones de $\mathrm{Ca}$. 


\section{3.- LA CLOROSIS FÉRRICA.}

La clorosis férrica es uno de los principales estreses abióticos en la zona mediterránea y otras regiones semiáridas. Se conoce por clorosis férrica un variado conjunto de síntomas relacionados con una nutrición deficiente de hierro, que afecta generalmente a plantas sensibles cultivadas en suelos calcáreos (Rombolà y Tagliavini, 2006). Estos suelos suponen el 39\% de la superficie total de suelos en el mundo con un total de 1000 millones de hectáreas (Celik y Katkat, 2010). Este tipo de suelos tienen con frecuencia más del $20 \%$ de carbonatos de calcio y magnesio, además de unos $\mathrm{pH}$ entre 7,5 y 8,5 . Estas condiciones reducen la disponibilidad de hierro en el suelo y afectan también a los procesos metabólicos de asimilación en las plantas (Pestana et al., 2005).

La clorosis férrica se manifiesta en multitud de especies frutales (melocotonero, manzano, kiwi, olivo, vid, cítricos), cultivos hortícolas (tomate, pepino, fresa), cereales (maíz, sorgo), leguminosas (altramuz, garbanzo, cacahuete, soja) (Sanz et al., 1992; Mengel y Kirkby, 2001; Rombolà y Tagliavini, 2006), muchos de ellos de gran importancia económica en España. Existen referencias que hacen alusión al problema de la clorosis férrica desde hace más de 150 años (Gris, 1844 y 1847; Moltz, 1907).

\subsection{1.- Síntomas de la clorosis férrica.}

Los viñedos afectados por clorosis manifiestan los primeros síntomas en primavera, cuando se produce el más activo desarrollo de la vegetación, progresando generalmente de forma irregular en el viñedo, en función de la uniformidad del terreno y de las condiciones propias de las plantas, incluyendo el portainjerto.

El nombre de clorosis férrica, derivado del término griego $x \lambda \omega \mu$ ó $($ (pálido), hace referencia al principal síntoma de la deficiencia de hierro: el amarilleamiento internervial de las hojas (Figura 1.1a), debido a la inhibición de la síntesis de clorofila. Las hojas afectadas son en este caso las más jóvenes, por la escasa movilidad del Fe en el floema de la planta (Korcak, 1987; Del Campillo y Torrent, 1992; Marschner, 1995). Si la carencia persiste, se puede llegar a una decoloración total de las hojas, con defoliación y muerte de la planta en casos extremos (Figura 1.1b). La actividad fotosintética se ve reducida según el contenido en clorofila va disminuyendo, con lo cual la clorosis férrica provoca una reducción del crecimiento de los brotes y hojas, problemas en el agostamiento y la maduración y escaso crecimiento del fruto (Hidalgo, 1999). Como consecuencia, el rendimiento de plantas herbáceas, frutales, olivo y vid se ve reducido (Tagliavini y Rombolà, 2001 y Alvarez-Fernandez et al., 2006). 

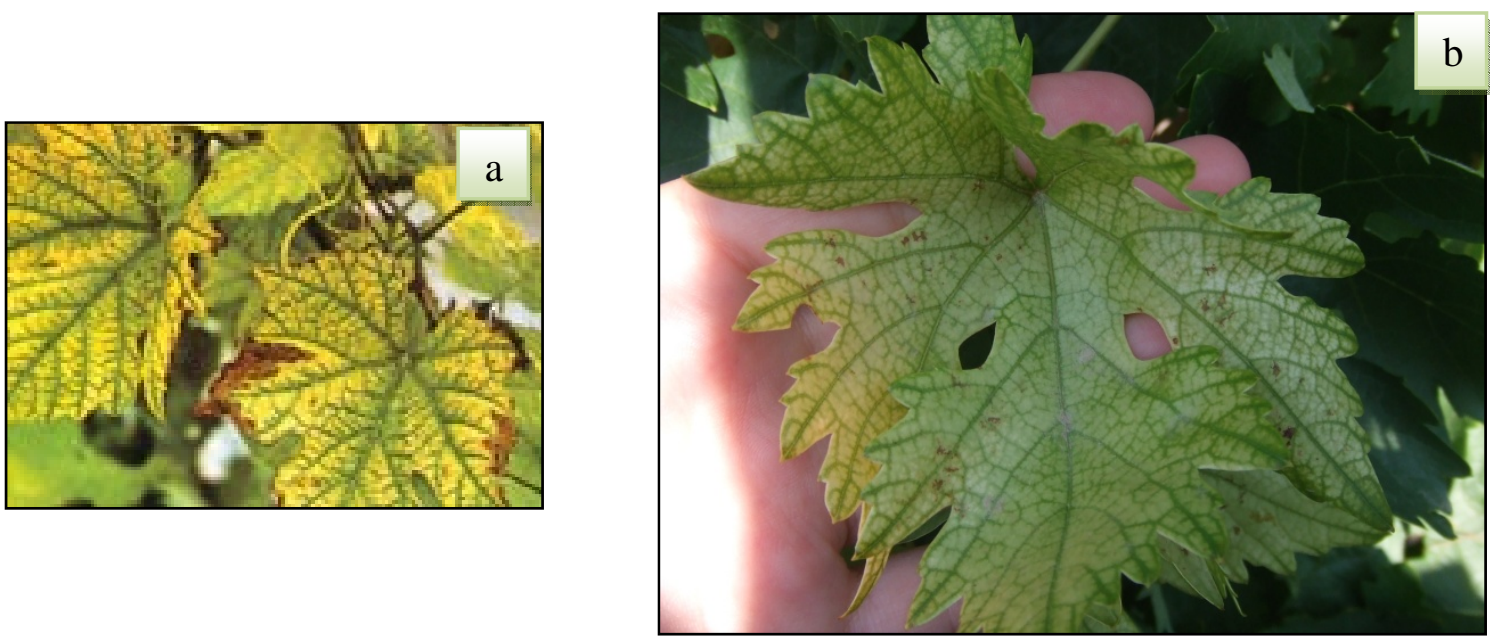

Figura 1.1. Hojas afectadas por clorosis férrica, a) tonalidades verde claro, que evolucionan a amarillento mientras los nervios permanecen verdes; b) con aparición de manchas necróticas en los bordes.

Consecuencias importantes de la clorosis férrica para la vid según Hidalgo (1999) son: i) Modificaciones en la composición de los tejidos y de la savia. ii) Las proporciones relativas de constituyentes minerales no son las mismas en los tejidos cloróticos que en los sanos. iii) Las relaciones $\mathrm{K} / \mathrm{Ca}$ y $\mathrm{P} / \mathrm{Fe}$ son más elevadas en las hojas cloróticas. iv) El Ca, $\mathrm{P}$ y $\mathrm{K}$ tienen tendencia a acumularse en los tejidos de las plantas atacadas de clorosis. v) El Fe es prácticamente tan abundante en las hojas cloróticas como en las sanas, e incluso en ocasiones más, cuando la clorosis no se produce por carencia directa del mismo. vi) Entre los constituyentes orgánicos, los compuestos nitrogenados no parecen sufrir variaciones cuantitativas. Los ácidos aminados libres son, sin embargo, más abundantes en los tejidos cloróticos, donde la síntesis de proteínas parece ralentizarse.

\subsection{2.- El hierro en el sistema suelo-planta.}

\subsubsection{1.- El hierro en el suelo.}

El hierro es un elemento abundante en la corteza terrestre donde supone el $5,1 \%$ en peso; solo es superado por el silicio, el oxígeno y el aluminio (Jackson, 1958). Cantidades entre $2,5-4,5 \mathrm{mg} \cdot \mathrm{kg}^{-1}$ de Fe extraído con DPTA en el suelo se consideran suficientes para satisfacer las necesidades de las vides (Lindsay and Norwell, 1978). La causa de la deficiencia de hierro no suele ser su escasez, sino su baja solubilidad o disponibilidad para las plantas en la solución del suelo (Marschner, 1995; Römheld y Nikolic, 2007).

El hierro es un microelemento, que se encuentra en combinaciones minerales, formando parte de compuestos edáficos más o menos estables: silicatos y 
aluminosilicatos, carbonatos, sulfuros, óxidos e hidróxidos. Se encuentra en la naturaleza tanto en forma de Fe (III) como de Fe (II), dependiendo del estado redox del sistema.

Las formas posibles del Fe en el suelo son las siguientes:

\section{Soluble:}

- Se encuentra en condiciones reductoras, como $\mathrm{Fe}^{2+}$ y sus formas hidroxiladas $\mathrm{Fe}(\mathrm{OH})^{\text {n2-n }}$ en la disolución del suelo.

- Cuando el potencial de oxidación y la acidez sean altos se encuentra como $\mathrm{Fe}^{3+}$ y sus formas hidroxiladas $\mathrm{Fe}(\mathrm{OH})^{\mathrm{n} 3-\mathrm{n}}$.

- En combinaciones orgánicas formando complejos, en forma divalente y trivalente.

\section{Insoluble:}

- Como oxihidróxidos férricos (goetita, hematita, maghemita, lepidocrocita, ferridrita...).

- En forma de oxihidróxidos mixtos de Fe (III) y Fe (II) como la magnetita o el óxido ferrósico.

- En forma de carbonato $\left(\mathrm{FeCO}_{3}{ }^{-}\right)$o siderita, en suelos muy reducidos.

Los contenidos de arcilla y materia orgánica influyen también en la disponibilidad del Fe. Según Lindsay, (1979) en los suelos arcillosos, existe una tendencia a adsorber el $\mathrm{Fe}$. Un contenido adecuado de materia orgánica actúa de forma favorable en el aprovechamiento del Fe por parte del cultivo, debido a sus propiedades acidificantes y reductoras, así como a la capacidad de determinadas sustancias húmicas para formar quelatos en condiciones adversas de $\mathrm{pH}$.

La mayoría del hierro se presenta en las estructuras cristalinas de numerosos minerales. Al igual que para el resto de nutrientes, el origen del $\mathrm{Fe}$ en el suelo son los minerales primarios, que incluyen silicatos ferromagnéticos, como olivino, augita hornblenda y biotita. Estos minerales constituyen la mayor fuente de hierro en las rocas ígneas. A partir de la meteorización de los minerales primarios se libera $\mathrm{Fe}$ soluble, que podrá ser utilizado por los organismos, unirse a distintos ligandos orgánicos, o bien ser transformado en minerales secundarios como sulfuros, carbonatos, minerales de arcilla, y fundamentalmente óxidos e hidróxidos de distinta composición y grados de cristalización.

Debido a la extremadamente baja solubilidad de los óxidos de $\mathrm{Fe}^{3+}$ en el rango de $\mathrm{pH}$ normal de los suelos, el hierro liberado precipita rápidamente como óxido o hidróxido. Sólo una pequeña parte del hierro oxidado se incorpora a silicatos laminares secundarios (arcillas) y/o es complejado por la materia orgánica (figura 1.2). La reversibilidad de la reacción de oxidación-reducción del hierro juega un papel importante en su comportamiento en los suelos (Schwertmann, 1991). Bajo condiciones de anaerobiosis, los microorganismos pueden utilizar los óxidos de $\mathrm{Fe}^{3+}$ 
como aceptores finales de electrones (pasando a $\mathrm{Fe}^{2+}$ ) para realizar la degradación oxidativa de la materia orgánica (Schwertmann y Taylor, 1989). A pesar de su baja concentración en los suelos, los óxidos de hierro tienen un alto poder pigmentante y determinan el color de muchos suelos, por encontrarse recubriendo muchas de las partículas de éstos (Allen y Hajek, 1989). Estos compuestos son muy eficaces en la retención de aniones como fosfato, molibdato y silicato, y elementos traza como $\mathrm{Cu}$, $\mathrm{Pb}, \mathrm{Zn}, \mathrm{Co}, \mathrm{Cr}$ y $\mathrm{Ni}$ (Schwertmann y Taylor, 1989), algunos de los cuales son esenciales para la nutrición de las plantas. Los óxidos de hierro poseen un efecto cementante que les permite influir en la estructura de los suelos (Allen y Hajek, 1989; Schwertmann, 1991). La goethita es el óxido de hierro más estable y por ello el más frecuente en los suelos, siendo responsable del color ocre de muchos de ellos. De acuerdo con Chen y Barak (1982) la solubilidad de los óxidos e hidróxidos de hierro disminuye en el orden siguiente: $\mathrm{Fe}(\mathrm{OH})_{3}$ amorfo $>\mathrm{Fe}(\mathrm{OH})_{3}$ del suelo $>\mathrm{Y}-\mathrm{Fe}_{2} \mathrm{O}_{3}$ maghemita $>\mathrm{\gamma}-\mathrm{FeOOH}$ lepidocrocita $>\alpha-\mathrm{Fe}_{2} \mathrm{O}_{3}$ hemita $>$ goethita.

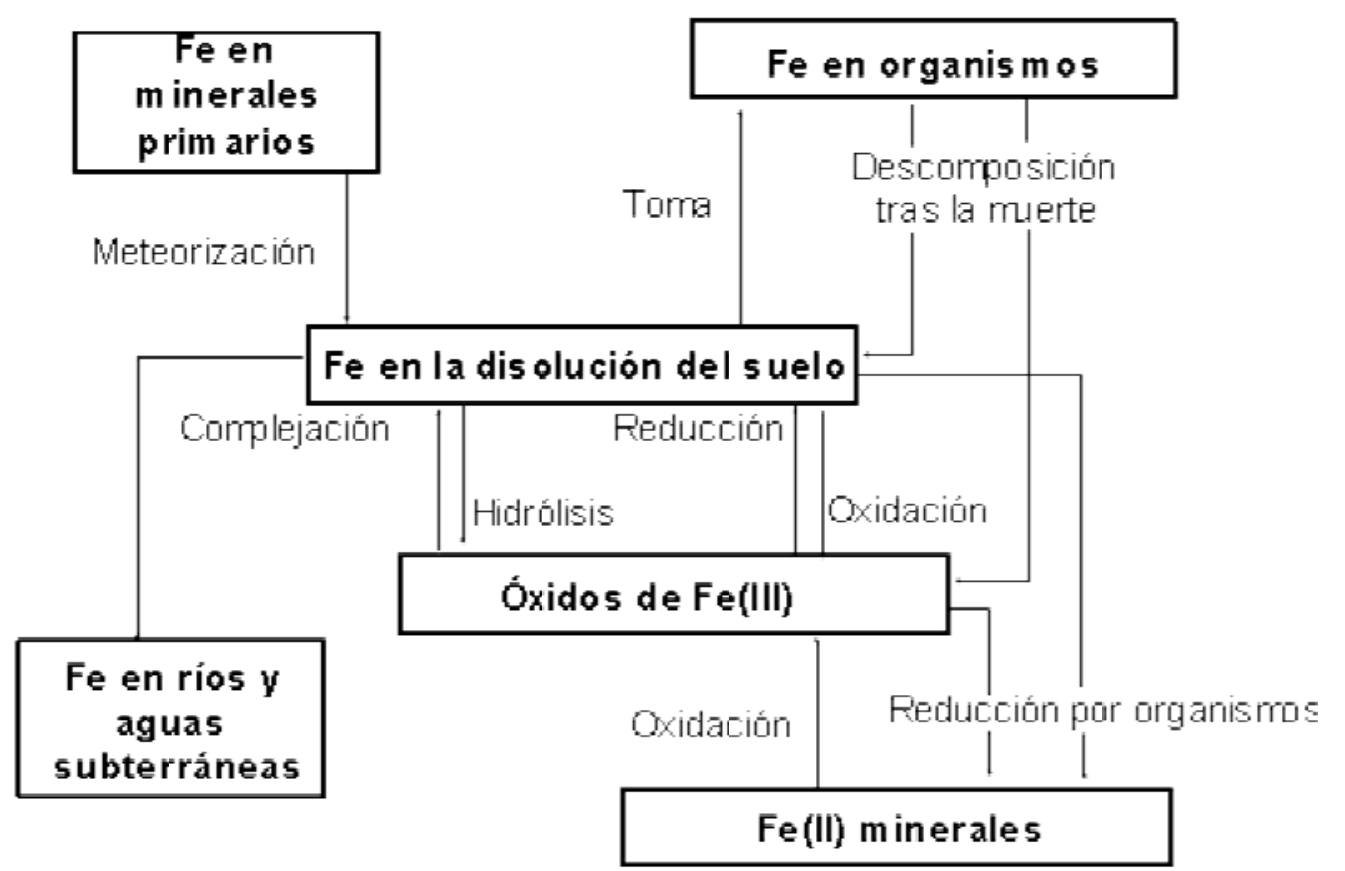

Figura 1.2. Ciclo del hierro en el suelo (Adaptada de Schwertmann, 1991).

\subsubsection{2.- Asimilación del hierro por la planta.}

De los dos estados de oxidación en que se presenta el hierro en el suelo, es conocido que la planta toma preferentemente el $\mathrm{Fe}^{2+}$ sobre el $\mathrm{Fe}^{3+}$. Para ello, se ve obligada a reducir la forma oxidada predominante en los suelos. Este proceso lo realiza un enzima reductasa (figura 1.3), situada en la membrana plasmática de las células de la raíz (Bienfait, 1985; Römheld y Marschner, 1986) que es capaz de reducir aceptores externos de electrones de alto potencial como el ferricianuro (+360 mV) y posiblemente $\mathrm{O}_{2}(+280 \mathrm{mV})$, así como moléculas de quelatos férricos sintéticos con 
potenciales menores (entre $+100 \mathrm{y}+250 \mathrm{mV}$ ) (Nikolic, 1998). Este enzima alcanza su máxima actividad a pH entre 4 y 5 (Schmidt y Bartels, 1997). Las temperaturas extremas (muy por encima o por debajo de $25^{\circ} \mathrm{C}$ ), los valores de $\mathrm{pH}$ mayores de $7,5 \mathrm{y}$ la presencia de metales pesados reducen la actividad de la enzima (Lucena, 2000).

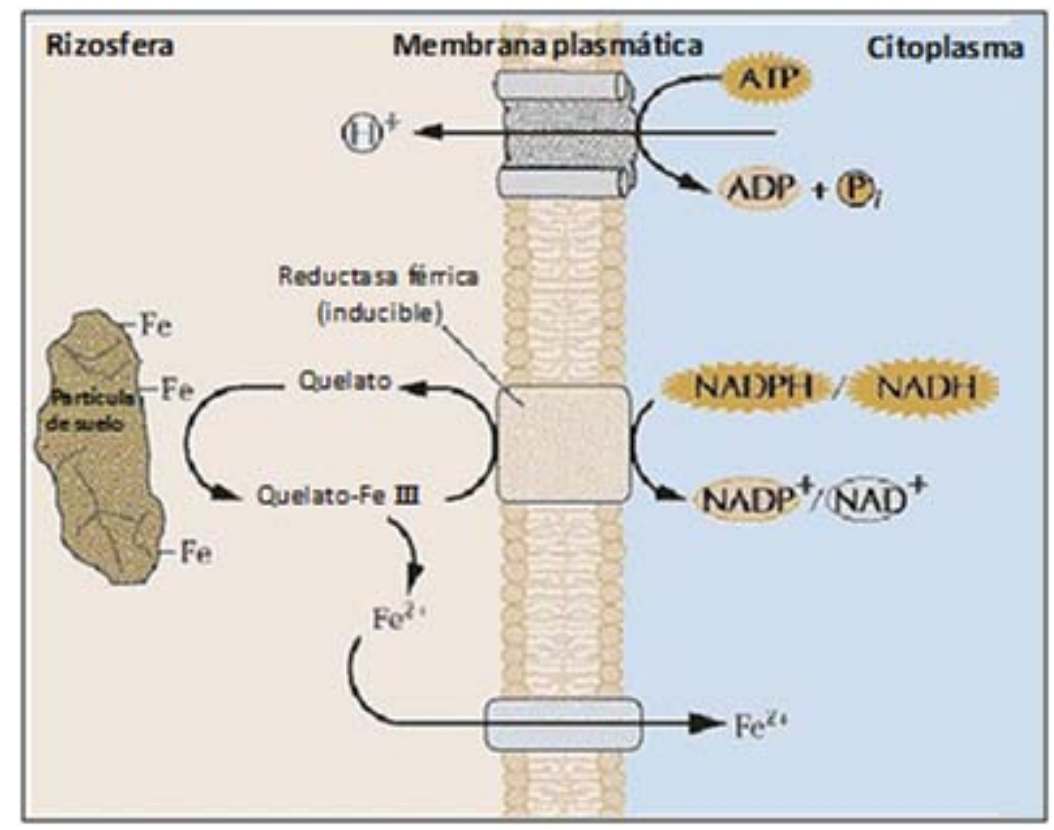

Figura 1.3. Sistema estándar de reducción de hierro en las plantas (Buchanan et al. ,2000)

\subsubsection{3.- Respuesta de las plantas a la deficiencia de hierro.}

En situaciones de carencia de hierro en el medio, las plantas superiores han desarrollado una serie de mecanismos para aumentar la disponibilidad del $\mathrm{Fe}$ en la disolución del suelo. Según Marschner et al. (1986) y Hopkins et al., (1992) existen dos grupos de plantas dependiendo del modelo de respuesta que desarrollen bajo este déficit, plantas de Estrategia I y de Estrategia II. La Estrategia I se presenta en dicotiledóneas y monocotiledóneas, excepto las gramíneas.

\section{Estrategia I.}

Se caracteriza por dos subestrategias diferentes, presentándose una tercera en algunos muchos casos. La primera subestrategia consiste en la expulsión de $\mathrm{H}^{+}$por las raíces a la rizosfera. Esta subestrategia es la menos frecuente y se presenta solo en algunas dicotiledóneas (Marschner et al., 1986; Zocchi y Cocucci, 1990; Toulon et al., 1992). Aunque la bomba redox transmembrana puede contribuir a la excreción neta de protones, es más probable que el fuerte aumento en esta excreción en situaciones de deficiencia de hierro se deba a una mayor actividad de la bomba de 
expulsión de protones de la membrana plasmática (ATPasa) que a la reductasa. La acidificación de la rizosfera, además de contribuir a la solubilización del hierro del suelo, mejora la actividad de la reductasa y su afinidad por el sustrato. Esto puede atribuirse a una neutralización de la carga negativa de las superficies celulares que impide la repulsión de los quelatos de hierro cargados negativamente por los lugares de reducción (Schmidt, 2006). La liberación de $\mathrm{H}^{+}$va unida a cambios morfológicos en el sistema radicular de las plantas, como engrosamientos subapicales, incremento del número de raíces secundarias, pelos absorbentes y células de transferencia (Römheld y Kramer, 1983; Marschner et al., 1986; López-Millán et al., 2001; Romera y Alcántara, 2004).

Las células rizodérmicas de transferencia son centros de flujo de protones en las raíces con deficiencia de hierro (Römheld y Marschner, 1986). Una vez que se suministra hierro, las células de transferencia degeneran en uno o dos días con la consiguiente disminución de la liberación de protones.

Junto a la emisión de protones, la exudación de ácidos orgánicos (cítrico, oxálico, málico) por parte de la raíz de las plantas contribuye a disminuir el pH rizosférico (Jones, 1998; Jones et al., 2003) y participa además en la disolución de Fe de procedencia mineral, favoreciendo el aumento de la disponibilidad del mismo para la planta. La concentración de ácidos orgánicos en la rizosfera varía en función de la especie vegetal y de la disponibilidad de $\mathrm{P}$ (la excreción de ácidos orgánicos también es una estrategia utilizada por muchas plantas para la absorción de $\mathrm{P}$ en situaciones de deficiencia) o Fe, pudiendo alcanzar valores de 50 a $9000 \mu \mathrm{M}$ (Jones et al., 1996 y Dinkelaker et al., 1989, respectivamente).

La subestrategia II, consiste en un aumento de la actividad de una reductasa unida a la membrana plasmática en las células de la rizodermis, responsable de la reducción del $\mathrm{Fe}^{3+}$, lo que incrementa la velocidad de descomposición de los quelatos de $\mathrm{Fe}^{3+}$ y consiguientemente la absorción del hierro reducido por la planta. Se trata de un enzima transmembrana (reductasa de quelatos férricos), capaz de reducir el Fe con electrones provenientes de NADPH citoplasmático (Brüggemann, 1993; Rabotti y Zocchi, 1994; Susín et al., 1996; Rombolà et al., 2000). Esta disociación de los quelatos es el principal mecanismo de la Estrategia I (figura 1.4). Según Brüggemann, (1993), las plantas de estrategia I poseen dos sistemas de reducción de $\mathrm{Fe}^{3+}$, la reductasa "estándar" y la reductasa "turbo", con una capacidad reductora unas 20 veces mayor que la anterior. La actividad de la reductasa es promovida por la emisión de $\mathrm{H}^{+}$(Marschner et al., 1986; Marschner y Römheld, 1994) e inhibida a alto pH (Schmidt, 2003) y con altas concentraciones de $\mathrm{HCO}_{3}^{-}$en suelos calcáreos (SiebnerFreibach et al., 2003).

La tercera subestrategia se pone en marcha en ciertas especies, como consecuencia de la acidificación de la rizosfera, y consiste en la liberación por las raíces de sustancias con propiedades reductoras, principalmente compuestos fenólicos (Römheld y Marschner, 1986) relacionados con la actividad de la enzima peroxidasa. Entre estos compuestos están los ácidos caféico (encontrado en tomate por Olsen et al., 1981), ferúlico, clorogénico y el p-curámico. Parece ser que la importancia de estos compuestos radica más en su poder quelante que en su 
capacidad reductora (Römheld y Marschner, 1986). La expulsión de estas sustancias aumenta al disminuir el $\mathrm{pH}$.

Las respuestas frente a estrés de Fe por parte de las plantas de estrategia I, están reguladas hormonalmente. El etileno y el óxido nítrico (NO) se consideran reguladores de genes para la adquisición de Fe en este tipo de plantas (Chen et al., 2010; García et al., 2011).

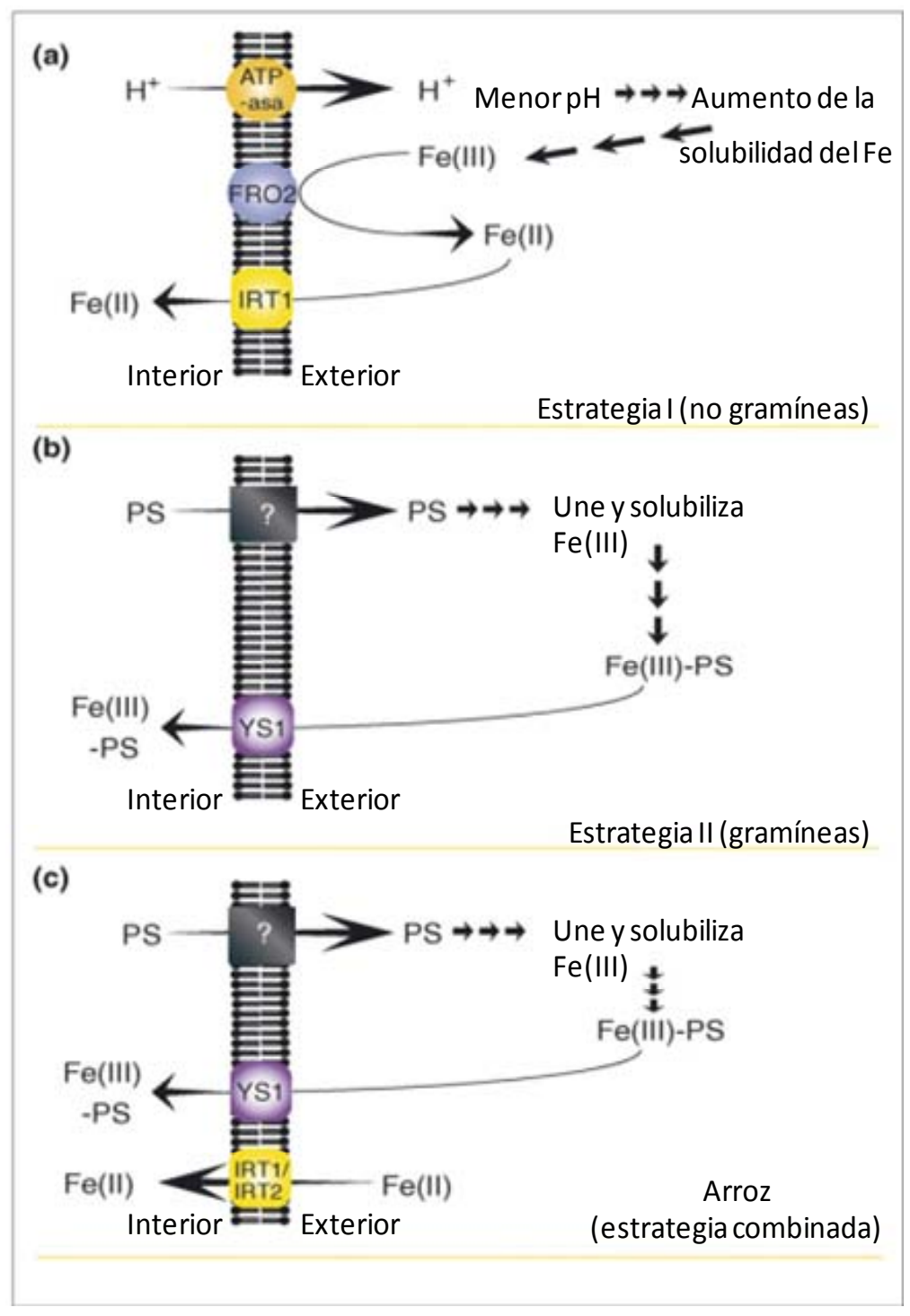

Figura 1.4. Modelos de respuesta de las plantas a la deficiencia de hierro. a) Estrategia I, b) Estrategia II y c) Estrategia combinada (Walker y Connolly, 2008). 


\section{Estrategia II.}

Las plantas gramíneas no presentan mecanismos de acidificación del medio o de incremento de la capacidad reductora en situaciones de escasa disponibilidad de Fe, pero cuentan con un mejor comportamiento que las plantas de estrategia I en dicha situación. Estas plantas producen una serie de compuestos capaces de quelatar el $\mathrm{Fe}^{3+}$ (Takagi, 1976; Römheld y Marschener, 1990; Kraemer et al., 2006) denominados fitosideróforos. La estrategia II ha sido descrita en trigo, cebada, sorgo, arroz, maíz y diversas pratenses (Marschner y Römheld, 1994)

Los fitosideróforos son aminoácidos que no forman parte de las proteínas. Tienen una alta afinidad por el Fe, siendo su constante de estabilidad de $10^{17}-10^{18}$, lo que les permite competir con la fracción húmica del suelo por la absorción del elemento (Cesco et al., 2000) y aumentar la biodisponibilidad del mismo (Kraemer et al., 2006). Además, los fitosideróforos son capaces de disolver los óxidos de Fe cristalinos, como la goethita (Hiradate y Inoue, 1998; Kraemer et al., 2006), poniendo a disposición de las plantas que los producen una parte del Fe a la que no tienen acceso el resto de plantas.

Las concentraciones de fitosideróforos en la rizosfera son variables, desde el rango micromolar (Shi et al., 1988) al milimolar (Römheld, 1991). Su producción es máxima en los ápices radiculares durante el día (a las 3-6 horas desde la salida del sol (Takagi et al., 1984; Marschner et al., 1987; Reichman y Parker, 2007). Dentro de las gramíneas, son las más eficientes en la producción de fitosideróforos las C3 que las C4 (Clark et al., 1988; Kawai et al., 1988; Onyezili y Ross, 1993).

Los fitosideróforos no son específicos para el Fe y forman también quelatos estables con otros cationes divalentes, como Zn, Ni y Cu (Murakami et al., 1989). Los sideróforos producidos por microorganismos presentan, por el contrario, una alta especificidad por el Fe frente a otros cationes (Parker et al., 2005; Kraemer et al., 2006).

En definitiva, la estrategia II es más eficiente en la adquisición de Fe que la estrategia I debido a que esta última precisa de la reducción de $\mathrm{Fe}^{+3}$ a $\mathrm{Fe}^{+2}$ mediante la reductasa, cuya actividad se ve drásticamente reducida en ambientes neutros y alcalinos (Römheld y Marschner, 1986; Römheld, 1991). El mayor inconveniente de la estrategia II es la rápida degradación de los fitosideróforos por parte de los microorganismos del suelo (Takagi et al., 1988).

\section{Cambios morfológicos y fisiológicos producidos en la raíz.}

La deficiencia de hierro en plantas de Estrategia I (Römheld, 1991; LópezMillán et al., 2001) da lugar a considerables cambios morfológicos y fisiológicos en la raíz, aumento en el diámetro de la zona apical radicular y en la formación de pelos radiculares. Estos cambios están asociados a la formación de células de transferencia que forman parte del mecanismo de Estrategia I para la absorción de hierro. Con el aporte de hierro desaparecen estos cambios. 
En raíces de plantas deficientes en hierro se han encontrado distintos cambios metabólicos que incluyen:

- Acumulación de ácidos orgánicos, principalmente citrato y malato (LópezMillán et al., 2001; Rombolà et al., 2000; Abadía et al., 2002).

- Cambio en el estado de oxidación de diversas sustancias en el citoplasma (Schmidt y Schuck, 1996). Zaharieva y Abadía, (2003) y Zaharieva et al., (2004) han encontrado, en raíces de remolacha azucarera deficientes en hierro, aumento de la concentración de ácido ascórbico y glutatión reducido (GSH), y cambios en la actividad de los enzimas ascorbato reductasa de radicales libres (AFR-R), ascorbato peroxidasa (APX), y glutatión reductasa (GR), que como componentes del ciclo ascórbico-glutatión participan en la defensa antioxidante de las células.

- Aumento en la actividad de la fosfoenolpiruvato carboxilasa (PEPC) y de varios enzimas del ciclo de los ácidos tricarboxílicos (Rombolà et al. 2000; López-Millán et al., 2001), probablemente como consecuencia de la alcalinización del citoplasma asociada a la liberación de protones al exterior (Rabotti et al., 1995). El enzima PEPC cataliza la reacción de bicarbonato con un ácido orgánico $\mathrm{C} 3$, fosfoenol piruvato, generando oxalacetato, que es trasformado a malato por malato deshidrogenasa (Rombolà, et al., 2000). Estos ácidos orgánicos (Pontiggia et al., 2003) podrían mantener el equilibrio iónico y de $\mathrm{pH}$ en el citoplasma de las células radiculares (Davies, 1986). Todos estos hechos parecen conducir en las raíces de plantas deficientes en hierro, a una mayor disponibilidad de aminoácidos libres, en particular aspartato y glutamato, que daría lugar a un aumento en la síntesis de ARN y proteínas.

\subsubsection{4.- Transporte de hierro en la planta.}

Las responsables del transporte Fe (II) al citoplasma parecen ser proteínas unidas a la reductasa. La activación de los mecanismos de respuesta en la membrana plasmática parece deberse a proteínas de la familia LEA (late embryofenesis abundant) con capacidad para unirse al hierro (Schmidt, 2006).

Diferentes investigaciones (Robinson et al., 1999; Waters et al., 2002; Li et al., 2004) han permitido conocer que:

- Los genes correspondientes a la reductasa férrica, AtFRO2, LeFRO1 y PsFRO1, dan lugar a polipéptidos de entre 712 y 725 aminoácidos con un peso molecular entre 80,5 y $81,5 \mathrm{KDa}$. Estas proteínas contienen lugares para la unión de FAD y NADPH.

- La regulación de los genes de reductasa LeFRO1 es diferente en raíces y en hojas (Schmidt, 2006), lo que indica importancia distinta de la etapa de reducción en la absorción de hierro por las hojas.

- La principal ruta para la entrada de hierro en las células radiculares es IRT1 (Iron Regulated Transporter 1) una proteína de la familia ZIP (Zrt-, Irt-like 
Protein), con gran afinidad por el hierro. Todos los transportadores ZIP caracterizados hasta la fecha introducen cationes divalentes en el citoplasma. Estos transportadores parecen estar codificados por familias multigénicas, lo que sugiere que cada uno de ellos tiene una función específica (Gaither y Eide, 2001). La naturaleza exacta del ión que transportan puede ser muy diversa, así como su especificidad, pero típicamente incluyen $\mathrm{Fe}^{2+}, \mathrm{Zn}^{2+}, \mathrm{Mn}^{2+}$ y $\mathrm{Co}^{2+}$ (Eide et al., 1996; Zhao y Eide, 1996; Korshunova et al., 1999), aunque también pueden transportar cationes no esenciales como el $\mathrm{Cd}^{2+}$ (Weber et al., 2004). Los miembros de esta familia de transportadores deben su nombre a dos de ellos: IRT1, de Arabidopsis thaliana (Eide et al., 1996) y ZRT1 (Zinc Regulated Transporter 1) de Saccharomyces cerevisiae (Zhao y Eide, 1996). Su expresión génica está inducida en la epidermis radicular por la deficiencia de hierro. Con el aporte de hierro la proteína se degrada impidiendo que se produzca una absorción de hierro hasta niveles tóxicos. Schmidt, (2006) ha encontrado una regulación similar para el enzima regulador de la reducción de hierro (AtFRO, enzima quelato reductasa, localizada en la membrana de las células epidérmicas de la raíz de Arabidopsis thaliana) que para IRT1.

- La activación de la proteína $\mathrm{H}^{+}$-ATPasa en la membrana plasmática no se produce en todas las especies de Estrategia I, y cuando lo hace varía en función de distintos factores como el equilibrio en la toma catión/anión, exudados radiculares, y la forma en que sea absorbido el nitrógeno (JuárezSanz et al., 2007).

Tras la absorción, el exceso de hierro es complejado o secuestrado en las células para evitar el efecto tóxico en el citoplasma debido a la generación de radicales libres vía efecto Fentón producida por el Fe (II) (Mengel y Kirkby, 2001). Para evitar esta toxicidad el ión ferroso es transportado hasta los cloroplastos donde es oxidado a $\mathrm{Fe}(\mathrm{OOH})$ y secuestrado por una fosfoproteína multimérica denominada fitoferritina (Theil, 1987), Esta fitoferritina constituye una reserva de Fe no tóxica en el interior de la célula, importante para procesos como la germinación de las semillas (Lobreaux y Briat, 1991) o la formación de nódulos de las leguminosas (Ko et al., 1987).

El hierro se transporta a través del córtex radicular vía simplasto por medio de los plasmodesmos, al parecer en forma de Fe (II)-nicotinamida (Stephan, 2002). A continuación, todavía en el simplasto del sistema radicular, el Fe (II) sufre una oxidación a Fe (III). Una vez en forma de Fe (III) se transporta a la parte aérea de la planta vía xilema, en forma de un complejo soluble de dicitrato (Tiffin, 1970; LópezMillán et al., 2001; Mengel y Kirkby, 2001; Stephan, 2002). Una vez el Fe llega a las hojas, debe atravesar de nuevo la membrana plasmática de las células foliares. Este paso requiere de nuevo la reducción de Fe (III) a Fe (II), Ilevada a cabo por un enzima reductasa similar al de la raíz (Brüggemann et al., 1993; González-Vallejo et al., 1998, 1999, 2000; Rombolà et al., 2000). La capacidad para transportar el hierro está relacionada con la respuesta de las plantas a estados carenciales.

Aunque el transporte se realiza fundamentalmente por vía xilema, también se ha encontrado Fe en el floema. El transporte en el floema se realiza como Fe(III)nicotinamina (Becker et al., 1992; Stephan y Scholz, 1993). 


\subsubsection{5.- Funciones del hierro en la planta.}

La facilidad del hierro para cambiar de estado de oxidación y formar quelatos estables y solubles hace que esté implicado en un gran número de funciones fisiológicas (figura 1.5). El hierro se presenta en los vegetales formando parte de numerosos sistemas enzimáticos (Marschner et al., 1986; Terry y Zayed, 1995; Mengel y Kirkby, 2001), tanto hemídicos como no hemídicos. Dentro de los sistemas enzimáticos hemídicos se encuentra en: citocromos y complejos proteicos hierroporfirínicos (constituyentes de los sistemas redox de cloroplastos, mitocondrias y de la nitrato reductasa), leghemoglobina (enzima implicada en el proceso de fijación del nitrógeno -Marschner, 1995-), catalasas (intervienen en la fotorespiración y en el ciclo de Calvin y facilitan la dismutación de $\mathrm{H}_{2} \mathrm{O}_{2}$ en $\mathrm{H}_{2} \mathrm{O}$ y $\mathrm{O}_{2}$ en los cloroplastos -Römheld y Marschner, 1990-) y peroxidasas (favorecen la eliminación de $\mathrm{H}_{2} \mathrm{O}_{2}$ en los cloroplastos y catalizan la polimerización de fenoles para producir lignina -Marschner, 1995-).

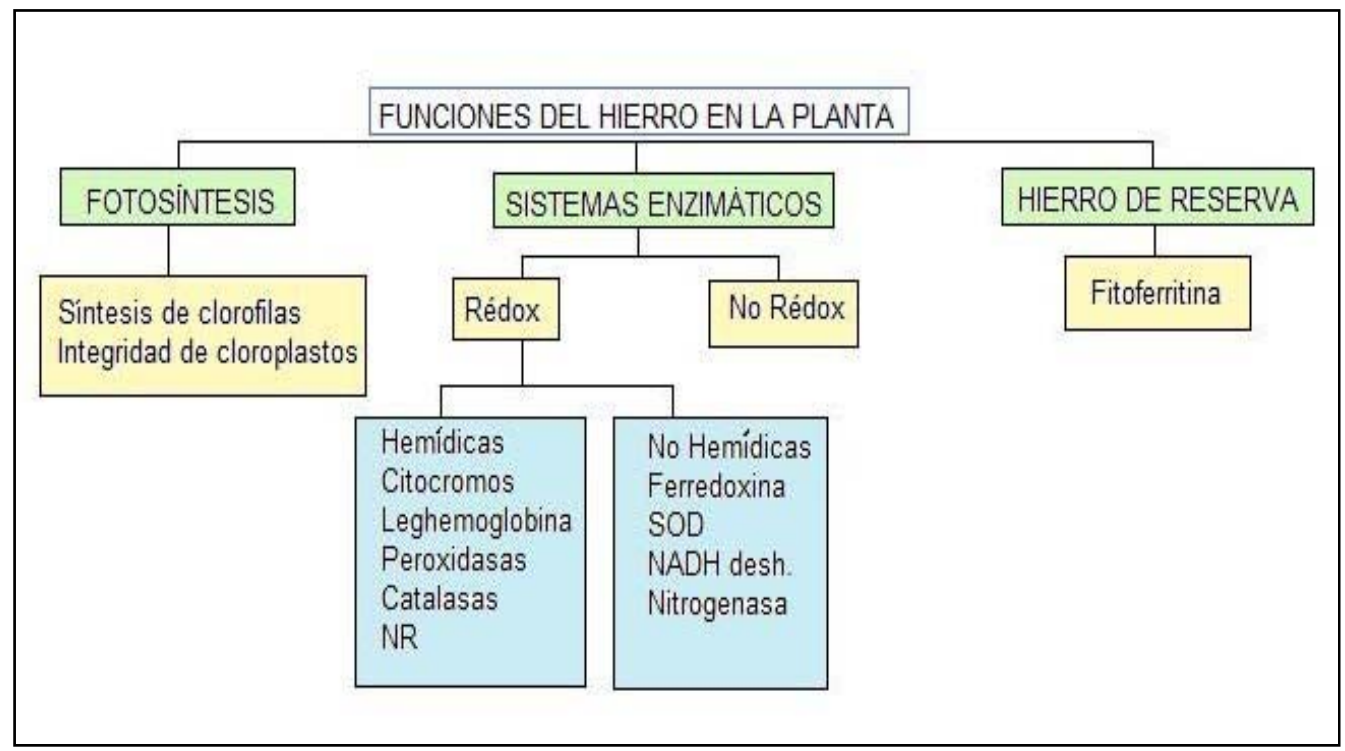

Figura 1.5. Funciones del Fe en la planta (Álvarez-Fernández, 2000).

El hierro juega un papel muy importante en la fotosíntesis, no sólo por su acción en la síntesis de clorofilas (Miller et al., 1984) sino también por su influencia en la morfología de los cloroplastos (Terry y Abadía, 1986; Marschner, 1995). Cuando el efecto de la deficiencia de hierro es considerado a nivel ultraestructural, el número de membranas tilacoides por cloroplasto disminuye marcadamente (Platt-Aloia et al., 1983).

Los sistemas enzimáticos no hemídicos se caracterizan porque el Fe está incorporado con un grupo tiol de cisteína o con $\mathrm{S}$ inorgánico formando enlaces Fe-S o con ambos a la vez (Römheld, 1991). El más conocido de los componentes de los sistemas no hemídicos es la ferredoxina, proteína que actúa como aceptor final de electrones en la fotosíntesis, la reducción de nitrato y de sulfato (Mengel y Kirkby 2001; Marschner, 1995). Otros enzimas con hierro no hemídico son las riboflavinas, la 
acotinasa (que cataliza la isomerización de citrato a isocitrato en el ciclo de los ácidos tricarboxílicos), y las superóxidodismutasas (isoenzimas que eliminan los radicales libres).

Las plantas deficientes en Fe acumulan unas 200 veces más riboflavinas que las plantas sanas. Esta acumulación se produce porque la carencia da lugar a alteraciones en el metabolismo de las purinas, donde el enzima xantina oxidasa se ve fuertemente dañado (Schlee et al., 1968).

Hay una serie de enzimas menos conocidas en las que el hierro actúa bien como un componente metálico en reacciones redox o como un elemento de unión entre enzima y sustrato (Marschner, 1995). Entre ellas están las lipoxigenasas que regulan la peroxidación de lípidos, estando implicadas en procesos de senescencia y en la resistencia a enfermedades.

\subsection{3.- Propiedades del suelo que afectan a la disponibilidad de hierro para las plantas.}

\subsubsection{1.- Formas de hierro en el suelo.}

En general, los óxidos de $\mathrm{Fe}^{+3}$ son poco solubles, y se ordenan por solubilidad decreciente en: ferrihidrita $\left(\mathrm{Fe}_{5} \mathrm{O}_{8} \mathrm{H} \cdot 4 \mathrm{H}_{2} \mathrm{O}\right)>$ maghemita $\left(\mathrm{\gamma}-\mathrm{Fe}_{2} \mathrm{O}_{3}\right)>$ lepidocrocita $(\mathrm{\gamma}-$ $\mathrm{FeOOH})>$ hematites $\left(\alpha-\mathrm{Fe}_{2} \mathrm{O}_{3}\right)>$ goethita $(\alpha-\mathrm{FeOOH})($ Lindsay y Schwab, 1982). En suelos calcáreos predominan los óxidos de Fe cristalinos como la goethita y hematites, en menor proporción ferrihidrita y más raramente lepidocrocita y maghemita (Schwertmann, 1991).

La disponibilidad de Fe para la planta está en función del contenido, mineralogía y cristalinidad de los óxidos de Fe del suelo (Loeppert y Hallmark, 1985), de manera que las formas amorfas, como la ferrihidrita, son más fácilmente movilizables por la planta (Vempati y Loeppert, 1986). El tamaño de partícula de los minerales de $\mathrm{Fe}^{+3}$ influye mucho en su reactividad, que esta lógicamente condicionada por su superficie reactiva.

Para determinar la disponibilidad de Fe en el suelo para las plantas se utilizan diferentes métodos:

- Extracción con oxalato amónico a pH 3 ( $\left.\mathrm{Fe}_{\mathrm{ox}}\right)$ (Schwertmann, 1964) modificado por Benítez et al. (2002) para suelos calcáreos a fin de evitar un aumento del $\mathrm{pH}$ de la disolución debido a los carbonatos. Este reactivo disuelve los óxidos de Fe poco cristalinos, el Fe complejado por la fracción orgánica y, parcialmente, los óxidos de Fe menos solubles (Borggaard, 1982). Es la fracción de Fe más interesante desde el punto de vista de la clorosis férrica, pues ha mostrado buena correlación con la concentración foliar de clorofila en varias especies cultivadas en suelos calcáreos (Morris et al., 1990; Del Campillo y Torrent, 1992; Yangüas et al., 1997; Benítez et al., 2002; Reyes et al., 2006; Díaz et al., 2009b). 
- Extracción con citrato-ascorbato a pH 6 ( $\left.\mathrm{Fe}_{\mathrm{ca}}\right)$ (Reyes y Torrent, 1997), que disuelve también los óxidos de Fe poco cristalinos. Tiene menor valor predictivo de clorosis férrica que el método de extracción con oxalato.

- Extracción con DTPA (ácido dietilentriaminopentaacético) a pH 7,3 (Fe $\left.\mathrm{DTPA}_{\mathrm{DT}}\right)$ (Lindsay y Norvell, 1978), utilizado como estimación del Fe "labil", es decir, el Fe de la disolución del suelo y el muy fácilmente soluble de la fase sólida.

- Extracción con hidroxilamina, propuesto para cuantificar los óxidos de Fe no cristalinos (Hall et al., 1996) y que ha sido modificado por de Santiago et al. (2008) para dar una estimación del Fe más fitodisponible en suelos calcáreos.

\subsubsection{2.- El pH del suelo.}

La solubilidad de Fe y, por tanto su disponibilidad para la planta, está influenciada por el $\mathrm{pH}$ de la disolución del suelo. Esta solubilidad disminuye 1000 veces por cada unidad que aumenta el $\mathrm{pH}$, para valores de $\mathrm{pH}$ superiores a 4 (Brown, 1978), llegándose a alcanzar concentraciones de $\mathrm{Fe}$ cercanas a $10^{-10} \mathrm{M}$ para los valores de $\mathrm{pH}$ típicos de los suelos calcáreos (figura 1.6). Estas concentraciones están muy alejadas de las necesarias para un crecimiento óptimo de las plantas, que deben ser superiores a $10^{-7} \mathrm{M}$ (Loeppert, 1986).

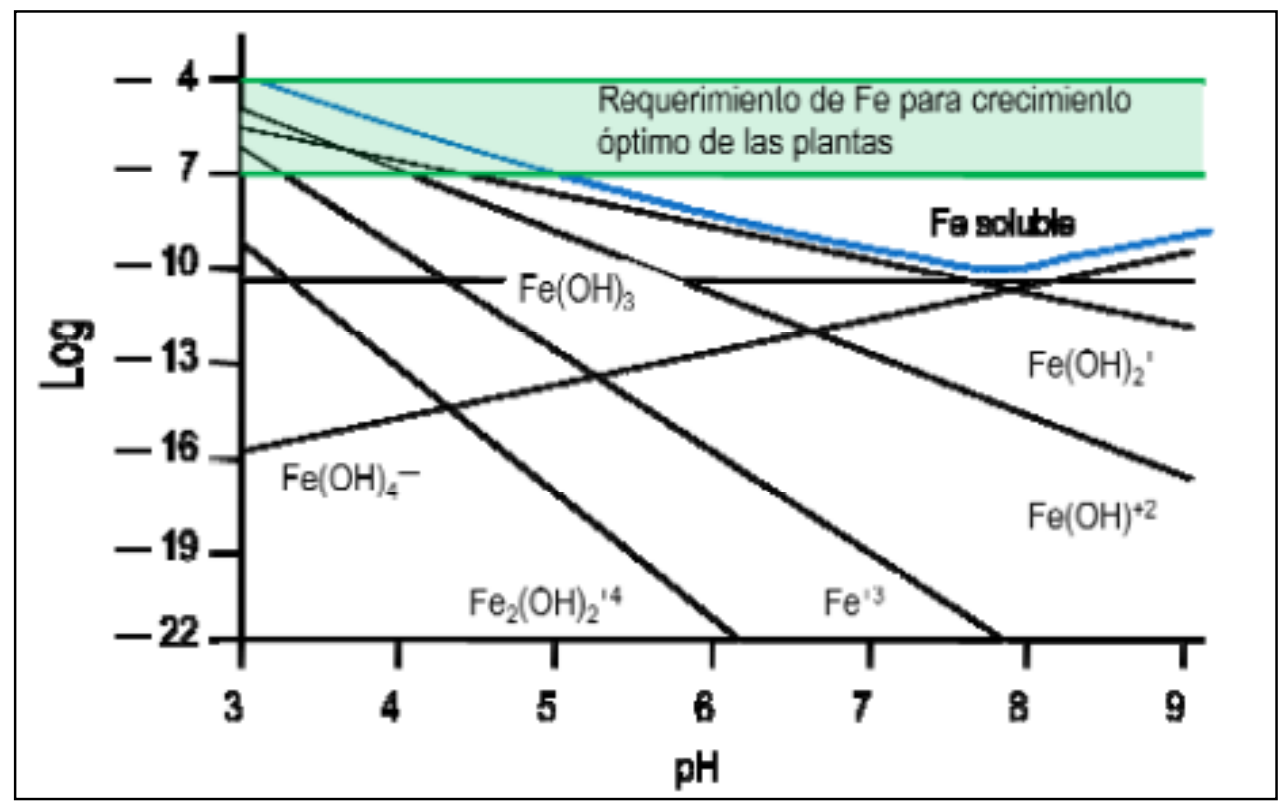

Figura 1.6. Solubilidad de las distintas especies de Fe.

En condiciones ácidas y no oxidantes predomina la forma $\mathrm{Fe}^{2+}$ soluble sobre la forma oxidada $\mathrm{Fe}^{3+}$ (figura 1.7). Sin embargo, en presencia de oxígeno y en medio alcalino, el $\mathrm{Fe}^{2+}$ es oxidado rápidamente a $\mathrm{Fe}^{3+}$, que precipita en forma de óxidos $\mathrm{e}$ hidróxidos 


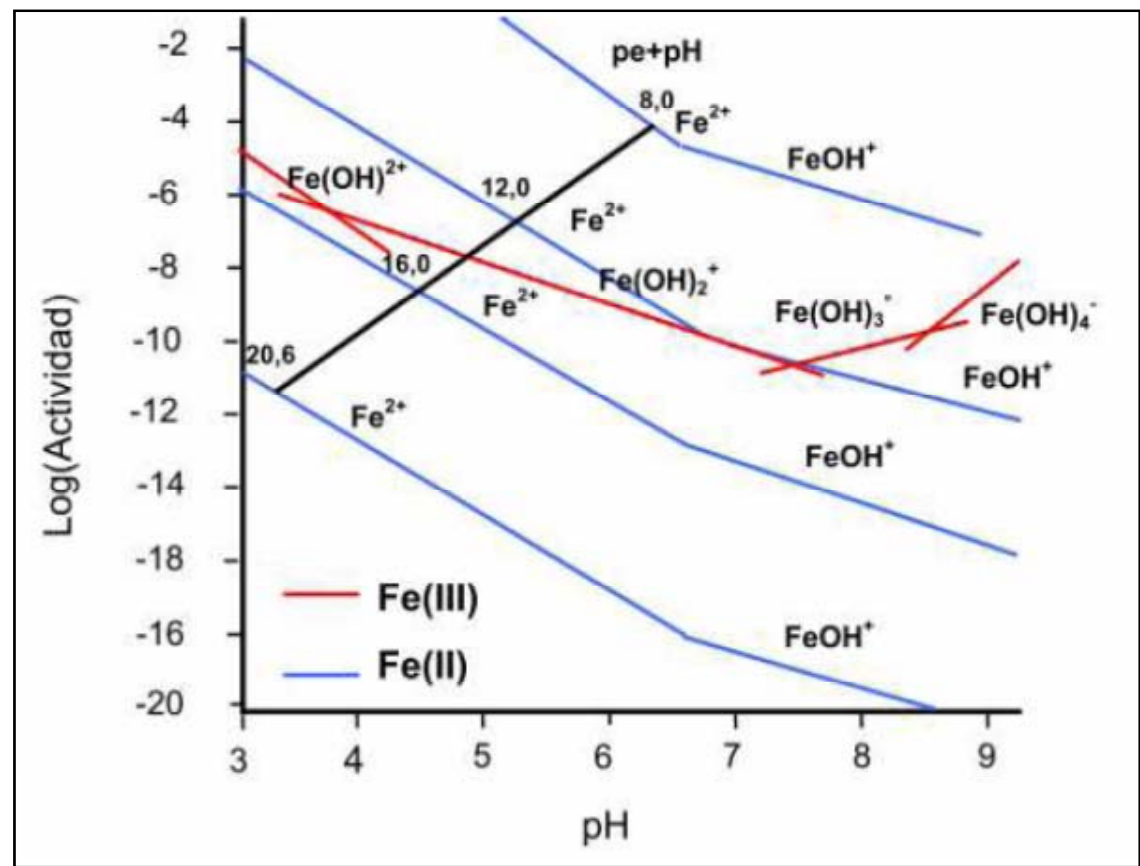

Figura 1.7. Efecto del $\mathrm{pH}$ sobre las especies $\mathrm{Fe}^{2+}$ y $\mathrm{Fe}(\mathrm{OH})^{+}$en comparación con las especies hidroxiladas de $\mathrm{Fe}(\mathrm{III})$ en equilibrio con el Fe del suelo (Lindsay y Schwab, 1982).

\subsubsection{3.- Carbonatos e ion bicarbonato.}

El contenido de carbonatos del suelo tiene gran influencia sobre las propiedades físicas y químicas de los suelos y con la disponibilidad de Fe. Sin embargo, diversos autores han mostrado que esta variable no está siempre bien correlacionada con el contenido de clorofila en hoja (Loeppert et al., 1988; del Campillo y Torrent, 1992; Yangüas et al., 1997).

(Drouineau, 1942) definió el equivalente de carbonato cálcico activo (ECCA) o "caliza activa", como la fracción de carbonato capaz de reaccionar con el oxalato amónico a $\mathrm{pH}$ alcalino. Este parámetro constituye una mejor herramienta que el contenido total en carbonatos para la predicción de la incidencia de la clorosis férrica en plantas sensibles en suelos calcáreos, dado que ofrece una medida del tamaño de partícula y de la superficie específica de los carbonatos. Esta fracción de los carbonatos es más reactiva y, por lo tanto, capaz de generar y mantener altos niveles de HCO3- en la solución del suelo (Inskeep y Bloom, 1986). Sin embargo, esta medida tampoco está sistemáticamente correlacionada con el grado de clorosis férrica (Clemens, 1990; del Campillo y Torrent, 1992; Benítez et al., 2002, Reyes et al., 2006). Juste y Pouget (1972) propusieron el "Índice de Poder Clorosante" (IPC), definido como la relación entre los contenidos en $\mathrm{CaCO}_{3}$ y el Fe del suelo extraído con DTPA $\left(\mathrm{mg} \cdot \mathrm{kg}^{-1}\right)\left[\mathrm{IPC}=\left(\mathrm{CaCO}_{3} / \mathrm{Fe}^{2}\right) 10^{4}\right]$ para predecir el riesgo de clorosis férrica en vid. La relación $\mathrm{Fe}_{o x} / \mathrm{ECCA}$, también ha resultado ser una buena variable explicativa de la 
concentración foliar de clorofila en girasol y garbanzo (del Campillo y Torrent, 1992) y vid (Reyes et al., 2006).

En los suelos calcáreos, la calcita $\left(\mathrm{CaCO}_{3}\right)$ regula la concentración del ion bicarbonato $\left(\mathrm{HCO}_{3}{ }^{-}\right)$en la disolución del suelo. Las reacciones de equilibrio de producción de $\mathrm{HCO}_{3}{ }^{-}$permiten apreciar que la hidrólisis del carbonato cálcico se ve favorecida por la actividad del agua y la presión parcial de dióxido de carbono:

$$
\begin{aligned}
& 2 \mathrm{H}^{+}(\mathrm{aq})+\mathrm{CaCO}_{3}(\mathrm{~s}) \rightarrow \mathrm{Ca}^{2+}+\mathrm{CO}_{2}(\mathrm{~g})+\mathrm{H}_{2} \mathrm{O}(\mathrm{I}) \\
& \mathrm{CO}_{2}(\mathrm{~g})+\mathrm{H}_{2} \mathrm{O}(\mathrm{l}) \rightarrow \mathrm{HCO}_{3}^{-}(\mathrm{aq})+\mathrm{H}^{+}(\mathrm{aq})
\end{aligned}
$$

La concentración de $\mathrm{HCO}_{3}{ }^{-}$es considerada por muchos investigadores como el parámetro más determinante en la inducción de clorosis férrica en plantas de estrategia I sobre suelos calcáreos y alcalinos (Boxma, 1972; Coulombe et al., 1984a, 1984b; Mengel et al., 1984; Romera et al., 1992; Nikolic y Kastori, 2000; Lucena et al., 2007). El $\mathrm{HCO}_{3}{ }^{-}$tampona el $\mathrm{pH}$ del suelo entre los valores de 7,5 y 8,5 en los que la disponibilidad del Fe es mínima (Loeppert et al. 1984; Lindsay, 1984; Loeppert, 1986, 1988; Wei et al. 1997), favoreciendo su oxidación y paso a compuestos de baja solubilidad (Lindsay, 1984).

A nivel de la planta, altas concentraciones de $\mathrm{HCO}_{3}{ }^{-}$se han relacionado con incrementos del $\mathrm{pH}$ del apoplasto y de Fe no disponible para las células (Mengel, 1994). Esto está de acuerdo con la "paradoja de la clorosis", fenómeno por el cual se detecta una mayor concentración de Fe total en hojas cloróticas que en hojas no cloróticas (Bavaresco et al., 1999). Diversos ensayos han mostrado una inhibición de la capacidad reductora de las raíces (Nikolic et al., 2000; Römheld, 2000; Nikolic y Römheld, 2002; Lucena et al., 2007) y de la expresión de genes implicados en la adquisición de Fe (Lucena et al., 2007) en presencia de altas concentraciones de $\mathrm{HCO}_{3}{ }^{-}$, lo que se puede traducir en una menor absorción y translocación de Fe a la parte aérea de las plantas.

García et al. (2011) propusieron un modelo de regulación de la expresión de genes relacionados con la absorción de Fe en plantas de estrategia I, en el que el óxido nítrico (NO) junto al etileno juegan un papel fundamental. Posteriormente, García et al. (2013) han mostrado que el bicarbonato puede bloquear la acción hormonal del etileno sobre la regulación génica de la respuesta a la deficiencia de Fe por parte de las plantas de estrategia I.

\subsubsection{4.- Presencia de sustancias complejantes: materia orgánica y actividad microbiana.}

El Fe tiene capacidad de asociarse con ciertos compuestos orgánicos naturales, formando complejos estables y facilitando la movilidad de este elemento en la disolución del suelo y su adquisición por la planta (Lindsay, 1991). Estas moléculas 
proceden principalmente de la transformación de la materia orgánica (ácidos húmicos y fúlvicos, aminoácidos...), de exudados de las raíces (fitosideróforos) o segregados por algunos microorganismos (sideróforos). Sin embargo, con un exceso de materia orgánica, el Fe puede quedar fijado en compuestos húmicos poco solubles (SanzEncinas y Montañés, 1997).

La presencia de materia orgánica aumenta la disponibilidad de Fe para las plantas por contribuir a acomplejar el $\mathrm{Fe}^{+3}$ (Bloom, 1981; Pinton et al., 1999) y estabilizar los óxidos de Fe poco cristalinos, evitando su cristalización (Schwertmann, 1964). Los suelos cultivados de áreas mediterráneas cuentan, por lo general, con contenidos bajos en materia orgánica (Torrent, 1995).

La actividad microbiana puede verse incrementada con la aportación de materia orgánica al suelo, aumentando la solubilidad del Fe por la mayor presencia de sideróforos (Chen et al., 2010) y ácidos orgánicos (Loeppert y Hallmark, 1985; Masalha et al., 2000; Crowley, 2001; Hoberg et al., 2005) de origen microbiano.

Por otra parte, la respiración de los microorganismos del suelo (junto a la de las raíces) puede incrementar la presión parcial de $\mathrm{CO}_{2}$ hasta niveles 10-100 veces superior a la atmosférica, reduciendo el pH (Hinsinger et al., 2003) pero favoreciendo la producción de $\mathrm{HCO}_{3}{ }^{-}$. Las condiciones que favorezcan la formación de $\mathrm{HCO}_{3}{ }^{-}$(alta humedad, compactación y drenaje inadecuado) pueden provocar un efecto de la materia orgánica contrario al descrito anteriormente (Chaney, 1984; Loeppert, 1986).

\subsubsection{5.- Interacción del hierro con otros elementos.}

La disponibilidad de Fe para la planta puede verse afectada por la concentración de otros nutrientes en la solución del suelo.

\section{Nitrógeno.}

La concentración y forma de nitrógeno predominante en la disolución del suelo puede incidir en la nutrición férrica de las plantas. La absorción del $\mathrm{N}$ en forma de nitrato $\left(\mathrm{NO}_{3}{ }^{-}\right)$, provoca un aumento del $\mathrm{pH}$ en la disolución del suelo, al contrario que cuando lo hace en forma de amonio $\left(\mathrm{NH}_{4}{ }^{+}\right)$, y esto puede alterar la disponibilidad de Fe. Los experimentos de Kosegarten et al. (1998 y 2001) con plántulas de girasol en cultivo hidropónico conteniendo distintas formas de $\mathrm{N}\left(\mathrm{NO}_{3}{ }^{-} \circ \mathrm{NH}_{4}{ }^{+}\right)$y en presencia de $\mathrm{HCO}_{3}{ }^{-}$(simulando condiciones de suelos calcáreos) revelaron que el $\mathrm{NO}_{3}{ }^{-}$aumenta el $\mathrm{pH}$ del apoplasto de las células de hojas jóvenes, inactiva el $\mathrm{Fe}$ e induce clorosis férrica (reduce la clorofila en hoja y el crecimiento foliar) a diferencia de lo ocurrido con el $\mathrm{N}$ en forma $\mathrm{NH}_{4}{ }^{+}$. Nikolic y Römheld, (2003) observaron que la presencia de $\mathrm{NO}_{3}{ }^{-}$en la solución nutritiva reducía el Fe disponible para las raíces al elevar el $\mathrm{pH}$ aunque no inactivaba el Fe en el apoplasto.

Evidencias de que la deficiencia de Fe es inducida y agravada con la aplicación de nitratos se han observado en especies tan variadas como el aguacate (Bar y Kafkafi, 1992), espinaca (Assimakopoulou, 2006) o guisante (Wiersma, 2010). 


\section{Fósforo.}

La concentración de $\mathrm{P}$ en disolución en suelos calcáreos es muy baja, por lo que algunos autores afirman que no puede ser inductor de clorosis férrica (Kolesch et al., 1987a; Mengel y Kirkby, 2001). No obstante, el $\mathrm{P}$ puede formar compuestos insolubles con el Fe (Hirsch et al., 2006) o ser adsorbido por los óxidos de Fe (Cornell y Schwertmann, 2003) debido a la alta afinidad por los grupos hidroxilo de la superficie de los mismos (Torrent, 1987; Schwertmann y Taylor, 1989; Bigham et al., 2002). Además, el fosfato compite con ciertos compuestos que facilitan la absorción de Fe, como los ácidos orgánicos (Geelhoed et al., 1999) y los sideróforos (Hiradate y Inoue, 1998) por los sitios de adsorción de la superficie de los óxidos de Fe. De esta manera, el fosfato puede reducir la solubilidad del Fe y, por tanto, su disponibilidad para la planta (Borggaard, 1991; Celi et al., 2003; Cornell y Schwertmann, 2003; Zheng et al., 2009).

Brown et al. (1955), citaron por primera vez al fosfato como uno de los factores que causan y/o agravan la clorosis férrica. Desde entonces, otros autores (Brown et al., 1959; Brown y Olsen, 1980; Chaney y Coulombe, 1982, Kolesch et al., 1987a, 1987b) han apoyado esta hipótesis. Estos autores indican que la inducción de clorosis férrica se produce por la precipitación del Fe del suelo como fosfato de $\mathrm{Fe}(\mathrm{III})$, la interferencia en la reducción de Fe(III) en los quelatos (Brown y Olsen, 1980), o la inmovilización de Fe dentro de la planta (Cumbus et al., 1977). Según Brown (1960), el bicarbonato actúa indirectamente porque incrementa la concentración de fosfato en la disolución del suelo, al que se considera causante de la clorosis férrica. SánchezSánchez-Rodríguez et al. (2014) informaron que la aplicación de fertilizantes fosfatados en suelos que inducen clorosis férrica agrava la deficiencia, con distinta intensidad dependiendo de la especie vegetal y del estatus de Fe y $\mathrm{P}$ en el suelo.

El fosfato puede adsorberse en la superficie de los óxidos de Fe, compitiendo con los agentes quelantes y haciendo al Fe menos disponible para la planta (Mengel y Guertzen, 1986). De Kock (1981) sugirió que relaciones altas de P/Fe y K/Ca en los tejidos vegetales identificarían situaciones de clorosis férrica. Maldonado-Torres et al. (2006) encontraron que el grado de clorosis férrica en las hojas de Citrus aurantifolia disminuía significativamente cuando las concentraciones foliares de $\mathrm{P} / \mathrm{Fe}$ y $\mathrm{K} / \mathrm{Ca}$ se incrementaban.

Sin embargo, según Mengel et al. (1984), los elevados niveles de $P$ encontrados en hojas cloróticas son probablemente el resultado de la inhibición del crecimiento (efecto de concentración) y de este modo serían una consecuencia y no una causa de la clorosis férrica.

Parece razonable asumir que en los suelos calcáreos, caracterizados por tener bajas concentraciones de $\mathrm{P}$ en disolución, el fosfato no sea el principal inductor de la clorosis férrica (Mengel y Kirkby, 2001). Las sales de Fe(III) en presencia de grandes cantidades de $\mathrm{P}$ (relación $\mathrm{P} / \mathrm{Fe}=0,5 \%$ ) evolucionan a óxidos de $\mathrm{Fe}$ poco cristalinos como ferrihidrita y lepidocrocita (Gálvez et al., 1999), ya que el ión fosfato dificulta la cristalización de los óxidos de Fe (Schwertmann y Taylor, 1989). 
En los estudios de Romera et al. (1991) sobre caracterización de la tolerancia de cultivares de melocotonero a la clorosis férrica, el fosfato aplicado a la solución nutritiva no indujo clorosis férrica. En ese mismo trabajo, la susceptibilidad a la clorosis férrica inducida por bicarbonato estuvo inversamente correlacionada con el contenido en Fe de las hojas jóvenes y con la capacidad reductora en las raíces, pero no con el contenido en P de las hojas jóvenes. Romera et al. (1992), estudiando el efecto del bicarbonato, el fosfato y $\mathrm{pH}$ alto sobre la capacidad reductora del $\mathrm{Fe}$ (III) de las raíces de plantas cloróticas de girasol y pepino, mostraron que un aumento de la dosis de fosfato exclusivamente no tenía efecto inhibitorio sobre la capacidad reductora, pero este efecto se incrementaba cuando se aplicaba conjuntamente fosfato y bicarbonato.

Ladouceur et al. (2006) estudiaron el efecto de la concentración de P sobre el nivel de nutrientes minerales en plantas de cebada. Los resultados mostraron que el crecimiento y el nivel de clorofila de las plantas fertilizadas con baja concentración de $\mathrm{P}\left(0.5,5\right.$ y $\left.50 \mu \mathrm{mol} \cdot \mathrm{L}^{-1}\right)$ eran mayores que en las plantas control. Igualmente, la cantidad acumulada de nutrientes minerales en la parte aérea fue mayor para K, Fe y $\mathrm{Cu}$ en plantas con baja dosis de $\mathrm{P}$ que en las plantas control, sugiriendo que el $\mathrm{P}$ compite fisiológicamente con el Fe en los tejidos vegetales.

Sin embargo, Samar et al. (2007) han mostrado en manzano que niveles de $\mathrm{P}$ en el suelo de hasta cuatro veces el de referencia no tenían un efecto negativo en el nivel de clorofila y peso seco de la hoja, superficie foliar, y peso de las raíces. De modo similar, Balal et al. (2011) han demostrado que diferentes niveles de fertilización fosfatada en patrones del género Prunus no incrementaban la sensibilidad a la clorosis férrica.

\section{Potasio.}

El potasio interviene en la absorción y transporte de Fe por la planta (Hughes et al., 1992). El potasio participa en el correcto funcionamiento de las enzimas implicadas en esos procesos (Tagliavini y Rombola, 2001) y en el balance iónico, que permite la adecuada nutrición férrica (Marscher, 1995).

Las plantas sensibles ven mermada su capacidad de respuesta a la clorosis férrica cuando la nutrición potásica es deficiente (Jolley et al., 2004), reduciéndose la emisión de $\mathrm{H}^{+}$, disminuyendo la capacidad reductora de Fe (plantas de estrategia I) y modificándose la emisión de fitosideróforos (plantas de estrategia II) (Hughes et al., 1990 y 1992; Sakaguchi et al., 1999; Neumann y Römheld, 2001). Por otra parte, el K potencialmente puede afectar a la absorción de Fe a través de su papel en el equilibrio iónico general y facilitar la circulación de ácidos orgánicos tales como el citrato dentro de la planta (Marschner 1995).

El potasio podría intervenir en la funcionalidad de dos enzimas críticos asociados con la respuesta al estrés por carencia de hierro, la ATPasa y la reductasa $\mathrm{Fe}^{3+}$, afectando también a la actividad de una proteína de membrana implicada en el movimiento de iones $\mathrm{H}^{+}$y a la acumulación de citrato para el transporte de $\mathrm{Fe}$ (Marschner et al. 1986). Mengel y Schubert (1985) han informado de que el K estimula la actividad de la ATPasa en la membrana plasmática de la raíz, mientras que el 
impacto sobre la actividad de la reductasa férrica podría ser indirecto, ya que esta regulación de la ATPasa proporcionaría niveles de $\mathrm{pH}$ apoplástico más favorables para la actividad de la reductasa férrica (Tagliavini y Rombola, 2001).

Chen y Barak (1982) y Loeppert et al. (1994) indicaron que altos contenidos de $\mathrm{K}^{+}$en el suelo pueden favorecer la dispersión de arcillas y su posterior compactación, limitando la respuesta de las plantas a la clorosis férrica. Loeppert et al. (1994) han apuntado que altos niveles de $\mathrm{Na}$ y $\mathrm{K}$ en el suelo pueden provocar un incremento en la incidencia de la clorosis debido al deterioro que se puede generar en la estructura, relaciones hídricas y aireación del suelo.

Belkhodja et al. (1998) han observado un aumento de la concentración de K y de la relación $\mathrm{K} / \mathrm{Ca}$ en tejidos vegetales de melocotoneros afectados por deficiencia de hierro. La alta concentración de $\mathrm{K}$ en las hojas y flores de los árboles cloróticos puede estar causada por el aumento de la actividad ATPasa de la membrana plasmática que interviene en la excreción de protones (Marschner, 1995), y estar asociada con la acumulación de ácidos orgánicos que se producen en condiciones de deficiencia de Fe (Welkie y Miller, 1993). Para Bavaresco y Poni (2003) y Russo et al. (2010), los contenidos foliares de $\mathrm{K}$ y $\mathrm{Ca}$ aumentan en paralelo a la intensidad de la clorosis férrica en vid, mientras que los de Mg bajan. El mayor contenido de $\mathrm{K}$ en las plantas cloróticas podría estar relacionado con un $\mathrm{pH}$ más alto en el apoplasto de la hoja (Nikolic y Römheld, 1999) que dificulta la movilización de Fe (Monge et al., 1993; Singh et al., 1995).

\section{Micronutrientes.}

La clorosis férrica puede ser confundida con otras carencias de micronutrientes, como $\mathrm{Cu}, \mathrm{Zn}$ o $\mathrm{Mn}$, que pueden aparecer simultáneamente. Por otro lado, la absorción de Fe puede ser interferida por la de esos otros metales, ya que los mecanismos de adquisición de todos estos micronutrientes por las plantas de estrategia I están muy relacionados. Así, concentraciones elevadas de $\mathrm{Cu}^{2+}, \mathrm{Zn}^{2+}$ y $\mathrm{Mn}^{2+}$ en el medio pueden inducir deficiencia de Fe (Cohen et al., 1998; Foy et al., 1998; Izaguirre-Mayoral y Sinclair, 2005; Adiloglu, 2006; Aref, 2011; Shanmugam et al., 2011), lo que se atribuye a la competencia entre los iones por los sitios de absorción (Kochian, 1991; Welch, 1995). Por esta misma razón, tanto $\mathrm{Zn}^{2+}$ como $\mathrm{Mn}^{2+}$ son más fácilmente absorbidos por las raíces de las plantas deficientes en Fe que por las plantas normales (Alcántara et al., 1994; Cohen et al., 1998; Korshunova et al., 1999; Eckhardt et al., 2001). La presencia de elevadas concentraciones de otros microelementos en el medio puede provocar alteraciones estructurales y bioquímicas en los sistemas de transporte que dificulten su afinidad por el $\mathrm{Fe}^{2+}$ (Zaharieva y Römheld, 2000). Lucena et al. (2003) indicaron que el Fe compite con otros micronutrientes por su translocación en la planta.

Vose (1982) presenta evidencias de que en suelos neutros o ligeramente ácidos la deficiencia de Fe puede ser inducida por altos niveles de $\mathrm{Cu}, \mathrm{Zn}$ o P. Para Loue (1988), la absorción de Fe tiende a decrecer según aumenta la presencia de iones de cobre, cinc y manganeso (con mayor intensidad en ese orden). Belkhodja et 
al., (1998) en estudios en melocotonero señalaron que la clorosis férrica aumentaba la concentración foliar de $\mathrm{Mn}$, mientras que las de $\mathrm{Cu}$ y Zn no se veían afectadas.

La deficiencia de Fe suele ir acompañada por la acumulación de Mn, Zn y Cu en los tejidos, mientras que las deficiencias de estos nutrientes estimulan la acumulación de Fe (Welch et al., 1993; Kobayashi et al., 2003; Chen et al., 2004b; Zheng et al., 2005; Russo et al., 2010). La causa de estas interacciones entre micronutrientes no parece ser debida a los efectos del $\mathrm{Mn}$ o $\mathrm{Zn}$ en la reductasa de $\mathrm{Fe}$ según Alcántara et al. (1994), que comprobaron que el Mn, Pb, Zn y Mo no tienen efecto sobre la enzima, al contrario que $\mathrm{Ni}, \mathrm{Cu}$ y $\mathrm{Cd}$. Sin embargo, para Bojovic et al. (2012) el $\mathrm{Pb}$ tiene la capacidad de bloquear ciertos transportadores de Fe. Yi y Guerinot (1996) sugirieron que la mayor tasa de movilización de $\mathrm{Cu}^{2+}$ por las plantas cloróticas si puede causar una inhibición de la actividad quelato reductasa de hierro. Concentraciones de $\mathrm{Mn}$ excesivas en los tejidos vegetales pueden alterar la actividad enzimática, la absorción, translocación y la utilización de otros elementos minerales (Ca, Mg, Fe y P), causando estrés oxidativo (Ducic y Polle, 2005; Lei et al, 2007).

Yi y Guerinot (1996) sugieren que el mayor porcentaje de $\mathrm{Mn}, \mathrm{Zn}$ y Cu en las plantas con clorosis férrica puede constituir una estrategia de defensa de las plantas para equilibrar la insuficiente disponibilidad de $\mathrm{Fe}^{2+}$. La competencia entre $\mathrm{Cu}^{2+}$ y $\mathrm{Fe}^{2+}$ ha sido observada en muchos estudios con soluciones deficientes en $\mathrm{Fe}$, donde la clorosis es menos evidente si las soluciones también eran deficientes en Cu (Russo et al., 2010).

Schenkeveld et al. (2008) observaron una disminución de la absorción de Mn con el aumento del contenido del quelato o,o-FeEDDHA en el suelo, que no puede atribuirse a una disminución de la concentración de Mn en disolución. Según los autores, si la absorción de Mn y Fe están regulados por los mismos sitios de captación en la superficie de la raíz, tratamientos con FeEDDHA pueden aumentar la competencia del Fe en estos lugares de absorción. La absorción de Fe tiene lugar ya sea a través de una reducción como de una división del quelato (Chaney et al., 1972; Marschner et al., 1989), o bien a través de la captación del complejo en su conjunto (Bienfait et al. 2004). Los complejos de FeEDDHA pueden servir como una reserva de reabastecimiento en solución, evitando el agotamiento de $\mathrm{Fe}^{3+}$ en la rizosfera debido a la absorción de Fe por la planta y la cinética de disolución lenta de hidróxidos de Fe.

Se asume que hay una competición entre los nutrientes por las moléculas que quelatan o transportan al Fe, como los ácidos orgánicos, fitosideróforos y las proteínas transportadoras (Kobayashi et al., 2003). En esta línea, Cohen et al. (1998) comprobaron que el transportador de Fe IRT1 (Iron Regulated Transporter) podía movilizar otros metales divalentes como $\mathrm{Mn}^{2+}$ and $\mathrm{Co}^{2+}, \mathrm{Zn}^{2+}$. La proteína NRAMP3 (Natural Resitance Associated Macrofage Protein) es capaz de transportar $\mathrm{Mn}^{2+}, \mathrm{Fe}^{2+}$ y $\mathrm{Cd}^{2+}$ (Millaleo et al., 2010). 


\subsubsection{6.- Otros factores.}

\section{$\underline{\text { Contenido en arcilla del suelo. }}$}

Las propiedades de la arcilla y, concretamente, su capacidad de intercambio catatónico $(\mathrm{ClC})$, tienen una considerable influencia en la incidencia de la clorosis férrica. Las arcillas participan en la estabilización de los óxidos de Fe poco cristalinos, aumentando la disponibilidad de Fe para las plantas (Vempati y Loeppert, 1986; Golden et al., 1997; Krishnamurti et al., 1998). Diversos ensayos mostraron correlaciones positivas entre el contenido de arcilla y la concentración de clorofila en hojas de sorgo y soja (Loeppert y Hallmark, 1985), garbanzo y girasol (Del Campillo y Torrent, 1992) y olivar (Benítez et al., 2002) desarrollados en suelos calcáreos.

Por otra parte, un alto contenido de arcilla en el suelo puede provocar problemas de compactación, dificultando la aireación y favoreciendo la producción de $\mathrm{HCO}_{3}^{-}$, al aumentar la presión parcial de $\mathrm{CO}_{2}$ (Mengel et al., 1984, Romera et al., 1992).

Arcillas como la montmorillonita y la caolinita adsorben Fe en suelos ácidos y condiciones reductoras (Ellis y Knezek, 1972). En suelos con elevados valores de $\mathrm{pH}$, la arcilla tiene una baja capacidad de retención de iones $\mathrm{Fe}^{3+}$ y $\mathrm{Fe}^{2+}$.

\section{Condiciones reductoras del suelo.}

Las condiciones reductoras pueden producirse en la rizosfera debido a la presencia de capas freáticas, por lluvias o riegos excesivos. El encharcamiento de los suelos calcáreos es un factor inductor de clorosis férrica al favorecer la producción de $\mathrm{HCO}_{3}{ }^{-}$. Sin embargo, en estas condiciones, una parte del Fe se encontrará en forma reducida, más soluble que la forma oxidada que predomina en condiciones de suelo aireado.

Diversos experimentos han puesto de manifiesto que, un drenaje adecuado de los suelos aumenta la biodisponibilidad de Fe para las plantas con el consiguiente alivio de la clorosis férrica (Velázquez et al., 2004; Sánchez-Alcalá 2012).

\section{Vigor y condiciones de crecimiento de las plantas.}

La luz intensa favorece el amarilleamiento de las hojas cloróticas (Hidalgo, 1999), mientras que por el contrario la luz tenue atenúa los síntomas.

Las bajas temperaturas disminuyen el desarrollo radicular y por tanto provocan una reducción de la absorción de Fe por la planta. Por otro lado, las temperaturas elevadas provocan un crecimiento más rápido aumentando con ello las necesidades de hierro con posible agravación de los síntomas de clorosis. 


\section{Otras causas.}

Todas las causas que disminuyen el vigor y, en consecuencia, la síntesis de materias hidrocarbonadas, como, por ejemplo: un tiempo frío en primavera, un mal agostamiento de la madera del año anterior, el granizo, etc. perturban el metabolismo de la vid, pudiendo acentuar la clorosis. Un desarrollo muy rápido de la vegetación, seguido de un periodo de crecimiento ralentizado, puede crear también un déficit de hierro soluble en las plantas cultivadas en terreno calizo.

El vigor del portainjerto y el conferido a la variedad por el mismo son factores importantes que intervienen en cierta medida para modificar la resistencia a la clorosis. La edad del viñedo es importante, en general las cepas más jóvenes son más sensibles que las que llevan muchos años vegetando (Hidalgo, 1999).

\subsection{4.- Efecto de la clorosis férrica en la planta.}

En plantas cloróticas el nivel de fotosíntesis es menor, lo que provoca un lento y reducido crecimiento, limita la productividad potencial y disminuye considerablemente el rendimiento y el vigor del viñedo (Anderson, 1982; Chen y Barak, 1982; Tagliavini y Rombola, 2001). Por otro lado, la clorosis produce una maduración deficiente de las uvas, con una reducción de la acumulación de azucares (Hidalgo, 1999), así como desequilibrios fenólicos y bajos niveles de pigmentos.

\subsubsection{1.- Pigmentos foliares.}

El efecto más claro de la deficiencia de Fe es una gran disminución de las concentraciones de pigmentos fotosintéticos en las hojas de las plantas afectadas (Val et al., 1987; Morales et al., 1990, 1994; Bavaresco et al., 2003). La inhibición de la formación de clorofila bajo condiciones de deficiencia de hierro es, al menos en parte, el resultado de una alteración de la síntesis de proteínas, consecuencia de un descenso drástico en el número de ribosomas en las hojas (Lin y Stocking, 1978).

El principal efecto de la deficiencia de hierro en hojas se produce en los cloroplastos, que ven alterada la estructura y funcionalidad de los tilacoides (Spiller y Terry, 1980; Terry y Abadía, 1986; Terry y Zayed 1995), que va acompañada de una disminución en todos los pigmentos captadores de luz: clorofilas a y b y carotenos. Sin embargo, la deficiencia de Fe no disminuye en la misma medida todos los pigmentos fotosintéticos. La clorofila $b$ se ve más afectada que la clorofila $a$, y la luteína y las xantofilas $\mathrm{V}+\mathrm{A}+\mathrm{Z}$ son menos afectadas que los otros carotenoides (Morales et al. 1990, 1994, 2000, 2001). Además, los carotenos disminuyen en menor proporción que las clorofilas (Terry, 1980; Abadía, 1992; Terry y Zayed, 1995).

Cuando las plantas se desarrollan en hidroponía se encuentra una correlación entre el contenido de clorofilas y de $\mathrm{Fe}$ en las hojas, dando lugar a contenidos de hierro total bajos en las hojas cloróticas (Terry, 1980; Terry y Low, 1982; Abadía, 1992; Chen et al., 2004a; Smith y Cheng, 2006; Sabir et al., 2010). Sin embargo, cuando las plantas se desarrollan en el campo, esa relación no se verifica, y las hojas cloróticas 
suelen contener una concentración de $\mathrm{Fe}$ igual o superior a la de las hojas verdes (Chen y Barak, 1982; Mengel y Malissiovas, 1982; Mengel y Bübl, 1983; Mengel et al., 1984; Abadía et al., 1985; Abadía et al., 1989; Abadía, 1992; Morales et al., 1998b). A este hecho se le denomina paradoja de la clorosis férrica (chlorosis paradox) (Zaharieva y Römheld, 2000; Bavaresco et al., 1999). Morales et al. (1998b) sugieren que, en condiciones de deficiencia de hierro, parte del hierro tomado desde el suelo por la reductasa se inmoviliza y se acumula como formas inactivas en las hojas.

En experiencias llevadas a cabo con remolacha cultivada en hidropónico y en peral cultivado en campo (Morales et al. 1990, 1994, 2000), se ha observado que la relación de contenidos de clorofila a/clorofila $b$ en hoja aumenta en condiciones de clorosis férrica. Una explicación para el incremento en esta relación podría ser una fotodestrucción preferencial de clorofila b (Díez-Altarés, 1959) en condiciones de campo a plena luz solar, especialmente en hojas cloróticas, donde la densidad de flujo de fotones incidente puede llegar a ser muy alta a causa del bajo contenido en pigmentos.

Las concentraciones foliares de carotenoides disminuyen con la deficiencia de Fe en menor grado que las de clorofilas (Terry, 1980; Morales et al., 1990, 1994, 2000). La deficiencia de Fe afecta también al ciclo de las xantofilas, que se desplaza hacia la zeaxantina (Morales et al., 1990, 1994, 2000).

La proporción carotenoides/clorofilas ha sido ampliamente estudiada como indicadora de estrés (Grover et al, 1986; Schöner y Krause, 1990; Peñuelas y Filella, 1998). El aumento de esta relación puede ser debido a varias razones: (1) una disminución en el contenido de clorofila por una menor síntesis o aumento de la degradación; (2) un aumento de los carotenoides que funcionan como fotoprotectores y antioxidantes en el metabolismo de la planta; y (3) una mayor persistencia de los carotenoides en relación a la clorofila en las hojas senescentes (Filella et al., 1995; Martínez-Peñalver et al., 2011).

\subsubsection{2.- Aparato fotosintético.}

El hierro es un constituyente de las cadenas de transporte de electrones, tanto en las mitocondrias como en los cloroplastos. Cuando el efecto de la deficiencia de hierro es considerado a nivel ultraestructural, el número de membranas tilacoides por cloroplasto disminuye marcadamente, mientras que otros orgánulos que contienen hierro, por ejemplo, mitocondrias y peroxisomas, no se ven afectados (Platt-Aloia et al., 1983).

Estos hechos conducen a una reducción en la capacidad fotosintética de las plantas afectadas por deficiencia de hierro que se traduce en una disminución de la síntesis de azúcares, almidón y algunos aminoácidos, y acumulación de otros, alteraciones en la síntesis de proteínas, y enriquecimiento de los lípidos en ácidos grasos insaturados (Terry y Abadía, 1986; Abadía, 1992; Terry y Zayed, 1995). Al igual que las raíces, en las hojas y en la savia del xilema se acumulan ácidos orgánicos, principalmente citrato y malato, y se incrementa la actividad de PEPC (Fosfoenolpiruvato carboxilasa) y de distintos enzimas del ciclo de los ácidos 
tricarboxílicos como malato deshidrogenasa $(\mathrm{MDH})$, aconitasa, fumarasa, citrato sintetasa y isocitrato deshidrogenasa (López-Millán et al., 2001). El incremento observado en las actividades de los enzimas implicados en la síntesis de ácidos orgánicos (PEPC y MDH) es menor que el aumento encontrado en citrato y malato, lo que indica que malato y citrato serían proporcionados a las hojas por las raíces vía xilema, algo posiblemente asociado con el aumento de la fijación anaplerótica del $\mathrm{CO}_{2}$ en las raíces de las plantas deficientes en hierro a través del enzima PEPC (LópezMillán et al., 2001; Rombolà et al., 2000). Es muy probable que los aniones orgánicos jueguen un importante papel en el transporte de hierro desde las raíces a las hojas (Tiffin, 1966; López-Millán et al., 2001).

La reducción en la fotosíntesis neta en condiciones de deficiencia de hierro ha sido observada en muchas especies de plantas (Terry and Abadía 1986, Abadía 1992, Morales et al. 2000, Larbi et al. 2006) y se atribuye principalmente a la disminución de la eficiencia del fotosistema II (PSII), debida al cierre de centros de reacción y a la propia reducción de la eficiencia intrínseca del fotosistema II (Morales et al. 2000; Covarrubias et al, 2014). Además, la eficiencia de captación de luz y de la carboxilación por parte de la Rubisco en las hojas se ve regulada a la baja en respuesta a la deficiencia de Fe (Larbi et al. 2006). Se ha visto que la deficiencia causa una reducción en la regeneración de RuBP, que no estaría asociada a niveles bajos de ATP y NADPH, y que tendría su causa en una inactivación de la enzima Ru5Pkinasa (Arulanantham et al., 1990).

Ranieri et al. (2003) han observado que las hojas de girasol deficientes en hierro presentan una acumulación significativa de $\mathrm{H}_{2} \mathrm{O}_{2}$ y una reducción significativa de la actividad del enzima ascorbato peroxidasa (APX) y del contenido en ácido ascórbico. La acumulación de $\mathrm{H}_{2} \mathrm{O}_{2}$ puede ser debida tanto a un aumento en su producción, como a una disminución en la capacidad de la hoja para eliminarlo, provocada por la disminución en las actividades de los enzimas eliminadores de radicales libres oxigenados, que tienen como componente o cofactor al hierro: ascorbato oxidasa (ASA), APX y peroxidasas (POD).

\subsubsection{3.- Vigor, rendimiento y calidad de la uva.}

Como consecuencia de la disminución de la capacidad fotosintética, la clorosis férrica reduce el crecimiento vegetativo y la producción de fruto en muchas especies vegetales (Hurley et al., 1986; Tagliavini y Rombolà, 2001; Pestana et al., 2003). Las pérdidas de rendimiento en cultivos frutales pueden ser debidas a la disminución en el número de frutos por árbol, la disminuciones en el tamaño del fruto o una combinación de ambos factores (Álvarez-Fernández, 2006). En la vid, la deficiencia de Fe induce una reducción de la tasa de cuajado, disminuye el diámetro de la baya y la compacidad de los racimos (Bavaresco et al., 2010a).

Las condiciones de estrés por clorosis férrica pueden disminuir el tamaño de la hoja, la fotosíntesis del conjunto del dosel y la producción total de materia seca (Kosegarten et al., 1999; Bavaresco y Poni, 2003; Bertamini y Nedunchezhian 2005). La clorosis puede inducir una reducción del crecimiento de los racimos, el 
acortamiento de los entrenudos de los pámpanos y una reducción del crecimiento de los brotes que puede llegar al 50\% en vid (Gruber y Kosegarten, 2002; Jiménez et al. 2007).

Bavaresco et al. (2006) observaron que la reducción marcada en el contenido en materia seca de las hojas en las plantas de vid cloróticas frente a los controles era debida a una disminución de grosor y de área de la hoja, lo que indicaba que la división y expansión celular fueron perjudicadas significativamente por la reducción de la asimilación de $\mathrm{CO}_{2}$.

Una severa carencia nutricional de hierro puede causar una drástica reducción en la longevidad y la productividad del viñedo, el crecimiento de la raíz y tallos y pérdidas en el rendimiento y la calidad de la uva (Bavaresco et al. 2003), lo que se traduce en una pobre calidad de los mostos, al reducir el contenido en azúcares y antocianos acumulados en las bayas durante la maduración, e incrementando la acidez total (Castino et al., 1987; Veilksar et al., 2005). Sin embargo, la clorosis férrica leve puede mejorar la calidad del vino debido al incremento en la calidad de la uva en cuanto a los sólidos solubles, $\mathrm{pH}$, antocianinas y el resveratrol (Bavaresco et al. 2005). Este autor atribuyó la alta concentración de azúcar y polifenoles como probablemente consecuencia de la reducción del rendimiento de uva, relacionado con un peso medio del racimo y de la baya más bajo. Las concentraciones totales de antocianinas y polifenoles fueron mayores en vides cloróticas debido a la mayor proporción de la hollejo/pulpa como consecuencia de la reducción de tamaño de las bayas.

La composición de los frutos juega un papel crítico en la calidad de los vinos. Los compuestos fenólicos, antocianinas y taninos, son los responsables del color y astringencia de los vinos tintos (Ribéreau-Gayon y Glories, 1987). La síntesis y acumulación de los compuestos fenólicos en las uvas durante la maduración (Pirie y Mullins, 1980; Smart y Robinson, 1991) está muy influenciado por la capacidad fotosintética de la viña y la exposición de los frutos a la radiación solar. La vid (Vitis vinifera L.) es rica en compuestos fenilpropanoides, como flavonoides y estilbenos, los cuales, están presentes en la mayoría de los tejidos, se describen como antioxidantes y se sabe que se acumulan en respuesta a estrés biótico y abiótico (Tavares et al., 2013). En este sentido, Bavaresco et al. (2005) encontró que las condiciones de estrés por deficiencia de hierro inducida en suelos calcáreos aumentaba los niveles de antocianinas no sólo debido a la concentración, sino también a una biosíntesis mejorada en los hollejos de las uvas. Los mecanismos bioquímicos involucrados no están claros, pero se pueden especular que el hierro es parte constitutiva de los enzimas implicadas en la síntesis de la lignina, y puede cambiar la vía shikimato hacia otros compuestos fenólicos incluyendo antocianinas.

Cuando la deficiencia de hierro no llega a ser severa, ésta provoca en las bayas una depresión de la actividad peroxidasa, aumenta la concentración de transresveratrol e incluso promueve una acumulación de antocianinas y polifenoles (Sijmons et al., 1985; Bavaresco et al, 2010a).

Las consecuencias de la clorosis férrica en la calidad de la uva están en función del nivel que alcance la fisiopatía en la campaña, y también en función de los 
efectos acumulativos de la misma que se manifiestan en las cepas año tras año, con la disminución de vigor y tamaño del follaje que ello conlleva (Martín et al., 2007a).

\subsection{5.- Métodos de diagnóstico de la clorosis férrica.}

El efecto más obvio de la deficiencia de Fe es la gran disminución de las concentraciones de pigmentos fotosintéticos en las hojas de las plantas afectadas (Val et al., 1987; Morales et al., 1990, 1994). Algunos instrumentos portátiles como por ejemplo el SPAD (Soil Plant Analysis Development) estiman el nivel de clorofila a partir de las diferencias en las absorbancias de las hojas a $650 \mathrm{~nm}$ y $940 \mathrm{~nm}$ (Minolta, 1989), y proporcionan una medición cuantitativa objetiva de la clorosis foliar asociada a la deficiencia de hierro (Peryea y Kammereck, 1997). No obstante, el amarillamiento del tejido foliar puede ser causado por otros factores distintos a la clorosis férrica, como drenaje insuficiente, sequia, daños parasitarios y otras deficiencias nutricionales como las de $\mathrm{Mn}$ y $\mathrm{Zn}$ (Keller, 2005). Por esta razón, el contenido clorofílico foliar no puede ser la única herramienta para el diagnóstico de la clorosis férrica.

El estado nutricional de las plantas respecto a un elemento habitualmente se valora comparando su concentración total en hoja con unos patrones considerados de referencia (por encima, exceso de asimilación, por debajo carencia). Sin embargo, este modo de operar no es válido para el caso de la clorosis férrica, ya que es muy común encontrar plantas cloróticas con concentraciones foliares de hierro, sobre materia seca, significativamente superiores que las de plantas sanas. El hecho, conocido como "paradoja de la clorosis" (Bavaresco et al., 1999; Zaharieva y Römheld, 2000), es consecuencia de una acumulación de hierro fisiológicamente inactivo en las hojas enfermas, así como de un menor desarrollo de estas hojas, lo que produce un efecto de concentración del elemento en los tejidos.

Pestana et al. (2003) subrayan que para el diagnóstico de la clorosis férrica inducida por carbonatos, es fundamental utilizar análisis de suelo en que se incluye mediciones de la disponibilidad de hierro obtenidas mediante extractantes capaces de quelatar el metal, así como pruebas que determinen el contenido de cal activa.

Se han desarrollado parámetros biométricos capaces de diagnosticar la deficiencia de hierro a nivel de laboratorio, como determinar el área foliar, el peso radicular y el peso foliar (Álvarez-Fernández et al., 2005).

Los análisis de la concentración de Fe total, Fe extractable, relaciones entre micronutrientes $u$ otros compuestos químicos en diferentes estructuras vegetales (hojas, flores, brotes, etc.) se han estudiado como métodos de diagnóstico de la clorosis férrica (Morales et al., 1998; Bavaresco et al., 1999; Römheld, 2000; Tagliavini y Rombolà, 2001; Nikolic y Römheld, 2002; Abadía et al., 2004; Álvarez-Fernández et al., 2005). Los análisis de flores se están investigando para obtener información anticipada respecto del estado nutricional de hierro en diferentes especies vegetales, tal como se ha señalado para cítricos y melocotonero (Belkhodja et al., 1998; Toselli et al., 2000; Pestana et al., 2003). Según Belkhodja et al. (1998) y Pestana et al. (2003), el patrón de acumulación de Fe en los árboles frutales es estacional, siendo mayor el contenido de Fe en flores que en hojas de las especies de hoja caduca. 
La deficiencia de hierro modifica la asimilación de otros nutrientes. Por ejemplo, en hojas cloróticas las concentraciones de fósforo y potasio tienden a ser más elevadas que en hojas sanas, mientras que las de calcio tienden a ser más bajas (Jones y Wallace, 1992). Modificaciones como éstas permiten que las proporciones relativas de nutrientes en los tejidos vegetales puedan utilizarse como índices de referencia del estado nutricional de la planta en cuanto al hierro. La eficacia de relaciones como $\mathrm{Fe} / \mathrm{Mn}, \mathrm{P} / \mathrm{Fe}$ y $\mathrm{K} / \mathrm{Ca}$ en hoja como parámetro de diagnóstico de la clorosis ha sido evaluada por varios autores (Abadia et al., 1989; Belkhodja et al., 1998), obteniéndose resultados diferentes en función de la especie y de las condiciones de cultivo consideradas.

Los estreses ambientales afectan los procesos de la fotosíntesis. Estos procesos pueden ser modificados de manera diferencial, ya que mientras algunos son inactivados o regulados a la baja, otros en cambio permanecen relativamente inalterados. En el caso de la deficiencia de Fe, la reducción de la tasa fotosintética en las hojas cloróticas se ha atribuido a la reducción de la eficiencia de fotosistema II (Morales et al. 2000; Covarrubias et al, 2014), una variable que puede ser estimada mediante medidas de la fluorescencia de la clorofila.

La medida de la fluorescencia de la clorofila podría ser una herramienta muy útil para detectar el estrés en las plantas en una etapa temprana, cuando no hay síntomas visibles. Esta técnica, no invasiva, proporciona información rápida y extensa acerca de la eficiencia fotosintética, la integridad del aparato fotosintético, la funcionalidad de los diferentes mecanismos fotoprotectores y la tasa de transferencia de electrones (Maxwell y Johnson, 2000; Baker y Rosenqvist, 2004). Muchos autores han estudiado el comportamiento de diferentes parámetros de la fluorescencia de la clorofila de las hojas en condiciones de clorosis férrica (Allakhverdiev et al., 1987; Setlik et al., 1990; Morales et al., 1994; 1998a; Bertamini et al., 2001; Bertamini et al., 2002; Netto et al., 2005; Bavaresco et al., 2006).

\subsection{6.- Prevención y métodos de corrección.}

En la inmensa mayoría de los casos, sufrir las consecuencias de la clorosis férrica en el viñedo y tener que recurrir de modo continuado a medios químicos de lucha, caros y poco eficientes, es la consecuencia directa de un grave error: no haber elegido el portainjerto adecuado en el momento de la plantación. Antes de establecer un viñedo es necesario realizar un análisis químico del suelo para considerar la posibilidad de realizar enmiendas y abonados de fondo y para elegir el patrón que mejor se adapta al tipo de suelo (González y Martín, 2006).

El patrón, al margen de otras posibles consideraciones, debe tener unos niveles de tolerancia superiores a los registros de IPC detectados en el suelo. La disponibilidad de portainjertos de vid tolerantes a niveles altos de caliza activa del suelo es muy amplia. El 41-B es el patrón que más se utiliza en los suelos calizos españoles, pero existen otros con niveles superiores de tolerancia de caliza como el 333-EMo el 140-Ru (González y Martín, 2006). 
En plantaciones ya establecidas existen diversos factores que pueden agravar o minimizar la carencia de hierro y que pueden ser modificados mediante las técnicas de cultivo. Conviene conocer estas medidas culturales que, aunque no son capaces de solucionar el problema de la clorosis, sí pueden servir para retrasar la aparición de los primeros síntomas, o disminuir los niveles de afectación en las plantas. Las prácticas vitícolas que eliminan la compactación del suelo (labores profundas, mejora de la estructura) y su alcalinización (aguas de riego apropiadas, abonados de reacción ácida), así como las que evitan los encharcamientos (buen drenaje, control de la frecuencia y volumen de riegos, etc.), contribuyen a defender mejor al cultivo frente a la clorosis.

Las cubiertas vegetales, temporales o permanentes, previenen la aparición de la enfermedad al reducir la compactación del suelo, aumentan la porosidad, la filtración de agua y el contenido en materia orgánica. Las gramíneas de las cubiertas en condiciones clorosantes generan fitosideróforos capaces de quelatar el hierro en el suelo. En este sentido, Bavaresco et al., (2010a) en cv. Merlot injertado sobre 3309C compararon tres tratamientos correctivos en suelo calcáreo: aplicación al suelo de quelato de hierro EDDHA, cubierta vegetal con Festuca ovina, y la aplicación al suelo de vivianita (fosfato de hierro), concluyendo que la gestión del suelo con Festuca ovina fue el método más eficaz y sostenible para superar la clorosis cálcica.

Con independencia de las medidas culturales comentadas anteriormente, cuando un viñedo presenta síntomas de clorosis férrica, es necesario recurrir a tratamientos correctores. Estos tratamientos consisten básicamente en la aportación de compuestos químicos que incrementan la disponibilidad de hierro para el cultivo. Se pueden aplicar mediante implantes sólidos en la planta, inyecciones de productos líquidos al suelo o al tronco, fertirrigación o pulverizaciones foliares.

Entre los correcciones aplicadas al suelo están las sales inorgánicas (sulfato ferroso, nitrato ferroso, fosfato ferroso...), quelatos de hierro sintéticos, complejos naturales de hierro (citratos, lignosulfonato, humatos, u otras materias orgánicas, enmiendas acidificantes (ácidos orgánicos o inorgánicos, azufre, polisulfuros...).

Una opción para luchar contra la clorosis férrica es la acidificación del suelo mediante la aplicación de ácidos orgánicos o inorgánicos o productos acidificantes como el azufre y los polisulfuros. Estos tratamientos disminuyen el $\mathrm{pH}$ del suelo, neutralizan los bicarbonatos, reducen la superficie reactiva de los carbonatos y aumentan la solubilidad de los óxidos de hierro. Sin embargo, el empleo de esta técnica en viticultura está muy limitado debido a que es necesario aplicar grandes cantidades de producto, con unos costes difícilmente asumibles (González y Martín, 2006).

La aplicación de sulfato ferroso al terreno da resultados variables y muchas veces de poca persistencia, sobre todo en suelos muy calizos donde el hierro se inactiva rápidamente. La localización del producto es un factor crítico para conseguir una buena eficacia de los compuestos inorgánicos de hierro. La apertura de surcos profundos en el terreno cuando se emplean abonadoras localizadoras secciona parte de las raíces de la viña, lo que favorece la emisión de nuevas raicillas que garantizan la absorción del hierro aplicado. 
El fosfato ferroso o vivianita $\left(\mathrm{Fe}_{3}\left(\mathrm{PO}_{4}\right)_{2} \cdot 8 \mathrm{H}_{2} \mathrm{O}\right)$ presenta un elevado contenido en hierro, mayor del $30 \%$, y unos efectos mucho más persistentes que los del sulfato ferroso. Aunque la vivianita es poco soluble al $\mathrm{pH}$ de la mayoría de los suelos, la liberación de hierro se ve favorecida al irse eliminando el ión fosfato por distintas vías: absorción por las raíces, adsorción superficial en algunos minerales y precipitación al reaccionar con cationes de la disolución del suelo. El fosfato impide la formación de compuestos cristalinos de hierro, de modo que el ión ferroso liberado por la vivianita puede ser tomado directamente por las raíces o bien oxidarse y precipitar como óxidos de hierro no cristalino (ferrihidrita). Estos óxidos constituyen una fuente fundamental de hierro para las plantas en suelos calizos (Roldán et al., 2002). El hecho de que las partículas de vivianita tengan un tamaño comprendido entre 5 y $10 \mu \mathrm{m}$ y baja solubilidad al $\mathrm{pH}$ de los suelos calcáreos, favorece la lenta liberación de $\mathrm{Fe}$ a la disolución. Esto permite que una aplicación de vivianita en el suelo tenga un efecto prolongado en el tiempo como se ha observado durante tres años en olivar (Benitez et al., 2002) cinco en peral (del Campillo et al., 1998) y tres en viñedo (Díaz et al., 2009a).

EI Fe-EDDHA y sus homólogos (Fe-EDDHMA, Fe-EDDHSA y Fe-EDDCHA) son los quelatos correctores de la clorosis más eficaces y comúnmente usados en terrenos calizos (Chen y Barak, 1982; Wallace, 1983), ya que son estables incluso a valores de $\mathrm{pH}$ de la solución del suelo superiores a 9 (Álvarez-Fernández et al., 2002). Los quelatos Fe-DTPA y Fe-EDTA, más baratos que los anteriores, deben emplearse exclusivamente en suelos ácidos, ya que con $\mathrm{pH}$ superiores a 6,5 ven desplazado el hierro de sus moléculas por elementos como $\mathrm{Ca}, \mathrm{Zn}$ y $\mathrm{Cu}$, precipitando a continuación en forma de óxidos e hidróxidos insolubles (Lucena et al., 1987).

Los quelatos sintéticos son productos más caros, pero su eficacia en la corrección de la clorosis férrica supera con creces a la de las sales inorgánicas de hierro, al menos en aplicaciones al suelo. Debido a su coste, los quelatos se emplean sobre todo en cultivos intensivos o en aquellos casos en que se requieran pocas dosis para la recuperación de las plantas. En viticultura, la aplicación de quelatos está indicada especialmente en producción de uva de mesa, aunque puede aplicarse también en uva de vinificación si el precio de la uva lo merece.

La aportación de quelatos de hierro al suelo debe hacerse antes de la brotación, a finales de invierno, localizando el producto en profundidad mediante inyectores, abonadoras localizadoras o riego localizado. La incorporación simultánea de quelatos y materia orgánica favorece la asimilación del hierro por parte de la planta.

En los complejos naturales de hierro, el agente complejante puede ser citrato, lignosulfonato, humatos u otras moléculas orgánicas. Estos productos son mucho más inestables que los quelatos sintéticos, y por ello se usan únicamente en fertirrigación o en pulverización foliar.

Entre los correctores aplicados a la planta se pueden citar las sales inorgánicas de hierro (principalmente sulfato ferroso), quelatos sintéticos, complejos organominerales de hierro (poliflavonoles o lignosulfonato). 
Las inyecciones de disoluciones férricas en el tronco tienen interés sobre todo en viñas jóvenes. Aunque su eficacia es moderada, los efectos del producto tienen una persistencia de unos dos o tres años (Rease et al., 1986). Las disoluciones más utilizadas incorporan sulfato ferroso, citrato-Fe y citrato-amónico-Fe. También existe la posibilidad de hacer implantes de productos sólidos en el tronco y brazos de las cepas, de modo similar a como se hace en árboles frutales. Se usan pastillas elaboradas con los mismos compuestos férricos que se aplican en las inyecciones, a los que se añaden sustancias peletizantes. Los implantes se colocan en orificios de unos $8 \mathrm{~mm}$ de diámetro que se abren con un taladro y que se sellan luego con mastic. Como en el caso de las inyecciones, la persistencia del producto es de varios años.

En caso de aplicar quelatos sintéticos por vía foliar, no es necesario tener en cuenta su comportamiento en función del pH. Se utilizan los más baratos: Fe-EDTA y Fe-DTPA. En viñedos muy afectados por la clorosis, los tratamientos foliares a base de sales inorgánicas de hierro pueden no resultar completamente efectivos por sí mismos, pero puede ser recomendable llevarlos a cabo como complemento a los tratamientos de suelo con quelatos sintéticos (Fernández y Ebert, 2005). Las aplicaciones foliares deben realizarse al observar las primeras manifestaciones de la carencia en primavera. Es conveniente pulverizar el líquido en finas gotas y con maquinaria adecuada para lograr una buena cobertura del follaje y también añadir tensoactivos y mojantes que favorezcan la adherencia del producto (Fernández et al., 2006).

Algunos complejos organominerales de hierro, como los poliflavonoides o lignosulfonatos, que se pueden utilizar como correctores de la clorosis por vía foliar (Raese et al., 1986), tienen gran interés en agricultura ecológica, cuya normativa reguladora permite su uso, y no el de los quelatos de síntesis. No obstante, las eficiencias obtenidas en la corrección de la clorosis con complejos naturales de hierro son muy variables en función de la naturaleza del producto y del cultivo considerados. 


\section{4.- PARÁMETROS DE FLUORESCENCIA CLOROFÍLICA. APLICACIONES PARA LA DETECCIÓN Y SEGUIMIENTO DE SITUACIONES DE ESTRÉS NUTRICIONAL.}

Solo una parte de la energía luminosa absorbida por las moléculas de la clorofila es aprovechada por la planta para realizar la fotosíntesis, esto es la energía fotoquímica. El exceso de energía puede ser disipado como calor, o puede ser reemitido en forma de fluorescencia. Entre estos tres fenómenos existe una competencia de modo que el aumento de un componente supone un descenso en los otros dos (Maxwell y Johnson, 2000). Habitualmente, la fluorescencia emitida por la clorofila supone entre un 1 y un 3\% de la luz total absorbida (Maxwell y Johnson, 2000; Lichtenthaler, 2003).

Los procesos de generación de fluorescencia de la clorofila se ilustran en la figura 1.8. Cualquier cosa que afecta a la fotosíntesis afectará a la emisión de fluorescencia de la clorofila, lo que hace de ella una herramienta versátil para evaluar el estado fotosintético y detectar cambios fisiológicos y ambientales de las plantas (Maxwell y Johnson, 2000).

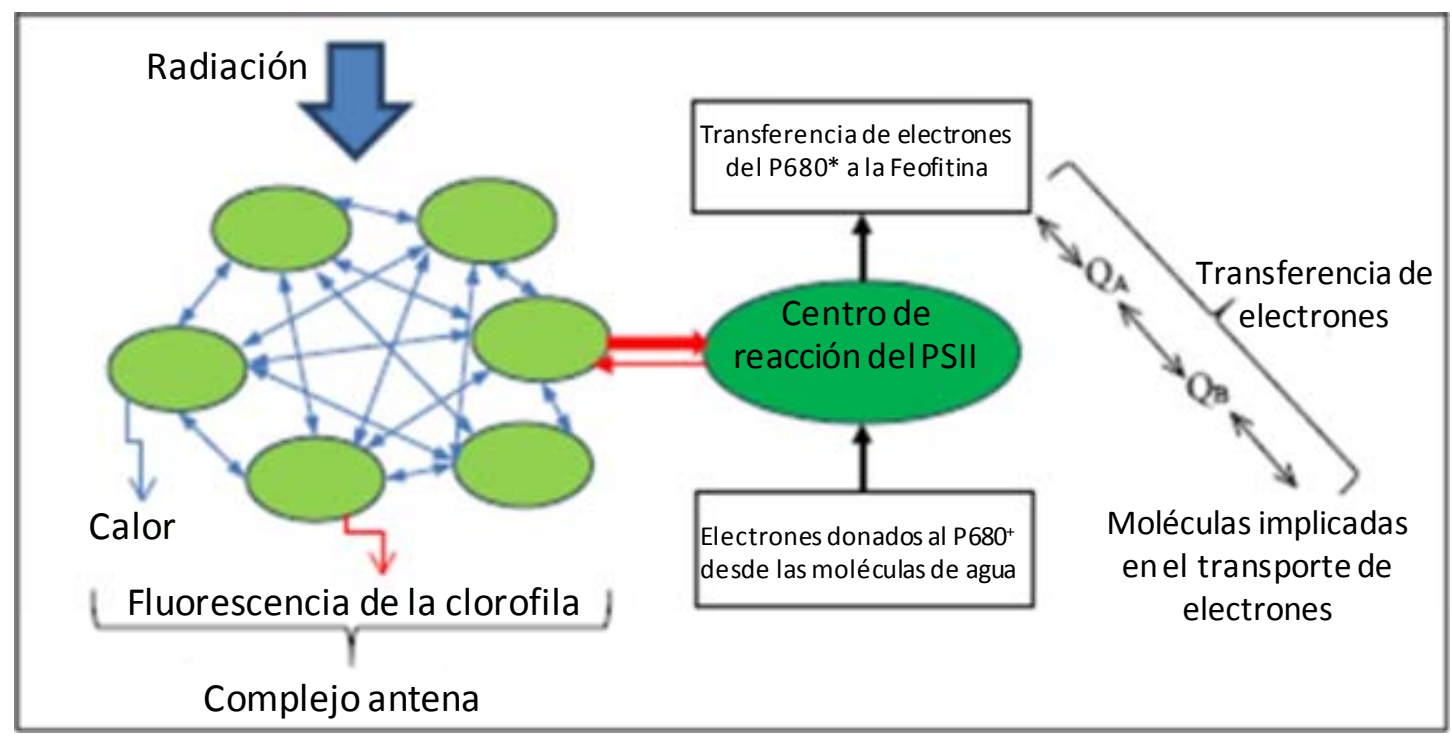

Figura 1.8. Generación de la fluorescencia de la clorofila en el fotosistema II (Guo y Tan, 2015).

El espectro de la fluorescencia es diferente al de la luz absorbida, con un pico de emisión a una longitud de onda mayor. En realidad, el espectro de emisión de la clorofila muestra un pico a $682 \mathrm{~nm}$ además de un "hombro" menor a $740 \mathrm{~nm}$ aproximadamente (Oxboroung, 2004). Por ello, la fluorescencia puede ser cuantificada mediante la exposición de la hoja a una longitud de onda conocida, menor de $670 \mathrm{~nm}$ 
y midiendo la luz emitida a una mayor longitud de onda, entre 670 y $750 \mathrm{~nm}$ (Maxwell y Johnson, 2000; Oxborouhg, 2004).

Es evidente que la medida de la fluorescencia de la clorofila es una de las técnicas más populares de la fisiología vegetal, debido a la facilidad con la que se puede obtener información detallada sobre el estado del fotosistema II en una amplia gama de situaciones a un costo relativamente bajo. Ha tenido un papel importante en el estudio de los mecanismos fundamentales de la fotosíntesis, las respuestas de las plantas a los cambios ambientales, la variación genética y la diversidad ecológica (Baker y Rosenqvist, 2004; Furbank et al., 2009; Murchie y Lawson, 2013).

Hay una gran demanda de metodologías para la evaluación del estado fotosintético que dan información detallada del estado fisiológico de las plantas, a menudo en relación con parámetros de crecimiento y desarrollo, nivel de rendimiento y detección de situaciones de estrés (Montes et al., 2007; Furbank et al., 2009). Estas metodologías requieren un elevado número de mediciones en un corto período de tiempo. Es muy importante que los protocolos utilizados y los parámetros medidos sean apropiados para el estudio particular que se plantee. El usuario se enfrenta a una gran variedad de opciones que incluyen el tipo de aparato de medición, la configuración del instrumento, la forma de alcanzar el período de adaptación a la oscuridad, y las condiciones ambientales en que se hacen las mediciones (Krause y Weiss, 1991; Maxwell y Johnson 2000; Adams et al., 2004; Logan et al 2007; Baker, 2008; Murchie y Lawson, 2013).

\subsection{1.- El efecto Kautsky.}

Al medir la fluorescencia de la clorofila, nos encontramos con que sus valores no permanecen constantes, sino que van variando según se desarrolla la medida. Este es el denominado "efecto Kautsky". Cuando una hoja adaptada a la oscuridad tras un periodo mínimo de unos 20 minutos (Lichtenthaler, 2003) es sometida de repente a condiciones de iluminación saturante, el valor de la fluorescencia aumenta durante un periodo de tiempo de aproximadamente un segundo. Esto se explica porque los centros de reacción del fotosistema II inicialmente se encuentran abiertos (la quinona primaria aceptora de electrones del fotosistema II está oxidada al máximo), pero se van cerrando a medida que los fotones inciden sobre ellos (Maxwell y Johnson, 2000). Estos cambios en la fluorescencia son muy interesantes a la hora de poder detectar diferencias en el estado fotosintético de las plantas (Baker y Rosenqvist, 2004).

A continuación, el nivel de fluorescencia cae progresivamente en unos pocos minutos. Este fenómeno es denominado "apagado o disipación de la fluorescencia".

Existen dos explicaciones para entender esto. En primer lugar, hay un incremento del flujo de electrones transportados por el fotosistema II, debido principalmente a la activación de enzimas del metabolismo del carbono por parte de la luz y la apertura de estomas, con la consiguiente transformación de la energía lumínica en energía química. Esto es conocido como "apagado fotoquímico" (photochemical quenching). En segundo lugar hay un incremento de la eficiencia con la que la energía es convertida en calor. Este último proceso es conocido como 
"apagado no fotoquímico" (non-photochemical quenching, NPQ) (Maxwell y Johnson, 2000).

Para distinguir entre el "apagado" fotoquímico y el no fotoquímico, en cultivo in vitro se puede recurrir a la aplicación de químicos que inhiben el fotosistema II, reduciendo así la parte fotoquímica a cero (Baker y Rosenqvist, 2004). Sin embargo, en condiciones normales de cultivo se aplica un flash de luz de alta intensidad y corta duración. De este modo se consigue cerrar momentáneamente todos los centros de reacción del fotosistema II. Si el pulso de luz es lo bastante breve, no se incrementa la fracción no fotoquímica, y no se producen cambios en la eficiencia de la fotosíntesis a largo plazo. La medida de la fluorescencia durante el flash, es el equivalente a la obtenida en ausencia de "apagado fotoquímico", es decir, la fluorescencia máxima (Fm). Comparando este valor con la medida de la fluorescencia en presencia de luz solar (Fs) y la medida de la fluorescencia en ausencia de luz fotosintéticamente activa (Fo) podemos obtener información acerca de la eficiencia del "apagado fotoquímico" y por tanto, del estado del fotosistema II (Maxwell y Johnson, 2000).

\subsection{2.- Parámetros de la fluorescencia.}

Las alteraciones del metabolismo fotosintético, que pueden ser inducidas por muchos factores bióticos y abióticos, modifican significativamente la cinética de la emisión de la fluorescencia característica de las plantas. Por otra parte, la inhibición de reacciones metabólicas no relacionadas directamente con la fotosíntesis también puede modificar los procesos intermediarios de la fotosíntesis $\mathrm{y}$, por tanto, alterar la tasa de fotosíntesis y la emisión de fluorescencia características (Barbagallo et al., 2003; Baker y Rosenqvist, 2004).

Al medir la fluorescencia se obtiene una gráfica de la que se pueden extraer el valor de algunos parámetros importantes (Figura 1.9). Al comenzar la medida obtenemos el valor de fluorescencia mínima (Fo) aplicando sobre una hoja adaptada a la oscuridad una luz de muy baja intensidad (por debajo de $1 \mathrm{~mol}$ de fotones $\mathrm{m}^{-2} \mathrm{~s}^{-1}$ ). Esta medida muestra el nivel de fluorescencia cuando la quinona primaria aceptora de electrones del fotosistema II $\left(Q_{A}\right)$ están oxidadas al máximo (centros de reacción del fotosistema II abiertos) (Baker y Rosenqvist, 2004). Cuando aplicamos un flash de luz saturante con la hoja adaptada a la oscuridad, la fluorescencia aumenta hasta un nivel máximo (Fm) (Maxwell y Johnson, 2000) y muestra el nivel de fluorescencia cuando la $Q_{A}$ está reducida al máximo (centros de reacción del fotosistema II cerrados). La diferencia entre $\mathrm{Fm}$ y Fo se llama fluorescencia variable (Fv), que muestra la habilidad del fotosistema II de fotorreducir la $Q_{A}$ (Baker y Rosenqvist, 2004). Al aplicar luz actínica y flashes de luz saturantes en intervalos apropiados, obtenemos los valores de fluorescencia máximos en la hoja adaptada a la presencia de luz (Fm'). Este valor de Fm' es considerablemente menor que el valor de $\mathrm{Fm}$ generado por la hoja adaptada a la oscuridad. En el caso de hojas adaptadas a la luz, la fluorescencia variable $\left(F v^{\prime}\right)$ es la diferencia entre $\mathrm{Fm}^{\prime}$ y $\mathrm{Fo}^{\prime}$. El valor de la fluorescencia inmediatamente anterior al flash se denomina Fs. Después del flash, eliminando la luz actínica se puede medir Fo' (Maxwell y Johnson, 2000). 


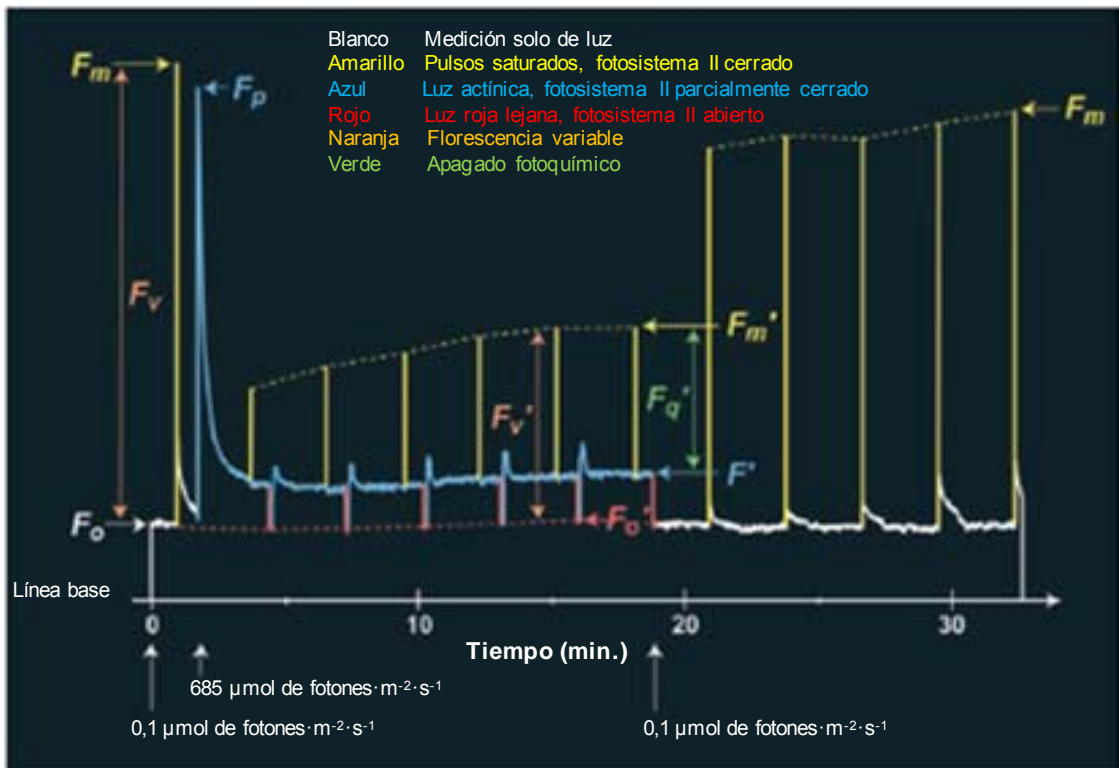

Figura 1.9. Gráfica del análisis de la fluorescencia usando un sistema modulado (Baker y Rosenqvist, 2004).

Como la medida de la fluorescencia se produce en unidades relativas a la intensidad de luz aplicada sobre la clorofila, las relaciones entre estos parámetros serán las herramientas más útiles para conocer el estado fotosintético de la planta.

Entre los coeficientes que hacen referencia a los procesos fotoquímicos de la hoja, hay que destacar la eficiencia del fotosistema II (ФPSII), que se puede calcular como:

$$
\Phi P S I I=\left(F m^{\prime}-F s\right) / F m^{\prime}
$$

Este parámetro indica la proporción de luz absorbida por la clorofila asociada al fotosistema II y que es usada en los procesos fotoquímicos. En laboratorio se ha encontrado una relación lineal entre este parámetro y la fijación de carbono, aunque en ciertas condiciones de estrés se pueden encontrar que esta relación puede no existir (Maxwell y Johnson, 2000).

El "apagado fotoquímico" (qP) se calcula como:

$$
\mathrm{qP}=\left(F m^{\prime}-\mathrm{Fs}\right) /\left(\mathrm{Fm}^{\prime}-\mathrm{Fo}^{\prime}\right)
$$

Este factor determina la eficiencia de la capacidad de la hoja para eliminar electrones de los aceptores de la quinona del PSII, que está directamente relacionado con la velocidad a la que los productos de la fotosíntesis de transporte de electrones (NADPH y ATP) se consumen.

A diferencia del parámetro anterior, qP da información acerca de la proporción de los centros de reacción del fotosistema II que se encuentran abiertos. Por el 
contrario, $(1-q P)$ nos dará la proporción de centros de reacción cerrados (Maxwell y Johnson, 2000).

La máxima eficiencia del fotosistema II (Fv/Fm). Máxima eficiencia con la que la luz absorbida por las antenas del fotosistema II es convertida en energía química (reducción de la $\mathrm{Q}_{\mathrm{A}}$ ):

$$
\mathrm{Fv} / \mathrm{Fm}=(\mathrm{Fm}-\mathrm{Fo}) / \mathrm{Fm}=(\Phi P S I I / q P)
$$

La dificultad de estimación de qP y Fv/Fm es la necesidad de estimar el valor de Fo en el momento de la medición. En el laboratorio se consigue poniendo las hojas en oscuridad y aplicando iluminación en el rojo cercano (>680 nm) unos segundos antes e inmediatamente después de la iluminación para la medida (Maxwell y Johnson, 2000).

Respecto a los procesos no fotoquímicos, el parámetro más utilizado es el "apagado no fotoquímico" (NPQ):

$$
N P Q=\left(F m-F m^{\prime}\right) / F m^{\prime}=\left(F m / F m^{\prime}\right)-1
$$

El valor obtenido tiene una relación lineal con la disipación de energía en forma de calor. NPQ evalúa aumentos del apagado no fotoquímico en hojas adaptadas a la luz con respecto al apagado fotoquímico en hojas adaptadas a la oscuridad. Dicho de otro modo, este parámetro sólo es válido para hacer comparaciones entre muestras que tienen las mismas características de NPQ en hojas adaptadas a la oscuridad; (Maxwell y Johnson, 2000; Baker y Rosenqvist, 2004)

El ratio de transporte de electrones (ETR):

$$
\mathrm{ETR}=\mathrm{PPFD} \times \Phi \mathrm{PSI} \times 0,5
$$

Con PPFD: Densidad del flujo de fotones incidente $\left(\mu \mathrm{mol}\right.$ de fotones $\left.\cdot \mathrm{m}^{-2} \cdot \mathrm{s}^{-1}\right)$. El factor 0,5 tiene en cuenta el reparto de energía entre el PSIl y el PSI. Asume que el $50 \%$ de la energía es absorbida por el PSII (Genty et al. 1989).

\subsection{3.- Fuentes de error.}

Cuando utilizamos la fluorescencia de la clorofila para analizar la actividad fotosintética de la planta y el estado del fotosistema II, nos encontramos con dos fuentes de error principales: la fluorescencia de la clorofila del fotosistema I y la absorción de la fluorescencia de la clorofila por las plastoquinonas (Oxborouhg, 2004).

Según Oxborouhg (2004), la primera fuente puede representar hasta el $30 \%$ de la señal de la fluorescencia de Fo en las plantas C3, y hasta el $40 \%$ en plantas C4. Con el descenso en el valor de ФPSIl que generalmente acompaña al incremento en la irradiación de fotones incidentes, el error debido a la fluorescencia del fotosistema I aumentará.

La segunda fuente de error, según la plastoquinona esté completamente oxidada o reducida, puede incrementar la medida de la fluorescencia hasta en un $20 \%$. 
Los mayores errores se producen en el cálculo de Fv/Fm, al basarse en la medida de Fo y de Fm (máximo estado de reducción de las plastoquinonas).

\subsection{4.- Medida de la eficiencia fotosintética a través de la fluorescencia clorofílica.}

Varios parámetros de la fluorescencia de la clorofila han mostrado ser útiles para evaluar el rendimiento fotosintético, conteniendo información sobre el estado fisiológico de las plantas y su respuesta a cambios ambientales. Sin embargo, cuando se comparan investigaciones en la materia puede haber contradicciones, de forma que un parámetro de fluorescencia puede resultar útil en un estudio pero no en otros. Estas inconsistencias sugieren que se necesita un marco fundamental para el análisis de la fluorescencia de la clorofila (Guo y Tan, 2015).

La fluorescencia se ha manifestado como un método interesante para la evaluación del estado fotosintético de las plantas, resultando versátil y rápido, y permitiendo así el diseño de experimento con un mayor número de tratamientos y replicaciones (lacono y Sommer, 1999). Utilizando las medidas de fluorescencia complementariamente con las medidas del intercambio gaseoso en las hojas se puede obtener una imagen completa de las respuestas de las plantas a las condiciones ambientales (Maxwell y Johnson, 2000; Baker y Rosenqvist, 2004).

La principal utilidad de la fluorescencia de la clorofila es su uso como fuente de información acerca del estado del fotosistema II en las hojas (figura 1.10). Esto nos permite estimar el estado fotosintético bajo condiciones en las que otros métodos podrían fallar y, además, de forma casi instantánea. Nos puede dar una buena medida, rápidamente y de una forma no invasiva, de los cambios producidos a nivel de hoja (Maxwell y Johnson, 2000).

Hay que tener en cuenta al diseñar los experimentos que la eficiencia del fotosistema II varía también a lo largo del día en función de la iluminación, reduciéndose a un mínimo al mediodía. También influye la presencia o ausencia de nubes o la posición de la hoja en la planta (Morales et al., 2000). Altas iluminaciones incrementan la disipación térmica en las antenas del fotosistema II además de aumentar el NPQ.

La principal determinación de la fluorescencia de la clorofila es el estado redox de la plastoquinona $Q_{A}$, el primer aceptor de electrones del PSII: cuando está en el estado oxidado, la fluorescencia es baja, y cuando se encuentra reducido es alta. Por lo tanto, la concentración neta de $Q_{A}$ está relacionada con el comportamiento de la fluorescencia de la clorofila (Govindjee, 1995, 2004).

Los daños en el fotosistema II, son con frecuencia la primera manifestación del estrés en las hojas (Maxwell y Johnson, 2000). Se ha demostrado que las alteraciones en el metabolismo fotosintético modifican significativamente la cinética de la emisión de fluorescencia de la clorofila característica de las plantas (Barbagallo et al., 2003). 


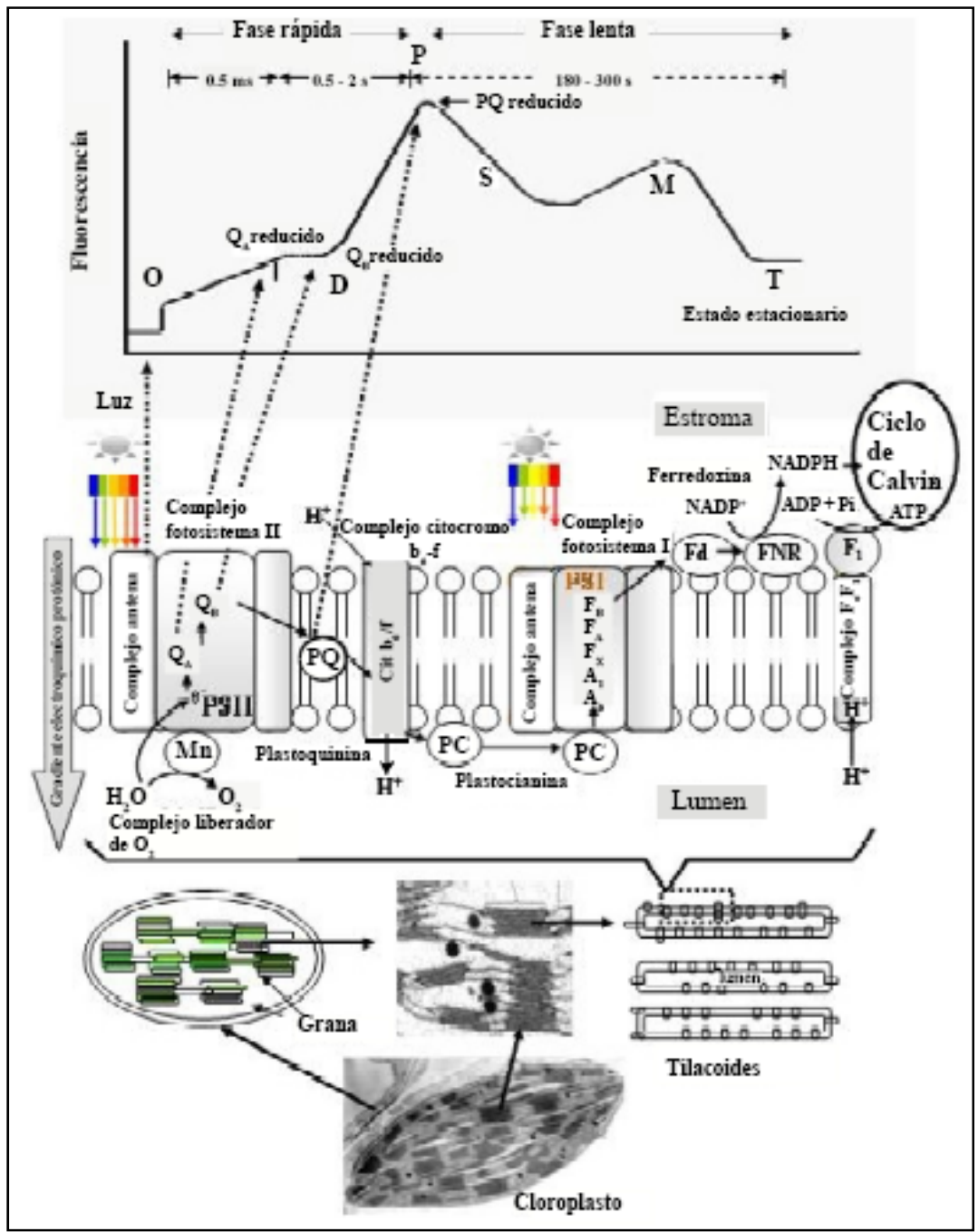

Figura 1.10. Curva de inducción de fluorescencia de clorofila a y su correspondencia con las reacciones de la cadena transportadora de electrones (González et al., 2008). La intensidad de la primera señal registrada (origen) se expresa como Fo (fluorescencia inicial o basal). En este punto, $Q_{A}$ está, en su mayor parte, oxidada. La fase I (inflexión) corresponde a la reducción de $Q_{A}$. La fase $D$ (declive) es indicativa de la oxidación de $Q_{A}$ en la transferencia de electrones de $Q_{A}$ a $Q_{B}$. El nivel de fluorescencia $P$ corresponde a la reducción de $P Q$ y su intensidad normalmente se denomina Fm (fluorescencia máxima). La fase $S$ (estado estacionario) de decaimiento de fluorescencia está relacionada con la re-oxidación de $Q_{A}$, la excitación de la membrana tilacoide debida a translocación de protones $(\Delta \mathrm{pH})$. Las fases $\mathrm{M}$ (máxima) y $\mathrm{T}$ (terminal) corresponden a la disminución de $\mathrm{qP}$ e incremento de $\mathrm{qN}(\Delta \mathrm{pH})$ y están relacionadas con la captación de $\mathrm{CO}_{2}$, velocidad de liberación de $\mathrm{O}_{2}$ y la disponibilidad de NADP ${ }^{+}$, ADP y fosfato. 


\subsection{5.- Detección de estrés nutricional mediante parámetros de fluorescencia.}

La relación entre el estado operativo del PSII y la asimilación de $\mathrm{CO}_{2}$ en las hojas permite que la fluorescencia pueda ser utilizada para detectar diferencias en la respuesta de las plantas a los factores medioambientales y, por consiguiente, para la detección de estrés ambiental (Baker, 1996). La tasa de asimilación de $\mathrm{CO}_{2}$ de la hoja es sensible a una amplia gama de variables ambientales, por ejemplo contaminantes atmosféricos, altas y bajas temperaturas, exceso de iluminación, deficiencia de nutrientes, irradiación UV-B, sequía.

Muchos autores han utilizado con éxito la fluorescencia de la clorofila para la detección de diferentes tipos de estrés. Así, Flexas et al. (1999, 2000, 2002c) mostraron que Fs y el ratio Fs/Fo podrían resultar útiles para la detección precoz del estrés hídrico en vides; Tang et al. (2007) encontraron que NPQ puede considerarse como el mejor parámetro para estudiar el estrés por calor en espinaca; Baker y Rosenqvist (2004) propusieron Fv/Fm como una buena herramienta para detectar el estrés por altas temperaturas; Calatayud et al. (2006) estudiaron el efecto del estrés por exceso de ozono en sandia observando una disminución significativa en Fv/Fm y ФPSIl en las plantas afectadas debido al cierre de centros de reacción del PSII (qP) y a un aumento de NPQ. En cuanto al estrés biótico, los parámetros de fluorescencia idóneos son dependientes del tipo de estrés (Nedbal y Whitmarsh 2004). En este sentido, Nebdal et al., (2000) propusieron Fv/Fm para detectar la infección de podredumbre verde (Penicilliurn digitatum) en limonero y Duraes et al. (2001) observaron cambios en Fv/Fo las plantas de maíz afectadas por roya (Puccinia polysora).

Los avances en la investigación sobre la utilización de parámetros de la fluorescencia de la clorofila para la detección de estrés nutricional en los últimos años son importantes. Así, Baker y Rosenqvist (2004) mostraron que el qP podría utilizarse como indicador de deficiencia de N; Spáčilová y Šafránková (2011) encontraron que el nivel de Fv/Fm disminuía en condiciones de deficiencia de $\mathrm{N}$, verificando una fuerte correlación con la concentración de $\mathrm{N}$ en las hojas de manzanos. Huang et al. (2004) observaron que los parámetros de fluorescencia ФPSII, Fv'/Fm', y QP disminuían en plantas de arroz deficientes de N. Stark et al. (2000) encontraron que la relación Fv/Fm era sensible al estrés provocado por deficiencia de P. Shmidts-Eiberger et al. (2002) propusieron la relación Fv/Fm para detectar una mala nutrición de Ca; Mallicka y Mohn (2003) y Wang y Jin (2005) concluyeron que Fv/Fm, y especialmente la relación Fo/Fv, se pueden utilizar como indicadores del estrés producido por carencia de $\mathrm{Cu}$ y $\mathrm{Zn}$. Martínez-Peñalver et al. (2011) corroboraron que estrés por deficiencia de $\mathrm{Cu}$ y $\mathrm{Zn}$ provocan una reducción global de Fv/Fm en Arabidopsis thaliana (L.) Heynh.

Diversos autores han estudiado el comportamiento de diferentes parámetros de la fluorescencia de la clorofila en condiciones de clorosis férrica. La deficiencia de hierro redunda a nivel fisiológico en un descenso de la concentración de pigmentos fotosintéticos y de la tasa de transporte de electrones en la fotosíntesis (Val et al., 1987, Nedunchezhian et al., 1997; Morales et al., 1998a; Bavaresco et al., 2006). Se ha demostrado que la eficiencia energética de la fotosíntesis, medida mediante 
fluorescencia de clorofila, disminuye en plantas deficientes en Fe (Morales et al., 1994, 2001), cianobacterias (Guikema y Sherman, 1983; Guikema, 1985), y en algas marinas (Greene et al., 1991, 1992). En cualquier caso, parece ser que la deficiencia de Fe afecta la conversión fotosintética de energía solamente por debajo de un cierto nivel de concentración de clorofila (Morales et al., 2001).

La deficiencia de $\mathrm{Fe}$ induce un aumento considerable del nivel inicial de fluorescencia Fo, y una disminución de la proporción de fluorescencia variable Fv (Morales et al., 1991; Greene et al., 1992). Estos dos fenómenos reflejan una pérdida de eficiencia fotoquímica del PSII (Greene et al., 1992). También puede apreciarse un descenso en la relación entre fluorescencia variable y fluorescencia inicial (Fv/Fo) (Molassiotis et al., 2006).

La variable Fm corresponde al estado de reducción completa de la $\mathrm{Q}_{\mathrm{A}}(\mathrm{qP}=0)$ y es considerado proporcional al contenido de clorofila total de la hoja (Miranda et al., 1981; Netto et al., 2005). La reducción producida en la eficiencia fotoquímica del PSII puede ser cuantificado mediante la ratio Fv/Fm (Nedunchezhian et al., 1997; Morales et al., 2000; Bertamini et al., 2001). Estudios realizados por Pestana et al. (2005) en naranjo han mostrado que un descenso en los valores de $\mathrm{Fm}$ y de la relación Fv/Fm a medida que se acentúa la clorosis férrica o la variedad es más sensible. Bertamini et al. (2002) y Bavaresco et al. (2006) en vid y Morales et al. (2000) en peral observaron que la relación Fv/Fm era menor en hojas cloróticas que en hojas sanas.

La deficiencia de hierro incrementa los valores de NPQ a baja iluminación, y aumenta la proporción de energía disipada en forma de calor (Morales et al., 2000). Bavaresco et al. (2006) han observado que la clorosis férrica reducía el transporte aparente de electrones (ETR) y del apagado fotoquímico (qP) frente a plantas control. Según Abadía et al. (1999) y Morales et al. (2000) la disminución de la eficiencia actual del PSII se debe a una disminución del "apagado" fotoquímico y de la eficiencia intrínseca del PSII.

\subsection{6.- Aplicaciones en viticultura de precisión.}

El manejo del viñedo de acuerdo a la variabilidad espacial y temporal de los factores de producción dentro de las parcelas es interesante para optimizar el rendimiento y la calidad de la uva en las explotaciones vitícolas. La identificación y la caracterización espacial de dicha variabilidad, la interpretación de su significado enológico, así como la posibilidad del manejo diferencial de dicha variabilidad, constituyen los principales objetivos de la viticultura de precisión (Urretavizcaya et al., 2014). Es posible diseñar diferentes estrategias para la gestión de los viñedos basadas en el crecimiento vegetativo (Tardaguila et al., 2011), el rendimiento de la viña (Bramley y Hamilton, 2004), e incluso la composición de las uvas (Bramley, 2005; Trought y Bramley, 2011).

Las imágenes multiespectrales permiten el cálculo de los denominados índices de vegetación (o índices de vigor), a partir de las reflectancias en canales del visible y del infrarrojo cercano. Los índices más utilizados en viticultura de precisión han sido el PCD (Plant Cell Density - Bramley et al., 2003-), el PVR (Photosynthetic Vigour Ratio - 
Bramley y Lamb, 2003-) y sobre todo el NDVI (Normalized Difference Vegetation Index - Rouse et al., 1973). El uso de estos índices permite la identificación y zonificación de áreas de diferente vigor dentro de las parcelas y en algunos casos, estimar el rendimiento. Sin embargo, la correspondencia entre la calidad de la uva con los índices de vegetación no está clara (Santesteban et al., 2010). En este sentido, los parámetros de calidad de uva suelen tener un rango de variación menor que el vigor y el rendimiento (Bramley, 2005). Además, si bien las zonas de vigor y/o rendimiento no suelen variar sustancialmente a lo largo de los años, la estabilidad espacio-temporal de los parámetros de calidad de la uva es menor (Tisseyre et al., 2008).

Frente a la viticultura tradicional, la viticultura de precisión puede permitir una gestión más adecuada para el control de la clorosis férrica, a través de la aplicación de distintos tratamientos en cepas o subparcelas específicas, más o menos afectadas. Por otra parte puede hacer posible la definición de zonas de calidad homogénea dentro de los viñedos afectados, para planificar una recolección diferencial por subparcelas que permita transformar la uva en concordancia con su potencialidad enológica (Martín et al., 2007a).

En suelos clorosantes la disponibilidad de hierro puede ser el factor limitante principal en el desarrollo del viñedo, por lo que la estimación del contenido foliar de clorofila mediante colorímetros portátiles tipo SPAD o mediante sensores remotos puede utilizarse para elaborar mapas de rendimiento y de calidad de uva en viñedos afectados por clorosis (Meggio et al., 2008; Zarco-Tejada et al., 2005). Estudios recientes muestran que índices fisiológicos relacionados con el contenido foliar de clorofilas, carotenoides y antocianinas, calculados en envero a partir de imágenes hiperespectrales, puede ser útiles para realizar mapas de calidad en viñedos afectados por deficiencia de hierro (Martín et al., 2007a; Meggio et al., 2010), guardando fuertes correlaciones con los niveles de madurez fenólica de la uva.

Actualmente se están poniendo a punto sensores digitales que, instalados en avión o en satélite, pueden detectar la fluorescencia natural emitida por las plantas utilizando bandas espectrales muy estrechas en la región de absorción del oxígeno atmosférico. Otra línea de trabajo interesante en teledetección de estrés pretende evaluar las tasas de disipación del exceso de energía en la fotosíntesis. Uno de los principales mecanismos no fotoquímicos implicados en esta disipación está relacionado con el ciclo de las xantofilas en las hojas (transformación de violaxantina en zeaxantina). Los cambios en las concentraciones de los pigmentos xantofílicos pueden ponerse de manifiesto con técnicas de teledetección mediante índices como el PRI (photochemical reflectance index) (Zarco-Tejada, 2013b).

En otra línea de trabajo se trata de detectar el nivel de estrés a través de la evaluación del rendimiento de la fotosíntesis mediante parámetros de fluorescencia clorofílica (Flexas et al., 2000; Moya et al., 2004). Los experimentos llevados a cabo a nivel de hoja en ambientes controlados han demostrado que los parámetros de fluorescencia han sido capaces de monitorizar los cambios diurnos en la fotosíntesis causados por el estrés térmico e hídrico (Dobrowski et al., 2005; Zarco-Tejada et al, 2013a). Flexas et al. (2000) observaron que las tasas de intercambio de gases $\left(\mathrm{CO}_{2} \mathrm{y}\right.$ $\mathrm{H}_{2} \mathrm{O}$ ) en las hojas mostraban un vínculo con la fluorescencia de la clorofila en la hoja bajo estrés hídrico en vides. Zarco-Tejada et al. (2012) han demostrado la viabilidad 
de la cartografia de la fluorescencia a $40 \mathrm{~nm}$ de resolución espectral utilizando una cámara micro-hiperespectral a bordo de un vehículo aéreo no tripulado (UAV). 

2. OBJETIVOS 


$$
\text { • }
$$




\section{2.- OBJETIVOS}

La presente Tesis Doctoral tiene los siguientes objetivos específicos:

1. Estudiar las relaciones entre el estado nutricional del viñedo, los contenidos en pigmentos foliares de la vid y los parámetros de eficiencia fotosintética a nivel de hoja, especialmente los relacionados con la fluorescencia de la clorofila.

2. Evaluar los efectos del estado nutricional sobre el desarrollo vegetativo, el rendimiento y la composición de la uva en viñedos cv. Tempranillo cultivados en suelos calizos de la Denominación de Origen Ribera del Duero.

3. Valorar el interés potencial de las medidas de fluorescencia de la clorofila, alternativamente al contenido en pigmentos foliares, como herramienta para la detección de clorosis férrica y otras deficiencias nutricionales, y para estimar el potencial enológico del viñedo, de cara a su aplicación en viticultura de precisión. 

3. MATERIAL $\Upsilon$ MÉTODOS 


$$
\text { • }
$$




\section{3.- MATERIAL Y MÉTODOS.}

\section{1.- DISEÑO EXPERIMENTAL.}

Para alcanzar los objetivos propuestos en este estudio de investigación se realizó un seguimiento de parámetros fisiológicos, agronómicos y de composición del fruto de un conjunto de subzonas de viñedo en la zona oeste de la Denominación de Origen Ribera del Duero, durante tres años consecutivos (2009-2011). Las subzonas, de $10 \times 10 \mathrm{~m}^{2}$ de superficie, corresponden a viñedo de secano en plena producción de la variedad Tempranillo injertada sobre 110-Richter y conducida en espaldera con densidades de plantación en torno a 2200 pies/ha. El seguimiento incluyó 22 subparcelas en el año 2009 y 24 en 2010 y 2011. La selección de estas parcelas se realizó buscando la máxima variabilidad en las características de suelo, de manera que estuviesen representadas zonas afectadas y no afectadas por clorosis férrica.

Se realizó un estudio del estado nutricional de las subparcelas mediante análisis de muestras de suelo al inicio de la investigación, y de la composición mineral de peciolos, recogidos en el estado fenológico de envero durante las tres campañas. En cada subparcela se analizó el contenido en clorofila, carotenoides y antocianinas foliares, asimilación neta y conductancia estomática, y parámetros de fluorescencia de la clorofila. En el seguimiento agronómico se controló el vigor, la superficie foliar, el rendimiento y sus componentes. Se analizó la composición del mosto de vendimia y sus características cromáticas, así como distintos parámetros de madurez fenólica de la uva.

Las relaciones entre el estado nutricional con el rendimiento fotosintético, los parámetros agronómicos y la calidad de la vendimia se han estudiado utilizando métodos de regresión lineal. Haciendo un diagnóstico nutricional previo de las subzonas de estudio, los efectos principales y la interacción de la clorosis férrica con el nivel de asimilación de otros elementos minerales diferentes al hierro sobre las variables fisiológicas, agronómicas y de calidad se han valorado mediante métodos de análisis factorial de la varianza y análisis de componentes principales. Finalmente, se ha estudiado la posibilidad de estimar el vigor, rendimiento y calidad de la vendimia en el conjunto de subparcelas utilizando parámetros de fluorescencia de la clorofila para su aplicación en la viticultura de precisión; para ello se han empleado métodos de regresión lineal y análisis de componentes principales. 


\section{2.- DESCRIPCIÓN DE LAS PARCELAS.}

Es necesario definir las condiciones previas a la realización del estudio de investigación. A continuación se describirán variables como la localización, el clima y la meteorología, el suelo o el material vegetal.

Las parcelas objeto de estudio corresponden al "viñedo tipo" de la zona en cuanto a material vegetal y forma de conducción. Las subzonas se seleccionaron buscando la máxima variabilidad posible en el estado nutricional, a partir de una alta variabilidad en las características de suelo, de manera que estuviesen representadas zonas afectadas y no afectadas por clorosis férrica. La selección de subparcelas con diferente grado de afección de la carencia de hierro se realizó atendiendo a síntomas visuales de la fisiopatía en los primeros estados del ciclo vegetativo, buscando una máxima variabilidad en el contenido en clorofila de las hojas, en función de los datos aportados por el Consejo Regulador y los técnicos de campo de las distintas bodegas.

Las subparcelas seleccionadas se ubican en diferentes viñedos en el término municipal de Pesquera de Duero (Valladolid), al oeste de la Denominación de Origen "Ribera del Duero". Cada una de ellas tiene un área de $10 \times 10 \mathrm{~m}^{2}$ y corresponde a la variedad. Tempranillo injertada sobre portainjerto $110 \mathrm{R}$.

De las 22 subparcelas muestreadas en 2009 se descartaron 8 para las dos campañas siguientes, por falta de homogeneidad con el resto y debido a que al estar más dispersas en el territorio alargaban en exceso el tiempo para la toma de datos de campo (especialmente las medidas de fotosíntesis). Por otro lado en 2010 y 2011 se seleccionaron 10 nuevas subzonas. En la tabla 3.1 se detallan las coordenadas UTM de las subzonas, las bodegas a las que pertenecen los viñedos, el marco de plantación y los años en que se ha realizado seguimiento de las mismas.

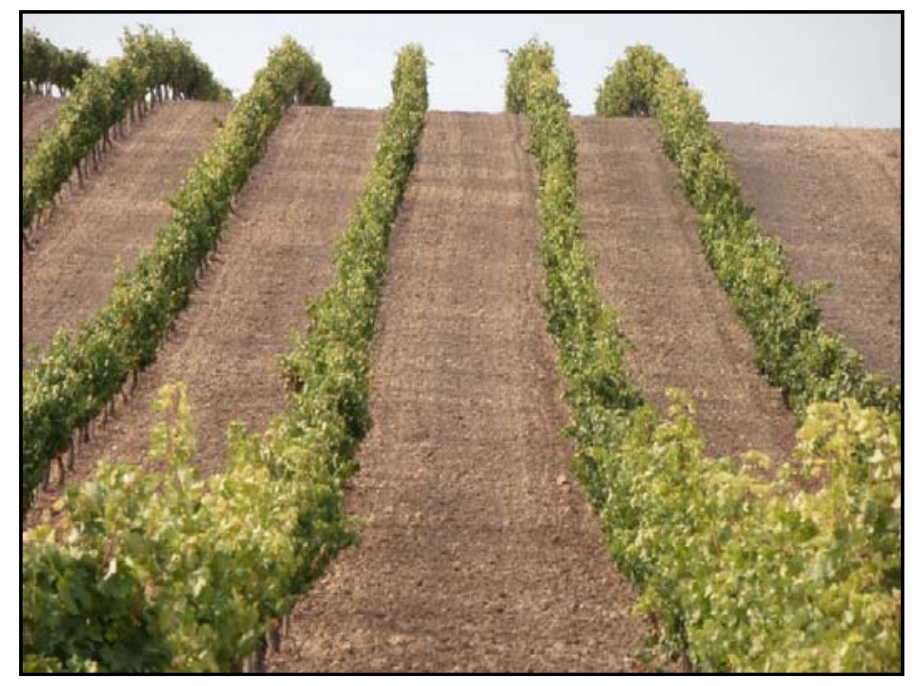

Figura 3.1. Aspecto del viñedo en la zona de estudio. (Subzona 5). 
El área de estudio se encuentra a una altitud media de 800 m.s.n.m. con pendientes suaves. Los viñedos tienen una edad comprendida entre los 15 y 25 años corresponden a la variedad Tempranillo, injertada sobre Richter 110. Las cepas están plantadas con densidades entre 2100 y 2900 plantas/ha, y están conducidas en espaldera en doble cordón Royat, alcanzando los troncos una altura media de $70 \mathrm{~cm}$ (figura 3.1). La carga habitual es de 16 yemas por planta, repartidas homogéneamente en cada brazo, resultando una carga aproximada de 36.000 yemas/ha.

Tabla 3.1. Localización, marcos de plantación y años de seguimiento de las subparcelas de viñedo.

\begin{tabular}{|c|c|c|c|c|}
\hline $\mathbf{N}^{\mathbf{O}}$ & Coordenadas UTM & BODEGAS & $\operatorname{Marco}(\mathrm{m})$ & Años \\
\hline 1 & $399710-4611728$ & Santos Arranz S.L. & $3,05 \times 1,50$ & 2009 \\
\hline 2 & $399735-4611797$ & Santos Arranz S.L. & $3,05 \times 1,50$ & 2009 \\
\hline 3 & $405432-4610100$ & Las Pinzas S.L. & $3,00 \times 1,30$ & 2009 \\
\hline 4 & $405533-4610133$ & Las Pinzas S.L. & $3,00 \times 1,40$ & 2009 \\
\hline 5 & $402464-4609706$ & Epifanio Rivera S.L. & $2,90 \times 1,20$ & 2009, 2010, 2011 \\
\hline 6 & $402577-4609913$ & Epifanio Rivera S.L. & $2,90 \times 1,20$ & 2009, 2010, 2011 \\
\hline 7 & $402773-4612783$ & Emilio Moro S.L. & $3,00 \times 1,50$ & 2009, 2010, 2011 \\
\hline 8 & $402803-4612796$ & Emilio Moro S.L. & $3,00 \times 1,50$ & 2009, 2010, 2011 \\
\hline 9 & $402772-4612706$ & Emilio Moro S.L. & $3,00 \times 1,50$ & 2009, 2010, 2011 \\
\hline 10 & $402787-4612695$ & Emilio Moro S.L. & $3,00 \times 1,50$ & 2009, 2010, 2011 \\
\hline 11 & $402073-4612442$ & Emilio Moro S.L. & $3,00 \times 1,50$ & 2009, 2010, 2011 \\
\hline 12 & $402068-4612454$ & Emilio Moro S.L. & $3,00 \times 1,50$ & 2009, 2010, 2011 \\
\hline 13 & $402973-4612240$ & Emilio Morc & $<1,50$ & 2010, 2011 \\
\hline 14 & $402895-4612255$ & Emilio Moro S.L. & $3,10 \times 1,50$ & 2010,2011 \\
\hline 15 & $398125-4610700$ & Hacienda de Monasterio S.L. & $2,50 \times 1,40$ & 2010,2011 \\
\hline 16 & $398110-4610690$ & Hacienda de Monasterio S.L. & $2,50 \times 1,40$ & 2010,2011 \\
\hline 17 & $401951-4612433$ & Emilio Moro S.L. & $3,10 \times 1,50$ & 2010,2011 \\
\hline 18 & $401977-4612438$ & Emilio Moro S.L. & $3,00 \times 1,50$ & 2010,2011 \\
\hline 19 & $399170-4610048$ & Dehesa de los Canónigos S.L. & $3,00 \times 1,30$ & 2009 \\
\hline 20 & $399185-4610067$ & Dehesa de los Canónigos S.L. & $3,00 \times 1,30$ & 2009 \\
\hline 21 & $399432-4609984$ & Dehesa de los Canónigos S.L. & $3,00 \times 1,50$ & 2009 \\
\hline 22 & $399451-4610015$ & Dehesa de los Canónigos S.L. & $3,00 \times 1,50$ & 2009 \\
\hline 23 & $403317-4611648$ & Emilio Moro S.L. & $3,00 \times 1,50$ & 2009, 2010, 2011 \\
\hline 24 & $403314-4611635$ & Emilio Moro S.L. & $3,00 \times 1,50$ & 2009, 2010, 2011 \\
\hline 25 & $402144-4611960$ & Emilio Moro S.L. & $3,00 \times 1,50$ & 2009, 2010, 2011 \\
\hline 26 & $402139-4611988$ & Emilio Moro S.L. & $3,00 \times 1,50$ & 2009, 2010, 2011 \\
\hline 27 & $403160-4612300$ & Emilio Moro S.L. & $3,00 \times 1,50$ & 2009, 2010, 2011 \\
\hline 28 & $403140-4612324$ & Emilio Moro S.L. & $3,00 \times 1,50$ & 2009, 2010, 2011 \\
\hline 29 & $400836-4611003$ & Emilio Moro S.L. & $3,00 \times 1,50$ & 2010,2011 \\
\hline 30 & $400824-4611029$ & Emilio Moro S.L. & $3,00 \times 1,50$ & 2010,2011 \\
\hline 31 & $400844-4611084$ & Emilio Moro S.L. & $3,00 \times 1,50$ & 2010,2011 \\
\hline 32 & $400849-4611098$ & Emilio Moro S.L. & $3,00 \times 1,50$ & 2010,2011 \\
\hline
\end{tabular}


La zona de estudio se encuentra dentro de la Denominación de Origen Ribera del Duero (figura 3.2). El Reglamento de la Denominación de Origen Ribera del Duero y de su Consejo Regulador actualmente en vigor fue aprobado por Orden de 1 de Diciembre de 1992 (publicada en el BOE del 10 de Diciembre de 1992) del Ministerio de Agricultura, Pesca y Alimentación.

El río Duero es el eje que une a más de 100 pueblos extendidos a lo largo de una franja vitícola de unos $115 \mathrm{~km}$ de longitud y 35 de anchura. Las tierras que se agrupan bajo la Denominación de Origen Ribera del Duero se sitúan en la meseta norte y en la confluencia de cuatro provincias integradas en la Comunidad Autónoma de Castilla y León: Burgos (60), Segovia (4), Soria (19) y Valladolid (19).

Actualmente están registradas en el Consejo Regulador de la D.O. Ribera del Duero 22.730 ha de viñedo, de las cuales 21.713 corresponden a la variedad Tempranillo (Consejo D.O. Ribera del Duero, 2014). La normativa actual de la D.O. permite unos rendimientos máximos en viñedos de Tempranillo de $7.000 \mathrm{~kg} \cdot \mathrm{ha}^{-1} \mathrm{con}$ una densidad de plantación de 2000-4000 cepas/ha y no más de 40.000 yemas por ha.

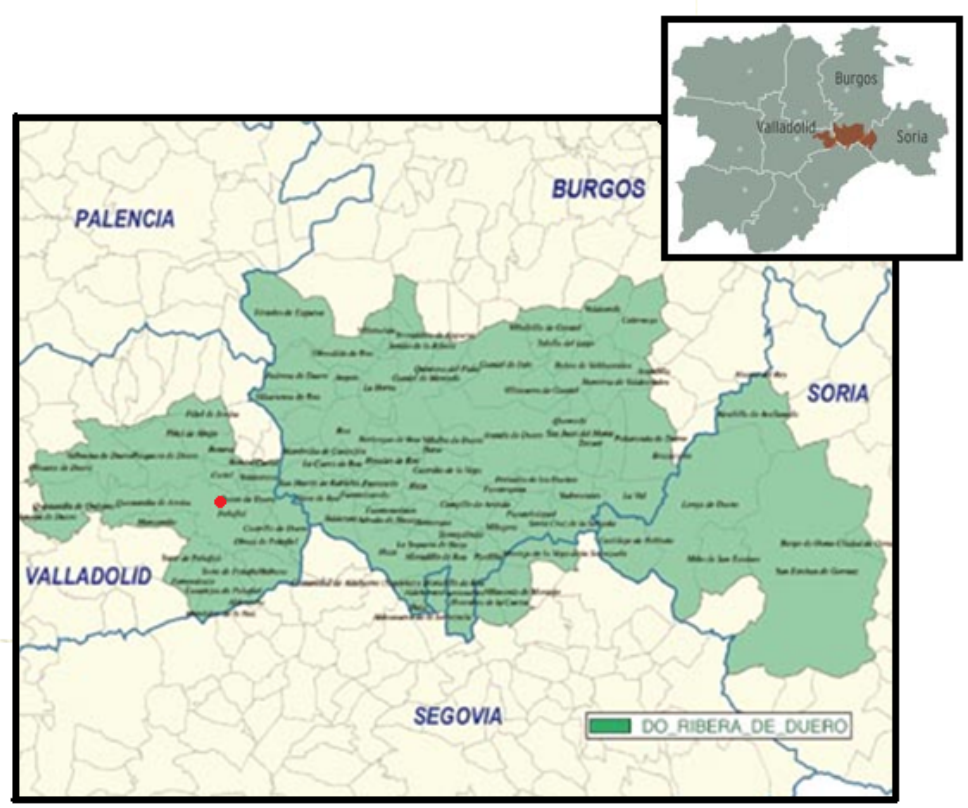

Figura 3.2. Localización de Pesquera de Duero dentro de la D.O. Ribera del Duero.

\subsection{1.- Material vegetal.}

La variedad Tempranillo (figura 3.3), conocida así por su precocidad, se encuentra extendida por toda la geografía nacional, destaca entre los cultivares autóctonos españoles y es la principal variedad de la Ribera de Duero. Posee multitud 
de sinónimos como Tinta del País, Tinta de Toro, Tinto Fino, Cencibel, Ulle de Llebre, Verdiel, Vid de Aranda o Escobera...

Las cepas $\mathrm{cv}$. Tempranillo tienen porte erguido, son vigorosas, con sarmientos largos, de color marrón muy claro, brotación relativamente tardía y maduración temprana. Es sensible a oídio y acariosis. Tiene excelentes cualidades para la elaboración, aunque en climas cálidos madura excesivamente perdiendo calidad en aromas. Muy equilibrada en taninos, es pobre en oxidasas, lo que le confiere un color estable ideal para crianzas y reservas.

La hoja del cv. Tempranillo es de tamaño grande, de forma pentagonal, con un seno peciolar con lóbulos ligeramente superpuestos; el envés es velloso, siendo la densidad de pelos media-alta en los nervios y baja en los peciolos. Se considera una variedad de desborre tardío y maduración temprana. Los racimos son compactos de tamaño medio-grande con pedúnculo corto-medio. Las bayas son pequeñas de color negro-azul, con forma esférica. La piel es gruesa y la baya se separa difícilmente del pedicelo. Su productividad es media-alta, en función del terreno (Chomé et al., 2003).

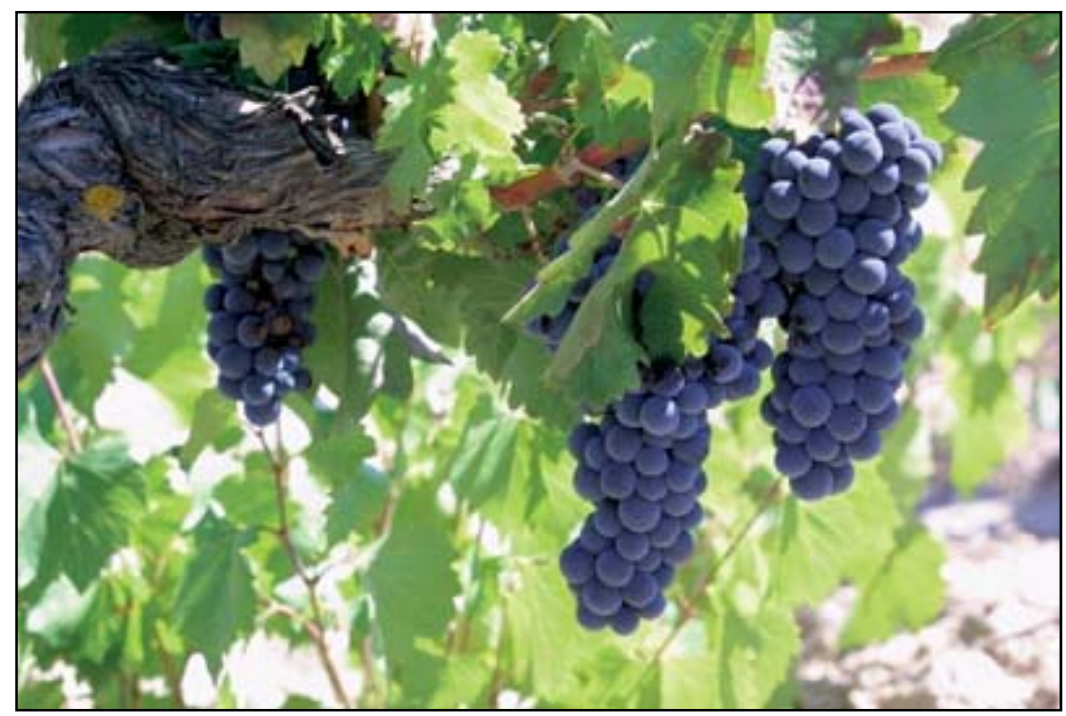

Figura 3.3. Cepa de la variedad de uva tinta "Tempranillo".

Por lo general, el vino cv. Tempranillo tiene color intenso y estable, desde púrpura a granate. Da aromas a frutos del bosque en especial frambuesa y fresa. Se emplea tanto para elaborar vinos jóvenes, ya sea en despalillado o con maceración carbónica, como para vinos de crianza.

El portainjerto 110 Richter (Vitis berlandieri cv. Rességuier $n^{\circ} 2 \times$ Vitis rupestris cv. Martin) tiene hojas reniformes, de color verde oscuro en el haz y verde amarillento mate en el envés. La forma del seno peciolar es en $U$ muy abierta y con dientes ojivales anchos. Los sarmientos son lampiños, de sección angulosa, con los entrenudos largos y la corteza de color chocolate-rojiza muy acanalada. 
Tabla 3.2. Resumen de las principales características del patrón 110-Richter (Hidalgo, 1999).

\section{PATRÓN 110 RICHTER}

\begin{tabular}{clr}
\hline ADAPTACIÓN AL SUELO. & CALIZA ACTIVA & 17 \\
COMPORTAMIENTO & IPC & 30 \\
FRENTE A: & Sequía & 3 \\
& Humedad & $0-1$ \\
& Compacidad & 3 \\
& Salinidad & 1 \\
& Carencia de potasio & 3 \\
& Carencia de magnesio & 2 \\
\hline PRENDIMIENTO DE INJERTOS & En campo & 3 \\
& En taller & 2 \\
\hline FACILIDAD DE & Producción de madera & $1-2$ \\
MULTIPLICACIÓN & Enraizamiento de estaquillas & 1 \\
\hline EFECTO SOBRE LA & Vigor & $\mathrm{V}$ \\
PLANTACIÓN & Ciclo vegetativo & $\mathrm{R}$ \\
\hline & Efecto sobre la maduración & 1 \\
\hline Vigor: V= muy vigoroso/M= vigor medio/D= débil; Ciclo Vegetativo: ML= muy largo/L= largo /C= corto \\
favorable, 2= nivel medio,1= nivel desfavorable,0= nivel muy desfavorable.
\end{tabular}

El 110-R es un patrón vigoroso (tabla 3.2). Tolera hasta el 17\% de caliza activa y presenta una amplia adaptabilidad a condiciones de suelo. Es tolerante a la sequia y sensible al encharcamiento. Retrasa la maduración, absorbe bien el potasio y es poco eficiente en la absorción del magnesio.

\subsection{2.- Características edáficas.}

La Ribera del Duero se localiza en la meseta septentrional de la Península Ibérica, formada por un gran zócalo antiguo erosionado $y$, en parte, recubierto por sedimentos terciarios, sobre todo arenas limosas o arcillosas. Destaca la alternancia de capas, tanto de calizas como de margas e, incluso, de concreciones calcáreas. La morfología del relieve está determinada por la naturaleza de los materiales terciarios y la influencia del propio río Duero y su red de afluentes. Los páramos, próximos a 1.000 $\mathrm{m}$ de altitud, las laderas y el sistema de terrazas del río, configuran el relieve de la zona (Consejo Regulador de la D.O. Ribera del Duero, 2014). 
Los suelos habituales de la Ribera del Duero se asientan sobre arcillas arenosas, ocres y rojizas (Terciario) y terrazas medias y bajas del Duero (Cuaternario), lo que da lugar a tipos de suelos Xerofluvent típico, Xerochrept típico, Xerochrept calcixeróllico y Haploxeralf cálcico (U.S.D.A., 2006). Según los estudios realizados en los suelos de la D.O. Ribera del Duero por Gómez-Miguel (2009), el suelo típico en el entorno es Xerochrept típico. Se trata de suelos poco evolucionados desarrollados sobre materiales calcáreos areniscas y calizas margosas) procedentes, muchas veces, de la erosión de otros suelos que se ubican en las partes dominantes de formas suavemente onduladas o en las laderas calcáreas de marcadas pendientes. Son suelos poco profundos caracterizados por un perfil fuertemente calcáreo, permeable y de textura predominantemente media a gruesa.

Para determinar las características del suelo de las subzonas seleccionadas se tomó una muestra a una profundidad de $0-50 \mathrm{~cm}$. Cada una de las muestras estuvo compuesta de 6 submuestras tomadas al azar en la superficie de terreno marcado en cada subparcela.

Los análisis de suelo fueron realizados por el laboratorio agrario del Centro Tecnológico ITAGRA C.T. en el que participa la Universidad de Valladolid. Los parámetros analizados, métodos de extracción y unidades de concentración se detallan en la tabla 3.3. La caliza activa sólo fue analizada en las muestras cuyo contenido en carbonatos totales superó el $10 \%$.

Tabla 3.3. Parámetros físico-químicos determinados en los suelos, métodos de extracción y unidades de concentración empleados.

\begin{tabular}{|c|c|c|}
\hline Parámetro & $\begin{array}{l}\text { Método de } \\
\text { extracción }\end{array}$ & Unidades \\
\hline Arcilla & & $(\%)$ \\
\hline Limo & ISS & $(\%)$ \\
\hline Arena & & (\%) \\
\hline pH & (1:2,5 suelo:agua) & - \\
\hline CE & (1:5 suelo:agua) & $\left(\mathrm{mS} \cdot \mathrm{cm}^{-1}\right)$ \\
\hline Materia Orgánica & Walkley-Black & $(\%)$ \\
\hline Carbonatos totales & Bernard & (\%) \\
\hline Caliza Activa & Bernard & $(\%)$ \\
\hline Fósforo & Olsen & $\left(\mathrm{mg} \cdot \mathrm{kg}^{-1}\right)$ \\
\hline Potasio & Acetato de amonio & $\left(\mathrm{meq} \cdot 100 \mathrm{~g}^{-1}\right)$ \\
\hline Calcio & Acetato de amonio & $\left(\mathrm{meq} \cdot 100 \mathrm{~g}^{-1}\right)$ \\
\hline Magnesio & Acetato de amonio & $\left(\mathrm{meq} \cdot 100 \mathrm{~g}^{-1}\right)$ \\
\hline Hierro & DTPA & $\left(\mathrm{mg} \cdot \mathrm{kg}^{-1}\right)$ \\
\hline Cobre & DTPA & $\left(\mathrm{mq} \cdot \mathrm{kq}^{-1}\right)$ \\
\hline Zinc & DTPA & $\left(\mathrm{mq} \cdot \mathrm{kq}^{-1}\right)$ \\
\hline Manqaneso & DTPA & $\left(\mathrm{mg} \cdot \mathrm{kq}^{-1}\right)$ \\
\hline
\end{tabular}


A ninguna de las diferentes áreas de estudio se les ha aplicado algún fertilizante orgánico ó inorgánico en los años en que ha transcurrido el estudio. Tampoco se ha aplicado riego sobre ninguno de los viñedos. Algunas de las vides de las diferentes zonas de muestreo presentaban estados visibles de clorosis férrica, amarilleamiento foliar, acortamiento de la distancia entre nudos, entre otros síntomas.

La caracterización físico-química de los suelos estudiados se detalla en el apartada 4.1 de la Tesis. En general los suelos son pobres en materia orgánica (< $1,5 \%)$, con una textura entre franca y arcillosa y un $\mathrm{pH}$ medio superior a 8,5. El intervalo de $\mathrm{pH}$ óptimo para el cultivo de la vid es 5,4 a 6,7, por lo que el valor de $\mathrm{pH}$ en las parcelas es claramente alto. El porcentaje de carbonatos está alrededor del $26 \%$ y la caliza activa sobre el $9 \%$, con gran variabilidad entre subzonas. Se trata de suelos típicamente calizos, con áreas con elevado poder clorosante donde se observan viñedos con claros síntomas de clorosis férrica.

\subsection{3.- Meteorología y seguimiento fenológico}

La D.O. Ribera del Duero, por su altitud y situación geográfica posee un clima mediterráneo con carácter continental, con inviernos muy duros, largos y fríos, y veranos cortos, secos y calurosos. Existe un largo período de heladas que comienza en Octubre y acaba en Mayos. La temperatura media anual es de $11^{\circ} \mathrm{C}$. Los veranos, soportan temperaturas máximas cercanas a los $40^{\circ} \mathrm{C}$, mientras los inviernos las mínimas absolutas pueden alcanzar los $-18^{\circ} \mathrm{C}$. La pluviometría se concentra principalmente en otoño y primavera, con un total de unos $450 \mathrm{~mm}$ anuales. La insolación media anual es de 2.400 h (Consejo Regulador de la D.O. Ribera del Duero, 2014).

Para caracterizar la meteorología del área de estudio, se realizó un seguimiento durante las tres campañas de ensayo, considerando los datos de la estación meteorológica de Valbuena de Duero, perteneciente a la red de Inforiego de Castilla y León (Inforiego, 2013). Esta estación está situada a $12 \mathrm{~km}$ del área de ensayo, a una altitud de $737 \mathrm{msnm}$. Los valores medios mensuales de temperatura y precipitación se recogen en la tabla 3.4, donde pueden compararse con los valores de un año medio. Dado que la serie climática de Valbuena de Duero era insuficiente para determinar dichos valores medios, se ha considerado la serie climática 1981-2010 de la estación meteorológica de Valladolid, perteneciente a la red de estaciones de la AEMET (2013), situada a $43 \mathrm{~km}$ de las parcelas estudiadas a $735 \mathrm{msnm}$ de altitud.

La acumulación de agua en el suelo durante el año 2009, a lo largo de la parada vegetativa de la vid fue inusualmente escasa frente a los valores habituales, por lo que la reserva de agua en el suelo al comienzo del ciclo vegetativo fue pobre. Por el contrario, las precipitaciones acumuladas durante la vegetación fueron algo superiores a los valores medios de los últimos 30 años. Las temperaturas medias registradas en el año 2009 estuvieron dentro de la normalidad (tabla 3.4). Las temperaturas medias registradas durante la maduración de las uvas en el año 2009 fueron de $19,6{ }^{\circ} \mathrm{C}$, similares a las de 2011 y las precipitaciones en este periodo alcanzaron $41 \mathrm{~mm}$, ligeramente más bajas a las registradas en 2010 y 2011. 
En el año 2010, las precipitaciones durante la parada invernal de las plantas fueron similares a los valores normales. Es importante destacar que en las noches del 4 y 5 de mayo se produjeron heladas de $-1,1^{\circ} \mathrm{C}$ que afectaron significativamente a los brotes de las vides, lo que se tradujo en un retraso del ciclo vegetativo de las plantas y una pérdida importante de rendimientos. Durante el periodo vegetativo, después de una primavera mas lluviosa de lo normal, se registró un verano más seco que en los otros dos años, sin apenas precipitaciones en julio y agosto. Esta situación, además fue acompañada de temperaturas anormalmente altas en el mes de julio (la temperatura media de las máximas absolutas fue de $31,8^{\circ} \mathrm{C}$ frente a 30,2 en 2009 y 28,4 en 2011). (Tabla 3.4). Además, entre los días 7-11 y 19-23 de Agosto la temperatura máxima absoluta fue sensiblemente elevada, de alrededor de $34^{\circ} \mathrm{C}$, Todo ello causó estrés térmico en las plantas que coincide con el periodo de mayor déficit de agua. Las temperaturas medias registradas durante la maduración de las uvas en el año 2010 fueron, dentro de la normalidad, ligeramente bajas respecto a los años 2009 y 2011 y las precipitaciones en este periodo alcanzaron $50 \mathrm{~mm}$.

Las precipitaciones acumuladas en el año 2011 antes del inicio del ciclo vegetativo de las plantas estuvieron dentro de los valores habituales en la zona, mientras que entre los estados fenológicos del desborre y envero fueron algo inferiores a las normales. Las temperaturas medias registradas en el mes de abril, $2^{\circ} \mathrm{C}$ por encima de los valores normales provocaron un desborre temprano. Durante el resto del año 2011, las temperaturas estuvieron dentro de los valores normales (tabla 3.4).

La tabla 3.5 muestra los valores de evapotranspiración potencial y precipitación efectiva durante las tres campañas de estudio. Aunque los tres años pueden considerarse secos, el déficit hídrico máximo se alcanzó en los veranos de 2009 y 2010 (diferencia máxima entre evapotranspiración y precipitación). 


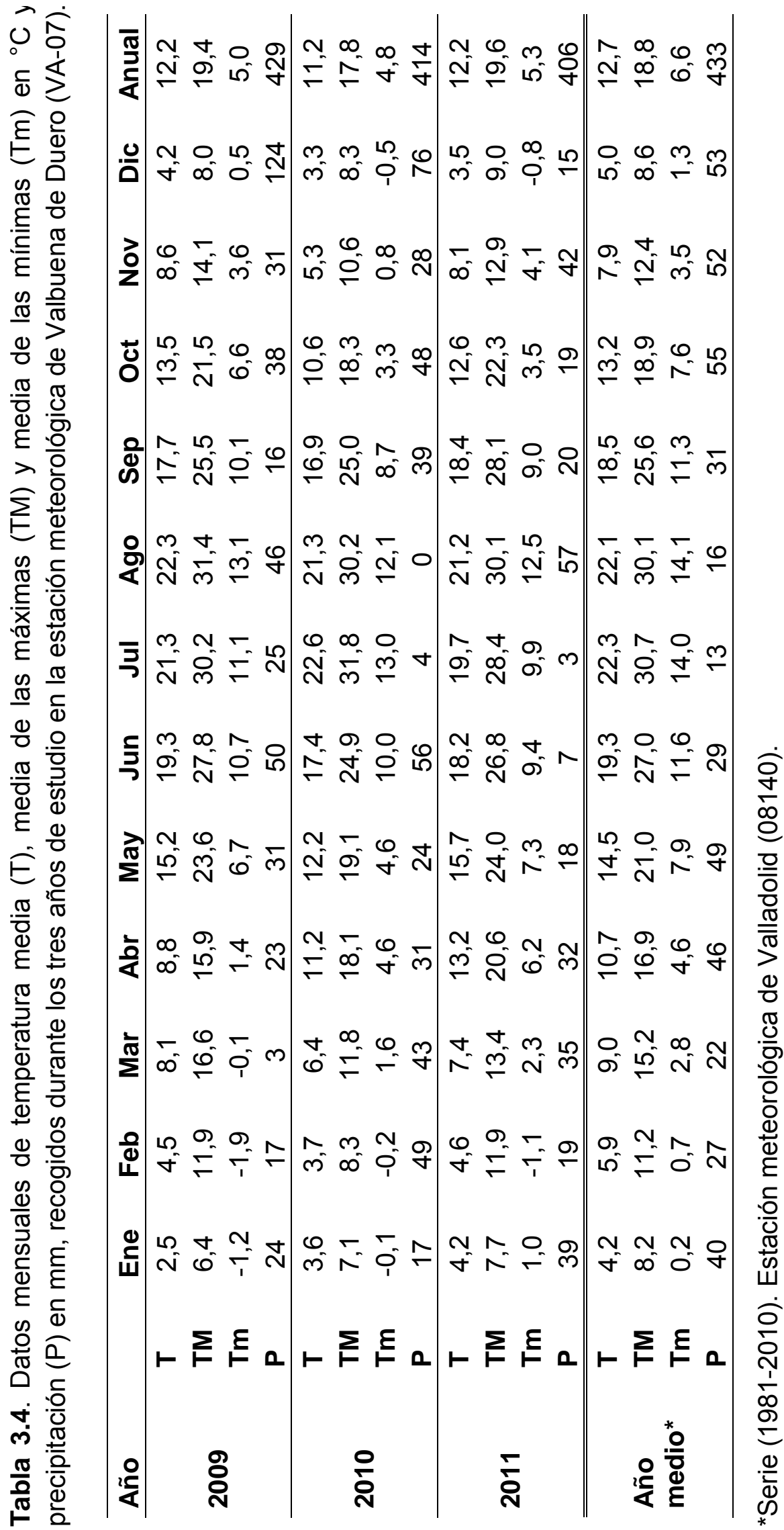


Tabla 3.5. Valores de evapotranspiración potencial (ETP) calculada por el método Penman-Monteith y de precipitación efectiva $(\mathrm{Pe})$, recogidos en la estación meteorológica de Valbuena de Duero (VA-07) para los tres años de estudio.

\begin{tabular}{lcccccc}
\hline Mes & \multicolumn{2}{c}{2009} & \multicolumn{2}{c}{2010} & \multicolumn{2}{c}{2011} \\
\cline { 2 - 7 } & ETPo $(\mathrm{mm})$ & $\mathrm{Pe}(\mathrm{mm})$ & ETPo $(\mathrm{mm})$ & $\mathrm{Pe}(\mathrm{mm})$ & ETPo $(\mathrm{mm})$ & $\mathrm{Pe}(\mathrm{mm})$ \\
\hline Enero & 24 & 8 & 23 & 0 & 24 & 16 \\
Febrero & 45 & 3 & 34 & 18 & 39 & 5 \\
Marzo & 94 & 0 & 60 & 12 & 67 & 11 \\
Abril & 100 & 8 & 98 & 11 & 108 & 15 \\
Mayo & 157 & 13 & 116 & 7 & 140 & 4 \\
Junio & 175 & 23 & 136 & 27 & 171 & 1 \\
Julio & 203 & 0 & 200 & 0 & 187 & 0 \\
Agosto & 183 & 15 & 184 & 0 & 168 & 27 \\
Septiembre & 128 & 7 & 108 & 21 & 124 & 20 \\
Octubre & 75 & 17 & 69 & 24 & 80 & 9 \\
Noviembre & 43 & 9 & 28 & 11 & 28 & 10 \\
Diciembre & 22 & 61 & 21 & 36 & 19 & 3 \\
\hline \hline Anual & 1248 & 165 & 1078 & 168 & 1154 & 121 \\
\hline
\end{tabular}

Las fechas de los estados fenológicos más representativos (desborre, cuajado, envero y madurez) registrados en los tres años de estudio se exponen en la tabla 3.6. Estas fechas corresponden a las subparcelas en su conjunto, y se han estimado en el momento en que más del $50 \%$ de las yemas ó racimos han superado el estado fenológico correspondiente.

Tabla 3.6. Fechas de los estados fenológicos más destacados registradas en los tres años de ensayo.

\begin{tabular}{lccc}
\hline Estado* & 2009 & 2010 & 2011 \\
\hline $\mathbf{B}_{2}$ (Brotación) & 1 Mayo & 27 Abril & 24 Abril \\
$\mathbf{I}_{2}$ (Cuajado) & 23 Junio & 26 Junio & 19 Junio \\
$\mathbf{M}_{2}$ (Envero) & 17 Agosto & 23 Agosto & 15 Agosto \\
$\mathbf{N}$ (Vendimia) & 24 Septiembre & 5 Octubre & 27 septiembre \\
\hline "Escala de Baggiolini & (1952) ampliada por el Grupo de trabajo de los \\
problemas fitosanitarios de la vid española (M.A.P.A., 2004)
\end{tabular}

La fecha de vendimia fue más tardía en 2010 que en los otros dos años de ensayo, debido principalmente a las heladas registradas durante el mes de mayo que retrasaron el desarrollo de las plantas, y también a la menor temperatura registrada durante la maduración con respecto a 2009 y 2011. La maduración de las uvas se produjo en un tiempo sensiblemente más corto en el año 2009 que en 2010 y 2011 (tabla

3.6). 


\section{3.- CONTROLES Y OBSERVACIONES.}

Para conseguir los objetivos marcados en el estudio se efectuaron en cada subparcela en diferentes momentos del ciclo determinaciones en campo del contenido de clorofila foliar, asimilación neta, conductancia estomática, parámetros de fluorescencia de la clorofila, vigor, superficie foliar, rendimiento y sus componentes. Por otro lado, se recogieron muestras de peciolos, hojas y uvas para el posterior análisis en laboratorio del contenido mineral peciolar, pigmentos foliares, parámetros físico-químicos y cromáticos del mosto y madurez fenólica de las bayas.

\subsection{1.- Contenido de elementos minerales en peciolos.}

Se ha realizado un análisis mineral de los peciolos de hojas, recogidos en envero, en cada subparcela y campaña. La realización del muestreo foliar se llevó a cabo siguiendo las normas indicadas por la O.I.V. (1996), seleccionando 60 peciolos de las hojas opuestas al primer racimo de un pámpano situado en la zona media de cada brazo en las cepas de cada subzona.

Una vez recogidos, los peciolos se metieron en bolsas de papel perfectamente etiquetadas y conservadas en neveras portátiles para su traslado al laboratorio. La preparación de la muestra consistió en un lavado con agua corriente, aclarado con agua destilada y posterior secado al aire.

Los análisis de elementos minerales fueron realizados por el laboratorio agrario del Centro Tecnológico ITAGRA C.T. en el que participa la Universidad de Valladolid. El contenido en nitrógeno de las muestras se determinó directamente sobre el material vegetal seco por el método Kjeldahl. Para la determinación del resto de elementos nutritivos se llevó a cabo la acenización de la muestra en un horno a $450^{\circ} \mathrm{C}$, extrayendo los minerales con $\mathrm{HCl} 2 \mathrm{~N}$. En el extracto obtenido de cada muestra se analizó el fósforo (colorimetría), el potasio (fotometría de llama) y calcio, magnesio, hierro, manganeso, cobre, zinc (espectrofotometría de absorción atómica).

Los resultados se expresan en tanto por ciento sobre materia seca para el caso de macronutrientes $(\mathrm{N}, \mathrm{P}, \mathrm{K}, \mathrm{Ca}$. Mg) y en partes por millón sobre materia seca para el caso de micronutrientes ( $\mathrm{Fe}, \mathrm{Cu}, \mathrm{Mn}, \mathrm{Zn}, \mathrm{B})$. Además de los contenidos absolutos de cada nutriente se han estudiado las relaciones $\mathrm{N} / \mathrm{K}, \mathrm{P} / \mathrm{K}, \mathrm{P} / \mathrm{N}, \mathrm{K} / \mathrm{Mg}, \mathrm{K} / \mathrm{Ca}, \mathrm{K} /(\mathrm{Ca}+\mathrm{Mg})$, $\mathrm{Ca} / \mathrm{Mg}, \mathrm{Zn} / \mathrm{Fe}, \mathrm{Fe} / \mathrm{Mn}, \mathrm{P} / \mathrm{Fe}$ y $\left[\left(10^{*} \mathrm{P}\right)+\mathrm{K}\right]^{*} 50 / \mathrm{Fe}$ en los peciolos.

La caracterización nutricional de las subparcelas se ha realizado teniendo en cuenta valores de referencia publicados en la literatura como los de Robinson (1995) y Fregoni (1998). Se dispone, además, de referencias nutricionales en hoja y peciolo para la variedad Tempranillo en la D.O. Ribera del Duero publicadas por González y Martín en 2005 (Tabla 3.7). 
Tabla 3.7. Niveles nutricionales de referencia de los peciolos en el estado fenológico de envero para el diagnóstico foliar del viñedo cv. Tempranillo en la Ribera del Duero (González y Martín, 2005).

\begin{tabular}{lcccc}
\hline Nutientes & Media & Bajo & Normal & Alto \\
\hline $\mathrm{N}(\%)$ & 0.54 & $<0.36$ & $0.36-0.72$ & $>0.72$ \\
$\mathrm{P}(\%)$ & 0.2 & $<0.14$ & $0.14-0.26$ & $>0.26$ \\
$\mathrm{~K}(\%)$ & 1.43 & $<0.58$ & $0.58-2.28$ & $>2.28$ \\
$\mathrm{Ca}(\%)$ & 1.77 & $<1.4$ & $1.4-2.14$ & $>2.14$ \\
$\mathrm{Mg}(\%)$ & 0.71 & $<0.46$ & $0.46-0.96$ & $>0.96$ \\
$\mathrm{Fe}(\mathrm{ppm})$ & 19.52 & $<13.19$ & $13.19-25.85$ & $>25.85$ \\
$\mathrm{Mn}(\mathrm{ppm})$ & 43.63 & $<3.62$ & $3.62-83.64$ & $>83.64$ \\
$\mathrm{Zn}(\mathrm{ppm})$ & 18.78 & $<11.67$ & $11.67-25.89$ & $>25.89$ \\
$\mathrm{Cu}(\mathrm{ppm})$ & 6.67 & $<2.04$ & $2.04-11.3$ & $>11.3$ \\
$\mathrm{~B}(\mathrm{ppm})$ & 35.29 & $<19.72$ & $19.72-50.86$ & $>50.86$ \\
\hline
\end{tabular}

\subsection{2.- Contenido de pigmentos foliares}

\subsubsection{1.- Determinación del nivel de clorofila foliar en campo}

Se ha realizado un seguimiento del contenido clorofílico foliar de las subparcelas a lo largo del ciclo vegetativo en los tres años de investigación. Se tomaron 4 controles de campo en 2009, 5 en 2010 y 6 en 2011 en diferentes momentos del ciclo (tabla 3.8).

Tabla 3.8. Fechas de las medidas del contenido foliar en clorofila realizadas de 9 a $12 \mathrm{~h}$.

\begin{tabular}{lccc}
\hline Estado fenológico & $\mathbf{2 0 0 9}$ & $\mathbf{2 0 1 0}$ & $\mathbf{2 0 1 1}$ \\
\hline Prefloración & 9 de Junio & 1 de Junio & 23 de Mayo \\
Cuajado & 15 de Julio & 6 de Julio & 21 de Junio \\
Entre cuajado y envero & - & 2 de Agosto & 12 de Julio \\
Envero & 20 de Agosto & 23 de Agosto & 16 de Agosto \\
Maduración & - & 19 de Septiembre & 14 de Septiembre \\
Vendimia & 13 de Octubre & - & 4 de octubre \\
\hline
\end{tabular}

Para realizar la medida de clorofila en campo se ha usado el medidor portátil de clorofila CL-01 (Hansatech Instruments Ltd., Norfolk, UK) (figura 3.4). El medidor usa un fotodiodo de silicona para detectar la transmitancia de la hoja desde dos luces emitidas por los diodos: una con un pico de emitancia de $650 \mathrm{~nm}$, y otra de $940 \mathrm{~nm}$. 
Los valores se calcularon como media de las medidas tomadas en el lóbulo central de 30 hojas elegidas al azar en cada subparcela, adultas y sanas, de la zona media del pámpano.

Las lecturas del CL-01 se correlacionan con la concentración de clorofila clorofila $a+b$ por unidad de superficie foliar. Tal y como se ha podido comprobar para la variedad "Tempranillo" (González et al., 2005a) con la recta de regresión siguiente:

$$
y=(6,0817 x)+7,6084
$$

Donde:

$$
\begin{aligned}
& x=A B S C L-01 \\
& y=\text { concentración de clorofila foliar }\left(\mu \mathrm{g} \cdot \mathrm{cm}^{-2}\right)
\end{aligned}
$$

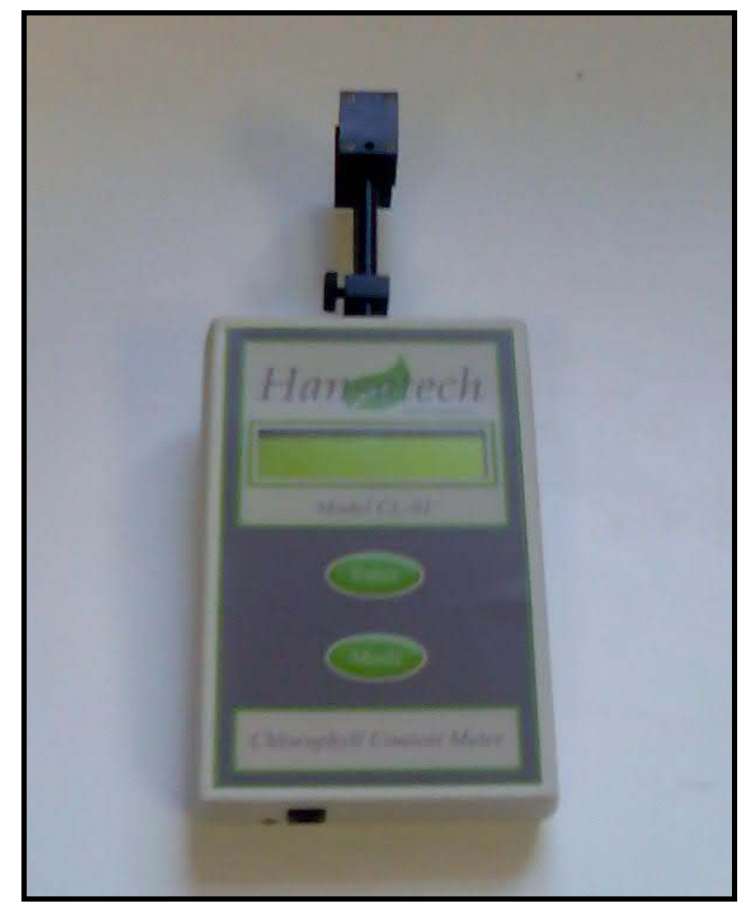

Figura 3.4. Medidor portátil de clorofila CL01 (Hansatech Instruments Ltd., Norfolk, UK).

3.3.2.2.- Determinación de las clorofilas, carotenoides y antocianinas en el laboratorio.

Con independencia de las medidas en campo comentadas anteriormente se procedió a evaluar los contenidos de pigmentos foliares en cuajado y envero mediante 
pruebas destructivas en laboratorio. Las muestras se recogieron en las fechas indicadas en la tabla (tabla 3.9).

Tabla 3.9. Fechas de muestreo para las medidas del contenido de clorofilas, carotenoides y antocianinas foliares.

\begin{tabular}{lccc}
\hline Estado fenológico & $\mathbf{2 0 0 9}$ & $\mathbf{2 0 1 0}$ & $\mathbf{2 0 1 1}$ \\
\hline Cuajado & 14 de Julio & 5 de Julio & 20 de Junio \\
Envero & 19 de Agosto & 22 de Agosto & 16 de Agosto \\
\hline
\end{tabular}

Se recogieron 20 hojas jóvenes totalmente extendidas de cada subzona, situadas en el tercio superior de los brotes. Las hojas se guardaron en bolsas de papel, perfectamente etiquetadas y conservadas en nevera portátil hasta su llegada al laboratorio, para una mejor conservación de las mismas. Posteriormente estas se conservaron en un congelador a $-20^{\circ} \mathrm{C}$ hasta su procesado. Las muestras se descongelaron de manera escalonada con el fin de ser procesadas de manera inmediata.

Para el análisis se realizaron 2 círculos de $0,8 \mathrm{~cm}$ de diámetro de cada una de las 20 hojas (en total 40 círculos por subzona) con un troquel. Uno fue destinado al análisis del contenido de clorofila $a, b$ y $a+b$, y carotenoides, y otro al análisis de antocianinas.

\section{Extracción y determinación del contenido de las clorofilas y carotenoides:}

El procedimiento seguido para la extracción de las clorofilas y los carotenoides fue el descrito por Lichtenthaler (1987). Se trituraron los 20 círculos de hoja con un mortero, en presencia de una disolución de extracción a base de acetona (80\%). Este proceso se realizó en tres pasos:

1. Se majaron los 20 discos con $5 \mathrm{ml}$ de disolución con especial cuidado, hasta que la pasta resultante tenga un aspecto completamente blanco.

2. Añadir $5 \mathrm{ml}$ más de disolución, reservando el extracto en tubos falcon.

3. Arrastrar los restos de extracto con la disolución y realizar un último lavado del mortero y la maza de porcelana hasta completar un total de $20 \mathrm{ml}$ de disolución.

Los $20 \mathrm{ml}$ de muestra obtenidos se centrifugaron en los tubos falcon a 3000 r.p.m durante $6 \mathrm{~min}$, teniendo cuidado de no agitar el tubo para no remover el pellet. Posteriormente se midieron las absorbancias del extracto resultante en el espectrofotómetro a 470, 645 y $662 \mathrm{~nm}$, con cubetas de cuarzo de $1 \mathrm{~cm}$ de espesor frente a la solución de extracción. 
Para los cálculos se aplicaron las siguientes fórmulas (Lichtenthaler, 1987):

Clorofila a $\left(\mu \mathrm{g} \cdot \mathrm{cm}^{-2}\right)=11,24 \cdot \mathrm{A} 662-2,04 \cdot \mathrm{A} 645$

Clorofila $b\left(\mu \mathrm{g} \cdot \mathrm{cm}^{-2}\right)=20,13 \cdot \mathrm{A} 645-4,19 \cdot \mathrm{A} 662$

Clorofila $\mathrm{a}+b\left(\mu \mathrm{g} \cdot \mathrm{cm}^{-2}\right)=7,05 \cdot \mathrm{A} 663+18,09 \cdot \mathrm{A} 645$

Carotenos totales $\left(\mu \mathrm{g} \cdot \mathrm{cm}^{-2}\right)=(1000 \cdot \mathrm{A} 470-1,90 \cdot$ Clorofila a $-63,14 \cdot$ Clorofila b)/214

\section{Extracción y determinación del contenido en antocianinas:}

El procedimiento seguido para el análisis es el descrito por Steele, et al. (2009). La metodología es la misma que para el caso de clorofilas y carotenoides, salvo que la disolución de extracción fue metanol puro con $0,1 \%$ de $\mathrm{HCl}$.

La absorbancia del extracto resultante se midió en el espectro a $530 \mathrm{~nm}$, con cubetas de cuarzo de $1 \mathrm{~cm}$ frente a la solución de extracción. Para los cálculos se aplicó la siguiente fórmula teniendo en cuenta el peso molecular $\left(449,2 \mathrm{~g} \cdot \mathrm{mol}^{-1}\right)$ y el coeficiente de absorción molar $\left(30 \mathrm{mM}^{-1} \cdot \mathrm{cm}^{-1}\right)$ de las antocianinas:

Antocianinas totales $\left(\mu \mathrm{g} \cdot \mathrm{cm}^{-2}\right)=449,2 \mathrm{~g} \cdot \mathrm{mol}^{-1} \cdot \mathrm{A} 530 / 30 \mathrm{mM}^{-1} \cdot \mathrm{cm}^{-1}$

\subsection{3.- Asimilación neta y conductancia estomática.}

La asimilación neta (An) y la conductancia estomática (gs) se han medido en las subparcelas en cuajado y envero en los tres años de investigación. Las medidas de cada subparcela corresponden a la media de los valores obtenidos en el lóbulo central de nueve hojas totalmente expandidas expuestas a la radiación solar directa, insertadas en el cuarto o quinto nudo desde el ápice de brotes elegidos al azar. Las medidas se realizaron entre las 11: 00-13: $00 \mathrm{~h}$, hora local, cuando la incidencia de la radiación solar es mayor, en días con condiciones meteorológicas despejadas, en las fechas que se indican en la tabla 3.10.

Tabla 3.10. Fechas en que se realizaron las medidas de fotosíntesis y fluorescencia de la clorofila.

\begin{tabular}{lccc}
\hline Estado fenológico & $\mathbf{2 0 0 9}$ & $\mathbf{2 0 1 0}$ & $\mathbf{2 0 1 1}$ \\
\hline Cuajado & $15-17$ de Julio & $6-8$ de Julio & $21-23$ de Junio \\
Envero & $20-22$ de Agosto & $23-25$ de Agosto & $16-18$ de Agosto \\
\hline
\end{tabular}

Las medidas se llevaron a cabo con un analizador portátil de gases por infrarrojo (IRGA) LI-Cor 6400, equipado con una cámara de medida de fluorescencia 6400-40 (Li-Cor, Inc. Lincoln, Nebr., EE.UU). Las condiciones de la cámara 
establecidas fueron constantes para todas las mediciones. La densidad de flujo de fotones fotosintético incidente (PPFD) en las hojas se fijó en $1500 \mu \mathrm{mol}$ fotones $\cdot \mathrm{m}^{-2} \mathrm{~s}^{-1}$, que está por encima de la saturación fotosintética en vides cultivadas en el campo (Escalona et al., 1999; Flexas et al., 1998). El nivel de $\mathrm{CO}_{2}$ en el analizador se mantuvo constante a $370 \mathrm{~mol} \mathrm{CO} \cdot \mathrm{mol}^{-1}$ de aire. La temperatura, presión y humedad relativa se mantuvieron a niveles ambientales. El caudal de aire a través de la cámara de medida se mantuvo a $500 \mathrm{~mol} \cdot \mathrm{s}^{-1}$. Los factores de absorción de los fotones en las longitudes de onda $635 \mathrm{~nm}$ (rojo) y $465 \mathrm{~nm}$ (azul) dentro del espectro de radiación fotosintética activa (PAR) de las hojas en cada subzona se introdujeron en el IRGA, ya que las propiedades espectrales de la hoja se ven fuertemente afectadas por diferentes variables, entre ellas la pigmentación (Walter-Shea et al., 1991), y por tanto la precisión de las medidas de la fluorescencia depende directamente de ello. Estos valores fueron estimados a partir de los datos de la concentración de clorofila en la hoja previamente obtenidos con un medidor portátil CL-01 (Hansatech Instruments Ltd., Norfolk, Reino Unido), como describen González et al. (2005a).

EI LI 6400 dispone de un circuito abierto, lo que significa que la fotosíntesis y la conductancia estomática se basan en las medidas de diferencia de concentración de $\mathrm{CO}_{2}$ y $\mathrm{H}_{2} \mathrm{O}$ entre el flujo de aire que fluye por la hoja y el de una corriente de aire análoga que no ha tenido contacto con la misma (figura 3.5). El aparato dispone de dos analizadores de gases para determinar las tasas de fotosíntesis neta y conductancia estomática a través de las siguientes expresiones:

Fotosíntesis neta $(\mathrm{An})=\left(\right.$ flujo de aire $\left.\mathrm{x} \Delta \mathrm{CO}_{2}\right) /$ área foliar

Conductancia estomática $(\mathrm{gs})=\left(\right.$ flujo de aire $\left.\times \Delta \mathrm{H}_{2} \mathrm{O}\right) /$ área foliar

EI LI 6400 dispone de un circuito abierto, lo que significa que la fotosíntesis y la conductancia estomática se basan en las medidas en las diferencias de concentración de $\mathrm{CO}_{2}$ y $\mathrm{H}_{2} \mathrm{O}$ entre el flujo de aire que fluye por la hoja y el de una corriente de aire análoga que no ha pasado sobre la misma (figura 3.5).

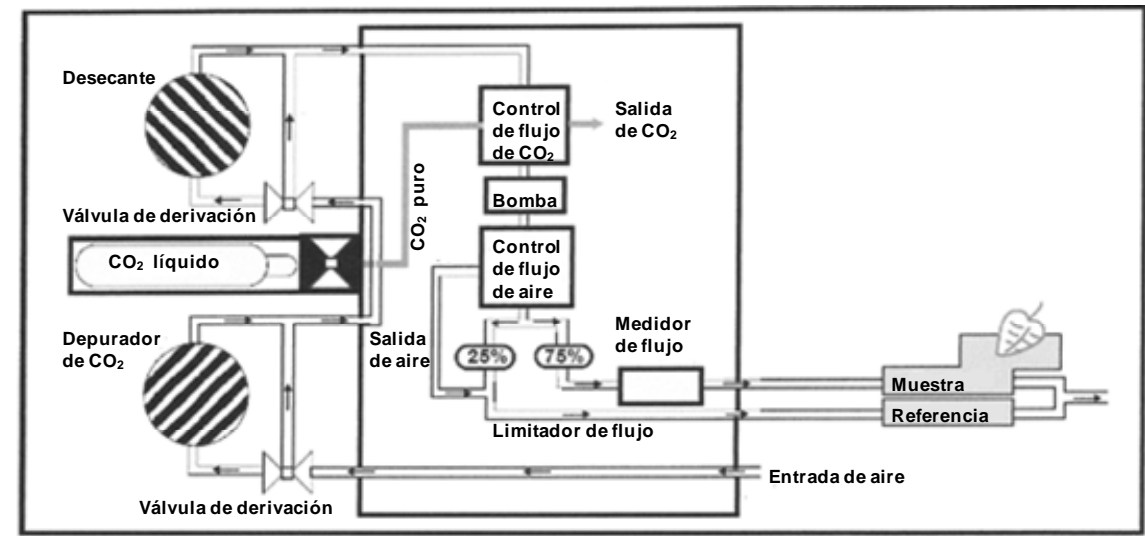

Figura 3.5: Fundamento de actuación un analizador de gases por infrarrojo. (LI-Cor, 2003). 


\subsection{4.- Medidas de la fluorescencia de la clorofila a nivel de hoja.}

Las medidas de la fluorescencia de la clorofila se llevaron a cabo sobre las mismas nueve hojas sobre las que se hicieron los controles de asimilación neta y conductancia estomática, en las fechas indicadas en la tabla 3.10, mediante la cámara de fluorescencia acoplada en el analizador portátil LI-Cor 6400. Los parámetros de fluorescencia de la clorofila de las hojas adaptados a la oscuridad se obtuvieron antes del amanecer (1: 00-3: $00 \mathrm{~h}$, hora local; figura 3.6), marcando las hojas con cintas rojas, mientras que los parámetros de fluorescencia de la clorofila de las hojas adaptadas a la luz se obtuvieron al mediodía (11: 00-13: $00 \mathrm{~h}$, hora local) simultáneamente con las variables intercambio de gases en las hojas previamente marcadas.

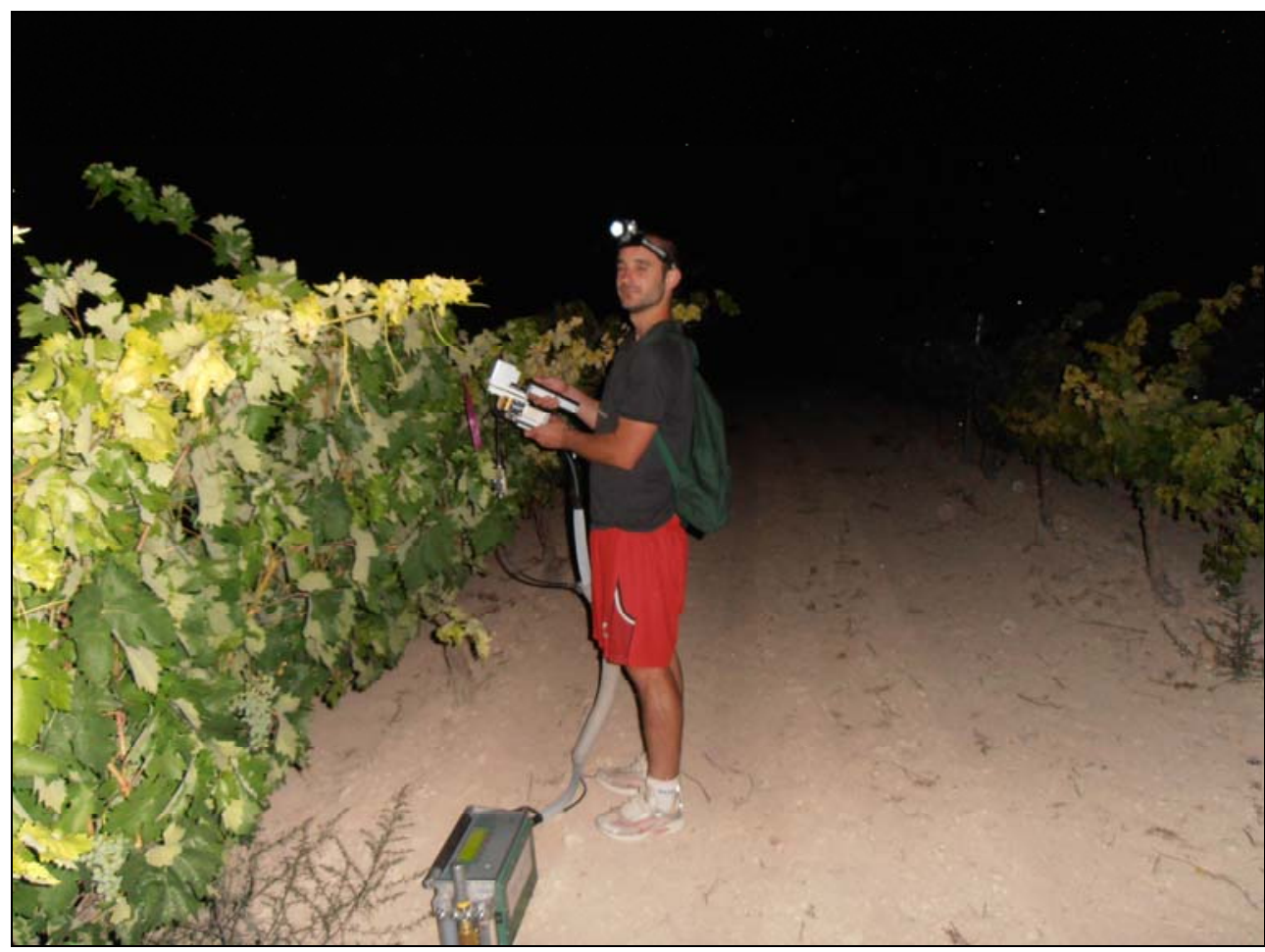

Figura 3.6. Realización de las medidas de fluorescencia de la clorofila en condiciones de oscuridad.

La cámara de fluorescencia del equipo, contiene una serie de diodos emisores de luz y detectores que captan la señal fluorescente.

Se utilizan distintas fuentes de luz con tres objetivos:

- Inducir la producción de fluorescencia.

- Suministrar luz de forma constante dentro del rango de la radiación PAR. 
- Producir múltiples pulsos de luz saturantes capaces de cerrar los centros de reacción del PSIl y realizar la medida de Fm y Fm'.

El hecho de que exista radiación solar con iguales características espectrales que la fluorescencia de la clorofila (entre $670-750 \mathrm{~nm}$ ) obliga a utilizar luz de medida modulada de pequeña intensidad para diferenciar la fluorescencia de la luz ambiente. La fuente de luz usada para la medida de la fluorescencia es encendida y apagada con una elevada frecuencia de forma que el sensor está preparado para detectar sólo la fluorescencia excitada por la luz de medida. Este es el fundamento de los fluorímetros P.A.M. (Pulse Amplitude Modulation), como el instalado en el LI 6400.

El espectro de la fluorescencia es diferente al de la luz absorbida, con un pico de emisión a una longitud de onda mayor. En realidad, el espectro de emisión de la clorofila muestra un pico a $682 \mathrm{~nm}$ además de un "hombro" menor a $740 \mathrm{~nm}$ aproximadamente (Oxboroung, 2004). Por ello, la fluorescencia puede ser cuantificada mediante la exposición de la hoja a una longitud de onda conocida, menor de $670 \mathrm{~nm}$ y midiendo la luz emitida a una mayor longitud de onda, entre 670 y $750 \mathrm{~nm}$ (Maxwell y Johnson, 2000; Oxborouhg, 2004).

Hay que tener en cuenta al diseñar los experimentos que la eficiencia del fotosistema II varía también a lo largo del día en función de la iluminación, reduciéndose a un mínimo al mediodía. También influye la presencia o ausencia de nubes o la posición de la hoja en la planta (Morales et al., 2000).

Los parámetros de fluorescencia medidos por el equipo en las hojas fueron los siguientes:

Fo: mínimo valor de fluorescencia en hojas adaptadas a la oscuridad. Se obtiene al comienzo de la medida aplicando sobre una hoja adaptada a la oscuridad una luz de muy baja intensidad (por debajo de 1 mol de fotones $\mathrm{m}^{-}$ ${ }^{1} \cdot \mathrm{s}^{-1}$ ) (Baker y Rosenqvist, 2004). Muestra el nivel de fluorescencia cuando la quinona primaria aceptora de electrones del fotosistema II $\left(Q_{A}\right)$ está oxidada al máximo, es decir, cuando los centros de reacción del fotosistema II están abiertos.

Fm: máximo valor de fluorescencia en hojas adaptadas a la oscuridad. Se obtiene aplicando un flash de luz saturante con la hoja adaptada a la oscuridad, aumentando la fluorescencia hasta un nivel máximo (Maxwell y Johnson, 2000). Muestra el nivel de fluorescencia cuando $Q_{A}$ está reducida al máximo, es decir, cuando los centros de reacción del fotosistema II están cerrados.

Fo': mínimo valor de fluorescencia en hojas adaptadas a la luz. Se obtiene después de la aplicación de un flash saturante, eliminando la luz actínica (Maxwel y Johnson, 2000).

Fm': máximo valor de fluorescencia en hojas adaptadas a la luz. Se obtiene al aplicar luz actínica y flashes de luz saturantes en intervalos apropiados.

Fs: fluorescencia estacionaria en hojas adaptadas a la luz. Se obtiene del valor de la fluorescencia inmediatamente anterior al flash. 
Por otra parte el equipo Li-6400, registra relaciones entre los parámetros anteriores, que aportan información sobre el comportamiento fotosintético de la planta. Son las siguientes:

Fv: diferencia entre el máximo y el mínimo valor de la fluorescencia en hojas adaptadas a la oscuridad. (Fv = Fm - Fo) (Baker y Rosenqvist, 2004). Muestra la habilidad del fotosistema II de fotorreducir la $Q_{A}$.

Fv': diferencia entre el máximo y el mínimo valor de fluorescencia en hojas adaptadas a la luz. $\left(F^{\prime}=\right.$ Fm' - Fo').

Fv/Fm: eficiencia máxima del fotosistema II. Es el cociente entre la fluorescencia variable y la fluorescencia máxima de la hoja adaptada a la oscuridad. Muestra la máxima eficiencia con la que la luz absorbida por las antenas del fotosistema II es convertida en energía química (reducción de la $\left.Q_{A}\right)$.

ФPSII: eficiencia del fotosistema II en operativo. La ФPSIl se obtiene de la formula: (Fm'-Fs)/Fm'. Este parámetro indica la proporción de luz absorbida por la clorofila asociada al fotosistema II y que es usada en los procesos fotoquímicos. En laboratorio se ha encontrado una relación lineal entre este parámetro y la fijación de carbono, aunque en ciertas situaciones de estrés se pueden encontrar anomalías (Maxwell y Johnson, 2000). El parámetro estima la eficiencia con la que la luz absorbida por las antenas del fotosistema II es convertida en energía química.

qP: apagado fotoquímico. Se obtiene de la formula: (Fm'-Fs)/(Fm'-Fo'). Este parámetro indica la proporción de los centros de reacción del fotosistema II que están abiertos. Relaciona la máxima eficiencia del fotosistema II con la eficiencia a la que opera.

NPQ: tasa de disipación térmica. EI NPQ se obtiene de la formula: (Fm$\left.\mathrm{Fm}^{\prime}\right) / \mathrm{Fm}^{\prime}$. El valor obtenido tiene una relación lineal con la disipación de energía en forma de calor. Sin embargo, hay que destacar que este valor es relativo a la adaptación de la hoja a la oscuridad. Por ello, si tenemos valores claramente diferentes en Fv/Fm hay que evitar comparar los valores de NPQ (Maxwell y Johnson, 2000; Baker y Rosenqvist, 2004).

\subsection{5.- Parámetros de vigor y desarrollo vegetativo.}

Como índice de vigor se ha tomado el peso de madera de poda (PMP) expresado en $\mathrm{kg}$ madera $\mathrm{m}^{-2}$. También se ha controlado el número (NMS) y peso (PMS) medio de los sarmientos por unidad de superficie, mediante el conteo y pesado de los mismos de 9 cepas de cada una de las subzonas, utilizando una báscula digital en campo, con un error de \pm 5 gramos.

En los estados fenológicos de cuajado y envero se midió el índice de área foliar (IAF) con el fin de caracterizar la superficie foliar que se ha desarrollado bajo las 
condiciones de cultivo de las subparcelas. También se ha considerado en el estudio el área media de las hojas (SF).

Para calcular el IAF se seguido la metodología propuesta por Sánchez de Miguel et al. (2010). Se seleccionaron al azar cinco cepas de cada subparcela, donde se marcaron 4 pámpanos representativos por planta (un total de 20 pámpanos). Se seleccionaron 2 pámpanos centrados y representativos de la cepa en cada brazo. Se tomaron tres medidas distintas del área de la hoja más grande $(L)$ y de la hoja más pequeña $(\mathrm{S})$, y el número de hojas $(\mathrm{NH})$ en los principales del pámpano y en los nietos. El área de las hojas se obtuvo con un medidor portátil de área foliar $\mathrm{Cl}-202$ (CIDNC, USA).

El promedio de la superficie foliar (SF, en $\mathrm{cm}^{2}$ hoja ${ }^{-1}$ ) se calculó tanto del pámpano como de los nietos. La superficie foliar de los pámpanos (SFB) será la obtenida en el conjunto de los principales con sus nietos. Los cálculos realizados fueron:

- $\quad$ Superficie foliar media $\left(\mathrm{SF}, \mathrm{cm}^{2}\right)=(\mathrm{L}+\mathrm{S}) / 2$

- $\quad$ Superficie foliar media por brote $\left(\mathrm{SFB}, \mathrm{cm}^{2} \cdot \mathrm{brote}^{-1}\right)=\mathrm{SF} \times \mathrm{NH}$

- $\quad$ Superficie foliar media por cepa $\left(\mathrm{cm}^{2} \cdot \mathrm{cepa}^{-1}\right)=\mathrm{SFB} x$ carga (número de yemas/cepa)

- I I Indice de área foliar $\left(\mathrm{IAF}, \mathrm{m}^{2} \cdot \mathrm{m}^{-2}\right)=(\mathrm{SFB} \times$ carga $)(10.000 /$ marco $)$

\subsection{6.- Rendimiento y sus componentes.}

Se realizó un seguimiento de la maduración para observar la evolución de los parámetros de composición de la baya y determinar la fecha óptima de vendimia. Para ello se recogieron muestras en tres momentos diferentes, aproximadamente 15, 25 y 30 días después del envero. En las muestras del seguimiento de maduración se determinaron el contenido en sólidos solubles totales, acidez total, $\mathrm{pH}$ y el índice de polifenoles totales. La vendimia se realizó en todas las subparcelas a la vez.

Para estimar el rendimiento de cada subparcela se contó el número de racimos en cada punto de muestreo, pesando en una bascula de campo la vendimia obtenida. A partir de estos datos se obtuvo el rendimiento (Rto, en $\mathrm{Kg} \mathrm{uva} \cdot \mathrm{m}^{-2}$ ) y el peso medio del racimo (PMR). El número medio de racimos por sarmiento (RPS) se obtuvo teniendo en cuenta el número de sarmientos por unidad de superficie contabilizados en la poda.

Además se determinó el peso de cien bayas ( $\mathrm{P} 100)$ en el momento de la vendimia, pesando las muestras que se utilizaron a continuación para los análisis de la composición de la uva.

El índice de Ravaz (IR) se obtuvo con el cociente Rto / PMP. 


\subsection{7.- Análisis físico-químicos de las bayas.}

Los análisis aquí enumerados y que a continuación se detallan se llevaron a cabo en el laboratorio de Viticultura de la ETSIIAA.

Composición físico-química de los mostos:

- Contenido en sólidos solubles (SST)

- $\quad \mathrm{pH}$ : método potenciométrico.

- Acidez total (AT): método potenciométrico

- Nitrógeno fácilmente asimilable (NFA)

- Índice de polifenoles totales (IPT): método espectro-fotométrico

- Potasio: método fotométrico de llama.

Parámetros colorimétricos de los mostos

- Parámetros cromáticos: método espectrofotométrico

Parámetros de madurez fenólica de la uva

- Determinación de fenoles totales: método espectrofotométrico

- Contenido de antocianos fácilmente extraíbles: método espectrofotométrico.

- Antocianos totales: método espectrofotométrico

Para la realización de los análisis se tomaron dos muestras independientes de 100 bayas cada una, en cada subzona, una para el análisis del mosto y otra para determinar los parámetros de madurez fenólica. La recogida de muestras se llevó a cabo al azar siempre siguiendo el mismo procedimiento, con el objetivo de obtener datos lo más representativos posible. Se tomaron 3 bayas de cada racimo (una de la parte superior, otra de la parte central y una última de la parte inferior) y de racimos expuestos a ambos lados de la línea, y en ambos brazos. Las uvas recogidas fueron depositadas en una bolsa de plástico perfectamente etiquetada y posteriormente se introdujeron en neveras portátiles para evitar su deterioro y oxidación hasta la llegada al laboratorio.

\subsubsection{1.- Composición de los mostos}

Las muestras de cien bayas se pesaron en el laboratorio en una balanza Europe 500 (Gibertini SRL, Milan, Italia) con una capacidad de $510 \mathrm{~g}$ y $1 \mathrm{mg}$ de precisión. El mosto se extrajo después triturando las uvas con una batidora manual doméstica, separándolo de la fracción sólida mediante un colador cónico metálico y un 
embudo. El mosto obtenido se depositó en tubos Falcon para centrifugarlo durante tres minutos a 3500 rpm en una centrífuga Centronic-BL (JP Selecta S.A., Barcelona). Las muestras se conservaron en cámara frigorífica a $4{ }^{\circ} \mathrm{C}$, procediendo a su análisis lo antes posible.

\subsubsection{1.- Contenido en sólidos solubles (SST)}

El contenido de azúcares del mosto representa el $90-94 \%$ de los sólidos solubles totales, y es el principal indicador de la madurez de las uvas. Los azúcares son el elemento más importante de los mostos pues sin ellos no hay fermentación alcohólica, y por lo tanto no hay producción de vino.

El contenido en sólidos solubles totales se determinó por refractometría, según los métodos oficiales de la UE establecidos en el reglamento CEE 2676/90 (Comisión Europea, 1990) y se expresa en ${ }^{\circ}$ Brix (peso de sacarosa por $100 \mathrm{~g}$ de disolución, medido a $20^{\circ} \mathrm{C}$ ).

Para este análisis se utilizó un refractómetro del tipo Abbe (WYA-S, Biotech S.L., Barcelona) que indica el ${ }^{\circ}$ Brix con una precisión del $0,1 \%$. Las medidas se realizaron a una temperatura de $20^{\circ} \mathrm{C}\left( \pm 5^{\circ} \mathrm{C}\right)$. En el caso de que el porcentaje en peso de sacarosa fuera determinado a una temperatura diferente a $20^{\circ} \mathrm{C}$, se ajustaron los valores con la ayuda de la tabla de corrección de temperaturas (Jaulmes et al., 1966).

\subsubsection{2.- $\mathrm{pH}$ y acidez total (AT)}

La acidez del vino se suele expresar como el contenido total de ácidos y refiriéndolo al más importante, el tartárico. La determinación de la acidez total se realiza mediante una valoración ácido-base.

La acidez total constituye un elemento importante de las características gustativas, marcando fundamentalmente la sensación de frescura. La impresión organoléptica de la astringencia y acidez es dependiente del $\mathrm{pH}$, más que de la acidez total.

Los ataques bacterianos y las quiebras metálicas son más probables cuanto más elevado es el pH. Por otra parte, el poder antiséptico del sulfuroso aumenta cuando el $\mathrm{pH}$ es bajo, debido a que la cantidad de dióxido de azufre libre en el vino es mayor.

Las medidas de acidez total y $\mathrm{pH}$ se obtuvieron mediante una valoración potenciométrica siguiendo la metodología oficial de la UE establecidos en el reglamento CEE 2676/90 (Comisión Europea, 1990). Se utilizó un equipo automatizado de valoración 702-SM Titrino acoplado a un cambiador de muestras 730SC (Metrohm Schweiz AG, Zofingen, Suiza). Una vez el equipo estuvo perfectamente calibrado con las correspondientes soluciones patrón, se procedió a realizar una 
medida del $\mathrm{pH}$ inicial del mosto, para posteriormente valorar las muestras con $\mathrm{NaOH}$ $0,1 \mathrm{~N}$, hasta alcanzar un $\mathrm{pH}$ de 7,00 . La acidez se expresó en gramos de ácido tartárico por litro según los $\mathrm{ml}$ de $\mathrm{NaOH} 0,1 \mathrm{~N}$ empleados para neutralizar la muestra, mediante la fórmula descrita por García-Barceló, (1990).

Acidez total $\left(g\right.$ ácido tartárico $\left.\cdot \mathrm{L}^{-1}\right)=\frac{\mathrm{V} \mathrm{NaOH}(\mathrm{ml}) \times \mathrm{N} \mathrm{NaOH} \times 75}{\mathrm{~V} \text { mosto }(\mathrm{ml})}$

\subsubsection{3.- Nitrógeno fácilmente asimilable (NFA)}

El nitrógeno fácilmente asimilable es la principal fuente de alimento de las levaduras durante la fermentación, por lo que es importante la acumulación de unas concentraciones mínimas para que no sea un factor limitante a la hora de la vinificación.

Para su estimación se utilizó un equipo automatizado de valoración 702-SM Titrino acoplado a un cambiador de muestras 730-SC (Metrohm Schweiz AG, Zofingen, Suiza). El método utilizado es una modificación del método de Sörensen propuesta por Masneuf y Dubourdieu (1999). Este método se basa en añadir una solución de formaldehído a la muestra en unas condiciones de $\mathrm{pH}$ concretas. La reacción del formaldehído con el amonio y las aminas primarias produce protones en el medio que hacen disminuir el $\mathrm{pH}$. La valoración con $\mathrm{NaOH}$ hasta restablecer el $\mathrm{pH}$ inicial permite hacer un cálculo del nitrógeno fácilmente asimilable que existe en el medio a partir del volumen de base utilizado.

Una vez el equipo estuvo perfectamente calibrado con las correspondientes soluciones patrón, se procedió a neutralizar las muestras con $\mathrm{NaOH} 0,1 \mathrm{~N}$, hasta alcanzar un $\mathrm{pH}$ de 8,5 . Posteriormente, sobre $10 \mathrm{ml}$ de cada una de las muestras obtenidas fueron añadidos $4 \mathrm{ml}$ de formaldehido previamente neutralizado a $\mathrm{pH} 8,5$. Para finalizar, se neutralizaron de nuevo las muestras a pH 8,5 con $\mathrm{NaOH} 0,1 \mathrm{~N}$ en el valorador. El cálculo del nitrógeno asimilable de la muestra fue:

Nitrógeno fácilmente asimilable $(\mathrm{mg} / \mathrm{l})=\mathrm{ml} \mathrm{NaOH} \mathrm{0,1 \textrm {N } \times 1 4}$

\subsubsection{4.- Índice de polifenoles totales (IPT)}

Los compuestos fenólicos son los responsables del color del mosto y del vino. La concentración de polifenoles en el vino aumenta con el tiempo de contacto del mosto con la piel y las semillas durante la vinificación, con el aumento de la temperatura, y con la intensidad del prensado.

Las características cromáticas del mosto se pueden evaluar mediante espectrofotometría. Para determinar el índice de polifenoles totales se aplica sobre la 
muestra un espectro de emisión opuesto (radiación UV a $280 \mathrm{~nm}$ ) y se mide la cantidad de radiación que la atraviesa. La absorbancia a $280 \mathrm{~nm}$ es una medida muy útil para estimar la intensidad colorante en mostos de uvas tintas ya que a ésta longitud de onda los anillos bencénicos, característicos de los compuestos fenólicos presentes en mostos y vinos, absorben fuertemente la radiación ultravioleta. Para las medidas espectrofotométricas de las muestras se emplea como medida de referencia agua destilada.

La absorbancia del mosto a $280 \mathrm{~nm}$ se determinó mediante un espectrofotómetro ultravioleta/visible (V-530, Jasco Inc, Easton, Maryland, Estados Unidos), utilizando una cubeta de cuarzo de $1 \mathrm{~mm}$ de longitud de paso. La medición se realizó directamente sobre las muestras de mostos. Cuando las muestras tenían un elevado contenido polifenólico se realizó una dilución 1:25 de las mismas.

El índice de polifenoles totales (IPT) se obtuvo multiplicando los resultados del espectrofotómetro por 10, para expresar el valor según el método oficial, que utiliza cubetas de $10 \mathrm{~mm}$. En el caso de haber diluido las muestras, se corrigen las medidas de absorbancia obtenidas multiplicándolas por el factor de dilución empleado (según lo indicado anteriormente este factor será 25).

\subsubsection{5.- Contenido en potasio (K)}

El potasio es un factor de considerable influencia sobre el balance ácido de mostos y vinos, afectando al $\mathrm{pH}$, y a la limpidez del vino, que puede verse disminuida por la formación de cristales de bitartrato.

El contenido en potasio se determinó mediante fotometría de llama siguiendo la metodología oficial de la UE establecidos en el reglamento CEE 2676/90 (Comisión Europea, 1990). Se utilizó un fotómetro PFP-7 Jenway (Bibby Scientific Limited, Staffordshire, Reino Unido), con filtro específico para mediciones de potasio. Para calibrar el aparato se preparó una solución de referencia con potasio y con diversos aniones, cationes y compuestos orgánicos (etanol, ácido cítrico, sacarosa, glicerol, fosfato monosódico, cloruro cálcico y cloruro magnésico) en proporciones similares a las que existe en el vino. Como el rango de concentración de potasio en el mosto es muy elevado para la sensibilidad del método, se realizaron diluciones de las muestras utilizando una solución que contenía los mismos componentes que la solución de referencia exceptuando el potasio. El contenido en potasio del mosto se expresó en $\mathrm{mg} / \mathrm{l}$.

\subsubsection{2.- Parámetros colorimétricos}

Las parámetros $\mathrm{CIEL}^{*} a^{*} b^{*}$ se muestran como una de las medidas más objetivas del color, que se define a partir de unas coordenadas denominadas $L^{*}$ (luminosidad), $a^{*}$ (relación color rojo-verde) y $b^{*}$ (relación color amarillo-azul). Los parámetros $\mathrm{C}^{*}$ (cromaticidad ó saturación cromática) y $\mathrm{H}^{*}$ (tonalidad ó tono) se calculan a partir de $a^{*}$ y $b^{*}$. 
Las coordenadas CIEL*a*b* se ubican dentro de un espacio tridimensional, estando cada una de ellas, en cada uno de los ejes que definen el espacio (figura 3.7).

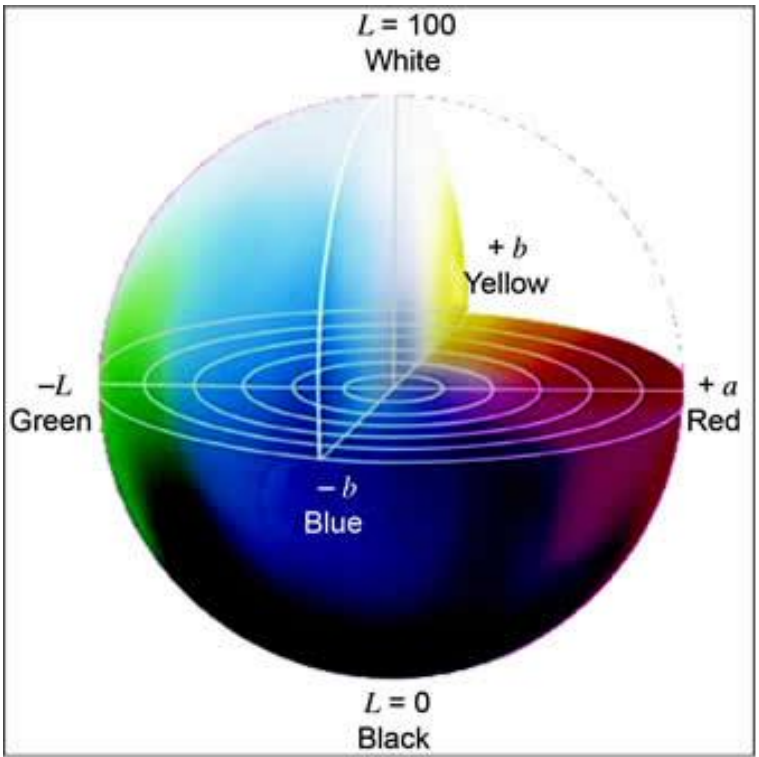

Figura 3.7. Coordenadas CIEL*a*b representadas en un sistema tridimensional. (Cheftel y Cheftel, 1992)

La coordenada $L^{*}$ se encuentra en el eje vertical, tomando valores entre 0 y 100 (indicando el valor 0 alta luminosidad y 100 baja luminosidad). La coordenada $a^{*}$, corresponde al eje de ordenadas, tomando valores entre +60 y -60 (siendo +60 la gama de matices rojos y -60 la gama de matices verdes). Y por último la coordenada $b^{*}$, corresponde al eje de abcisas con valores entre +60 y -60 (siendo +60 la gama de matices amarillos y -60 la gama de matices azules).

La relación existente entre las coordenadas $\mathrm{CIEL}{ }^{*} a^{*} b^{*}$ y $\mathrm{CIEL}{ }^{*} \mathrm{C}^{*} \mathrm{H}$ es directa, ya que $L^{*}$ es la misma en los dos casos, y las coordenadas $\mathrm{C}^{*}$ y $\mathrm{H}$ son las formas polares de las coordenadas en el mismo espacio CIE tridimensional. De modo que se puede presentar el color en forma cartesiana, con las coordenadas $\mathrm{CIEL}^{*} \mathrm{a}^{*} \mathrm{~b}^{*}$, y en forma polar, ya que:

$$
C^{*}=\left(\left(a^{*}\right)^{2}+\left(b^{*}\right)^{2}\right)^{1 / 2} \text { y } \quad H=\operatorname{arctg} \frac{b^{*}}{a^{*}} .
$$

Las coordenadas $\mathrm{CIEL}{ }^{*} a^{*} b^{*}$ y $\mathrm{CIEL}^{*} \mathrm{C}^{*} \mathrm{H}$ se midieron en el espectrofotómetro UV-Visible (V-530, Jasco Inc, Easton, Maryland, Estados Unidos) en cubetas de cuarzo de $1 \mathrm{~mm}$ de trayecto óptico. Se empleó el paquete informático "Spectra 
manager JASCO corporation", con el observador patrón CIE64 (10 de campo de visión) y el iluminate D65 (según lo establecido por la CIE, 1986).

También se ha estudiado el índice cromático de uvas tintas (CIRG: Colour index for red grape), propuesto por Carreño et al. (1995), que tiene la siguiente expresión:

$$
C I R G=\frac{180-H}{L^{*}+C^{*}}
$$

\subsubsection{3.- Madurez fenólica de la uva}

Se han determinado diferentes parámetros de madurez fenólica de las muestras tomadas mediante los análisis que a continuación se detallan. Ha sido necesario un tratamiento previo de las muestras para todas las determinaciones, siguiendo la metodología descrita por Saint-Cricq et al. (1998).

Las soluciones se prepararon a partir de muestras de 100 bayas, que se trituraron con una batidora. Con la pasta obtenida en vasos de precipitados se realizaron dos preparados de $50 \mathrm{~g}$ cada uno. A uno se le añadió $50 \mathrm{ml}$ de una solución a pH 1 y al otro $50 \mathrm{ml}$ de una solución a pH 3,2.

- Solución a pH 3,2: En un matraz de $1000 \mathrm{ml}$ se añadieron $120 \mathrm{ml}$ de etanol $96 \%, 5 \mathrm{~g}$ de ácido tartárico y $2,5 \mathrm{ml}$ de $\mathrm{NaOH} 32 \%$ y se enrasó con agua destilada.

- Solución a pH 1: En un matraz de $1000 \mathrm{ml}$ se añadieron 8,3 ml de $\mathrm{HCl} 37 \%$ y se enrasó con agua destilada.

Obtenidos los preparados (pasta + soluciones a distintos $\mathrm{pH}$ ), se dejaron reposar durante 4 horas a temperatura ambiente, y a continuación se filtraron con lana de vidrio, guardando la solución en tubos falcon perfectamente identificados.

Las muestras se centrifugaron a 3500 r.p.m. durante 3 min y se evaluaron por espectrometría:

- Muestra pH 3,2

- Contenido de polifenoles totales (CFT): Absorbancia a $280 \mathrm{~nm}$

- Antocianos fácilmente extraíbles (AFE).

- Muestra pH 1

- Antocianos totales (ANT).

Tanto AFE como ANT se determinaron a partir del método de García-Barceló (1990), basado en la decoloración con bisulfito sódico de las muestras. Se prepararon 
las muestras en tres baterías de tubos de ensayo, adicionando a cada batería los compuestos y cantidades que se indican a continuación:

Batería 1: Para la preparación se añadieron $0,75 \mathrm{ml}$ de muestra y $15,75 \mathrm{ml}$ de la solución de etanol $+\mathrm{HCl}(2 \mathrm{~L}$ de $\mathrm{HCl} 2 \%+104 \mathrm{ml}$ de etanol 96\%). A partir de esta batería se prepararon las siguientes.

Batería 2 (D1): Se añadieron $5 \mathrm{ml}$ de la batería 1 y $2 \mathrm{ml}$ de bisulfito sódico.

Batería 3 (D0): Se añadieron $5 \mathrm{ml}$ de la batería 1 y $2 \mathrm{ml}$ de agua destilada.

Preparadas las baterías 2 y 3, se dejó reposar durante 20 minutos. Se ajustó la longitud de onda del espectrofotómetro a $520 \mathrm{~nm}$, y el cero de absorbancia respecto al aire (sin cubetas en el trayecto óptico). Se realizaron mediciones de las muestras tomando de referencia agua destilada en cubetas de $10 \mathrm{~mm}$ de espesor.

La concentración de ANT se obtiene de la curva patrón definida como:

$$
\text { ANT }(p p m \text { de mavidina })=(D 0-D 1) \times 1500
$$

Siendo:

D0: lecturas a $520 \mathrm{~nm}$ de la batería 3

D1: lecturas a $520 \mathrm{~nm}$ de la batería 2

Los índices de madurez de la pepita e índice de madurez celular se calculan a partir estas lecturas.

Índice de madurez celular: IMC $(\%)=(($ ANT-AFE $) / A N T) \times 100$

Índice de madurez de las pepitas: IMP $(\%)=((C F T-A F E \times 40) / C F T) \times 100$

A lo largo de la maduración disminuye la diferencia entre el total de antocianos y los fácilmente extraíbles, por ello el IMC disminuye. Cuanto más bajo sea, más fácil será la extracción de compuestos fenólicos de la piel de la uva.

EI IMP representa el porcentaje de la contribución de los taninos de las pepitas al contenido fenólico total de la uva y por lo tanto, se puede relacionar con la astringencia de los taninos. El porcentaje de estos taninos está relacionado con el "terroir" y su extracción depende mucho de la técnica de vinificación. Un IMP bajo, sobre 20 , indica una alta polimerización de los taninos de la pepita, que pasan a ser no extraíbles y por ello dejan de contribuir al cuerpo del vino. Índices altos indican mayor maduración de estos compuestos, lo que facilita su extracción durante la vinificación. 


\section{4.- Análisis de datos}

El tratamiento de los datos se ha realizado mediante el programa estadístico SAS versión 9.1 (SAS Institute INC, 2004).

Los efectos del estado nutricional del viñedo sobre el rendimiento fotosintético, el vigor, el rendimiento y la calidad de la vendimia se ha analizado mediante métodos de regresión lineal y análisis factoriales de la varianza. Las separaciones de medias se realizaron con el test Tukey.

Se han realizado análisis de componentes principales con los datos obtenidos en el vigor, rendimiento y análisis físico-químico de mostos. Estas técnicas también se han empleado para el estudio multivariante de los parámetros de fluorescencia de la clorofila. 



\section{RESULTADOS $\Upsilon$ DISCUSIÓN}




$$
\text { • }
$$




\section{4.- RESULTADOS Y DISCUSIÓN.}

\section{1.- CARACTERIZACIÓN NUTRICIONAL DE LAS PARCELAS DE ESTUDIO.}

La mayor parte del viñedo español ocupa suelos calizos. El exceso de calcio, en combinación con otras condiciones físico-químicas del suelo, origina en la viña una problemática nutricional muy específica (Martín et al., 2008).

Los suelos calizos tienen, por definición, una gran concentración de carbonato cálcico libre, $\mathrm{pH}$ básico, saturación de bases del 100\% y un complejo de cambio dominado por el calcio. El manejo de la fertilización debe ser diferente en suelos calcáreos que en suelos normales, debido a que tanto la elevada concentración de bicarbonato cálcico como el elevado $\mathrm{pH}$ afectan a la disponibilidad de los nutrientes y a las reacciones de fijación-inmovilización de los mismos en el suelo:

- La superficie de las partículas de caliza son un soporte para la adsorción y precipitación de fosfato, elementos metálicos y ácidos orgánicos.

- La reactividad del carbonato afecta a las tasas de volatilización del amoniaco en el suelo.

- El ambiente de la rizosfera es modificado por la caliza, viéndose afectados los procesos de absorción de elementos donde la acidificación del medio es un aspecto clave, como en el caso del hierro.

La clorosis férrica afecta a una superficie amplia de viñedo en la Denominación de Origen Ribera del Duero, sobre todo en la zona más occidental En líneas generales, los suelos de la Denominación de Origen presentan elevados contenidos en calcio y bajos en magnesio (salvo en los terrenos más arcillosos)(Martín et al., 2008). La disponibilidad de nitrógeno está muy correlacionada con los contenidos en materia orgánica, pobres en general, mientras que el fósforo sufre una fuerte retrogradación en la mayor parte de los suelos.

La nutrición mineral es un importante factor de productividad y de calidad en el viñedo y, como tal, su optimización ha de ser objetivo prioritario en el marco de la viticultura actual. Para conseguir ese objetivo es necesario disponer de técnicas de evaluación del estado nutricional de las cepas, adecuadas a las condiciones ecofisiológicas de la zona concreta de que se trate en cada caso. La realización de análisis de suelo y foliares permite conocer la riqueza del terreno en nutrientes y su disponibilidad, así como la absorción efectiva de los mismos por la planta, pudiendo detectar carencias, desequilibrios nutricionales, etc ... 
En la tabla 4.1 se recoge la estadística descriptiva de las variables físicoquímicas de los suelos de las subparcelas de viñedo estudiadas. Las muestras presentan de manera predominante texturas medias (56,25 \%) yarcillosas(31,25\%), siendo sólo un $12,5 \%$ de las muestras de textura arenosa, según el método ISSS (1999).

Tabla 4.1. Características físico-químicas de los suelos de viñedo en el conjunto de las zonas de estudio.

\begin{tabular}{|c|c|c|c|c|c|}
\hline Parámetro & Método de análisis & Mínimo & Máximo & Media & CV (\%) \\
\hline Arcilla (\%) & & 3,28 & 56,52 & 29,81 & 43 \\
\hline Limo (\%) & ISSS & 5,28 & 43,28 & 17,02 & 58 \\
\hline Arena (\%) & & 18,4 & 86,72 & 53,25 & 32 \\
\hline $\mathrm{pH}$ & (1:2,5 suelo:agua) & 7,22 & 9,2 & 8,59 & 4 \\
\hline CE $\left(\mathrm{mS} \cdot \mathrm{cm}^{-1}\right)$ & (1:5 suelo:agua) & 0,07 & 0,22 & 0,14 & 29 \\
\hline MO (\%) & Walkley-Black & 0,19 & 1,33 & 0,74 & 32 \\
\hline CT (\%) & Bernard & 0,64 & 58,78 & 25,19 & 67 \\
\hline CA (\%) & Bernard & 3,32 & 15,53 & 9,30 & 41 \\
\hline$P\left(\mathbf{m g} \cdot \mathrm{kg}^{-1}\right)$ & Olsen & 4,4 & 31,8 & 12,38 & 62 \\
\hline$K\left(\right.$ meq $\left.\cdot 100 \mathrm{~g}^{-1}\right)$ & Acetato de amonio & 0,14 & 1,18 & 0,53 & 48 \\
\hline $\mathrm{Ca}\left(\mathrm{meq} \cdot 100 \mathrm{~g}^{-1}\right)$ & Acetato de amonio & 2,17 & 26,0 & 17,5 & 34 \\
\hline $\operatorname{Mg}\left(\mathrm{meq} \cdot 100 \mathrm{~g}^{-1}\right)$ & Acetato de amonio & 0,26 & 3,29 & 1,53 & 46 \\
\hline $\mathrm{Fe}\left(\mathrm{mg} \cdot \mathrm{kg}^{-1}\right)$ & DTPA & 2,34 & 9,94 & 4,27 & 35 \\
\hline $\mathrm{Cu}\left(\mathrm{mg} \cdot \mathrm{kg}^{-1}\right)$ & DTPA & 0,32 & 3,84 & 1,14 & 93 \\
\hline $\mathrm{Zn}\left(\mathrm{mg} \cdot \mathrm{kg}^{-1}\right)$ & DTPA & 0,56 & 1,6 & 1,00 & 36 \\
\hline $\operatorname{Mn}\left(\mathrm{mg} \cdot \mathrm{kg}^{-1}\right)$ & DTPA & 3,3 & 12,04 & 7,62 & 33 \\
\hline
\end{tabular}

CE: Conductividad eléctrica; MO: Materia Orgánica; CT: Carbonatos totales; CA: Caliza activa; CV: Coeficiente de variación

Ninguno de los suelos muestreados presentó condiciones de salinidad, ya que la totalidad de los valores de conductividad eléctrica estuvo por debajo de 0,25 ms. $\mathrm{cm}^{-1}$, rango que se considera no problemático para los cultivos (Mengel y Kirkby, 2001). El contenido de materia orgánica en el conjunto de subzonas es bajo; todas los suelos estudiados estuvieron por debajo de un nivel de referencia que se puede establecer en 1,5\% (Yañez, 1989), teniendo en cuenta que los viñedos están cultivados en secano (tabla 4.2).

Realizado un análisis de varianza de los contenidos en elementos minerales de los peciolos en envero en función del año de seguimiento, se han observado diferencias significativas entre cada uno de los tres años en los que se llevó a cabo el estudio, para todos los nutrientes excepto para el Mg (tabla 4.3). Los resultados obtenidos sugieren que el $\mathrm{Mg}$ peciolar en plantas cultivadas en suelos calizos sería el elemento menos sensible a las condiciones meteorológicas (variación interanual). El 
nivel foliar de Mg también podría ser poco sensible a la aplicación exógena de correctores de la clorosis férrica. Así, Bavaresco et al. (2010) estudiaron el efecto de varios métodos de corrección de la clorosis férrica en plantas sobre suelos calcáreos, observando que los únicos elementos cuya acumulación foliar no se veía afectada por los tratamientos fueron $\mathrm{Mg}$ y $\mathrm{Zn}$.

Tabla 4.2. Interpretación de los niveles de las características físico-químicas de los suelos en el conjunto de zonas de estudio.

\begin{tabular}{|c|c|c|c|c|c|c|c|c|c|c|c|c|}
\hline Subparcela & $\mathrm{pH}^{*}$ & MO* & $\mathrm{CT}^{*}$ & $\mathrm{CA}^{*}$ & $\mathbf{P}^{* *}$ & $\mathrm{~K}^{* *}$ & $\mathrm{Ca}^{*}$ & $\mathbf{M g}^{* *}$ & $\mathrm{Fe}^{* * *}$ & $\mathrm{Cu}^{\star \star \star}$ & $\mathrm{Zn}^{* * *}$ & $\mathbf{M n}^{* * * *}$ \\
\hline 1 & MA & $B$ & $A$ & MA & $\mathrm{MB}$ & MA & MA & $M$ & $M$ & - & - & - \\
\hline 2 & MA & B & $\mathrm{M}$ & MA & MB & B & MA & B & $\mathrm{M}$ & - & - & - \\
\hline 3 & $A$ & B & $A$ & $\mathrm{M}$ & $A$ & MA & MA & $M$ & $M$ & - & - & - \\
\hline 4 & A & B & $A$ & $M$ & B & $\mathrm{M}$ & MA & $A$ & $M$ & - & - & - \\
\hline 5 & MA & B & $M$ & $M$ & $A$ & $B$ & MA & MB & $M$ & $M$ & $A$ & A \\
\hline 6 & MA & B & $B$ & $B$ & MA & $M$ & MA & $B$ & $A$ & $\mathrm{M}$ & A & A \\
\hline 7 & MA & B & MA & MA & $B$ & B & MA & B & A & $M$ & $M$ & $M$ \\
\hline 8 & MA & B & $\mathrm{M}$ & $A$ & $B$ & $M$ & MA & B & A & $M$ & $M$ & $A$ \\
\hline 9 & MA & B & $A$ & MA & MB & B & $\mathrm{M}$ & B & $M$ & $M$ & $M$ & $M$ \\
\hline 10 & MA & B & MA & MA & MB & B & $M$ & $M$ & $M$ & $M$ & $M$ & A \\
\hline 11 & MA & B & MA & $\mathrm{M}$ & B & B & $\mathrm{M}$ & B & B & $\mathrm{M}$ & $\mathrm{M}$ & $\mathrm{M}$ \\
\hline 12 & MA & B & MA & MA & MB & MB & $M$ & B & B & $M$ & $M$ & $M$ \\
\hline 13 & MA & B & $\mathrm{M}$ & MA & B & $M$ & MA & B & A & $M$ & $M$ & $A$ \\
\hline 14 & MA & B & $M$ & MA & $M$ & $M$ & MA & B & $M$ & $M$ & $M$ & $A$ \\
\hline 15 & MA & B & MA & MA & B & $B$ & MA & B & $M$ & $M$ & $M$ & $A$ \\
\hline 16 & MA & B & A & MA & B & $\mathrm{M}$ & MA & B & $\mathrm{M}$ & A & $\mathrm{M}$ & A \\
\hline 17 & MA & B & MA & $A$ & MB & $M$ & MA & A & $\mathrm{M}$ & $\mathrm{M}$ & $M$ & $\mathrm{M}$ \\
\hline 18 & MA & B & $A$ & A & B & B & MA & A & $M$ & $M$ & $M$ & A \\
\hline 19 & MA & B & $\mathrm{MB}$ & B & B & $\mathrm{MB}$ & MA & B & $A$ & - & - & - \\
\hline 20 & MA & B & $\mathrm{MB}$ & B & B & B & MA & B & $\mathrm{M}$ & - & - & - \\
\hline 21 & $\mathrm{M}$ & B & MB & B & B & B & $\mathrm{MB}$ & $\mathrm{MB}$ & $A$ & - & - & - \\
\hline 22 & MA & B & MB & B & $\mathrm{MB}$ & A & MA & B & $\mathrm{M}$ & - & - & - \\
\hline 23 & $A$ & B & B & B & B & $M$ & MA & $\mathrm{M}$ & $M$ & $\mathrm{M}$ & $M$ & $A$ \\
\hline 24 & A & B & $\mathrm{MB}$ & $B$ & B & A & $A$ & B & $\mathrm{M}$ & $\mathrm{M}$ & $M$ & $A$ \\
\hline 25 & MA & B & $\mathrm{M}$ & $M$ & $B$ & A & MA & $B$ & $M$ & $M$ & $M$ & $A$ \\
\hline 26 & $A$ & B & $\mathrm{MB}$ & $B$ & $\mathrm{MB}$ & A & MA & $M$ & $M$ & $M$ & $M$ & A \\
\hline 27 & A & B & $\mathrm{MB}$ & B & B & A & MA & $\mathrm{M}$ & $\mathrm{M}$ & $\mathrm{M}$ & $M$ & A \\
\hline 28 & $A$ & B & $\mathrm{MB}$ & $B$ & $B$ & A & MA & $B$ & $\mathrm{M}$ & $\mathrm{M}$ & $\mathrm{M}$ & A \\
\hline 29 & MA & B & $A$ & MA & $M$ & A & MA & $M$ & $M$ & $M$ & $M$ & $A$ \\
\hline 30 & MA & B & B & B & $B$ & $M$ & MA & $B$ & A & $M$ & $M$ & $A$ \\
\hline 31 & MA & B & $M$ & $M$ & $\mathrm{M}$ & $A$ & MA & B & $A$ & $\mathrm{M}$ & $M$ & $A$ \\
\hline 32 & MA & B & $\mathrm{M}$ & $\mathrm{A}$ & $\mathrm{A}$ & A & MA & B & $M$ & $M$ & $\mathrm{M}$ & A \\
\hline \multicolumn{13}{|c|}{$\begin{array}{c}\text { MO: Materia orgánica; CT: Carbonatos totales; CA: Caliza activa } \\
\text { MA, muy alto; A, alto; M, medio o satisfactorio; B, bajo; MB, muy bajo } \\
\text { *Valores de referencia propuestos por Yañez (1989) } \\
{ }^{* *} \text { Valores de referencia propuestos por Horneck et al. (2011) } \\
{ }^{* * *} \text { Valores de referencia propuestos por Lindsay y Norwell (1978) } \\
{ }^{* * * *} \text { Valores de referencia propuestos por Sims y Johnson (1991) }\end{array}$} \\
\hline
\end{tabular}


Tabla 4.3. Valores de $F$ de Fisher y nivel de significación del análisis de la varianza (ANOVA) de los contenidos peciolares de nutrientes en el envero en función de los años de estudio.

\begin{tabular}{|c|c|}
\hline Nutriente & $\mathbf{F}$ \\
\hline N (\%) & 7,06 ** \\
\hline P (\%) & 4,54 * \\
\hline K (\%) & 7,08 ** \\
\hline $\mathrm{Ca}(\%)$ & $9,88^{* *}$ \\
\hline Mg (\%) & 0,01 \\
\hline $\mathrm{Fe}\left(\mathrm{mg} \cdot \mathrm{kg}^{-1}\right)$ & 4,38 * \\
\hline $\mathrm{Cu}\left(\mathrm{mg} \cdot \mathrm{kg}^{-1}\right)$ & $8,97^{* *}$ \\
\hline $\mathrm{Zn}\left(\mathrm{mg} \cdot \mathrm{kg}^{-1}\right)$ & 8,53 ** \\
\hline $\operatorname{Mn}\left(\mathrm{mg} \cdot \mathrm{kg}^{-1}\right)$ & 4,06 * \\
\hline $\mathrm{B}\left(\mathrm{mg} \cdot \mathrm{kg}^{-1}\right)$ & $17,79 * * *$ \\
\hline
\end{tabular}

En la tabla 4.4 se presenta la composición mineral promedio de los peciolos, indicando una alta variabilidad, en especial para el $\mathrm{P}$ y los microelementos $\mathrm{Cu}$ y $\mathrm{Mn}$. En general, los elementos que se encontraron en mayor concentración en el tejido peciolar de las plantas son el Ca y el K, seguido, en orden, por $\mathrm{Mg}, \mathrm{N}, \mathrm{P}, \mathrm{Mn}, \mathrm{B}, \mathrm{Zn}, \mathrm{Fe}$ y $\mathrm{Cu}$. Estos resultados coinciden con los valores de referencia establecidos para la vid en la D.O. Ribera de Duero por González y Martín (2005) y en la D.O. Rioja por Laibarra et al.(2004).

Tabla 4.4.Composición mineral de las muestras de tejido peciolar de vides tomadas en los viñedos estudiados en el estado fenológico de envero.

\begin{tabular}{|c|c|c|c|c|c|c|c|c|c|c|c|}
\hline \multirow[b]{2}{*}{ Año } & \multirow{2}{*}{ Valor } & $\mathbf{N}$ & $\mathbf{P}$ & $\mathbf{K}$ & $\mathrm{Ca}$ & $\mathrm{Mg}$ & $\mathrm{Fe}$ & $\mathrm{Cu}$ & $\mathrm{Zn}$ & Mn & $\mathbf{B}$ \\
\hline & & $(\%)$ & \multicolumn{4}{|c|}{ (\% s.m.s.) } & \multicolumn{5}{|c|}{ (mg.kg ${ }^{-1}$ s.m.s.) } \\
\hline \multirow{4}{*}{$\begin{array}{c}2009 \\
(n=22)\end{array}$} & Mínimo & 0,40 & 0,08 & 1,08 & 1,23 & 0,76 & 12,9 & 1,40 & 15,7 & 10,9 & 23,1 \\
\hline & Máximo & 0,58 & 0,37 & 3,21 & 2,83 & 2,10 & 43,6 & 3,20 & 45,5 & 193 & 43,7 \\
\hline & Media & 0,50 & 0,20 & 2,20 & 2,11 & 1,22 & 20,4 & 2,29 & 28,6 & 57,7 & 31,5 \\
\hline & C.V. (\%) & 9 & 41 & 29 & 20 & 37 & 33 & 22 & 31 & 87 & 16 \\
\hline \multirow{4}{*}{$\begin{array}{c}2010 \\
(n=24)\end{array}$} & Mínimo & 0,39 & 0,06 & 0,71 & 1,99 & 0,73 & 12,5 & 2,50 & 7,40 & 25,3 & 37,0 \\
\hline & Máximo & 0,55 & 0,32 & 3,22 & 3,33 & 1,94 & 30,5 & 39,5 & 34,0 & 394 & 54,0 \\
\hline & Media & 0,46 & 0,14 & 2,00 & 2,61 & 1,23 & 19,7 & 8,37 & 22,3 & 116 & 45,7 \\
\hline & C.V. (\%) & 10 & 45 & 35 & 14 & 31 & 24 & 131 & 28 & 75 & 10 \\
\hline \multirow{4}{*}{$\begin{array}{c}2011 \\
(n=24)\end{array}$} & Mínimo & 0,41 & 0,07 & 0,39 & 1,54 & 0,64 & 12,3 & 1,00 & 12,9 & 21,1 & 0,15 \\
\hline & Máximo & 0,53 & 0,42 & 2,19 & 3,01 & 1,86 & 51,2 & 7,30 & 52,0 & 334 & 57,3 \\
\hline & Media & 0,46 & 0,18 & 1,54 & 2,27 & 1,22 & 25,3 & 3,05 & 32,3 & 107 & 39,3 \\
\hline & C.V. $(\%)$ & 9 & 41 & 32 & 17 & 33 & 36 & 49 & 31 & 73 & 31 \\
\hline
\end{tabular}




\subsection{1.- Nutrientes minerales.}

\subsubsection{1.- Nitrógeno.}

Aunque el contenido en materia orgánica de los suelos es en general bajo y no se ha aportado ningún tipo de abono orgánico, ni fertilizantes inorgánicos nitrogenados durante los años de estudio, todas las áreas de muestreo tuvieron un contenido de nitrógeno medio en los peciolos en los tres años de estudio según González y Martín (2005).

\subsubsection{2.- Fósforo.}

Confirmando estudios previos en la zona (Martín et al., 2008), como se muestra en la tabla 4.1 existe una alta variabilidad en las concentraciones de fósforo asimilable en el conjunto de los suelos estudiados, con un coeficiente de variación del $62 \%$. Como muestra la tabla 4.2 las subparcelas $1,2,9,10,12,17,22$ y 26 tienen una concentración muy baja de fósforo en el suelo, la 4, 7, 8, 11, 13, 15, 16, 18, 19, 20, 21, $23,24,25,27,28$ y 30 baja, la 14, 29 y 31 normal, la 3, 5 y 32 alta y sólo la 6 muy alta, según Horneck et al. (2011). El fosfato puede reducir la solubilidad del Fe y, por tanto, su disponibilidad para la planta (Cornell y Schwertmann, 2003; Zheng et al., 2009).Sin embargo, al ser la concentración de $P$ en disolución de suelos calcáreos muy baja, algunos autores ponen en duda este papel inductor de clorosis férrica (Kolesch et al., 1987a; Mengel y Kirkby, 2001).

Como muestra la figura 4.1, el reparto de porcentajes de áreas de muestreo según su contenido de fósforo en los peciolos teniendo en cuenta los patrones nutricionales obtenidos para la Ribera del Duero (González y Martín, 2005)fue similar en los años 2009 y 2011, siendo más elevado el porcentaje de subparcelas con concentración baja en el año 2010. Así, en el año 2009 las subparcelas 1, 2, 9 y 26 tuvieron un contenido bajo de fósforo en los peciolos, la $3,4,5,6,7,8,10,11,12,22$, 23, 25 y 27 medio y la 19, 20, 21, 24 y 28 alto. En el año 2010 el contenido peciolar de fósforo para las subparcelas $5,7,8,9,10,11,12,13,15,16,17,18,23,25,26$ у 29 fue bajo, el de la $6,14,24,27,28,30$ y 32 fue medio y sólo el de la subparcela 31 fue alto. En el año 2011 las subparcelas 10, 11, 13, 15, 16, 18 y 26 tuvieron una concentración de fósforo en los peciolos baja, la 5, 6, 7, 8, 12, 14, 17, 23, 24, 25, 27 , 28,29 y 30 media y la 31 y 32 alta.

Esta diferencia en el nivel de fósforo en los peciolos en el envero en el año 2010 con respecto a 2009 y 2011, pudo estar relacionada con una situación de estrés hídrico y térmico provocado por un verano más seco y caluroso que en los otros dos años, sin apenas precipitaciones en julio y agosto, acompañado de unas temperaturas máximas absolutas anormalmente altas en el mes de julio y principios de agosto. Esto pudo haber modificado la dinámica del $P$ en las plantas. Viets (1972) generalizó la opinión de que el estrés hídrico induce una disminución de la asimilación de fósforo en las plantas, lo que ha sido comprobado por otros autores como por ejemplo Pinkerton y Simpson (1986) y Schreiner et al. (2006). 


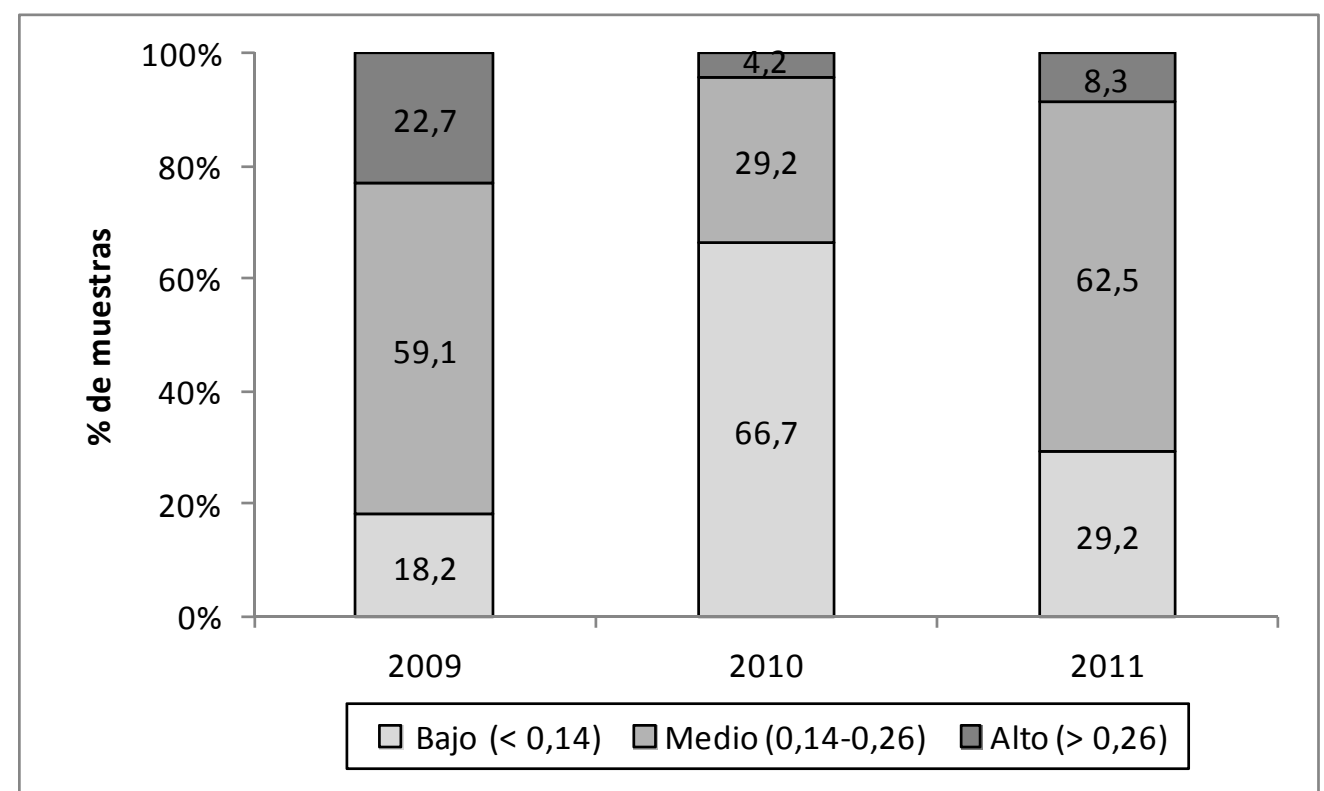

Figura 4.1. Distribución de las subparcelas en función de los contenidos de fósforo (\% s.m.s.) en el peciolo en las tres campañas de estudio, teniendo en cuenta los valores de referencia propuestos por González y Martín(2005).

Teniendo en cuenta todo lo anterior, se ha realizado un diagnostico general de la nutrición de fósforo en las áreas de muestreo, con el fin de estudiar la influencia de esta en los parámetros fisiológicos y agronómicos en apartados posteriores. Así se ha considerado que las parcelas $3,5,6,7,8,14,21,22,23,24,27,28,29,30,31$ у 32 tienen una nutrición adecuada de $\mathrm{P}$, mientras que el resto tiene un déficit de nutrición de dicho elemento.

\subsubsection{3.- Potasio.}

Como se observa en la tabla 4.1 existe una alta variabilidad entre las concentraciones de potasio en el suelo, con un coeficiente de variación del $48 \%$. De acuerdo con la tabla 4.2 , el contenido de potasio en las subparcelas 12 y 19 fue muy bajo, el de la $2,5,7,9,10,11,15,18,20$ y 21 bajo, el de la4, 6, 8, 13, 14, 16, 17, 23 y 30 medio, el de la $22,24,25,26,27,28,29,31$ y 32 alta, y el de la 1 y 3 muy alta, según Horneck et al. (2011).

La nutrición potásica es compleja, debido a la interacción, tanto en el suelo como en la planta, entre los cationes potasio, sodio, calcio y magnesio. Morris y Cawthon (1982) mostraron una disminución en las concentraciones de $\mathrm{Mg}$ y Ca como resultado de la aplicación de sulfato potásico, comprobando las interacciones entre $\mathrm{K}$ y los otros nutrientes. García et al. (1999) investigaron la interacción entre K y Ca y los efectos de sus proporciones en la nutrición de la vid cultivadas en medio hidropónico, observando una reacción de antagonismo entre $\mathrm{K}$ y Ca de modo que la adición de $\mathrm{Ca}$ puede inhibir la absorción de $\mathrm{K}$. La relación $\mathrm{Ca} / \mathrm{K}$ en el suelo promedio está en torno a 
37 (contenidos en meq. $100 \mathrm{~g}^{-1}$ ), un valor muy elevado que indica que existen situaciones de antagonismo de Ca con $\mathrm{K}$, sobre todo en los suelos más arcillosos y calizos.

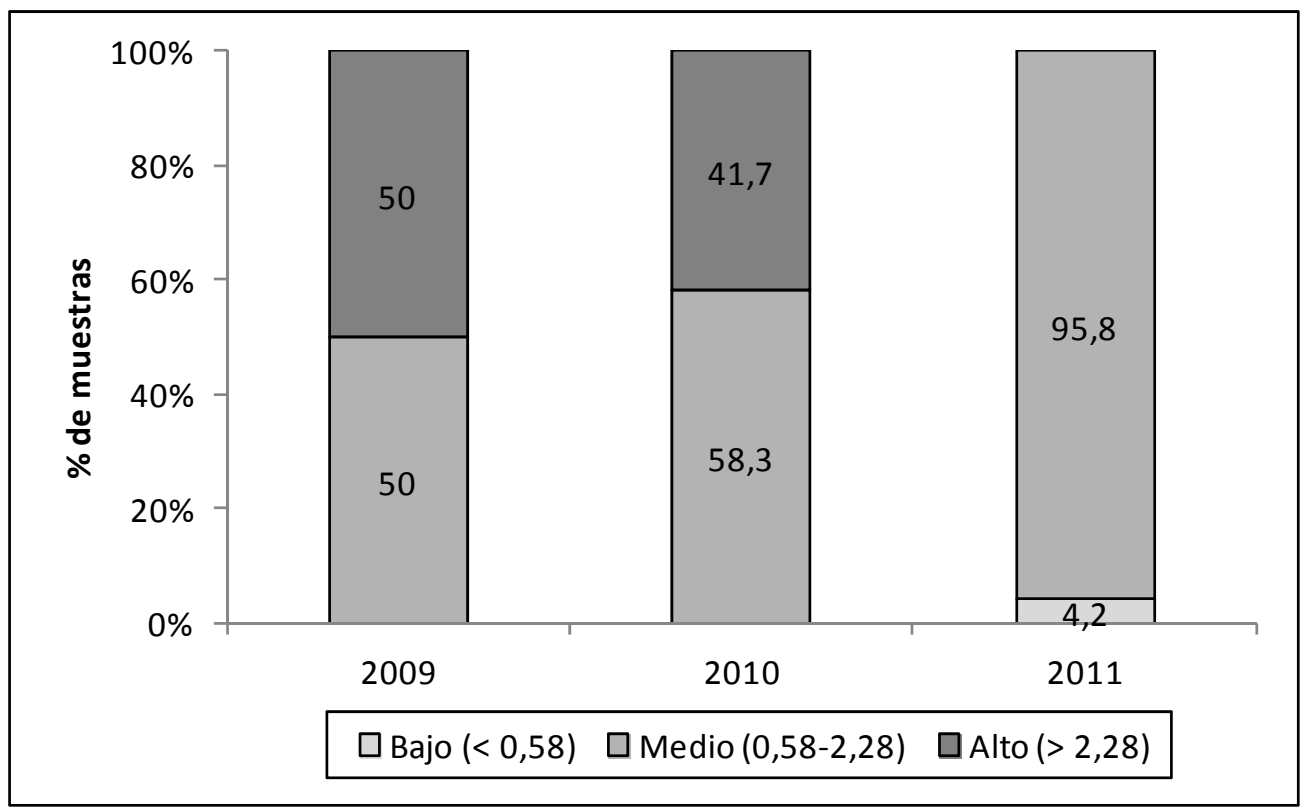

Figura 4.2. Distribución de las subparcelas en función de los contenidos de potasio (\% s.m.s.) en el peciolo en las tres campañas de estudio, teniendo en cuenta los valores de referencia propuestos por González y Martín (2005).

La carencia de potasio también puede ser inducida por un exceso de magnesio. La relación $\mathrm{K} / \mathrm{Mg}$ promedio de la zona de estudio está en 0,40 ,valor ligeramente por encima de los niveles adecuados $\left(0,16-0,35 \mathrm{meq} \cdot 100 \mathrm{~g}^{-1}\right)$ recomendados por Legaz et al. (1995), existiendo situaciones de antagonismo de $\mathrm{K}$ con $\mathrm{Mg}$ a favor del primero en algunas de las subparcelas.

En cuanto al contenido peciolar de potasio, teniendo en cuenta patrones nutricionales dados por Robinson (1995), sólo en uno de los puntos estudiados en 2009 y en dos en 2010 se obtuvo un contenido alto de $\mathrm{K}$ en los peciolos, teniendo el $70 \%$ de las muestras un contenido medio en los años 2010 y 2011 , y el $85 \%$ en 2009.Sin embargo, como se puede ver en la figura 4.2, durante los años de estudio el número de muestras con una concentración media ha ido aumentando en detrimento de muestras con un contenido elevado de dicho elemento, llegando a ser el $95.8 \%$ de las muestras en 2011, apareciendo por primera vez en este año peciolos con deficiencia según las recomendaciones obtenidas para la Ribera del Duero por González y Martín (2005).Concretamente, en el año 2009 las subparcelas 1, 2, 3, 4, 5, $7,9,12,21,22,23$ y 24 tuvieron un contenido medio de potasio en los peciolos y la 6 , $8,10,11,19,20,23,25,26,27$ y 28 alto. En el año 2010 el contenido para las 
subparcelas $7,8,9,10,11,12,14,15,16,17,18,23,24$ y 30 fue medio y el de las subparcelas 5, 6, 13, 25, 26, 27, 28, 29, 31 y 32 fue alto. En el año 2011 la subparcela 24 tuvo una concentración en los peciolos baja, mientras que en el resto media.

Teniendo en cuenta todo lo anterior, con el fin de estudiar la influencia de esta en los parámetros fisiológicos y agronómicos en apartados posteriores. Se ha considerado que las subparcelas $1,2,3,4,7,8,9,10,11,12,14,15,16,17,18,21$, 22, 23 y 24 tienen una nutrición adecuada de $\mathrm{K}$, mientras que el resto tiene un exceso de nutrición de dicho elemento.

\subsubsection{4.- Magnesio.}

Como se puede ver en la tabla 4.1, la concentración de magnesio en el suelo de los diferentes puntos de muestreo estuvo entre 0,26 y $3,29 \mathrm{meq} \cdot 100 \mathrm{~g}^{-1}$, lo que refleja una alta variabilidad, (coeficiente de variación del 46\%), confirmando estudios previos en la zona (Martín et al, 2008). Como muestra la tabla 4.2 las subparcelas 5 , 21 y 30 mantuvieron una concentración muy baja de magnesio en el suelo, la 2, 6, 7, $8,9,11,12,13,14,15,16,19,20,22,24,25,28,31$ y 32 baja, la $1,3,10,23,26,27$ y 29media y la 4, 17 y 18alta, no existiendo subparcelas con contenido muy alto de $\mathrm{Mg}$, según Horneck et al. (2011). Las necesidades del magnesio, aun siendo relativamente importantes, son inferiores a las del potasio. El problema fundamental es el establecimiento de una relación adecuada entre ambos elementos antagónicos, según se indicó al referirnos al $\mathrm{K}$, presentándose deficiencias de magnesio para valores superiores a 0,35 en la relación $\mathrm{K} / \mathrm{Mg}$. En el caso de este estudio, los valores de este ratio de muchas de las zonas estudiadas se encuentran por encima de ese nivel, por lo que es de esperar situaciones de deficiencia inducida de $\mathrm{Mg}$. La relación Ca/Mg para el suelo promedio es 12,8 y, en general, las muestras tienen un valor de la relación por encima de 6, valor crítico que propone Legaz et al (1995), por lo que desde este punto de vista también se ven favorecidas las deficiencias de Mg.

La distribución de los porcentajes de muestras por su contenido peciolar de magnesio, como se aprecia en la figura 4.3, ha permanecido más o menos constante a lo largo de los tres años de seguimiento, siendo el porcentaje de muestras con una concentración media del $40 \%$, y el $60 \%$ con alto contenido, según los patrones nutricionales obtenidos para la Ribera del Duero por González y Martín (2005). Los valores observados son cercanos a las recomendaciones generales dadas por Fregoni (1998). En el año 2009 las áreas de muestreo 2, 5, 6, 21, 24, 25, 26, 27 y 28 tuvieron una concentración media de magnesio en los peciolos, y la 1, 3, 4, 7, 8, 9, 10, 11, 12, 19, 20, 22 y 23 alta. En el año 2010, las subparcelas 6, 25, 26, 27, 28, 29, 30, 31, 32 tuvieron un contenido medio de magnesio, y la $5,7,8,9,10,11,12,13,14,15,16,17$, 18, 23 y 24 alto. $Y$ en el año 2011, las subparcelas $5,6,24,25,26,27,28,30,31,32$ tuvieron un contenido medio, y la $7,8,9,10,11,12,13,14,15,16,17,18,23$ у 29 alto.

Es de destacar que, aunque, la mayor parte de las parcelas tuvieron un contenido bajo de magnesio en el suelo, la concentración de dicho elemento en el 
tejido peciolar fue medio o alto. Rodecap et al. (1994) informaron de que las plantas de Arabidopsis deficientes en Fe acumulaban concentraciones más altas de Mg en frutos y semillas en comparación con las plantas sin carencia de Fe.

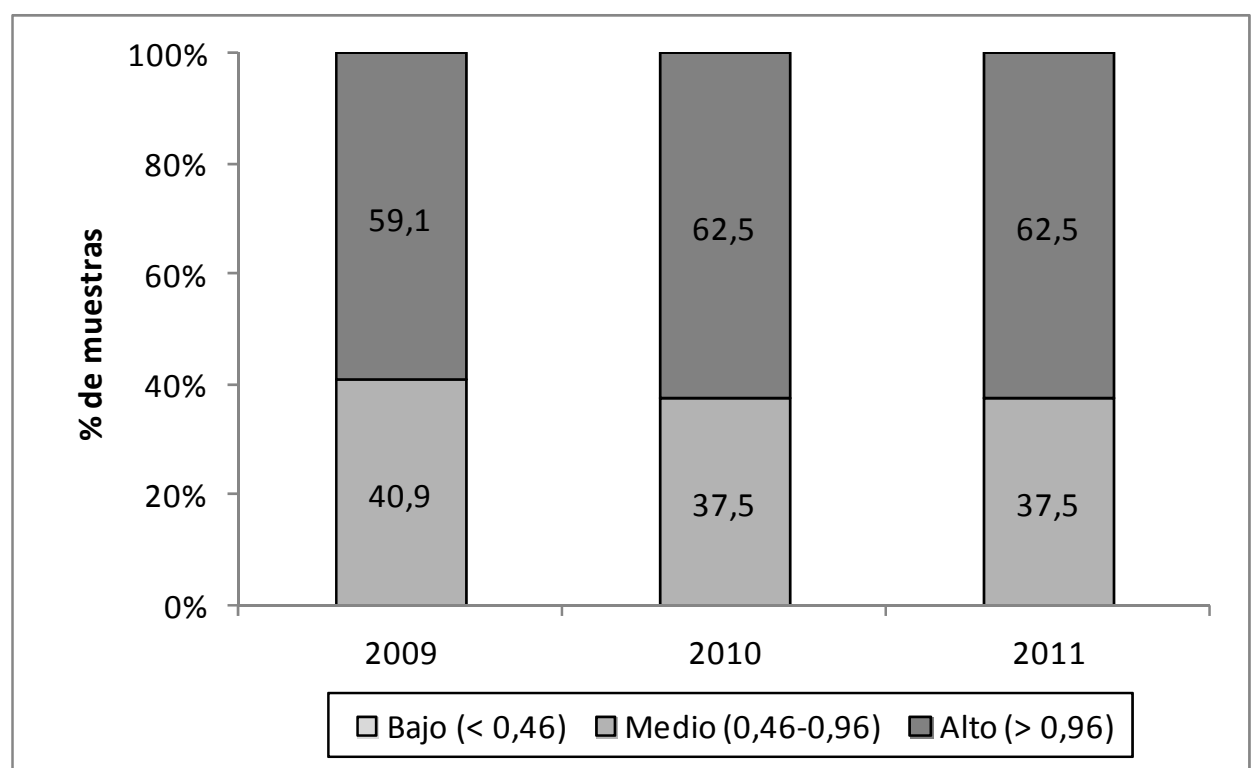

Figura 4.3. Distribución de las subparcelas en función de los contenidos de magnesio (\% s.m.s.) en el peciolo en las tres campañas de estudio, teniendo en cuenta los valores de referencia propuestos por González y Martín (2005).

Teniendo en cuenta todo lo anterior, se ha realizado un diagnostico general de la nutrición del magnesio de las áreas de muestreo, con el fin de estudiar la influencia de esta en los parámetros fisiológicos y agronómicos en apartados posteriores. Así, las parcelas $2,5,6,21,24,25,26,27,28,29,30,31$ y 32 tendrían una nutrición adecuada de $\mathrm{Mg}$, mientras que el resto tendría un exceso de nutrición de este elemento.

También se han estudiado los valores de la relación $\mathrm{K} / \mathrm{Mg}$ de las áreas de muestreo, con el fin de analizar posteriormente la influencia de esta sobre los parámetros fisiológicos y agronómicos. Así, las parcelas 2, 4, 7, 11, 12, 15, 16, 17, 18, 22, 23, y 24 tuvieron una baja relación $\mathrm{K} / \mathrm{Mg}$, las parcelas 1, 3, 8, 9, 10, 13, 14, 19, 29 y 30 tuvieron una relación $\mathrm{K} / \mathrm{Mg}$ media y las parcelas 5, 6, 20, 21, 25, 26, 27, 28, 31 y 32 tuvieron una relación K/Mg alta (González y Martín, 2005). 


\subsubsection{5.- Calcio.}

La concentración media de calcio de cambio en el suelo en las diferentes áreas de muestreo es elevada de $17,5 \mathrm{meq} \cdot 100 \mathrm{~g}^{-1}$ (Tabla 4.1). Teniendo en cuenta la tabla 4.2, el contenido de calcio en las áreas de estudio 9, 10, 11, 12fuemedio, el de la 24 alta, el de la $1,2,3,4,5,6,7,8,13,14,15,16,17,18,19,20,21,22,23,25,26,27$, 28, 29, 30, 31 y 32muy alta, no existiendo zonas con concentraciones muy bajas o bajas según Yañez (1989). El exceso de calcio puede inducir a carencias por insolubilizaciones de boro, manganeso o cinc (Hidalgo, 1999), algo que podría ocurrir en las zonas muestreadas en este estudio.

Este contenido de calcio medio, alto o muy alto obtenido en los suelos muestreados se ve reflejado en los niveles peciolares del elemento (figura 4.4), donde especialmente en los años 2009 y 2011 la concentración de calcio fue media o alta para prácticamente todas las áreas muestreadas, mientras que en el año 2010, fue alta para casi todas las muestras según las recomendaciones para la Ribera del Duero de González y Martín (2005). Concretamente, en el año 2009 el contenido de calcio en los peciolos fue bajo para las subparcelas 19 y 20 , medio para las zonas de estudio 2 , $3,8,10,21,23,24,27$ y 28 y alta para las $1,4,5,6,7,9,11,12,22,25$ y 26 .En el año 2010, la concentración de calcio fue media sólo para la subparcela 8 , mientras que para el resto fue alta. Y en el año 2011, las subparcelas 7, 8, 13, 17, 18, 23, 25, 26, 27 , 28,29 y 30 tuvieron un contenido medio, y la $5,6,9,10,11,12,14,15,16,24,31$ у 32 alto.

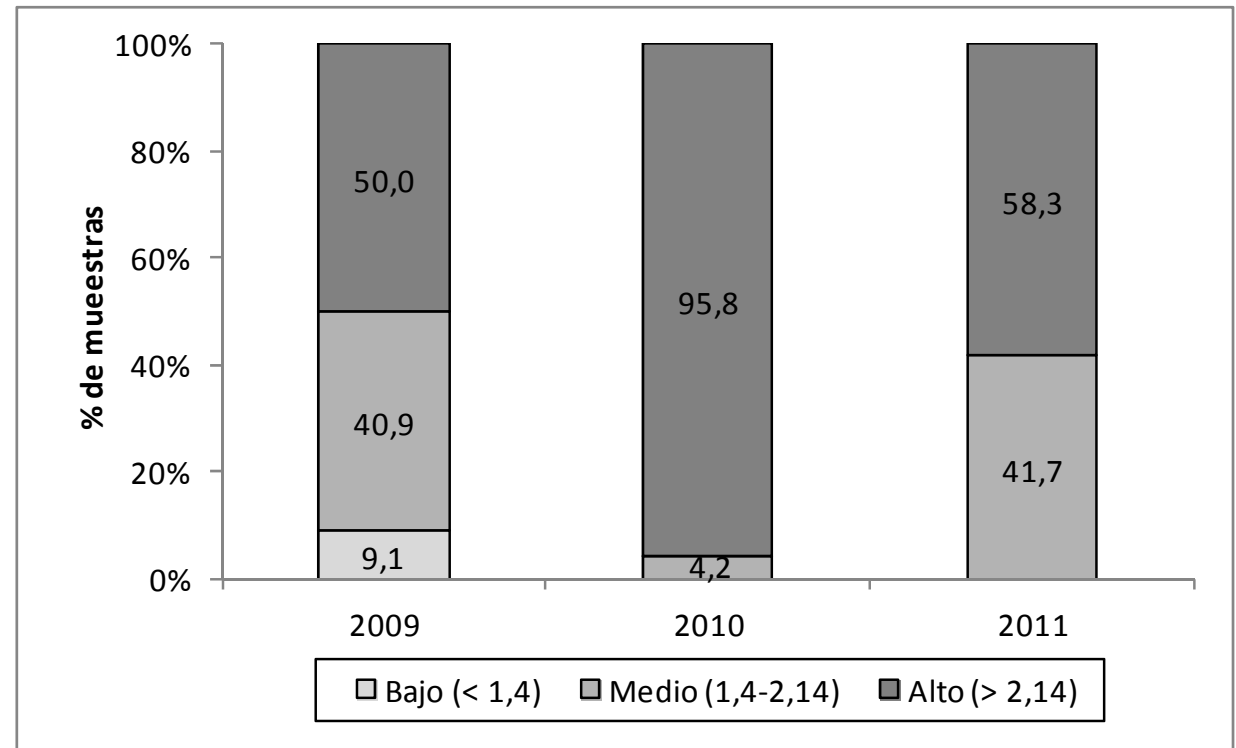

Figura 4.4. Distribución de las subparcelas en función de los contenidos de calcio (\% s.m.s.) en el peciolo en las tres campañas de estudio, teniendo en cuenta los valores de referencia propuestos por González y Martín (2005). 
Este mayor número de parcelas con un contenido elevado de Ca en los peciolos en 2010 pudo ser debido a un estrés hídrico y térmico provocado por unas nulas precipitaciones registradas durante julio y agosto y un verano más seco que en los otros dos años, que fue acompañado de unas temperaturas máximas absolutas anormalmente altas en el mes de julio y principios de agosto. Esto pudo haber modificado la dinámica del $\mathrm{Ca}$ en el sistema suelo-planta. Así, Abdel Rahman et al. (1971) informaron que el estrés hídrico incrementaba la concentración de Ca y disminuye la de $\mathrm{P}$ en los tejidos de las plantas.

\subsubsection{6.- Hierro.}

La concentración media de hierro asimilable en el suelo para las diferentes áreas de muestreo fue de $4,27 \mathrm{mg} \cdot \mathrm{kg}^{-1}$ (tabla 4.1), nivel considerado más que suficiente para una buena nutrición férrica del viñedo según Lindsay y Norwell (1978), quienes propusieron unos valores críticos de Fe extraído con DTPA entre 2,5 y 4,5 $\mathrm{mg} \cdot \mathrm{kg}^{-1}$. Sin embargo, recientemente Díaz et al. (2010) han estimado los valores de referencia del Fe extraído con DTPA para suelos calizos en $5 \mathrm{mg} \cdot \mathrm{kg}^{-1}$. Altos contenidos de hierro en el suelo no garantizan una óptima nutrición de este elemento ya que en la mayoría de los casos la carencia es inducida por elevados niveles de caliza y alto $\mathrm{pH}$ en el suelo (Chen y Barak, 1982), debido a las fuertes interacciones del hierro con el ión bicarbonato $\mathrm{HCO}_{3}{ }^{-}$. La tabla 4.2 muestra que las subparcelas $11 \mathrm{y}$ 12 tienen una concentración baja de hierro en el suelo, la 1, 2, 3, 4, 5, 9, 10, 14, 15, $16,17,18,20,22,23,24,25,26,27,28,29$ y 32 media y la $6,7,8,13,19,21,30$ y 31 alta.

Todos los valores de la concentración de hierro peciolar están dentro de los recomendados a nivel general (Fregoni, 1998). Sin embargo, teniendo en cuenta los valores nutricionales obtenidos para la Ribera del Duero (González y Martín, 2005), aunque la mayor parte de las áreas de ensayo tienen un contenido medio de hierro en el tejido peciolar, existen algunas con valores altos (sobre todo en 2011) o bajos (figura 4.5). Concretamente, en el año 2009 la subparcela 25 tuvo un contenido bajo de hierro peciolar, la 1 y la 6 alto, mientras que para el resto el contenido fue medio. En el año 2010 el contenido para la subparcela 17 fue bajo y la 29 alta, mientras que para el resto la concentración de hierro fue media. Y en el año 2011 la subparcela 29 tuvo una concentración en los peciolos baja, la 11, 12, 13, 14, 15, 17, 18, 24, 25, 26, 28,29 y 30 media y la $5,6,7,8,9,10,16$ y 23 alta.

En cualquier caso los niveles peciolares de hierro no son válidos para el diagnóstico de la clorosis férrica ya que, con frecuencia las plantas cloróticas tienen concentraciones foliares de hierro, sobre materia seca, mayores que las no cloróticas. Este efecto, conocido como "paradoja de la clorosis" (Römheld, 1997), se asocia con la acumulación de hierro inactivo en los tejidos y con una reducción drástica del crecimiento en las plantas afectadas, que reduce el peso por unidad de superficie de hoja, lo que produce un efecto de concentración. 


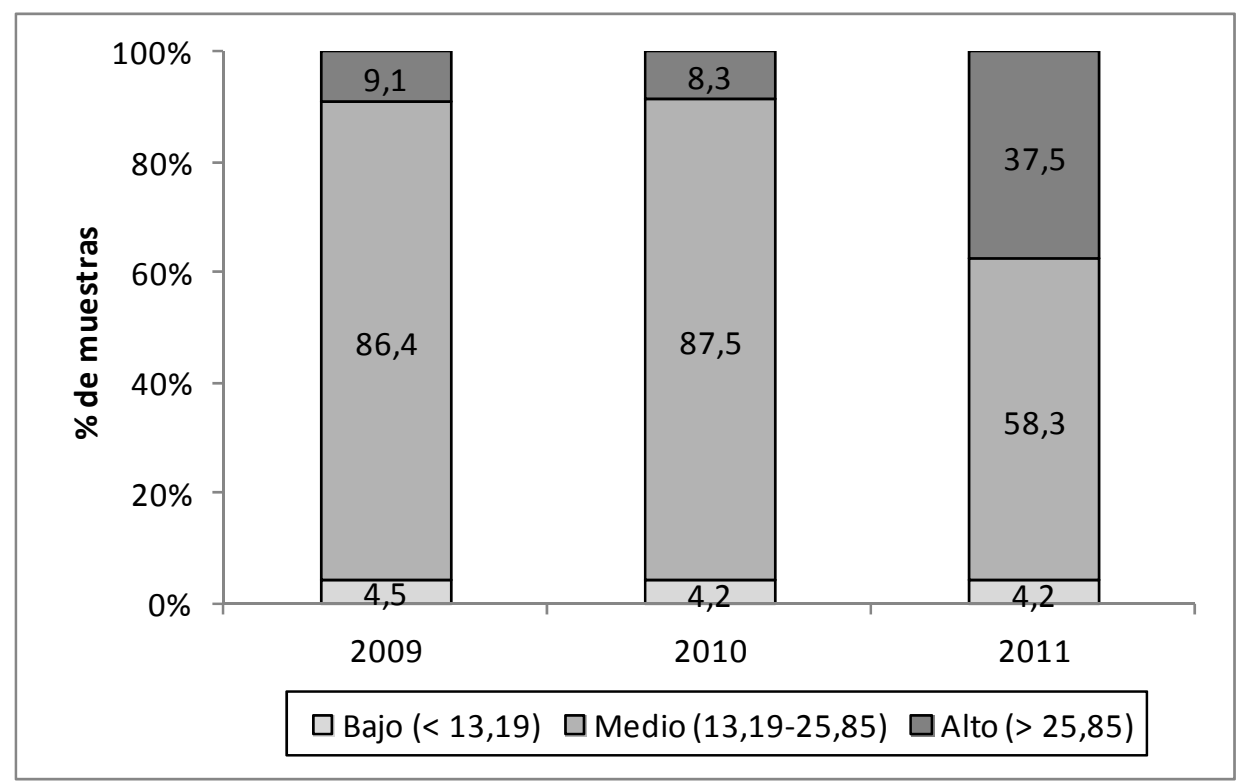

Figura 4.5. Distribución de las subparcelas en función de los contenidos de hierro ( $\mathrm{mg} \cdot \mathrm{kg}^{-1}$ s.m.s.) en el peciolo en las tres campañas de estudio, teniendo en cuenta los valores de referencia propuestos por González y Martín (2005).

\subsubsection{7.- Cobre.}

Los niveles de cobre en el conjunto de los suelos muestreados está entre $0,32-$ $3,84 \mathrm{mg} \cdot \mathrm{kg}^{-1}$, existiendo una alta variabilidad, con un coeficiente de variación de93\% (tabla 1). Lindsay y Norwell (1978) citan como valores críticos de suelo para el Cu 0,1$2,0 \mathrm{mg} \cdot \mathrm{kg}^{-1}$.Como se observa en la tabla 4.2 , la concentración de cobre en todas las zonas de estudio fue media, exceptuando la subparcela 16 que fue alta.

Aunque prácticamente en los tres años de estudio el $100 \%$ de las áreas ensayadas tuvieron una concentración de cobre peciolar por debajo de la recomendada por Fregoni (1998), como muestra la figura 4.6, los valores fueron medios para más de la mitad de las áreas muestreadas, siendo del $100 \%$ en el año 2010 según los patrones nutricionales obtenidos para la Ribera del Duero (González y Martín, 2005). En el año 2009 las subparcelas 3, 4, 7, 8, 10, 11, 12, 20 y 25 tuvieron una concentración baja de cobre peciolar, y el resto media. En el año 2010todas las subparcelas tuvieron una concentración media de cobre peciolar. En el año 2011, las subparcelas $5,6,9,10,11,12$ y 14 tuvieron la concentración baja y en el resto media.

Menzel et al. (1986) observaron que la concentración de Cu se incrementaba en plantas con estrés hídrico. El mayor número de parcelas con un contenido elevado de $\mathrm{Cu}$ en los peciolos recogidos en 2010, respecto a los otros dos años, pudo ser debido al estrés hídrico y térmico durante el verano de ese año, tal y como se ha comentado para el caso de otros nutrientes. 


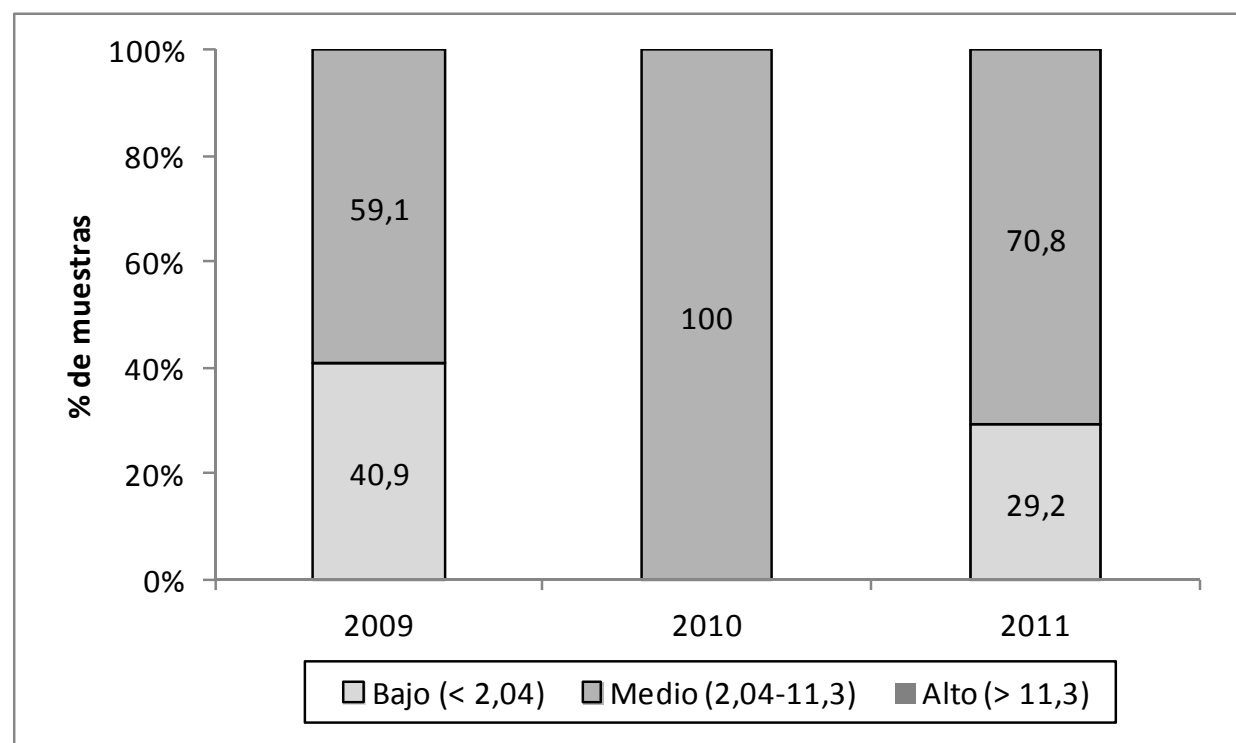

Figura 4.6. Distribución de las subparcelas en función de los contenidos de cobre (mg $\mathrm{kg}^{-1}$ s.m.s.) en el peciolo en las tres campañas de estudio, teniendo en cuenta los valores de referencia propuestos por González y Martín (2005).

El diagnostico general de la nutrición de cobre en las áreas de muestreo para estudiar la influencia de esta en los parámetros fisiológicos y agronómicos en apartados posteriores, permite considerar que las subparcelas $1,2,5,6,13,15,16$, $17,18,19,21,22,23,24,25,26,27,28,29,30,31$ y 32 tienen una nutrición adecuada de $\mathrm{Cu}$, mientras que el resto tiene un déficit de nutrición de $\mathrm{Cu}$.

\subsubsection{8.- Manganeso.}

El contenido de manganeso asimilable medio en el conjunto de los suelos muestreados es de $7,62 \mathrm{mg} \cdot \mathrm{kg}^{-1}$, siendo el coeficiente de variación de $33 \%$ (tabla 4.1). Los valores normales de contenido en manganeso en los suelos están comprendidos entre 1 y $5 \mathrm{mg} \cdot \mathrm{kg}^{-1}$ (Sims y Johnson, 1991). En las subparcelas 7, 9, 11, 12 y 17 el contenido de manganeso en el suelo fue medio, mientras que en el resto fue alto (tabla 4.2),por lo que no es de esperar que exista una deficiencia de dicho elemento.

La mayoría de los valores del contenido peciolar de Mn se encuentran dentro de los recomendados por Fregoni (1998). Sin embargo, como se puede ver en la figura 4.7, en el año 2009 el $82 \%$ de las áreas muestreadas tenían una concentración de manganeso en los peciolos elevada, disminuyendo hasta el $46 \%$ en el año 2011 . El resto de las zonas tienen un contenido medio de manganeso en los peciolos según los patrones nutricionales obtenidos para la Ribera del Duero (González y Martín, 2005).Concretamente, en el año 2009 las subparcelas 7, 9, 10 y 12, en el año 2010 las subparcelas $7,9,10,11,12,13,14,16,17,18,25$ y 31 y en el año 2011 las subparcelas $7,9,10,11,12,13,14,16,17,18$ y 25 tuvieron un contenido alto de 
manganeso peciolar, siendo en el resto medio. Todas las zonas muestreadas que tuvieron un contenido medio de $\mathrm{Mn}$ en el suelo, acumularon una concentración alta de Mn en los peciolos los tres años ensayados.

La absorción de Fe está estrechamente relacionada con la de otros metales. Las concentraciones elevadas de $\mathrm{Zn}^{2+}$ y $\mathrm{Mn}^{2+}$ en el medio interfieren en la absorción de $\mathrm{Fe}^{2+}$ en la raíz, reduciendo la concentración de $\mathrm{Fe}$ en la planta, que incluso pueden mostrar síntomas de deficiencia (Izaguirre-Mayoral y Sinclair, 2005; Adiloglu, 2006; Aref, 2011; Shanmugam et al., 2011). Este efecto ha sido atribuido a la competencia entre los iones por los sitios de absorción (Kochian, 1991; Welch, 1995). Por el contrario, tanto $\mathrm{Zn}^{2+}$ como $\mathrm{Mn}^{2+}$ son más fácilmente absorbidos por las raíces de las plantas deficientes en Fe (Alcántara et al., 1994; Cohen et al., 1998; Korshunova et al., 1999; Eckhardt et al., 2001).

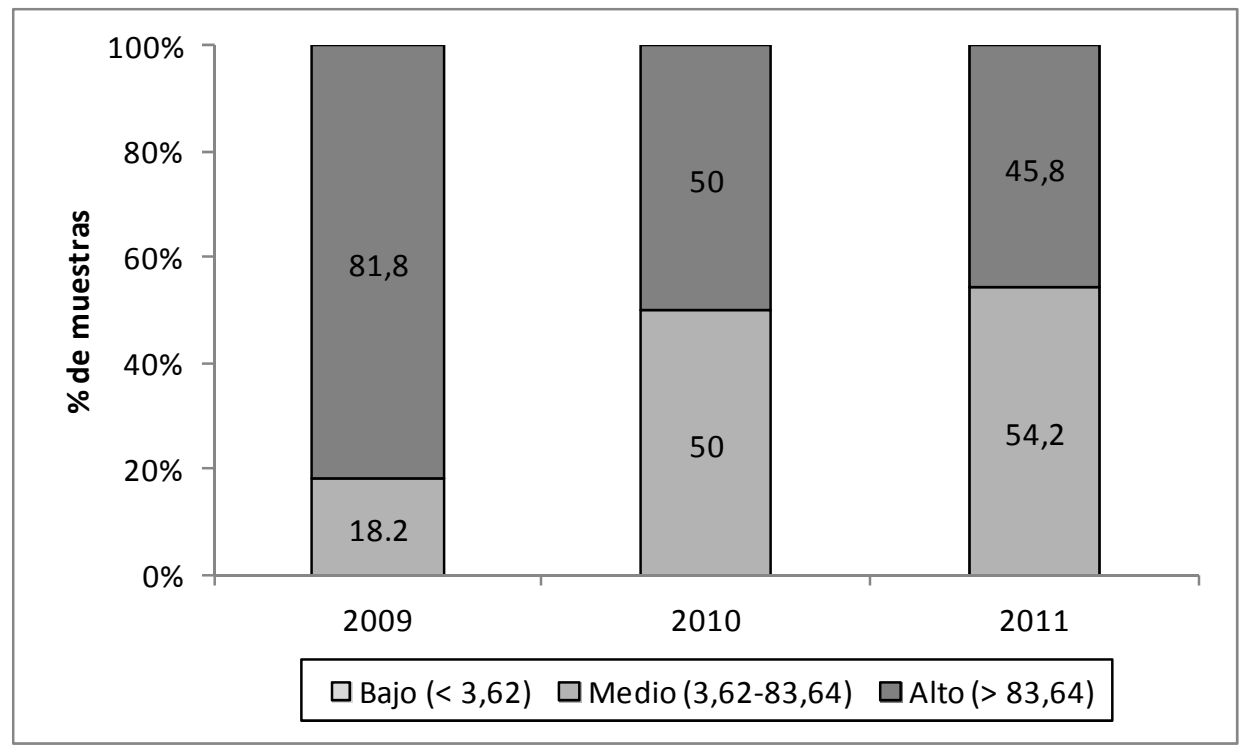

Figura 4.7. Distribución de las subparcelas en función de los contenidos de manganeso ( $\mathrm{mg} \cdot \mathrm{kg}^{-1} \mathrm{~s}$.m.s.) en el peciolo en las tres campañas de estudio, teniendo en cuenta los valores de referencia propuestos por González y Martín (2005).

Aunque normalmente los suelos con $\mathrm{pH}$ elevado reducen fuertemente la absorción de manganeso por la planta (Rengel, 2000), las vides de las parcelas estudiadas con alto contenido en carbonatos (clorosantes) presentan contenidos elevados de $\mathrm{Mn}$ en los peciolos. Hay que tener en cuenta que las plantas deficientes en Fe tienen tendencia a acumular Mn (Pittman, 2005; Martín et al., 2008 y Keller, 2010). En este contexto, Zuo y Zhang (2008) observaron una elevada concentración de $\mathrm{Mn}$ en plantas de cacahuete deficientes de hierro. Welch y Norvell, (1993) y Cohen et al., (1998) informaron que tanto la deficiencia de Fe como de Zn pueden mejorar la absorción de $\mathrm{Mn}^{2+}$ en algunas especies. Hay varias vías alternativas por las cuales el $\mathrm{Mn}^{2+}$ podría acumularse en las células vegetales. Se ha postulado, por ejemplo, que 
los canales de $\mathrm{Ca}^{2+}$ de la membrana plasmática pueden permitir el transporte de $\mathrm{Mn}^{2+}$, (White, 1998).

\subsubsection{9.- Zinc.}

Los valores críticos de cinc en el suelo propuestos por Lindsay y Norwell (1978) son de $<1 \mathrm{mg} \cdot \mathrm{kg}^{-1}$ de tierra, siendo la vid una planta muy sensible a la carencia de este elemento (Hidalgo, 1999). La media para el conjunto de los suelos muestreados es de $1 \mathrm{mg} \cdot \mathrm{kg}^{-1}$, siendo el coeficiente de variación de $36 \%$ (taba 4.1). La tabla 4.2 muestra que en general las áreas estudiadas tuvieron una concentración baja de zinc en el suelo, salvo la 5, 6, 14, 15, 16, 18 y 29, con nivel adecuado. La escasez de zinc puede ser producida principalmente por un $\mathrm{pH}$ elevado, y/o por un exceso de fósforo, con valores por encima de 30 en la relación P/Zn (Alloway, 2004), lo que ocurre sólo en dos de los suelos muestreados. También inmovilizan el zinc los carbonatos, así como un exceso de potasio, produciéndose entonces una sintomatología específica con disminución del crecimiento, pérdida de producción y calidad de frutos, apareciendo pequeñas hojas deformes con clorosis (Bavaresco et al., 2010b).

Teniendo en cuenta los patrones nutricionales de Fregoni (1998), el contenido peciolar de $\mathrm{Zn}$ fue bajo o medio para todas las áreas de estudio en los tres años de seguimiento, siendo especialmente elevado el porcentaje $(67 \%)$ de parcelas con deficiencia en 2010. No obstante, atendiendo a las recomendaciones obtenidas para la Ribera del Duero (González y Martín, 2005), como se puede ver en la figura 4.8, la concentración de zinc en los peciolos se encuentra en valores medios ó altos en todas las áreas estudiadas durante los tres años de seguimiento, salvo el $4,2 \%$ de ellas en el año 2010. Concretamente, en el año 2009 el contenido de cinc en los peciolos fue medio para las subparcelas $1,2,3,4,5,9,12,24$ y 28 y alto para la $6,7,8,10,11,19$, 20, 21, 22, 23, 25, 26 y 27. En el año 2010, la concentración de cinc fue baja sólo para la subparcela 16, media para la $5,6,8,9,10,11,12,14,15,17,23,26,27,28,29,30$, 31 y 32, y alta para las subparcelas $7,13,18,24$ y 25 . $Y$ en el año 2011, las subparcelas $5,6,14,15$ y 16 tuvieron un contenido medio, y el resto alto.

Esta diferencia en el nivel de $\mathrm{Zn}$ en los peciolos en el envero en el año 2010 con respecto a 2009 y 2011 , está relacionada probablemente con las situaciones de estrés hídrico y térmico producidas en ese año. Esta situación, tal y como se ha comentado anteriormente para otros nutrientes, podría haber modificado la dinámica del $\mathrm{Zn}$ en las plantas. La baja humedad del suelo puede inducir deficiencia de Zn (Hu y Schmidhalter, 2005).

Es de destacar que, aun existiendo una concentración baja de $\mathrm{Zn}$ en el suelo en gran parte de las subparcelas, el contenido del elemento en los peciolos fue medio o alto. Los valores peciolares podrían reflejar la incidencia de la clorosis férrica en el área de estudio, ya que la carencia de hierro favorece la absorción y acumulación de $\mathrm{Zn}$ en los tejidos. Cohen et al. (1998) comprobaron que un transportador de Fe (IRT1) podía transportar otros metales divalentes, como el $\mathrm{Zn}$. En las condiciones de cultivo de este estudio el Zn podría prevalecer sobre el Fe. 


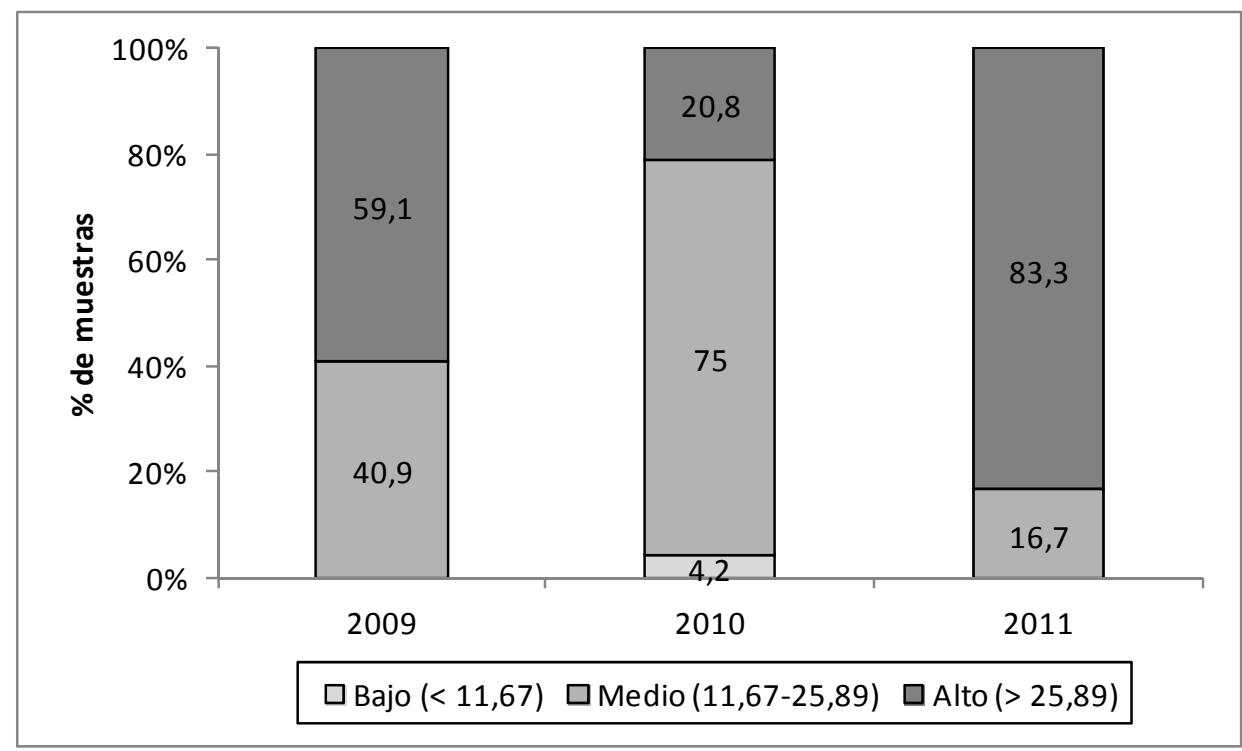

Figura 4.8. Distribución de las subparcelas en función de los contenidos de zinc ( $\mathrm{mg} \cdot \mathrm{kg}^{-1}$ s.m.s.) en el peciolo en las tres campañas de estudio, teniendo en cuenta los valores de referencia propuestos por González y Martín (2005).

Teniendo en cuenta todo lo anterior, se ha realizado un diagnóstico de la nutrición de zinc de las áreas de muestreo, con el fin de estudiar la influencia de este elemento en los parámetros fisiológicos y agronómicos del viñedo en apartados posteriores. Así, las parcelas 1, 2, 3, 4, 5, 6, 9, 12, 14, 15 y 16 tendrían unos niveles de nutrición medio de $\mathrm{Zn}$, mientras que el resto tendría un nivel alto.

\subsubsection{0.- Boro.}

Teniendo en cuenta los patrones nutricionales de Fregoni (1998), el contenido peciolar de B fue alto para todas las áreas de estudio en los tres años de seguimiento. Atendiendo a las recomendaciones obtenidas para la Ribera del Duero (González y Martín, 2005), como se puede ver en la figura 4.9, la concentración de B en los peciolos se encuentra en valores medios en todas las áreas estudiadas en $2009 \mathrm{y}$ prácticamente en todas en 2010 y 2011 .El $12,5 \%$ de las subparcelas tuvieron un contenido elevado de dicho elemento en 2010 (subparcelas 14, 15 y 16) y 2011 (subparcelas 10, 13 y 14). 


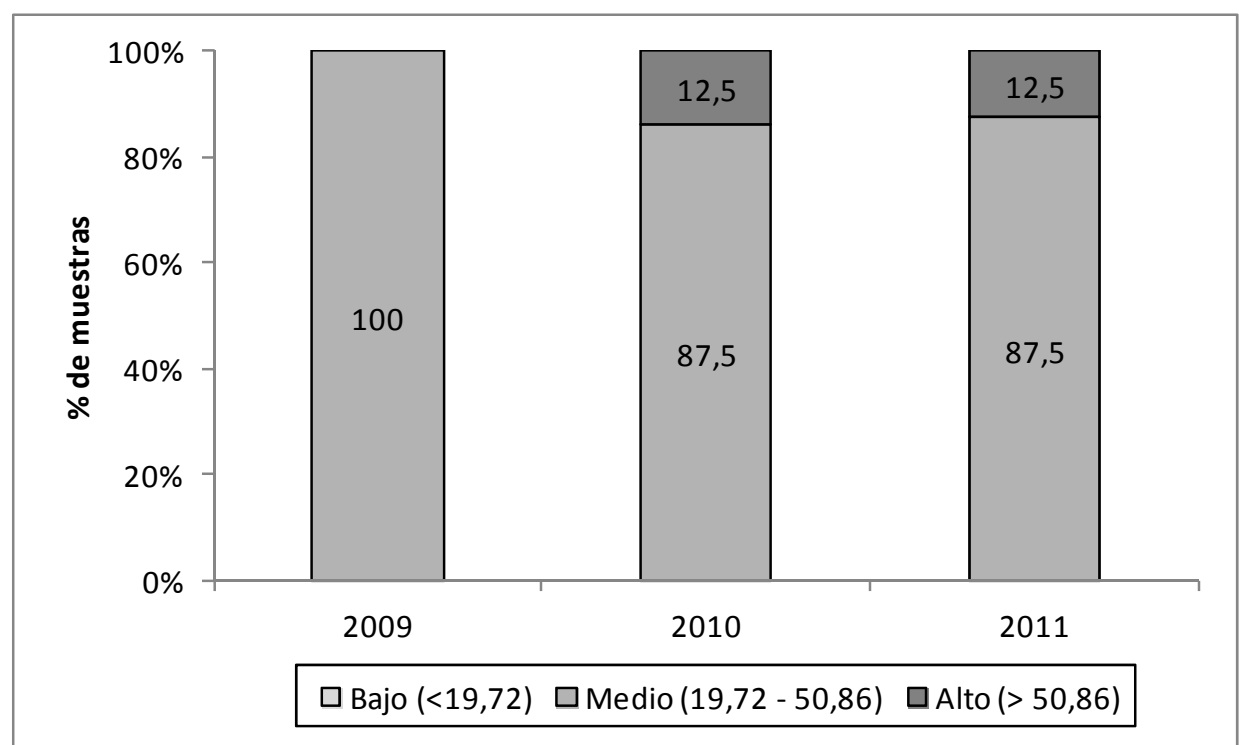

Figura 4.9. Distribución de las subparcelas en función de los contenidos de boro ( $\mathrm{mg} \cdot \mathrm{kg}^{-1}$ s.m.s.) en el peciolo en las tres campañas de estudio, teniendo en cuenta los valores de referencia propuestos por González y Martín (2005).

\subsection{2.- Relaciones entre las características físico-químicas del suelo y la composición mineral de los peciolos.}

El pH condiciona la absorción de todos los elementos minerales, al determinar la solubilidad de los mismos. Así, la absorción de nitrógeno es más favorable a pH neutro, mientras que la del fósforo, potasio, calcio y magnesio lo es a $\mathrm{pH}$ ligeramente alcalino. Los microelementos $\mathrm{Fe}, \mathrm{Mn}, \mathrm{B}, \mathrm{Cu}$ y $\mathrm{Zn}$ son absorbidos más fácilmente a $\mathrm{pH}$ ácido. Fregoni (1998) encontró correlaciones significativas del $\mathrm{pH}$ con las concentraciones de $\mathrm{Ca}, \mathrm{P}$ y el ratio $\mathrm{K} / \mathrm{Ca}$ en el suelo. En el presente estudio el $\mathrm{pH}$ se ha relacionado significativamente con el contenido de $\mathrm{K}, \mathrm{Fe}, \mathrm{Zn}, \mathrm{Mn}$ y los ratios $\mathrm{P} / \mathrm{Ca}$, $\mathrm{K} / \mathrm{Mg}, \mathrm{K} / \mathrm{Ca}$ y $\mathrm{Ca} / \mathrm{Mg}$ presentes en el suelo. Sin embargo, no se ha encontrado ninguna relación significativa repetida en las tres campañas del $\mathrm{pH}$ del suelo con la composición mineral específica de los peciolos.

Como se ve en la tabla 4.5, el porcentaje de arcilla del suelo se ha relacionado significativamente con el contenido de $\mathrm{P}, \mathrm{Mg}$ y $\mathrm{Mn}$ peciolar en el envero. La regresión del nivel peciolar de fosforo sobre el contenido en arcilla fue negativa, mientras que fue positivas para Mg y Mn. Estos resultados coinciden con los observados por Martínez et al. (2001) en el conjunto de la Ribera del Duero. También se observó una regresión lineal significativamente positiva de la relación $\mathrm{Ca} / \mathrm{P}$ y negativa dela ratio $\mathrm{Fe} / \mathrm{Mn}$ con el porcentaje de arcilla del suelo. 
Tabla 4.5. Coeficiente de determinación $\left(R^{2}\right)$, nivel de significación y pendiente de la regresión del contenido en $\mathrm{P}, \mathrm{Mg}, \mathrm{Mn}$ y los ratios $\mathrm{Ca} / \mathrm{P}$ y Fe/Mn de los peciolos en el envero sobre el porcentaje de arcilla del suelo.

\begin{tabular}{lccc}
\hline & \multicolumn{3}{c}{ Arcilla (\%) } \\
\cline { 2 - 4 } Nutrientes & $\mathbf{2 0 0 9}$ & $\mathbf{2 0 1 0}$ & $\mathbf{2 0 1 1}$ \\
\hline $\mathbf{P}$ (\% s.m.s.) & $(-) 0,23^{*}$ & $(-) 0,34^{* *}$ & $(-) 0,18^{*}$ \\
Mg (\% s.m.s.) & $(+) 0,23^{*}$ & $(+) 0,35^{* *}$ & $(+) 0,32^{* *}$ \\
Mn (mg.kg ${ }^{-1}$ s.m.s.) & $(+) 0,43^{* *}$ & $(+) 0,41^{* *}$ & $(+) 0,48^{* *}$ \\
\hline Ca/P & $(+) 0,11$ & $(+) 0,47^{* *}$ & $(+) 0,22^{*}$ \\
Fe/Mn & $(-) 0,32^{* *}$ & $(-) 0,40^{* *}$ & $(-) 0,31^{* *}$ \\
\hline \multicolumn{1}{c}{ Niveles de significación: ${ }^{*} p<0,05 ;{ }^{* *} p<0,01 ;{ }^{* * *} p<0,0001$}
\end{tabular}

El contenido en carbonatos totales del suelo se ha relacionado significativamente de forma positiva con la concentración de $\mathrm{Mg}$ y $\mathrm{Mn}$ en los peciolos (Tabla 4.6). Otros autores como Demirer et al. (2007) y Díaz et al. (2009b) también han observado una relación significativamente positiva entre el $\mathrm{Mg}$ foliar con los carbonatos del sustrato. Puede decirse que, en las condiciones de cultivo de este estudio, una elevada concentración de carbonatos en el suelo está relacionada de forma importante con un mayor nivel peciolar de estos elementos. Los niveles de carbonatos totales también se han relacionado negativamente con el ratio $\mathrm{Fe} / \mathrm{Mn}$ en peciolos en los años 2010 y 2011 . Esto tendría que ver con la respuesta fisiológica de la raíz a la deficiencia de hierro, que activa proteínas transportadoras de hierro como la IRT1 ó la NRAMP3,implicadas también en el transporte de $\mathrm{Mn}$, y en las que prevalecen la afinidad por el Mn sobre la de Fe (Milalleo, 2010), La relación significativamente negativa entre el contenido de carbonatos totales y los ratios $\mathrm{K} / \mathrm{Mg}$, $\mathrm{K} / \mathrm{Ca}$ y $\mathrm{K} /(\mathrm{Ca}+\mathrm{Mg})$ de los peciolos refleja el antagonismo de $\mathrm{Ca}$ y $\mathrm{Mg}$ con el $\mathrm{K}$. Además, se ha encontrado una relación negativa para la ratio $\mathrm{Ca} / \mathrm{Mg}$, por lo que sería más importante la acumulación de Mg en los tejidos vegetal es que la de Ca en suelos con niveles crecientes de carbonatos. Por último, en los años 2010 y 2011 la relación significativamente positiva entre los niveles de carbonatos y el ratio $\mathrm{Ca} / \mathrm{P}$ en los peciolos apunta como es lógico, a una mayor acumulación de Ca en detrimento del P en los suelos clorosantes.

El contenido de arcilla y el contenido en carbonatos totales del suelo tienen una influencia similar sobre la acumulación en los peciolos de algunos de los nutrientes estudiados. La figura 4.10 muestra la correlación significativamente positiva que se ha dado entre los contenidos de arcilla y carbonatos totales. Esto indica que los suelos clorosantes (alto contenido en carbonatos) de la zona tienen un marcado carácter arcilloso. En distintas zonas, Metwally (1969), Shehata (1975) encontraron una correlación positiva entre el $\mathrm{CaCO}_{3}$ y el porcentaje de arcilla y limo, y el grado de 
agregación del suelo. La estabilidad los agregados estructurales está relacionada con el porcentaje de arcilla y el contenido de $\mathrm{CaCO}_{3}$.

Tabla 4.6. Coeficiente de determinación $\left(R^{2}\right)$, nivel de significación y pendiente de la regresión de la composición mineral y los ratios $\mathrm{Ca} / \mathrm{P}, \mathrm{K} / \mathrm{Mg}, \mathrm{K} / \mathrm{Ca}, \mathrm{K} /(\mathrm{Ca}+\mathrm{Mg}), \mathrm{Ca} / \mathrm{Mg}$ y $\mathrm{Fe} / \mathrm{Mn}$ de los peciolos en el envero sobre el contenido en carbonatos totales del suelo.

\begin{tabular}{|c|c|c|c|c|c|c|}
\hline \multirow[b]{2}{*}{ Nutrientes } & \multicolumn{6}{|c|}{ Carbonatos totales (\%) } \\
\hline & 2009 & & & 2010 & 2011 & \\
\hline N (\%) & (-) 0,00 & & $(-)$ & 0,14 & (-) 0,06 & \\
\hline P (\% s.m.s.) & (-) 0,02 & & $(-)$ & $0,33 * *$ & (-) 0,09 & \\
\hline K (\% s.m.s.) & $(-) 0,23$ & * & $(-)$ & $0,25 *$ & (-) 0,03 & \\
\hline Ca (\% s.m.s.) & (+) 0,19 & * & $(+)$ & 0,12 & (+) 0,17 & * \\
\hline Mg (\% s.m.s.) & (+) 0,57 & $* *$ & $(+)$ & $0,66^{* * *}$ & (+) 0,67 & $* * *$ \\
\hline $\mathrm{Fe}\left(\mathrm{mg} \cdot \mathbf{k g}^{-1}\right)$ & (+) 0,01 & & $(+)$ & 0,00 & (+) 0,00 & \\
\hline $\mathrm{Cu}\left(\mathrm{mg} \cdot \mathrm{kg}^{-1}\right)$ & (-) 0,52 & ** & $(-)$ & $0,27 *$ & (-) 0,00 & \\
\hline$M n\left(m g \cdot k g^{-1}\right)$ & (+) 0,50 & ** & $(+)$ & $0,33 * *$ & (+) 0,48 & $* *$ \\
\hline $\mathrm{Zn}\left(\mathrm{mg} \cdot \mathrm{kg}^{-1}\right)$ & (-) 0,27 & * & $(-)$ & 0,10 & (-) 0,04 & \\
\hline$B\left(\mathrm{mg} \cdot \mathrm{kg}^{-1}\right)$ & (+) 0,46 & ** & $(-)$ & 0,08 & (-) 0,02 & \\
\hline $\mathrm{Ca} / \mathrm{P}$ & $(+) 0,02$ & & $(+)$ & 0,48 ** & $(+) 0,20$ & * \\
\hline $\mathrm{K} / \mathrm{Mg}$ & (-) 0,57 & $* *$ & $(-)$ & $0,42 * *$ & (-) 0,37 & $* *$ \\
\hline $\mathrm{K} / \mathrm{Ca}$ & (-) 0,27 & * & $(-)$ & 0,29 ** & (-) 0,10 & \\
\hline $\mathrm{K} /(\mathrm{Ca}+\mathrm{Mg})$ & (-) 0,45 & $* *$ & $(-)$ & $0,37^{* *}$ & (-) 0,22 & * \\
\hline $\mathrm{Ca} / \mathrm{Mg}$ & (-) 0,40 & $* *$ & $(-)$ & 0,39 ** & (-) 0,40 & $* *$ \\
\hline $\mathrm{Fe} / \mathrm{Mn}$ & (-) 0,23 & * & $(-)$ & 0,29 ** & (-) 0,28 & $* *$ \\
\hline
\end{tabular}

La relación del contenido de cada mineral en el suelo y su acumulación en los órganos de las plantas es un aspecto interesante para estudiar el estado nutricional de las plantas. Observando la tabla 4.7, podemos destacar las relaciones significativamente positivas en los años 2010 y 2011 del potasio y magnesio presente en el suelo con los respectivos niveles peciolares. Otros autores, como Poni et al. (2003) y Delgado et al. (2004) han observado un aumento del contenido en $\mathrm{K}$ en el pecíolo, limbo y uva como resultado de la aplicación de K al suelo. Wolf et al. (1983) también observaron que el aumento de las concentraciones de $\mathrm{Mg}$ en el suelo aumentaba las concentraciones de $\mathrm{Mg}$ en la hoja. 


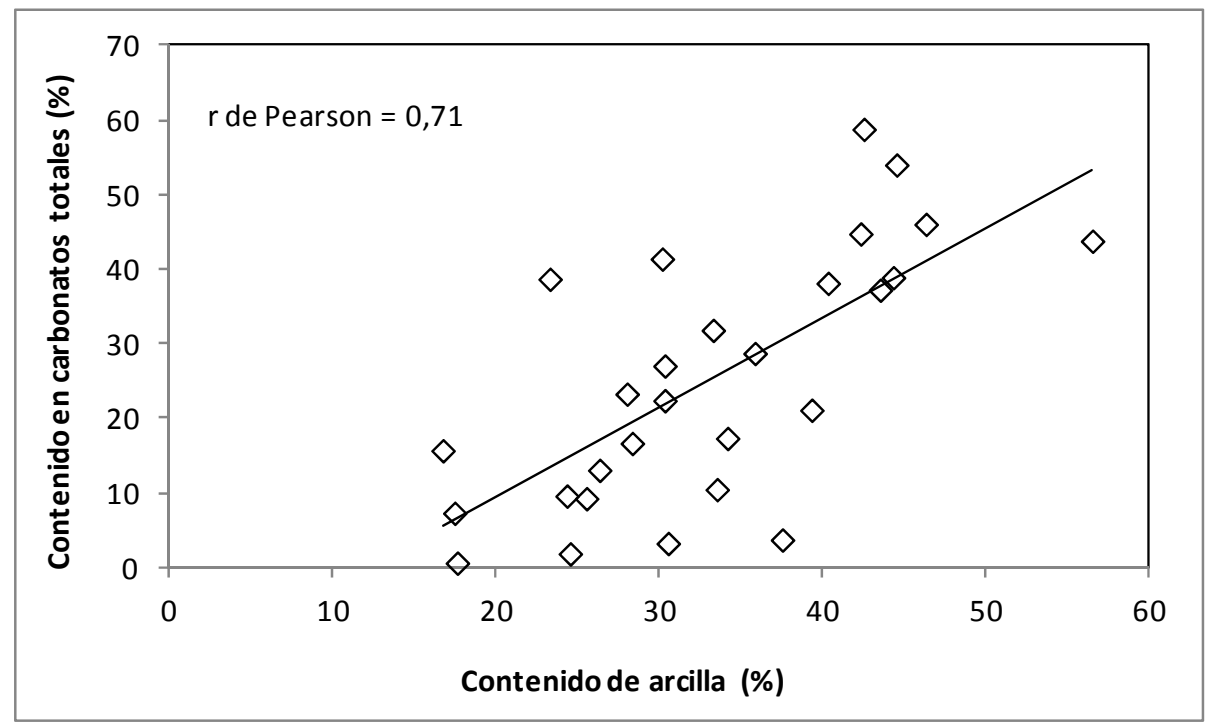

Figura 4.10. Gráfico de dispersión del contenido de arcilla y el contenido de carbonatos totales en el suelo.

En el caso del cobre, en los años 2009 y 2011, se encontró una relación significativamente positiva entre las concentraciones de este elemento en el suelo y en los peciolos en el envero. Es de destacar que para el fósforo, calcio, hierro y manganeso no se ha encontrado ninguna relación significativa entre el nivel en los peciolos y el contenido de cada elemento en el suelo, lo que demuestra la existencia influencia de otras muchas variables en la acumulación de los nutrientes en las plantas, así como la existencia de interacciones entre unos nutrientes y otros.

Tabla 4.7. Coeficiente de determinación $\left(R^{2}\right)$, nivel de significación y pendiente de la regresión del contenido mineral del suelo sobre el contenido mineral de los peciolos en el envero para cada elemento entre sí mismo.

\begin{tabular}{|c|c|c|c|c|c|c|c|}
\hline \multirow{2}{*}{$\begin{array}{l}\text { Contenido mineral } \\
\text { del Suelo }\end{array}$} & \multicolumn{7}{|c|}{ Contenido mineral peciolar } \\
\hline & & 2009 & & 2010 & & 2011 & \\
\hline$P\left(\mathbf{m g} \cdot \mathbf{k g}^{-1}\right)$ & $(-)$ & 0,00 & $(+)$ & 0,07 & $(+)$ & 0,02 & \\
\hline $\mathrm{K}\left(\mathbf{m g} \cdot \mathbf{k g}^{-1}\right)$ & $(+)$ & 0,05 & $(+)$ & 0,30 & $* *(+)$ & 0,17 & * \\
\hline $\mathrm{Ca}\left(\mathrm{meq} \cdot 100 \mathrm{~g}^{-1}\right)$ & $(+)$ & 0,05 & $(-)$ & 0,00 & $(-)$ & 0,00 & \\
\hline $\operatorname{Mg}\left(\mathrm{meq} \cdot 100 \mathrm{~g}^{-1}\right)$ & $(+)$ & 0,13 & $(+)$ & 0,26 & * $(+)$ & 0,23 & * \\
\hline $\mathrm{Fe}\left(\mathrm{mg} \cdot \mathrm{kg}^{-1}\right)$ & $(+)$ & 0,07 & $(+)$ & 0,15 & $(-)$ & 0,00 & \\
\hline $\mathrm{Cu}\left(\mathrm{mg} \cdot \mathrm{kg}^{-1}\right)$ & $(+)$ & 0,32 & $*(+)$ & 0,11 & $(+)$ & 0,47 & ** \\
\hline $\mathrm{Zn}\left(\mathrm{mg} \cdot \mathrm{kg}^{-1}\right)$ & $(-)$ & 0,02 & $(-)$ & 0,04 & $(-)$ & 0,30 & ** \\
\hline$M n\left(\mathbf{m g} \cdot \mathbf{k g}^{-1}\right)$ & $(-)$ & 0,17 & $(-)$ & 0,09 & $(-)$ & 0,15 & \\
\hline
\end{tabular}


Como se observa en la tabla 4.8, exceptuando el año 2009, el nivel de $\mathrm{K}$ y las ratios $\mathrm{K} / \mathrm{Mg}, \mathrm{K} / \mathrm{Ca}$ y $\mathrm{K} /(\mathrm{Ca}+\mathrm{Mg})$ del suelo se han relacionado significativamente de forma negativa con el nivel peciolar de $\mathrm{Mg}$ y la ratio $\mathrm{Ca} / \mathrm{P}$, y de forma positiva con el $\mathrm{P}$ y la ratio $\mathrm{P} / \mathrm{Fe}$ en los peciolos, sin que se verificasen relaciones similares en el caso del Ca. Morris y Cowthan (1982), García et al. (2001) y Demirer et al. (2007) han documentado que el aumento de la concentración de $\mathrm{K}$ en el suelo reduce la concentración de Mg en los tejidos de la vid. Wolf et al. (1983) también han observado una relación antagónica entre los dos elementos. Para confirmar esto, en el presente estudio se ha encontrado una correlación significativamente negativa entre el contenido en $\mathrm{K}$ y Mg de los peciolos en los años 2010 y 2011 (figura 4.11). No se ha relacionado la concentración de $\mathrm{K}$ del suelo y sus ratios con el contenido de hierro peciolar en el envero.

Tabla 4.8. Coeficiente de determinación $\left(R^{2}\right)$, nivel de significación y pendiente de la regresión del contenido de $\mathrm{K}$ y los ratios $\mathrm{K} / \mathrm{Mg}, \mathrm{K} / \mathrm{Ca}$ y $\mathrm{K} /(\mathrm{Ca}+\mathrm{Mg})$ en el suelo sobre el contenido en $\mathrm{P}, \mathrm{Ca}, \mathrm{Mg}$ (\% s.m.s.), Fe (mg.kg ${ }^{-1}$ s.m.s.) y los ratios $\mathrm{Ca} / \mathrm{P}$ y $\mathrm{P} / \mathrm{Fe}$ de los peciolos en el envero.

\begin{tabular}{|c|c|c|c|c|c|c|c|}
\hline \multirow{2}{*}{\multicolumn{2}{|c|}{$\begin{array}{l}\text { Contenido mineral de } \mathrm{K} \\
\text { y sus ratios en el suelo }\end{array}$}} & \multicolumn{6}{|c|}{ Contenido mineral de los peciolos en envero } \\
\hline & & $\mathbf{P}$ & $\mathrm{Ca}$ & $\mathrm{Mg}$ & $\mathrm{Fe}$ & $\mathrm{Ca} / \mathrm{P}$ & $\mathrm{P} / \mathrm{Fe}$ \\
\hline \multirow{4}{*}{2009} & K & (+) 0,08 & (-) 0,00 & (-) 0,11 & (-) 0,01 & $(-) 0,05$ & $(+) 0,00$ \\
\hline & $\mathrm{K} / \mathrm{Mg}$ & (+) 0,03 & (-) 0,01 & (-) $0,32^{* *}$ & (+) 0,09 & (-) 0,02 & (+) 0,00 \\
\hline & $\mathrm{K} / \mathrm{Ca}$ & (+) 0,03 & (-) 0,03 & $(-) 0,13$ & (+) 0,04 & (-) 0,01 & (+) 0,00 \\
\hline & $\mathrm{K} /(\mathrm{Ca}+\mathrm{Mg})$ & $(+) 0,03$ & $(-) 0,07$ & (-) 0,14 & (+) 0,04 & (-) 0,01 & $(+) 0,00$ \\
\hline \multirow{4}{*}{2010} & K & (+) $0,37^{* *}$ & $(-) 0,00$ & $(-) 0,41^{* *}$ & (+) 0,00 & $(-) 0,41$ ** & $(+) 0,32 * *$ \\
\hline & $\mathrm{K} / \mathrm{Mg}$ & $(+) 0,61 * * *$ & (-) 0,01 & (-) $0,66^{* * *}$ & $(+) 0,15$ & $(-) 0,71 * * *$ & $(+) 0,28$ * \\
\hline & $\mathrm{K} / \mathrm{Ca}$ & (+) 0,24 * & (-) 0,06 & (-) 0,31* & (-) 0,02 & (-) 0,46 ** & (+) 0,30 * \\
\hline & $\mathrm{K} /(\mathrm{Ca}+\mathrm{Mg})$ & (+) 0,28 * & $(-) 0,06$ & $(-) 0,36^{* *}$ & $(-) 0,01$ & $(-) 0,51^{* *}$ & (+) $0,33^{* *}$ \\
\hline \multirow{4}{*}{2011} & $\mathrm{~K}$ & $(+) 0,23^{*}$ & $(-) 0,15$ & $(-) 0,31^{* *}$ & $(-) 0,25^{*}$ & $(-) 0,28$ ** & $(+) 0,36$ ** \\
\hline & $\mathrm{K} / \mathrm{Mg}$ & (+) 0,46 ** & (-) 0,00 & (-) $0,58 * * *$ & $(-)$ 0,03 & $(-) 0,33^{* *}$ & (+) $0,43^{* *}$ \\
\hline & $\mathrm{K} / \mathrm{Ca}$ & $(+) 0,10$ & $(-) 0,27$ * & (-) 0,28 ** & (-) 0,00 & $(-) 0,35^{* *}$ & $(+) 0,05$ \\
\hline & $\mathrm{K} /(\mathrm{Ca}+\mathrm{Mg})$ & $(+) 0,12$ & $(-) 0,25$ * & $(-) 0,31^{* *}$ & (-) 0,00 & $(-) 0,37^{* *}$ & (+) 0,07 \\
\hline
\end{tabular}
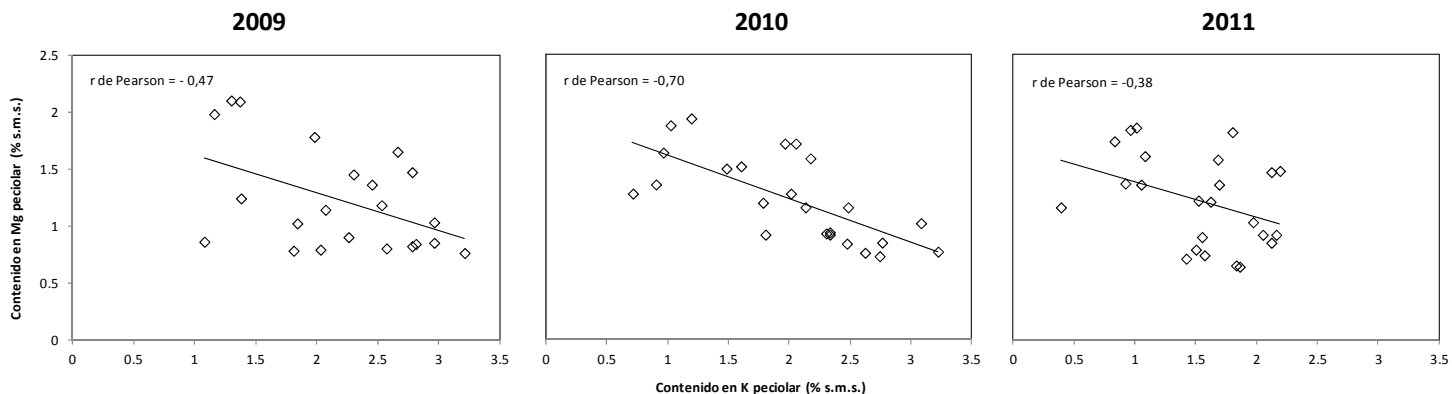

Figura 4.11. Gráfico de dispersión del contenido de $\mathrm{K}$ y el contenido de $\mathrm{Mg}$ en los peciolos recogidos en el envero. 
Se ha encontrado una correlación significativamente positiva entre el contenido en $\mathrm{Mg}$ y $\mathrm{Mn}$ de los peciolos (figura 4.12). La concentración de $\mathrm{Mg}$ en el suelo se ha relacionado significativamente de forma positiva con el nivel de Mn peciolar en los años 2010 y 2011, y la relación entre carbonatos totales (CT) y $\mathrm{Mg}$ se ha relacionado significativamente con el Mn peciolar en 2009 (tabla 4.9). Existe una regresión lineal significativamente positiva del ratio CT/Mg sobre el contenido en $\mathrm{Mg}$ en los peciolos en los tres años de estudio, siendo el coeficiente de determinación de ésta sensiblemente mayor que el de la relación del contenido en $\mathrm{Mg}$ del suelo sobre el de los peciolos. También se ha observado una regresión significativamente negativa del contenido de $\mathrm{Mn}$ en el suelo sobre la concentración de $\mathrm{Mg}$ en los peciolos en los tres años de estudio. El ratio $\mathrm{CT} / \mathrm{Mn}$ también se ha relacionado significativamente de forma positiva con el nivel de $\mathrm{Mn}$ en los peciolos, no habiéndose relacionado significativamente estos con la concentración de $\mathrm{Mn}$ en el suelo. Por último, la ratio $\mathrm{Mg} / \mathrm{Mn}$ en el suelo se ha relacionado significativamente de forma positiva tanto con el contenido de $\mathrm{Mg}$, como de $\mathrm{Mn}$ en los peciolos. Heenan y Campbell (1981) demostraron que el aumento de la reserva de $\mathrm{Mn}$ en el suelo podía reducir la concentración de $\mathrm{Mg}$ foliar en la soja mediante la reducción de la tasa de absorción de este último nutriente. Safford (1975) sugirió que el Mn también inhibe el movimiento de Mg desde las raíces al tejido foliar.
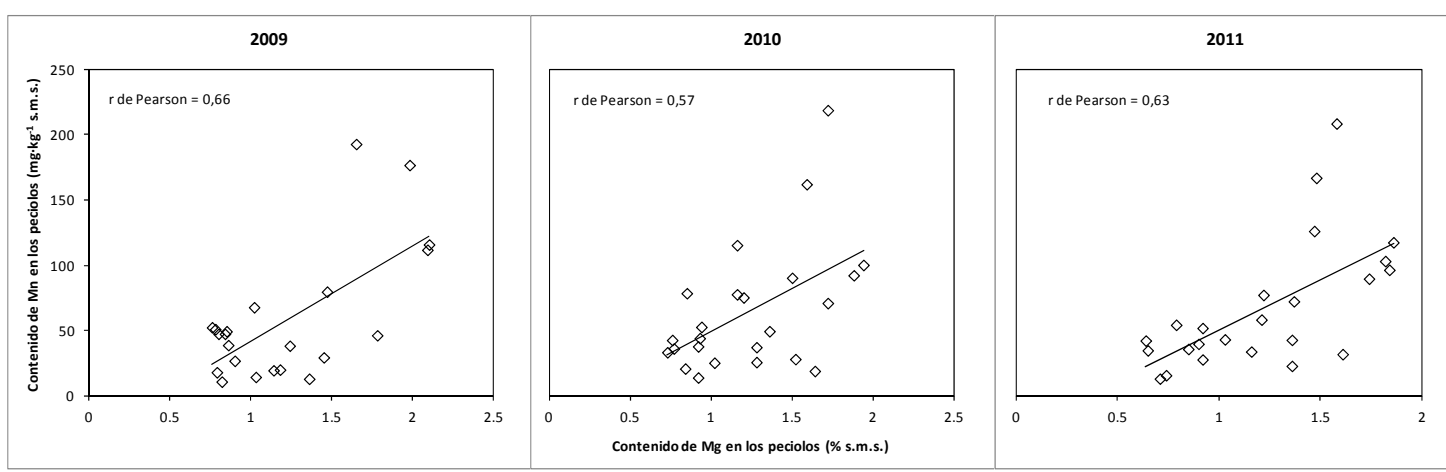

Figura 4.12. Gráfico de dispersión del contenido de Mg y el contenido de Mn en los peciolos recogidos en el envero.

Tabla 4.9. Coeficiente de determinación $\left(R^{2}\right)$, nivel de significación y pendiente de la regresión del contenido de $\mathrm{Mg}$ y $\mathrm{Mn}$ en los peciolos en el envero sobre el nivel de $\mathrm{Mg}$, $\mathrm{Mn}$ y los ratios CT/Mg, CT/Mn y Mg/Mn del suelo.

\begin{tabular}{|c|c|c|c|c|c|c|}
\hline \multirow{2}{*}{$\begin{array}{l}\text { Nutrientes en } \\
\text { en suelo }\end{array}$} & \multicolumn{3}{|c|}{ Mg peciolar (\% s.m.s.) } & \multicolumn{3}{|c|}{ Mn peciolar (mg/kg s.m.s.) } \\
\hline & 2009 & 2010 & 2011 & 2009 & 2010 & 2011 \\
\hline$M g\left(m e q \cdot 100 g^{-1}\right)$ & (+) 0,13 & $(+) 0,26$ * & $(+) 0,23$ * & (+) 0,17 & $(+) 0,38$ ** & (+) 0,46 ** \\
\hline $\mathrm{CT} / \mathrm{Mg}$ & (+) $0,37^{* *}$ & (+) 0,33 ** & (+) 0,41 ** & (+) 0,30 * & (+) 0,08 & (+) 0,14 \\
\hline$M n\left(\mathbf{m g} \cdot \mathbf{k g}{ }^{-1}\right)$ & $(-) 0,43^{* *}$ & $(-) 0,36 * *$ & $(-) 0,38$ ** & $(-) 0,17$ & (-) 0,09 & (-) 0,15 \\
\hline CT/Mn & (+) $0,67 * *$ & (+) $0,63 * * *$ & (+) $0,67^{* * *}$ & (+) $0,58 * *$ & (+) 0,24 * & (+) 0,36 ** \\
\hline $\mathrm{Mg} / \mathrm{Mn}$ & (+) $0,57^{* * *}$ & (+) $0,39 * *$ & (+) $0,39 * *$ & (+) 0,50 ** & (+) 0,25 * & (+) 0,36 ** \\
\hline
\end{tabular}


La concentración de $\mathrm{Mg}$ asimilable en el suelo se ha relacionado significativamente de forma negativa con el nivel peciolar de $P$ en los años 2009 y 2010 , con una $R^{2}$ de 0,23 y 0,20 respectivamente $(p<0,05)$. Por otra parte, solo en el año 2010 la concentración de $\mathrm{Mg}$ en el suelo se relacionó negativamente de forma significativa con el contenido peciolar de Fe.

Se ha encontrado para los años 2009 y 2010 una relación significativamente negativa del contenido de Cu extraíble en el suelo con la concentración de $\mathrm{Mg}$ y $\mathrm{Mn}$ en los peciolos. Elevados contenidos de $\mathrm{Cu}$ en el medio disminuirían la acumulación de Mg y Mn en los peciolos. Fargašová y Beinrohr (1998) observaron que la acumulación de $\mathrm{Mn}$ en los tejidos de la raíz puede ser inhibida por el $\mathrm{Cu}$. Zhao et al. (2012) indicaron que la absorción de $\mathrm{Cu}$ compite con la de $\mathrm{Fe}, \mathrm{Mn}$ y $\mathrm{Zn}$. 


\section{2.-NIVELES FOLIARES DE CLOROFILAS, CAROTENOIDES Y ANTOCIANINAS.}

\subsection{1.- Evolución estacional de los contenidos foliares de clorofila.}

Se ha realizado un seguimiento del contenido clorofílico foliar de las subparcelas a lo largo del ciclo vegetativo en los tres años de investigación. Como se puede apreciar en la figura 4.13 , los contenidos de clorofila foliar $\left(\mu \mathrm{g} \cdot \mathrm{cm}^{-2}\right)$ son más elevados en 2011 que en 2010 y 2009 durante todo el ciclo vegetativo, siguiendo una progresión ascendente hasta alcanzar un máximo a principios de septiembre, donde inicia un descenso constante hasta la vendimia. En el caso de los años 2009 y 2010 , durante el inicio del ciclo vegetativo el nivel de clorofila es similar, evolucionando en una progresión ascendente. Sin embargo, aunque esta progresión es continua en el año 2009 hasta la época de vendimia, en el año 2010 se produce una disminución drástica del contenido de clorofila foliar durante el mes de agosto, volviendo a incrementarse en el mes de septiembre. Esta singularidad pudo ser la consecuencia de una situación de estrés hídrico y térmico en el verano de 2010 que no existió en los otros dos años, con ausencia de precipitaciones y temperaturas máximas absolutas anormalmente altas en el mes de julio y principios de agosto (apartado 3.2.3). En relación a esto hay que tener en cuenta que, en el envero del año 2010 el porcentaje de parcelas con plantas con contenidos bajos, medios o altos de $\mathrm{P}, \mathrm{Ca}, \mathrm{Cu}$ y $\mathrm{Zn}$ en los peciolos variaron sustancialmente con respecto a 2009 y 2011 (apartado 4.1.1).

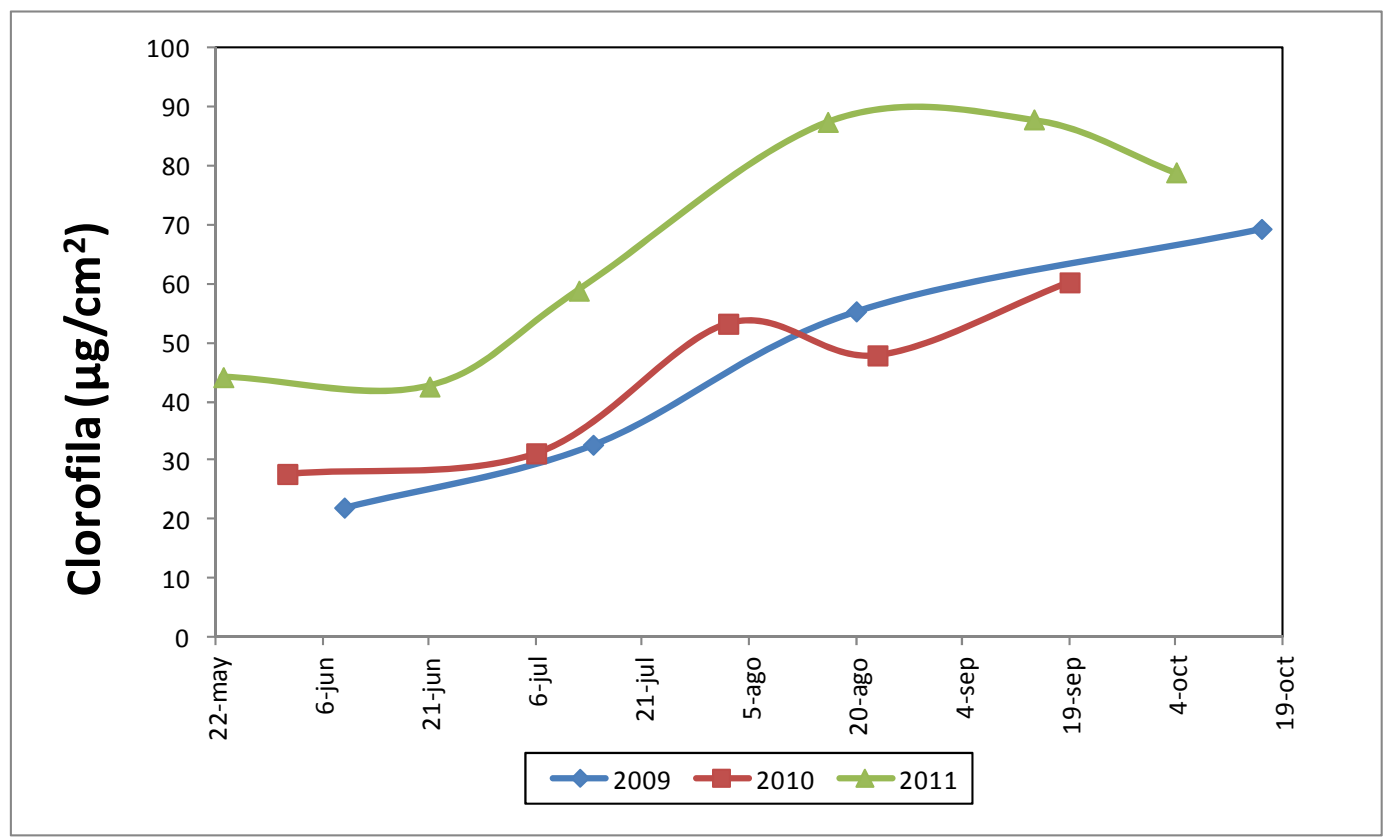

Figura 4.13. Seguimiento del nivel foliar de clorofila $\left(\mu \mathrm{g} \cdot \mathrm{cm}^{-2}\right)$ a lo largo del ciclo vegetativo. 


\subsection{2.- Relaciones entre el estado nutricional y los contenidos foliares de pigmentos.}

El efecto más obvio de la deficiencia de Fe es la gran disminución de las concentraciones de pigmentos fotosintéticos en las hojas de las plantas afectadas (Val et al., 1987; Morales et al., 1990, 1994). Por esta razón es especialmente interesante investigar el posible efecto del estado nutricional sobre la formación de clorofilas y carotenoides.

Además del seguimiento del contenido clorofílico foliar de las subparcelas a lo largo del ciclo, se ha medido el contenido de antocianinas, clorofila a, clorofila b y carotenoides en las hojas en el estado fenológico de cuajado en 2010 y 2011, en el envero en los tres años de investigación, y en la vendimia en el año 2011. A continuación se muestran los resultados del estudio de las relaciones de las concentraciones de estos pigmentos con los contenidos minerales del suelo y los peciolos recogidos en envero.

Los análisis de la varianza de las concentraciones de los diferentes pigmentos foliares, medidos en el cuajado y el envero, en función de los años de seguimiento, fueron estadísticamente significativos (tabla 4.10). Por ello los datos se analizarán a continuación año por año.

Tabla 4.10. Valores de la $F$ de Fisher y el nivel de significación del análisis de la varianza (ANOVA) de los contenidos foliares de clorofila, antocianinas y carotenoides en cuajado y envero en función de los años de estudio.

\begin{tabular}{|c|c|c|c|c|}
\hline \multirow{2}{*}{$\begin{array}{l}\text { Pigmento } \\
\left(\mu \mathrm{g} \cdot \mathrm{cm}^{2}\right)\end{array}$} & \multicolumn{2}{|l|}{ Cuajado } & \multicolumn{2}{|l|}{ Envero } \\
\hline & $\mathbf{F}$ & & $\mathbf{F}$ & \\
\hline Antocianinas & 69,69 & $* * *$ & 27,66 & $* * *$ \\
\hline Clorofila a & 11,87 & $* *$ & 15,91 & $* * *$ \\
\hline Clorofila b & 6,86 & * & 23,08 & $* * *$ \\
\hline Clorofila $a+b$ & 27,44 & $* * *$ & 19,60 & $* * *$ \\
\hline Carotenoides & 380,04 & $* * *$ & 32,97 & $* * *$ \\
\hline
\end{tabular}

Como se ve en la tabla 4.11, el porcentaje de arcilla del suelo se ha relacionado negativamente con el contenido de algunos de los pigmentos foliares, concretamente en el cuajado en 2011 y en el envero en 2009 y 2010 . En los suelos más arcillosos, al coincidir con los que contienen mayores niveles de carbonatos en el 
área de estudio, se produce una menor síntesis de pigmentos por las plantas (suelos clorosantes). Por otra parte, los contenidos de arcilla influyen por sí mismos en la disponibilidad de Fe para las plantas. Según Lindsay (1979), los suelos arcillosos tienden a retener el Fe. No obstante, diversos estudios han mostrado correlaciones positivas entre el contenido de arcilla y la concentración de clorofila en hojas de sorgo y soja (Loeppert y Hallmark, 1985), garbanzo y girasol (del Campillo y Torrent, 1992) y olivos 'Hojiblanca', 'Manzanilla' y 'Picual' (Benitez et al., 2002).

Tabla 4.11. Coeficiente de determinación $\left(R^{2}\right)$, nivel de significación y pendiente de la regresión de la concentración de los diferentes pigmentos foliares $\left(\mu \mathrm{g} \cdot \mathrm{cm}^{-2}\right), y$ relaciones entre ellos, sobre el contenido en arcilla en el suelo.

\begin{tabular}{|c|c|c|c|c|c|c|c|}
\hline \multirow{2}{*}{$\begin{array}{l}\text { Pigmentos } \\
\text { foliares }\end{array}$} & \multicolumn{4}{|c|}{ Cuajado } & \multicolumn{3}{|c|}{ Envero } \\
\hline & 2009 & 2010 & 2011 & & 2009 & 2010 & 2011 \\
\hline Antocininas & $(-) \quad 0,01$ & (-) 0,05 & $(-) \quad 0,16$ & & (-) 0,06 & $(-) 0,15$ & $(-) 0,18$ \\
\hline Clorofila a & - & $(-) \quad 0,11$ & (-) 0,30 & $* *$ & (-) 0,28 * & (-) 0,18 * & * $(-) \quad 0,18$ \\
\hline Clorofila b & - & (-) 0,02 & $(-) \quad 0,17$ & & (-) 0,30 ** & $(-) 0,13$ & (-) 0,04 \\
\hline Clarofila $a+b$ & $(-) \quad 0,06$ & (-) 0,08 & (-) 0,26 & * & (-) 0,30 * & (-) 0,22 * & * $\quad(-) \quad 0,07$ \\
\hline Carotenoides & - & (-) 0,09 & $(-) \quad 0,44$ & $* *$ & (-) 0,36 ** & (-) 0,07 & (-) 0,04 \\
\hline Clo a+b/Car & - & (-) 0,05 & (-) 0,02 & & $(-) 0,19$ * & (-) 0,20 * & * $\quad(-) \quad 0,09$ \\
\hline Clo a/Clo b & - & (-) 0,01 & $(-) \quad 0,29$ & ** & (-) 0,14 & (-) 0,00 & (-) 0,00 \\
\hline
\end{tabular}

En el presente trabajo todas las relaciones significativas encontradas entre los carbonatos totales del suelo y los contenidos en pigmentos foliares han sido negativas (tabla 4.12). No se ha encontrado relación significativa alguna entre niveles de pigmentos y contenido de hierro asimilable en el suelo (datos no mostrados). En consecuencia se puede afirmar que la carencia de hierro en la zona de estudio está claramente inducida por el carácter calcáreo de los suelos. Además, como se puede ver en la figura 4.14, el análisis de la varianza de la concentración de clorofila foliar tomada a lo largo del ciclo vegetativo ha resultado significativa en función del contenido alto, medio o bajo de carbonatos totales en el suelo (apartado 4.1)en muchas de las medidas realizadas. Como era de esperar, la concentración de clorofila foliar fue significativamente mayor en las parcelas con un contenido bajo de carbonatos totales que en las parcelas con un contenido alto, salvo para las medidas realizadas a comienzos de Junio y a finales de agosto (envero) en los años 2009 y 2010. 
Tabla 4.12. Coeficiente de determinación $\left(R^{2}\right)$, nivel de significación y pendiente de la regresión de los carbonatos totales (\%) sobre el contenido de pigmentos foliares y sus ratios $\left(\mathrm{mg} \cdot \mathrm{cm}^{-2}\right)$.

\begin{tabular}{|c|c|c|c|c|c|c|c|}
\hline \multirow{3}{*}{$\begin{array}{l}\text { Pigmentos } \\
\text { Foliares }\end{array}$} & \multicolumn{7}{|c|}{ Carbonatos Totales (\%) } \\
\hline & \multicolumn{2}{|c|}{2009} & \multicolumn{2}{|c|}{2010} & \multicolumn{3}{|c|}{2011} \\
\hline & Cuajado & Envero & Cuajado & Envero & Cuajado & Envero & Vendimia \\
\hline Antocianinas & $(-) 0,29$ * & $(-) 0,24$ * & $(-) 0,00$ & $(-) 0,21^{*}$ & $(-) 0,40$ ** & $(-) 0,38$ ** & $(-) 0,39$ ** \\
\hline Clorofila a & - & $(-) 0,20$ & $(-) 0,44$ ** & $(-) 0,21 *$ & $(-) 0,34$ ** & $(-) 0,28$ ** & $(-) 0,31$ ** \\
\hline Clorofila b & - & $(-) 0,31$ * & $(-) 0,28$ ** & $(-) 0,29 * *$ & $(-) 0,10$ & $(-) 0,17^{*}$ & $(-) 0,30$ ** \\
\hline Clarofila $a+b$ & $(-) 0,36$ * & $(-) 0,23$ * & (-) $0,42 * *$ & $(-) 0,31$ ** & (-) 0,29 ** & $(-) 0,25 *$ & $(-) 0,31 * *$ \\
\hline Carotenoides & - & $(-) 0,27$ * & $(-) 0,44$ ** & $(-) 0,06$ & $(-) 0,30$ ** & $(-) 0,19 *$ & $(-) 0,30$ ** \\
\hline Clo a+b/Car & - & $(-) 0,17$ & (-) 0,29 ** & $(-) 0,40$ ** & $(-) 0,10$ & $(-) 0,22 *$ & $(-) 0,28$ ** \\
\hline Clo a/Clo b & - & $(-) 0,03$ & $(-) 0,02$ & $(-) 0,02$ & $(-) 0,34^{* *}$ & $(-) 0,00$ & $(-) 0,12$ \\
\hline
\end{tabular}

Se ha relacionado negativamente el contenido en carbonatos del suelo con la

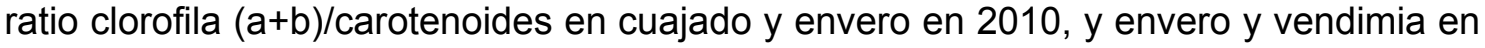
2011 (tabla 4.12). Esto indica que las elevadas concentraciones de carbonatos en el suelo afectan de manera más acusada a la síntesis de clorofila que de carotenoides o, dicho de otro modo, las concentraciones foliares de carotenoides disminuyen con la deficiencia de $\mathrm{Fe}$ en menor grado que las de clorofilas, en concordancia con resultados de otros autores (Terry, 1980; Morales et al., 1990, 1994, 2000). Estas relaciones no se han observado para el contenido en caliza activa del suelo, medido en subparcelas con más del $10 \%$ de carbonatos totales. Además, cuando se han analizado en estas subparcelas las relaciones entre el índice de poder clorosante IPC (Juste y Pouget, 1972) y los contenidos de pigmentos foliares no han sido significativas, o bien han sido menos intensas que para los contenidos en carbonatos totales (datos no mostrados). Díez et al. (2009b) y Cambrollé et al. (2014) también correlacionaron negativamente los carbonatos totales del suelo con los niveles foliares de clorofila.

La relación detectada entre la concentración de pigmentos foliares y el nivel de carbonatos totales es notablemente mayor que la observada con los contenidos en arcilla del suelo. En cualquier caso, existe una correlación significativamente positiva entre los contenidos de arcilla y carbonatos totales en los suelos de la zona (figura 4.10). 

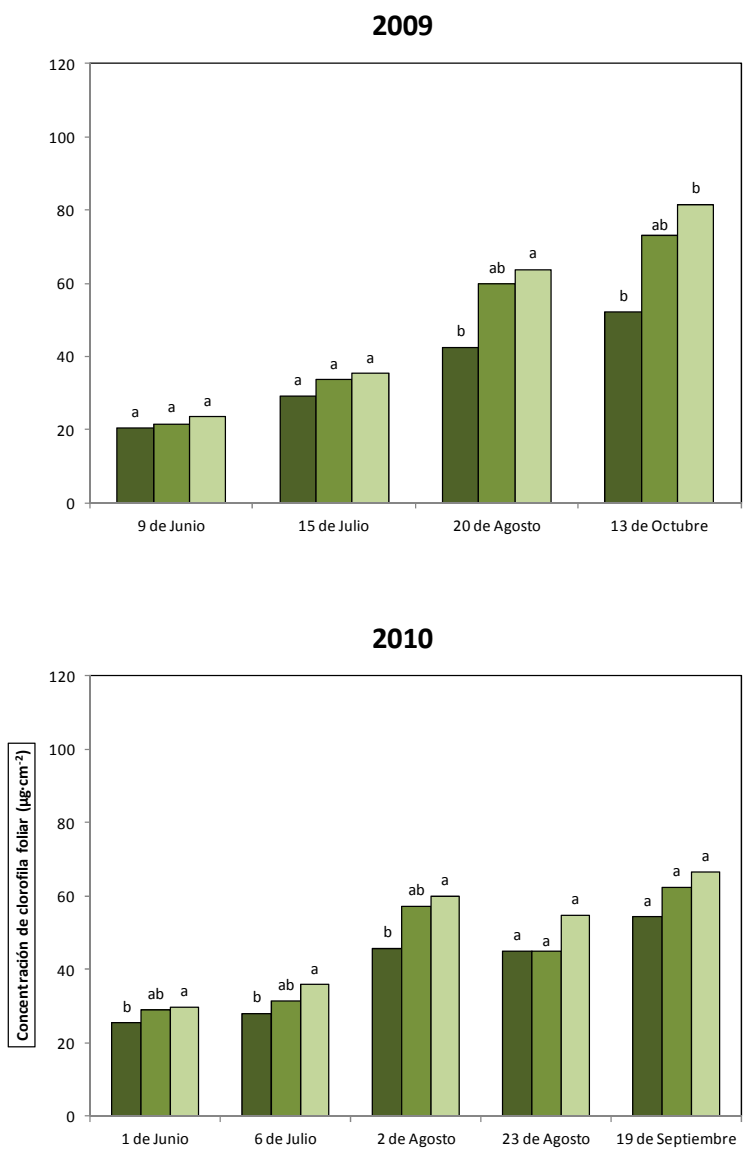

2011

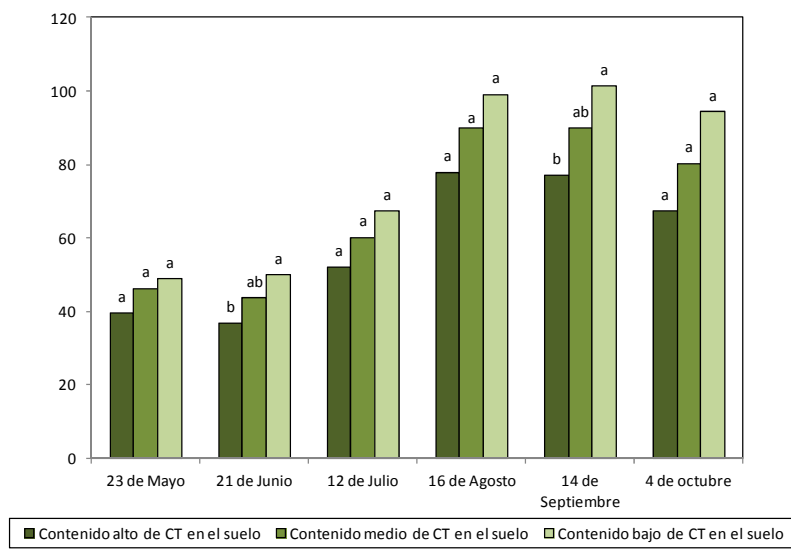

Figura 4.14. Evolución de la concentración de clorofila foliar a lo largo del ciclo vegetativo en función del contenido de carbonatos totales en el suelo (Yañez, 1989) en los tres años del estudio. 
A continuación se muestran los resultados más significativos obtenidos para las relaciones entre los contenidos minerales y sus ratios, tanto en el suelo como en los peciolos recogidos en el envero, con la concentración de los diferentes pigmentos foliares en los tres años de estudio. No se ha encontrado una relación significativa entre los contenidos de $\mathrm{P}, \mathrm{Fe}, \mathrm{Zn}$ y $\mathrm{Cu}$ en el suelo y los peciolos con la concentración de pigmentos foliares (datos no mostrados).

El estudio del contenido de potasio disponible en el suelo es muy interesante ya que es uno de los factores que modulan la solubilidad del Fe y su absorción por la planta en suelos calcáreos (Chen y Barak, 1982). El potasio podría afectar potencialmente a la absorción de Fe en las raíces a través de su papel general en el equilibrio iónico, facilitando la circulación de ácidos orgánicos como el citrato (Marschner, 1995).En el presente estudio, se ha relacionado significativamente el contenido de potasio en el suelo con la concentración de todos los pigmentos foliares en el cuajado, con los de clorofila en el envero en 2010, y con todos los pigmentos en el envero en 2011 (tabla 4.13). Por otra parte, teniendo en cuenta la concentración de clorofila foliar monitorizada a lo largo del ciclo vegetativo en los años del estudio (figura 4.15), se observan diferencias significativas entre los valores de los puntos de muestreo con contenido alto, medio y bajo de $\mathrm{K}$ en el suelo (apartado 4.1) en casi la totalidad de las fechas. La concentración de clorofila foliar fue significativamente mayor en las parcelas con un contenido alto de $\mathrm{K}$ que en las parcelas con un contenido bajo de dicho mineral en el suelo, salvo para las medidas realizas a comienzos de Junio y a finales de Agosto (envero), en los años 2009 y 2010. Excepto para el año 2009, se han observado relaciones significativas de la concentración de algunos de estos pigmentos foliares con los ratios $\mathrm{K} / \mathrm{Mg}, \mathrm{K} / \mathrm{Ca}, \mathrm{K} /(\mathrm{Ca}+\mathrm{Mg})$ y $\mathrm{Ca} / \mathrm{Mg}$, especialmente en el cuajado en 2010 y en el envero de 2011.Los contenidos de pigmentos foliares después de la vendimia (medidos exclusivamente en 2011) se han relacionado significativamente de forma positiva con el contenido de potasio y los ratios $\mathrm{K} / \mathrm{Mg}, \mathrm{K} / \mathrm{Ca}$ y $\mathrm{K} /(\mathrm{Ca}+\mathrm{Mg})$ presentes en el suelo (tabla 4.13).

A diferencia de lo ocurrido con el contenido en $\mathrm{K}$ del suelo, el contenido de $\mathrm{K}$ peciolar apenas se ha relacionado significativamente con la concentración de pigmentos foliares. Sin embargo, los ratios $\mathrm{K} / \mathrm{Mg}, \mathrm{K} / \mathrm{Ca}, \mathrm{K} /(\mathrm{Ca}+\mathrm{Mg})$ y $\mathrm{Ca} / \mathrm{Mg}$ presentes han estado relacionados positivamente con el contenido de algunos de estos pigmentos, especialmente en 2010 (tabla 4.14), de acuerdo con lo observado en estudios previos en la misma región (González et al, 2005b; Catalina et al., 2011b). El aumento del nivel de $\mathrm{K}$ en los peciolos con respecto al $\mathrm{Mg}$ y el Ca mejora el contenido de clorofila en las hojas. 
Tabla 4.13. Coeficiente de determinación $\left(R^{2}\right)$, nivel de significación y pendiente de la regresión del contenido en $\mathrm{K}$ y los ratios $\mathrm{K} / \mathrm{Mg}, \mathrm{K} / \mathrm{Ca}$ y $\mathrm{K} /(\mathrm{Ca}+\mathrm{Mg})$ en el suelo sobre la concentración de pigmentos foliares $\left(\mu \mathrm{g} \cdot \mathrm{cm}^{-2}\right)$ y los ratios clorofila $(\mathrm{a}+\mathrm{b}) /$ carotenoides y clorofila a/clorofila b en el cuajado, el envero y en postvendimia en los tres años de estudio.

\begin{tabular}{|c|c|c|c|c|c|c|c|}
\hline \multirow{3}{*}{\begin{tabular}{|l}
$\begin{array}{l}\text { Nutrientes } \\
\text { minerales }\end{array}$ \\
2009
\end{tabular}} & \multicolumn{7}{|c|}{ Pigmentos foliares } \\
\hline & \multirow[t]{2}{*}{ Antocininas } & \multirow[t]{2}{*}{ Clorofila a } & \multirow[t]{2}{*}{ Clorofila b } & \multirow{2}{*}{$\begin{array}{l}\text { Clarofila a+b } \\
\text { Cuajado }\end{array}$} & \multirow[t]{2}{*}{ Carotenoides } & \multirow[t]{2}{*}{ Clo $a+b / C a r$} & \multirow{2}{*}{ Clo a/Clo b } \\
\hline & & & & & & & \\
\hline $\mathrm{K}\left(\mathrm{meq} \cdot 100 \mathrm{~g}^{-1}\right)$ & $(+) 0,02$ & - & - & $(+) 0,03$ & - & - & - \\
\hline K/Mg & $(+) 0,00$ & - & - & (+) 0,02 & - & - & - \\
\hline $\mathrm{K} / \mathrm{Ca}$ & $(+) 0,01$ & - & - & (+) 0,02 & - & - & - \\
\hline $\mathrm{K} /(\mathrm{Ca}+\mathrm{Mg})$ & $(+) 0,01$ & - & - & (+) 0,04 & - & - & - \\
\hline $\mathrm{Ca} / \mathrm{Mg}$ & $(-) 0$ & - & - & $(-) 0,02$ & - & - & - \\
\hline \multicolumn{8}{|l|}{2010} \\
\hline$K\left(\right.$ meq $\left.\cdot 100 g^{-1}\right)$ & & $(+) 0,31^{* *}$ & (+) 0,23 * & $(+) 0,32$ ** & $(+) 0,50$ *** & (+) 0,10 & (-) 0,02 \\
\hline $\mathrm{K} / \mathrm{Mg}$ & & (+) 0,24 * & (+) 0,24 * & (+) 0,27 ** & (+) 0,27 ** & (+) 0,16 * & (-) 0,06 \\
\hline $\mathrm{K} / \mathrm{Ca}$ & & (+) 0,31 ** & (+) 0,18 * & (+) $0,29 * *$ & $(+) 0,41$ ** & $(+) 0,12$ & (-) 0,00 \\
\hline$a+M g)$ & & $(+) 0,33$ ** & (+) 0,19 * & & $(+) 0,43$ ** & (+) 0,12 & (-) 0,00 \\
\hline & & $(+) 0,04$ & (+) 0,08 & & (+) 0,03 & (+) 0,07 & (-) 0,06 \\
\hline \multicolumn{8}{|l|}{2011} \\
\hline$K$ (meq 1 & & $(+) 0,12$ & (+) 0,09 & & $(+) 0,06$ & $(+) 0,06$ & $(+) 0,23$ * \\
\hline & & $(+)$ & ,03 & & o* & $(+) 0,01$ & (+) $0,31^{* *}$ \\
\hline $\mathrm{K} / \mathrm{C}$ & & $(+)$ &, 07 & & $(+)$ & $(+) 0,07$ & (+) 0,22 * \\
\hline$a+M g)$ & &, 23 * &, 07 & $(+)$ & 19 * & (+) 0,07 & (+) 0,25 * \\
\hline $\mathrm{Ca} / \mathrm{Mg}$ & & $(+)$ &, 00 & $(+) 0,06$ & & (+) 0,00 & $(+) 0,13$ \\
\hline 2009 & \multicolumn{7}{|c|}{ Envero } \\
\hline$K\left(\right.$ meq $\left.\cdot 100 g^{-1}\right)$ & & $(+) 0,09$ & (+) 0,14 & $(+) 0,10$ & (+) 0,09 & $(+) 0,09$ & $(+) 0,02$ \\
\hline $\mathrm{K} / \mathrm{Mg}$ & $(+)$ & (+) 0,05 & (+) 0,15 & & (+) 0,09 & (+) 0,06 & (+) 0,00 \\
\hline $\mathrm{K} / \mathrm{Ca}$ & (+) 0,04 & (+) 0,03 & (+) 0,06 & $(+)$ & (+) 0,02 & (+) 0,05 & (+) 0,00 \\
\hline $\mathrm{K} /(\mathrm{Ca}+\mathrm{Mg})$ & (+) 0,02 & (+) 0,03 & (+) 0,06 & & (+) 0,05 & (+) 0,02 & (+) 0,00 \\
\hline $\mathrm{Ca} / \mathrm{Mg}$ & & (+) 0,02 & (+) 0,06 & & (+) 0,0 & (+) 0,04 & (+) 0,00 \\
\hline \multicolumn{8}{|l|}{2010} \\
\hline $\mathrm{K}$ (meq-1 & & $(+) 0,1$ & $(+) 0,20$ * & & & $(+) 0,15$ & $(-) 0,01$ \\
\hline $\mathrm{K} / \mathrm{N}$ & 0,28 ** & (+) 0,31 ** & (+) 0,26 * & $(+) 0,3$ & (+) 0,22 * & (+) 0,18 * & (-) 0,00 \\
\hline $\mathrm{K} / \mathrm{Ca}$ & & (+) 0,07 & (+) 0,04 & $(+) 0,0$ & (+) 0,01 & (+) 0,12 & (+) 0,00 \\
\hline $\mathrm{K} /(\mathrm{Ca}+\mathrm{Mg})$ & (+) 0,02 & (+) 0,08 & (+) 0,05 & (+) 0,1 & (+) 0,02 & (+) 0,14 & $(-) 0,00$ \\
\hline $\mathrm{Ca} / \mathrm{Mg}$ & $(+)$ & (+) 0,18 * & (+) 0,28 ** & $(+) 0,27^{* *}$ & (+) 0,18 * & (+) 0,10 & (-) 0,01 \\
\hline \multicolumn{8}{|l|}{2011} \\
\hline K (meq. & & & $0,21^{*}$ & & $(+) 0,23$ * & $0,29^{* *}$ & $(+) 0,00$ \\
\hline $\mathrm{K} / \mathrm{Mg}$ & $7^{* *}$ & (+) 0,25 * & (+) 0,18 * & $(+)$ & (+) 0,18 * & (+) 0,20 * & $(+) 0,00$ \\
\hline $\mathrm{K} / \mathrm{Ca}$ & $18^{*}$ & (+) 0,18 * & (+) 0,08 & $(+)$ & $(+) 0,11$ & $(+) 0,13$ & (+) 0,01 \\
\hline $\mathrm{K} /(\mathrm{Ca}+\mathrm{Mg})$ & (+) 0,20 * & (+) 0,19 * & (+) 0,09 & (+) 0,16 & (+) 0,12 & (+) 0,14 & (+) 0,01 \\
\hline $\mathrm{Ca} / \mathrm{Mg}$ & & $(+) 0,09$ & (+) 0,09 & $(+) 0,10$ & (+) 0,07 & (+) 0,09 & (+) 0,02 \\
\hline 2011 & \multicolumn{7}{|c|}{ Postvendimia } \\
\hline$K\left(\right.$ meq $\left.100 g^{-1}\right)$ & $(+) 0,27^{* *}$ & $(+) 0,37^{* *}$ & $(+) 0,36$ ** & $(+) 0,37^{* *}$ & $(+) 0,34$ ** & $(+) 0,30$ ** & (-) 0,09 \\
\hline $\mathrm{K} / \mathrm{Mg}$ & $(+) 0,28$ ** & $(+) 0,22$ * & (+) 0,27 ** & $(+) 0,24$ * & $(+) 0,19$ * & $(+) 0,30$ ** & $(-) 0,16$ \\
\hline $\mathrm{K} / \mathrm{Ca}$ & $(+) 0,20$ * & $(+) 0,25$ * & (+) 0,27 ** & (+) 0,26 * & (+) 0,24 * & $(+) 0,22$ * & (-) 0,16 \\
\hline $\mathrm{K} /(\mathrm{Ca}+\mathrm{Mg})$ & $(+) 0,22$ * & $(+) 0,26$ * & $(+) 0,28$ ** & $(+) 0,27$ * & $(+) 0,25$ * & $(+) 0,23$ * & $(-) 0,17$ * \\
\hline $\mathrm{Ca} / \mathrm{Mg}$ & $(+) 0,09$ & $(+) 0,04$ & $(+) 0,04$ & $(+) 0,04$ & $(+) 0,03$ & $(+) 0,07$ & (-) 0,01 \\
\hline
\end{tabular}




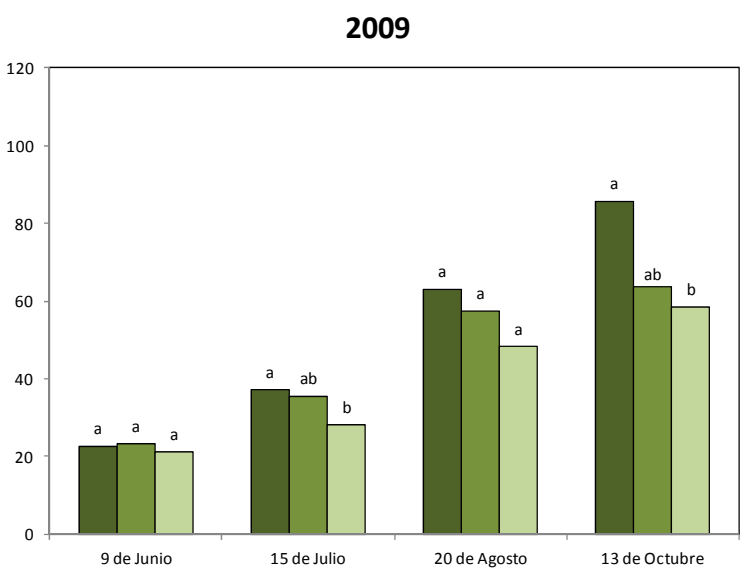

2010

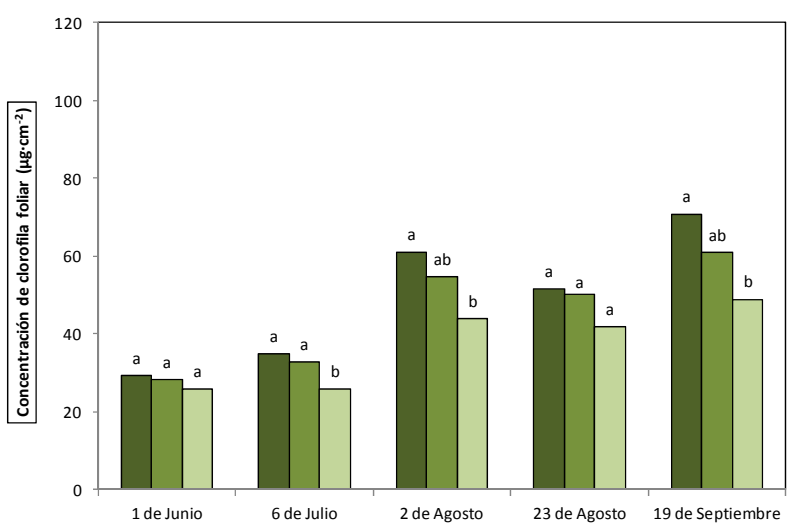

2011

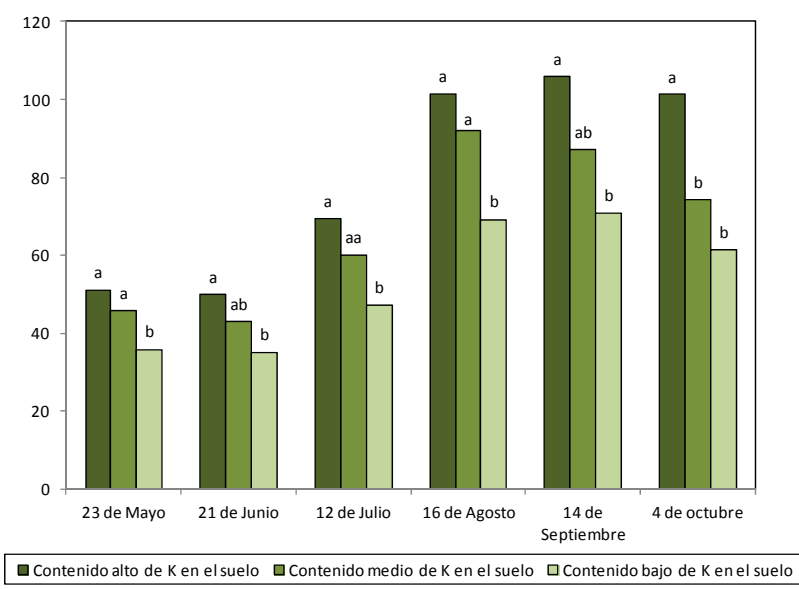

Figura 4.15.Evolución de la concentración de clorofila foliar a lo largo del ciclo vegetativo en función del contenido de $\mathrm{K}$ en el suelo (Horneck et al., 2011) en los tres años del estudio. 
Tabla 4.14. Coeficiente de determinación $\left(R^{2}\right)$, nivel de significación y pendiente de la regresión del contenido en $\mathrm{K}$ y los ratios $\mathrm{K} / \mathrm{Mg}, \mathrm{K} / \mathrm{Ca}$ y $\mathrm{K} /(\mathrm{Ca}+\mathrm{Mg})$ en el los peciolos sobre la concentración de pigmentos foliares $\left(\mu \mathrm{g} \cdot \mathrm{cm}^{-2}\right)$ y los ratios clorofila $(a+b) / c a r o t e n o i d e s$ y clorofila $a / c l o r o f i l a ~ b$ en el cuajado, envero y postvendimia en los tres años de estudio.

\begin{tabular}{|c|c|c|c|c|c|c|c|}
\hline \multirow{3}{*}{$\begin{array}{l}\text { Nutrientes } \\
\text { minerales } \\
2009 \\
\end{array}$} & \multicolumn{7}{|c|}{ Pigmento foliares } \\
\hline & Antocininas & Clorofila a & Clorofila b & Clarofila $a+b$ & Carotenoides & Clo $a+b / C a r$ & Clo a/Clo b \\
\hline & & & & Cuajado & & & \\
\hline K (\% s.m.s.) & $(+) 0,15$ & - & - & (+) 0,21 * & - & - & - \\
\hline $\mathrm{K} / \mathrm{Mg}$ & (+) 0,25 * & - & - & (+) 0,24 * & - & - & - \\
\hline $\mathrm{K} / \mathrm{Ca}$ & (+) 0,18 & - & - & (+) 0,33 ** & - & - & - \\
\hline $\mathrm{K} /(\mathrm{Ca}+\mathrm{Mg})$ & (+) 0,25 * & - & - & (+) 0,36 ** & - & - & - \\
\hline $\mathrm{Ca} / \mathrm{Mg}$ & (+) 0,04 & - & - & (+) 0,00 & - & - & - \\
\hline \multicolumn{8}{|l|}{2010} \\
\hline K (\% s.m.s.) & (+) 0,00 & (+) 0,13 & (+) 0,34 ** & (+) 0,22 * & $(+) 0,18$ * & (+) 0,19 * & $(-) 0,28$ ** \\
\hline $\mathrm{K} / \mathrm{Mg}$ & (+) 0,00 & (+) 0,32 ** & (+) $0,49 * * *$ & (+) 0,42 ** & $(+) 0,37^{* *}$ & (+) $0,31 * *$ & $(-) 0,21$ * \\
\hline $\mathrm{K} / \mathrm{Ca}$ & (+) 0,02 & (+) 0,18 * & (+) 0,36 ** & (+) 0,27 ** & $(+) 0,20$ * & (+) 0,24 * & $(-) 0,24$ * \\
\hline $\mathrm{K} /(\mathrm{Ca}+\mathrm{Mg})$ & (+) 0,00 & (+) 0,23 * & (+) 0,43 ** & (+) 0,34 ** & $(+) 0,27$ ** & (+) 0,28 ** & $(-) 0,25$ * \\
\hline $\mathrm{Ca} / \mathrm{Mg}$ & (-) 0,05 & (+) 0,26 * & (+) 0,36 ** & (+) $0,33^{* *}$ & $(+) 0,34^{* *}$ & (+) 0,20 * & $(-) 0,13$ \\
\hline \multicolumn{8}{|c|}{, } \\
\hline K (\% s.m.s.) & (-) 0,00 & $(-) 0,03$ & (-) 0,02 & (-) 0,03 & (-) 0,00 & (-) 0,04 & $(-) 0,00$ \\
\hline $\mathrm{K} / \mathrm{Mg}$ & (+) 0,13 & (+) 0,07 & (+) 0,00 & (+) 0,05 & (+) 0,10 & (+) 0,00 & (+) 0,17 * \\
\hline $\mathrm{K} / \mathrm{Ca}$ & (+) 0,03 & (+) 0,00 & (+) 0,01 & (+) 0,00 & (+) 0,00 & (-) 0,00 & (+) 0,00 \\
\hline $\mathrm{K} /(\mathrm{Ca}+\mathrm{Mg})$ & (+) 0,07 & (+) 0,01 & (+) 0,00 & $(+) 0,00$ & (+) 0,02 & (-) 0,00 & (+) 0,05 \\
\hline $\mathrm{Ca} / \mathrm{Mg}$ & (+) 0,15 & (+) 0,22 * & (+) 0,04 & (+) 0,18 * & (+) 0,23 * & (+) 0,05 & (+) 0,26 * \\
\hline 2009 & \multicolumn{7}{|c|}{ Envero } \\
\hline K (\% s.m.s.) & (+) 0,06 & (+) 0,03 & (+) 0,10 & (+) 0,05 & (+) 0,02 & (+) 0,12 & (+) 0,00 \\
\hline $\mathrm{K} / \mathrm{Mg}$ & (+) 0,08 & (+) 0,04 & (+) 0,2 * & (+) 0,07 & (+) 0,06 & (+) 0,12 & (+) 0,01 \\
\hline $\mathrm{K} / \mathrm{Ca}$ & (+) 0,09 & (+) 0,2 * & (+) 0,15 & (+) 0,2 * & (+) 0,17 & (+) 0,21 * & (+) 0,16 \\
\hline $\mathrm{K} /(\mathrm{Ca}+\mathrm{Mg})$ & (+) 0,10 & (+) 0,16 & (+) 0,22 * & (+) 0,18 & (+) 0,16 & (+) 0,22 * & (+) 0,06 \\
\hline $\mathrm{Ca} / \mathrm{Mg}$ & (+) 0,01 & (+) 0,00 & (+) 0,08 & (+) 0,00 & (+) 0,00 & (+) 0,01 & (+) 0,18 \\
\hline \multicolumn{8}{|l|}{2010} \\
\hline K (\% s.m.s.) & (+) 0,09 & $(+) 0,06$ & (+) 0,03 & (+) 0,07 & (+) 0,02 & (+) 0,05 & (+) 0,00 \\
\hline $\mathrm{K} / \mathrm{Mg}$ & (+) 0,19 * & (+) 0,20 * & (+) 0,13 & (+) 0,23 * & (+) 0,10 & (+) 0,17 * & (+) 0,00 \\
\hline $\mathrm{K} / \mathrm{Ca}$ & (+) 0,08 & (+) 0,06 & (+) 0,01 & (+) 0,06 & (+) 0,02 & (+) 0,05 & (+) 0,00 \\
\hline $\mathrm{K} /(\mathrm{Ca}+\mathrm{Mg})$ & (+) 0,12 & $(+) 0,11$ & (+) 0,05 & (+) 0,12 & (+) 0,04 & (+) 0,10 & (+) 0,00 \\
\hline $\mathrm{Ca} / \mathrm{Mg}$ & (+) 0,20 * & (+) 0,18 * & (+) 0,29 ** & (+) 0,28 ** & $(+) 0,10$ & (+) 0,22 * & (-) 0,01 \\
\hline \multicolumn{8}{|l|}{2011} \\
\hline K (\% s.m & (+) 0,01 & $(+) 0,04$ & (+) 0,01 & (+) 0,02 & (+) 0,01 & (+) 0,04 & (+) 0,04 \\
\hline $\mathrm{K} / \mathrm{Mg}$ & (+) 0,25 * & (+) 0,21 * & (+) 0,10 & (+) 0,17 * & (+) 0,16 & (+) 0,09 & (+) 0,01 \\
\hline $\mathrm{K} / \mathrm{Ca}$ & (+) 0,06 & (+) 0,11 & (+) 0,03 & (+) 0,08 & (+) 0,07 & (+) 0,06 & (+) 0,03 \\
\hline $\mathrm{K} /(\mathrm{Ca}+\mathrm{Mg})$ & $(+) 0,14$ & (+) 0,16 & (+) 0,05 & (+) 0,12 & (+) 0,11 & (+) 0,07 & (+) 0,03 \\
\hline $\mathrm{Ca} / \mathrm{Mg}$ & (+) 0,28 ** & (+) 0,16 * & (+) 0,12 & $(+) 0,15$ & $(+) 0,13$ & (+) 0,08 & (+) 0,00 \\
\hline 2011 & \multicolumn{7}{|c|}{ Postvendimia } \\
\hline K (\% s.m.s.) & (+) 0,10 & $(+) 0,07$ & (+) 0,11 & $(+) 0,08$ & (+) 0,04 & (+) 0,19 * & $(-) 0,10$ \\
\hline $\mathrm{K} / \mathrm{Mg}$ & (+) 0,33 ** & (+) 0,24 * & (+) 0,28 ** & (+) 0,26 * & (+) 0,21 * & (+) 0,34 ** & (-) 0,18 * \\
\hline $\mathrm{K} / \mathrm{Ca}$ & (+) 0,18 * & (+) 0,13 & (+) 0,14 & (+) 0,14 & (+) 0,11 & (+) 0,18 * & (-) 0,07 \\
\hline $\mathrm{K} /(\mathrm{Ca}+\mathrm{Mg})$ & (+) 0,25 * & (+) 0,17 * & (+) 0,19 * & (+) 0,18 * & (+) 0,15 & (+) 0,25 * & (-) 0,10 \\
\hline $\mathrm{Ca} / \mathrm{Mg}$ & (+) 0,25 * & (+) 0,19 * & (+) 0,22 * & (+) $0,21 *$ & (+) 0,18 * & (+) 0,26 * & (-) 0,13 \\
\hline
\end{tabular}
Niveles de significación: * $p<0,05 ;{ }^{* *} p<0,01 ;{ }^{* *} p<0,0001$ 
Se han encontrado relaciones significativamente negativas entre el nivel peciolar de magnesio y la concentración de pigmentos foliares en prácticamente todas las fechas de muestreo (tabla 4.15), en consonancia con estudios previos realizados en la misma zona (Martín et al, 2008.; Catalina et al., 2011b y 2012). Esto se puede comprobar también en la separación de medias de la figura 4,16. Además, el contenido de $\mathrm{Mg}$ se ha relacionado significativamente de forma negativa con la ratio

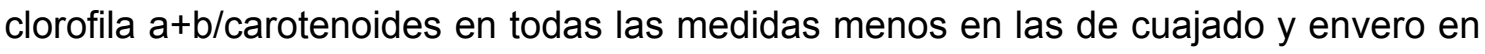
2011. Estos resultados reflejan que, en los suelos calizos del estudio, se produce una mayor acumulación de $\mathrm{Mg}$, antagónico con $\mathrm{K}$, en los peciolos de las plantas afectadas por clorosis férrica. A tenor de los resultados, cabe destacar la importancia del seguimiento de estos dos elementos tanto en su contenido en el suelo como en los peciolos para un mejor entendimiento del desarrollo de la fisiopatía.

Tabla 4.15. Coeficiente de determinación $\left(R^{2}\right)$, nivel de significación y pendiente de la regresión del contenido de $\mathrm{Mg}$ peciolar en el enverosobrela concentración de pigmentos foliares y sus ratios $\left(\mu \mathrm{g} \cdot \mathrm{cm}^{-2}\right)$.

\begin{tabular}{|c|c|c|c|c|c|c|c|}
\hline \multirow{3}{*}{$\begin{array}{l}\text { Pigmentos } \\
\text { Foliares }\end{array}$} & \multicolumn{7}{|c|}{ Contenido de Mg peciolar (\% s.m.s.) } \\
\hline & \multicolumn{2}{|c|}{2009} & \multicolumn{2}{|c|}{2010} & \multicolumn{3}{|c|}{2011} \\
\hline & Cuajado & Envero & Cuajado & Envero & Cuajado & Envero & Vendimia \\
\hline Antocininas & $(-) 0,20$ * & $(-) 0,14$ & $(-) 0,03$ & $(-) 0,19 *$ & $(-) 0,33$ ** & $(-) 0,39 * *$ & $(-) 0,38$ ** \\
\hline Clorofila a & - & $(-) 0,17$ & $(-) 0,37^{* *}$ & $(-) 0,19 *$ & (-) 0,25 * & $(-) 0,28$ ** & (-) 0,28 ** \\
\hline $\begin{array}{l}\text { Clorofila } b \\
\text { Clarofila } a+b\end{array}$ & (-) 0,19 * & $\begin{array}{l}(-) 0,38^{* *} \\
(-) 0,21^{*}\end{array}$ & $\begin{array}{l}(-) 0,50^{* * *} \\
(-) 0,47^{* *}\end{array}$ & $\begin{array}{l}(-) 0,30 \text { ** } \\
(-) 0,30^{* *}\end{array}$ & $\begin{array}{l}(-) 0,07 \\
(-) 0,21 \text { * }\end{array}$ & $\begin{array}{l}(-) 0,17^{*} \\
(-) 0,25^{*}\end{array}$ & $\begin{array}{l}(-) 0,26 \text { * } \\
(-) 0,28 \text { ** }\end{array}$ \\
\hline Carotenoides & - & $(-) 0,25^{*}$ & $(-) 0,44$ ** & $(-) 0,09$ & $(-) 0,23$ * & $(-) 0,22^{*}$ & $(-) 0,26$ * \\
\hline Clo a+b/Car & - & $(-) 0,20 *$ & $(-) 0,35^{* *}$ & $(-) 0,27^{* *}$ & $(-) 0,08$ & $(-) 0,15$ & $(-) 0,30 * *$ \\
\hline Clo a/Clo b & - & $(-) 0,01$ & $(+) 0,20$ * & $(+) 0,02$ & $(+) 0,25^{*}$ & $(-) 0,00$ & (+) 0,08 \\
\hline
\end{tabular}

Los resultados del estudio ponen de manifiesto que, en los suelos calizos de la zona de estudio, la nutrición potásica y su balance con el $\mathrm{Mg}$ y $\mathrm{Ca}$, son factores fundamentales en la nutrición mineral de los viñedos, y deben tenerse en cuenta en el diagnóstico de la clorosis férrica. El déficit de potasio afecta negativamente a la actividad fotosintética debido a que la concentración de clorofila foliar disminuye (Watson y Malmberg, 1996; Chen y Cheng, 2003). Bajo la deficiencia de nutrientes, las hojas utilizan sólo una pequeña fracción de la densidad de flujo de fotones fotosintéticos absorbidos (Cheng y Fuchigami 2000), y el exceso de energía de excitación puede conducir a la producción de especies reactivas de oxígeno (ROS), al daño del aparato fotosintético y de la estructura celular. 


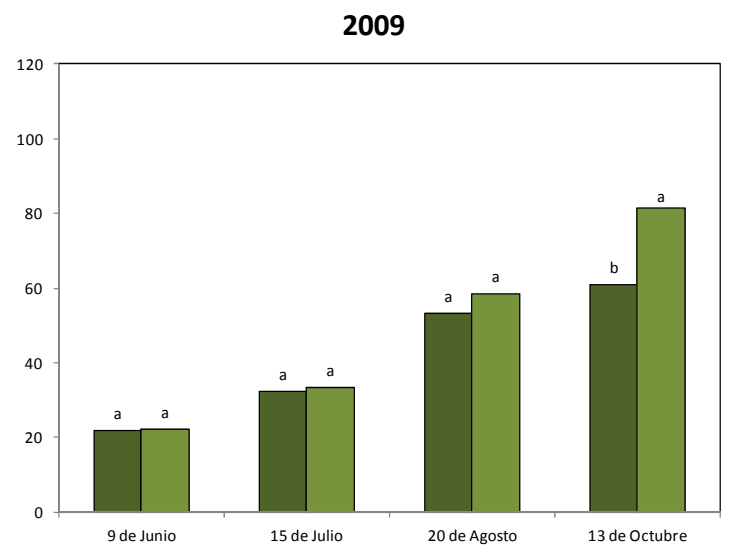

2010

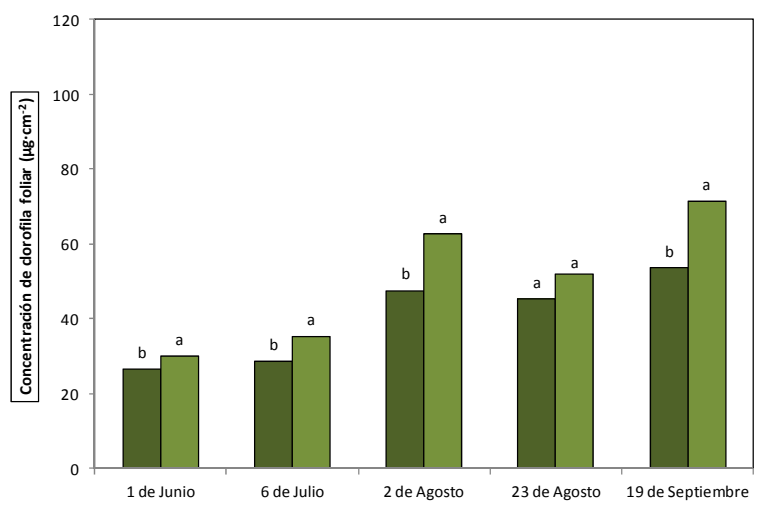

2011

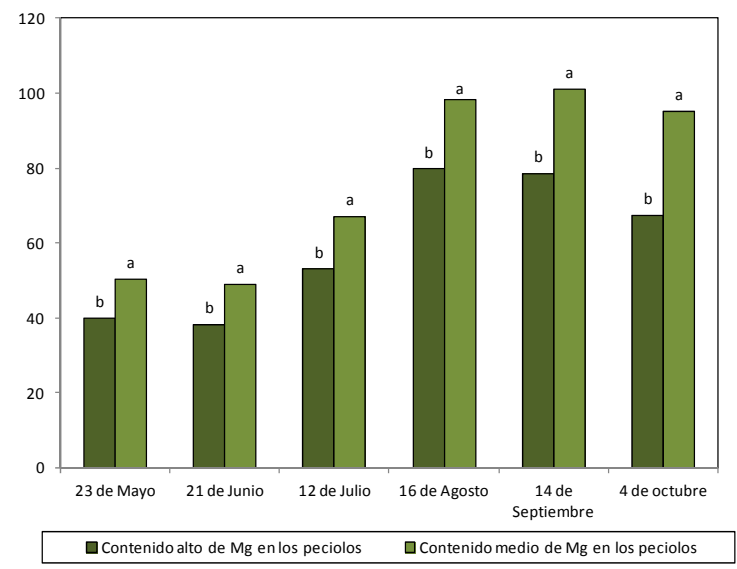

Figura 4.16.Evolución de la concentración de clorofila foliar a lo largo del ciclo vegetativo en función del contenido de $\mathrm{Mg}$ en los peciolos en el estado fenológico de envero (González y Martín, 2005) en los tres años del estudio. 
La concentración de los diferentes pigmentos foliares también se ha relacionado significativamente de forma positiva con el contenido de $\mathrm{Mn}$ en el suelo. Así (tabla 4.16), en el año 2009 y 2010 el nivel de Mn se relacionó con el contenido de la mayoría de los pigmentos, tanto en cuajado como en envero, mientras que en 2011 solo se relacionó con las antocianinas. La concentración de clorofila foliar monitorizada a lo largo del ciclo vegetativo ha resultado estadísticamente diferente en función del contenido de $\mathrm{Mn}$ en el suelo (apartado 4.1) en casi la totalidad de las medidas realizadas (figura 4.17). La concentración de clorofila foliar es significativamente mayor en las subparcelas con un contenido alto de $\mathrm{Mn}$ en el suelo, salvo para las medidas realizas a comienzos de Junio, antes de la floración, en los años 2009 y 2010.

Tabla 4.16. Coeficiente de determinación $\left(R^{2}\right)$, nivel de significación y pendiente de la regresión del contenido de $\mathrm{Mn}$ en el suelo sobre el contenido de pigmentos foliares y sus ratios $\left(\mathrm{mg} \cdot \mathrm{cm}^{-2}\right)$.

\begin{tabular}{|c|c|c|c|c|c|c|c|}
\hline \multirow{3}{*}{$\begin{array}{l}\text { Pigmentos } \\
\text { Foliares }\end{array}$} & \multicolumn{7}{|c|}{ Contenido de Mnen el suelo $\left(\mathrm{mg} \cdot \mathrm{kg}^{-1}\right)$} \\
\hline & \multicolumn{3}{|c|}{2009} & \multicolumn{2}{|c|}{2010} & \multicolumn{2}{|c|}{2011} \\
\hline & Cuajad & & Envero & Cuajado & Envero & Cuajado & Envero \\
\hline Antocininas & $(+) 0,37$ & * & (+) 0,30 * & $(+) 0.00$ & (+) 0,07 & (+) 0,28 ** & (+) 0,26 * \\
\hline Clorofila a & - & & (+) 0,34 * & (+) 0,26 * & (+) 0,19 * & (+) 0,12 & (+) 0,15 \\
\hline Clorofila b & - & & (+) 0,28 * & (+) 0,26 * & (+) 0,19 * & (+) 0,01 & (+) 0,09 \\
\hline Clarofila $\mathbf{a}+\mathbf{b}$ & $(+) 0,59$ & ** & (+) 0,34 * & (+) 0,30 ** & (+) 0,25 * & (+) 0,09 & (+) 0,13 \\
\hline Carotenoides & - & & (+) 0,42 * & (+) 0,39 ** & (+) 0,11 & (+) 0,07 & (+) 0,12 \\
\hline Clo a+b/Car & - & & $(+) 0,18$ & $(+) 0,14$ & (+) 0,17 * & (+) 0,06 & (+) 0,10 \\
\hline Clo a/Clo b & - & & (+) 0,25 * & (+) 0,05 & (+) 0,00 & (+) 0,21 * & (+) 0,00 \\
\hline
\end{tabular}



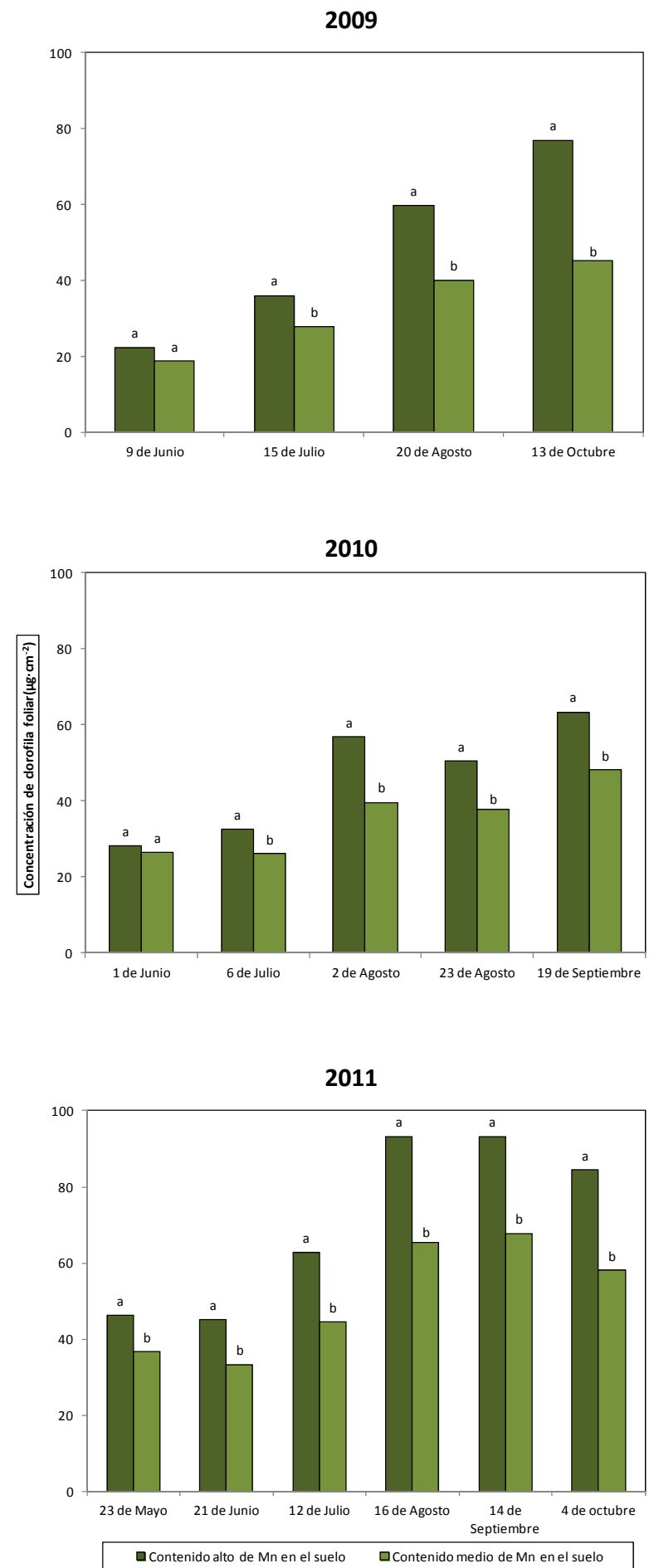

Figura 4.17. Evolución de la concentración de clorofila foliar a lo largo del ciclo vegetativo en función del contenido de $\mathrm{Mn}$ en el suelo (Sims y Johnson, 1991) en los tres años del estudio. 
Sin embargo, las relaciones entre el manganeso peciolar y la concentración de los pigmentos foliares has sido significativamente negativas en los tres años de muestreo (tabla 4.17). Como se puede ver en la figura 4.18, la concentración de clorofila foliar es significativamente mayor en las subparcelas con un contenido medio de $\mathrm{Mn}$ en los peciolos que en las parcelas con un nivel alto de $\mathrm{Mn}$ peciolar, salvo para las medidas realizas en prefloración en los años 2009 y 2010. La discrepancia en los resultados referentes a contenidos de $\mathrm{Mn}$ en suelo y peciolos se debe probablemente a que el elemento, antagónico con el hierro, se acumula en los tejidos vegetales de las plantas afectadas por clorosis férrica, en consonancia con los resultados obtenidos por Martín et al. (2008). En investigaciones llevadas a cabo por Bavaresco et al. (2010a), la concentración de $\mathrm{Mn}$ foliar se vio reducida significativamente con diferentes tratamientos correctores de hierro.

Tabla 4.17. Coeficiente de determinación $\left(R^{2}\right)$, nivel de significación y pendiente de la regresión del contenido de $\mathrm{Mn}$ peciolar en el envero sobre la concentración de pigmentos foliares y sus ratios $\left(\mathrm{mg} \cdot \mathrm{cm}^{-2}\right)$.

\begin{tabular}{|c|c|c|c|c|c|c|c|}
\hline \multirow{3}{*}{$\begin{array}{l}\text { Pigmentos } \\
\text { Foliares }\end{array}$} & \multicolumn{7}{|c|}{ Contenido de Mn peciolar (mg $\cdot \mathrm{kg}^{-1}$ s.m.s.) } \\
\hline & \multicolumn{2}{|c|}{2009} & \multicolumn{2}{|c|}{2010} & \multicolumn{3}{|c|}{2011} \\
\hline & Cuajado & Envero & Cuajado & Envero & Cuajado & Envero & Vendimia \\
\hline Antocininas & $(-)$ 0,02 & $(-) 0,32 * *$ & $(-) 0,01$ & $(-) 0,24$ * & $(-) 0,40 * *$ & $(-) 0,32 * *$ & $(-) 0,32^{* *}$ \\
\hline Clorofila a & - & $(-) 0,34$ ** & $(-) 0,31$ ** & $(-) 0,24$ * & $(-) 0,24$ * & $(-) 0,33^{* *}$ & $(-) 0,26$ * \\
\hline Clorofila b & - & $(-) 0,46$ ** & $(-) 0,06$ & $(-) 0,07$ & (-) 0,05 & $(-) 0,14$ & $(-) 0,30$ ** \\
\hline Clarofila $\mathbf{a}+\mathbf{b}$ & $(-) 0,12$ & $(-) 0,38$ ** & $(-) 0,21$ * & $(-) 0,24$ * & $(-) 0,20$ * & $(-) 0,26$ * & $(-) 0,28 * *$ \\
\hline Carotenoides & - & $(-) 0,43^{* *}$ & $(-) 0,22$ * & $(-) 0,19$ * & $(-) 0,28$ ** & $(-) 0,30$ ** & (-) 0,25 * \\
\hline Clo a+b/Car & 一 & (-) 0,29 * & (-) 0,17 * & $(-) 0,08$ & (-) 0,29 & $(-) 0,03$ & (-) 0,29 ** \\
\hline Clo a/Clo b & 一 & $(-) 0,12$ & (-) 0,06 & (-) 0,06 & (-) 0,28 ** & $(-) 0,03$ & (+) 0,23 * \\
\hline
\end{tabular}




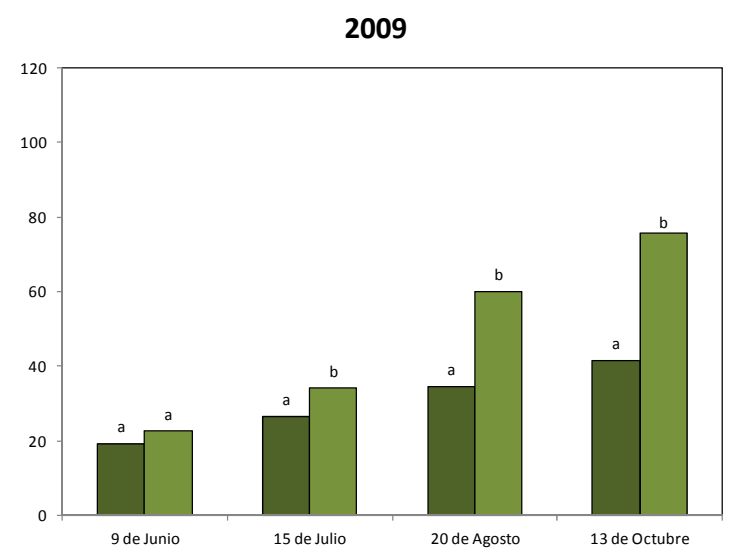

2010

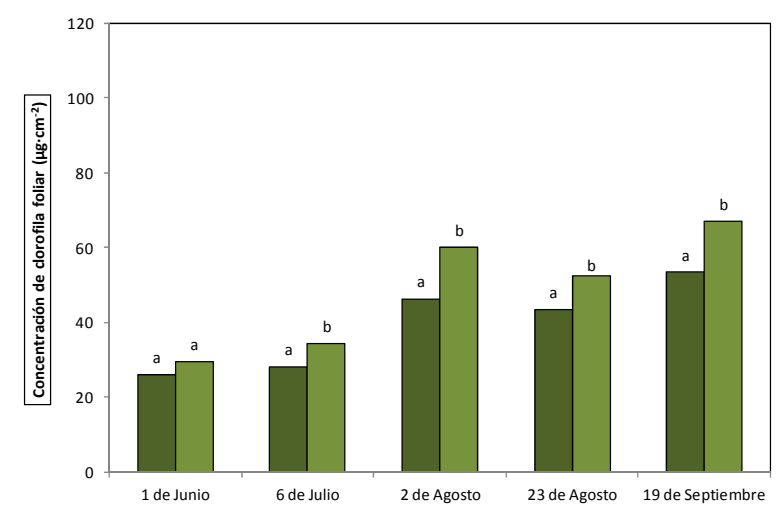

2011

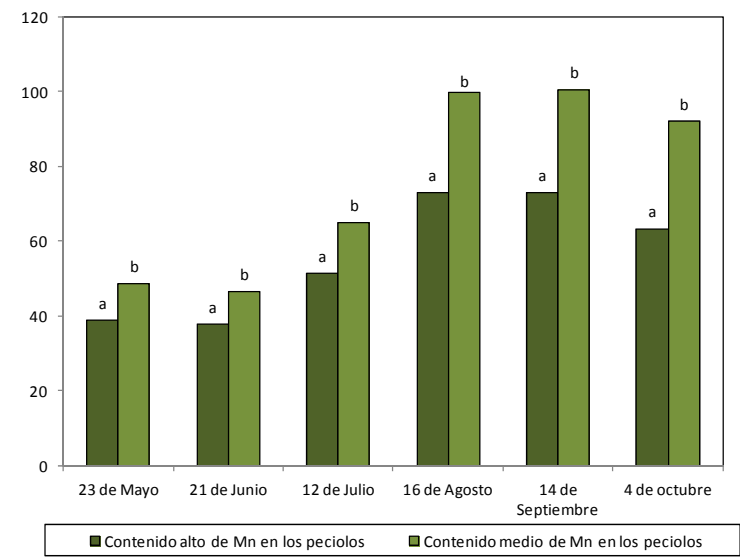

Figura 4.18. Evolución de la concentración de clorofila foliar a lo largo del ciclo vegetativo en función del contenido de $\mathrm{Mn}$ en los peciolos en el estado fenológico de envero (González y Martín, 2005) en los tres años del estudio. 


\subsection{3.- Diagnóstico de la clorosis férrica.}

Con el fin de estudiar la influencia de la clorosis férrica en los parámetros fisiológicos y agronómicos del viñedo en apartados posteriores, se ha realizado una caracterización de las subparcelas de estudio en función de la incidencia de la fisiopatía teniendo en cuenta los resultados expuestos en epígrafes anteriores.

Como se ha indicado en el apartado 4.1.1, la mayor parte de las áreas de muestreo tienen una concentración media o alta de Fe extraíble con DTPA en el suelo. Sin embargo, esto no garantiza una óptima absorción de este elemento, ya que en la mayoría de los casos la carencia es inducida por elevados contenidos en caliza activa y alto $\mathrm{pH}$ en el suelo (Chen y Barak, 1982), que elevan la concentración de bicarbonato, que interfiere con la asimilación del hierro. Mengel (1994) explicó que el bicarbonato se produce sobre todo en la superficie de las raíces, donde la respiración de los tejidos proporciona $\mathrm{CO}_{2}$ para la disolución de $\mathrm{CaCO}_{3}$.Por otro lado, teniendo en cuenta los valores nutricionales obtenidos para la Ribera del Duero (González y Martín, 2005), la mayor parte de las subparcelas tienen un contenido medio de hierro en el tejido peciolar (apartado 4.1.1). Cuando se analizan hojas de plantas cloróticas en condiciones de campo, la concentración de Fe sobre materia seca es relativamente alta en muchos casos, siendo incluso más elevada que en plantas control (Mengel et al., 1979; Chen y Barak, 1982; Mengel et al., 1984; Abadía et al., 1985; Abadía et al., 1989). La causa de esta denominada "paradoja de la clorosis" (Römheld, 1997; Morales et al., 1998b; Bavaresco et al., 1999)puede ser la acumulación de hierro inactivo en los tejidos de la planta (Marschner, 1995) y/o el menor tamaño de las hojas cloróticas, que produce un efecto de concentración (Toselli et al., 2000). En definitiva, la concentración de hierro en los peciolos no es un parámetro válido para el diagnóstico de la clorosis férrica.

En el presente trabajo, todas las relaciones significativas encontradas entre los niveles de carbonatos totales en el suelo y las concentraciones de pigmentos foliares han sido negativas. Las concentraciones tanto de antocianinas, como de clorofilas y carotenoides, no se han relacionado con el contenido de hierro en el suelo, por lo que la carencia está claramente inducida por el carácter calcáreo del mismo. Los suelos más clorosantes coinciden en la zona de estudio con los de textura más arcillosa; el coeficiente de correlación entre contenidos de arcilla y de carbonatos en el suelo en la zona de estudio es altamente significativo $(r=0,71, p<0,001)$.

Los niveles de $\mathrm{Mg}$ y $\mathrm{Mn}$ peciolar se han relacionado directamente con la concentración de clorofila en la hoja. Puede decirse que, en las condiciones de cultivo del área de estudio, una elevada concentración de carbonatos en el suelo, y por tanto una clorosis férrica más severa, acarrea una acumulación de estos elementos en los peciolos. La mayor concentración de Mg peciolar en vides cloróticas puede haberse debido a un desequilibrio con otros nutrientes en los suelos calcáreos, como lo demuestran las relaciones significativamente negativas observadas entre el contenido de carbonatos totales del suelo y los ratios $\mathrm{Ca} / \mathrm{Mg}, \mathrm{K} / \mathrm{Mg}, \mathrm{K} / \mathrm{Ca}$ y $\mathrm{K} /(\mathrm{Ca}+\mathrm{Mg})$ de los peciolos. La acumulación de $\mathrm{Mn}$ en peciolos de plantas cloróticas se puede explicar por la respuesta fisiológica de la raíz a la deficiencia de hierro, que activa proteínas 
transportadoras de hierro como la IRT1 ó la NRAMP3, que están también implicadas en el transporte de Mn, el cuál prevalece sobre el de Fe (Milalleo, 2010). De hecho, los carbonatos totales del suelo se han relacionado negativamente con la ratio Fe/Mn en los años 2010 y 2011 (Tabla 4.6.).

Teniendo en cuenta todo lo anterior, y considerando que la clorosis observada en la zona del estudio es debida fundamentalmente a la carencia de hierro, las subparcelas se han clasificado en cloróticas y no cloróticas en función de la concentración de clorofila en las hojas y los contenidos en arcilla y carbonatos totales ( $\sin$ tener en cuenta el hierro asimilable en el suelo) expuestos en el apartado 4.1. Así, en el año 2009, las subparcelas 1, 2, 4, 5, 6, 7, 9, 10, 11, 12 y 21 estuvieron afectadas por clorosis férrica. En el año 2010 y 2011, las subparcelas cloróticas fueron la 5, 6, 7, $9,10,11,12,13,15,16$ y 18 .

La deficiencia de hierro en suelos calcáreos modifica la asimilación de otros nutrientes en el viñedo. Dado que la concentración de hierro en los tejidos no es un valor para la detección de la deficiencia, es interesante analizar estos cambios nutricionales, con objeto de identificar índices o relaciones entre nutrientes apropiadas para el diagnóstico foliar de la fisiopatía. Las proporciones relativas de algunos nutrientes en los tejidos vegetales puedan utilizarse como índices de referencia del estado nutricional de la planta en cuanto al hierro. Tal es el caso de las relaciones como $\mathrm{Fe} / \mathrm{Mn}, \mathrm{P} / \mathrm{Fe}$ y $\mathrm{K} / \mathrm{Ca}$, que han obtenido resultados diferentes en función de la especie y de las condiciones de cultivo consideradas (Abadia et al., 1989; Belkhodja et al., 1998). En el presente estudio la ratio $\mathrm{Fe} / \mathrm{Mn}$ ha obtenido una relación lineal significativamente positiva con el contenido de clorofila foliar en el cuajado y en el envero en 2009, y en todas las medidas realizadas en 2010 (tabla 4.18). La ratio Ca/P se ha relacionado negativamente de forma significativa sólo con las medidas realizadas en 2010. Como se ha descrito anteriormente, estos elementos tuvieron un contenido peciolar en el envero muy diferente en 2010 respecto a 2009 y 2011 debido una situación de estrés hídrico y térmico a la que se vieron sometidas las plantas en el verano del segundo año de seguimiento.

De todas las relaciones de nutrientes estudiadas, se pueden destacar los ratios $\mathrm{K} / \mathrm{Mg}, \mathrm{K} / \mathrm{Ca}, \mathrm{K} /(\mathrm{Ca}+\mathrm{Mg})$ y $\mathrm{Ca} / \mathrm{Mg}$ presentes en los peciolos recolectados en el envero, que se han relacionado significativamente de forma positiva con el contenido de clorofila en las hojas, especialmente en 2010 y 2011 (tabla 4.18), en consonancia con estudios previos en la misma región (González et al, 2005b). El aumento del nivel de K en los peciolos con respecto al de $\mathrm{Mg}$ y Ca eleva el contenido foliar de clorofila. Todo esto pone de manifiesto la importancia de la interacción de estos tres elementos entre sí, y en relación al hierro, sobre el grado de clorosis férrica en plantas cultivadas en suelos calizos, de forma que las referidas ratios serían susceptibles de ser utilizadas como herramienta de diagnóstico de la fisiopatía. 
Tabla 4.18. Coeficiente de determinación $\left(R^{2}\right)$, nivel de significación y pendiente de la regresión de la concentración de clorofila foliar $\left(\mathrm{mg} \cdot \mathrm{cm}^{-2}\right)$ sobre diferentes ratios entre contenidos peciolares de nutrientes.

\begin{tabular}{|c|c|c|c|c|c|c|}
\hline \multirow[b]{2}{*}{2009} & \multicolumn{6}{|c|}{ Contenido en clorofila foliar $\left(\mathrm{mg} \cdot \mathrm{cm}^{-2}\right)$} \\
\hline & $\begin{array}{l}\text { Brotes } \\
30 \mathrm{~cm}\end{array}$ & Cuajado & $\begin{array}{l}\text { Post- } \\
\text { cuajado }\end{array}$ & Envero & Maduración & $\begin{array}{c}\text { Post- } \\
\text { vendimia }\end{array}$ \\
\hline $\mathrm{Ca} / \mathrm{P}$ & - & (-) 0,17 & (+) 0,00 & (-) 0,01 & - & (-) 0,06 \\
\hline $\mathrm{N} / \mathrm{K}$ & - & (-) 0,08 & (-) 0,13 & (-) 0,11 & - & $(-) 0,20$ * \\
\hline P/K & - & (-) 0,01 & (-) 0,05 & (-) 0,00 & - & $(-) 0,00$ \\
\hline $\mathbf{P} / \mathbf{N}$ & - & $(+) 0,11$ & $(+) 0,00$ & $(+) \quad 0,4$ & - & $(+) 0,08$ \\
\hline $\mathrm{K} / \mathrm{Mg}$ & - & $(+) 0,07$ & $(+) 0,12$ & $(+) 0,19$ * & - & $(+) 0,48$ ** \\
\hline $\mathrm{K} / \mathrm{Ca}$ & - & $(+) 0,20$ * & (+) 0,06 & $(+) 0,17$ & - & $(+) 0,15$ \\
\hline $\mathrm{K} /(\mathrm{Ca}+\mathrm{Mg})$ & - & $(+) 0,17$ & $(+) 0,11$ & $(+) 0,21$ * & - & (+) 0,33 ** \\
\hline $\mathrm{Ca} / \mathrm{Mg}$ & - & $(-)$ 0,00 & $(+) 0,04$ & $(+) 0,07$ & - & $(+) 0,25$ * \\
\hline $\mathrm{Zn} / \mathrm{Fe}$ & - & $(+) 0,00$ & $(+) 0,16$ & $(+) 0,08$ & - & $(+) 0,10$ \\
\hline $\mathrm{Fe} / \mathrm{Mn}$ & - & (+) 0,34 ** & (+) 0,07 & (+) 0,30 ** & - & (+) 0,10 \\
\hline $\mathrm{P} / \mathrm{Fe}$ & - & (+) 0,07 & (+) 0,04 & (+) 0,05 & - & $(+) 0,17$ \\
\hline$[(10 \times \mathrm{P})+\mathrm{K}] \times 50 / \mathrm{Fe}$ & - & (+) 0,07 & (+) 0,14 & (+) 0,09 & - & $(+) 0,29$ * \\
\hline \multicolumn{7}{|l|}{2010} \\
\hline $\mathrm{Ca} / \mathrm{P}$ & $(-) 0,24$ * & (-) 0,62 *** & (-) $0,59 * * *$ & $(-) 0,21$ * & $(-) 0,30$ * & - \\
\hline$N / K$ & (-) 0,00 & $(-) 0,05$ & $(-) 0,05$ & (-) 0,02 & (-) 0,07 & - \\
\hline$P / K$ & (+) 0,07 & (+) 0,03 & (+) 0,06 & (+) 0,02 & (+) 0,00 & - \\
\hline $\mathrm{P} / \mathrm{N}$ & (+) 0,16 & (+) 0,31 * & (+) 0,46 ** & (+) 0,13 & (+) 0,19 & - \\
\hline $\mathrm{K} / \mathrm{Mg}$ & $(+) 0,06$ & (+) $0,45^{* *}$ & (+) 0,40 ** & (+) 0,08 & (+) 0,23 * & - \\
\hline $\mathrm{K} / \mathrm{Ca}$ & (+) 0,02 * & (+) 0,37 ** & (+) 0,24 * & (+) 0,06 & $(+) 0,16$ & - \\
\hline $\mathrm{K} /(\mathrm{Ca}+\mathrm{Mg})$ & (+) 0,03 & (+) 0,43 ** & (+) 0,31 * & (+) 0,07 & (+) 0,19 & - \\
\hline $\mathrm{Ca} / \mathrm{Mg}$ & (+) 0,05 & (+) 0,26 * & (+) 0,30 * & (+) 0,03 & (+) 0,18 & - \\
\hline $\mathrm{Zn} / \mathrm{Fe}$ & $(-) 0,05$ & (-) 0,05 & (-) 0,09 & $(-) 0,01$ & $(-) 0,09$ & - \\
\hline $\mathrm{Fe} / \mathrm{Mn}$ & (+) 0,26 * & (+) 0,40 ** & (+) $0,34^{* *}$ & (+) 0,25 * & (+) 0,44 ** & - \\
\hline $\mathrm{P} / \mathrm{Fe}$ & (+) 0,06 & (+) 0,29 * & (+) 0,23 * & (+) 0,07 & (+) 0,04 & - \\
\hline$[(10 \times \mathrm{P})+\mathrm{K}] \times 50 / \mathrm{Fe}$ & (+) 0,02 & $(+) 0,28$ * & $(+) 0,14$ & (+) 0,04 & (+) 0,03 & - \\
\hline \multicolumn{7}{|l|}{2011} \\
\hline $\mathrm{Ca} / \mathrm{P}$ & (-) 0,08 & (-) 0,07 & (-) 0,04 & (-) 0,05 & $(-) 0,17^{*}$ & (-) 0,16 \\
\hline$N / K$ & (-) 0,02 & (-) 0,03 & (-) 0,05 & (-) 0,03 & (-) 0,04 & (-) 0,05 \\
\hline$P / K$ & (+) 0,01 & (-) 0,01 & (-) 0,01 & (-) 0,00 & (-) 0,00 & (-) 0,00 \\
\hline$P / N$ & (+) 0,23 * & (+) 0,04 & (+) 0,08 & (+) 0,12 & (+) 0,18 * & $(+) 0,16$ \\
\hline $\mathrm{K} / \mathrm{Mg}$ & (+) 0,23 * & (+) 0,39 ** & (+) 0,26 * & (+) 0,20 * & (+) 0,33 ** & (+) 0,42 ** \\
\hline $\mathrm{K} / \mathrm{Ca}$ & (+) 0,04 & (+) 0,20 * & (+) 0,19 * & $(+) 0,13$ & (+) 0,25 * & (+) 0,28 ** \\
\hline $\mathrm{K} /(\mathrm{Ca}+\mathrm{Mg})$ & $(+) 0,11$ & (+) 0,30 ** & (+) 0,24 * & (+) 0,17 * & (+) 0,30 ** & (+) 0,36 ** \\
\hline $\mathrm{Ca} / \mathrm{Mg}$ & (+) 0,34 ** & (+) $0,27^{* *}$ & (+) 0,15 & $(+) 0,15$ & (+) 0,17 * & (+) 0,21 * \\
\hline $\mathrm{Zn} / \mathrm{Fe}$ & (+) 0,30 ** & (+) 0,08 & (+) 0,12 & (+) 0,07 & $(+) 0,12$ & $(+) 0,14$ \\
\hline $\mathrm{Fe} / \mathrm{Mn}$ & (+) 0,03 & (+) 0,08 & (+) 0,02 & (+) 0,04 & (+) 0,04 & (+) 0,02 \\
\hline $\mathrm{P} / \mathrm{Fe}$ & (+) 0,33 ** & (+) 0,02 & (+) 0,07 & (+) 0,21 * & (+) 0,24 * & (+) 0,18 * \\
\hline$[(10 \times \mathrm{P})+\mathrm{K}] \times 50 / \mathrm{Fe}$ & $(+) 0,35 * *$ & (+) 0,02 & (+) 0,09 & $(+) 0,22$ * & $(+) 0,24$ * & (+) 0,20 * \\
\hline
\end{tabular}




\section{3.- PARÁMETROS DE EFICIENCIA FOTOSINTÉTICA.}

En este apartado se muestran los resultados obtenidos al estudiar las relaciones observadas entre la eficiencia fotosintética (asimilación neta conductancia estomática y parámetros de fluorescencia de la clorofila) en los estados fenológicos de cuajado y envero con los contenidos minerales de nutrientes en el suelo y en los peciolos en el envero y los niveles foliares de pigmentos.

El análisis de la varianza de los niveles de los valores de asimilación neta, conductancia estomática y diferentes parámetros de la fluorescencia de la clorofila medidos en el cuajado y el envero según cada año de seguimiento, mostró diferencias significativas entre los tres años objeto de estudio para todos los parámetros, excepto para la tasa de transporte de electrones ETR (tabla 4.19). Como consecuencia de esto los datos se tratarán estadísticamente separados año por año.

Tabla 4.19. Valores de la $F$ de Fisher y el nivel de significación del análisis de la varianza (ANOVA) de la asimilación neta (An), conductancia estomática (gs) y los parámetros de fluorescencia de la clorofila en el cuajado y el envero en función de los años de estudio.

\begin{tabular}{|c|c|c|c|c|}
\hline \multirow{2}{*}{$\begin{array}{l}\text { Parámetros de la } \\
\text { fluorescencia }\end{array}$} & \multicolumn{2}{|c|}{ Cuajado } & \multicolumn{2}{|c|}{ Envero } \\
\hline & $\mathbf{F}$ & & & $\mathbf{F}$ \\
\hline AN $\left(\mu \mathrm{mol} \mathrm{CO}_{2} \cdot \mathrm{m}^{-2} \mathrm{~s}^{-1}\right)$ & 30,76 & $* * *$ & 3,23 & * \\
\hline $\operatorname{gs}\left(\mathrm{mmol} \mathrm{H}_{2} \mathrm{O} \cdot \mathrm{m}^{-2} \mathrm{~s}^{-1}\right)$ & 58,22 & $* * *$ & 6,69 & $* *$ \\
\hline Fo & 52,67 & $* * *$ & 27,37 & $* * *$ \\
\hline Fm & 222,4 & $* * *$ & 6,63 & $* *$ \\
\hline $\mathbf{F v}$ & 113,98 & $* * *$ & 7,64 & ** \\
\hline Fo' & 124,66 & $* * *$ & 2,12 & \\
\hline Fm & 87,18 & $* * *$ & 20,31 & $* * *$ \\
\hline Fv' & 54,75 & $* * *$ & 32,34 & $* * *$ \\
\hline Fs & 65,38 & $* * *$ & 23,72 & $* * *$ \\
\hline Fv/Fm & 2,30 & & 10,95 & $* * *$ \\
\hline Fv'/Fm` & 35,02 & $* * *$ & 44,07 & $* \star *$ \\
\hline ФPSII & 30,88 & $* * *$ & 18,57 & $* \star *$ \\
\hline $\mathbf{q P}$ & 8,65 & $* *$ & 68,69 & $* \star *$ \\
\hline NPQ & 14,6 & $* * *$ & 34,30 & $* \star *$ \\
\hline ETR & 0,40 & & 0,82 & \\
\hline Fs/Fo & 17,34 & $* * *$ & 36,06 & $* * *$ \\
\hline Fo/Fv & 4,09 & * & 12,04 & $* * *$ \\
\hline
\end{tabular}




\subsection{1.- Relación entre el estado nutricional del viñedo y la} asimilación neta, conductancia estomática y parámetros de la fluorescencia de la clorofila.

Como se observa en la tabla 4.20, la asimilación neta en el cuajado de 2009 y 2011 y en el envero de 2011 y la conductancia estomática medida en el envero de 2009 y 2011 se relacionaron significativamente de forma negativa con el contenido de arcilla en el suelo. Los niveles de carbonatos totales tuvieron una relación negativa con la asimilación neta en el cuajado de 2011 y positiva en el envero de 2011. En investigaciones de Covarrubias y Rombolà (2014) se observó que el aumento del contenido de $\mathrm{CaCO}_{3}$ reducía la tasa de fotosíntesis neta y la conductancia estomática. Covarrubias y Rombolà (2013) registraron una disminución importante de la actividad de la fosfoenolpiruvato carboxilasa (PEPC) en un portainjerto de vid tolerante a la clorosis férrica (140 Ruggeri), al incrementarse la presencia de bicarbonato en la solución nutritiva.

Tabla 4.20.Coeficiente de determinación $\left(R^{2}\right)$, nivel de significación y pendiente de la regresión de la asimilación neta $\left(\mu \mathrm{mol} \mathrm{CO}_{2} \cdot \mathrm{m}^{-2} \mathrm{~s}^{-1}\right)$ y la conductancia estomática (mmol $\mathrm{H}_{2} \mathrm{O} \cdot \mathrm{m}^{-2} \mathrm{~s}^{-1}$ ) medidas en cuajado y envero sobre el contenido en nutrientes de suelo y peciolos.

\begin{tabular}{|c|c|c|c|c|c|c|c|}
\hline \multirow{2}{*}{\multicolumn{2}{|c|}{ Variables }} & \multicolumn{6}{|c|}{ Asimilación neta } \\
\hline & & \multicolumn{3}{|c|}{ Cuajado } & \multicolumn{3}{|c|}{ Envero } \\
\hline & & 2009 & 2010 & 2011 & 2009 & 2010 & 2011 \\
\hline \multirow{5}{*}{ Suelo } & Arcilla (\%) & $(-) 0,41^{\text {** }}$ & $(-) 0,00$ & $(-) 0,30^{* *}$ & $(-) 0,00$ & $(+) 0,15$ & $(-) 0,21^{*}$ \\
\hline & СТ (\%) & $(-) 0,12$ & $(+) 0,01$ & $(-) 0,52$ ** & $(-) 0,09$ & $(+) 0,34^{* *}$ & $(-) 0,15$ \\
\hline & $\mathrm{K}\left(\mathrm{meq} \cdot 100 \mathrm{~g}^{-1}\right)$ & $(-) 0,17$ & $(+) 0,05$ & $(+) 0,44^{* *}$ & $(+) 0,35^{* *}$ & $(-) 0,01$ & $(+) 0,27^{*}$ \\
\hline & $\operatorname{Mg}\left(\mathrm{meq} \cdot 100 \mathrm{~g}^{-1}\right)$ & $(-) 0,46$ ** & $(+) 0,08$ & $(-) 0,06$ & $(+) 0,03$ & $(+) 0,17$ & $(-) 0,16$ \\
\hline & $\mathrm{Mn}\left(\mathrm{mg} \cdot \mathrm{kg}^{-1}\right)$ & $(+) 0,02$ & $(+) 0,00$ & $(+) 0,34$ ** & $(+) 0,66^{* *}$ & $(-) 0,07$ & $(+) 0,33^{* *}$ \\
\hline \multirow{4}{*}{ Peciolo } & K (\% s.m.s.) & $(-) 0,02$ & $(+) 0,02$ & $(+) 0,43^{* *}$ & $(+) 0,06$ & $(-) 0,01$ & $(+) 0,03$ \\
\hline & Mg (\% s.m.s.) & $(-) 0,08$ & $(+) 0,01$ & $(-) 0,50$ ** & $(-) 0,24$ * & $(+) 0,24$ * & $(-) 0,36$ ** \\
\hline & $\mathrm{Mn}\left(\mathrm{mg} \cdot \mathrm{kg}^{-1}\right)$ & $(-) 0,13$ & $(-) 0,00$ & $(-) 0,15$ & $(-) 0,01$ & $(+) 0,25^{*}$ & $(-) 0,16$ \\
\hline & & \multicolumn{6}{|c|}{ Conductancia estomática } \\
\hline \multirow{5}{*}{ Suelo } & Arcilla (\%) & - & $(+) 0,08$ & $(+) 0,00$ & $(-) 0,21^{*}$ & $(-) 0,03$ & $(-) 0,24$ * \\
\hline & СТ (\%) & - & $(-) 0,00$ & $(+) 0,02$ & $(-) 0,20$ & $(+) 0,04$ & $(-) 0,07$ \\
\hline & $\mathrm{K}\left(\mathrm{meq} \cdot 100 \mathrm{~g}^{-1}\right)$ & - & $(+) 0,09$ & $(+) 0,03$ & $(+) 0,00$ & $(+) 0,00$ & $(+) 0,15$ \\
\hline & $\operatorname{Mg}\left(\operatorname{meq} \cdot 100 g^{-1}\right)$ & - & $(+) 0,15$ & $(-) 0,01$ & $(-) 0,04$ & $(+) 0,00$ & $(-) 0,12$ \\
\hline & $\operatorname{Mn}\left(\mathbf{m g} \cdot \mathrm{kg}^{-1}\right)$ & - & $(-) 0,01$ & $(+) 0,00$ & $(+) 0,22$ & $(-) 0,02$ & $(+) 0,27^{*}$ \\
\hline \multirow{3}{*}{ Peciolo } & K (\% s.m.s.) & - & $(+) 0,01$ & $(+) 0,07$ & $(-) 0,00$ & $(+) 0,02$ & $(+) 0,02$ \\
\hline & Mg (\% s.m.s.) & - & $(-) 0,00$ & $(+) 0,00$ & $(-) 0,06$ & $(+) 0,00$ & $(-) 0,11$ \\
\hline & $\mathrm{Mn}\left(\mathrm{mg} \cdot \mathrm{kg}^{-1}\right)$ & - & $(+) 0,03$ & $(+) 0,00$ & $(-) 0,08$ & $(+) 0,04$ & (-) 0,01 \\
\hline
\end{tabular}


Se ha obtenido una regresión significativamente positiva de la asimilación neta en el cuajado de 2011 y en el envero de 2009 y 2011 sobre el contenido en K y Mn del suelo. De los nutrientes peciolares, podemos destacar la relación significativamente negativa del contenido en $\mathrm{Mg}$ con la asimilación neta en el cuajado de 2011, y en el envero de 2009 y 2011 y positiva en el envero de 2010. En cuanto a la conductancia estomática, solo se ha observado una relación significativa de forma negativa con el porcentaje de arcilla en el envero de 2009 y 2011 y de forma positiva con el contenido en $\mathrm{Mn}$ del suelo en el envero de 2011. No se han detectado relaciones relevantes entre la asimilación neta y la conductancia estomática para los niveles del resto de elementos minerales estudiados (datos no mostrados).

Como se ve en la tabla 4.21, el porcentaje de arcilla del suelo se ha relacionado significativamente con algunos de los parámetros de la fluorescencia de la clorofila en el cuajado en 2010 y en el envero en 2009 y 2011. En concreto, la relación del contenido de arcilla fue significativamente positiva con Fo', Fm` y Fs en el cuajado de 2010 y con Fo en los tres años de seguimiento. En las medidas de envero se pueden destacar las relaciones negativas del contenido en arcilla con Fo, Fm y Fv en 2009; con Fm`, Fv', Fv'/Fm`en 2009 y 2011, y con Fo`y Fs en los tres años de seguimiento.

Tabla 4.21. Coeficiente de determinación $\left(R^{2}\right)$, nivel de significación y pendiente de la regresión de los parámetros de fluorescencia de la clorofila medidos en cuajado y envero sobre el contenido en arcilla del suelo (\%).

\begin{tabular}{|c|c|c|c|c|c|c|}
\hline \multirow{3}{*}{$\begin{array}{l}\text { Parámetros de } \\
\text { Fluorescencia }\end{array}$} & \multicolumn{6}{|c|}{ Contenido en arcilla } \\
\hline & \multicolumn{3}{|c|}{ Cuajado } & \multicolumn{3}{|c|}{ Envero } \\
\hline & 2009 & 2010 & 2011 & 2009 & 2010 & 2011 \\
\hline Fo & $(+) 0,21^{*}$ & $(+) 0,34^{* *}$ & $(+) 0,24$ * & $(-) 0,26$ * & $(+) 0,03$ & $(+) 0,06$ \\
\hline Fm & $(+) 0,02$ & $(+) 0,03$ & $(-) 0,00$ & (-) 0,25 * & (+) 0,00 & (-) 0,04 \\
\hline $\mathbf{F v}$ & $(+) 0,00$ & $(-) 0,03$ & (-) 0,08 & (-) 0,23 * & (+) 0,00 & (-) 0,05 \\
\hline Fo' & $(-) 0,00$ & (+) 0,38 ** & (-) 0,04 & (-) 0,17 * & (+) 0,17 * & (-) 0,18 * \\
\hline Fm & $(-) 0,00$ & (+) 0,24 * & (-) 0,05 & $(-) 0,28$ * & $(+) 0,14$ & (-) 0,26 * \\
\hline Fv' & $(-) 0,00$ & $(+) 0,15$ & (-) 0,04 & $(-) 0,32$ ** & $(+) 0,11$ & (-) 0,28 ** \\
\hline Fs & (-) 0,00 & (+) 0,20 * & (-) 0,03 & $(-) 0,26$ * & (+) 0,17 * & $(-) 0,27^{* *}$ \\
\hline Fv/Fm & $(-) 0,08$ & $(-) 0,15$ & (-) 0,18 * & (-) 0,11 & (-) 0,02 & (-) 0,04 \\
\hline $\mathrm{Fv}^{`} / \mathrm{Fm}{ }^{`}$ & $(+) 0,01$ & (+) 0,00 & $(-) 0,05$ & $(-) 0,26$ * & (+) 0,05 & (-) 0,29 ** \\
\hline ФPSII & $(-) 0,16$ & (-) 0,01 & (+) 0,03 & $(+) 0,00$ & $(-) 0,05$ & (-) 0,01 \\
\hline $\mathbf{q P}$ & $(-) 0,06$ & (-) 0,02 & (+) 0,00 & (+) 0,04 & (-) 0,18 * & $(+) 0,15$ \\
\hline NPQ & $(+) 0,05$ & (-) 0,17 & (+) 0,06 & (+) 0,05 & (-) 0,10 & (+) 0,20 * \\
\hline ETR & - & (-) 0,01 & (+) 0,08 & - & (-) 0,07 & $(-)$ 0,01 \\
\hline Fs/Fo & $(-) 0,05$ & (-) 0,00 & (-) 0,16 & (-) 0,17 & (+) 0,05 & $(-) 0,25$ * \\
\hline Fo/Fv & $(+) 0,08$ & (+) 0,16 & (+) 0,16 & (+) 0,09 & (+) 0,01 & $(+) 0,04$ \\
\hline
\end{tabular}


Por su parte, el contenido de carbonatos totales del suelo se ha relacionado negativamente con Fo', Fm`, Fv' y Fs medidas en el cuajado en 2009 y 2011, y positivamente en 2010 (tabla 4.22). En este mismo estado fenológico también se han relacionado los carbonatos significativamente de forma negativa con la ratio Fs/Fo en 2009 y 2011, con Fv y Fv/Fm en los tres años del estudio, y de forma positiva con Fo y la ratio Fo/Fv en 2009, 2010 y 2011. En el envero, podemos destacar las relaciones significativamente negativas de los contenidos en carbonatos con Fm, Fv, Fm`, Fv' y Fv'/Fm`en el año 2011. Los resultados están de acuerdo con los de Cambrollé et al. (2014) y Bavaresco et al. (2006), que observaron que la eficiencia cuántica máxima del fotosistema II $(\mathrm{Fv} / \mathrm{Fm}=(\mathrm{Fm}-\mathrm{Fo}) / \mathrm{Fm})$ se reducía al aumentar el contenido de $\mathrm{CaCO}_{3}$ del suelo, principalmente como resultado de un incremento del nivel de Fo, que se puede atribuir a una merma en la transferencia de energía desde el complejo antena del fotosistema II a los centros de reacción (Maxwell y Johnson, 2000), posiblemente debido a la disminución registrada en la concentración de clorofila con el aumento de carbonatos.

Tabla 4.22. Coeficiente de determinación $\left(R^{2}\right)$, nivel de significación y pendiente de la regresión de los parámetro de fluorescencia de la clorofila medidos en cuajado y envero sobre el contenido en carbonatos totales del suelo (\%).

\begin{tabular}{|c|c|c|c|c|c|c|}
\hline \multirow{3}{*}{$\begin{array}{l}\text { Parámetros de } \\
\text { Fluorescencia }\end{array}$} & \multicolumn{6}{|c|}{ Contenido en carbonatos totales } \\
\hline & \multicolumn{3}{|c|}{ Cuajado } & \multicolumn{3}{|c|}{ Envero } \\
\hline & 2009 & 2010 & 2011 & 2009 & 2010 & 2011 \\
\hline Fo & $(-) 0,00$ & $(+) 0,37^{* *}$ & $(+) 0,44^{* *}$ & $(-) 0,13$ & $(+) 0,03$ & $(+) 0,00$ \\
\hline Fm & $(-) 0,30 *$ & $(-)$ 0,04 & $(-)$ 0,04 & $(-) 0,16$ & $(-) 0,12$ & $(-) 0,17$ * \\
\hline Fv & $(-) 0,35$ ** & $(-) 0,20$ * & $(-) 0,27^{* *}$ & $(-) 0,15$ & $(-) 0,14$ & $(-) 0,17$ * \\
\hline Fo` & $(-) 0,31$ * & (+) $0,50 * * *$ & $(-) 0,17$ * & $(-)$ 0,04 & $(+) 0,12$ & $(-) 0,16$ \\
\hline Fm` & $(-), 29$ * & $(+) 0,41$ ** & $(-) 0,18$ * & (-) 0,03 & $(+) 0,14$ & $(-) 0,22$ * \\
\hline Fv' & $(-) 0,20$ * & (+) 0,31 ** & (-) 0,09 & (-) 0,02 & (+) 0,14 & (-) 0,22 * \\
\hline Fs & (-) 0,31 * & (+) 0,38 ** & (-) 0,20 * & (-) 0,02 & (+) 0,17 * & (-) 0,23 * \\
\hline Fv/Fm & (-) $0,37^{* *}$ & $(-) 0,37^{* *}$ & $(-) 0,39 * *$ & $(-) 0,13$ & $(-) 0,10$ & (-) 0,05 \\
\hline Fv'/Fm` & (-) 0,02 & (+) 0,11 & $(-)$ 0,09 & (-) 0,03 & (+) 0,08 & (-) 0,26 * \\
\hline ФPSII & (+) 0,04 & $(-) 0,10$ & (+) 0,07 & (-) 0,13 & (-) 0,12 & $(-) 0,00$ \\
\hline qP & (+) 0,14 & (-) 0,16 & (+) 0,00 & (-) 0,09 & (-) 0,30 ** & (+) $0,17^{*}$ \\
\hline NPQ & (+) 0,05 & (-) 0,42 ** & (+) 0,05 & (-) 0,05 & (-) 0,22 * & (+) 0,08 \\
\hline ETR & - & (-) 0,09 & (+) 0,11 & - & (-) 0,12 & $(-) 0,00$ \\
\hline Fs/Fo & $(-) 0,23$ * & (+) 0,02 & $(-) 0,33$ ** & (-) 0,00 & (+) 0,05 & $(-) 0,18$ * \\
\hline Fo/Fv & (+) $0,34^{* *}$ & (+) 0,36 ** & (+) $0,37^{* *}$ & (+) 0,09 & (+) 0,08 & (+) 0,12 \\
\hline
\end{tabular}

Es de destacar el signo contrario de las regresiones de los parámetros de la fluorescencia medidos en condiciones de iluminación, sobre el porcentaje de arcilla como el contenido en carbonatos totales del suelo, encontradas en 2010 con respecto a 2009 y 2011. Esto sería debido a que en el verano de 2010 se produjo una disminución de la concentración de clorofila como consecuencia de una situación de 
estrés ambiental provocado por altas temperaturas y déficit hídrico (ver apartado 4.3.1), ya que se registró un verano más seco que en los otros dos años, sin apenas precipitaciones en julio y agosto. Esta situación, además fue acompañada de unas temperaturas máximas absolutas anormalmente altas en el mes de julio y principios de agosto. Además, en el envero del año 2010 el porcentaje de parcelas con plantas con contenidos bajos, medios o altos de $\mathrm{P}, \mathrm{Ca}, \mathrm{Cu}$ y $\mathrm{Zn}$ en los peciolos varió sustancialmente con respecto a 2009 y 2011 (apartado 4.1.1).

La fuerte influencia mostrada tanto por el porcentaje de arcilla como el contenido en carbonatos totales del suelo sobre los niveles de fluorescencia de la clorofila emitida por las plantas se estaría relacionado con que ambos parámetros de suelo producen variaciones importantes en el estado nutricional del viñedo en la zona de estudio respecto a $\mathrm{K}, \mathrm{Mg}$ y $\mathrm{Mn}$, y en particular a situaciones de déficit de hierro, que afectan a la eficiencia fotoquímica del fotosistema II. Es bien conocido que la deficiencia de hierro produce un descenso en la eficiencia fotoquímica del fotosistema II en los cultivos, cuantificable como Fv/Fm, (Nedunchezhian et al., 1997; Morales et al., 2000; Bertamini et al. 2002; Bavaresco et al. 2006) atribuible a las alteraciones de la ruta biosintética de la clorofila, una estequiometría alterada entre el PSI y PSII, o la inactividad de proteínas del PSI y PSII como el complejo citocromo $b_{6} f$ del que el Fe es un constituyente fundamental.

Diferentes estudios han demostrado que los parámetros de la fluorescencia de la clorofila pueden ser buenos indicadores de la deficiencia de nutrientes específicos. Así, Baker y Rosenqvist (2004) propusieron que qP podía mostrar deficiencia de N; Spáčilová y Šafránková (2011) encontraron que de Fv/Fm disminuía en condiciones de deficiencia de $\mathrm{N}$ en manzanos; Huang et al. (2004) observaron que los parámetros de fluorescencia ФPSII, Fv '/ Fm', y qP disminuían en plantas deficientes de N; Stark et al. (2000) encontraron Fv/Fm sensible al estrés provocado por deficiencia de P; ShmidtsEiberger et al (2002) han propuesto a Fv/Fm para detectar una nutrición deficiente de Ca; Mallicka y Mohn (2003), y Wang y Jin (2005), han demostrado que la eficiencia del fotosistema II , y especialmente la relación Fo/Fv se pueden utilizar como indicadores del estrés producido por deficiencia de oligoelementos como el $\mathrm{Cu}$ y el $\mathrm{Zn}$; MartínezPeñalver et al (2011) corroboraron que el estrés nutricional de $\mathrm{Cu}$ y $\mathrm{Zn}$ provoca una reducción global de Fv/Fm en Arabidopsis thaliana (L.) Heynh.

En los próximos párrafos se analizan las relaciones entre los niveles de $\mathrm{K}, \mathrm{Mg}$ y Mn de suelo y peciolos, para los que se ha encontrado suficiente variabilidad, sobre los parámetros de fluorescencia. La influencia de la deficiencia de Fe sobre estas variables se abordará en los dos apartados siguientes.

Como se ve en la tabla 4.23, el contenido de $\mathrm{K}$ asimilable en el suelo se ha relacionado significativamente de forma negativa con Fo y Fo/Fv, y de forma positiva con Fm, Fv y Fv/Fm medidas en el cuajado en los años 2010 y 2011 . En este mismo estado fenológico el contenido de $\mathrm{K}$ en el suelo también se ha relacionado significativamente con Fm`, Fv' y Fs de forma negativa y con NPQ y ETR de forma positiva en el año 2010. Además, tanto en el cuajado como en el envero, el contenido de potasio se relacionó significativamente con ФPSII y el apagado fotoquímico en 
2009 y 2010. A pesar de las relaciones mencionadas con el contenido de $\mathrm{K}$ en el suelo, no se ha detectado ninguna regresión significativa de los parámetros de fluorescencia de la clorofila sobre el contenido de $\mathrm{K}$ en los peciolos en envero. Probablemente estos contenidos peciolares, afectados por la interacción con otros nutrientes como el $\mathrm{Mg}, \mathrm{Ca}$ o $\mathrm{Fe}$, tengan un reflejo en la actividad fotosintética más difícil de interpretar que el derivado de la disponibilidad del elemento en el suelo.

Como para los carbonatos totales, en el caso del $\mathrm{K}$ la diferencia de signo en la pendiente de las regresiones de los años 2009 y 2011 con respecto a 2010, se ha dado únicamente en parámetros de la fluorescencia de la clorofila medidos en condiciones de iluminación. En el envero, podemos destacar las relaciones significativamente positivas del contenido en $\mathrm{K}$ del suelo con Fm y Fv en 2010.El potasio desempeña un papel importante en la fotosíntesis, de forma que una mayor nutrición potásica se correlaciona con una asimilación neta (An) mayor. La relación mostrada con los parámetros de fluorescencia de la clorofila indican que una eficiente nutrición potásica podría mejorar la conservación de la ultraestructura del cloroplasto, manteniendo los centros de reacción de la fotosíntesis menos dañados, menos sensibles a la fotoinhibición, incrementando la capacidad asimiladora. En este contexto, Weng et al (2007) corroboraron la sensibilidad de qP y NPQ para detectar la carencia de $\mathrm{K}$ en arroz, mientras que Guo y Tan (2015) encontraron diferencias significativas de Fo, Fm, Fv/Fm y Fo/Fv en variedades de arroz ineficientes en la absorción de $\mathrm{K}$ bajo condiciones de baja y alta disponibilidad del nutriente.

Tabla 4.23. Coeficiente de determinación $\left(R^{2}\right)$, nivel de significación y pendiente de la regresión de los parámetro de fluorescencia de la clorofila medidos en cuajado y envero sobre el contenido de $\mathrm{K}$ en el suelo $\left(\mathrm{mg} \cdot \mathrm{kg}^{-1}\right)$.

\begin{tabular}{|c|c|c|c|c|c|c|}
\hline \multirow{3}{*}{$\begin{array}{l}\text { Parámetros de } \\
\text { Fluorescencia }\end{array}$} & \multicolumn{6}{|c|}{ Contenido de $\mathrm{K}$ en el suelo } \\
\hline & \multicolumn{3}{|c|}{ Cuajado } & \multicolumn{3}{|c|}{ Envero } \\
\hline & 2009 & 2010 & 2011 & 2009 & 2010 & 2011 \\
\hline Fo & $(+) 0,03$ & $(-) 0,19$ * & $(-) 0,24$ * & $(+) 0,05$ & $(-) 0,00$ & $(+) 0,04$ \\
\hline Fm & $(+) 0,05$ & $(+) 0,38$ ** & $(+) 0,18$ * & $(+) 0,10$ & (+) 0,26 * & $(+) 0,12$ \\
\hline Fv & $(+) 0,05$ & (+) $0,45^{* *}$ & $(+) 0,21$ * & $(+) 0,09$ & (+) 0,19 * & (+) 0,09 \\
\hline Fo' & $(+) 0,02$ & $(-) 0,15$ & $(+) 0,03$ & $(+) 0,02$ & $(-)$ 0,00 & (+) 0,11 \\
\hline Fm & $(+) 0,06$ & (-) 0,19 * & (+) 0,00 & $(-) 0,02$ & (+) 0,00 & (+) 0,05 \\
\hline Fv' & $(+) 0,08$ & (-) 0,18 * & $(+) 0,00$ & (-) 0,07 & $(+) 0,00$ & (+) 0,02 \\
\hline Fs & $(+) 0,09$ & $(-) 0,22$ * & $(+) 0,01$ & $(-) 0,05$ & (+) 0,00 & (+) 0,05 \\
\hline Fv/Fm & $(+) 0,02$ & $(+) 0,32$ ** & (+) 0,23 * & (+) 0,06 & (+) 0,03 & (+) 0,01 \\
\hline $\mathrm{Fv}^{`} / \mathrm{Fm}{ }^{`}$ & $(+) 0,07$ & (-) 0,12 & (+) 0,02 & (-) 0,08 & (+) 0,00 & (+) 0,01 \\
\hline ФPSII & $(-) 0,37$ ** & (+) 0,28 ** & $(+) 0,11$ & (+) 0,46 ** & (+) 0,23 * & (+) 0,01 \\
\hline$q P$ & $(-) 0,37^{* *}$ & (+) 0,31 ** & (+) 0,06 & (+) $0,43^{* *}$ & (+) 0,18 * & (-) 0,00 \\
\hline NPQ & $(-) 0,02$ & (+) 0,32 ** & (-) 0,02 & (+) 0,16 & (+) 0,04 & (-) 0,01 \\
\hline ETR & - & (+) 0,32 ** & $(+) 0,13$ & - & (+) 0,12 & (+) 0,02 \\
\hline Fs/Fo & $(+) 0,04$ & (-) 0,02 & (+) 0,06 & (-) 0,09 & (+) 0,00 & (+) 0,01 \\
\hline Fo/Fv & $(-) 0,01$ & (-) 0,29 ** & (-) 0,22 * & (-) 0,05 & (-) 0,08 & (-) 0,02 \\
\hline
\end{tabular}


Como se aprecia en la tabla 4.24, el contenido en $\mathrm{Mg}$ del suelo se ha relacionado significativamente de forma negativa con la ФPSII y qP en 2009 y de forma positiva con Fm, Fo' y Fm`en 2010 medidas en el cuajado. En el envero, el nivel de $\mathrm{Mg}$ se ha relacionado negativamente con Fo, Fm`, Fv', Fv'/Fm`y Fs/Fo en 2009 y 2011. Fs y qP tuvieron regresiones de distinto signo en unos años y otros.

Tabla 4.24. Coeficiente de determinación $\left(R^{2}\right)$, nivel de significación y pendiente de la regresión de los parámetros de fluorescencia de la clorofila medidos en cuajado y envero sobre el contenido de $\mathrm{Mg}$ en el suelo (meq· $100 \mathrm{~g}^{-1}$ ).

\begin{tabular}{|c|c|c|c|c|c|c|}
\hline \multirow{3}{*}{$\begin{array}{l}\text { Parámetros de } \\
\text { Fluorescencia }\end{array}$} & \multicolumn{6}{|c|}{ Contenido de $\mathrm{Mg}$ en el suelo } \\
\hline & \multicolumn{3}{|c|}{ Cuajado } & \multicolumn{3}{|c|}{ Envero } \\
\hline & 2009 & 2010 & 2011 & 2009 & 2010 & 2011 \\
\hline Fo & $(+) 0,06$ & $(+) 0,10$ & $(-) 0,07$ & $(-) 0,18^{*}$ & $(+) 0,02$ & $(-) 0,19$ * \\
\hline Fm & $(+) 0,00$ & $(+) 0,25$ * & (+) 0,05 & $(-) 0,10$ & $(+) 0,14$ & $(+) 0,00$ \\
\hline Fv & $(-) 0,00$ & $(+) 0,06$ & (+) 0,00 & $(-)$ 0,09 & (+) 0,08 & (+) 0,00 \\
\hline Fo' & $(-) 0,00$ & (+) 0,28 ** & $(-)$ 0,01 & (-) 0,08 & $(+) 0,12$ & $(-) 0,08$ \\
\hline Fm & $(-) 0,00$ & (+) 0,19 * & (-) 0,03 & $(-) 0,26$ * & $(+) 0,12$ & $(-) 0,18$ * \\
\hline Fv' & $(-) 0,00$ & (+) 0,12 & (-) 0,03 & (-) 0,33 ** & (+) 0,11 & (-) 0,23 * \\
\hline Fs & $(+) 0,00$ & (+) 0,13 & (-) 0,02 & (-) 0,28 * & (+) 0,17 * & (-) 0,18 * \\
\hline Fv/Fm & $(-) 0,05$ & (-) 0,00 & (+) 0,03 & (-) 0,03 & (+) 0,00 & (-) 0,01 \\
\hline $\mathrm{Fv}^{`} / \mathrm{Fm}{ }^{`}$ & $(+) 0,01$ & (+) 0,02 & (-) 0,03 & $(-) 0,26$ * & (+) 0,05 & (-) $0,25^{*}$ \\
\hline ФPSII & $(-) 0,35$ ** & (-) 0,04 & (+) 0,02 & $(+) 0,13$ & (-) 0,07 & (-) 0,02 \\
\hline$q P$ & $(-) 0,19$ * & (+) 0,01 & (+) 0,00 & (+) 0,22 * & (-) 0,19 * & (+) 0,10 \\
\hline NPQ & $(+) 0,00$ & (-) 0,06 & (+) 0,06 & (+) 0,15 & (-) 0,01 & (+) 0,25 * \\
\hline ETR & - & (+) 0,04 & (+) 0,04 & - & (-) 0,08 & (-) 0,01 \\
\hline Fs/Fo & $(-) 0,01$ & (+) 0,03 & (-) 0,06 & (-) 0,20 * & (+) 0,04 & (-) 0,21 * \\
\hline Fo/Fv & $(+) 0,06$ & (+) 0,00 & (-) 0,03 & $(+) 0,02$ & (-) 0,01 & (+) 0,01 \\
\hline
\end{tabular}

Como se ve en la tabla 4.25, la concentración de Mg en los peciolos se ha relacionado significativamente de forma negativa con $\mathrm{Fm}^{\prime}$, Fv' y $\mathrm{Fs}$ medidas en el cuajado en los años 2009 y 2011, y de forma positiva en 2010. Además, Fm, Fv y el ratio Fs/Fo se han relacionado significativamente de forma negativa con el Mg peciolar en 2009 y 2010, Fv/Fm en 2009, 2010 y 2011, y de forma positiva con Fo/Fv en estos mismos años. En el envero, el nivel de $\mathrm{Mg}$ de los peciolos se ha relacionado significativamente de forma negativa con Fo, Fm, Fv, Fo' y Fv/Fm en 2009 y con Fo', Fm`, Fv', Fs, Fv`/Fm`y la ratio Fs/Fo en 2011.

Las regresiones negativas de Fv/Fm sobre la concentración de Mg peciolar en envero no coincide con los resultados de Godde y Hefer (1994), Balakrishnan et al., 
(2000) y Hermans et al (2004) que, en diversas especies vegetales, observaron una disminución de Fv/Fm en las hojas deficientes en Mg frente a hojas de plantas control. Es posible que en la zona de estudio los niveles peciolares de $\mathrm{Mg}$ se incrementen en subzonas afectadas por clorosis férrica, lo cuál sería verdaderamente la causa de la disminución de la eficiencia del PSII. Atendiendo a estos resultados, podemos asumir que la concentración de $\mathrm{Mg}$ en los peciolos en envero es una potencial herramienta para la caracterización del estado nutricional en viñedos afectados por clorosis férrica.

Tabla 4.25. Coeficiente de determinación $\left(R^{2}\right)$, nivel de significación y pendiente de la regresión de los parámetros de fluorescencia de la clorofila medidos en cuajado y envero sobre el contenido de $\mathrm{Mg}$ en los peciolos (\% s.m.s.).

\begin{tabular}{|c|c|c|c|c|c|c|}
\hline \multirow{3}{*}{$\begin{array}{l}\text { Parámetros de } \\
\text { Fluorescencia }\end{array}$} & \multicolumn{6}{|c|}{ Contenido de Mg en los peciolos } \\
\hline & \multicolumn{3}{|c|}{ Cuajado } & \multicolumn{3}{|c|}{ Envero } \\
\hline & 2009 & 2010 & 2011 & 2009 & 2010 & 2011 \\
\hline Fo & $(+) 0,03$ & $(+) 0,22$ * & $(+) 0,42$ * & $(+) 0,43^{* *}$ & $(+) 0,01$ & $(+) 0,00$ \\
\hline Fm & $(-) 0,19$ * & $(-) 0,01$ & $(-) 0,24$ * & $(-) 0,49 * *$ & (-) 0,08 & $(-) 0,14$ \\
\hline Fv & $(-) 0,27$ * & (-) 0,09 & $(-) 0,25$ * & $(-) 0,45 * *$ & (-) 0,08 & $(-) 0,13$ \\
\hline Fo' & $(-) 0,14$ & (+) 0,38 ** & $(-) 0,00$ & $(-) 0,22$ * & (+) 0,03 & $(-) 0,26$ * \\
\hline Fm` & $(-) 0,18$ * & $(+) 0,30 * *$ & $(-) 0,18$ * & $(-) 0,18$ * & 0,04 & $(-) 0,35$ ** \\
\hline Fv ${ }^{`}$ & $(-) 0,18$ * & $(+) 0,22$ * & $(-) 0,20$ * & (-) 0,09 & 0,04 & (-) 0,36 ** \\
\hline Fs & $(-) 0,18$ * & (+) 0,25 * & (-) 0,19 * & (-) 0,11 & 0,07 & $(-) 0,36$ ** \\
\hline Fv/Fm & $(-) 0,44$ ** & (-) 0,20 * & (-) 0,38 ** & (-) 0,30 ** & (-) 0,05 & (-) 0,05 \\
\hline Fv`/Fm` & $(-) 0,03$ & (+) 0,06 & (-) 0,13 & $(-) 0,06$ & (+) 0,02 & (-) 0,36 ** \\
\hline ФPSII & $(-) 0,00$ & (-) 0,01 & (+) 0,21 * & (-) 0,12 & (-) 0,16 & (-) 0,01 \\
\hline$q P$ & $(+) 0,02$ & (-) 0,05 & (+) 0,04 & (-) 0,04 & (-) 0,15 & (+) 0,12 \\
\hline NPQ & $(+) 0,03$ & (-) 0,27 * & (+) 0,03 & (-) 0,01 & (-) 0,07 & (+) 0,19 * \\
\hline ETR & - & (-) 0,02 & (+) 0,26 * & - & (-) 0,14 & (-) 0,02 \\
\hline Fs/Fo & $(-) 0,23$ * & (+) 0,02 & (-) 0,26 * & $(-)$ 0,03 & (+) 0,02 & (-) 0,27 * \\
\hline Fo/Fv & $(+) 0,43^{* *}$ & (+) 0,19 * & (+) 0,37 ** & (+) 0,28 * & (+) 0,05 & (+) 0,22 * \\
\hline
\end{tabular}

Como se puede observar en la tabla 4.26, el contenido de $\mathrm{Mn}$ en el suelo se ha relacionado significativamente de forma negativa con Fo y la ratio Fo/Fv en los años 2010 y 2011, y con Fv/Fm en 2010 y 2011 medidas en el cuajado. En este mismo estado fenológico, el nivel de $\mathrm{Mn}$ en el suelo se ha relacionado significativamente de forma negativa con Fo', Fm`, Fv' y Fs en 2010. En el envero, el Mn se ha relacionado significativamente con la ФPSIl de forma positiva en 2009 y 2010. También se ha relacionado positivamente con Fm, Fv, Fo', Fm`, Fv', Fs, Fv/Fm y las ratio Fs/Fo y Fo/Fv en 2011, y con ФPSIl y qP en 2009 y 2010.

Kriedemann (1985) observó que las hojas de plantas de trigo que crecen bajo deficiencia de manganeso mostraban mayor Fo y una muy reducida Fv respecto a 
plantas sanas. Posteriormente, autores como Kriedemann (1985), Hannam (1985), Sayed (1998) y Adams et al. (2000)han demostrado que la ratio Fo/Fv presenta una gran sensibilidad para detectar precozmente la deficiencia de Mn. Por otra parte, Henriques (2003) también ha mostrado una reducción en la eficiencia fotoquímica del PSII (Fv/Fm) con deficiencia de $\mathrm{Mn}$. El Mn es conocido por ser fundamental para la fotolisis del agua en la fotosíntesis (Kalaji, 2011), y también como activador de muchas enzimas (Salisbury y Ross, 1992).

Tabla 4.26. Coeficiente de determinación $\left(R^{2}\right)$, nivel de significación y pendiente de la regresión de los parámetro de fluorescencia de la clorofila medidos en cuajado y envero sobre el contenido de $\mathrm{Mn}$ en el suelo $\left(\mathrm{mg} \cdot \mathrm{kg}^{-1}\right)$.

\begin{tabular}{|c|c|c|c|c|c|c|}
\hline \multirow{3}{*}{$\begin{array}{l}\text { Parámetros de } \\
\text { Fluorescencia }\end{array}$} & \multicolumn{6}{|c|}{ Contenido de Mn en el suelo } \\
\hline & \multicolumn{3}{|c|}{ Cuajado } & \multicolumn{3}{|c|}{ Envero } \\
\hline & 2009 & 2010 & 2011 & 2009 & 2010 & 2011 \\
\hline Fo & $(+) 0,00$ & $(-) 0,23$ * & $(-) 0,24$ * & $(+) 0,01$ & $(-) 0,04$ & $(-) 0,01$ \\
\hline Fm & $(+) 0,07$ & (+) 0,02 & $(+) 0,04$ & $(+) 0,12$ & $(+) 0,06$ & $(+) 0,23$ * \\
\hline Fv & $(+) 0,07$ & $(+) 0,13$ & $(+) 0,16$ & $(+) 0,13$ & (+) 0,09 & $(+) 0,24$ * \\
\hline Fo' & $(+) 0,00$ & $(-) 0,19$ * & (+) 0,00 & (+) 0,00 & $(-) 0,14$ & (+) $0,30 * *$ \\
\hline Fm` & $(+) 0,00$ & $(-) 0,21$ * & $(+) 0,02$ & (-) 0,00 & (-) 0,09 & $(+) 0,27$ ** \\
\hline Fv' & $(-) 0,00$ & $(-) 0,19$ * & (+) 0,03 & (-) 0,00 & (-) 0,05 & (+) 0,22 * \\
\hline Fs & $(+) 0,00$ & (-) 0,19 * & (+) 0,01 & (-) 0,02 & (-) 0,14 & (+) 0,26 ** \\
\hline Fv/Fm & $(+) 0,11$ & (+) 0,22 * & (+) 0,23 * & $(+) 0,17$ & $(+) 0,10$ & (+) 0,18 * \\
\hline Fv'/Fm` & $(-) 0,03$ & (-) 0,07 & (+) 0,05 & (+) 0,00 & $(-)$ 0,02 & (+) 0,15 \\
\hline ФPSII & (-) 0,09 & (+) 0,04 & (+) 0,09 & (+) 0,82 *** & (+) 0,25 * & (+) 0,06 \\
\hline $\mathbf{q P}$ & $(-) 0,04$ & (+) 0,07 & (-) 0,03 & (+) 0,70 ** & (+) 0,56 *** & (-) 0,02 \\
\hline NPQ & $(+) 0,04$ & (+) 0,17 * & (-) 0,00 & (+) 0,18 & (+) 0,18 * & (-) 0,10 \\
\hline ETR & - & (+) 0,05 & (+) 0,12 & - & (+) 0,30 ** & (+) 0,06 \\
\hline Fs/Fo & $(+) 0,00$ & (-) 0,00 & $(+) 0,13$ & (-) 0,04 & (-) 0,02 & (+) 0,21 * \\
\hline Fo/Fv & $(-) 0,09$ & (-) 0,22 * & (-) 0,23 * & $(-) 0,13$ & (-) 0,09 & (-) 0,19 * \\
\hline
\end{tabular}

En el caso del Mn, las relaciones observadas entre los niveles peciolares con los parámetros de fluorescencia son similares a las obtenidas con los contenidos de suelo. La concentración de $\mathrm{Mn}$ en los peciolos se ha relacionado significativamente de forma negativa en 2009 y positiva en 2010 con Fo', y de forma positiva en 2010 y negativa en 2011 con Fm` y Fv' medidas en el cuajado (tabla 4.27). Además, Fv/Fm se ha relacionado significativamente de forma negativa en los tres años de ensayo, la ratio Fs/Fo en 2009 y 2011, y de forma positiva Fo en 2010 y 2011, y Fo/Fv en 2009, 2010 y 2011 con el nivel de Mn peciolar. En el envero, se han encontrado regresiones del contenido de Mn en los peciolos significativamente negativas con Fm, Fv, Fo', Fm', Fv', Fs y Fv/Fm en 2009 y con Fm`, Fv', Fs, Fv'/Fm` y Fs/Fo en 2011. Fo se ha relacionado de forma significativa con el Mn peciolar en los tres años de estudio. 
El hecho de que la clorosis férrica se manifieste en una acumulación de Mn en los peciolos (Martín et al., 2008), es congruente con las regresiones negativas obtenidas entre los niveles peciolares de $\mathrm{Mn}$ y la eficiencia fotosintética del PSII (Fv/Fm). Teniendo en cuenta los resultados obtenidos, se puede afirmar que Fo, Fv/Fm y Fo/Fv podrían ser utilizadas como herramienta de diagnóstico del estado nutricional del viñedo en cuanto al Mn en zonas afectadas por clorosis férrica.

Tabla 4.27. Coeficiente de determinación $\left(R^{2}\right)$, nivel de significación y pendiente de la regresión de los parámetro de fluorescencia de la clorofila medidos en cuajado y envero sobre el contenido de $\mathrm{Mn}$ en los peciolos ( $\mathrm{mg} \cdot \mathrm{kg}^{-1}$ s.m.s.).

\begin{tabular}{|c|c|c|c|c|c|c|}
\hline \multirow{3}{*}{$\begin{array}{l}\text { Parámetros de } \\
\text { Fluorescencia }\end{array}$} & \multicolumn{6}{|c|}{ Contenido de Mn en los peciolos } \\
\hline & \multicolumn{3}{|c|}{ Cuajado } & \multicolumn{3}{|c|}{ Envero } \\
\hline & 2009 & 2010 & 2011 & 2009 & 2010 & 2011 \\
\hline Fo & $(+) 0,07$ & $(+) 0,46$ ** & $(+) 0,50 * * *$ & $(+) 0,51^{* *}$ & $(+) 0,20$ * & $(+) 0,28$ * \\
\hline Fm & $(-) 0,03$ & $(+) 0,00$ & $(-) 0,03$ & $(-) 0,43^{* *}$ & $(-) 0,00$ & $(-) 0,10$ \\
\hline Fv & $(-) 0,07$ & $(-) 0,10$ & $(-) 0,28 * *$ & $(-)$ 0,39 ** & $(-)$ 0,03 & $(-) 0,14$ \\
\hline Fo' & $(-) 0,20$ * & $(+) 0,48$ ** & $(-) 0,00$ & $(-)$ (-22 * & (+) 0,03 & $(-) 0,16$ \\
\hline Fm & $(-) 0,17$ & $(+) 0,29$ ** & $(-) 0,20$ * & $(-) 0,24$ * & (+) 0,01 & $(-) 0,26$ * \\
\hline Fv' & $(-) 0,11$ & $(+) 0,18$ * & (-) 0,19 * & $(-) 0,21$ * & $(+) 0,00$ & (-) 0,29 ** \\
\hline Fs & $(-) 0,17$ & (+) 0,26 * & (-) 0,09 & (-) 0,22 * & (+) 0,02 & (-) 0,25 * \\
\hline Fv/Fm & $(-) 0,20$ * & (-) 0,32 ** & (-) 0,40 ** & (-) 0,18 * & (-) 0,12 & (-) 0,15 \\
\hline $\mathrm{Fv}^{`} / \mathrm{Fm}^{`}$ & $(-) 0,00$ & (+) 0,00 & (-) 0,25 * & (-) 0,15 & (+) 0,00 & (-) 0,36 ** \\
\hline ФPSII & $(+) 0,00$ & (-) 0,05 & $(-) 0,11$ & (-) 0,01 & (-) 0,09 & (-) 0,06 \\
\hline$q P$ & $(+) 0,02$ & (-) 0,05 & (-) 0,00 & (+) 0,00 & (-) 0,06 & (-) 0,08 \\
\hline NPQ & $(+) 0,21$ * & (-) 0,21 * & (+) 0,09 & (+) 0,00 & (-) 0,01 & (+) 0,19 * \\
\hline ETR & - & (-) 0,05 & $(-) 0,18$ * & - & (-) 0,09 & (-) 0,05 \\
\hline Fs/Fo & $(-) 0,28$ * & (-) 0,00 & (-) 0,35 ** & (-) 0,09 & (-) 0,03 & (-) 0,29 ** \\
\hline Fo/Fv & $(+) 0,20$ * & (+) $0,33^{* *}$ & (+) 0,38 ** & (+) 0,15 & (+) 0,09 & (+) 0,24 * \\
\hline
\end{tabular}

\subsection{2.- Relación del contenido en pigmentos foliares del viñedo con} la asimilación neta, conductancia estomática y los parámetros de fluorescencia de la clorofila.

Como se observa en la tabla 4.28 , la asimilación neta se ha relacionado positivamente con los niveles de antocianinas foliares en el cuajado de 2010 y el envero de 2011, mientras que en el resto de fechas de medida la regresión no fue significativa. La conductancia estomática medida en el envero de 2009 se relacionó significativamente de forma positiva con los contenidos foliares en clorofilas y carotenoides. Además, los niveles de antocianinas tuvieron una relación significativa de forma positiva con la conductancia estomática en envero de 2010. 
El efecto más obvio de la deficiencia de Fe es una gran disminución de las concentraciones de pigmentos fotosintéticos en las hojas de las plantas afectadas (Val et al., 1987; Morales et al., 1990, 1994).La concentración de clorofila foliar por unidad de superficie se considera un indicador de la capacidad fotosintética de las plantas (Taiz y Zeiger, 2002), e indica también el contenido de nitrógeno foliar y la salud general de la planta (Ling et al. 2011). Sin embargo, los resultados del presente estudio no han mostrado relaciones significativas de la asimilación neta sobre la clorofila foliar, en contra de lo observado por Bavaresco et al. (2006) en plantas afectadas y no afectadas por clorosis férrica.

Tabla 4.28. Coeficiente de determinación $\left(R^{2}\right)$, nivel de significación y pendiente de la regresión de la asimilación neta $\left(\mu \mathrm{mol} \mathrm{CO}_{2} \cdot \mathrm{m}^{-2} \mathrm{~s}^{-1}\right)$ y la conductancia estomática (mmol $\mathrm{H}_{2} \mathrm{O} \cdot \mathrm{m}^{-2} \mathrm{~s}^{-1}$ ) medidas en cuajado y envero sobre el contenido en pigmentos de las hojas.

\begin{tabular}{|c|c|c|c|c|c|c|}
\hline \multirow{3}{*}{$\begin{array}{l}\text { Pigmentos } \\
\text { foliares }\end{array}$} & \multicolumn{6}{|c|}{ Asimilación neta } \\
\hline & \multicolumn{3}{|c|}{ Cuajado } & \multicolumn{3}{|c|}{ Envero } \\
\hline & 2009 & 2010 & 2011 & 2009 & 2010 & 2011 \\
\hline Clorofila a & - & (+) 0,00 & (+) 0,09 & (+) 0,06 & (+) 0,00 & $(+) 0,16$ \\
\hline Clorofila b & - & (+) 0,00 & (+) 0,02 & (+) 0,12 & (-) 0,04 & (+) 0,11 \\
\hline Clorofila $a+b$ & (+) 0,09 & (+) 0,00 & (+) 0,08 & (+) 0,07 & (-) 0,00 & (+) 0,15 \\
\hline Carotenos & - & (+) 0,00 & (+) 0,06 & (+) 0,08 & (+) 0,03 & (+) 0,18 \\
\hline \multirow[t]{2}{*}{ Antocianinas } & (+) 0,03 & (+) 0,20 * & $(+) 0,13$ & $(+) 0,02$ & (+) 0,01 & (+) $0,40^{* *}$ \\
\hline & \multicolumn{6}{|c|}{ Conductancia estomática } \\
\hline Clorofila a & - & (+) 0,00 & $(-) 0,01$ & (+) 0,39 ** & $(-) 0,01$ & (+) 0,02 \\
\hline Clorofila b & - & (+) 0,01 & (+) 0,01 & (+) 0,25 * & (+) 0,02 & (+) 0,03 \\
\hline Clorofila $a+b$ & - & (+) 0,01 & (-) 0,01 & (+) $0,37^{* *}$ & (-) 0,00 & (+) 0,02 \\
\hline Carotenos & - & (+) 0,02 & (-) 0,04 & (+) 0,36 ** & (-) 0,00 & (+) 0,02 \\
\hline Antocianinas & - & (+) $0,42^{* *}$ & (-) 0,01 & (+) 0,06 & (-) 0,00 & (+) 0,13 \\
\hline
\end{tabular}

Numerosos autores han estudiado el comportamiento de diferentes parámetros de la fluorescencia de la clorofila de las hojas en condiciones de clorosis férrica. Así, Bertamini et al. $(2001,2002)$ y Bavaresco et al. (2006) concluyeron que la relación Fv/Fm disminuía en hojas de vides cloróticas respecto a las medidas en vides sanas. En estos trabajos (Allakhverdiev et al., 1987; Setlik et al., 1990), la medida de la fluorescencia variable se redujo notablemente en las hojas cloróticas, pero el nivel de Fo no se veía afectado (a pesar de que si los receptores del fotosistema II se inhiben Fo debería incrementarse). Resultados similares se han encontrado en pera y remolacha (Morales et al. 1994, 1998). Por su parte, la variable Fm corresponde al estado de reducción completa de la $\mathrm{Qa}(\mathrm{qP}=0)$, y su valor es considerado proporcional al contenido de clorofila total de una muestra (Miranda et al., 1981; Netto et al. (2005). 
Como se ve en la tabla 4.29 , el contenido de clorofila a de las hojas se ha relacionado significativamente con la mayoría de los parámetros de la fluorescencia de la clorofila. Así, se ha dado una regresión negativa sobre Fo y positiva sobre la ETR en el cuajado en 2010 y 2011 y en el envero en 2010. La clorosis férrica reduce el transporte aparente de electrones (ETR) y el apagado fotoquímico (qP) (Bavaresco et al., 2006).

Hay que destacar, que la relación del contenido de clorofila a fue significativamente negativa con Fo`, Fm`, Fv`y Fs en el cuajado en el año 2010 y positiva con el resto de regresiones lineales significativas. También son de destacar las relaciones significativamente positivas del contenido en clorofila a con Fm y Fv, Fv/Fm, Fv'/Fm`, ФPSII y la ratio Fs/Fo en la mayoría de las medidas realizadas a lo largo de los tres años de seguimiento, y negativa sobre la ratio Fo/Fv en todos los casos.

Tabla 4.29. Coeficiente de determinación $\left(R^{2}\right)$, nivel de significación y pendiente de la regresión de los parámetro de fluorescencia de la clorofila medidos en cuajado y envero sobre el contenido en clorofila a de las hojas $\left(\mu \mathrm{g} \cdot \mathrm{cm}^{-2}\right)$.

\begin{tabular}{|c|c|c|c|c|c|c|}
\hline \multirow{3}{*}{$\begin{array}{l}\text { Parámetros de } \\
\text { Fluorescencia }\end{array}$} & \multicolumn{6}{|c|}{ Contenido de clorofila a foliar } \\
\hline & \multicolumn{3}{|c|}{ Cuajado } & \multicolumn{3}{|c|}{ Envero } \\
\hline & 2009 & 2010 & 2011 & 2009 & 2010 & 2011 \\
\hline Fo & - & $(-) 0,60 * * *$ & $(-) 0,50 * * *$ & $(-) 0,11$ & $(-) 0,37^{* *}$ & $(-) 0,06$ \\
\hline Fm & - & $(+) 0,26$ * & $(+) 0,00$ & (+) 0,46 ** & $(+) 0,08$ & $(+) 0,24$ * \\
\hline Fv & - & (+) $0,61^{* * *}$ & (+) 0,22 * & $(+) 0,47^{* *}$ & (+) 0,23 * & (+) 0,26 * \\
\hline Fo' & - & $(-) 0,39 * *$ & $(+) 0,00$ & (+) 0,36 ** & $(+) 0,11$ & (+) 0,26 * \\
\hline Fm ${ }^{\circ}$ & - & $(-) 0,30 * *$ & $(+) 0,07$ & $(+) 0,28$ * & $(+) 0,17$ * & (+) 0,30 ** \\
\hline Fv' & - & (-) 0,21 * & (+) 0,19 * & (+) 0,21 * & (+) 0,18 * & (+) 0,28 ** \\
\hline Fs & - & (-) $0,34^{* *}$ & (+) 0,04 & (+) 0,23 * & (+) 0,13 & (+) 0,26 * \\
\hline Fv/Fm & - & (+) $0,77^{* * *}$ & (+) 0,39 ** & (+) 0,40 ** & (+) 0,40 ** & (+) 0,13 \\
\hline $\mathrm{Fv}^{`} / \mathrm{Fm}^{`}$ & - & (-) 0,02 & (+) 0,19 * & (+) 0,12 & (+) 0,18 * & (+) 0,27 ** \\
\hline ФPSII & - & (+) $0,37^{* *}$ & (+) 0,30 ** & (+) 0,10 & (+) $0,30 * *$ & (+) 0,17 * \\
\hline$q P$ & - & (+) 0,31 ** & (-) 0,03 & (+) 0,02 & (+) 0,05 & (-) 0,01 \\
\hline NPQ & - & (+) 0,44 ** & (-) 0,08 & (-) 0,02 & (-) 0,05 & (-) 0,13 \\
\hline ETR & - & (+) 0,39 ** & (+) 0,31 ** & - & (+) 0,32 ** & (+) 0,18 \\
\hline Fs/Fo & - & (+) 0,00 & (+) 0,32 ** & $(+) 0,17$ & (+) 0,30 ** & (+) 0,25 * \\
\hline Fo/Fv & - & $(-) 0,75^{* * *}$ & $(-) 0,36$ ** & $(-) 0,38$ ** & $(-) 0,40$ ** & $(-) 0,26$ * \\
\hline
\end{tabular}

El contenido de clorofila $b$ de las hojas se ha relacionado significativamente de forma positiva con $\mathrm{Fv}$ y $\mathrm{Fv} / \mathrm{Fm}$, y de forma negativa con Fo y el ratio Fo/Fv en el cuajado en los años 2010 y 2011, y en el envero en 2009. Además, la clorofila b se relacionó positivamente con Fm`y Fv' en el envero de 2009 y 2011, y con ФPSII y ETR en el cuajado de 2011 y en el envero de 2010 y 2011. En los capítulos 4.2 .1 y 4.3.1. se han puesto en evidencia fuertes relaciones de la concentración de $\mathrm{Mn}$ en el suelo y en 
los peciolos con los niveles foliares de clorofila b, Fv/Fm y Fo/Fv. El Mn es conocido por ser una parte importante en la fotolisis del agua en la fotosíntesis y también como un activador de muchas enzimas (Salisbury y Ross, 1992). En definitiva, la acumulación de manganeso en los peciolos como consecuencia del déficit de hierro se correlaciona de forma importante con los valores de concentración foliar de clorofila b, la eficiencia máxima del fotosistema II y la actividad del complejo de oxidación del agua en el donador de electrones del PSII (Fo/Fv).

En el caso de la clorofila b, el número de regresiones significativas sobre los parámetros de fluorescencia fue sensiblemente menor que para la clorofila a (Tabla 4.30). En este orden de cosas, la deficiencia de Fe no disminuye en la misma medida todos los pigmentos fotosintéticos, la clorofila $b$ se ve más afectada que la clorofila $a$ (Morales et al. 1994, 2000, 2001).

Tabla 4.30. Coeficiente de determinación $\left(R^{2}\right)$, nivel de significación y pendiente de la regresión de los parámetro de fluorescencia de la clorofila medidos en cuajado y envero sobre el contenido en clorofila b de las hojas $\left(\mu \mathrm{g} \cdot \mathrm{cm}^{-2}\right)$.

\begin{tabular}{|c|c|c|c|c|c|c|}
\hline \multirow{3}{*}{$\begin{array}{l}\text { Parámetros de } \\
\text { Fluorescencia }\end{array}$} & \multicolumn{6}{|c|}{ Contenido de clorofila b foliar } \\
\hline & \multicolumn{3}{|c|}{ Cuajado } & \multicolumn{3}{|c|}{ Envero } \\
\hline & 2009 & 2010 & 2011 & 2009 & 2010 & 2011 \\
\hline Fo & - & $(-) 0,18^{*}$ & $(-) 0,23$ * & $(+) 0,30^{* *}$ & $(-) 0,11$ & $(-) 0,02$ \\
\hline Fm & - & $(+) 0,13$ & $(+) 0,08$ & (+) $0,62 * * *$ & (+) 0,02 & $(+) 0,12$ \\
\hline Fv & - & (+) 0,26 * & (+) 0,21 * & (+) $0,61^{* * *}$ & (+) 0,06 & (+) 0,13 \\
\hline Fo' & - & $(-) 0,13$ & $(+) 0,00$ & (+) 0,49 ** & $(-) 0,01$ & $(+) 0,13$ \\
\hline Fm` & - & (-) 0,09 & (+) 0,04 & (+) 0,36 ** & (+) 0,00 & (+) 0,17 * \\
\hline Fv' & - & $(-) 0,06$ & (+) 0,06 & (+) 0,27 * & (+) 0,02 & (+) 0,17 * \\
\hline Fs & - & $(-) 0,09$ & $(+) 0,02$ & (+) $0,32 * *$ & (-) 0,00 & $(+) 0,13$ \\
\hline Fv/Fm & - & (+) 0,25 * & (+) 0,25 * & (+) $0,45^{* *}$ & (+) 0,12 & (+) 0,06 \\
\hline $\mathrm{Fv}^{`} / \mathrm{Fm}^{`}$ & - & $(-) 0,01$ & (+) 0,16 & (+) 0,15 & (+) 0,09 & (+) 0,18 * \\
\hline ФPSII & - & (+) 0,04 & (+) 0,22 * & (+) 0,05 & (+) 0,38 ** & (+) 0,21 * \\
\hline$q P$ & - & (+) 0,05 & $(-) 0,02$ & (+) 0,00 & (+) 0,15 & (-) 0,01 \\
\hline NPQ & - & (+) 0,16 & (-) 0,04 & (-) 0,04 & (+) 0,00 & (-) 0,08 \\
\hline ETR & - & (+) 0,05 & (+) 0,20 * & - & (+) 0,36 ** & (+) 0,22 * \\
\hline Fs/Fo & - & (-) 0,00 & (+) 0,13 & (+) 0,20 * & (+) 0,00 & (+) 0,13 \\
\hline Fo/Fv & - & (-) 0,23 * & (-) 0,23 * & (-) 0,43 ** & (-) 0,09 & (-) 0,12 \\
\hline
\end{tabular}

La tabla 4.31 muestra que la concentración de clorofilas $a+b$ en las hojas se ha relacionado significativamente con varios parámetros de fluorescencia de la clorofila. Son de destacar las relaciones negativas con Fo y Fo/Fv, y positivas con Fm, Fv, Fv/Fm, Fv'/Fm', ФPSII, ETR y la ratio Fs/Fo. La deficiencia de Fe induce cambios en las cinéticas de la fluorescencia de clorofila con un aumento considerable del nivel 
inicial de fluorescencia Fo, y una disminución de la proporción de fluorescencia variable Fv (Morales et al., 1991; Greene et al., 1992), lo que refleja una pérdida de eficiencia fotoquímica en el PSII. La clorosis férrica reduce el transporte aparente de electrones (ETR) y el apagado fotoquímico (qP) (Bavaresco et al., 2006).

Como muestra la tabla 4.32, la concentración de carotenoides totales en las hojas se ha relacionado significativamente con los parámetros de fluorescencia de la clorofila en la mayoría de las medidas realizadas durante los tres años de seguimiento. Como en el caso de la clorofila, la relación del contenido de carotenoides fue significativamente negativa con Fo', Fm`, Fv'y Fs en el cuajado en el año 2010, y positiva en el resto de las regresiones lineales significativas. Además, se han observado relaciones significativamente positivas del contenido en carotenoides con Fm y Fv, Fv/Fm, Fv'/Fm`, ФPSII, NPQ, ETR y la ratio Fs/Fo en la mayoría de las medidas realizadas a lo largo de los tres años de seguimiento, y negativa sobre Fo y la ratio Fo/Fv en todos los casos.

Tabla 4.31. Coeficiente de determinación $\left(R^{2}\right)$, nivel de significación y pendiente de la regresión de los parámetro de fluorescencia de la clorofila medidos en cuajado y envero sobre el contenido en clorofila $a+b$ de las hojas $\left(\mu \mathrm{g} \cdot \mathrm{cm}^{-2}\right)$.

\begin{tabular}{|c|c|c|c|c|c|c|}
\hline \multirow{3}{*}{$\begin{array}{l}\text { Parámetros de } \\
\text { Fluorescencia }\end{array}$} & \multicolumn{6}{|c|}{ Contenido de clorofila $a+b$ foliar } \\
\hline & \multicolumn{3}{|c|}{ Cuajado } & \multicolumn{3}{|c|}{ Envero } \\
\hline & 2009 & 2010 & 2011 & 2009 & 2010 & 2011 \\
\hline Fo & $(-) 0,02$ & $(-) 0,44$ ** & $(-) 0,45^{* *}$ & $(-) 0,15$ & $(-) 0,37^{* *}$ & $(-) 0,04$ \\
\hline $\mathbf{F m}$ & $(+) 0,06$ & (+) 0,26 * & $(+) 0,02$ & $(+) 0,51 * *$ & $(+) 0,07$ & $(+) 0,20$ * \\
\hline Fv & $(+) 0,10$ & $(+) 0,53^{* * *}$ & $(+) 0,23$ * & $(+) 0,52 * *$ & $(+) 0,20$ * & $(+) 0,22$ * \\
\hline Fo' & $(+) 0,01$ & $(-) 0,32$ ** & $(+) 0,00$ & $(+) 0,40$ ** & $(+) 0,06$ & $(+) 0,21$ * \\
\hline Fm` & $(+) 0,00$ & $(-) 0,23$ * & $(+) 0,07$ & (+) $0,31^{* *}$ & $(+) 0,12$ & $(+) 0,26$ * \\
\hline Fv' & $(+) 0,01$ & $(-) 0,16$ & $(+) 0,11$ & (+) 0,23 * & (+) 0,15 & (+) 0,25 * \\
\hline Fs & $(+) 0,00$ & (-) $0,25^{*}$ & (+) 0,04 & (+) 0,26 * & (+) 0,09 & (+) 0,22 * \\
\hline Fv/Fm & $(+) 0,24$ * & (+) $0,61^{* * *}$ & (+) 0,38 ** & (+) 0,42 ** & (+) 0,40 ** & $(+) 0,11$ \\
\hline Fv'/Fm` & $(-) 0,08$ & $(-) 0,01$ & (+) 0,20 * & $(+) 0,13$ & (+) 0,20 * & (+) 0,24 * \\
\hline ФPSII & $(+) 0,01$ & (+) 0,24 * & (+) 0,30 ** & (+) 0,09 & (+) 0,42 ** & *) 0,20 * \\
\hline$q P$ & $(+) 0,04$ & (+) 0,22 * & (-) 0,03 & (+) 0,02 & $(+) 0,10$ & (-) 0,00 \\
\hline NPQ & $(-) 0,06$ & (+) $0,37^{* *}$ & (-) 0,08 & $(-) 0,03$ & $(-) 0,03$ & (-) 0,12 \\
\hline ETR & - & (+) 0,26 * & (+) 0,31 ** & - & $(+) 0,44$ ** & (+) 0,20 * \\
\hline Fs/Fo & $(+) 0,00$ & (+) 0,00 & (+) 0,29 ** & $(+) 0,18$ & (+) 0,26 * & (+) 0,21 * \\
\hline Fo/Fv & $(-) 0,21$ * & $(-) 0,59 * * *$ & (-) 0,35 ** & (-) 0,41 ** & (-) 0,38 ** & (-) 0,21 * \\
\hline
\end{tabular}

Los carotenoides tienen en las plantas una función doble, como pigmentos accesorios en la captación de energía lumínica y como moléculas capaces de disipar la energía de excitación excedente en forma de calor, evitando daños en el aparato 
fotosintético. Mientras que como transductores de energía hacia los centros de reacción no son muy eficientes (30\%-40\%), sí lo son como disipadores del exceso de energía. La deficiencia de Fe no disminuye en la misma medida todos los pigmentos fotosintéticos, la concentración de carotenos se reduce en menor proporción que las clorofilas (Terry, 1980; Abadía, 1992; Terry y Zayed, 1995). En realidad, el característico color amarillo de las hojas cloróticas es la consecuencia de este desequilibrio entre los contenidos de clorofila y carotenos. En diversos trabajos se ha constatado un aumento significativo en la ratio carotenos/clorofilas con diferentes tipos de estrés abiótico, que puede deberse a las siguientes causas: (1) una disminución en el contenido de clorofila por una menor síntesis o aumento de su degradación; (2) un aumento de los carotenoides que funcionan como fotoprotectores y antioxidantes en el metabolismo de la planta; y (3) una mayor persistencia de los carotenoides en relación a la clorofila en las hojas senescentes (Filella et al., 1995; Martínez-Peñalver et al., 2011).

Tabla 4.32. Coeficiente de determinación $\left(R^{2}\right)$, nivel de significación y pendiente de la regresión de los parámetro de fluorescencia de la clorofila medidos en cuajado y envero sobre el contenido en carotenoides de las hojas $\left(\mu \mathrm{g} \cdot \mathrm{cm}^{-2}\right)$.

\begin{tabular}{|c|c|c|c|c|c|c|}
\hline \multirow{3}{*}{$\begin{array}{l}\text { Parámetros de } \\
\text { Fluorescencia }\end{array}$} & \multicolumn{6}{|c|}{ Contenido de carotenoides foliares } \\
\hline & \multicolumn{3}{|c|}{ Cuajado } & \multicolumn{3}{|c|}{ Envero } \\
\hline & 2009 & 2010 & 2011 & 2009 & 2010 & 2011 \\
\hline Fo & - & $(-) 0,45^{* *}$ & $(-) 0,29 * *$ & $(+) 0,14$ & $(-) 0,31 * *$ & $(-) 0,13$ \\
\hline Fm & - & (+) 0,25 * & $(+) 0,00$ & (+) $0,57^{* * *}$ & (+) 0,01 & (+) 0,18 \\
\hline Fv & - & (+) $0,53 * * *$ & $(+) 0,09$ & (+) $0,58 * * *$ & $(+) 0,08$ & (+) 0,22 * \\
\hline Fo` & - & $(-) 0,32 * *$ & $(+) 0,00$ & (+) $0,39 * *$ & (+) 0,18 * & (+) 0,26 * \\
\hline Fm & - & (-) $0,29 * *$ & (+) 0,01 & (+) 0,35 ** & (+) 0,28 ** & (+) 0,32 ** \\
\hline Fv' & - & (-) 0,23 * & (+) 0,02 & (+) 0,28 * & (+) 0,32 ** & (+) 0,31 ** \\
\hline Fs & - & $(-) 0,32$ ** & (+) 0,00 & (+) 0,29 * & (+) 0,25 * & (+) 0,28 ** \\
\hline Fv/Fm & - & (+) $0,61 * * *$ & (+) 0,21 * & (+) 0,50 ** & (+) 0,25 * & (+) 0,14 \\
\hline Fv`/Fm` & - & $(-) 0,06$ & $(+) 0,05$ & (+) 0,19 * & (+) 0,28 ** & (+) 0,30 ** \\
\hline ФPSII & - & (+) 0,34 ** & (+) 0,21 * & (+) 0,11 & (+) 0,27 ** & (+) 0,21 * \\
\hline $\mathbf{q P}$ & - & (+) 0,32 ** & (-) 0,05 & (+) 0,02 & (+) 0,02 & $(-) 0,00$ \\
\hline NPQ & - & (+) 0,41 ** & (-) 0,03 & (-) 0,03 & $(-) 0,17$ * & (-) 0,19 * \\
\hline ETR & - & (+) 0,36 ** & (+) 0,23 * & - & (+) 0,30 ** & (+) 0,21 * \\
\hline Fs/Fo & - & $(-) 0,00$ & (+) 0,12 & (+) 0,22 * & (+) 0,40 ** & (+) 0,30 ** \\
\hline Fo/Fv & - & (-) 0,58 *** & (-) 0,19 * & $(-) 0,48$ ** & $(-) 0,27^{* *}$ & (-) $0,27^{* *}$ \\
\hline
\end{tabular}

La concentración de antocianinas en las hojas se ha relacionado significativamente de forma positiva con $\mathrm{Fv}$ y $\mathrm{Fv} / \mathrm{Fm}$ en todas las medidas realizadas a lo largo de los tres años de seguimiento (tabla 4.33). En el envero se han observado relaciones significativamente positivas del contenido de antocianinas sobre 
prácticamente todos los parámetros de fluorescencia de la clorofila en los años 2010 y 2011, al igual que en el cuajado de 2011.

Las antocianinas son pigmentos rojos no fotosintéticos. Algunos autores sugieren que las antocianinas tienen un papel fotoprotector (Gould et al., 2002; Manetas et al., 2002, 2003; Steyn et al., 2002; Hughes et al., 2005), pero esta hipótesis no está confirmada, ya que algunos resultados experimentales muestran que el filtro antociánico no es ventajoso para la fotosíntesis (Burger y Edwards, 1996; Lee et al., 2003). La acumulación de antocianinas en los tejidos vegetales requiere luz, y se ve favorecida por situaciones de estrés. Coincide con períodos donde hay un mayor potencial de daño foto-oxidativo debido a un desequilibrio entre la captación de luz, la asimilación de $\mathrm{CO}_{2}$ y la utilización de carbohidratos (por ejemplo la senescencia de los órganos y las condiciones ambientales adversas). En este contexto, las relaciones encontradas entre los parámetros de fluorescencia y los niveles de antocianinas de las hojas en el presente estudio ponen de manifiesto que estos pigmentos tienen un impacto importante en la eficiencia fotosintética del viñedo y podrían ser útiles para controlar el nivel de estrés de las plantas.

Tabla 4.33. Coeficiente de determinación $\left(R^{2}\right)$, nivel de significación y pendiente de la regresión de los parámetro de fluorescencia de la clorofila medidos en cuajado y envero sobre el contenido en antocianinas de las hojas $\left(\mu \mathrm{g} \cdot \mathrm{cm}^{-2}\right)$.

\begin{tabular}{|c|c|c|c|c|c|c|}
\hline \multirow{3}{*}{$\begin{array}{l}\text { Parámetros de } \\
\text { Fluorescencia }\end{array}$} & \multicolumn{6}{|c|}{ Contenido de antocianinas foliares } \\
\hline & \multicolumn{3}{|c|}{ Cuajado } & \multicolumn{3}{|c|}{ Envero } \\
\hline & 2009 & 2010 & 2011 & 2009 & 2010 & 2011 \\
\hline Fo & $(+) 0,02$ & $(-) 0,05$ & $(-) 0,74^{* * *}$ & $(+) 0,05$ & $(-) 0,39 * *$ & $(+) 0,12$ \\
\hline Fm & $(+) 0,13$ & $(+) 0,32$ ** & (+) 0,18 * & (+) 0,19 * & $(+) 0,03$ & $(+) 0,22$ * \\
\hline $\mathbf{F v}$ & $(+) 0,20$ * & $(+) 0,32$ ** & $(+) 0,57^{* * *}$ & (+) 0,20 * & $(+) 0,17^{*}$ & (+) 0,26 * \\
\hline Fo' & $(+) 0,02$ & $(+) 0,06$ & $(+) 0,05$ & $(+) 0,07$ & $(+) 0,17^{*}$ & (+) $0,50 * * *$ \\
\hline Fm & $(+) 0,00$ & $(+) 0,09$ & (+) 0,30 ** & $(+) 0,08$ & $(+) 0,24$ * & (+) $0,57^{* * *}$ \\
\hline Fv` & $(+) 0,00$ & $(+) 0,10$ & (+) 0,39 ** & (+) 0,07 & (+) 0,26 * & (+) 0,54 *** \\
\hline Fs & $(+) 0,00$ & (+) 0,04 & (+) 0,23 * & (+) 0,06 & (+) 0,19 * & (+) 0,54 *** \\
\hline Fv/Fm & $(+) 0,36$ ** & (+) 0,18 * & (+) $0,70^{* * *}$ & (+) 0,20 * & (+) 0,38 ** & (+) 0,24 * \\
\hline $\mathrm{Fv}^{`} / \mathrm{Fm}^{`}$ & $(-) 0,02$ & $(+) 0,11$ & (+) 0,44 ** & (+) 0,08 & (+) 0,32 ** & (+) 0,42 ** \\
\hline ФPSII & $(+) 0,00$ & (+) 0,16 & (+) 0,28 * & (+) 0,08 & (+) 0,50 *** & $(+) 0,12$ \\
\hline qP & $(+) 0,01$ & (+) 0,03 & (-) 0,01 & (+) 0,03 & (+) 0,06 & (-) 0,02 \\
\hline NPQ & $(+) 0,08$ & (-) 0,01 & (-) 0,20 * & (+) 0,01 & $(-) 0,14$ & (-) 0,32 ** \\
\hline ETR & - & $(+) 0,16$ & (+) 0,30 ** & - & (+) 0,48 ** & (+) 0,15 \\
\hline Fs/Fo & $(+) 0,02$ & (+) 0,22 * & (+) $0,67^{* * *}$ & $(+) 0,04$ & (+) 0,39 ** & (+) $0,53^{* * *}$ \\
\hline Fo/Fv & $(-) 0,33^{* *}$ & $(-) 0,15$ & $(-) 0,67^{* * *}$ & (-) 0,19 & $(-) 0,38$ ** & $(-) 0,31$ ** \\
\hline
\end{tabular}




\subsection{3.- Influencia del estado nutricional de los viñedos sobre los parámetros de la fluorescencia de la clorofila foliar.}

Se ha realizado un análisis de la varianza de los valores de asimilación neta, conductancia estomática y parámetros de fluorescencia de la clorofila medidos en hoja en función de la clasificación de las subparcelas en cloróticas y no cloróticas, realizada a partir de la concentración foliar de clorofila y el contenido en arcilla y carbonatos totales de los suelos (ver apartado 4.2.3). Las separaciones de medias se muestran en la tabla 4.34 .

Las subzonas cloróticas tienen tasas más bajas de asimilación y conductancia estomática en comparación con las sanas (Bavaresco et al., 2006). En el presente estudio, la asimilación neta de las vides afectadas por clorosis férrica fue menor que la de vides sanas, aunque no se encontraron diferencias significativas al $5 \%$ (tabla 4.34).La reducción de la tasa fotosintética en las hojas cloróticas deficientes en Fe se ha atribuido fundamentalmente a la reducción de la eficiencia del fotosistema II (PSII) debido al cierre de centros de reacción y a la reducción de la eficiencia intrínseca del PSII (Morales et al. 2000; Covarrubias et al, 2014). Además, la carboxilación por parte de la Rubisco en las hojas se ve regulada a la baja en respuesta a la deficiencia de Fe (Larbi et al. 2006).Se ha propuesto que la deficiencia interfiere la regeneración de la ribulosa bifosfato (RuBP), lo que no estaría asociado a niveles bajos de ATP y NADPH sino a la disminución de la actividad de la enzima Ru5Pkinasa (Arulanantham et al., 1990).

Como se puede observar en la tabla4.34, los valores de Fo medidos en cuajado fueron mayores en las zonas de muestreo cloróticas que en las zonas sanas en los tres años de estudio, de acuerdo con Bavaresco et al. (2006), mientras que comparando las medidas en envero las diferencias no fueron significativas. La fluorescencia mínima refleja la pérdida de una parte de la energía absorbida por las moléculas del complejo-antena antes que éstas hayan podido transferirla hacia los centros de reacción (Briantais et al. 1986). Este nivel corresponde a un estado donde todos los aceptores primarios de electrones del PSII $\left(Q_{A}\right)$ están oxidados (con falta de electrones) y, por tanto, es independiente de los procesos fotoquímicos. En definitiva, se puede afirmar que la medida de Fo durante el cuajado puede ser una buena herramienta de diagnóstico del grado de clorosis férrica.

En las medidas de los parámetros de fluorescencia se puede apreciar un descenso generalizado en las plantas afectadas por clorosis férrica de los valores de, especialmente acusado en Fm. Tanto Fm y Fv fueron significativamente mayores en las subzonas no cloróticas que en las subzonas cloróticas, tanto en el cuajado como en el envero de los tres años de estudio (tabla4.32). Cuanto mayor es el valor de Fv mayor es la capacidad del PSII y, en consecuencia, mayor es la capacidad de asimilación de $\mathrm{CO}_{2}$ en la fotosíntesis (Baker y Rosenqvist, 2004), como se ha visto reflejado en el presente trabajo. Por lo tanto, las medidas de Fm y Fv podrían permitir diagnosticar de forma temprana la clorosis férrica. 
Tabla 4.34. Valores medios de diferentes parámetros de fluorescencia de la clorofila medidos en cuajado y envero en áreas de muestreo afectadas (C) y no afectadas (NC) por clorosis férrica.

\begin{tabular}{|c|c|c|c|c|c|c|}
\hline \multirow{2}{*}{$\begin{array}{l}\text { Parámetros } \\
\text { Cuajado }\end{array}$} & \multicolumn{2}{|c|}{2009} & \multicolumn{2}{|c|}{2010} & \multicolumn{2}{|c|}{2011} \\
\hline & NC & C & NC & C & NC & C \\
\hline An & $11,10 a$ & $10,17 a$ & $10,63 a$ & $9,72 a$ & $9,98 a$ & $9,32 a$ \\
\hline gs & - & - & $0,209 a$ & $0,183 a$ & $0,072 b$ & $0,109 a$ \\
\hline Fo & $499 b$ & $593 a$ & $491 b$ & $600 \mathrm{~b}$ & $575 b$ & $786 a$ \\
\hline Fm & $2421 a$ & $2058 b$ & $2186 a$ & $2033 b$ & $2663 a$ & $2530 b$ \\
\hline Fv & $1922 a$ & $1465 b$ & $1694 a$ & $1432 b$ & $2088 a$ & $1744 b$ \\
\hline Fo' & $494 a$ & $451 \mathrm{a}$ & $401 \mathrm{~b}$ & $460 a$ & $546 a$ & $521 a$ \\
\hline Fm & $1037 a$ & $815 b$ & $677 b$ & $798 a$ & $1046 a$ & $903 a$ \\
\hline Fv' & $543 a$ & $364 b$ & $276 b$ & $338 a$ & $500 a$ & $382 b$ \\
\hline Fs & $915 a$ & $748 a$ & $573 b$ & $702 a$ & $917 a$ & $803 a$ \\
\hline Fv/Fm & $0,79 a$ & $0,70 b$ & $0,78 a$ & $0,69 b$ & $0,78 a$ & $0,68 b$ \\
\hline $\mathrm{Fv}^{`} / \mathrm{Fm}{ }^{`}$ & $0,48 a$ & $0,38 b$ & $0,39 a$ & $0,40 a$ & $0,46 a$ & $0,39 b$ \\
\hline ФPSII & $0,12 a$ & $0,08 a$ & $0,16 a$ & $0,12 b$ & $0,13 a$ & $0,11 a$ \\
\hline $\mathbf{q P}$ & $0,23 a$ & $0,20 a$ & $0,41 a$ & $0,30 \mathrm{~b}$ & $0,31 a$ & $0,30 a$ \\
\hline NPQ & $1,38 a$ & $1,65 a$ & $2,32 a$ & $1,58 b$ & $1,63 a$ & $1,88 a$ \\
\hline ETR & - & - & $105 a$ & $79,9 b$ & $90,0 a$ & $75,7 b$ \\
\hline Fs/Fo & $1,84 a$ & $1,28 b$ & $1,17 a$ & $1,18 a$ & $1,61 a$ & $1,06 b$ \\
\hline Fo/Fv & $0,26 b$ & $0,42 a$ & $0,29 b$ & $0,42 a$ & $0,27 b$ & $0,47 a$ \\
\hline \multicolumn{7}{|l|}{ Envero } \\
\hline An & $9,55 a$ & $8,72 a$ & $7,07 a$ & $8,33 a$ & $7,77 a$ & $5,60 a$ \\
\hline gs & $0,222 a$ & $0,125 a$ & $0,079 a$ & $0,083 a$ & $0,110 a$ & $0,103 a$ \\
\hline Fo & $488 a$ & $477 a$ & $566 a$ & $600 a$ & $494 a$ & $501 a$ \\
\hline Fm & $2541 a$ & $2197 b$ & $2572 a$ & $2404 b$ & $2746 a$ & $2532 b$ \\
\hline $\mathbf{F v}$ & $2053 a$ & $1719 b$ & $2006 a$ & $1804 b$ & $2253 a$ & $2032 b$ \\
\hline Fo' & $575 a$ & $510 a$ & $506 a$ & $499 a$ & $541 a$ & $500 a$ \\
\hline Fm & $1247 a$ & $1034 a$ & $829 a$ & $800 a$ & $903 a$ & $804 a$ \\
\hline$F^{\prime}{ }^{\prime}$ & $672 a$ & $524 a$ & $323 a$ & $300 a$ & $362 a$ & $305 a$ \\
\hline Fs & $1131 a$ & $942 a$ & $731 a$ & $706 a$ & $787 a$ & $709 a$ \\
\hline Fv/Fm & $0,81 a$ & $0,77 b$ & $0,78 a$ & $0,75 b$ & $0,81 a$ & $0,80 a$ \\
\hline $\mathrm{Fv}^{`} / \mathrm{Fm}^{`}$ & $0,52 a$ & $0,48 b$ & $0,37 a$ & $0,36 a$ & $0,39 a$ & $0,36 a$ \\
\hline ФPSII & $0,097 a$ & $0,087 a$ & $0,13 a$ & $0,12 a$ & $0,13 a$ & $0,12 a$ \\
\hline$q P$ & $0,19 a$ & $0,18 a$ & $0,34 a$ & $0,33 a$ & $0,35 a$ & $0,35 a$ \\
\hline NPQ & $1,08 a$ & $1,19 a$ & $2,18 a$ & $2,07 a$ & $2,12 a$ & $2,23 a$ \\
\hline ETR & $1,00 a$ & $1,00 a$ & $86,0 a$ & $79,3 a$ & $89,6 a$ & $82,2 a$ \\
\hline Fs/Fo & $2,31 a$ & $1,97 a$ & $1,30 a$ & $1,21 a$ & $1,60 a$ & $1,44 a$ \\
\hline Fo/Fv & $0,24 b$ & $0,29 a$ & $0,28 b$ & $0,34 a$ & $0,22 b$ & $0,25 a$ \\
\hline
\end{tabular}

Dentro de un mismo año, los valores con diferente letra son significativamente diferentes $(p<0,05$, test Tukey) 
La variable $\mathrm{Fv} / \mathrm{Fm}$ fue significativamente menor en las plantas afectadas de clorosis en los tres años de estudio en el cuajado, y en el envero en 2009 y 2010, lo que indica una menor eficiencia del fotosistema II en las subzonas afectadas por la fisiopatía (Bertamini et al., 2001; Bavaresco et al., 2006; Malassiotis et al., 2006). Estos resultados están en línea con los de otros trabajos (Bertamini et al, 2002; Martín et al., 2007b; Catalina et al., 2010 y 2011a). Fv/Fm ha demostrado ser útil en la detección del estrés ambiental (temperatura, déficit de agua y estrés nutricional) antes de que aparezcan signos visibles de deterioro en las plantas (Demmig y Björkman 1987; Maxwell y Johnson, 2000).

La ratio Fo/Fv fue significativamente mayor en las subparcelas cloróticas que en las sanas, tanto en el cuajado como en el envero, en los tres años de estudio (tabla4.32), lo que ha sido apreciado también por Molassiotis et al.(2006). El hecho de que la separación de medias se mantenga en todas las fechas de medida y campañas remarca el interés de esta ratio para el seguimiento de la clorosis férrica, tal como se ha indicado en apartados anteriores.

No se han encontrado diferencias significativas para Fs, Fv'/Fm' entre subparcelas. En cuanto a otros parámetros de fluorescencia en hojas adaptadas a la luz, Fm' y Fv' medidas en el cuajado fueron significativamente menores en las áreas de muestreo cloróticas en 2009 y 2011, y mayores en 2010 (tabla4.32). Estos resultados de 2010puedenestar relacionados con la disminución del contenido foliar en clorofila que se produjo durante el verano a causa de estrés hídrico y térmico acaecido durante el verano. En las medidas de cuajado de 2010, Fo' fue significativamente mayor en las plantas cloróticas, mientras quela eficiencia del fotosistema II, el apagado fotoquímico y no fotoquímico y el ratio de transferencia de electrones fueron menores en plantas afectadas de clorosis que en plantas sanas. Resultados de Ravazi et al. (2008) en fresa, mostraron cambios en qP, NPQ y ФPSII, con el nivel de estrés hídricoo sequía, no siendo así para Fv/Fm.De modo similar, en viñedo se ha podido relacionar el estrés hídrico con NPQ (Flexas et al., 2002a), con la fluorescencia estacionaria (Flexas et al., 2002b), y la fluorescencia mínima, máxima y variable medidas en hojas adaptadas a la luz (Catalina et al., 2011a), pero no con Fv/Fm. Según Baker y Rosenqvist (2004), el estrés hídrico no tiene gran impacto sobre la eficiencia del fotosistema II. 


\section{4.- DESARROLLO VEGETATIVO, RENDIMIENTO DEL VIÑEDO Y CALIDAD DE LA UVA.}

Para analizar la influencia del estado nutricional en las componentes de la expresión vegetativa (vigor, rendimiento y calidad de la uva), en cada uno de los apartados de este epígrafe se ha estudiado por este orden:

- Las regresiones lineales entre las variables de cada componente sobre el contenido en nutrientes del suelo y los peciolos recogidos en envero.

- Los efectos de la clorosis férrica y del nivel de nutrición de P, K, Mg, Cu, Zn y la relación $\mathrm{K} / \mathrm{Mg}$, a través de análisis factoriales de la varianza donde se identifican efectos principales y de interacción. Para ello las parcelas se han clasificado en cloróticas y no cloróticas en función de la concentración de clorofila en las hojas y los contenidos en carbonatos totales y en hierro asimilable del suelo tal y como se ha expuesto en el apartado 4.2.3. Para el resto de nutrientes distintos al Fe las subparcelas se han dividido en grupos en función del diagnóstico realizado en el apartado 4.1.1.

Se incluye el análisis de componentes principales (ACP) a partir de las variables de composición de la uva, representando en el primer plano factorial las subzonas cloróticas y no cloróticas.

\subsection{1.- Efectos del estado nutricional en los parámetros de vigor y rendimiento del viñedo.}

El análisis de la varianza de los valores de prácticamente todas las variables de vigor y rendimiento del viñedo ha mostrado diferencias significativas entre los tres años en los que se llevó a cabo el estudio (tabla 4.35), por lo que es necesario analizar estadísticamente las variables año por año.

Estas oscilaciones interanuales en las componentes de la expresión vegetativa del viñedo se deberían, en gran medida, a la variabilidad de las condiciones meteorológicas en las tres campañas de estudio, descrita en el apartado 3.2.3. Así, podemos destacar la inusualmente escasa precipitación, a lo largo de la parada vegetativa de la vid, previa a la campaña de 2009, lo que minimizó la reserva de agua en el suelo al comienzo del ciclo vegetativo. En el año 2010 , se dio un verano especialmente seco, acompañado de temperaturas anormalmente altas en el mes de julio y picos de temperaturas máximas absolutas muy elevadas en algunos días de agosto. Además, a primeros de mayo de 2010 se produjeron heladas que redujeron los rendimientos. En general, en el año 2011 se observaron unas precipitaciones y temperaturas apropiadas para el desarrollo de la planta, sin registrarse accidentes meteorológicos de ningún tipo. 
Tabla 4.35. Valores de la $F$ de Fisher y nivel de significación del análisis de la varianza (ANOVA) de los parámetros de vigor y rendimiento del viñedo en función de los años de estudio.

\begin{tabular}{|c|c|c|}
\hline Parámetros & $\mathbf{F}$ & \\
\hline Peso de la madera de poda (kg madera $\cdot \mathrm{m}^{-2}$ ) & 42,54 & *** \\
\hline Peso medio del sarmiento (q) & 20,60 & *** \\
\hline Número medio de sarmientos $\cdot \mathrm{m}^{-2}$ & 16,26 & *** \\
\hline Índice de área foliar en el cuajado $\left(\mathrm{m}^{2} \cdot \mathrm{m}^{-2}\right)$ & 4,38 & * \\
\hline Índice de área foliar en el envero $\left(\mathrm{m}^{2} \cdot \mathrm{m}^{-2}\right)$ & 0,85 & \\
\hline Superficie media de la hoja en el cuajado $\left(\mathrm{cm}^{2}\right)$ & 44,32 & *** \\
\hline Superficie media de la hoja en el envero $\left(\mathrm{cm}^{2}\right)$ & 28,17 & *** \\
\hline Rendimiento (kg uva $\cdot \mathrm{m}^{-2}$ ) & 30,58 & $* * *$ \\
\hline Peso medio del racimo $(\mathrm{g})$ & 41,83 & *** \\
\hline Número medio de racimos por sarmiento & 15,78 & *** \\
\hline Peso medio de 100 bayas $(\mathrm{g})$ & 10,08 & $* * *$ \\
\hline Índice de Ravaz & 24,28 & *** \\
\hline
\end{tabular}

En la tabla 4.36 se recogen las medias y coeficientes de variación de los parámetros relacionados con el desarrollo vegetativo y el rendimiento de los viñedos en el conjunto de las zonas de muestreo en los tres años de seguimiento. Los parámetros que muestran mayor coeficiente de variación son el rendimiento, el número medio de racimos por sarmiento y el índice de Ravaz. De estos resultados, se puede deducir que la alta variabilidad del rendimiento, se debería fundamentalmente a la fertilidad de las yemas, ya que las otras dos componentes, peso medio del racimo y tamaño de la baya se muestran más constantes.

Como ya se ha descrito en el apartado 4.1.1, existe en general una amplia variación de las características del suelo de las áreas de estudio. Como se verá más adelante, la variabilidad del estado nutricional de las plantas y en particular la incidencia de la carencia de hierro está relacionada con la variabilidad detectada en los parámetros de vigor y rendimiento del viñedo. Por otra parte, la variación en el estado hídrico de las plantas en el área de estudio también es una fuente de variación importante en el comportamiento agronómico del viñedo (Hailemichael, 2014).

Los viñedos presentaron el menor peso de la madera de poda en 2009 y el mayor en 2011. En cuanto a los parámetros de rendimiento, todos ellos tuvieron su valor menor en el año 2010, debido probablemente a la helada primaveral ocurrida a primeros de mayo de ese año. En este orden de cosas, en 2010 se registró un índice de Ravaz muy reducido. En esta campaña, se observó el menor índice de área foliar en el cuajado y el mayor en el envero, lo que supuso un crecimiento vegetativo muy intenso durante el espacio de tiempo entre ambos estados fenológicos. Es destacable, que en el año 2011 el rendimiento medio en las parcelas fue 1,7 veces mayor que en 2009 y 3,7 veces mayor que en 2010 . 
Tabla 4.36. Parámetros de superficie foliar, vigor y rendimiento en el conjunto de las zonas de viñedo en los tres años de seguimiento.

\begin{tabular}{|c|c|c|c|c|c|}
\hline & Parámetros & Mínimo & Máximo & Media & $\begin{array}{l}\text { Coeficiente de } \\
\text { variación (\%) }\end{array}$ \\
\hline \multicolumn{6}{|c|}{ Superficie foliar } \\
\hline \multirow{4}{*}{$\begin{array}{c}\text { Año } 2009 \\
(n=22)\end{array}$} & IAFc $\left(m^{2} \cdot m^{-2}\right)$ & 0,49 & 1,14 & 0,78 & 26 \\
\hline & IAFe $\left(\mathrm{m}^{2} \cdot \mathrm{m}^{-2}\right)$ & 0,58 & 1,57 & 0,97 & 28 \\
\hline & $\mathrm{SHc}\left(\mathrm{cm}^{2}\right)$ & 75 & 124 & 100 & 15 \\
\hline & $\mathrm{SHe}\left(\mathrm{cm}^{2}\right)$ & 70 & 157 & 118 & 19 \\
\hline \multirow{4}{*}{$\begin{array}{c}\text { Año } 2010 \\
(n=24)\end{array}$} & IAFc $\left(m^{2} \cdot m^{-2}\right)$ & 0,41 & 1,12 & 0,66 & 30 \\
\hline & IAFe $\left(\mathrm{m}^{2} \cdot \mathrm{m}^{-2}\right)$ & 0,49 & 1,46 & 1,09 & 22 \\
\hline & SHc $\left(\mathrm{cm}^{2}\right)$ & 92 & 134 & 115 & 10 \\
\hline & $\mathrm{SHe}\left(\mathrm{cm}^{2}\right)$ & 91 & 172 & 135 & 18 \\
\hline \multirow{4}{*}{$\begin{array}{c}\text { Año } 2011 \\
(n=24)\end{array}$} & IAFc $\left(m^{2} \cdot m^{-2}\right)$ & 0,35 & 1,34 & 0,85 & 28 \\
\hline & IAFe $\left(\mathrm{m}^{2} \cdot \mathrm{m}^{-2}\right)$ & 0,63 & 1,91 & 1,02 & 33 \\
\hline & $\mathrm{SHc}\left(\mathrm{cm}^{2}\right)$ & 50 & 101 & 80 & 14 \\
\hline & $\mathrm{SHe}\left(\mathrm{cm}^{2}\right)$ & 61 & 123 & 90 & 16 \\
\hline \multicolumn{6}{|l|}{ Vigor } \\
\hline \multirow{3}{*}{$\begin{array}{c}\text { Año } 2009 \\
(n=22)\end{array}$} & PMP $\left(\mathrm{Kg} \cdot \mathrm{m}^{-2}\right)$ & 0,12 & 0,24 & 0,19 & 20 \\
\hline & PMS (g) & 37,0 & 82,9 & 62,6 & 20 \\
\hline & NMS $\cdot \mathbf{m}^{-2}$ & 2,10 & 3,83 & 2,99 & 14 \\
\hline \multirow{3}{*}{$\begin{array}{c}\text { Año } 2010 \\
(n=24)\end{array}$} & PMP $\left(\mathrm{Kg} \cdot \mathrm{m}^{-2}\right)$ & 0,05 & 0,51 & 0,31 & 35 \\
\hline & PMS (g) & 16 & 199 & 92 & 46 \\
\hline & NMS $\cdot \mathbf{m}^{-2}$ & 2,30 & 4,50 & 3,56 & 13 \\
\hline \multirow{3}{*}{$\begin{array}{c}\text { Año } 2011 \\
(n=24)\end{array}$} & PMP $\left(\mathrm{Kg} \cdot \mathrm{m}^{-2}\right)$ & 0,16 & 0,69 & 0,45 & 27 \\
\hline & PMS (g) & 38 & 181 & 120 & 22 \\
\hline & $\mathrm{NMS} \cdot \mathrm{m}^{-2}$ & 2,67 & 4,84 & 3,79 & 15 \\
\hline \multicolumn{6}{|c|}{ Rendimiento } \\
\hline \multirow{5}{*}{$\begin{array}{c}\text { Año } 2009 \\
(n=22)\end{array}$} & Rto $\left(\mathrm{kg} \cdot \mathrm{m}^{-2}\right)$ & 0,09 & 0,81 & 0,44 & 39 \\
\hline & PMR (g) & 161 & 268 & 215 & 15 \\
\hline & RPS & 0,12 & 1,16 & 0,72 & 40 \\
\hline & P100 (g) & 125 & 226 & 175 & 14 \\
\hline & IR & 0,49 & 4,67 & 2,53 & 45 \\
\hline \multirow{5}{*}{$\begin{array}{c}\text { Año } 2010 \\
(n=24)\end{array}$} & Rto $\left(\mathrm{kg} \cdot \mathrm{m}^{-2}\right)$ & 0,05 & 0,61 & 0,20 & 70 \\
\hline & PMR (g) & 51 & 231 & 148 & 31 \\
\hline & RPS & 0,12 & 0,71 & 0,36 & 48 \\
\hline & P100 (g) & 123 & 187 & 158 & 10 \\
\hline & IR & 0,21 & 1,75 & 0,77 & 53 \\
\hline \multirow{5}{*}{$\begin{array}{c}\text { Año } 2011 \\
(n=24)\end{array}$} & Rto $\left(\mathrm{kg} \cdot \mathrm{m}^{-2}\right)$ & 0,30 & 1,33 & 0,73 & 41 \\
\hline & PMR (g) & 179 & 397 & 274 & 19 \\
\hline & RPS & 0,34 & 1,16 & 0,68 & 30 \\
\hline & P100 (g) & 147 & 247 & 188 & 13 \\
\hline & IR & 0,69 & 3,09 & 1,58 & 46 \\
\hline
\end{tabular}

IAFc: Índice de área foliar en el cuajado; IAFe: Índice de área foliar en el envero; SHc: Superficie media de la hoja en el cuajado; SHe: Superficie media de la hoja en el envero; PMP: Peso de la madera de poda; PMS: Peso medio de los sarmientos; NMS: Número medio de sarmientos ; Rto: Rendimiento; PMR: Peso medio de los racimos; RPS: Número medio de racimos por sarmientos; P100: Peso de 100 bayas; IR: Índice de Ravaz. 
La tabla 4.37 muestra los resultados del análisis factorial de la varianza donde se han evaluado los efectos aditivos y de interacción de la clorosis férrica con el nivel nutricional de otros elementos diferentes al hierro, tomando como base la clasificación de subzonas realizada en los apartados4.1 y 4.2.3.

Tabla 4.37.Valores de la $\mathrm{F}$ de Fisher y nivel de significación del análisis factorial de la varianza (ANOVA) del peso de la madera de poda (PMP), el rendimiento (Rto) y el índice de Ravaz (IR) en las áreas de estudio cloróticas (C) y no cloróticas (NC) y con distinto estado nutricional de $\mathrm{P}, \mathrm{K}, \mathrm{Mg}$ y $\mathrm{Cu}$.

\begin{tabular}{|c|c|c|c|c|c|c|c|c|}
\hline Nutriente & & Parámetro & Model & & CF & nt & $C F \times n$ & \\
\hline \multirow{9}{*}{$n t=P$} & \multirow{3}{*}{2009} & PMP & 3,26 & & 0,70 & 0,01 & 9,38 * & ** \\
\hline & & Rto & 1,50 & & 0,40 & 0,01 & 3,20 & \\
\hline & & IR & 3,71 , & * & 0,08 & 0,01 & $9,85 *$ & ** \\
\hline & \multirow{3}{*}{2010} & PMP & 2,20 & & 2,18 & 0,96 & 0,03 & \\
\hline & & Rto & 1,08 & & 0,44 & 0,82 & 1,40 & \\
\hline & & IR & 1,04 & & 1,73 & 0,88 & 0,51 & \\
\hline & \multirow{3}{*}{2011} & PMP & 0,53 & & 1,20 & 0,72 & 0,72 & \\
\hline & & Rto & 3,36 * & * & 2,94 & 1,73 & 0,40 & \\
\hline & & IR & 4,13 & * & 2,08 & 3,98 & 0,39 & \\
\hline \multirow{9}{*}{$n t=K$} & \multirow{3}{*}{2009} & PMP & 0,72 & & 0,11 & 1,23 & 0,12 & \\
\hline & & Rto & 0,78 & & 0,04 & 1,10 & 0,53 & \\
\hline & & IR & 0,40 & & 0,03 & 0,16 & 0,78 & \\
\hline & \multirow{3}{*}{2010} & PMP & 2,68 & & 3,03 & 2,16 & 0,02 & \\
\hline & & Rto & 2,10 & & 1,25 & 1,32 & 4,27 & \\
\hline & & IR & 2,37 & & 2,73 & 0,49 & 4,83 * & * \\
\hline & \multirow{3}{*}{2011} & PMP & 0,22 & & 0,32 & 0,06 & 0,18 & \\
\hline & & Rto & 6,59 * & ** & 5,69 & 7,99 & 0,15 & \\
\hline & & IR & $5,03 \times$ & * & 4,38 & 5,97 & 0,32 & \\
\hline \multirow{9}{*}{$\mathrm{nt}=\mathrm{Mg}$} & \multirow{3}{*}{2009} & PMP & 1,01 & & 0,53 & 0,08 & 1,96 & \\
\hline & & Rto & 3,88 * & * & 0,76 & 3,12 & 7,87 & * \\
\hline & & IR & 3,40 . & * & 0,27 & 1,61 & 8,32 * & ** \\
\hline & \multirow{3}{*}{2010} & PMP & 2,41 & & 1,88 & 0,97 & 0,43 & \\
\hline & & Rto & $3,39 \times$ & * & 3,45 & 4,74 & $4,75 *$ & * \\
\hline & & IR & 4,03 & * & 7,17 & 6,06 & 3,74 & \\
\hline & \multirow{3}{*}{2011} & PMP & 0,24 & & 0,70 & 0,32 & 0,01 & \\
\hline & & Rto & 5,90 . & ** & 1,77 & 6,22 & 0,35 & \\
\hline & & IR & 5,95 * & ** & 1,08 & 7,93 & 0,04 & \\
\hline \multirow{9}{*}{$\mathrm{nt}=\mathrm{Cu}$} & \multirow{3}{*}{2009} & PMP & 0,62 & & 0,35 & 0,95 & 0,04 & \\
\hline & & Rto & 0,52 & & 0,00 & 0,34 & 1,16 & \\
\hline & & IR & 0,25 & & 0,00 & 0,00 & 0,72 & \\
\hline & \multirow{3}{*}{2010} & PMP & 2,71 & & 0,73 & 0,19 & 2,16 & \\
\hline & & Rto & 1,10 & & 0,90 & 2,37 & 0,02 & \\
\hline & & IR & 3,07 & & 3,28 & 5,32 & 0,00 & \\
\hline & \multirow{3}{*}{2011} & PMP & 1,01 & & 0,20 & 0,60 & 0,62 & \\
\hline & & Rto & 5,80 * & ** & 0,56 & 6,59 & 0,28 & \\
\hline & & IR & $5,40 *$ & ** & 0,53 & 6,16 & 0,16 & \\
\hline
\end{tabular}


La influencia de la clorosis férrica y del nivel de fósforo sobre el peso de la madera de poda, el rendimiento y el índice de Ravaz no han resultado estadísticamente significativas. El análisis de IR fue significativo para el nivel nutricional del $\mathrm{K}$ en el año 2011. Además, en este mismo año, la afección de clorosis férrica y el estado nutricional del $\mathrm{K}$ mostraron un efecto aditivo sobre el rendimiento. Tanto el nivel nutricional del Mg, como su interacción con la clorosis férrica tuvieron un efecto significativo sobre el rendimiento en 2010. En 2011, el estado nutricional del Mg también afectó significativamente el rendimiento y el IR. Por último, el efecto del nivel nutricional de Cu fue significativo sobre IR en 2010 y 2011 y sobre el rendimiento en el año 2011. El análisis factorial de la varianza no se ha realizado para el $\mathrm{Zn}$ porque no han resultado grupos con suficientes número de subzonas para ello. Así, no hay subparcelas no afectadas por clorosis férrica con un nivel medio de nutrición de $\mathrm{Zn}$ simultáneamente.

\subsubsection{1.- Parámetros de vigor}

De las regresiones lineales estudiadas del vigor (peso de la madera de poda)y sus componentes en los viñedos sobre las variables de composición del suelo expuestas en la tabla 4.38, puede destacarse la relación significativamente negativa del peso de la madera de poda en 2009 sobre el porcentaje de arcilla. Por otra parte, la regresión lineal de PMP y PMS en 2010 sobre los carbonatos totales es significativamente negativa. Además, como se puede ver en la tabla 4.39, IAFe en 2009 y SHe en los tres años de estudio se han relacionado negativamente de forma significativa con el porcentaje de arcilla y carbonatos totales presentes en el suelo. IAFc y SHc se han relacionado con el contenido en carbonatos en 2009. En los años 2010 y 2011 las relaciones significativas obtenidas con SHe no se correspondieron con las relaciones negativas del IAFe, por lo que el contenido de arcilla y carbonatos se pueden relacionar más claramente con el tamaño de la hoja que con el número de hojas por brote. Estos resultados están en contra de los mostrados por Díaz et al. (2009b), que observaron una correlación negativa entre la concentración de carbonatos totales del suelo y la longitud del tallo, el número y el tamaño de las hojas en vides cultivadas en macetas con diferentes sustratos.

La disminución del vigor y el rendimiento en los suelos clorosantes (alto contenido en arcilla y carbonatos) se puede explicar por la disminución de la capacidad fotosintética de las plantas debido a la carencia de hierro (Hurley et al., 1986; Bavaresco y Poni, 2003; Bertamini y Nedunchezhian, 2005; Bavaresco et al., 2006). Como se ha descrito anteriormente, se ha observado una fuerte correlación ( $r=$ $0,71, p<0,001)$ entre el contenido de arcilla y la concentración de carbonatos en el suelo (apartado 4.1.2), habiéndose relacionado ambos, de forma negativa con el contenido de pigmentos en las hojas (apartado 4.2.1), la asimilación neta y parámetros de la fluorescencia de la clorofila relacionados con la eficiencia del fotosistema II (apartado 4.3.1). Por lo tanto, la reducción del vigor de los viñedos tanto en crecimiento en madera como en la superficie de la hoja observada en las subparcelas con suelos más arcillosos y calcáreos se debe a la disminución en el contenido en 
pigmentos fotosintéticos y en la eficiencia del fotosistema II ocasionada por la clorosis férrica. La disminución del tamaño de la hoja a causa de la clorosis férrica (Bertamini y Nedunchezhian, 2005; Bavaresco et al., 2006) produce un efecto de concentración del hierro foliar, que ha sido denominado por algunos autores como "paradoja de la clorosis férrica" (Häussling et al. 1985; Bavaresco et al., 1999; Römheld, 2000).Gruber y Kosegarten (2002) sugirieron que la depresión en el crecimiento de la vid es un síntoma de la deficiencia de hierro que precede a la clorosis de las hojas.

En cuanto a los contenidos de nutrientes en el suelo (tablas 4.38 y 4.39 ), se pueden destacar las regresiones positivas de PMP y PMS en 2010 y 2011 sobre el K y el Mn y negativa sobre el Cu; así como una relación positiva de PMP en 2009 y 2011 sobre el Mg. Del contenido mineral peciolar, se han encontrado regresiones lineales significativamente positivas de PMP y PMS sobre el P, K y Zn en 2010, y PMP sobre K, Cu y Mn. Martín et al. (2008) detectó altas correlaciones positivas de los niveles de $\mathrm{P}$ y $\mathrm{Zn}$ con el peso de la madera de poda en la misma zona de estudio y SánchezRodríguez et al. (2014) observaron que la aplicación de $\mathrm{P}$ al suelo resultaba en un cierto aumento en el crecimiento de plantas de olivo afectadas de clorosis férrica (Sánchez-Rodríguez et al., 2014).

Solo para el caso del $\mathrm{K}$ se han obtenido simultáneamente relaciones significativas del contenido en el suelo y en los peciolos con SHe y PMP. Hailemichael et al. (2014) en investigaciones en las misma zona de estudio sostuvo que el potasio fue el nutriente cuyos niveles peciolares reflejaron un mayor impacto en la expresión vegetativa del viñedo, con una relación directa con el peso medio de la madera de poda. Estos resultados ponen de manifiesto la importancia de la nutrición potásica en el desarrollo vegetativo del viñedo, con independencia de que estén afectados o no por clorosis férrica. El $\mathrm{K}$ es un activador de enzimas que son esenciales para la fotosíntesis y la respiración, así como de enzimas que producen almidón y proteínas, y en consecuencia, mejora el crecimiento de hojas y brotes (Bavaresco et al. 2010b).

La regresión lineal de la $\mathrm{SHe}$ sobre el $\mathrm{K}$ presente en el suelo fue significativamente positiva en 2010 y 2011, lo mismo que la de IAF en el cuajado y el envero sobre el $\mathrm{Mn}$ en 2009. En cuanto a los contenidos peciolares, SHe se ha relacionado de forma positiva con el contenido peciolar en $\mathrm{P}$ y K en 2010 y 2011, y el IAFc con el K en 2009 y 2011. Se ha encontrado una regresión significativa con pendiente negativa del IAF y SH en cuajado y envero sobre el $\mathrm{Mg}$ y el $\mathrm{Mn}$ y positiva sobre el Cu en 2009. Martín et al. (2008) detectó relaciones positivas de los niveles de $\mathrm{P}, \mathrm{Cu}$ y $\mathrm{Zn}$ con los tamaños de las hojas en la misma zona de estudio. Diversas investigaciones han comprobado que el aumento en los niveles nutricionales de $\mathrm{Zn}$ afecta de manera positiva al crecimiento de las vides (Volschenk et al., 1996; Ashoori et al., 2013). Los síntomas de deficiencia de Cu incluyen, entre otros, la inhibición del crecimiento de las raíces, brotes raquíticos y hojas pequeñas (Marschner, 1995).El aumento del nivel de fertilización fosfatada sobre dos patrones del género Prunus en suelos calcáreos incrementó su diámetro de tronco, el peso seco de las hojas y la longitud de los brotes frente a testigos (Balal et al., 2011). El incremento del vigor en vides también ha sido observado por Grant y Matthews (1996) como resultado de aplicaciones crecientes de fósforo. 
No se han encontrado regresiones lineales significativas de los parámetros de vigor y desarrollo vegetativo sobre los contenidos de $\mathrm{Ca}$ y $\mathrm{Fe}$ en el suelo y los contenidos de N, Ca, Fe y B de los peciolos recogidos en envero (tablas 4.38 y 4.39). 


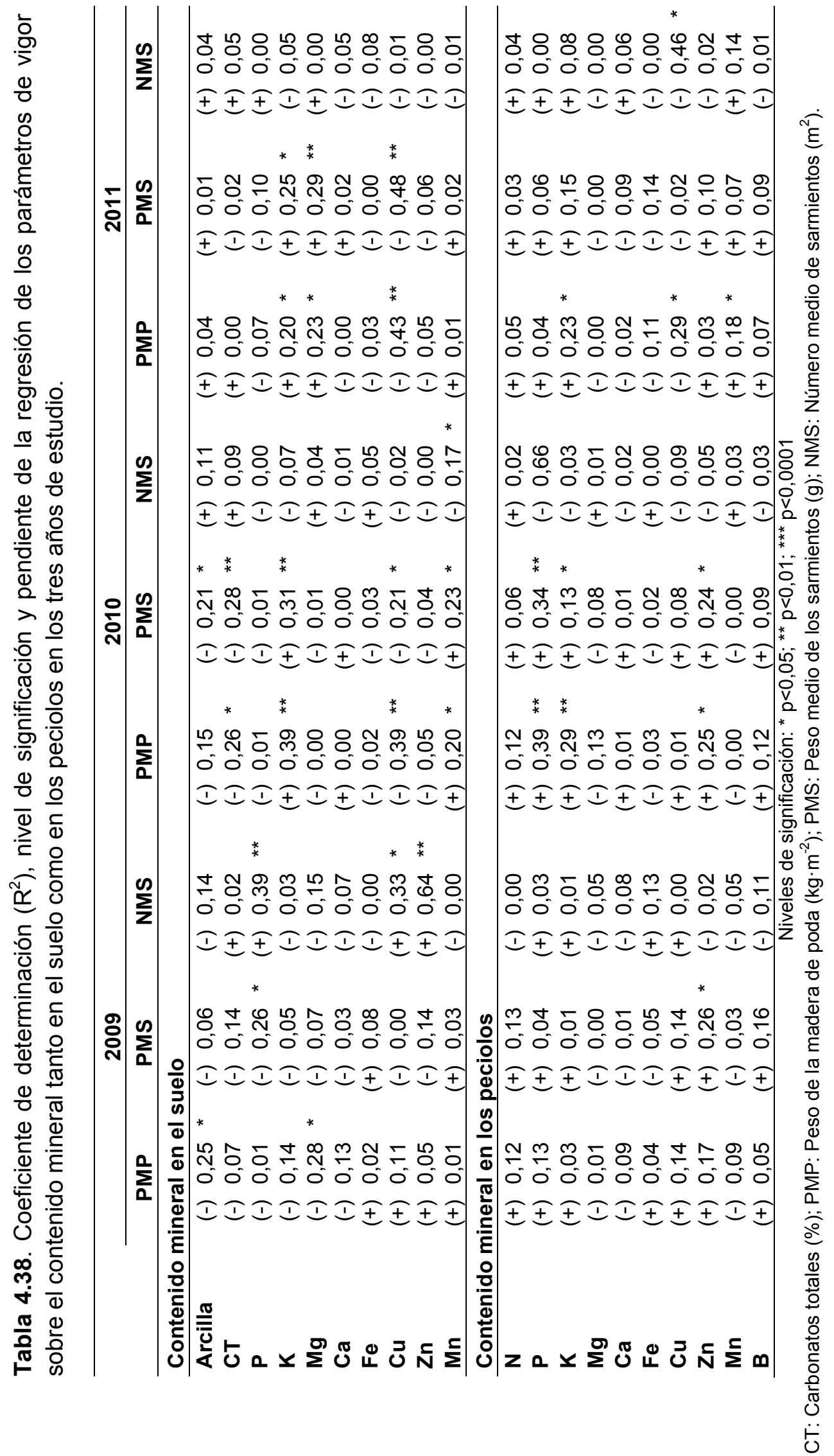


* o. o- 0000000

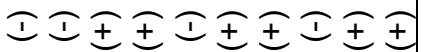

둥 0000 玨王王王王王

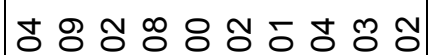

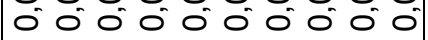
巩さ王王卫さ

$8=85085885$ 000000000 狂王卫干工工干 *** *

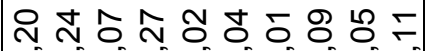
00000000000 玨さ王卫さ王

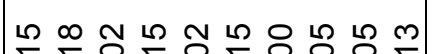
0000000000 玨王王王王王王王

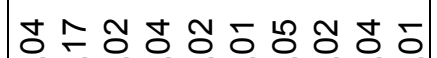
0.00000000000

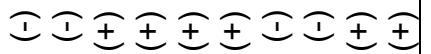
粋。

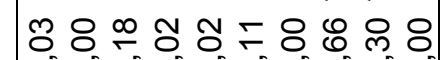
0000000000 狂ささ王王王 $* *$

m\&.กㄴ. 0.000000000 列王工王王王王 *

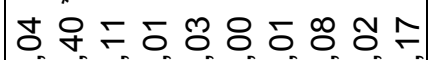
o 00000

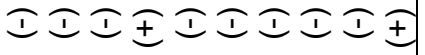

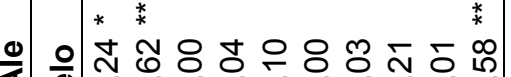

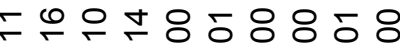
o 000000000 王王卫工卫王卫干 $*$

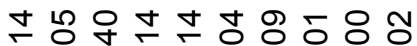

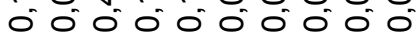

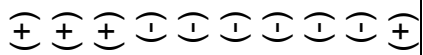
**

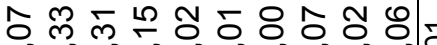
00000000000

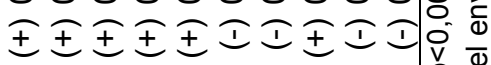

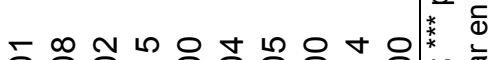

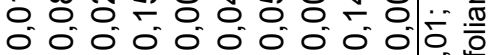

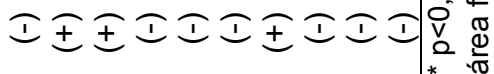

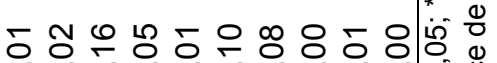

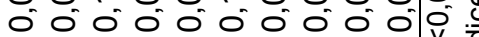

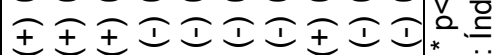

ช. 0.000000000

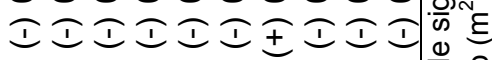

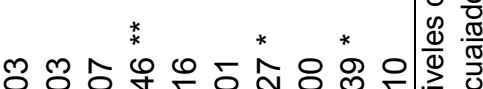

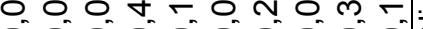
0.000000000 王王卫工王王卫卫

৪ ৪ ำ $000^{0} 00^{\circ} 0^{\circ} 0^{\circ} 0$

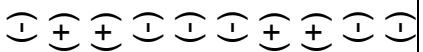
* *

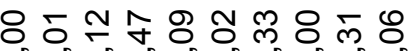
0.000000000 王王王工王王さ工 ब

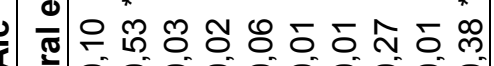
๑

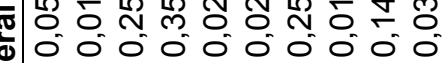

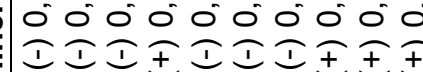
王王王工工工王王工们 
Como muestra la tabla 4.37, el análisis factorial de la varianza del peso de la madera de poda no ha resultado significativo para la incidencia de la clorosis férrica. Como se puede observar en la tabla4.40, el peso de la madera de poda en 2010 fue significativamente mayor en las subzonas sanas que en las afectadas por clorosis férrica. En las otras dos campañas la tendencia fue similar pero las diferencias no fueron significativas al 5\%. El peso medio del sarmiento fue mayor en las zonas no cloróticas en 2009 y 2010. En el año 2009, tanto la superficie de la hoja como el índice de área foliar en cuajado y envero fueron significativamente menores en las parcelas cloróticas que en las sanas. Este mismo resultado se dio para las dos variables medidas en envero en 2011.

Numerosos autores han observado reducciones importantes del vigor y rendimiento de viñedos asociados a la clorosis férrica (Gruber y Kosegarten, 2002; Bertamini y Nedunchezhian, 2005; Bavaresco y Poni, 2003; Bavaresco et al., 2006, 2010). En este contexto, se ha relacionado significativamente de forma positiva la asimilación neta en cuajado con el peso de la madera de poda en 2009 y 2011 (capítulo 4.5), por lo que el descenso en el vigor da las plantas cloróticas está relacionado con el rendimiento fotosintético de las vides. Bavaresco y Poni (2003) y Bertamini y Nedunchezhian (2005) observaron que la deficiencia de hierro reducía considerablemente la tasa de fotosíntesis de la hoja, el área foliar y la producción de materia seca.

Tabla 4.40. Valores medios de diferentes parámetros de vigor en áreas de muestreo afectadas (C) y no afectadas (NC) por clorosis férrica.

\begin{tabular}{|c|c|c|c|c|c|c|}
\hline \multirow{2}{*}{$\begin{array}{l}\text { Componentes } \\
\text { del vigor }\end{array}$} & \multicolumn{2}{|c|}{2009} & \multicolumn{2}{|c|}{2010} & \multicolumn{2}{|c|}{2011} \\
\hline & $\begin{array}{c}N C \\
(n=11)\end{array}$ & $\underset{(n=11)}{C}$ & $\begin{array}{c}N C \\
(n=12)\end{array}$ & $\underset{(n=12)}{C}$ & $\begin{array}{c}N C \\
(n=12)\end{array}$ & $\underset{(n=12)}{C}$ \\
\hline PMP $\left(\mathrm{Kg} \cdot \mathrm{m}^{-2}\right)$ & $0,19 a$ & $0,17 a$ & $0,36 a$ & $0,26 b$ & $0,47 a$ & $0,44 a$ \\
\hline PMS (g) & $69 a$ & $56 b$ & $109 a$ & $73,3 b$ & $129 a$ & $110 a$ \\
\hline NMS $\left(\mathbf{m}^{2}\right)$ & $2,82 a$ & $3,15 a$ & $3,50 a$ & $3,61 a$ & $3,61 a$ & $3,97 a$ \\
\hline IAFc & $0,89 a$ & $0,67 b$ & $0,61 a$ & $0,68 a$ & $0,90 a$ & $0,78 a$ \\
\hline IAFe & $1,12 a$ & $0,84 b$ & $1,15 a$ & $1,05 a$ & $1,15 a$ & $0,88 b$ \\
\hline $\mathrm{SHc}\left(\mathrm{cm}^{2}\right)$ & $108 a$ & $92 b$ & $120 a$ & $112 a$ & $83 a$ & $75 a$ \\
\hline $\mathrm{SHe}\left(\mathrm{cm}^{2}\right)$ & $134 a$ & $105 b$ & $146 a$ & $127 a$ & $97 a$ & $83 b$ \\
\hline
\end{tabular}

PMP: Peso de la madera de poda; PMS: Peso medio de los sarmientos; NMS: Número medio de sarmientos; IAFc: Índice de área foliar en el cuajado; IAFe: Índice de área foliar en el envero; SHc: Superficie media de la hoja en el cuajado; SHe: Superficie media de la hoja en el envero.

Dentro de un mismo año, los valores con diferente letra son significativamente diferentes $(p<0,05$, test Tukey)

No se han detectado diferencias significativas del peso de la madera de poda, el índice de área foliar y la superficie de la hoja en función del nivel de nutrición fosfórico en ninguno de los años de estudio (tabla 4.41). 
Como se puede observar en la tabla 4.41, el índice de área foliar y la superficie media de la hoja en el cuajado y el envero fueron significativamente menores en las parcelas con un nivel medio de nutrición potásica que en las parcelas con un nivel alto en 2009, mientras que en 2010 y 2011 este resultado solo se obtuvo para la superficie de la hoja en el envero. En general, existe una tendencia al incremento del IAF y PMP con el aumento del nivel de nutrición potásica, aunque en algunos casos las diferencias no fueron significativas al $5 \%$. El potasio juega un papel importante en la mejora del crecimiento de los pámpanos (Bavaresco et al., 2010b)

En las áreas de estudio con un nivel alto de nutrición magnésica, el índice de área foliar y la superficie de la hoja fueron significativamente menores que en las áreas con un nivel medio de nutrición en el año 2009. Este mismo resultado se ha dado para la superficie de la hoja en cuajado y envero en los años 2010 y 2011.

Como se puede observar en la tabla 4.41, el índice de área foliar en el cuajado y el envero y la superficie media de la hoja en el envero fueron significativamente mayores en las parcelas con una elevada relación $\mathrm{K} / \mathrm{Mg}$ que en las parcelas con una relación media y baja en 2009, mientras que en 2010 este resultado solo se obtuvo para la superficie de la hoja en el envero y en 2011 para el índice de área foliar en cuajado. El exceso de magnesio se asocia con un menor desarrollo vegetativo. Este exceso es compensado por el aumento del nivel de nutrición potásica, que equilibra la relación $\mathrm{K} / \mathrm{Mg}$, e incrementa el vigor de las plantas como se comentó anteriormente. En este orden de cosas, las plantas sensibles ven mermada su capacidad de respuesta a la deficiencia de Fe cuando la nutrición potásica es deficiente (Jolley et al., 2004), reduciéndose la emisión de $\mathrm{H}^{+}$, disminuyendo la capacidad reductora de $\mathrm{Fe}$ (plantas de estrategia I) (Hughes et al., 1990 y 1992). Tagliavini y Rombola (2001) plantearon la hipótesis de que la actividad y la regulación de la ATPasa de la membrana plasmática podían proporcionar niveles del $\mathrm{pH}$ apoplástico favorables y mejorar la actividad de la reductasaFe ${ }^{3+}$. El potasio podría afectar potencialmente a la absorción de $\mathrm{Fe}$ a través de su papel general en el equilibrio iónico y facilitar la circulación de ácidos orgánicos como citrato (Marschner 1995).

En las áreas de estudio con un nivel bajo de nutrición de cobre, el índice de área foliar y la superficie de la hoja fueron significativamente menores que en las áreas con un nivel medio de nutrición en el año 2009. Este mismo resultado se ha dado para la superficie de la hoja en cuajado y envero en los años 2010 y 2011. El cobre es un elemento de transición que participa en reacciones redox con papeles destacados en la transferencia de electrones de la fotosíntesis y la cadena respiratoria, el metabolismo de la pared celular y la protección contra el estrés oxidativo (Burkhead et al., 2009). El Cu está involucrado en la síntesis de lignina en los tallos (Marschner, 1995). 
Tabla 4.41. Valores medios del índice de área foliar y superficie de la hoja en cuajado y envero para áreas de muestreo con diferente estado nutricional.

\begin{tabular}{|c|c|c|c|c|c|c|c|c|}
\hline \multirow[b]{2}{*}{ Nutriente } & \multicolumn{8}{|c|}{ Estado nutricional del viñedo } \\
\hline & Año & Nivel $^{*}$ & $\mathrm{n}$ & PMP & IAFc & IAFe & SHc & SHe \\
\hline \multirow{6}{*}{ Fósforo } & \multirow{2}{*}{2009} & Bajo & 8 & $0,18 a$ & $0,71 a$ & $0,87 a$ & $97,6 a$ & $112 a$ \\
\hline & & Medio & 11 & $0,18 a$ & $0,85 a$ & $1,04 a$ & $102 a$ & $119 a$ \\
\hline & \multirow[b]{2}{*}{2010} & Bajo & 10 & $0,26 a$ & $0,67 a$ & $1,09 a$ & $113 a$ & $127 a$ \\
\hline & & Medio & 14 & $0,35 a$ & $0,65 a$ & $1,09 a$ & $118 a$ & $143 a$ \\
\hline & \multirow{2}{*}{2011} & Bajo & 10 & $0,46 a$ & $0,82 a$ & $0,94 a$ & $79,6 a$ & $82,9 a$ \\
\hline & & Medio & 14 & $0,45 a$ & $0,86 a$ & $1,07 a$ & $79,8 a$ & $95,5 a$ \\
\hline \multirow{6}{*}{ Potasio } & \multirow{2}{*}{2009} & Alto & 8 & $0,20 a$ & $0,96 a$ & $1,20 a$ & $112 a$ & $135 a$ \\
\hline & & Medio & 14 & $0,18 a$ & $0,68 b$ & $0,82 b$ & $94 b$ & $107 b$ \\
\hline & \multirow{2}{*}{2010} & Alto & 10 & $0,37 a$ & $0,66 a$ & $1,18 a$ & $121 a$ & $153 a$ \\
\hline & & Medio & 14 & $0,28 b$ & $0,65 a$ & $1,03 a$ & $112 a$ & $122 b$ \\
\hline & \multirow{2}{*}{2011} & Alto & 10 & $0,47 a$ & $0,93 a$ & $1,13 a$ & $84 a$ & $97 a$ \\
\hline & & Medio & 14 & $0,44 a$ & $0,78 a$ & $0,93 a$ & $77 a$ & $85 b$ \\
\hline \multirow{6}{*}{ Magnesio } & \multirow{2}{*}{2009} & Alto & 13 & $0,19 a$ & $0,70 b$ & $0,82 b$ & $95 b$ & $110 b$ \\
\hline & & Medio & 9 & $0,18 a$ & $0,91 \mathrm{a}$ & $1,19 a$ & $108 a$ & $131 a$ \\
\hline & \multirow{2}{*}{2010} & Alto & 13 & $0,27 b$ & $0,65 a$ & $1,04 a$ & $111 b$ & $123 b$ \\
\hline & & Medio & 11 & $0,37 a$ & $0,67 a$ & $1,17 a$ & $122 a$ & $153 a$ \\
\hline & \multirow{2}{*}{2011} & Alto & 13 & $0,46 a$ & $0,81 a$ & $0,90 a$ & $75 b$ & $84 b$ \\
\hline & & Medio & 11 & $0,45 a$ & $0,89 a$ & $1,15 a$ & $85 a$ & $97 a$ \\
\hline \multirow{9}{*}{$\begin{array}{l}\mathrm{K} / \mathrm{Mg} \\
\text { (peciolos) }\end{array}$} & \multirow{3}{*}{2009} & Alto & 8 & $0,19 a$ & $0,94 a$ & $1,17 a$ & $109 a$ & $133 a$ \\
\hline & & Medio & 8 & $0,18 a$ & $0,73 b$ & $0,82 b$ & $98 a$ & $108 b$ \\
\hline & & Bajo & 6 & $0,18 a$ & $0,65 b$ & $0,85 b$ & $93 a$ & $110 b$ \\
\hline & \multirow{3}{*}{2010} & Alto & 9 & $0,37 a$ & $0,68 a$ & $1,17 a$ & $121 a$ & $155 a$ \\
\hline & & Medio & 6 & $0,31 a$ & $0,53 a$ & $1,12 a$ & $111 a$ & $124 b$ \\
\hline & & Bajo & 9 & $0,27 a$ & $0,74 a$ & $0,98 a$ & $114 a$ & $123 b$ \\
\hline & \multirow{3}{*}{2011} & Alto & 6 & $0,48 a$ & $1,00 a$ & $1,19 a$ & $85 a$ & $101 a$ \\
\hline & & Medio & 9 & $0,49 a$ & $0,93 a$ & $1,02 a$ & $79 a$ & $89 a$ \\
\hline & & Bajo & 9 & $0,42 a$ & $0,66 b$ & $0,90 a$ & $77 a$ & $84 a$ \\
\hline \multirow{6}{*}{ Cobre } & \multirow{2}{*}{2009} & Bajo & 9 & $0,17 a$ & $0,64 b$ & $0,74 b$ & $92 b$ & $104 b$ \\
\hline & & Medio & 13 & $0,19 a$ & $0,88 a$ & $1,16 a$ & $106 a$ & $130 a$ \\
\hline & \multirow{2}{*}{2010} & Bajo & 7 & $0,29 a$ & $0,51 b$ & $0,99 a$ & $105 b$ & $121 b$ \\
\hline & & Medio & 17 & $0,32 a$ & $0,73 a$ & $1,15 a$ & $121 a$ & $142 a$ \\
\hline & \multirow{2}{*}{2011} & Bajo & 7 & $0,49 a$ & $0,86 a$ & $0,85 a$ & $69 b$ & $81 b$ \\
\hline & & Medio & 17 & $0,44 a$ & $0,84 a$ & $1,09 a$ & $84 a$ & $94 a$ \\
\hline \multirow{6}{*}{ Zinc } & \multirow{2}{*}{2009} & Alto & 14 & $0,20 a$ & $0,84 a$ & $1,02 a$ & $104 a$ & $122 a$ \\
\hline & & Medio & 8 & $0,16 b$ & $0,68 a$ & $0,89 a$ & $95 a$ & $113 a$ \\
\hline & 2010 & Alto & 13 & $0,34 a$ & $0,56 b$ & $1,12 a$ & $111 a$ & $134 a$ \\
\hline & 2010 & Medio & 7 & $0,23 b$ & $0,79 a$ & $1,09 a$ & $117 a$ & $127 a$ \\
\hline & & Alto & 13 & $0,49 a$ & $0,87 a$ & $1,01 a$ & $78 a$ & $92 a$ \\
\hline & 2011 & Medio & 7 & $0,40 b$ & $0,82 a$ & $0,91 \mathrm{a}$ & $79 a$ & $81 a$ \\
\hline
\end{tabular}

PMP: Peso de la madera de poda $\left(\mathrm{kg} \cdot \mathrm{m}^{-2}\right)$; IAFc: Índice de área foliar en el cuajado $\left(\mathrm{m}^{2} \cdot \mathrm{m}^{-2}\right)$; IAFe: Índice de área foliar en el envero $\left(\mathrm{m}^{2} \cdot \mathrm{m}^{-2}\right)$; SHc: Superficie media de la hoja en el cuajado $\left(\mathrm{cm}^{2}\right)$; SHe: Superficie media de la hoja en el envero $\left(\mathrm{cm}^{2}\right)$

En un mismo año, valores con diferente letra, son significativamente diferentes $(p<0,05$, test Tukey) *según diagnóstico nutricional realizado en el apartado 4.1 
Se han observado diferencias significativas en el peso de la madera de poda de parcelas con diferente estado nutricional de $\mathrm{Zn}$. Así, las subparcelas con un nivel medio de nutrición de zinc tuvieron un peso de la madera de poda significativamente menor que las subparcelas con un nivel de nutrición alto para dicho mineral. Los resultados están de acuerdo con los obtenidos por Ashoori et al., (2013), o por Martín et al. (2008) y Catalina et al. (2012) en la misma zona de estudio comprobándose una relación positiva del contenido en $\mathrm{Zn}$ de los peciolos en envero con el vigor del viñedo. En las plantas, el Zn juega un papel clave como componente estructural, o como cofactor regulador de una amplia gama de proteínas y enzimas en muchas vías bioquímicas importantes. Estas funciones incluyen el metabolismo de los hidratos de carbono (tanto en la fotosíntesis como en la conversión de los azúcares en almidón), el metabolismo de las proteínas, el metabolismo de las auxinas y el mantenimiento de la integridad de las membranas biológicas (Alloway, 2004; Krämer y Clemens, 2006). Por lo tanto, una nutrición de $\mathrm{Zn}$ deficiente hace que el crecimiento de las plantas se vea afectado negativamente (Srivastava y Singh, 2009).

Generalmente se admite que los mecanismos de adquisición de Fe y otros micronutrientes por las plantas de estrategia I están relacionados entre sí, y que la deficiencia de Fe suele ir acompañada de la acumulación de Mn y $\mathrm{Zn}$ en la planta (Kobayashi et al., 2003). Sin embargo, las zonas de estudio afectadas por clorosis férrica, las cuales han mostrado un menor peso de madera de poda que el resto, no han tenido un nivel de nutrición de $\mathrm{Zn}$ alto. En este estudio las subparcelas con una nutrición alta de $\mathrm{Zn}$ tuvieron un peso de la madera de poda mayor que en las subparcelas con una nutrición media. Así, no se han detectado subparcelas no afectadas por clorosis férrica con un nivel medio de nutrición de Zn simultáneamente.

\subsubsection{2.- Parámetros de rendimiento}

Se han encontrado varias regresiones lineales significativas del rendimiento del viñedo $\left(\mathrm{kg} \cdot \mathrm{m}^{-2}\right)$ y sus componentes sobre las variables de composición del suelo (tabla 4.41); se puede destacar la relación significativamente negativa del rendimiento en los tres años de estudio sobre el porcentaje de arcilla y los carbonatos presentes en el suelo. Por otra parte, se ha dado una regresión lineal negativa del peso medio del racimo y el peso medio de 100 bayas sobre el porcentaje de arcilla en los tres años de estudio y sobre el contenido en carbonatos totales(suelos clorosantes) en 2010 y 2011. No se han encontrado relaciones significativas con la fertilidad de las yemas. La deficiencia de $\mathrm{Fe}$ induce una reducción de la producción del viñedo debido a una disminución de la tasa de cuajado, del tamaño del racimo y el diámetro de las bayas (Bavaresco et al., 2010a).

Existe una alta correlación $(r=0,71, p<0,001)$ entre el contenido de arcilla y la concentración de carbonatos en el suelo (apartado 4.1.2), habiéndose relacionado ambos, de forma negativa con el contenido de pigmentos en las hojas (apartado 4.2.1), la asimilación neta y parámetros de la fluorescencia de la clorofila relacionados con la eficiencia del fotosistema II (apartado 4.3.1). La disminución del vigor y el rendimiento en los suelos clorosantes (alto contenido en carbonatos) se puede explicar 
por la disminución de la capacidad fotosintética de las plantas debido a la carencia de hierro (Hurley et al., 1986; Bavaresco y Poni, 2003; Bertamini y Nedunchezhian, 2005; Bavaresco et al., 2006). Además, se ha dado una regresión lineal negativa del índice de Ravaz sobre el porcentaje de arcilla en los tres años de estudio y sobre el contenido en carbonatos totales en 2011.

En cuanto al contenido en elementos minerales del suelo, se detectaron regresiones lineales positivas del rendimiento sobre el K, Ca y Mn en los años 2009 y 2011 (tabla 4.42). En este contexto, todas las componentes del rendimiento, peso medio del racimo, racimos por sarmiento y peso de 100 bayas se relacionaron positivamente con el nivel de $\mathrm{K}$ y $\mathrm{Mn}$, y sólo el número de racimos por sarmiento con el nivel de Ca en 2009 y 2011. En estos mismos años, el paso de 100 bayas se relacionó de forma positiva con el contenido de $\mathrm{Cu}$ en el suelo. Además, el índice de Ravaz también se relacionó de manera positiva con los contenidos en $\mathrm{K}, \mathrm{Ca}$, $\mathrm{Fe} \mathrm{y} \mathrm{Mn}$ en estas dos campañas.

En lo referente al contenido mineral de los peciolos en envero, han resultado regresiones lineales positivas del rendimiento sobre el $\mathrm{P}$ y el $\mathrm{K}$ y negativa sobre el $\mathrm{Mg}$ en el año 2011 (tabla 4.42). Además, en ese mismo año, PMR y RPS se relacionaron positivamente con $\mathrm{P}$, mientras que PMR, RPS y P100 se relacionaron negativamente con el Mg peciolar.P100 y PMR se relacionaron significativamente de forma positiva en 2010 conel K. Rogiers et al. (2006) y Etchebarne et al. (2009) indicaron que debido a la fuerte correlación encontrada entre la acumulación de $\mathrm{K}$ y el peso de la baya, el $\mathrm{K}$ juega un papel clave en la expansión de las células, y por lo tanto el crecimiento de la baya. En los años 2009 y 2010 el peso de 100 bayas se ha relacionado significativamente de forma negativa con el contenido de B. No se han encontrado regresiones lineales significativas del rendimiento y sus componentes sobre las concentraciones de $\mathrm{N}, \mathrm{Ca}, \mathrm{Fe}, \mathrm{Cu}$ y $\mathrm{Zn}$ de los peciolos recogidos en envero. El IR se ha relacionado con el contenido peciolar de $\mathrm{P}$ positivamente y con el $\mathrm{Mg}$ y $\mathrm{Mn}$ negativamente en el año 2011.

Han resultado regresiones lineales negativas de PMR y P100 sobre el Mn peciolar. Es de destacar que el rendimiento y sus componentes tienen mayor relación con el contenido de $\mathrm{Mn}$ en el suelo que con su contenido en los peciolos, siendo para el primero positiva, y para el segundo negativa, debido como se ha descrito en el apartado 4.2.1, a que la clorosis férrica acarrea una mayor acumulación de $\mathrm{Mn}$ en los peciolos. Martín et al. (2008) observaron también relaciones significativamente negativas entre la concentración de $\mathrm{Mn}$ en los peciolos y el rendimiento del viñedo. En este contexto, el $\mathrm{Mn}^{2+}$ es más fácilmente asimilado por las raíces de las plantas deficientes en Fe (Alcántara et al., 1994; Cohen et al., 1998; Korshunova et al., 1999; Eckhardt et al., 2001), lo que ha sido atribuido a la competencia entre los dos iones por los sitios de absorción (Kochian, 1991; Welch, 1995). 


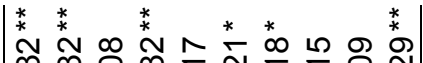
m

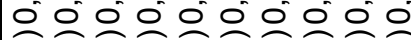

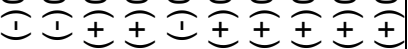

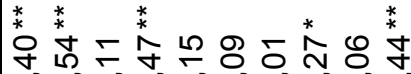

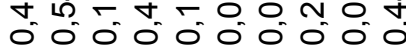

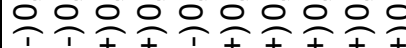
응 ำ

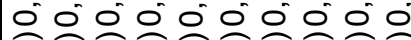

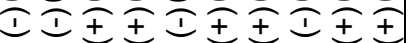
* * * * * * * *

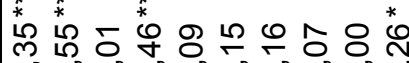

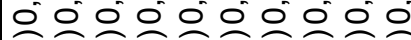
II王王王王王王 ** * * * * * * * * * * の

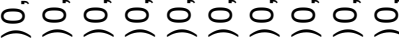
II王声声㐊芭 సิ ৪ ํำ ᄂ

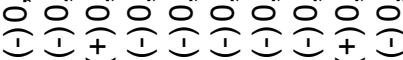
* *

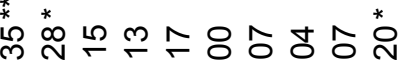

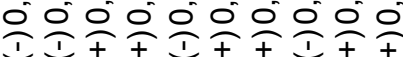

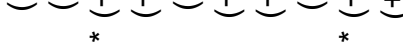
ㄷㅇำ

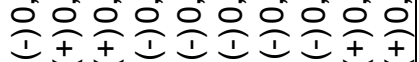

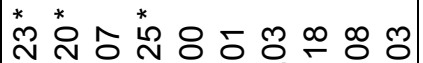
응ㅇㅇㅇㅇㅇㅇㅇㅇㅇㅇㅇㅇ

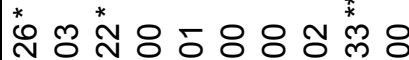

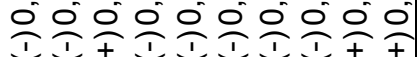
苂

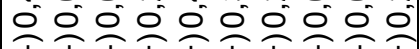
III王王王II王

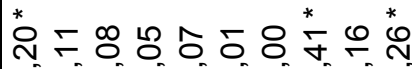
웅ㅇㅇㅇㅇㅇㅇㅇㅇㅇㅇㅇㅇ은 II王政吉士

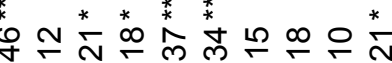
0000000000 III王㐊工王士

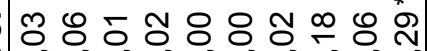

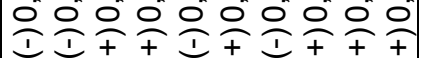

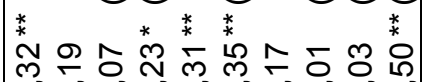

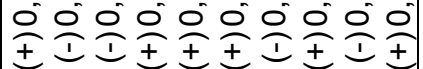

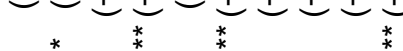
****** * * II声I王声声

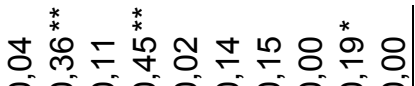

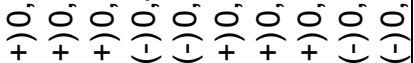

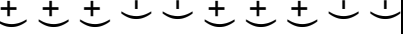

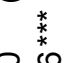
*

ऽ 응응ㅇㅇㅇㅇㅇㅇㅇㅇㅇㅇㅇㅣ

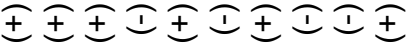
유 뉴 $\stackrel{*}{\sim}$ த 웅ㅇㅇㅇㅇㅇㅇㅇㅇㅇ

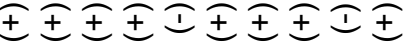

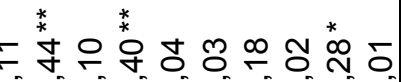

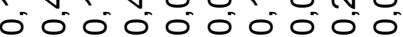

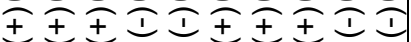
*****

ก ำ

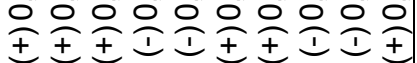

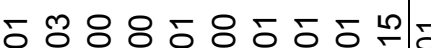

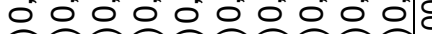

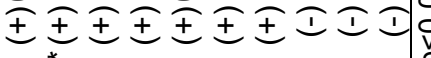

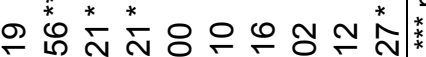

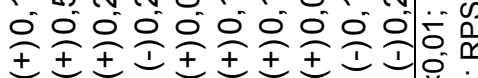

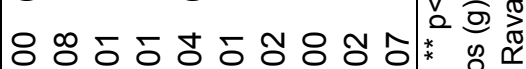

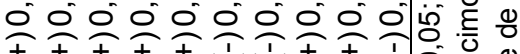

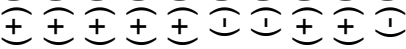
先

으 원 设 을

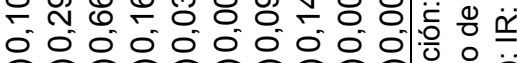

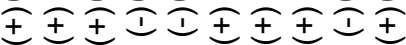
\& 은

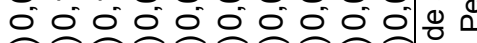

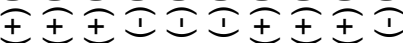
๙ำ ㅇำ o 0 O

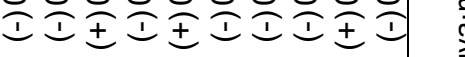

승ㅇㅇ융ㅇㅇ으동 응

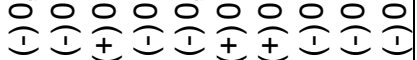
: 을

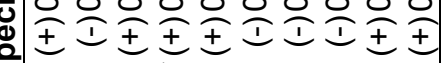
으

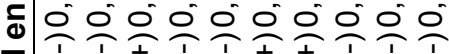
万II王III

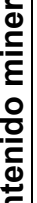

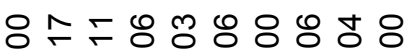

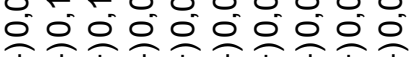

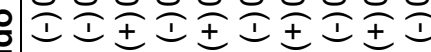


Como se observa en la tabla 4.43, en el año 2011, el rendimiento fue significativamente menor en las zonas cloróticas que en las zonas sanas. En este mismo año, todas las componentes del rendimiento, el peso medio del racimo, el número de racimos por sarmiento y el peso de cien bayas fueron significativamente mayores en las subzonas sanas que en las afectadas por clorosis férrica. Además, el peso de cien bayas fue significativamente mayor en las subzonas sanas que en las afectadas por clorosis férrica en 2010. Numerosos autores han observado reducciones importantes del vigor y rendimiento de viñedos asociadas a la clorosis férrica (Gruber y Kosegarten, 2002; Bertamini y Nedunchezhian, 2005; Bavaresco y Poni, 2003; Bavaresco et al., 2006, 2010a; Martín et al., 2008). Bavaresco et al. (2005) indicaron que la clorosis afectaba negativamente la productividad, reduciendo el número de racimos por planta, el peso del racimo y el peso de la baya en comparación con las condiciones de crecimiento normales.

En el año 2011, el rendimiento en las parcelas no afectadas por clorosis férrica fue 1,9 veces mayor que en 2009 y 4,5 veces mayor que en 2010. Estas diferencias se pueden deber, en gran medida, a la variabilidad de las condiciones meteorológicas en las tres campañas de estudio, especialmente en lo referente a la cantidad de precipitaciones (apartado 3.2.3). El hecho de haber obtenido mayores diferencias en las componentes del rendimiento de subparcelas sanas y cloróticas cuando la disponibilidad de agua para las plantas era mayor, está de acuerdo con González et al., (2006) quienes, en un ensayo de campo llevado a cabo en la Ribera del Duero en la campaña de 2005, fuertemente marcada por la sequía, no encontraron diferencias significativas en el rendimiento entre plantas cloróticas y plantas tratadas con lignosulfato de hierro. En 2011, el rendimiento se ha relacionado significativamente de forma positiva con la concentración de clorofila foliar en cuajado y la eficiencia máxima del fotosistema II (apartado 4.5), y de forma negativa con la fluorescencia mínima(con valores de Fo más altos en plantas cloróticas). Estas relaciones ponen de manifiesto que las diferencias de productividad observadas entre subzonas afectadas y no afectadas por clorosis férrica se deben fundamentalmente al efecto de la fisiopatía sobre el nivel foliar de clorofila y el rendimiento fotosistema II (Maxwell y Johnson, 2000).

Tabla 4.43. Valores medios del rendimiento, sus componentes y el índice de Ravaz en áreas de muestreo afectadas $(\mathrm{C})$ y no afectadas $(\mathrm{NC})$ por clorosis férrica.

\begin{tabular}{|c|c|c|c|c|c|c|}
\hline \multirow[b]{2}{*}{ Parámetros } & \multicolumn{2}{|c|}{2009} & \multicolumn{2}{|c|}{2010} & \multicolumn{2}{|c|}{2011} \\
\hline & $\begin{array}{c}N C \\
(n=11)\end{array}$ & $\underset{(n=11)}{C}$ & $\begin{array}{c}N C \\
(n=12)\end{array}$ & $\underset{(n=12)}{C}$ & $\begin{array}{c}N C \\
(n=12)\end{array}$ & $\begin{array}{c}C \\
(n=12)\end{array}$ \\
\hline Rto $\left(\mathrm{kg} \cdot \mathrm{m}^{-2}\right)$ & $0,46 a$ & $0,43 a$ & $0,19 a$ & $0,21 a$ & $0,87 a$ & $0,55 b$ \\
\hline $\operatorname{PMR}(\mathbf{q})$ & $213 a$ & $217 a$ & $169 a$ & $133 a$ & $308 a$ & $233 b$ \\
\hline RPS & $0,78 a$ & $0,65 a$ & $0,29 a$ & $0,39 a$ & $0,77 a$ & $0,58 b$ \\
\hline $\mathrm{P} 100(\mathrm{~g})$ & $176 a$ & $174 a$ & $167 a$ & $152 b$ & $198 a$ & $176 b$ \\
\hline IR & $2,55 a$ & $2,51 \mathrm{a}$ & $0,64 a$ & $0,85 a$ & $1,91 \mathrm{a}$ & $1,17 b$ \\
\hline
\end{tabular}

Rto: Rendimiento; PMR: Peso medio del racimo; RPS: Número medio de racimos por sarmientos; P100: Peso de 100 bayas; IR: Índice de Ravaz.

Dentro de un mismo año, valores con diferente letra son significativamente diferentes $(p<0,05$, test Tukey) 
En las áreas de estudio con un nivel bajo de nutrición fosfórica, el rendimiento fue significativamente menor que en las áreas con un nivel medio de nutrición en el año 2011 (tabla 4.44). En este mismo año, las componentes del rendimiento peso medio del racimo y peso de cien bayas fueron significativamente menores en las subparcelas con una nutrición baja de fósforo que en las parcelas con un nivel de nutrición medio.

El análisis de la varianza del rendimiento ha resultado significativo en función de la incidencia de la clorosis férrica y el nivel de nutrición de potasio en el año 2011, (tabla 4.37)por lo que se dio un efecto aditivo de ambas factores. Como se puede observar en la tabla 4.44, el rendimiento fue significativamente menor en las subparcelas con una nutrición media de potasio que en las parcelas con un nivel alto de nutrición en 2011. En este mismo año, todas las componentes del rendimiento, el peso medio del racimo, el número de racimos por sarmiento y el peso de cien bayas fueron significativamente menores en las subparcelas con una nutrición media de potasio que en las parcelas con un nivel de nutrición alto. Esto mismo ocurrió para el peso medio del racimo y el peso de cien bayas en 2010. En general, existe una tendencia al incremento del rendimiento y todas sus componentes con el aumento en la nutrición potásica, aunque en muchos de los casos las diferencias no fueron significativas al 5\%. En este orden de cosas, Smolarz y Marcik (1997) concluyeron que la carencia de $\mathrm{K}$ provocaba una disminución en el rendimiento y en el peso de la fruta en viñedo. Conradie y Saayman (1989a) mostraron un incremento significativo en el rendimiento de vides asociado a las aplicaciones de $\mathrm{K}$.

En el año 2010 y 2011, el análisis de la varianza del rendimiento fue significativo en función del estado nutricional del magnesio (tabla 4.37). Así, en las áreas de estudio con un nivel alto de nutrición magnésica, el rendimiento del viñedo fue significativamente menor que en las áreas con un nivel medio de nutrición en el año 2011. En este mismo año, todas las componentes del rendimiento, el peso medio del racimo, el número de racimos por sarmiento y el peso de cien bayas fueron significativamente menores en las parcelas con un nivel alto de nutrición de magnesio que en las parcelas con una nutrición media. Este resultado también se ha dado para el peso medio del racimo en el año 2010 y el peso de 100 bayas en los años 2010 y 2011. Al contrario que para la nutrición potásica, la tendencia del rendimiento y todas sus componentes con el aumento en la nutrición magnésica, es a disminuir.

En el análisis factorial de la varianza del rendimiento en la campaña de 2009 ha resultado significativa la interacción de la clorosis férrica y el nivel nutricional de magnesio Además, en el año 2010, el análisis factorial de la varianza del rendimiento fue significativo tanto para el nivel nutricional de Mg como la interacción de este con la clorosis férrica (tabla 4.37). Dentro de las subparcelas no afectadas por clorosis férrica, el rendimiento fue significativamente mayor en las áreas de estudio con un nivel nutricional medio de $\mathrm{Mg}$ que en las áreas que tenían un nivel alto en 2009, mientras en 2010 y 2011 las diferencias no fueron significativas en esas (figura 4.19). 
Tabla 4.44. Valores medios del rendimiento y sus componentes en áreas de muestreo con diferente estado nutricional.

\begin{tabular}{|c|c|c|c|c|c|c|c|}
\hline \multirow[b]{2}{*}{ Nutriente } & \multicolumn{7}{|c|}{ Estado nutricional del viñedo } \\
\hline & Año & Nivel* $^{*}$ & $\mathrm{n}$ & Rto & PMR & RPS & P100 \\
\hline \multirow{6}{*}{ Fósforo } & \multirow{2}{*}{2009} & Bajo & 8 & $0,46 a$ & $223 a$ & $0,74 a$ & $179 a$ \\
\hline & & Medio & 11 & $0,47 a$ & $213 a$ & $0,78 a$ & $173 a$ \\
\hline & \multirow[b]{2}{*}{2010} & Bajo & 10 & $0,17 a$ & $134 a$ & $0,33 a$ & $149 a$ \\
\hline & & Medio & 14 & $0,23 a$ & $163 a$ & $0,38 a$ & $168 a$ \\
\hline & \multirow{2}{*}{2011} & Bajo & 10 & $0,55 b$ & $233 b$ & $0,59 a$ & $172 b$ \\
\hline & & Medio & 14 & $0,83 a$ & $298 a$ & $0,74 a$ & $198 a$ \\
\hline \multirow{6}{*}{ Potasio } & \multirow{2}{*}{2009} & Alto & 8 & $0,51 a$ & $221 a$ & $0,77 a$ & $182 a$ \\
\hline & & Medio & 14 & $0,41 a$ & $212 a$ & $0,69 a$ & $171 a$ \\
\hline & \multirow{2}{*}{2010} & Alto & 10 & $0,24 a$ & $181 a$ & $0,37 a$ & $168 a$ \\
\hline & & Medio & 14 & $0,18 a$ & $126 b$ & $0,35 a$ & $152 b$ \\
\hline & \multirow{2}{*}{2011} & Alto & 10 & $0,92 a$ & $304 a$ & $0,79 a$ & $205 a$ \\
\hline & & Medio & 14 & $0,56 b$ & $249 b$ & $0,59 b$ & $174 b$ \\
\hline \multirow{6}{*}{ Magnesio } & \multirow{2}{*}{2009} & Alto & 13 & $0,40 a$ & $206 a$ & $0,66 a$ & $165 b$ \\
\hline & & Medio & 9 & $0,52 a$ & $228 a$ & $0,80 a$ & $189 a$ \\
\hline & \multirow{2}{*}{2010} & Alto & 13 & $0,17 a$ & $128 b$ & $0,34 a$ & $149 b$ \\
\hline & & Medio & 11 & $0,25 a$ & $179 a$ & $0,38 a$ & $172 a$ \\
\hline & \multirow{2}{*}{2011} & Alto & 13 & $0,53 b$ & $243 b$ & $0,57 b$ & $172 b$ \\
\hline & & Medio & 11 & $0,92 a$ & $305 a$ & $0,80 a$ & $205 a$ \\
\hline \multirow{9}{*}{$\begin{array}{l}\text { K/Mg } \\
\text { (peciolos) }\end{array}$} & \multirow{3}{*}{2009} & Alto & 8 & $0,50 a$ & $225 a$ & $0,74 a$ & $184 a$ \\
\hline & & Medio & 8 & $0,43 a$ & $209 a$ & $0,73 a$ & $172 a$ \\
\hline & & Bajo & 6 & $0,39 a$ & $210 a$ & $0,67 a$ & $167 a$ \\
\hline & \multirow{3}{*}{2010} & Alto & 9 & $0,25 a$ & $182 a$ & $0,37 a$ & $171 a$ \\
\hline & & Medio & 6 & $0,15 a$ & $137 a b$ & $0,29 a$ & $153 b$ \\
\hline & & Bajo & 9 & $0,20 a$ & $124 b$ & $0,40 a$ & $150 \mathrm{~b}$ \\
\hline & \multirow{3}{*}{2011} & Alto & 6 & $0,97 a$ & $312 a$ & $0,78 a$ & $211 a$ \\
\hline & & Medio & 9 & $0,73 a b$ & $265 a$ & $0,72 a$ & $182 b$ \\
\hline & & Bajo & 9 & $0,51 \mathrm{~b}$ & $253 a$ & $0,56 a$ & $176 b$ \\
\hline \multirow{6}{*}{ Cobre } & \multirow{2}{*}{2009} & Bajo & 9 & $0,42 a$ & $192 b$ & $0,74 a$ & $155 b$ \\
\hline & & Medio & 13 & $0,46 a$ & $231 a$ & $0,70 a$ & $189 a$ \\
\hline & \multirow{2}{*}{2010} & Bajo & 7 & $0,14 a$ & $123 a$ & $0,30 a$ & $152 a$ \\
\hline & & Medio & 17 & $0,24 a$ & $162 a$ & $0,38 a$ & $162 a$ \\
\hline & \multirow{2}{*}{2011} & Bajo & 7 & $0,44 b$ & $220 b$ & $0,48 b$ & $166 b$ \\
\hline & & Medio & 17 & $0,86 a$ & $299 a$ & $0,76 a$ & $199 a$ \\
\hline \multirow{6}{*}{ Zinc } & \multirow{2}{*}{2009} & Alto & 14 & $0,45 a$ & $213 a$ & $0,75 a$ & $171 a$ \\
\hline & & Medio & 8 & $0,44 a$ & $218 a$ & $0,65 a$ & $183 a$ \\
\hline & \multirow{2}{*}{2010} & Alto & 13 & $0,18 a$ & $149 a$ & $0,31 a$ & $156 a$ \\
\hline & & Medio & 7 & $0,22 a$ & $126 a$ & $0,40 a$ & $152 a$ \\
\hline & & Alto & 13 & $0,65 a$ & $273 a$ & $0,62 a$ & $187 a$ \\
\hline & 2011 & Medio & 7 & $0,59 a$ & 235 & $0,60 a$ & $183 a$ \\
\hline
\end{tabular}

Rto: Rendimiento (kg uva $\cdot \mathrm{m}^{-2}$ ); PMR: Peso medio del racimo (g); RPS: Número medio de racimos por sarmientos; P100: Peso de 100 bayas (g).

Dentro de un mismo año, los valores con diferente letra son significativamente diferentes $(p<0,05$, test Tukey)

*según diagnóstico nutricional realizado en el apartado 4.1 
El rendimiento del viñedo fue significativamente menor en las subparcelas con baja relación $\mathrm{K} / \mathrm{Mg}$ que en las parcelas con alta relación en 2011, debido fundamentalmente a un descenso en el tamaño de la baya. En 2010, las subparcelas con baja relación $\mathrm{K} / \mathrm{Mg}$ registraron menores valores tanto del peso medio del racimo como del peso de 100 bayas. El menor rendimiento provocado por el exceso de magnesio es compensado por el aumento de potasio, equilibrando la relación $\mathrm{K} / \mathrm{Mg}$. Hughes et al. (1992) sugirieron que el potasio está implicado en la toma y transporte de Fe por la planta, participando en el correcto funcionamiento de las enzimas implicadas en ello (Tagliavini y Rombolà, 2001) y en el balance iónico, que permite la adecuada nutrición férrica (Marscher, 1995).

2009

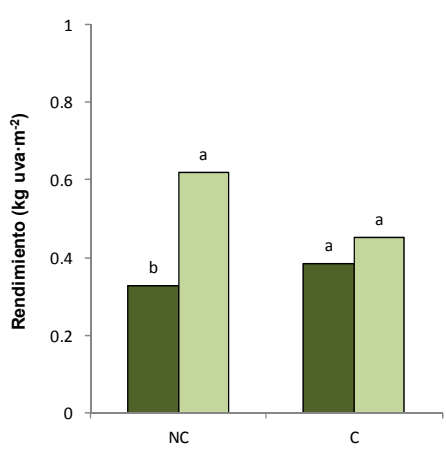

2010

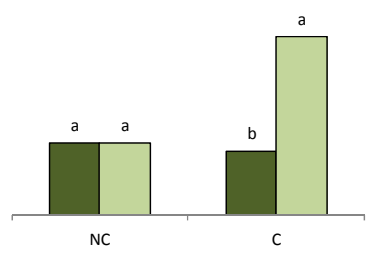

2011

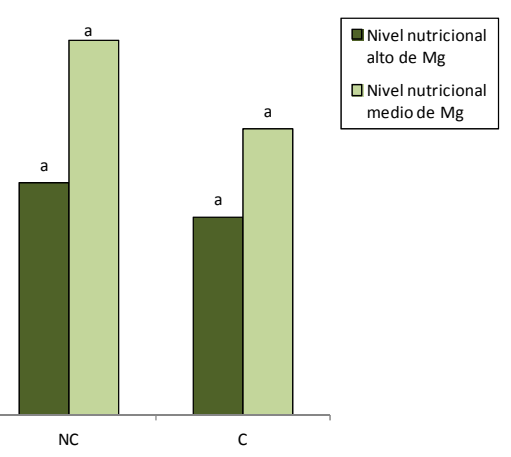

Figura 4.19. Rendimiento en las áreas de estudio cloróticas (C) y no cloróticas (NC) con distinto nivel nutricional de Mg.

Como se puede observar en la tabla 4.37, el análisis de la varianza del rendimiento ha resultado significativo para el estado nutricional del Cu en el año 2011. En las áreas de estudio con un nivel bajo de nutrición cúprica, el rendimiento del viñedo fue significativamente menor que en las áreas con una nutrición media en el año 2011. En este mismo año, todas las componentes del rendimiento, el peso medio del racimo, el número de racimos por sarmiento y el peso de cien bayas fueron significativamente menores en las parcelas con un nivel bajo de nutrición cúprica que en las parcelas con una nutrición media. Este mismo resultado se ha dado para el peso medio del racimo y el peso de 100 bayas en el año 2009. Uno de los principales papeles biológicos del cobre deriva de su presencia necesaria en la formación del polen y en la fecundación de las flores (Bavaresco et al., 2010b). Chen et al. (2004b) han observado que la deficiencia de Fe podría estimular la asimilación y acumulación de $\mathrm{Cu}$ en Commelina communis, y viceversa, constatando que tanto la deficiencia de $\mathrm{Cu}$ como la de $\mathrm{Fe}$ inducen la actividad de quelato-Fe(III) reductasa en las raíces. Todo esto demuestra que existe una relación fisiológica entre el metabolismo de $\mathrm{Fe}$ y $\mathrm{Cu}$. 
No se han detectado diferencias significativas del rendimiento y sus componentes en función del nivel de nutrición de $\mathrm{Zn}$ en ninguno de los años de estudio (tabla 4.44).

\subsection{2.- Efectos del estado nutricional del viñedo en la composición} de la uva.

El análisis de la varianza de las variables de composición de la uva, en cuanto a los parámetros físico-químicos del mosto, los parámetros de la madurez fenólica de las bayas y los parámetros cromáticos del mosto según cada año de seguimiento, ha mostrado diferencias significativas entre los tres años en los que se llevó a cabo el estudio (tabla 4.45), por lo que es necesario analizar estadísticamente las variables año por año.

Tabla 4.45. Valores de la F de Fisher y nivel de significación del análisis de la varianza (ANOVA) de los parámetros físico-químicos del mosto en función de los años de estudio.

\begin{tabular}{|c|c|}
\hline Composición del mosto & $\mathbf{F}$ \\
\hline Sólidos solubles totales ( ${ }^{\circ}$ Brix) & $28,81^{* * *}$ \\
\hline Acidez Total ( $\mathrm{g}$ ácido tartárico $\cdot \mathrm{L}^{-1}$ ) & $47,41^{* * *}$ \\
\hline $\mathrm{pH}$ & $52,24^{* * *}$ \\
\hline Índice de polifenoles totales & $24,30^{* * *}$ \\
\hline Nitrógeno fácilmente asimilable $\left(g \cdot I^{-1}\right)$ & $15,74^{* * *}$ \\
\hline Potasio (ppm) & $113,9^{* * *}$ \\
\hline \multicolumn{2}{|l|}{ Madurez fenólica de las bayas } \\
\hline Contenido en fenoles totales & $40,76^{* * *}$ \\
\hline Antocianos fácilmente extraíbles (mg malvidina $\cdot \mathrm{kg}^{-1}$ ) & $44,08^{* * *}$ \\
\hline Antocianos totales (mg malvidina $\cdot \mathrm{kg}^{-1}$ ) & $14,47^{\star * *}$ \\
\hline Índice de madurez celular & $39,02^{* * *}$ \\
\hline Índice de madurez de las pepitas & $103,9^{* * *}$ \\
\hline \multicolumn{2}{|l|}{ Características cromáticas del mosto } \\
\hline Croma (C) & $26,62^{* * *}$ \\
\hline Tono $(\mathrm{H})$ & $65,41^{* * *}$ \\
\hline Luminosidad (L) & $37,04^{* * *}$ \\
\hline Relación verde/rojo (a*) & $48,34^{* * *}$ \\
\hline Relación amarillo/azul (b*) & $61,35^{* * *}$ \\
\hline Índice cromático uvas tintas (CIRG) & $20,04^{* * *}$ \\
\hline
\end{tabular}


Las diferencias interanuales en la composición de la uva se deberían, en gran medida, a la variabilidad de las condiciones meteorológicas en las tres campañas de estudio, descrita en el apartado 3.2.3. Así, se puede destacar la inusualmente escasa precipitación a lo largo del reposo de la vid, previa a la campaña de 2009 , lo que minimizó la reserva de agua en el suelo al comienzo del ciclo vegetativo. En el año 2010, se dio un verano especialmente seco, acompañado de temperaturas anormalmente altas en el mes de julio y temperaturas máximas absolutas muy elevadas en algunos días de agosto. En general, en el año 2011 se observaron unas precipitaciones y temperaturas más favorables para el desarrollo de la planta que en las otras dos campañas. Las temperaturas medias registradas durante la maduración de las uvas en el año 2010 fueron ligeramente más bajas que en 2009 y 2011. El tiempo transcurrido desde el desborre hasta la vendimia fue de 116 días en 2009, 130 días en 2010 y 127 días en 2011. Hay que destacar, que a primeros de mayo de 2010 se produjeron heladas que redujeron drásticamente los rendimientos y retrasaron el crecimiento y desarrollo de las plantas.

\subsubsection{1.- Composición del mosto}

En la tabla 4.46 se recogen las medias y los coeficientes de variación de los parámetros de composición físico-química del mosto en el conjunto de las zonas de estudio en los tres años de seguimiento. Los parámetros que muestran menor coeficiente de variación son el contenido en sólidos solubles totales, el pH y el contenido de potasio, los cuáles serían los menos afectados por la variación en las características del suelo de las áreas de estudio (apartado 4.1.1), incluyendo el grado de afección de clorosis férrica y el estado nutricional de las plantas en general. Por otra parte, la variación en el estado hídrico de las plantas en el área de estudio también es una fuente de variación importante para la composición del mosto (Hailemichael, 2014).Jackson y Lombard (1993) detectaron disminuciones de acidez total en condiciones de déficit hídrico.

Las muestras de mosto presentaron el menor contenido en sólidos solubles totales en 2009 y el mayor en 2011. El índice de polifenoles totales fue mayor en 2011, siendo equiparable en 2009 y 2010. La acidez total en los mostos fue notablemente más baja en 2011. Por último, la concentración de $\mathrm{K}$ en el mosto fue sensiblemente mayor en el año 2010. En resumen, en el año 2011 se obtuvieron uvas con mejor índice de madurez tecnológica y mayor contenido fenólico que en 2009 y 2010, coincidiendo con la campaña de mayores rendimientos del estudio, y de mayor disponibilidad de aguapara las plantas (apartado 4.4.1). 
Tabla 4.46. Valores de los parámetros físico-químicos del mosto en el conjunto de las zonas de viñedo en los tres años de seguimiento.

\begin{tabular}{clcccc}
\hline & $\begin{array}{l}\text { Composición } \\
\text { del mosto }\end{array}$ & Mínimo & Máximo & Media & $\begin{array}{c}\text { Coeficiente de } \\
\text { variación (\%) }\end{array}$ \\
\hline & SST & 20.1 & 24.2 & 22.9 & 5 \\
Año 2009 & AT & 3.38 & 5.25 & 4.27 & 14 \\
(n=22) & IPT & 3.46 & 4.00 & 3.72 & 4 \\
& NFA & 17.0 & 30.0 & 23.4 & 13 \\
& K & 77 & 191 & 139 & 24 \\
\hline & SST & 1070 & 1375 & 1198 & 7 \\
\hline Año 2010 & AT & 22.9 & 26.2 & 24.6 & 4 \\
(n=24) & IPT & 2.35 & 4.80 & 3.61 & 17 \\
& NFA & 3.75 & 4.11 & 3.95 & 3 \\
& K & 16.4 & 42.3 & 23.4 & 26 \\
\hline & SST & 130 & 268 & 193 & 17 \\
& AT & 1968 & 2965 & 2340 & 8 \\
Año 2011 & pH & 23.5 & 26.9 & 25.2 & 4 \\
(n=24) & IPT & 2.12 & 3.56 & 2.72 & 13 \\
& NFA & 3.90 & 4.33 & 4.11 & 3 \\
& K & 22.4 & 37.5 & 31.8 & 14 \\
\hline
\end{tabular}

IPT: Índice de polifenoles totales; AT: Acidez total ( $\mathrm{g}$ ácido tartárico $\left.\cdot \mathrm{I}^{-1}\right)$; SST: Sólidos solubles totales ( ${ }^{\circ}$ Brix); NFA: Nitrógeno fácilmente asimilable $\left(\mathrm{g} \cdot \mathrm{l}^{-1}\right)$; K: Potasio $(\mathrm{ppm})$.

De las regresiones lineales estudiadas de los parámetros físico-químicos del mosto de vendimia sobre las variables de composición del suelo expuestas en la tabla 4.47, en el año 2009 se puede destacar la relación significativamente negativa de SST e IPT y positiva del contenido de $\mathrm{K}$ en los mostos sobre el contenido en $\mathrm{Cu}$ y $\mathrm{Zn}$ del suelo. En 2010, puede destacarse la regresión positiva de IPT y SST sobre el porcentaje de arcilla, de AT y SST sobre el contenido en carbonatos y de IPT y AT sobre el contenido en Cu del suelo. En 2011, la mayoría de las variables analizadas en el mosto se relacionaron significativamente con el porcentaje de arcilla y los carbonatos totales del suelo. Además, este mismo año, IPT se relacionó de forma negativa y AT de forma positiva con los contenidos en $\mathrm{K}$ y $\mathrm{Mn}$ del suelo. SST se relacionó significativamente con gran número de nutrientes del suelo en 2011.No se han encontrado regresiones lineales significativas de los parámetros de composición del mosto sobre los contenidos de Ca y Fe en el suelo.

Como se ha descrito en el epígrafe 4.4.1.2, tanto el contenido en arcilla, como el de carbonatos totales presentes en el suelo aumentan en los suelos clorosantes, y se relacionan con menores rendimientos de los viñedos debido a la reducción de la concentración de clorofila en la hoja y de la capacidad fotosintética de las plantas. De acuerdo con Bavaresco et al. (2005) y Bavaresco y Poni (2003), la mayor concentración de azúcares e índice de polifenoles totales en las uvas procedentes de 
suelos clorosantes sería probablemente una consecuencia de la reducción del rendimiento y del tamaño de la baya(tabla 4.43).

Tabla 4.47. Coeficiente de determinación $\left(R^{2}\right)$, nivel de significación y pendiente de la regresión de los parámetros de composición del mosto sobre el contenido en arcilla, carbonatos totales (CT) y concentración de elementos minerales en el suelo.

\begin{tabular}{|c|c|c|c|c|c|c|c|}
\hline \multicolumn{2}{|c|}{ Composición del suelo ${ }^{1}$} & SST & AT & $\mathrm{pH}$ & IPT & NFA & $\mathbf{K}$ \\
\hline \multirow{10}{*}{2009} & Arcilla (\%) & $(+) 0,16$ & $(-) 0,05$ & $(-) 0,02$ & $(-) 0,00$ & $(-) 0,28$ * & $(-) 0,33$ ** \\
\hline & CT (\%) & $(+) 0,32^{*}$ & (-) 0,19 & $(+) 0,08$ & $(-) 0,00$ & $(+) 0,07$ & $(-) 0,14$ \\
\hline & $P\left(\mathbf{m g} \cdot \mathbf{k g}^{-1}\right)$ & $(-) 0,06$ & $(-) 0,15$ & $(+) 0,16$ & $(-) 0,06$ & $(+) 0,10$ & $(+) 0,20$ * \\
\hline & $K\left(\right.$ meq $\left.100 g^{-1}\right)$ & $(+) 0,01$ & $(+) 0,00$ & $(-) 0,04$ & $(-) 0,03$ & $(-) 0,23$ * & $(+) 0,00$ \\
\hline & $\operatorname{Mg}\left(\mathrm{meq} \cdot 100 \mathrm{~g}^{-1}\right)$ & $(+) 0,14$ & $(-) 0,02$ & (-) 0,09 & (-) 0,02 & $(-) 0,34$ ** & ${ }^{*}(-) 0,12$ \\
\hline & $\mathrm{Ca}\left(\mathrm{meq} \cdot 100 \mathrm{~g}^{-1}\right)$ & $(+) 0,00$ & $(-) 0,04$ & $(-) 0,05$ & $(-) 0,14$ & $(-) 0,14$ & $(-) 0,00$ \\
\hline & $\mathrm{Fe}\left(\mathrm{mg} \cdot \mathrm{kg}^{-1}\right)$ & $(-) 0,02$ & $(+) 0,03$ & $(+) 0,02$ & $(+) 0,01$ & $(+) 0,13$ & $(+) 0,08$ \\
\hline & $\mathrm{Cu}\left(\mathrm{mg} \cdot \mathrm{kg}^{-1}\right)$ & $(-) 0,60$ ** & $(-) 0,02$ & $(+) 0,04$ & $(-) 0,20$ & $(+) 0,04$ & $(+) 0,48$ ** \\
\hline & $\mathrm{Zn}\left(\mathrm{mg} \cdot \mathbf{k g}^{-1}\right)$ & $(-) 0,48$ ** & $(-) 0,19$ & $(+) 0,22$ & $(-) 0,30$ * & $(+) 0,26$ & $(+) 0,39$ * \\
\hline & $M n\left(m g \cdot \mathbf{k g}^{-1}\right)$ & $(-) 0,03$ & $(+) 0,28$ * & $(-) 0,05$ & $(+) 0,01$ & $(-) 0,14$ & $(+) 0,11$ \\
\hline \multirow{10}{*}{2010} & Arcilla (\%) & $(+) 0,24$ * & $(-) 0,07$ & $(-) 0,03$ & $(+) 0,25^{*}$ & $(+) 0,05$ & $(-) 0,02$ \\
\hline & CT (\%) & $(+) 0,25^{*}$ & $(-) 0,22$ * & $(+) 0,04$ & $(+) 0,16$ & $(+) 0,06$ & $(-) 0,01$ \\
\hline & $P\left(\mathbf{m g} \cdot \mathbf{k g}^{-1}\right)$ & $(-) 0,07$ & $(-) 0,04$ & $(+) 0,10$ & $(-) 0,05$ & $(-) 0,12$ & $(+) 0,00$ \\
\hline & $K\left(\mathrm{meq} \cdot 100 \mathrm{~g}^{-1}\right)$ & $(-) 0,01$ & $(+) 0,24$ * & $(+) 0,02$ & $(-) 0,04$ & $(+) 0,00$ & $(+) 0,16$ \\
\hline & $\operatorname{Mg}\left(\mathrm{meq} \cdot 100 \mathrm{~g}^{-1}\right)$ & $(+) 0,14$ & $(-) 0,00$ & $(+) 0,00$ & $(+) 0,09$ & $(+) 0,16$ & $(-) 0,00$ \\
\hline & $\mathrm{Ca}\left(\mathrm{meq} \cdot 100 \mathrm{~g}^{-1}\right)$ & $(+) 0,06$ & $(+) 0,01$ & $(+) 0,05$ & $(+) 0,12$ & $(+) 0,01$ & (+) 0,04 \\
\hline & $\mathrm{Fe}\left(\mathrm{mg} \cdot \mathrm{kg}^{-1}\right)$ & $(-) 0,06$ & $(+) 0,12$ & $(-) 0,06$ & $(-) 0,06$ & $(-) 0,08$ & $(+) 0,05$ \\
\hline & $\mathrm{Cu}\left(\mathrm{mg} \cdot \mathrm{kg}^{-1}\right)$ & $(+) 0,08$ & $(-) 0,38^{* *}$ & ${ }^{*}(+) 0,02$ & $(+) 0,52^{* *}$ & $(+) 0,00$ & (-) 0,19 \\
\hline & $\mathrm{Zn}\left(\mathrm{mg} \cdot \mathrm{kg}^{-1}\right)$ & $(-) 0,02$ & $(-) 0,13$ & $(+) 0,17$ & $(-) 0,00$ & $(-) 0,05$ & (-) 0,04 \\
\hline & $M n\left(\mathbf{m g} \cdot \mathbf{k g}^{-1}\right)$ & $(+) 0,00$ & $(+) 0,03$ & $(+) 0,02$ & $(-) 0,00$ & $(-) 0,07$ & $(+) 0,02$ \\
\hline \multirow{10}{*}{2011} & Arcilla (\%) & $(+) 0,67^{* * *}$ & $(-) 0,21$ * & $(+) 0,48^{* *}$ & * $(+) 0,24^{*}$ & $(+) 0,14$ & $(+) 0,27$ * \\
\hline & CT (\%) & $(+) 0,60^{* * *}$ & $(-) 0,02$ & $(+) 0,30$ * & $(+) 0,45^{* *}$ & $(+) 0,40$ ** & * $(+) 0,28$ * \\
\hline & $P\left(\mathbf{m g} \cdot \mathbf{k g}^{-1}\right)$ & $(-) 0,35^{*}$ & $(+) 0,30$ * & $(-) 0,01$ & $(-) 0,02$ & $(+) 0,03$ & $(+) 0,03$ \\
\hline & $K\left(\right.$ meq $\left.\cdot 100 g^{-1}\right)$ & $(-) 0,38$ ** & (+) 0,19 * & $(-) 0,24$ * & $(-) 0,63^{* * *}$ & * $(-) 0,17$ & $(-) 0,18$ \\
\hline & $\operatorname{Mg}\left(\operatorname{meq} \cdot 100 \mathrm{~g}^{-1}\right)$ & $(+) 0,30$ * & $(-) 0,10$ & $(+) 0,20$ & $(+) 0,08$ & $(+) 0,08$ & $(+) 0,03$ \\
\hline & $\mathrm{Ca}\left(\mathrm{meq} \cdot 100 \mathrm{~g}^{-1}\right)$ & $(-) 0,03$ & $(+) 0,05$ & $(-) 0,02$ & $(-) 0,33^{* *}$ & $(-) 0,03$ & $(-) 0,03$ \\
\hline & $\mathrm{Fe}\left(\mathrm{mg} \cdot \mathrm{kg}^{-1}\right)$ & $(-) 0,09$ & $(+) 0,00$ & (-) 0,01 & $(-) 0,03$ & $(-) 0,02$ & $(+) 0,00$ \\
\hline & $\mathrm{Cu}\left(\mathrm{mg} \cdot \mathrm{kg}^{-1}\right)$ & $(-) 0,40$ ** & $(+) 0,00$ & $(-) 0,02$ & $(-) 0,03$ & $(-) 0,03$ & (-) 0,05 \\
\hline & $\mathrm{Zn}\left(\mathrm{mg} \cdot \mathrm{kg}^{-1}\right)$ & $(-) 0,20$ * & $(+) 0,04$ & $(+) 0,01$ & $(-) 0,00$ & $(+) 0,03$ & $(+) 0,01$ \\
\hline & $M n\left(m g \cdot k^{-1}\right)$ & $(-) 0,38$ ** & $(+) 0,21$ * & $(-) 0,17$ & $(-) 0,47^{* *}$ & $(-) 0,42$ ** & * $(-) 0,04$ \\
\hline
\end{tabular}

SST: Sólidos solubles totales ( $\left.{ }^{\circ} B r i x\right)$; AT: Acidez total ( $g$ ácido tartárico $\mathrm{I}^{-1}$ ); IPT: Índice de polifenoles totales; NFA: Nitrógeno fácilmente asimilable $\left(\mathrm{g} \cdot \mathrm{l}^{-1}\right)$; K: Potasio $(\mathrm{ppm})$.

${ }^{1}$ Método de extracción: Arcilla (ISSS); Carbonatos totales (Bernard); P (Olsen); K, Ca y Mg (Acetato de amonio); $\mathrm{Fe}, \mathrm{Cu}, \mathrm{Zn}$ y Mn (DTPA)

Como se puede ver en la tabla 4.48, el IPT de los mostos se ha relacionado negativamente de forma significativa con el contenido peciolar de $\mathrm{P}, \mathrm{K}$ y Zn en 2010 y 
de Mg y Mn en 2011,y positivamente con el nivel de B en 2010 y de $\mathrm{P}$ y Cu en 2011.Además, se ha encontrado una regresión lineal positiva de AT sobre el contenido de Cu en 2009 y 2010 y sobre el nivel de K y Zn en 2010. Los SST se han relacionado significativamente de forma positiva con la concentración de Mg y Mn en 2009 y 2011 y de forma negativa con el nivel de $\mathrm{Zn}$ en 2010 y de $\mathrm{N}$ en 2010 y 2011 . En el año 2010, el K presente en el mosto se relacionó positivamente con los contenidos peciolares de $\mathrm{P}$ y K.

Tabla 4.48. Coeficiente de determinación $\left(R^{2}\right)$, nivel de significación y pendiente de la regresión de los parámetros de composición del mosto sobre el contenido de nutrientes minerales en los peciolos.

\begin{tabular}{|c|c|c|c|c|c|c|c|}
\hline \multicolumn{2}{|c|}{ Nutrientes peciolos } & SST & AT & $\mathrm{pH}$ & IPT & NFA & $\mathrm{K}$ \\
\hline \multirow{10}{*}{2009} & $\mathbf{N}(\%)$ & (-) 0,02 & $(+) 0,00$ & $(+) 0,02$ & (-) 0,02 & (+) 0,07 & $(+) 0,02$ \\
\hline & $\mathbf{P}(\%)$ & (+) 0,00 & (+) 0,02 & (+) 0,02 & (+) 0,04 & (+) 0,08 & (-) 0,00 \\
\hline & $K(\%)$ & $(-)$ ) 0,08 & (-) 0,02 & (+) 0,09 & (+) 0,00 & (+) 0,00 & $(+) 0,00$ \\
\hline & $\operatorname{Mg}(\%)$ & (+) $0,31^{* *}$ & (-) 0,00 & (-) 0,01 & (-) 0,01 & (+) 0,01 & (-) 0,06 \\
\hline & $\mathrm{Ca}(\%)$ & (+) 0,04 & (-) 0,01 & (-) 0,01 & (-) 0,00 & (-) 0,00 & $(-) 0,00$ \\
\hline & $\mathrm{Fe}\left(\mathrm{mg} \cdot \mathrm{kg}^{-1}\right)$ & (-) 0,00 & $(-) 0,11$ & (+) 0,16 & (-) 0,09 & (+) 0,08 & (+) 0,04 \\
\hline & $\mathrm{Cu}\left(\mathrm{mg} \cdot \mathrm{kg}^{-1}\right)$ & (-) 0,04 & $(+) 0,26$ * & (-) 0,08 & (-) 0,00 & (-) 0,00 & $(+) 0,12$ \\
\hline & $\mathrm{Zn}\left(\mathrm{mg} \cdot \mathrm{kg}^{-1}\right)$ & $(-)$ 0,02 & (+) 0,02 & (-) 0,00 & (+) 0,05 & (+) 0,01 & (+) 0,00 \\
\hline & $M n\left(m g \cdot k g^{-1}\right)$ & (+) 0,33 ** & (-) 0,00 & (-) 0,00 & (+) 0,03 & (-) 0,06 & (-) 0,21 * \\
\hline & $B(n$ & $(+) 0,16$ & $(-) 0,01$ & (-) 0,01 & $(+) 0,00$ & (+) 0,04 & (-) 0,07 \\
\hline \multirow{10}{*}{2010} & & $(-) 0,21$ * & $(+) 0$ & (+) 0,01 & $(-) 0,16$ & $(+) 0,01$ & $(+) 0,10$ \\
\hline & & (-) 0,10 & (+) 0,12 & (+) 0,07 & (-) 0,25 * & (-) 0,00 & (+) 0,38 * \\
\hline & & & & & & & (+) 0,25 * \\
\hline & & (+) 0,13 & $(-) 0$ & (+) 0,00 & $(+) 0,10$ & (+) 0,10 & $(-) 0,06$ \\
\hline & & (-) 0,03 & $(+) 0$ & 0,00 & (-) 0,00 & (+) 0,01 & (+) 0,02 \\
\hline & Fe ( & (+) 0,02 & & (-) 0,00 & (-) 0,03 & (-) 0,17 & (+) 0,02 \\
\hline & $\mathrm{Cu}($ & (-) 0,03 & (+) 0,25 * & (-) 0,00 & (-) 0,19 & (+) 0,00 & (+) 0,04 \\
\hline & $\mathrm{Zn}(\mathrm{m}$ & (-) 0,23 * & (+) 0,39 ** & (-) 0,06 & (-) 0,43 ** & (-) 0,15 & (+) 0,07 \\
\hline & Mn ( & $(+) 0,10$ & $(-) 0,00$ & (+) 0,00 & $(+) 0,00$ & (-) 0,00 & (+) 0,09 \\
\hline & $B(r$ & $(+) 0,14$ & $(+) 0,00$ & (-) 0,00 & (+) 0,42 ** & $(+) 0,02$ & (+) 0,00 \\
\hline \multirow{10}{*}{2011} & & $(-) 0,25$ * & $(+) 0$ & (-) 0,00 & $(-) 0,02$ & $(+) 0,17$ & $(+) 0,07$ \\
\hline & & (-) 0,08 & (+) 0,09 & (-) 0,06 & (-) 0,20 * & (+) 0,00 & $(-) 0,00$ \\
\hline & & (-) 0,02 & $(+) 0,00$ & (+) 0,14 & (-) 0,07 & (+) 0,02 & (+) 0,27 * \\
\hline & & (+) 0,48 ** & (-) 0,06 & (+) 0,12 & (+) 0,52 ** & (+) 0,17 & (+) 0,10 \\
\hline & $\mathrm{Ca}(\%)$ & (+) 0,01 & $(+) 0,00$ & (-) 0,01 & $(+) 0,00$ & $(+) 0,15$ & (+) 0,02 \\
\hline & $\mathrm{Fe}\left(\mathrm{mg} \cdot \mathrm{kg}^{-1}\right)$ & (-) 0,05 & & (+) 0,07 & (+) 0,14 & (+) 0,03 & $(+) 0,12$ \\
\hline & $\mathrm{Cu}\left(\mathrm{mg} \cdot \mathrm{kg}^{-1}\right)$ & (-) 0,02 & (+) 0,00 & (-) 0,25 * & $(-) 0,33$ ** & (-) 0,21 * & (-) 0,52 * \\
\hline & $\mathrm{Zn}\left(\mathrm{mg} \cdot \mathrm{kg}^{-1}\right)$ & (+) 0,06 & (-) 0,08 & (-) 0,02 & $(+) 0,03$ & $(-) 0,13$ & (-) 0,01 \\
\hline & $M n\left(m g \cdot k g^{-1}\right)$ & (+) 0,48 ** & (-) 0,09 & (+) 0,23 * & (+) 0,24 * & (+) 0,08 & (+) 0,13 \\
\hline & $B\left(\mathbf{m g} \cdot \mathbf{k g}^{-1}\right)$ & $(-) 0,03$ & $(+) 0,06$ & $(-) 0,03$ & $(-) 0,09$ & (-) 0,12 & $(+) 0,00$ \\
\hline
\end{tabular}

SST: Sólidos solubles totales ( ${ }^{\circ} \mathrm{Brix}$ ); AT: Acidez total (g ácido tartárico $\mathrm{I}^{-1}$ ); IPT: Índice de polifenoles totales; NFA: Nitrógeno fácilmente asimilable $\left(\mathrm{g} \cdot \mathrm{l}^{-1}\right)$; K: Potasio $(\mathrm{ppm})$. 
No se han encontrado regresiones lineales significativas de los parámetros de composición del mosto sobre las concentraciones de $\mathrm{Ca}$, $\mathrm{Fe}$ y $\mathrm{B}$ en los peciolos en envero. Apenas se han dado coincidencias de las relaciones significativas encontradas para la composición de los mostos entre contenidos minerales en el suelo y en los peciolos.

Morris et al. (1980) encontraron que la fertilización potásica en niveles crecientes conduce a un incremento en el contenido de $\mathrm{K}$ en los peciolos y en el mosto. Sin embargo otros autores han encontrado pobres correlaciones entre el contenido de K peciolar y el del mosto (Mpelasoka et al., 2003). Esta relación puede alterarse durante el ciclo debido a cambios en el potencial de crecimiento y desarrollo de los órganos (Mpelasoka et al., 2003), así como a cambios estacionales en las condiciones meteorológicas (Etchebarne et al., 2009).

Las relaciones significativas de SST e IPT con el nivel de Zn presente en el suelo y en los peciolos fueron siempre negativas. Sin embargo, muchos son los autores que han informado que tratamientos de $\mathrm{Zn}$ aumentan el contenido de SST en uva (Mustafa et al., 1986; Singh, 2002) lo que estaría relacionado con un aumento en la actividad enzimática de la fructosa-1 y 6- bis fosfatasa (Bybordi y Shabanov, 2010). Song et al., (2015) detectaron que tratamientos foliares con $\mathrm{Zn}$ aumentaban la acumulación de sólidos solubles totales, fenoles totales, flavonoides, taninos y antocianinas en las uvas, y disminuían la concentración de ácidos.

La tabla 4.49 muestra los resultados del análisis factorial de la varianza de los parámetros de composición del mosto, donde se han evaluado los efectos aditivos y de interacción de la clorosis férrica con el nivel nutricional de otros elementos, tomando como base la clasificación de subzonas realizada en los apartados4.2.3. y 4.1 respectivamente. La influencia de la clorosis férrica solo ha resultado significativa en el ANOVA del índice de polifenoles totales en 2011. El nivel nutricional de P tuvo un efecto significativo sobre SST, AT y el pH en el año 2011. El nivel nutricional del K afectó significativamente a SST en los tres años de estudio. Tanto el nivel nutricional de $\mathrm{Mg}$, como su interacción con la clorosis férrica fueron significativos para SST en 2009 y 2011. Además, en 2011, la clorosis férrica y el estado nutricional del Mg tuvieron un efecto aditivo y de interacción sobre IPT. El nivel nutricional del Cu y la interacción de este con la clorosis férrica fueron significativos para AT en 2009. Por último, en el año 2011, el efecto del nivel nutricional de Cu fue significativo sobre SST e IPT. El análisis factorial de la varianza no se ha realizado para el Zn porque no han resultado grupos suficientes para ello. Así, no hay subparcelas no afectadas por clorosis férrica con un nivel medio de nutrición de Zn simultáneamente.

Como se puede ver en la tabla 4.49, la influencia de la clorosis férrica sobre los parámetros físico-químicos del mosto solo ha resultado significativa en el año 2011. La tabla 4.50 muestra cómo la acidez total en 2010, fue significativamente mayor en las subzonas sanas que en las afectadas por clorosis. En las otras dos campañas la tendencia fue similar pero las diferencias no fueron significativas al $5 \%$. Aunque no se han observado diferencias estadísticamente significativas para SST, la tendencia en las tres campañas fue a aumentar en las subparcelas cloróticas. 
Tabla 4.49.Valores de la $\mathrm{F}$ de Fisher y nivel de significación del análisis factorial de la varianza (ANOVA) de los parámetros físico-químicos del mosto en función del nivel de afección de clorosis férrica (CF) y el nivel nutricional de diversos nutrientes (nt), según diagnóstico realizado en los apartados 4.2.3. y 4.1 respectivamente.

\begin{tabular}{|c|c|c|c|c|c|c|}
\hline Nutriente & & Parámetro & Modelo & CF & nt & CF $\times n t$ \\
\hline \multirow{12}{*}{$n t=P$} & \multirow{4}{*}{2009} & SST & 1,94 & 0,00 & 2,25 & 2,21 \\
\hline & & AT & 0,89 & 1,44 & 0,25 & 0,09 \\
\hline & & pH & 1,09 & 1,93 & 0,00 & 0,45 \\
\hline & & IPT & 0,20 & 0,24 & 0,09 & 0,19 \\
\hline & \multirow{4}{*}{2010} & SST & 2,04 & 0,01 & 0,33 & $4,58^{*}$ \\
\hline & & AT & $4,11^{*}$ & 4,45 & 0,25 & $5,27^{*}$ \\
\hline & & pH & 0,10 & 0,12 & 0,22 & 0,00 \\
\hline & & IPT & 1,94 & 0,02 & 3,00 & 0,80 \\
\hline & \multirow{4}{*}{2011} & SST & $6,49^{* *}$ & 0,02 & $13,50^{* *}$ & 1,00 \\
\hline & & AT & 2,12 & 0,95 & $6,29^{*}$ & 0,12 \\
\hline & & $\mathrm{pH}$ & $4,08^{*}$ & 0,78 & $4,84^{*}$ & 1,84 \\
\hline & & IPT & $4,19^{*}$ & $4,99^{*}$ & 1,28 & 0,26 \\
\hline \multirow{12}{*}{$n t=K$} & \multirow{4}{*}{2009} & SST & $5,46^{* *}$ & 1,52 & $12,95^{* *}$ & $6,18^{*}$ \\
\hline & & AT & 1,11 & 3,21 & 1,06 & 0,76 \\
\hline & & pH & 2,07 & 3,10 & 3,19 & 0,10 \\
\hline & & IPT & 0,87 & 1,23 & 1,24 & 1,81 \\
\hline & \multirow{4}{*}{2010} & SST & $5,06^{*}$ & 1,61 & $11,19^{* *}$ & 2,80 \\
\hline & & AT & 1,53 & 2,75 & 0,44 & 0,09 \\
\hline & & $\mathrm{pH}$ & 0,23 & 0,07 & 0,26 & 0,45 \\
\hline & & IPT & 2,13 & 0,00 & 3,27 & 1,83 \\
\hline & \multirow{4}{*}{2011} & SST & $6,77^{* *}$ & 0,12 & $15,65^{* *}$ & 3,40 \\
\hline & & AT & 0,79 & 0,05 & 2,21 & 0,01 \\
\hline & & $\mathrm{pH}$ & 1,91 & 3,58 & 0,66 & 0,00 \\
\hline & & IPT & $11,27^{\text {** }}$ & $11,00^{* *}$ & $11,36^{* *}$ & 1,66 \\
\hline \multirow{12}{*}{$\mathrm{nt}=\mathrm{Mg}$} & \multirow{4}{*}{2009} & SST & $6,29^{* *}$ & 0,00 & $9,28^{* *}$ & $9,39^{* *}$ \\
\hline & & AT & 1,56 & 2,27 & 1,10 & 1,50 \\
\hline & & pH & 0,77 & 1,15 & 0,07 & 1,41 \\
\hline & & IPT & 0,83 & 0,32 & 0,46 & 1,82 \\
\hline & \multirow{4}{*}{2010} & SST & 1,83 & 1,33 & 4,35 & 0,89 \\
\hline & & AT & 1,38 & 2,79 & 0,00 & 0,11 \\
\hline & & pH & 0,29 & 0,47 & 0,83 & 0,01 \\
\hline & & IPT & 1,63 & 0,18 & 3,18 & 0,80 \\
\hline & \multirow{4}{*}{2011} & SST & $7,46^{* *}$ & 0,71 & $16,79^{* *}$ & $4,69 *$ \\
\hline & & AT & 0,15 & 0,04 & 0,42 & 0,01 \\
\hline & & $\mathrm{pH}$ & 2,22 & 2,63 & 0,34 & 0,84 \\
\hline & & IPT & $12,05^{* *}$ & $4,82^{*}$ & $8,52^{* *}$ & $5,11^{*}$ \\
\hline \multirow{12}{*}{$\mathrm{nt}=\mathrm{Cu}$} & \multirow{4}{*}{2009} & SST & 2,86 & 0,48 & 2,42 & 4,72 \\
\hline & & AT & $5,87^{\text {** }}$ & 0,16 & $6,69^{*}$ & $9,39^{* *}$ \\
\hline & & $\mathrm{pH}$ & 1,73 & 0,10 & 0,74 & 3,86 \\
\hline & & IPT & 0,90 & 0,02 & 0,96 & 1,85 \\
\hline & \multirow{4}{*}{2010} & SST & 0,07 & 0,01 & 0,16 & 0,01 \\
\hline & & AT & 2,53 & 2,74 & 0,71 & 0,60 \\
\hline & & pH & 1,88 & 2,46 & 3,57 & 2,00 \\
\hline & & IPT & 0,55 & 0,27 & 0,15 & 0,33 \\
\hline & \multirow{4}{*}{2011} & SST & $3,56^{*}$ & 0,00 & $5,75^{*}$ & 0,12 \\
\hline & & AT & 0,26 & 0,15 & 0,73 & 0,07 \\
\hline & & pH & 2,13 & 0,86 & 1,16 & 0,11 \\
\hline & & IPT & $7,88^{* *}$ & 0,50 & $8,17^{*}$ & 2,90 \\
\hline
\end{tabular}

SST: Sólidos solubles totales ( ${ }^{\circ}$ Brix);AT: Acidez total ( $\mathrm{g}$ ácido tartárico ${ }^{-1}$ );IPT: Índice de polifenoles Niveles de significación: ${ }^{*} p<0,05 ;{ }^{* *} p<0,01 ;{ }^{* * *} p<0,0001$ 
Bavaresco y Poni (2003) demostraron que los contenidos en sólidos solubles se incrementaban en condiciones de estrés nutricional en suelos calizos en uva de mesa cv. Aurora. La mayor concentración de azúcares es probablemente una consecuencia de la reducción del rendimiento de uva en las plantas estresadas (Bavaresco et al., 2005).

Tabla 4.50.Valores medios de los parámetros físico-químicos del mostoen áreas de muestreo afectadas (C) y no afectadas (NC) por clorosis férrica.

\begin{tabular}{|c|c|c|c|c|c|c|}
\hline \multirow{2}{*}{$\begin{array}{l}\text { Composición } \\
\text { del mosto }\end{array}$} & \multicolumn{2}{|c|}{2009} & \multicolumn{2}{|c|}{2010} & \multicolumn{2}{|c|}{2011} \\
\hline & $\begin{array}{c}N C \\
(n=11)\end{array}$ & $\begin{array}{c}C \\
(n=11)\end{array}$ & $\begin{array}{c}N C \\
(n=12)\end{array}$ & $\begin{array}{c}C \\
(n=12)\end{array}$ & $\begin{array}{c}N C \\
(n=12)\end{array}$ & $\begin{array}{c}C \\
(n=12)\end{array}$ \\
\hline SST & $22,7 a$ & $23,1 a$ & $24,6 a$ & $24,7 a$ & $24,9 a$ & $25,5 a$ \\
\hline AT & $4,43 a$ & $4,09 a$ & $3,94 a$ & $3,39 b$ & $2,73 a$ & $2,70 a$ \\
\hline pH & $3,71 \mathrm{a}$ & $3,76 a$ & $3,94 a$ & $3,95 a$ & $4,06 b$ & $4,17 a$ \\
\hline IPT & $23,6 a$ & $23,1 \mathrm{a}$ & $22,1 \mathrm{a}$ & $24,3 a$ & $29,5 b$ & $34,7 a$ \\
\hline NFA & $131 a$ & $146 a$ & $201 a$ & $187 a$ & $164 b$ & $192 a$ \\
\hline K & $1191 \mathrm{a}$ & $1203 a$ & $2412 a$ & $2290 a$ & $1662 b$ & $1994 a$ \\
\hline
\end{tabular}

En este contexto, como se observa en la tabla 4.51, no se han encontrado correlaciones significativas de la concentración de SST e IPT en 2009. Sin embargo, en el año 2010, el IPT se correlacionó significativamente de forma negativa con el Rto y los componentes PMR y P100, mientras que el contenido de SST no lo ha hecho con Rto. En el año 2011, el IPT se correlacionó significativamente de forma negativa con el Rto y todos sus componentes, mientras que el contenido de SST no lo ha hecho con RPS. Los resultados de la correlación indicaron claramente que SST e IPT se relacionaban negativamente con el rendimiento, siendo afectados principalmente por el peso del racimo y el tamaño de las bayas.

El índice de polifenoles totales, $\mathrm{pH}$, nitrógeno fácilmente asimilable y el contenido en potasio del mosto fueron significativamente mayores en las subzonas cloróticas en 2011. Estos resultados nos indican que las parcelas afectadas por clorosis tuvieron un mayor contenido en polifenoles precisamente en 2011, la campaña de mayores rendimientos (con mayor disponibilidad de agua para las plantas como se comenta en el apartado 4.4.1). En este contexto, González et al., (2006) en un ensayo de corrección de la clorosis férrica llevado a cabo en la misma zona de estudio en la campaña de 2005, fuertemente marcada por la sequía, registraron una composición del mosto similar para plantas cloróticas y plantas tratadas. 
Tabla 4.51. Coeficientes de correlación de Pearson ( $r$ ) entre el IPT y el contenido en SST con el rendimiento y sus componentes en los tres años de estudio.

\begin{tabular}{|c|c|c|c|c|c|}
\hline \multicolumn{2}{|c|}{ Parámetros } & \multirow{2}{*}{$\begin{array}{r}\text { Rto } \\
0,02\end{array}$} & \multirow{2}{*}{$\begin{array}{c}\text { PMR } \\
-0,18\end{array}$} & \multirow{2}{*}{$\begin{array}{c}\text { RPS } \\
0,20\end{array}$} & \multirow{2}{*}{$\begin{array}{c}\text { P100 } \\
-0,28\end{array}$} \\
\hline 2009 & SST & & & & \\
\hline 2009 & IPT & $-0,07$ & 0,29 & 0,07 & 0,06 \\
\hline \multirow{2}{*}{2010} & SST & $-0,28$ & $-0,46^{*}$ & $-0,16$ & $-0,46^{*}$ \\
\hline & IPT & $-0,47^{*}$ & $-0,66^{* *}$ & $-0,26$ & $-0,54^{*}$ \\
\hline \multirow{2}{*}{2011} & SST & $-0,51^{*}$ & $-0,66^{* *}$ & $-0,36$ & $-0,81^{* * *}$ \\
\hline & IPT & $-0,88^{* * *}$ & $-0,75^{* * *}$ & $-0,73^{* *}$ & $-0,70^{* *}$ \\
\hline \multicolumn{6}{|c|}{ Niveles de significación: ${ }^{*} p<0,05 ;{ }^{* *} p<0,01 ;{ }^{* * *} p<0,0001$} \\
\hline
\end{tabular}

Diversos autores han mostrado que la deficiencia de hierro ocasiona una pobre calidad de los mostos, reduciendo la cantidad de azucares y antocianos acumulados en las uvas durante la maduración, e incrementando la acidez total. (Castino et al., 1987; Veilksar et al., 2005).Sin embargo, en este estudio, la composición del mosto fue similar en las dos primeras campañas, con una tendencia a la reducción de la acidez en plantas cloróticas, mientras que en el año 2011, las uvas con mejor IPT pertenecieron a las subparcelas afectadas por clorosis férrica. En la misma zona de estudio, Catalina et al. (2011a) observaron que el contenido fenólico total de las uvas estaba más influido por el estado hídrico de las cepas que por los niveles de asimilación de hierro.

La mayor concentración de potasio en mostos procedentes de plantas cloróticas en 2011 coincidió con mayores niveles de pH, en concordancia con Boulton (1980), Jackson y Lombard (1993).

Como se puede observar en la tabla 4.52, SST, pH e IPT fueron significativamente menores en las parcelas con una nutrición media de fósforo que en las parcelas con un nivel nutricional bajo en 2011, mientras que en 2010 este resultado solo se obtuvo para el IPT. Por otro lado, AT fue significativamente mayor en subparcelas con un nivel nutricional medio de fósforo que en subparcelas con nivel bajo en 2011. En las otras dos campañas la tendencia fue similar sin ser significativa al $5 \%$. Estos resultados coinciden con los de Conradie et al. (1989b), que manifestaron que el aporte de $\mathrm{P}$ al suelo de viñedos cv. Chenin blanc inducía una concentración significativamente mayor de acidez total en el mosto. Debido a que se han encontrado relaciones significativamente positivas del $\mathrm{P}$ peciolar con el rendimiento y el vigor (tablas 4.38 y 4.42 ) estos resultados comparten la idea de que las viñas más vigorosas y mayores rendimientos producen mostos con una acidez mayor. 
Tabla 4.52. Valores medios de la composición del mosto para áreas de muestreo con diferente estado nutricional.

\begin{tabular}{|c|c|c|c|c|c|c|c|}
\hline \multirow[b]{2}{*}{ Nutriente } & \multicolumn{7}{|c|}{ Estado nutricional del viñedo } \\
\hline & Año & Nivel $^{*}$ & $\mathbf{n}$ & SST & AT & $\mathrm{pH}$ & IPT \\
\hline \multirow{6}{*}{ Fósforo } & \multirow{2}{*}{2009} & Bajo & 8 & $23,5 a$ & $4,13 a$ & $3,74 a$ & $23,8 a$ \\
\hline & & Medio & 11 & $22,6 a$ & $4,44 a$ & $3,71 \mathrm{a}$ & $23,5 a$ \\
\hline & \multirow{2}{*}{2010} & Bajo & 10 & $24,9 a$ & $3,38 a$ & $3,94 a$ & $26,3 a$ \\
\hline & & Medio & 14 & $24,4 a$ & $3,84 a$ & $3,96 a$ & $20,6 b$ \\
\hline & \multirow{2}{*}{2011} & Bajo & 10 & $26,2 a$ & $2,51 b$ & $4,19 a$ & $34,4 a$ \\
\hline & & Medio & 14 & $24,7 b$ & $2,85 a$ & $4,07 b$ & $30,5 b$ \\
\hline \multirow{6}{*}{ Potasio } & \multirow{2}{*}{2009} & Alto & 8 & $22,1 b$ & $4,22 a$ & $3,80 a$ & $22,9 a$ \\
\hline & & Medio & 14 & $23,4 a$ & $4,29 a$ & $3,70 a$ & $23,7 a$ \\
\hline & \multirow{2}{*}{2010} & Alto & 10 & $23,9 b$ & $3,83 a$ & $3,96 a$ & $20,2 b$ \\
\hline & & Medio & 14 & $25,1 \mathrm{a}$ & $3,47 a$ & $3,95 a$ & $25,6 a$ \\
\hline & \multirow{2}{*}{2011} & Alto & 10 & $24,5 b$ & $2,85 a$ & $4,08 a$ & $28,9 b$ \\
\hline & & Medio & 14 & $25,9 a$ & $2,62 a$ & $4,14 a$ & $34,5 a$ \\
\hline \multirow{6}{*}{ Magnesio } & \multirow{2}{*}{2009} & Alto & 13 & $23,4 a$ & $4,14 a$ & $3,75 a$ & $23,0 a$ \\
\hline & & Medio & 9 & $22,2 b$ & $4,44 a$ & $3,72 a$ & $24,0 a$ \\
\hline & \multirow{2}{*}{2010} & Alto & 13 & $25,0 a$ & $3,49 a$ & $3,94 a$ & $25,6 a$ \\
\hline & & Medio & 11 & $24,2 a$ & $3,80 a$ & $3,97 a$ & $20,3 b$ \\
\hline & \multirow{2}{*}{2011} & Alto & 13 & $25,9 a$ & $2,67 a$ & $4,16 a$ & $35,0 a$ \\
\hline & & Medio & 11 & $24,6 \mathrm{~b}$ & $2,77 a$ & $4,07 a$ & $28,9 b$ \\
\hline \multirow{9}{*}{$\begin{array}{l}\mathrm{K} / \mathrm{Mg} \\
\text { (peciolos) }\end{array}$} & \multirow{3}{*}{2009} & Alto & 8 & $22,0 b$ & $4,24 a$ & $3,80 a$ & $23,9 a$ \\
\hline & & Medio & 8 & $23,3 a$ & $4,22 a$ & $3,70 a$ & $23,1 a$ \\
\hline & & Bajo & 6 & $23,5 a$ & $4,37 a$ & $3,70 a$ & $23,1 a$ \\
\hline & \multirow{3}{*}{2010} & Alto & 9 & $24,1 a$ & $3,83 a$ & $3,98 a$ & $20,3 b$ \\
\hline & & Medio & 6 & $24,8 a$ & $3,76 a$ & $3,88 a$ & $22,7 a b$ \\
\hline & & Bajo & 9 & $25,1 \mathrm{a}$ & $3,27 a$ & $3,99 a$ & $27,3 a$ \\
\hline & \multirow{3}{*}{2011} & Alto & 6 & $23,9 b$ & $3,08 a$ & $4,05 a$ & $28,3 b$ \\
\hline & & Medio & 9 & $25,7 a$ & $2,51 b$ & $4,17 a$ & $32,2 a b$ \\
\hline & & Bajo & 9 & $25,7 a$ & $2,69 a b$ & $4,09 a$ & $34,7 a$ \\
\hline \multirow{6}{*}{ Cobre } & \multirow{2}{*}{2009} & Bajo & 9 & $23,4 a$ & $3,96 a$ & $3,77 a$ & $22,7 a$ \\
\hline & & Medio & 13 & $22,6 a$ & $4,28 a$ & $3,72 a$ & $23,9 a$ \\
\hline & \multirow{2}{*}{2010} & Bajo & 7 & $24,8 a$ & $3,71 a$ & $3,90 a$ & $22,5 a$ \\
\hline & & Medio & 17 & $24,6 a$ & $3,56 a$ & $3,98 a$ & $23,9 a$ \\
\hline & \multirow{2}{*}{2011} & Bajo & 7 & $26,1 a$ & $2,63 a$ & $4,18 a$ & $35,9 a$ \\
\hline & & Medio & 17 & $24,8 b$ & $2,77 a$ & $4,08 a$ & $30,1 b$ \\
\hline \multirow{6}{*}{ Zinc } & \multirow{2}{*}{2009} & Alto & 14 & $23,0 a$ & $4,49 a$ & $3,71 a$ & $24,5 a$ \\
\hline & & Medio & 8 & $22,8 \mathrm{a}$ & $3,87 b$ & $3,78 a$ & $21,6 b$ \\
\hline & \multirow{2}{*}{2010} & Alto & 13 & $24,4 a$ & $3,87 a$ & $3,90 a$ & $22,2 a$ \\
\hline & & Medio & 7 & $24,8 a$ & $3,20 b$ & $3,98 a$ & $26,4 a$ \\
\hline & 2011 & Alto & 13 & $25,4 a$ & $2,68 a$ & $4,10 a$ & $32,4 a$ \\
\hline & 2017 & Medio & 7 & $25,1 a$ & $2,78 a$ & $4,18 a$ & $34,7 a$ \\
\hline
\end{tabular}

SST: Sólidos solubles totales ( ${ }^{\circ} B$ rix);AT: Acidez total ( $\mathrm{g}$ ácido tartárico $\left.\digamma^{-1}\right)$;IPT: Índice de polifenoles totales Dentro de un mismo año, los valores con diferente letra son significativamente diferentes $(p<0,05$, test Tukey)

*según diagnóstico nutricional realizado en el apartado 4.1 
En las áreas de estudio con nivel alto de nutrición potásica, SST fue significativamente menor que en las áreas con nutrición media en los tres años de estudio (tabla 4.52). Este mismo resultado se ha dado para IPT en 2010 y 2011. Gran parte del potasio presente en las uvas es traslocado desde las hojas al mismo tiempo que se transporta la sacarosa durante el proceso de maduración. Sin embargo, hay pocas evidencias de que la acumulación de azúcares en las uvas se vea reforzada por grandes aportaciones de K (Treeby, 2005). En cualquier caso los valores más bajos de SST e IPT en plantas con nivel alto de nutrición potásica pueden ser debidos más bien a la carencia inducida de magnesio que esos niveles generan, tal y como se explica más adelante al evaluar la relación $\mathrm{K} / \mathrm{Mg}$.

En el año 2011, el análisis factorial de la varianza de SST ha reflejado un efecto aditivo de la incidencia de la clorosis férrica con el nivel nutricional de potasio (tabla 4.49). La separación de medias de esta variable en los tres años de estudio se ha representado en la figura 4.20. Autores como Dundon et al. (1984) y Delgado et al. (2004) no encontraron ningún cambio significativo en las concentraciones de sólidos solubles de las uvas con aplicaciones de $\mathrm{K}$ en el suelo. Por el contrario, otras autores como Conradie y De Wet (1985), Rogiers et al. (2006), Raath (2012) y Schreiner (2013) observaron un efecto positivo de la fertilización potásica sobre el contenido de azúcares de la uva. Rogiers et al. (2006) manifestaron que siendo el $\mathrm{K}^{+}$el principal catión osmóticamente activo en el floema, contribuye al flujo de azúcares al fruto, ayudando a establecer un gradiente de potencial osmótico entre las hojas y las uvas.

2009

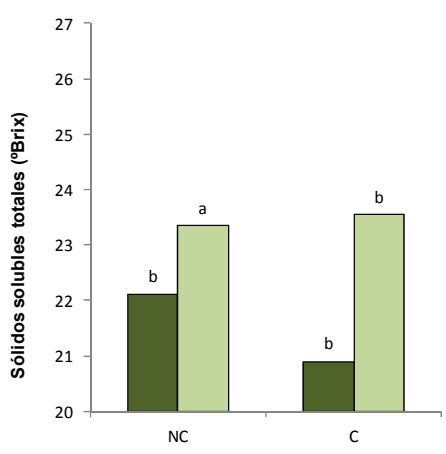

2010

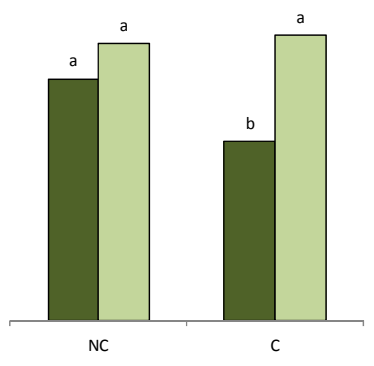

2011

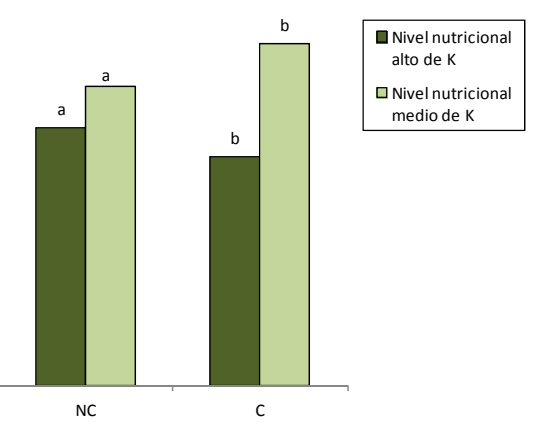

Figura 4.20.Contenido en sólidos solubles totales del mosto en las áreas de estudio afectadas (C) y no afectadas por clorosis férrica (NC), en función del nivel nutricional de potasio.

Las áreas de estudio con un nivel alto de nutrición magnésica alcanzaron un IPT del mosto significativamente mayor que las áreas con una nutrición media en los años 2010 y 2011. En 2011, el análisis factorial de la varianza de IPT ha mostrado efectos aditivo y de interacción entre la incidencia de la clorosis férrica y el estado 
nutricional del Mg (tabla 4.49). El Mg, de modo similar al Zn, aumenta la actividad de la enzima fructosa-1 y 6- bis fosfatasa, causando un aumento de la síntesis de azúcares en la uva (Bybordi y Shabanov, 2010) e incrementa la translocación de las moléculas sintetizadas por la fotosíntesis de la hoja a la uva (Malakouti, 2006).

Por otro lado, en los años 2009 y 2011 , en el análisis factorial de la varianza de SST pone de manifiesto un efecto de interacción entre la incidencia de la clorosis férrica y el estado nutricional del $\mathrm{Mg}$. Como se observa en la figura 4.21, en las subparcelas afectadas por clorosis férrica, los valores de SST fueron significativamente mayores en las áreas de estudio con un nivel nutricional alto de $\mathrm{Mg}$ que en las que tenían un nivel medio en los años 2009 y 2011, mientras que en las subparcelas no afectadas por clorosis férrica, el estado nutricional de $\mathrm{Mg}$ no afectó a SST.
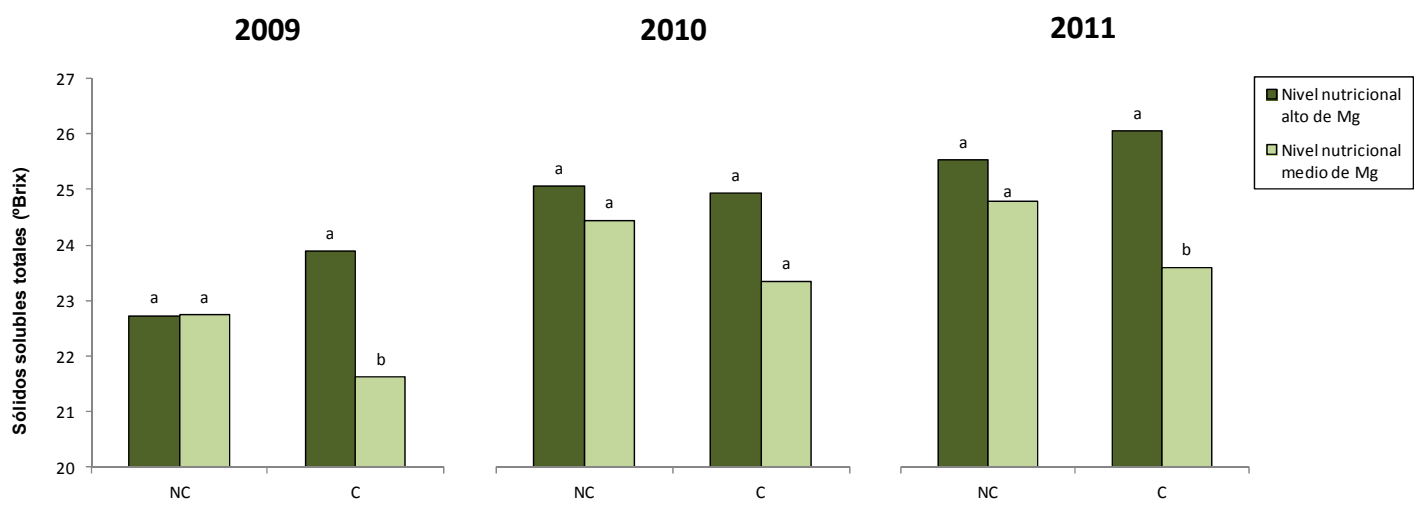

Figura 4.21. Contenido en sólidos solubles totales del mosto en las áreas de estudio afectadas (C) y no afectadas por clorosis férrica (NC), en función del nivel nutricional deMagnesio.

Valores elevados de la proporción $\mathrm{K} / \mathrm{Mg}$ en peciolos se relacionaron con niveles bajos de IPT y SST en el mosto en 2009 y 2011. A su vez, como se ha descrito en párrafos anteriores, niveles altos de nutrición potásica y medios de nutrición magnésica se han relacionado con concentraciones de SST e IPT bajos. La relación entre los dos elementos antagónicos debe ser equilibrada, presentándose por ejemplo deficiencias inducidas de $\mathrm{Mg}$ para valores de $\mathrm{K} / \mathrm{Mg}$ superiores a 0,35en el suelo (Legaz et al., 1995). En el caso de este estudio, los valores de este ratio de muchas de las zonas estudiadas se encuentran por encima de esta cifra, por lo que es de esperar situaciones de deficiencia de Mg. Además, como se ha manifestado en el epígrafe 4.1.2, el contenido en $\mathrm{K}$ en el suelo y los peciolos, y el ratio $\mathrm{K} / \mathrm{Mg}$ en el suelo, se han relacionado significativamente de forma negativa con la concentración de $\mathrm{Mg}$ peciolar. Morris y Cowthon (1982), García et al. (2001) y Demirer et al. (2007) han documentado 
que el aumento de la concentración de $\mathrm{K}$ reduce la concentración de $\mathrm{Mg}$ en las hojas de vid.

Leonhardt (1987) recomienda mantener una proporción de 2:1 de K y Mg en las hojas. En este estudio, el 45\% en 2009, 55\% en 2010 y $67 \%$ en 2011 de las zonas estudiadas mostraron unos niveles del ratio $\mathrm{K} / \mathrm{Mg}$ por encima de 2 , por lo que el número de subparcelas con posibilidades de deficiencia inducida de $\mathrm{Mg}$ aumentó con los años.

En las áreas de estudio con un nivel bajo de nutrición de Cu, SST e IPT fueron significativamente menores que en las áreas con un nivel medio de nutrición en el año 2011. No hubo interacciones significativas entre $\mathrm{Cu}$ y Fe sobre estos parámetros (tabla 4.49). Sin embargo, la competencia entre estos nutrientes ha sido confirmada por muchos estudios con soluciones deficientes en $\mathrm{Fe}$, donde la clorosis fue menos evidente si las soluciones eran también deficiente en Cu. (Russo et al., 2010).Debido al papel del $\mathrm{Cu}$ en el PS I, no es sorprendente que las plantas deficientes en $\mathrm{Cu}$ tengan tasas de fotosíntesis bajas y una reducción de la síntesis de hidratos de carbono frente a las plantas normales (Marschner, 1995).

Las subparcelas con un nivel alto de nutrición de $\mathrm{Zn}$ tuvieron una AT significativamente mayor que las subparcelas con un nivel de nutrición medio para dicho mineral en 2009 y 2010 (tabla 4.52). Además, las subparcelas con un nivel alto de nutrición de $\mathrm{Zn}$ tuvieron un peso de la madera de poda significativamente mayor que las subparcelas con un nivel de nutrición medio para dicho mineral (tabla 4.41), en consonancia con los resultados obtenidos por Cortell et al., (2007), Martín et al. (2008) y Ashoori et al., (2013),por lo que la mayor acidez en las uvas de plantas con estado nutricional alto de $\mathrm{Zn}$ puede estar relacionado con un mayor vigor, al registrarse una síntesis de ácidos más elevada por parte del follaje y/o un mayor sombreamiento de los racimos (Jackson y Lombard, 1993).

En el análisis de componentes principales (figura 4.22) realizado a partir de los componentes físico-químicos del mosto se puede observar que con dos componentes principales se explica el $63 \%$ en 2009 , el $66 \%$ en 2010 y el $78 \%$ en 2011 de la variabilidad existente en los datos. La representación correspondiente al año 2009, se observa una correlación positiva de la primera componente con NFA y el pH y negativa con AT. En 2010 se correlacionó positivamente con SST e IPT del mosto y negativamente con AT. En 2011 se correlacionó positivamente con todas las variables físico-químicas, salvo la AT del mosto. La segunda componente se correlacionó positivamente con AT y K en mosto y negativamente con el SST en 2009. En 2010 se correlacionó positivamente con el pH y K del mosto. En 2011 se correlacionó positivamente con AT, $\mathrm{K}$ y NFA.

El análisis de componentes principales realizado a partir de los componentes físico-químicos de mosto, no ha permitido una discriminación clara de grupos de observaciones en función de las parcelas afectadas o no por clorosis férrica (figura 4.22). 


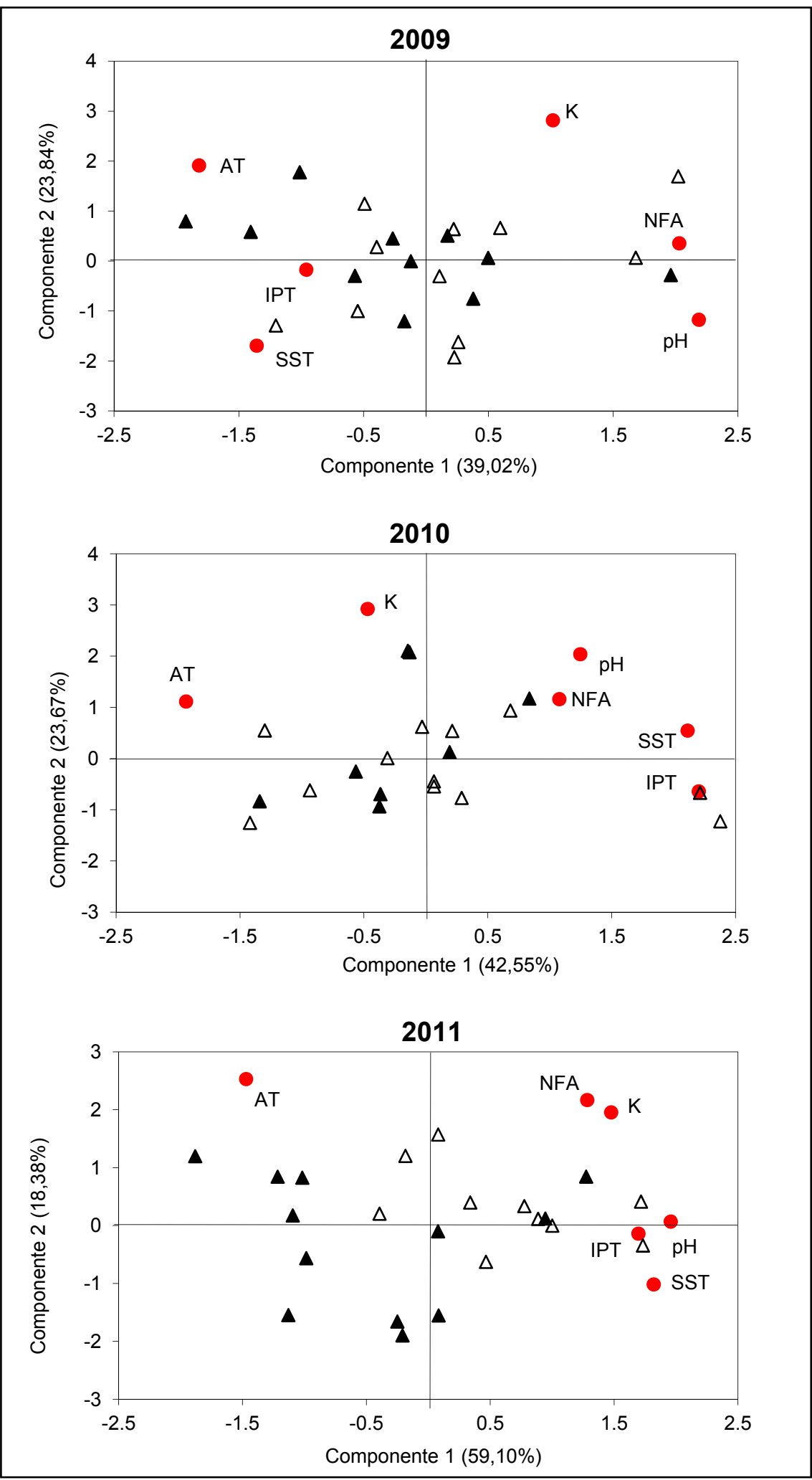

Figura 4.22. Primer plano factorial del análisis de componentes principales realizado con los datos de los parámetros físico-químicos del mosto en el conjunto de las zonas de estudio en los tres años de seguimiento. Los círculos rojos representan las variables físicoquímicas de mosto y vino, los triángulos negros representan las áreas de muestreo no afectadas por clorosis férrica y los triángulos en blanco representan las áreas de muestreo con clorosis férrica. 


\subsubsection{2.- Características cromáticas}

En la tabla 4.53 se recogen las medias y coeficientes de variación de los parámetros cromáticos del mosto en el conjunto de las zonas de estudio en los tres años de seguimiento. La luminosidad y el índice cromático de uvas tintas CIRG (Carreño et al., 1995) han mostrado un menor coeficiente de variación, mientras que el tono y la coordenada $b^{*}$ mostraron el mayor coeficiente. En los dos capítulos precedentes se ha expuesto que el rendimiento y el índice de polifenoles totales del mosto han mostrado una alta variabilidad, lo que sugiere que estos parámetros influirían de manera más acusada que otros en el tono y la coordenada $b^{*}$ del mosto. Por otra parte, se puede afirmar que estas componentes del color del mosto son las más afectadas por al grado de afección de clorosis férrica y el estado nutricional en general.

Las muestras de mosto presentaron la menor cromaticidad y coordenada $a^{*}$ en 2010 y el mayor en 2011. El tono y la coordenada $b^{*}$ fueron notablemente más elevados en 2010 que en 2009 y 2011. Los mostos de 2011 presentaron menor luminosidad media que los de 2009 y 2010. Puesto que en 2011 se dieron rendimientos claramente mayores que en 2009 y 2010, siendo también los pesos de 100 bayas más elevados (tabla 4.36), es lógico esperar en la tercera campaña mostos con mayor cromaticidad y coordenada $a^{*}$, y con menor luminosidad, tono $y$ coordenada $b^{*}$. Estas diferencias interaunales estuvieron generadas principalmente, por la variabilidad de las condiciones meteorológicas (apartado 3.2.3).

Tabla 4.53. Coordenadas CIELAB e índice cromático de uvas tintas (Carreño et al., 1995) del mosto de vendimia en el conjunto de las zonas de estudio en los tres años de seguimiento.

\begin{tabular}{|c|c|c|c|c|c|}
\hline & $\begin{array}{l}\text { Parámetros } \\
\text { cromáticos }\end{array}$ & Mínimo & Máximo & Media & $\begin{array}{l}\text { Coeficiente de } \\
\text { variación (\%) }\end{array}$ \\
\hline \multirow{6}{*}{$\begin{array}{c}2009 \\
(n=22)\end{array}$} & C & 8,39 & 21,05 & 15,94 & 20 \\
\hline & $\mathrm{H}$ & $-1,58$ & 39,39 & 8,17 & 116 \\
\hline & L & 82,4 & 90,5 & 86,0 & 2 \\
\hline & $a^{*}$ & 6,49 & 25,72 & 16,13 & 25 \\
\hline & $\mathbf{b}^{*}$ & $-0,50$ & 5,33 & 1,88 & 92 \\
\hline & CIRG & 1,43 & 1,76 & 1,68 & 4 \\
\hline \multirow{6}{*}{$\begin{array}{c}2010 \\
(n=24)\end{array}$} & C & 8,8 & 18,1 & 12,2 & 20 \\
\hline & H & 18,7 & 43,8 & 29,5 & 25 \\
\hline & $\mathbf{L}$ & 74,8 & 87,5 & 83,3 & 4 \\
\hline & $a^{*}$ & 6,37 & 17,05 & 10,70 & 26 \\
\hline & $\mathbf{b}^{*}$ & 4,50 & 7,05 & 5,75 & 19 \\
\hline & CIRG & 1,42 & 1,73 & 1,58 & 5 \\
\hline \multirow{6}{*}{$\begin{array}{c}2011 \\
(n=24)\end{array}$} & C & 3,0 & 32,1 & 22,2 & 29 \\
\hline & H & $-0,50$ & 17,61 & 5,16 & 83 \\
\hline & L & 68,7 & 84,3 & 77,9 & 5 \\
\hline & $a^{*}$ & 15,0 & 32,1 & 22,8 & 21 \\
\hline & $\mathbf{b}^{*}$ & $-0,27$ & 4,76 & 1,85 & 70 \\
\hline & CIRG & 1,67 & 2,23 & 1,75 & 6 \\
\hline
\end{tabular}


Como se puede ver en la tabla 4.54, se encontraron regresiones lineales significativas de los parámetros CIELAB exceptuando la coordenada $b^{*}$, sobre el contenido de $\mathrm{Cu}$ y $\mathrm{Zn}$ en el suelo en 2009. En el año 2010, las componentes del color $C, H, L, a^{*}$ y CIRG se relacionaron significativamente con el porcentaje de arcilla y el nivel de Mg; $L$ y CIRG con el contenido en carbonatos totales, $\mathrm{H}$ y CIRG con la concentración de $\mathrm{P}$, y C y L con el nivel de Cu. En el año 2011 se observaron gran número de regresiones significativas de los parámetros CIELAB y los componentes del suelo analizados. No se han encontrado regresiones lineales significativas de los parámetros cromáticos del mosto sobre las concentraciones de Ca y Fe en el suelo.

Tabla 4.54.Coeficiente de determinación $\left(R^{2}\right)$, nivel de significación y pendiente de la regresión de las coordenadas CIELAB e índice cromático de uvas tintas (Carreño et al., 1995) del mosto de vendimia sobre el contenido en arcilla, carbonatos totales (CT) y concentración de elementos minerales en el suelo.

\begin{tabular}{|c|c|c|c|c|c|c|c|}
\hline \multicolumn{2}{|c|}{ Composición del suelo ${ }^{1}$} & C & $\mathbf{H}$ & $\mathrm{L}^{*}$ & $a^{*}$ & $\mathbf{b}^{*}$ & CIRG \\
\hline \multirow{10}{*}{2009} & Arcilla (\%) & $(+) 0,02$ & $(-) 0,00$ & (-) 0,08 & (-) 0,01 & $(+) 0,00$ & $(+) 0,00$ \\
\hline & CT (\%) & (-) 0,00 & (-) 0,03 & (+) 0,00 & (-) 0,00 & (-) 0,03 & (+) 0,04 \\
\hline & $P\left(\mathbf{m g} \cdot \mathrm{kg}^{-1}\right)$ & (-) 0,29 * & (+) 0,11 & (+) 0,32 ** & (-) 0,05 & (+) 0,01 & $(-0,11$ \\
\hline & $K\left(\mathrm{meq} \cdot 100 \mathrm{~g}^{-1}\right)$ & (-) 0,00 & (-) 0,00 & (+) 0,01 & (-) 0,00 & 0,00 & (+) 0,00 \\
\hline & $M g\left(m e q \cdot 100 g^{-1}\right)$ & (+) 0,03 & (-) 0,02 & (-) 0,05 & (-) 0,00 & (-) 0,01 & (+) 0,03 \\
\hline & $\mathrm{Ca}\left(\right.$ meq $\left.\cdot 100 \mathrm{~g}^{-1}\right)$ & (-) 0,00 & (-) 0,00 & (-) 0,00 & (-) 0,11 & (-) 0,00 & (+) 0,01 \\
\hline & $\mathrm{Fe}\left(\mathrm{mg} \cdot \mathrm{kg}^{-1}\right)$ & (-) 0,02 & (-) 0,00 & (+) 0,11 & (+) 0,08 & (-) 0,01 & (-) 0,00 \\
\hline & $\mathrm{Cu}\left(\mathrm{mg} \cdot \mathrm{kg}^{-1}\right)$ & (-) 0,30 * & (+) 0,33 * & (+) 0,27 * & (-) 0,31 * & (+) 0,15 & (-) 0,31 * \\
\hline & $\mathrm{Zn}\left(\mathrm{mg} \cdot \mathrm{kg}^{-1}\right)$ & (-) $0,55^{\text {** }}$ & (+) 0,52 ** & (+) 0,36 * & (-) $0,57^{* *}$ & (+) 0,23 & (-) 0,53 * \\
\hline & $M n\left(\mathbf{m g} \cdot \mathbf{k g}^{-1}\right)$ & $(+) 0,03$ & $(+) 0,00$ & $(-) 0,10$ & (+) 0,02 & (+) 0,02 & $(-) 0,00$ \\
\hline \multirow{10}{*}{2010} & Arcilla (\%) & $(+) 0,39^{* \star}$ & $(-) 0,56$ ** & $(-) 0,39$ ** & $(+) 0,44^{* *}$ & $(-) 0,14$ & $(+) 0,59 * * *$ \\
\hline & CT (\%) & $(+) 0,17$ & (-) 0,17 & (-) 0,30 * & $(+) 0,17$ & (-) 0,01 & (+) 0,27 * \\
\hline & $P\left(\mathrm{mg} \cdot \mathrm{kg}^{-1}\right)$ & (-) 0,14 & (+) 0,36 ** & (+) 0,07 & (-) 0,18 & (+) 0,11 & $(-) 0,27$ * \\
\hline & $K\left(\mathrm{meq} \cdot 100 \mathrm{~g}^{-1}\right)$ & (-) 0,03 & (+) 0,00 & (+) 0,09 & (-) 0,02 & (+) 0,00 & (-) 0,03 \\
\hline & $M g\left(\right.$ meq $\left.100 g^{-1}\right)$ & (+) 0,21 * & $(-)$ ) 0,34 ** & (-) 0,19 * & (+) 0,24 * & (-) 0,08 & (+) 0,32 ** \\
\hline & $\mathrm{Ca}\left(\mathrm{meq} \cdot 100 \mathrm{~g}^{-1}\right)$ & $(+) 0,10$ & (-) 0,09 & (-) 0,03 & (+) 0,10 & (-) 0,00 & $(+) 0,06$ \\
\hline & $\mathrm{Fe}\left(\mathrm{mg} \cdot \mathrm{kg}^{-1}\right)$ & (-) 0,08 & (+) 0,14 & (+) 0,11 & (-) 0,10 & (+) 0,14 & (-) 0,17 \\
\hline & $\mathrm{Cu}\left(\mathrm{mg} \cdot \mathrm{kg}^{-1}\right)$ & (+) 0,25 * & (-) 0,04 & (-) 0,31 * & (+) 0,21 & (+) 0,01 & (+) 0,10 \\
\hline & $\mathrm{Zn}\left(\mathrm{mg} \cdot \mathrm{kg}^{-1}\right)$ & (-) 0,02 & (+) 0,19 & (+) 0,02 & (-) 0,07 & (+) 0,04 & (-) 0,13 \\
\hline & $M n\left(m g \cdot \mathbf{k g}^{-1}\right)$ & (-) 0,01 & (+) 0,01 & (+) 0,03 & (-) 0,02 & (-) 0,00 & (-) 0,02 \\
\hline \multirow{10}{*}{2011} & Arcilla (\%) & $(+) 0,30$ * & $(-) 0,40^{* *}$ & $(-) 0,43^{* *}$ & $(+) 0,50$ ** & (-) 0,32 * & $(+) 0,00$ \\
\hline & СТ (\%) & (+) 0,17 & $(-) 0,14$ & (-) 0,39 ** & (+) 0,36 ** & (-) 0,13 & (+) 0,00 \\
\hline & $P\left(\mathbf{m g} \cdot \mathbf{k g}^{-1}\right)$ & $(-) 0,34$ ** & (+) $0,64 * * *$ & $(+) 0,13$ & $(-) 0,35^{* *}$ & (+) 0,45 ** & (+) 0,02 \\
\hline & $\mathrm{K}\left(\mathrm{meq} \cdot 100 \mathrm{~g}^{-1}\right)$ & (-) 0,18 & (+) 0,05 & (+) 0,34 ** & (-) 0,27 * & (+) 0,02 & (+) 0,00 \\
\hline & $\operatorname{Mg}\left(\mathrm{meq} \cdot 100 \mathrm{~g}^{-1}\right)$ & (+) 0,15 & (-) 0,25 * & $(-) 0,15$ & (+) 0,23 * & (-) 0,22 * & (-) 0,00 \\
\hline & $\mathrm{Ca}\left(\mathrm{meq} \cdot 100 \mathrm{~g}^{-1}\right)$ & 0,20 & (+) 0,01 & (+) 0,12 & $(-) 0,11$ & (+) 0,01 & (+) 0,07 \\
\hline & $\mathrm{Fe}\left(\mathrm{mg} \cdot \mathrm{kg}^{-1}\right)$ & (-) 0,00 & (+) 0,17 & (+) 0,05 & (-) 0,20 & (+) 0,13 & (-) 0,06 \\
\hline & $\mathrm{Cu}\left(\mathrm{mg} \cdot \mathrm{kg}^{-1}\right)$ & (-) 0,06 & (+) 0,27 * & (+) 0,21 * & (-) 0,24 * & (+) 0,15 & (-) 0,06 \\
\hline & $\mathrm{Zn}\left(\mathrm{mg} \cdot \mathrm{kg}^{-1}\right)$ & (-) 0,18 & (+) 0,48 ** & $(+) 0,12$ & (-) 0,26 * & (+) 0,30 * & (-) 0,00 \\
\hline & $\operatorname{Mn}\left(\mathrm{mg} \cdot \mathrm{kg}^{-1}\right)$ & (-) 0,51 ** & (+) 0,05 & (+) 0,29 * & (-) 0,22 * & (+) 0,03 & (+) 0,19 \\
\hline
\end{tabular}


Las componentes del color en 2010 y en 2011 se relacionaron de forma significativa con el contenido de arcilla (tabla 4.54). Aunque como se ha descrito en el epígrafe 4.2.1., el contenido en arcilla presente en los suelos clorosantes disminuye el rendimiento de los viñedos debido a la reducción de la concentración de clorofila en la hoja y de la capacidad fotosintética de las plantas, esta tiene un efecto sobre el color, obteniendo mostos con un mayor croma y coordenada $a^{*}$ y con un menor tono, luminosidad y coordenada $b^{*}$.

Tabla 4.55.Coeficiente de determinación $\left(R^{2}\right)$, nivel de significación y pendiente de la regresión de las coordenadas CIELAB e índice cromático de uvas tintas (Carreño et al., 1995) del mosto de vendimia sobre el contenido de nutrientes minerales en los peciolos.

\begin{tabular}{|c|c|c|c|c|c|c|c|}
\hline \multicolumn{2}{|c|}{ Nutrientes peciolos } & C & $\mathbf{H}$ & $L^{*}$ & $\mathbf{a}^{*}$ & $\mathbf{b}^{*}$ & CIRG \\
\hline \multirow{10}{*}{2009} & N (\%) & $(-) 0,01$ & $(+) 0,02$ & (-) 0,02 & $(-) 0,01$ & (+) 0,02 & (-) 0,00 \\
\hline & $P(\%)$ & $(+) 0,05$ & $(-) 0,03$ & (-) 0,04 & $(+) 0,11$ & (-) 0,00 & $(+) 0,03$ \\
\hline & $K(\%)$ & $(+) 0,00$ & $(+) 0,02$ & (-) 0,03 & $(+) 0,00$ & (+) 0,01 & $(-) 0,02$ \\
\hline & $\operatorname{Mg}(\%)$ & $(+) 0,00$ & $(-) 0,01$ & (-) 0,00 & $(-) 0,00$ & (-) 0,00 & (+) 0,00 \\
\hline & $\mathrm{Ca}(\%)$ & $(-) 0,04$ & $(+) 0,05$ & (+) 0,02 & $(-) 0,06$ & (+) 0,02 & $(-) 0,06$ \\
\hline & $\mathrm{Fe}\left(\mathrm{mg} \cdot \mathrm{kg}^{-1}\right)$ & (-) 0,10 & $(+) 0,12$ & (+) 0,15 & $(-) 0,11$ & (+) 0,03 & (-) 0,17 \\
\hline & $\mathrm{Cu}\left(\mathrm{mg} \cdot \mathrm{kg}^{-1}\right)$ & $(+) 0,00$ & $(+) 0,00$ & $(+) 0,00$ & $(+) 0,01$ & (+) 0,00 & (-) 0,00 \\
\hline & $\mathrm{Zn}\left(\mathrm{mg} \cdot \mathrm{kg}^{-1}\right)$ & $(+) 0,01$ & $(+) 0,00$ & (+) 0,00 & $(+) 0,07$ & (+) 0,00 & (-) 0,02 \\
\hline & $M n\left(m g \cdot k g^{-1}\right)$ & $(+) 0,06$ & $(-) 0,00$ & (-) 0,09 & $(+) 0,01$ & (+) 0,00 & $(-) 0,00$ \\
\hline & $B\left(\mathrm{mg} \cdot \mathrm{kg}^{-1}\right)$ & $(-) 0,08$ & $(-) 0,01$ & $(-) 0,12$ & $(+) 0,03$ & (+) 0,00 & $(+) 0,02$ \\
\hline \multirow{10}{*}{2010} & $\mathbf{N}(\%)$ & $(-) 0,27^{*}$ & $(+) 0,26$ * & $(+) 0,26$ * & $(-) 0,28$ * & (+) 0,03 & $(-) 0,29$ * \\
\hline & $P(\%)$ & $(-) 0,25^{*}$ & $(+) 0,32$ ** & (+) 0,30 * & $(-) 0,36$ ** & (+) 0,05 & (-) 0,34 ** \\
\hline & K (\%) & $(-) 0,35^{* *}$ & $(+) 0,24$ * & (+) $0,43^{* *}$ & $(-) 0,33^{* *}$ & (+) 0,00 & (-) 0,33 ** \\
\hline & $\operatorname{Mg}(\%)$ & $(+) 0,14$ & $(-) 0,13$ & $(-) 0,23$ * & $(+) 0,14$ & (-) 0,00 & $(+) 0,20$ * \\
\hline & $\mathrm{Ca}(\%)$ & $(-) 0,00$ & (-) 0,00 & (-) 0,00 & $(-) 0,00$ & (-) 0,02 & $(+) 0,00$ \\
\hline & $\mathrm{Fe}\left(\mathrm{mg} \cdot \mathrm{kg}^{-1}\right)$ & $(-) 0,13$ & $(+) 0,14$ & $(+) 0,09$ & $(-) 0,14$ & (+) 0,07 & $(-) 0,13$ \\
\hline & $\mathrm{Cu}\left(\mathrm{mg} \cdot \mathrm{kg}^{-1}\right)$ & $(-) 0,25^{*}$ & $(+) 0,29$ * & (+) 0,36 * & $(-) 0,27^{*}$ & (+) 0,13 & (-) 0,41 ** \\
\hline & $\mathrm{Zn}\left(\mathrm{mg} \cdot \mathrm{kg}^{-1}\right)$ & $(-) 0,26$ * & $(+) 0,06$ & (+) 0,38 ** & $(-) 0,20$ * & (-) 0,02 & $(-) 0,15$ \\
\hline & $\operatorname{Mn}\left(\mathrm{mg} \cdot \mathrm{kg}^{-1}\right)$ & $(+) 0,03$ & $(-) 0,11$ & $(+) 0,05$ & $(+) 0,05$ & (-) 0,05 & $(+) 0,12$ \\
\hline & $B\left(\mathrm{mg} \cdot \mathrm{kg}^{-1}\right)$ & $(+) 0,58^{* * *}$ & $(-) 0,46$ ** & $(-) 0,43^{* *}$ & $(+) 0,58^{* * *}$ & (-) 0,01 & (+) 0,46 ** \\
\hline \multirow{10}{*}{2011} & $\mathbf{N}(\%)$ & $(-) 0,07$ & $(+) 0,14$ & $(+) 0,01$ & $(-) 0,06$ & (+) 0,07 & $(+) 0,01$ \\
\hline & P (\%) & $(-) 0,06$ & $(+) 0,13$ & $(+) 0,11$ & $(-) 0,22$ * & (+) 0,05 & (-) 0,01 \\
\hline & K (\%) & $(-) 0,00$ & $(-) 0,00$ & $(+) 0,00$ & $(-) 0,00$ & (-) 0,03 & $(+) 0,00$ \\
\hline & $\operatorname{Mg}(\%)$ & $(+) 0,21$ * & $(-) 0,16$ & $(-)$ 0,46 ** & $(+) 0,40 * *$ & (-) 0,05 & $(-) 0,01$ \\
\hline & $\mathrm{Ca}(\%)$ & $(+) 0,00$ & (-) 0,04 & (-) 0,02 & $(+) 0,07$ & (+) 0,02 & (-) 0,00 \\
\hline & $\mathrm{Fe}\left(\mathrm{mg} \cdot \mathrm{kg}^{-1}\right)$ & $(+) 0,12$ & (-) 0,00 & $(-) 0,18$ & $(+) 0,10$ & (+) 0,00 & (-) 0,01 \\
\hline & $\mathrm{Cu}\left(\mathrm{mg} \cdot \mathrm{kg}^{-1}\right)$ & $(-) 0,01$ & $(+) 0,00$ & (+) $0,25^{*}$ & $(-) 0,14$ & (+) 0,08 & (-) 0,06 \\
\hline & $\mathrm{Zn}\left(\mathrm{mg} \cdot \mathrm{kg}^{-1}\right)$ & $(+) 0,38^{* *}$ & $(-) 0,14$ & $(-) 0,08$ & $(+) 0,09$ & (-) 0,09 & $(-) 0,16$ \\
\hline & $M n\left(m g \cdot k^{-1}\right)$ & $(+) 0,12$ & $(-) 0,10$ & (-) $0,35^{* *}$ & $(+) 0,35^{* *}$ & (-) 0,04 & $(+) 0,02$ \\
\hline & $B\left(\mathbf{m g} \cdot \mathbf{k g}^{-1}\right)$ & $(-) 0,13$ & $(+) 0,00$ & $(+) 0,07$ & $(-) 0,05$ & (-) 0,00 & (+) 0,07 \\
\hline
\end{tabular}


Como muestra la tabla 4.55 , no se encontraron regresiones lineales significativas de los parámetros de color sobre los contenidos de minerales en los peciolos en 2009. Sin embargo, en 2010, las componentes del color C, H, L, a y CIRG se relacionaron significativamente con el contenido de $\mathrm{N}, \mathrm{P}, \mathrm{K}, \mathrm{Cu}, \mathrm{Zn}$ y $\mathrm{B}$ en los peciolos, mientras que $L$ y CIRG se relacionaron con el nivel de $\mathrm{Mg}$ peciolar. En el año 2011, podemos destacar las regresiones lineales significativas de $C, L$ y a* sobre el contenido de $\mathrm{Mg}$ y $\mathrm{Mn}$. Se puede deducir que existe una estrecha relación del contenido peciolar de $\mathrm{K}, \mathrm{Zn}, \mathrm{Mg}$ y $\mathrm{Mn}$ con las características cromáticas de los mostos. No se han encontrado regresiones lineales significativas de los parámetros cromáticos del vino sobre las concentraciones de $\mathrm{Ca}$ y $\mathrm{Fe}$ en los peciolos en envero.

Como se puede observar en la tabla 4.56, existen diferencias significativas de la luminosidad del mosto entre subzonas en 2011, siendo mayor en los puntos de muestreo no afectados por clorosis férrica que en los cloróticos. En general el nivel de afección de clorosis férrica en la zona de estudio no ha tenido una influencia significativa sobre los parámetros cromáticos del mosto, en contra de los resultados de Bavaresco et al. (2010a), donde la deficiencia de Fe induce una reducción de la producción de uva, del diámetro de la baya y de la compacidad de los racimos que redunda en un aumento de la coloración de la uva.

Tabla 4.56. Valores medios de las coordenadas CIELAB e índice cromático de uvas tintas (Carreño et al., 1995) del mosto de vendimia en áreas de muestreo afectadas (C) y no afectadas (NC) por clorosis férrica.

\begin{tabular}{|c|c|c|c|c|c|c|}
\hline \multirow{2}{*}{$\begin{array}{l}\text { Parámetros } \\
\text { cromáticos }\end{array}$} & \multicolumn{2}{|c|}{2009} & \multicolumn{2}{|c|}{2010} & \multicolumn{2}{|c|}{2011} \\
\hline & $\begin{array}{c}N C \\
(n=11)\end{array}$ & $\begin{array}{c}C \\
(n=11)\end{array}$ & $\begin{array}{c}\mathrm{NC} \\
(\mathrm{n}=12)\end{array}$ & $\begin{array}{c}C \\
(n=12)\end{array}$ & $\begin{array}{c}N C \\
(n=12)\end{array}$ & $\begin{array}{c}C \\
(n=12)\end{array}$ \\
\hline C & $16,9 a$ & $14,9 a$ & $11,4 a$ & $12,7 a$ & $21,8 a$ & $22,6 a$ \\
\hline H & $5,84 a$ & $10,5 a$ & $31,2 a$ & $28,2 a$ & $4,96 a$ & $5,42 a$ \\
\hline$L^{*}$ & $85,0 a$ & $86,4 a$ & $84,7 a$ & $82,3 a$ & $79,7 a$ & $75,5 b$ \\
\hline$a^{*}$ & $16,8 a$ & $15,4 a$ & $9,78 a$ & $11,3 a$ & $21,1 \mathrm{a}$ & $24,9 a$ \\
\hline $\mathbf{b}^{*}$ & $1,65 a$ & $2,10 a$ & $5,85 a$ & $5,67 a$ & $1,69 a$ & $2,06 a$ \\
\hline CIRG & $1,70 a$ & $1,67 a$ & $1,54 a$ & $1,60 a$ & $1,72 a$ & $1,78 a$ \\
\hline
\end{tabular}

Dentro de un mismo año, los valores con diferente letra son significativamente diferentes $(p<0,05$, test Tukey)

Como se puede ver en la tabla 4.57, todas las coordenadas CIELAB fueron significativamente diferentes según el estado nutricional de fósforo en 2010 y 2011. Así, los mostos de las parcelas con una nutrición media de fósforo se caracterizaron por tener una mayor cromaticidad y coordenada $a^{*}$, y un menor tono, luminosidad y coordenada $b^{*}$ que las parcelas con un nivel de nutrición bajo de dicho elemento. Estos resultados son similares a los obtenidos en la composición fenólica de las bayas como se describe en el epígrafe siguiente, debido a que los compuestos fenólicos y, principalmente las antocianinas son los responsables del color de los vinos (RibéreauGayon y Glories, 1987). 
Tabla 4.57. Valores medios de las coordenadas CIELAB e índice cromático de uvas tintas (Carreño et al., 1995) del mosto de vendimia para áreas de muestreo con diferente estado nutricional.

\begin{tabular}{|c|c|c|c|c|c|c|c|c|c|}
\hline \multirow[b]{2}{*}{ Nutriente } & \multicolumn{9}{|c|}{ Estado nutricional del viñedo } \\
\hline & Año & Nivel* $^{*}$ & $\mathbf{n}$ & C & $\mathbf{H}$ & $\mathbf{L}$ & $\mathbf{a}^{*}$ & $\mathbf{b}^{*}$ & CIRG \\
\hline \multirow{6}{*}{ Fósforo } & \multirow{2}{*}{2009} & Bajo & 8 & $16,4 a$ & $5,91 a$ & $85,9 a$ & $16,2 a$ & $1,51 \mathrm{a}$ & $1,70 a$ \\
\hline & & Medio & 11 & $15,5 a$ & $11,5 a$ & $86,0 a$ & $16,0 \mathrm{a}$ & $2,50 a$ & $1,66 a$ \\
\hline & \multirow{2}{*}{2010} & Bajo & 10 & $13,7 a$ & $24,5 b$ & $81,5 b$ & $12,4 a$ & $5,51 b$ & $1,64 a$ \\
\hline & & Medio & 14 & $10,9 b$ & $34,4 a$ & $85,1 \mathrm{a}$ & $8,98 b$ & $5,99 a$ & $1,52 b$ \\
\hline & \multirow{2}{*}{2011} & Bajo & 10 & $26,1 a$ & $2,94 b$ & $75,3 b$ & $26,1 a$ & $1,28 a$ & $1,75 a$ \\
\hline & & Medio & 14 & $19,7 b$ & $6,53 a$ & $79,5 a$ & $20,8 b$ & $2,21 a$ & $1,76 a$ \\
\hline \multirow{6}{*}{ Potasio } & \multirow{2}{*}{2009} & Alto & 8 & $15,4 a$ & $11,04 a$ & $86,0 a$ & $15,0 a$ & $2,25 a$ & $1,67 a$ \\
\hline & & Medio & 14 & $16,3 a$ & $6,53 a$ & $86,0 a$ & $16,8 a$ & $1,66 a$ & $1,69 a$ \\
\hline & \multirow{2}{*}{2010} & Alto & 10 & $10,7 b$ & $33,4 a$ & $85,6 a$ & $8,97 b$ & $5,70 a$ & $1,52 b$ \\
\hline & & Medio & 14 & $13,3 a$ & $26,9 b$ & $81,8 b$ & $11,86 a$ & $5,78 a$ & $1,61 \mathrm{a}$ \\
\hline & \multirow{2}{*}{2011} & Alto & 10 & $19,7 a$ & $7,41 a$ & $80,9 a$ & $19,5 b$ & $2,35 a$ & $1,72 a$ \\
\hline & & Medio & 14 & $24,0 a$ & $3,47 b$ & $75,7 b$ & $25,3 a$ & $1,48 a$ & $1,78 a$ \\
\hline \multirow{6}{*}{ Magnesio } & \multirow{2}{*}{2009} & Alto & 13 & $16,3 a$ & $5,93 a$ & $86,0 a$ & $16,1 a$ & $1,50 a$ & $1,70 a$ \\
\hline & & Medio & 9 & $15,4 a$ & $11,4 a$ & $86,0 a$ & $16,1 \mathrm{a}$ & $2,42 a$ & $1,66 a$ \\
\hline & \multirow{2}{*}{2010} & Alto & 13 & $13,4 a$ & $26,3 b$ & $81,6 b$ & $12,0 a$ & $5,77 a$ & $1,62 a$ \\
\hline & & Medio & 11 & $10,5 b$ & $34,3 a$ & $85,8 a$ & $8,68 b$ & $5,72 a$ & $1,51 \mathrm{~b}$ \\
\hline & \multirow{2}{*}{2011} & Alto & 13 & $24,5 a$ & $3,35 b$ & $75,0 b$ & $25,9 a$ & $1,48 a$ & $1,78 a$ \\
\hline & & Medio & 11 & $19,6 a$ & $7,15 a$ & $81,1 \mathrm{a}$ & $19,4 b$ & $2,27 a$ & $1,72 a$ \\
\hline \multirow{9}{*}{$\begin{array}{l}\mathrm{K} / \mathrm{Mg} \\
\text { (peciolos) }\end{array}$} & \multirow{3}{*}{2009} & Alto & 8 & $15,2 a$ & $10,7 a$ & $86,1 a$ & $16,1 a$ & $2,14 a$ & $1,67 a$ \\
\hline & & Medio & 8 & $17,0 a$ & $6,00 a$ & $85,5 a$ & $16,9 a$ & $1,66 a$ & $1,70 a$ \\
\hline & & Bajo & 6 & $15,4 a$ & $7,68 a$ & $86,5 a$ & $15,2 a$ & $1,82 a$ & $1,69 a$ \\
\hline & \multirow{3}{*}{2010} & Alto & 9 & $10,6 b$ & $34,17 a$ & $85,6 a$ & $8,8 b$ & $5,72 a$ & $1,52 b$ \\
\hline & & Medio & 6 & $12,6 a b$ & $27,88 b$ & $83,2 a b$ & $11,1 \mathrm{ab}$ & $5,76 a$ & $1,59 a b$ \\
\hline & & Bajo & 9 & $13,7 a$ & $26,14 \mathrm{~b}$ & $81,0 \mathrm{~b}$ & $12,3 a$ & $5,77 a$ & $1,63 a$ \\
\hline & \multirow{3}{*}{2011} & Alto & 6 & $17,7 a$ & $9,76 a$ & $82,1 a$ & $17,4 b$ & $2,86 a$ & $1,71 \mathrm{a}$ \\
\hline & & Medio & 9 & $22,7 a$ & $3,18 b$ & $76,5 b$ & $24,4 a$ & $1,22 a$ & $1,79 a$ \\
\hline & & Bajo & 9 & $24,6 a$ & $4,42 b$ & $76,7 \mathrm{~b}$ & $24,5 \mathrm{a}$ & $1,95 a$ & $1,73 a$ \\
\hline \multirow{6}{*}{ Cobre } & \multirow{2}{*}{2009} & Bajo & 9 & $15,8 a$ & $7,29 a$ & $86,0 a$ & $15,6 a$ & $1,76 a$ & $1,70 a$ \\
\hline & & Medio & 13 & $16,0 \mathrm{a}$ & $8,78 a$ & $86,0 a$ & $16,5 \mathrm{a}$ & $1,95 a$ & $1,68 a$ \\
\hline & \multirow{2}{*}{2010} & Bajo & 7 & $12,5 a$ & $28,2 a$ & $82,7 a$ & $11,0 a$ & $5,80 a$ & $1,59 a$ \\
\hline & & Medio & 17 & $12,1 a$ & $30,2 a$ & $83,6 a$ & $10,5 a$ & $5,72 a$ & $1,57 a$ \\
\hline & \multirow{2}{*}{2011} & Bajo & 7 & $24,7 a$ & $4,56 a$ & $74,0 a$ & $27,0 a$ & $1,24 a$ & $1,81 \mathrm{a}$ \\
\hline & & Medio & 17 & $20,9 a$ & $6,46 a$ & $79,9 a$ & $23,7 a$ & $2,16 a$ & $1,72 a$ \\
\hline \multirow{6}{*}{ Zinc } & \multirow{2}{*}{2009} & Alto & 14 & $17,1 \mathrm{a}$ & $6,72 a$ & $85,2 a$ & $17,6 a$ & $1,86 a$ & $1,69 a$ \\
\hline & & Medio & 8 & $13,9 a$ & $10,7 a$ & $87,3 a$ & $13,5 a$ & $1,91 \mathrm{a}$ & $1,67 a$ \\
\hline & & Alto & 13 & $12,2 a$ & $28,5 a$ & $83,6 a$ & $10,8 a$ & $5,76 a$ & $1,58 a$ \\
\hline & 2010 & Medio & 7 & $13,3 a$ & $28,1 a$ & $81,6 a$ & $11,8 \mathrm{a}$ & $5,69 a$ & $1,60 a$ \\
\hline & & Alto & 13 & $24,0 a$ & $4,20 a$ & $77,6 a$ & $23,5 a$ & $1,71 \mathrm{a}$ & $1,73 a$ \\
\hline & 2011 & Medio & 7 & $20,0 a$ & $5,56 a$ & $75,0 a$ & $25,3 a$ & $1,72 \mathrm{a}$ & $1,86 a$ \\
\hline
\end{tabular}

Dentro de un mismo año, los valores con diferente letra son significativamente diferentes $(p<0,05$, test Tukey)

*según diagnóstico nutricional realizado en el apartado 4.1 
En las áreas de estudio con un nivel alto de nutrición potásica, la cromaticidad y la coordenada $a^{*}$ fueron significativamente menores y el tono, luminosidad y coordenada $b^{*}$ fueron significativamente mayores que en las áreas con una nutrición media en 2010 y 2011 (tabla 4.57). Mlikota-Gabler et al. (2009) y Obenland et al. (2015) informaron que aplicaciones de soluciones potásicas sobre los racimos en variedades de mesa pueden ser interesantes para mejorar el color de las uvas.

En las subparcelas con un nivel medio de nutrición magnésica, el mosto se caracterizó por tener una menor cromaticidad y coordenada $a^{*}$ y un mayor tono, luminosidad y coordenada $b^{*}$ que las parcelas con un nivel alto de nutrición de dicho elemento en 2010 y 2011 (tabla 4.57). En las zonas de estudio con un nivel alto de la relación $\mathrm{K} / \mathrm{Mg}$, la cromaticidad y la coordenada $\mathrm{a}^{*}$ fueron significativamente menores y el tono, luminosidad y coordenada $b^{*}$ fueron significativamente mayores que en las áreas con una nivel de la relación K/Mg baja en 2010 y 2011. Como hemos manifestado anteriormente, estos resultados pueden estar relacionados por la carencia de $\mathrm{Mg}$ inducida por el desequilibrio provocado por el antagonismo de $\mathrm{K}$ y $\mathrm{Mg}$ a favor del primero, relacionado con un mayor tamaño de las bayas (mayor relación pulpa/hollejo), y por lo tanto con mostos de menor coloración.

No se han detectado diferencias significativas de los parámetros cromáticos del mosto en función del nivel de nutrición de $\mathrm{Cu}$ y $\mathrm{Zn}$ en ninguno de los años de estudio (tabla 4.57).

\subsubsection{3.- Madurez fenólica de las bayas}

Los compuestos fenólicos de la uva contribuyen al color, sabor, textura y astringencia del vino, y a sus propiedades antioxidantes (Teixeira et al. 2013). La concentración de fenoles totales en la baya aumenta lentamente durante la maduración hasta que se alcanza un máximo una o dos semanas antes de la vendimia, según la variedad, las condiciones climáticas, el estado nutricional y las prácticas culturales (Downey et al. 2006). La concentración de taninos y fenoles sintetizados durante el desarrollo de las uvas, disminuye durante el período de maduración (Ojeda et al. 2002).

El índice de madurez celular (diferencia entre el potencial total de antocianos y los fácilmente extraíbles) disminuye a lo largo de la maduración, indicando un aumento de la extractabilidad de los antocianos (Glories y Augustin, 1993; Saint-Criq et al., 1998). Algunos autores señalan que la facilidad con la que se extraen los antocianos está relacionada con la degradación progresiva de las estructuras celulares de los hollejos por la actividad de pectinasas endógenas, lo que está relacionado con el grado de madurez de las uvas (Glories y Augustin, 1993; Saint-Criq et al., 1998). Por otra parte, la facilidad de extracción de los antocianos tiene una fuerte componente varietal, poco afectada por las condiciones agroclimáticas (Romero-Cascales et al., 2005; Ortega-Regules et al., 2006). 
Glories y Augustin (1993) y Saint-Criq et al. (1998) consideran interesante el índice de madurez de las pepitas, expresado como la proporción de taninos de la semilla sobre el contenido fenólico total de la uva. Los valores son decrecientes a lo largo de la maduración de la uva debido a una menor solubilización de los taninos de las semillas como consecuencia del aumento en el grado de polimerización de estas moléculas durante la maduración (Saint-Criq et al., 1998; González-Neves et al., 2010).

En la tabla 4.58 se recogen las medias y coeficientes de variación de diferentes componentes de la madurez fenólica de las bayas en el conjunto de las zonas de estudio en los tres años de seguimiento. El índice de madurez de las pepitas ha mostrado el menor coeficiente de variación, mientras que el índice de madurez celular mostró el mayor coeficiente. El contenido fenólico total, antocianos totales y antocianos fácilmente extraíbles mostraron un coeficiente de variación similar. De estos resultados se puede deducir que la alta variabilidad de los diferentes componentes del suelo de las áreas de estudio descrita en el apartado 4.1.1, que provoca diferente grado de afección de clorosis férrica y del estado nutricional en general, se ha traducido en una alta variabilidad en el contenido y extractabilidad de los antocianos del hollejo entre las subparcelas estudiadas. Además, Catalina et al. (2011a) han mostrado que la variación en el contenido fenólico de la uva en la zona de estudio está estrechamente relacionada con el estado hídrico de los viñedos.

Tabla 4.58. Valores de parámetros de madurez fenólica de las bayas en el conjunto de las zonas de viñedo en los tres años de seguimiento.

\begin{tabular}{|c|c|c|c|c|c|}
\hline & $\begin{array}{l}\text { Madurez } \\
\text { fenólica }\end{array}$ & Mínimo & Máximo & Media & $\begin{array}{c}\text { Coeficiente de } \\
\text { variación }(\%)\end{array}$ \\
\hline \multirow{5}{*}{$\begin{array}{c}\text { Año } 2009 \\
(n=22)\end{array}$} & CFT & 17,0 & 46,8 & 25,9 & 26 \\
\hline & AFE & 287 & 536 & 444 & 15 \\
\hline & ANT & 545 & 1317 & 957 & 20 \\
\hline & IMC & 11,1 & 70,3 & 52,1 & 23 \\
\hline & IMP & 42,5 & 69,5 & 52,9 & 15 \\
\hline \multirow{5}{*}{$\begin{array}{c}\text { Año } 2010 \\
(n=24)\end{array}$} & CFT & 32,3 & 46,7 & 38,2 & 10 \\
\hline & AFE & 489 & 829 & 687 & 14 \\
\hline & ANT & 902 & 1818 & 1201 & 17 \\
\hline & IMC & 27,8 & 57,6 & 42,1 & 19 \\
\hline & IMP & 42,9 & 59,5 & 51,8 & 9 \\
\hline \multirow{5}{*}{$\begin{array}{c}\text { Año } 2011 \\
(n=24)\end{array}$} & CFT & 55,3 & 85,7 & 66,9 & 11 \\
\hline & AFE & 506 & 960 & 664 & 17 \\
\hline & ANT & 669 & 1129 & 920 & 15 \\
\hline & IMC & 13,6 & 42,6 & 26,4 & 30 \\
\hline & IMP & 68,2 & 77,9 & 73,6 & 4 \\
\hline
\end{tabular}

CFT: Contenido en fenoles totales; AFE: Antocianos fácilmente extraíbles (mg malvidina $\left.\cdot \mathrm{kg}^{-1}\right)$; $\mathrm{ANT}$ : Antocianos totales (mg malvidina $\cdot \mathrm{kg}^{-1}$ ); IMC: Índice de madurez celular; IMP: Índice de madurez de las pepitas. 
Los resultados muestran un valor notablemente mayor del contenido en compuestos fenólicos totales (CFT) en 2011 que en 2009 y 2010 (tabla 4.58). El contenido en antocianos fácilmente extraíbles (AFE) fue menor en 2009, mientras que la acumulación de antocianos totales fue sensiblemente mayor en 2010 que en 2009 y 2011. En el año 2011 se registró el menor índice de madurez celular y el mayor índice de madurez de las pepitas, lo que se traduce en una menor extractabilidad de los antocianos del hollejo y un mayor nivel fenólico de las pepitas, poco deseable.

Tabla 4.59. Coeficiente de determinación $\left(R^{2}\right)$, nivel de significación y pendiente de la regresión de los parámetros de madurez fenólica de las bayas sobre el contenido en arcilla, carbonatos totales (CT) y concentración de elementos minerales en el suelo.

\begin{tabular}{|c|c|c|c|c|c|c|c|}
\hline \multicolumn{2}{|c|}{ Composición del suelo ${ }^{1}$} & CFT & AFE & ANT & \multicolumn{2}{|c|}{ IMC } & IMP \\
\hline \multirow{10}{*}{2009} & Arcilla (\%) & (+) 0,01 & (+) 0,08 & (+) 0,09 & $(+)$ & 0,01 & (-) 0,01 \\
\hline & СТ (\%) & (+) 0,03 & (+) 0,15 & (-) 0,06 & $(-)$ & 0,21 & (-) 0,03 \\
\hline & $P\left(\mathbf{m g} \cdot \mathbf{k g}^{-1}\right)$ & $(-) 0,11$ & $(-) 0,11$ & (-) 0,27 * & $(-)$ & 0,04 & (-) 0,01 \\
\hline & $K\left(\right.$ meq $\left.\cdot 100 \mathrm{~g}^{-1}\right)$ & (-) 0,07 & (-) 0,10 & (+) 0,00 & $(+)$ & 0,05 & (-) 0,00 \\
\hline & $\operatorname{Mg}\left(\mathrm{meq} \cdot 100 \mathrm{~g}^{-1}\right)$ & (+) 0,04 & (+) 0,03 & (+) 0,15 & $(+)$ & 0,06 & (+) 0,00 \\
\hline & $\mathrm{Ca}\left(\mathrm{meq} \cdot 100 \mathrm{~g}^{-1}\right)$ & (+) 0,02 & (+) 0,00 & (+) 0,12 & $(+)$ & 0,06 & (+) 0,00 \\
\hline & $\mathrm{Fe}\left(\mathrm{mg} \cdot \mathrm{kg}^{-1}\right)$ & (-) 0,03 & (-) 0,02 & (-) 0,11 & $(-)$ & 0,07 & (-) 0,00 \\
\hline & $\mathrm{Cu}\left(\mathrm{mg} \cdot \mathrm{kg}^{-1}\right)$ & (-) 0,23 & (-) 0,26 & (-) 0,03 & $(+)$ & 0,05 & (+) 0,00 \\
\hline & $\mathrm{Zn}\left(\mathrm{mg} \cdot \mathrm{kg}^{-1}\right)$ & (-) 0,14 & (-) 0,11 & (-) 0,16 & $(-)$ & 0,00 & (-) 0,00 \\
\hline & $M n\left(\mathbf{m g} \cdot \mathbf{k g}^{-1}\right)$ & (-) 0,05 & $(-) 0,21$ & (+) 0,05 & $(+)$ & 0,20 & (+) 0,04 \\
\hline \multirow{10}{*}{2010} & Arcilla (\%) & (+) 0,15 & (+) 0,21 * & (+) 0,02 & $(-)$ & 0,08 & (-) 0,08 \\
\hline & CT (\%) & (+) 0,06 & (+) 0,05 & (+) 0,00 & $(-)$ & 0,02 & (-) 0,00 \\
\hline & $P\left(\mathbf{m g} \cdot \mathbf{k g}^{-1}\right)$ & $(-) 0,00$ & $(-) 0,02$ & (+) 0,00 & $(+)$ & 0,05 & (+) 0,05 \\
\hline & $\mathrm{K}\left(\mathrm{meq} \cdot 100 \mathrm{~g}^{-1}\right)$ & $(-) 0,02$ & (+) 0,01 & (-) 0,00 & $(-)$ & 0,02 & $(-) \quad 0,14$ \\
\hline & $\operatorname{Mg}\left(\mathrm{meq} \cdot 100 \mathrm{~g}^{-1}\right)$ & (+) 0,01 & (+) 0,09 & (+) 0,01 & $(-)$ & 0,02 & (-) 0,09 \\
\hline & $\mathrm{Ca}\left(\mathrm{meq} \cdot 100 \mathrm{~g}^{-1}\right)$ & (+) 0,04 & (+) 0,07 & (-) 0,00 & $(-)$ & 0,09 & (-) 0,04 \\
\hline & $\mathrm{Fe}\left(\mathrm{mg} \cdot \mathrm{kg}^{-1}\right)$ & (-) 0,00 & (-) 0,08 & (+) 0,04 & $(+)$ & 0,13 & (+) 0,14 \\
\hline & $\mathrm{Cu}\left(\mathrm{mg} \cdot \mathrm{kg}^{-1}\right)$ & (+) $0,40^{* *}$ & (+) 0,06 & (+) 0,00 & $(-)$ & 0,01 & (+) 0,06 \\
\hline & $\mathrm{Zn}\left(\mathbf{m g} \cdot \mathbf{k g}^{-1}\right)$ & (+) 0,00 & (-) 0,02 & (+) 0,00 & $(+)$ & 0,08 & (+) 0,04 \\
\hline & $M n\left(\mathrm{mg} \cdot \mathrm{kg}^{-1}\right)$ & (+) 0,01 & (+) 0,05 & (+) 0,01 & $(-)$ & 0,01 & (-) 0,08 \\
\hline \multirow{10}{*}{2011} & Arcilla (\%) & (+) 0,16 & (+) 0,42 ** & (+) $0,43^{* *}$ & $(-)$ & 0,01 & (-) $0,36^{* *}$ \\
\hline & CT (\%) & (+) 0,13 & (+) 0,26 * & (+) 0,29 * & $(-)$ & 0,00 & (-) 0,21 * \\
\hline & $P\left(\mathbf{m g} \cdot \mathbf{k g}^{-1}\right)$ & (-) 0,05 & (-) 0,13 & (-) $0,33^{* *}$ & $(-)$ & 0,07 & (+) 0,12 \\
\hline & $K\left(\mathrm{meq} \cdot 100 \mathrm{~g}^{-1}\right)$ & (-) 0,30 * & (-) 0,16 & (-) 0,23 * & $(-)$ & 0,01 & (+) 0,00 \\
\hline & $M g\left(m e q \cdot 100 g^{-1}\right)$ & (+) 0,00 & $(+) 0,12$ & (+) 0,26 * & $(+)$ & 0,03 & (-) 0,26 * \\
\hline & $\mathrm{Ca}\left(\mathrm{meq} \cdot 100 \mathrm{~g}^{-1}\right)$ & (-) 0,17 & (-) 0,04 & (-) 0,12 & $(-)$ & 0,04 & (-) 0,02 \\
\hline & $\mathrm{Fe}\left(\mathrm{mg} \cdot \mathrm{kg}^{-1}\right)$ & (+) 0,01 & (-) 0,04 & (-) 0,07 & $(-)$ & 0,00 & (+) 0,18 \\
\hline & $\mathrm{Cu}\left(\mathrm{mg} \cdot \mathrm{kg}^{-1}\right)$ & (-) 0,09 & (-) 0,21 * & (-) 0,18 & $(+)$ & 0,02 & (+) 0,18 \\
\hline & $\mathrm{Zn}\left(\mathrm{mg} \cdot \mathrm{kg}^{-1}\right)$ & (-) 0,07 & (-) 0,16 & $(-) 0,15$ & $(+)$ & 0,01 & (+) 0,14 \\
\hline & $\mathrm{Mn}\left(\mathbf{m g} \cdot \mathbf{k g}^{-1}\right)$ & (-) 0,14 & (-) 0,12 & (-) 0,23 * & $(-)$ & 0,02 & (+) 0,02 \\
\hline \multicolumn{8}{|c|}{ Niveles de significación: ${ }^{*} p<0,05 ;{ }^{* *} p<0,01 ;{ }^{* * *} p<0,0001$} \\
\hline
\end{tabular}


Como muestra la tabla 4.59, hubo una regresión lineal significativa negativa de la concentración de ANT sobre el contenido de $\mathrm{P}$ en el suelo en el año 2009 y positiva del nivel de AFE sobre el porcentaje de arcilla en el año 2010. En el año 2011, los contenidos de AFE y ANT se relacionaron significativamente de forma positiva e IMP de forma negativa con el porcentaje de arcilla y el contenido en carbonatos totales en el suelo. Además, podemos destacar las relaciones de la concentración de ANT significativamente negativas con el nivel de $\mathrm{P}, \mathrm{K}$ y $\mathrm{Mn}$, y positivas con el nivel de $\mathrm{Mg}$ en el suelo. No se han encontrado regresiones lineales significativas de los parámetros de madurez fenólica de las bayas sobre los contenidos de Ca y Fe en el suelo.

Al igual que las componentes del color, el contenido de AFE en 2010 y CFT y AFE en 2011 se relacionaron de forma positiva con el contenido de arcilla (tabla 4.59). Aunque como se ha descrito en el epígrafe 4.2.1., tanto el contenido en arcilla como el de carbonatos totales presentes en los suelos clorosantes disminuyen el rendimiento de los viñedos debido a la reducción de la concentración de clorofila en la hoja y de la capacidad fotosintética de las plantas, esta tiene un efecto positivo sobre el contenido fenólico de las bayas, modificando el color de los mostos.

La mayoría de las relaciones comentadas para los contenidos en antocianos en 2011 también se dieron para la concentración de SST e IPT de los mostos. Debido al hecho de que los azúcares son un regulador positivo de la biosíntesis de compuestos fenólicos, en particular flavonoides (Solfanelli et al., 2006), altos niveles de azucares van acompañados de altos niveles de flavonoides.

Como se puede ver en la tabla 4.60 , se ha obtenido una regresión lineal significativa con pendiente positiva de la concentración de AFE y negativa del IMC sobre el contenido de $\mathrm{Mg}$ peciolar en el año 2009. En el año 2010, CFT se relacionó significativamente de forma negativa con el nivel de $\mathrm{K}$ y $\mathrm{Zn}$, el contenido de AFE con el nivel de $\mathrm{Zn}$ y los contenidos de CFT, AFE y ANT con el nivel de $B$ en los peciolos. No obstante, Song et al., (2015) observaron que tratamientos foliares del viñedo con $\mathrm{Zn}$ aumentaban la acumulación de sólidos solubles totales, fenoles totales, flavonoides, flavonoides, taninos y antocianinas en la piel de la uva. Sin embargo, aún no se ha dilucidado cómo los genes de la vía de biosíntesis de compuestos fenólicos y genes reguladores relacionados responden a diferentes concentraciones de sulfato de zinc rociado sobre la vegetación. En cuanto a los resultados de 2011, se puede destacar las relaciones positivamente significativas de los niveles de CFT y AFE con el contenido de $\mathrm{Mg}$ y $\mathrm{Mn}$ peciolar, relaciones que también se han dado para los contenidos en el suelo, confirmando la influencia de la nutrición de ambos elementos en la calidad de la vendimia. Similares resultados se han obtenido para las componentes del color como se ha visto en el epígrafe anterior. Esto demuestra la estrecha relación del contenido peciolar de $\mathrm{K}, \mathrm{Zn}, \mathrm{Mg}$ y $\mathrm{Mn}$ con el contenido fenólico y las características cromáticas de los mostos.

No se han encontrado regresiones lineales significativas de los parámetros de madurez fenólica de las bayas sobre las concentraciones de $\mathrm{N}$, Ca y Fe en los peciolos en envero. Apenas se han dado coincidencias de las relaciones significativas 
encontradas de la composición fenólica de las uvas sobre los minerales contenidos en el suelo y los peciolos.

Tabla 4.60. Coeficiente de determinación $\left(R^{2}\right)$, nivel de significación y pendiente de la regresión de los parámetros de madurez fenólica de las bayas sobre el contenido de nutrientes minerales en los peciolos.

\begin{tabular}{|c|c|c|c|c|c|c|c|}
\hline \multicolumn{2}{|c|}{ Nutrientes peciolos } & \multirow{2}{*}{$\begin{array}{c}\text { CFT } \\
(+) 0,04\end{array}$} & \multirow{2}{*}{$\begin{array}{r}\text { AFE } \\
(+) 0,17\end{array}$} & \multirow{2}{*}{$\begin{array}{r}\text { ANT } \\
(+) 0,04\end{array}$} & IMC & \multicolumn{2}{|c|}{ IMP } \\
\hline \multirow{10}{*}{2009} & N (\%) & & & & (-) 0,05 & $(+)$ & 0,03 \\
\hline & $\mathbf{P}(\%)$ & (+) 0,01 & (+) 0,01 & (+) 0,04 & (+) 0,01 & $(+)$ & 0,00 \\
\hline & $\mathrm{K}(\%)$ & (-) 0,01 & (+) 0,00 & (+) 0,09 & (+) 0,08 & $(-)$ & 0,01 \\
\hline & $\operatorname{Mg}(\%)$ & (+) 0,09 & (+) 0,29 ** & (-) 0,01 & (-) 0,26 * & $(-)$ & 0,01 \\
\hline & $\mathrm{Ca}(\%)$ & (+) 0,01 & (+) 0,03 & (-) 0,07 & $(-) 0,16$ & $(-)$ & 0,00 \\
\hline & $\mathrm{Fe}\left(\mathrm{mg} \cdot \mathrm{kg}^{-1}\right)$ & (-) 0,14 & (-) 0,11 & (-) 0,18 & (-) 0,05 & $(-)$ & 0,01 \\
\hline & $\mathrm{Cu}\left(\mathrm{mg} \cdot \mathrm{kg}^{-1}\right)$ & (-) 0,01 & (-) 0,05 & (-) 0,01 & (+) 0,01 & $(+)$ & 0,00 \\
\hline & $\mathrm{Zn}\left(\mathrm{mg} \cdot \mathrm{kg}^{-1}\right)$ & (+) 0,00 & (+) 0,00 & (-) 0,00 & (-) 0,02 & $(+)$ & 0,01 \\
\hline & $M n\left(m g \cdot k^{-1}\right)$ & (+) 0,00 & (+) 0,12 & (+) 0,00 & (-) 0,08 & $(-)$ & 0,04 \\
\hline & $B\left(\mathbf{m g} \cdot \mathbf{k g}^{-1}\right)$ & (+) 0,06 & (+) 0,05 & (+) 0,00 & (-) 0,03 & $(+)$ & 0,02 \\
\hline \multirow{10}{*}{2010} & $\mathbf{N}(\%)$ & $(-) 0,18$ & $(-) 0,18$ & (-) 0,01 & (+) 0,07 & $(+)$ & 0,03 \\
\hline & P (\%) & $(-) 0,13$ & (-) 0,09 & (-) 0,08 & (-) 0,01 & $(+)$ & 0,01 \\
\hline & K (\%) & $(-) 0,20$ * & (-) 0,04 & (-) 0,03 & (-) 0,00 & $(-)$ & 0,03 \\
\hline & $M g(\%)$ & (+) 0,04 & (+) 0,03 & (+) 0,03 & (+) 0,00 & $(-)$ & 0,00 \\
\hline & $\mathrm{Ca}(\%)$ & (-) 0,10 & (-) 0,09 & $(-) 0,17$ & (-) 0,03 & $(+)$ & 0,04 \\
\hline & $\mathrm{Fe}\left(\mathrm{mg} \cdot \mathrm{kg}^{-1}\right)$ & (-) 0,00 & (-) 0,02 & (+) 0,00 & (+) 0,00 & $(+)$ & 0,01 \\
\hline & $\mathrm{Cu}\left(\mathrm{mg} \cdot \mathrm{kg}^{-1}\right)$ & (-) 0,06 & (-) 0,17 & (-) 0,00 & (+) 0,13 & $(+)$ & 0,17 \\
\hline & $\mathrm{Zn}\left(\mathrm{mg} \cdot \mathrm{kg}^{-1}\right)$ & (-) 0,52 ** & (-) 0,36 ** & (-) 0,04 & (+) 0,13 & $(+)$ & 0,03 \\
\hline & $M n\left(m g \cdot k g^{-1}\right)$ & (-) 0,02 & (+) 0,00 & (+) 0,00 & (-) 0,00 & $(-)$ & 0,05 \\
\hline & $B\left(\mathrm{mg} \cdot \mathrm{kg}^{-1}\right)$ & (+) 0,28 * & (+) 0,29 * & (+) 0,20 * & (+) 0,00 & $(-)$ & 0,06 \\
\hline \multirow{10}{*}{2011} & $\mathbf{N}(\%)$ & (-) 0,01 & (+) 0,00 & $(-) 0,17$ & (-) 0,18 & $(-)$ & 0,02 \\
\hline & $P(\%)$ & (-) 0,02 & (-) 0,05 & (-) 0,14 & (-) 0,04 & $(+)$ & 0,05 \\
\hline & K (\%) & (+) 0,00 & (+) 0,02 & $(-) 0,01$ & (-) 0,18 & $(-)$ & 0,02 \\
\hline & $M g(\%)$ & (+) 0,26 * & (+) 0,27 * & (+) $0,33^{* *}$ & (+) 0,01 & $(-)$ & 0,10 \\
\hline & $\mathrm{Ca}(\%)$ & (+) 0,01 & (+) 0,01 & $(-) 0,06$ & (-) 0,08 & $(+)$ & 0,00 \\
\hline & $\mathrm{Fe}\left(\mathrm{mg} \cdot \mathrm{kg}^{-1}\right)$ & (+) 0,12 & (+) 0,02 & (+) 0,02 & (+) 0,01 & $(+)$ & 0,02 \\
\hline & $\mathrm{Cu}\left(\mathrm{mg} \cdot \mathrm{kg}^{-1}\right)$ & (-) 0,21 * & (-) 0,13 & (-) 0,05 & (+) 0,04 & $(+)$ & 0,01 \\
\hline & $\mathrm{Zn}\left(\mathrm{mg} \cdot \mathrm{kg}^{-1}\right)$ & (+) 0,15 & (+) 0,03 & (+) 0,19 & (+) 0,14 & $(+)$ & 0,02 \\
\hline & $M n\left(m g \cdot k^{-1}\right)$ & (+) 0,20 * & (+) 0,20 * & (+) 0,33 ** & (+) 0,02 & $(-)$ & 0,14 \\
\hline & $B\left(\mathbf{m g} \cdot \mathbf{k g}^{-1}\right)$ & $(-) 0,06$ & $(-) 0,04$ & $(-) 0,03$ & (-) 0,00 & $(+)$ & 0,00 \\
\hline
\end{tabular}

La tabla 4.61 muestra los resultados del análisis factorial de la varianza donde se han evaluado los efectos aditivos y de interacción de la clorosis férrica con el nivel 
nutricional de otros elementos, tomando como base la clasificación de subzonas realizada en los apartados4.3.3 y 4.1 respectivamente. La influencia de la clorosis férrica sobre los parámetros de la madurez fenólica de las bayas solo ha resultado estadísticamente significativa para el contenido en ANT.

Tabla 4.61. Valores de la $F$ de Fisher y nivel de significación del análisis factorial de la varianza (ANOVA) de los parámetros de madurez fenólica de las bayas en función del nivel de afección de clorosis férrica (CF) y el nivel nutricional de diversos nutrientes (nt), según diagnóstico realizado en los apartados 4.2 .3 y 4.1 respectivamente.

\begin{tabular}{|c|c|c|c|c|c|c|c|c|c|}
\hline Nutriente & & Parámetros & Modelc & & CF & & nt & & CF $\times n t$ \\
\hline \multirow{9}{*}{$\mathrm{nt}=\mathrm{P}$} & \multirow{3}{*}{2009} & CFT & 1,51 & & 2,78 & & 2,77 & & 1,72 \\
\hline & & AFE & 0,54 & & 0,11 & & 1,32 & & 0,52 \\
\hline & & ANT & 4,39 & * & 5,89 & * & 0,19 & & 3,86 \\
\hline & & CFT & 1,40 & & 0,12 & & 0,32 & & 2,79 \\
\hline & \multirow[t]{2}{*}{2010} & AFE & 0,87 & & 0,16 & & 0,94 & & 0,93 \\
\hline & & ANT & 0,14 & & 0,16 & & 0,35 & & 0,00 \\
\hline & & CFT & 0,69 & & 1,04 & & 0,16 & & 0,16 \\
\hline & \multirow[t]{2}{*}{2011} & AFE & 2,28 & & 0,23 & & 4,14 & & 0,00 \\
\hline & & ANT & 2,09 & & 0,22 & & 2,82 & & 1,38 \\
\hline \multirow{9}{*}{$n t=K$} & \multirow{3}{*}{2009} & CFT & 0,44 & & 0,09 & & 1,26 & & 0,08 \\
\hline & & AFE & 1,16 & & 0,01 & & 0,23 & & 2,61 \\
\hline & & ANT & 1,92 & & 4,49 & * & 0,01 & & 0,77 \\
\hline & & CFT & 1,03 & & 0,04 & & 2,65 & & 0,10 \\
\hline & \multirow[t]{2}{*}{2010} & AFE & 1,36 & & 0,63 & & 2,41 & & 1,30 \\
\hline & & ANT & 0,93 & & 0,10 & & 2,45 & & 0,47 \\
\hline & & CFT & 3,74 & * & 0,45 & & 8,40 & ** & 0,02 \\
\hline & \multirow[t]{2}{*}{2011} & AFE & 3,05 & & 0,60 & & 6,30 & * & 0,50 \\
\hline & & ANT & 4,12 & * & 0,09 & & 10,67 & ** & 0,70 \\
\hline \multirow{9}{*}{$\mathrm{nt}=\mathbf{M g}$} & \multirow{3}{*}{2009} & CFT & 1,08 & & 0,02 & & 1,38 & & 1,91 \\
\hline & & AFE & 2,54 & & 0,10 & & 4,03 & & 3,79 \\
\hline & & ANT & 3,29 & * & 7,25 & * & 0,04 & & 4,06 \\
\hline & \multirow{3}{*}{2010} & CFT & 0,91 & & 0,27 & & 2,50 & & 0,03 \\
\hline & & AFE & 1,47 & & 1,68 & & 4,27 & & 0,06 \\
\hline & & ANT & 2,49 & & 0,86 & & 4,60 & * & 3,21 \\
\hline & & CFT & 3,17 & * & 0,00 & & 5,74 & * & 0,63 \\
\hline & \multirow[t]{2}{*}{2011} & AFE & 4,74 & * & 0,12 & & 10,95 & ** & 0,22 \\
\hline & & ANT & 4,75 & * & 0,67 & & 12,78 & ** & 0,36 \\
\hline \multirow{9}{*}{$\mathrm{nt}=\mathrm{Cu}$} & \multirow{3}{*}{2009} & CFT & 2,40 & & 0,14 & & 1,06 & & 5,45 \\
\hline & & AFE & 5,65 & ** & 0,01 & & 6,38 & * & 8,65 \\
\hline & & ANT & 3,40 & * & 5,19 & * & 1,29 & & 2,63 \\
\hline & \multirow{3}{*}{2010} & CFT & 1,47 & & 0,57 & & 0,98 & & 4,14 \\
\hline & & AFE & 0,77 & & 1,12 & & 1,99 & & 1,56 \\
\hline & & ANT & 6,86 & ** & 7,76 & * & 15,53 & ** & 16,23 * \\
\hline & \multirow{3}{*}{2011} & CFT & 11,47 & ** & 4,48 & * & 30,02 & $* * *$ & 5,55 * \\
\hline & & AFE & 6,66 & ** & 0,56 & & 14,34 & ** & 0,25 \\
\hline & & ANT & 2,53 & & 0,34 & & 5,92 & * & 0,22 \\
\hline
\end{tabular}

CFT: Contenido en fenoles totales; AFE: Antocianos fácilmente extraíbles(mg malvidina $\left.\cdot^{-1}\right)$; ANT: Antocianos totales(mg malvidina $\cdot^{-1}$ )

Niveles de significación: * $p<0,05 ;{ }^{* *} p<0,01 ;{ }^{* * *} p<0,0001$ 
La incidencia del nivel nutricional de fósforo no ha sido estadísticamente significativa para ningún parámetro de la madurez fenólica. Los niveles nutricionales de $\mathrm{K}$ y $\mathrm{Mg}$ afectaron significativamente a la concentración en CFT, AFE, ANT en el año 2011. La incidencia del nivel nutricional del $\mathrm{Cu}$ y la interacción de este con la clorosis férrica fueron significativas para el contenido en AFE en 2009 y 2011. Por último, en el año 2010, la afección de la clorosis férrica y el estado nutricional de Cu mostraron un efecto de interacción sobre el nivel en ANT en 2010 y sobre CFT en 2011. El análisis factorial de la varianza no se ha realizado para el $\mathrm{Zn}$ porque no han resultado grupos suficientes para ello. Así, no hay subparcelas no afectadas por clorosis férrica con un nivel medio de nutrición de Zn simultáneamente.

Como se puede ver en la tabla 4.61, la influencia de la clorosis férrica sobre los parámetros de la madurez fenólica solo ha resultado estadísticamente significativa para la concentración de ANT. La tabla 4.62 muestra como ANT e IMC fueron significativamente mayores en los puntos de muestreo con plantas sanas que en las subparcelas afectadas por clorosis férrica en 2009. En la campaña de 2011, sin ser las diferencias significativas al $5 \%$, la tendencia fue distinta, registrándose los valores más elevados de CFT, ANT y AFE en las parcelas afectadas por clorosis férrica debido probablemente a la mayor proporción hollejo/pulpa como consecuencia de la reducción de tamaño de las bayas (tabla 4.43), en consonancia con los resultados obtenidos por Martín et al. (2007b).

Tabla 4.62.Valores medios de la composición fenólica de las bayas en áreas de muestreo afectadas (C) y no afectadas (NC) por clorosis férrica.

\begin{tabular}{lcccccc}
\hline Madurez & \multicolumn{2}{c}{$\mathbf{2 0 0 9}$} & \multicolumn{2}{c}{$\mathbf{2 0 1 0}$} & \multicolumn{2}{c}{2011} \\
\cline { 2 - 7 } fenólica & $\begin{array}{c}\mathbf{N C} \\
(\mathbf{n}=11)\end{array}$ & $\begin{array}{c}\mathbf{C}=11) \\
(\mathbf{n}=\end{array}$ & $\begin{array}{c}\mathbf{N}=12) \\
\mathbf{n}=12\end{array}$ & $\begin{array}{c}\mathbf{C}=12) \\
\mathbf{n}=12)\end{array}$ & $\begin{array}{c}\mathbf{C} \\
(\mathbf{n}=12)\end{array}$ \\
\hline CFT & $25,5 a$ & $26,2 a$ & $37,6 a$ & $38,4 a$ & $65,0 a$ & $69,2 a$ \\
AFE & $441 a$ & $447 a$ & $689 a$ & $685 a$ & $631 a$ & $703 a$ \\
ANT & $1041 a$ & $873 b$ & $1190 a$ & $1208 a$ & $891 a$ & $949 a$ \\
IMC & $57 a$ & $47 b$ & $41 a$ & $43 a$ & $27 a$ & $25 a$ \\
IMP & $53 a$ & $52 a$ & $51 a$ & $52 a$ & $74 a$ & $73 a$ \\
\hline
\end{tabular}

CFT: Contenido en fenoles totales; AFE: Antocianos fácilmente extraíbles (mg malvidina. $l^{-1}$ ); ANT:

Antocianos totales (mg malvidina $\cdot{ }^{-1}$ ); IMC: Índice de madurez celular; IMP: Índice de madurez de las pepitas.

En un mismo año, los valores con diferente letra son significativamente diferentes $(p<0,05$, test Tukey)

En uvas, una incipiente deficiencia de hierro provoca una depresión de la actividad peroxidasa, aumenta la concentración de trans-resveratrol (compuesto estilbénico) y promueve la acumulación de antocianinas y polifenoles en el fruto (Sijmons et al., 1985; Bavaresco et al, 2010a). Bavaresco et al. (2005) observaron un aumento del porcentaje de antocianinas en el peso fresco de la baya de plantas cloróticas frente a plantas sanas, indicando que en las vides afectadas por clorosis puede haberse visto afectado de algún modo la biosíntesis de estos compuestos. Los mecanismos bioquímicos implicados no están claros, pero se puede especular que, 
formando parte el hierro de los constituyentes de las enzimas implicadas en la síntesis de la lignina, la deficiencia de hierro puede cambiar la vía shikimato hacia otros compuestos fenólicos incluyendo antocianinas. En investigaciones en la misma zona de estudio llevados a cabo por Catalina et al. (2011a) se observó que el contenido fenólico total de las uvas estuvo más influido por el estado hídrico que por los niveles de asimilación de hierro.

Como se observa en la tabla 4.63, los valores de CFT, AFE y ANT fueron significativamente diferentes según el estado nutricional de fósforo, potasio, magnesio y cobre en 2011. Así, las uvas de las subparcelas con un nivel de nutrición medio de fosforo se caracterizaron por tener un menor contenido de antocianos que las parcelas con un nivel bajo de nutrición de dicho elemento. La concentración de compuestos fenólicos aumenta en las uvas de plantas deficientes en $\mathrm{P}$ (Deldaldechamp et al., 1995), siendo la acumulación de antocianinas en hojas un síntoma típico de plantas deficientes en $P$ (Marschner, 1995). Además, se ha demostrado que el exceso de $P$ puede inhibir la inducción de la actividad fenilalanina amoníaco-liasa y chalcona sintasa y puede conducir a una reducción del contenido de antocianinas en las células de plantas de vid (Kakegawa et al. 1995). Sin embargo, Schreiner et al., (2014) observaron que diferentes niveles de fertilización fosfórica no alteraban la composición fenólica de las bayas.

Los valores de CFT, AFE y ANT en el año 2011 fueron significativamente mayores en las subzonas con un nivel medio de nutrición potásica que en las parcelas con un nivel alto de nutrición de dicho elemento. En las otras dos campañas la tendencia fue similar pero las diferencias no fueron significativas al $5 \%$. Morris et al. (1980), Morris et al. (1982), Dundon (1984) y Schreiner et al. (2014) encontraron que la fertilización potásica por encima de los niveles adecuados no tenía ningún efecto positivo sobre el contenido de polifenoles totales en la uva y no observaron mejoría en el color. Por su parte, Schreiner et al. (2014) manifestaron que el estrés nutricional de $\mathrm{K}$ no alteraba la composición fenólica de la uva.

Por el contrario, las uvas de las subparcelas con un nivel medio de nutrición magnésica se caracterizaron por tener un menor CFT que las subparcelas con un nivel alto de nutrición de dicho elemento en 2011. En las otras dos campañas la tendencia fue similar pero las diferencias no fueron significativas al $5 \%$. Los valores de CFT, AFE y ANT en el año 2011 fueron significativamente menores en las subzonas con una alta relación $\mathrm{K} / \mathrm{Mg}$ en los peciolos (carencia inducida de $\mathrm{Mg}$ ) que en las parcelas con un nivel medio y bajo de relación K/Mg. Májer et al. (2004) observó que la aplicación de fertilizantes magnésicos afectan de una manera positiva el contenido fenólico de las bayas, mientras que Zatloukalová et al., (2014) no observaron diferencias en la composición de las bayas entre tratamientos de Mg. Ruhl et al. (1992) y Trolove et al. (2008) encontraron que la deficiencia de Mg no afectaba la calidad de la baya. Se ha detectado una relación negativa entre el contenido en $\mathrm{K}$ en el suelo y los peciolos, y el ratio $\mathrm{K} / \mathrm{Mg}$ en el suelo, y la concentración de $\mathrm{Mg}$ peciolar (epígrafe 4.1.2), en consonancia con trabajos de Gluhić et al. (2009) en suelos calcáreos. 
Tabla 4.63. Valores medios delos parámetros de madurez fenólica de las bayas para áreas de muestreo con diferente estado nutricional.

\begin{tabular}{|c|c|c|c|c|c|c|}
\hline & & Esta & nut & onal d & ñedo & \\
\hline Nutriente & Año & Nivel* $^{*}$ & $\mathbf{n}$ & CFT & AFE & ANT \\
\hline \multirow{6}{*}{ Fósforo } & \multirow{2}{*}{2009} & Bajo & 8 & $26,3 a$ & $454 a$ & $929 a$ \\
\hline & & Medio & 11 & $24,2 a$ & $420 a$ & $951 a$ \\
\hline & \multirow{2}{*}{2010} & Bajo & 10 & $39,1 a$ & $712 a$ & $1176 a$ \\
\hline & & Medio & 14 & $37,2 a$ & $663 a$ & $1226 a$ \\
\hline & \multirow{2}{*}{2011} & Bajo & 10 & $69,1 a$ & $740 a$ & $997 a$ \\
\hline & & Medio & 14 & $65,7 a$ & $621 b$ & $869 b$ \\
\hline \multirow{6}{*}{ Potasio } & \multirow{2}{*}{2009} & Alto & 8 & $23,8 a$ & $459 a$ & $1013 a$ \\
\hline & & Medio & 14 & $27,1 \mathrm{a}$ & $436 a$ & $925 a$ \\
\hline & \multirow{2}{*}{2010} & Alto & 10 & $36,4 a$ & $649 a$ & $1118 a$ \\
\hline & & Medio & 14 & $39,3 a$ & $713 a$ & $1257 a$ \\
\hline & \multirow{2}{*}{2011} & Alto & 10 & $62,1 \mathrm{~b}$ & $599 b$ & $816 b$ \\
\hline & & Medio & 14 & $71,0 \mathrm{a}$ & $719 a$ & $990 a$ \\
\hline \multirow{6}{*}{ Magnesio } & \multirow{2}{*}{2009} & Alto & 13 & $27,2 a$ & $465 a$ & $943 a$ \\
\hline & & Medio & 9 & $23,9 a$ & $413 a$ & $978 a$ \\
\hline & \multirow{2}{*}{2010} & Alto & 13 & $39,2 a$ & $715 a$ & $1262 a$ \\
\hline & & Medio & 11 & $36,6 a$ & $646 a$ & $1110 a$ \\
\hline & \multirow{2}{*}{2011} & Alto & 13 & $71,1 a$ & $737 a$ & $1001 a$ \\
\hline & & Medio & 11 & $62,8 b$ & $591 b$ & $822 b$ \\
\hline \multirow{9}{*}{$\begin{array}{l}\text { K/Mg } \\
\text { (peciolos) }\end{array}$} & \multirow{3}{*}{2009} & Alto & 8 & $24,0 a$ & $449 a$ & $993 a$ \\
\hline & & Medio & 8 & $24,9 a$ & $417 a$ & $967 a$ \\
\hline & & Bajo & 6 & $29,6 a$ & $473 a$ & $897 a$ \\
\hline & \multirow{3}{*}{2010} & Alto & 9 & $36,5 a$ & $655 a$ & $1125 a$ \\
\hline & & Medio & 6 & $38,9 a$ & $720 a$ & $1302 a$ \\
\hline & & Bajo & 9 & $39,1 \mathrm{a}$ & $691 a$ & $1190 a$ \\
\hline & \multirow{3}{*}{2011} & Alto & 6 & $61,0 b$ & $572 b$ & $767 b$ \\
\hline & & Medio & 9 & $70,7 a$ & $724 a$ & $972 a$ \\
\hline & & Bajo & 9 & $67,2 \mathrm{a}$ & $666 a$ & $971 \mathrm{a}$ \\
\hline \multirow{6}{*}{ Cobre } & \multirow{2}{*}{2009} & Bajo & 9 & $27,9 a$ & $482 a$ & $983 a$ \\
\hline & & Medio & 13 & $24,5 a$ & $417 \mathrm{~b}$ & $940 a$ \\
\hline & \multirow{2}{*}{2010} & Bajo & 7 & $38,2 a$ & $710 a$ & $1292 a$ \\
\hline & & Medio & 17 & $38,1 \mathrm{a}$ & $675 a$ & $1152 a$ \\
\hline & \multirow{2}{*}{2011} & Bajo & 7 & $74,7 a$ & $781 a$ & $1021 a$ \\
\hline & & Medio & 17 & $63,3 b$ & $610 \mathrm{~b}$ & $866 \mathrm{~b}$ \\
\hline \multirow{6}{*}{ Zinc } & \multirow{2}{*}{2009} & Alto & 14 & $26,4 a$ & $449 a$ & $990 a$ \\
\hline & & Medio & 8 & $24,9 a$ & $434 a$ & $901 a$ \\
\hline & \multirow{2}{*}{2010} & Alto & 13 & $37,3 a$ & $674 a$ & $1240 a$ \\
\hline & & Medio & 7 & $39,8 \mathrm{a}$ & $713 a$ & $1226 a$ \\
\hline & \multirow{2}{*}{2011} & Alto & 13 & $67,2 a$ & $671 a$ & $959 a$ \\
\hline & & Medio & 7 & $69,5 a$ & $711 a$ & $928 a$ \\
\hline
\end{tabular}

CFT: Contenido en fenoles totales; AFE: Antocianos fácilmente extraíbles(mg malvidina $\left.\digamma^{-1}\right)$; ANT: Antocianos totales (mg malvidina. $\digamma^{-1}$ )

Dentro de un mismo año, los valores con diferente letra son significativamente diferentes ( $p<0,05$, test Tukey)

*según diagnóstico nutricional realizado en el apartado 4.1 
Las uvas de las parcelas con un nivel bajo de nutrición de Cu se caracterizaron por tener un mayor CFT que las parcelas con una nutrición media de dicho elemento (tabla 4.63). Por el contrario, como se ha descrito en el capítulo 4.4.1., en las áreas de estudio con déficit de $\mathrm{Cu}$, el rendimiento y sus componentes fueron significativamente menores que en las áreas con una nutrición adecuada en el año 2011. Así pues, el mayor rendimiento, y especialmente el mayor tamaño de la baya (aumento de la relación pulpa/hollejo) obtenido en las subparcelas con un nivel medio de nutrición de Cu ha provocado un efecto de "dilución" de los compuestos fenólicos en las uvas. Por otro lado, en 2009 y 2011, el análisis factorial de la varianza de AFE ha mostrado un efecto de interacción entre el nivel nutricional de $\mathrm{Cu}$ y la incidencia de la clorosis férrica (tabla 4.61). En las subparcelas afectadas por clorosis férrica, los valores de AFE fueron significativamente mayores en las áreas de estudio con un nivel nutricional bajo de $\mathrm{Cu}$ que en las que tienen un nivel medio (años 2009 y 2011). Este mismo resultado se ha dado para las subparcelas no cloróticas en 2011 (figura 4.23). Chen et al. (2004b) han observado que la deficiencia de Fe podría estimular la asimilación y acumulación de $\mathrm{Cu}$ en Commelina communis, y viceversa, constatando que tanto la deficiencia de $\mathrm{Cu}$ como la de $\mathrm{Fe}$ inducen la actividad de quelato-Fe(III) reductasa en las raíces. La relación entre estos nutrientes ha sido confirmada por muchos estudios con plantas deficientes en $\mathrm{Fe}$, donde la clorosis fue menos evidente si las soluciones eran también deficiente en $\mathrm{Cu}$. (Russo et al., 2010). Todo esto demuestra que existe una relación fisiológica entre el metabolismo de $\mathrm{Fe}$ y $\mathrm{Cu}$.

2009

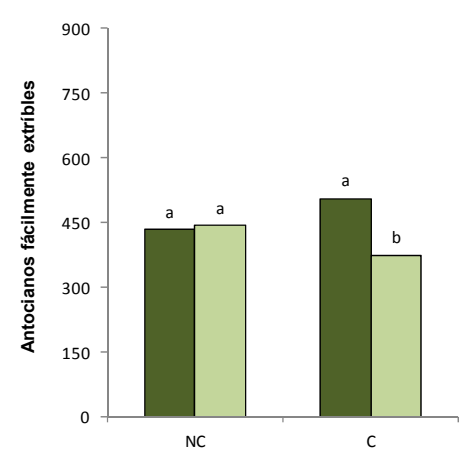

2010

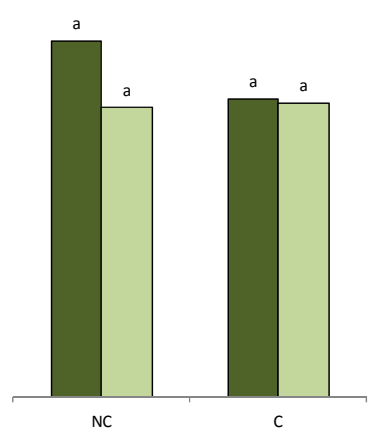

2011

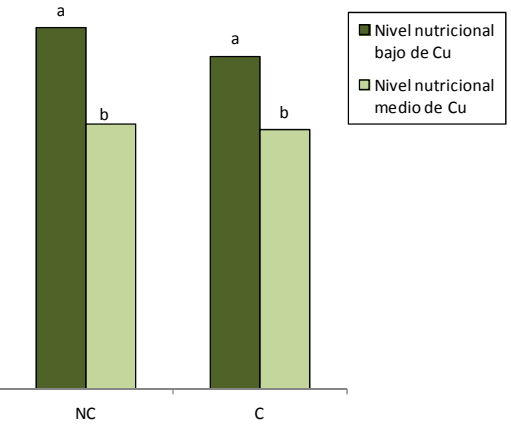

Figura 4.23.Contenido en antocianos fácilmente extraíbles de la baya en las áreas de estudio afectadas (C) y no afectadas por clorosis férrica (NC), en función del nivel nutricional de cobre.

No se han detectado diferencias significativas del contenido fenólico de las uvas en función del nivel de nutrición de $\mathrm{Zn}$ en ninguno de los años de estudio (tabla 4.63). 


\section{5.- UTILIZACIÓN DEL CONTENIDO FOLIAR DE PIGMENTOS Y PARÁMETROS DE FLUORESCENCIA DE LA CLOROFILA PARA LA ESTIMACIÓN DEL VIGOR, RENDIMIENTO Y POTENCIAL ENOLÓGICO DE VIÑEDOS CON DIFERENTE ESTADO NUTRICIONAL.}

En los capítulos anteriores se han estudiado, por un lado, los efectos del estado nutricional del viñedo sobre la concentración de pigmentos foliares y los parámetros de fluorescencia de la clorofila. Por otro lado, se ha valorado la influencia del estado nutricional sobre el desarrollo vegetativo, rendimiento de las cepas y la composición de la uva. En este capítulo, se analizará la viabilidad en la utilización de las concentraciones de pigmentos foliares y los parámetros de fluorescencia de la clorofila para evaluar el comportamiento agronómico y el potencial enológico de los viñedos con diferente estado nutricional, para su aplicación en viticultura de precisión.

En numerosos trabajos se ha puesto de manifiesto que la disminución del contenido foliar de pigmento y de la actividad fotosintética asociada a la carencia de hierro (Bavaresco et al., 2005; Martín et al., 2007a) modifican la productividad del viñedo y la calidad de la uva. Por esta razón, las medidas de la fluorescencia de la clorofila, como estimadoras del rendimiento fotosintético podrían servir para estimar el potencial productivo y de calidad en viñedos afectados por clorosis férrica.

Los avances en la investigación sobre la utilización de parámetros de la fluorescencia de la clorofila para la detección de estrés nutricional en los últimos años son importantes. Así, algunos autores han mostrado resultados favorables al uso de estos parámetros como indicadores de deficiencias nutricionales en diferentes cultivos (Stark et al., 2000; Shmidts-Eiberger et al., 2002; Mallicka y Mohn 2003; Baker y Rosenqvist, 2004; Huang et al., 2004; Wang y Jin, 2005; Spáčilová y Šafránková, 2011; Martínez-Peñalver et al., 2011).

\subsection{1.- Parámetros de vigor}

De las componentes del vigor, solo el número medio de sarmientos por $\mathrm{m}^{2} \mathrm{se}$ relacionó con los pigmentos foliares medidos en cuajado, siendo la relación negativa con la concentración de antocianinas en 2009 y con el contenido en clorofila y antocianinas en 2011 (tabla 4.64).

El peso de la madera de poda se relacionó de forma positiva con la asimilación neta y la conductancia estomática en el cuajado de 2011. Además, PMS se relacionó significativamente con la asimilación neta en el cuajado de 2011 (tabla 4.64). En definitiva, los contenidos de pigmentos de las hojas tienen una mayor relación con el número de brotes de las vides, mientras que los parámetros de intercambio de gases y de la fluorescencia de la clorofila en el cuajado tienen una fuerte relación con el peso medio de los sarmientos y el peso de la madera de poda. Es comúnmente aceptado que la disminución del vigor en los suelos clorosantes (alto contenido en carbonatos) 
se puede explicar por la disminución de la capacidad fotosintética de las plantas debido a la carencia de hierro (Hurley et al., 1986; Bavaresco y Poni, 2003; Bertamini y Nedunchezhian, 2005; Bavaresco et al., 2006). Es de destacar que no se han observado regresiones significativas de las componentes del vigor con los contenidos de pigmentos de las hojas y los niveles de intercambio de gases medidos en envero, por lo que en este estudio solo serían útiles las medidas de cuajado para la estimación del vigor.

De las regresiones lineales de los parámetros de vigor de los viñedos sobre las variables de fluorescencia de la clorofila en cuajado (tabla 4.64), se pueden destacar los coeficientes de determinación significativos de PMS y NMS en 2010, y sobre todo en 2011. En cuanto a los parámetros monitorizados en el envero, se encontró una regresión lineal significativamente positiva de PMP sobre Fm, Fv y NPQ en 2010. En 2011, PMP y PMS se relacionaron significativamente de forma positiva con Fm y Fv (tabla 4.65). Cuanto mayor sea el valor de Fv, mayor será la capacidad del PSII para realizar los procesos fotoquímicos primarios $\mathrm{y}$, en consecuencia, mayor será la capacidad de asimilación de $\mathrm{CO}_{2}$ en la fotosíntesis (Baker y Rosenqvist, 2004). En el presente trabajo, el aumento del vigor de las plantas pudo ser la consecuencia de una mayor capacidad de disipación de la energía capturada por el PSII en forma de calor (apagado no fotoquímico, NPQ).

En definitiva, las medidas de fluorescencia realizadas en el estado fenológico de cuajado del fruto estimaron mejor el número medio de sarmientos por $\mathrm{m}^{2}$ mientras que el peso de la madera de poda se correlaciona mejor con las medidas en envero. Los parámetros de fluorescencia de la clorofila medidos en condiciones de iluminación son mejores indicadores del número medio de sarmientos por $\mathrm{m}^{2}$ que el contenido en clorofila foliar con coeficientes de determinación $\left(R^{2}\right)$ son claramente mayores (tabla 4.64 y 4.65). En cuanto a las medidas realizadas en el envero, solo Fm, Fv y NPQ se han relacionado con el peso de la madera de poda y el peso medio de los sarmientos.

Los contenidos de carbonatos totales del suelo y los niveles de $\mathrm{K}, \mathrm{Mg}$ y $\mathrm{Mn}$ se han relacionado significativamente con el contenido en clorofila foliar (ejercen una importante influencia en la afección de la clorosis férrica) y los parámetros de fluorescencia de la clorofila, tal como se ha descrito en los epígrafes 4.2 .1 y 4.3.1. El peso de la madera de podase ha relacionado también de forma negativa con el contenido en carbonatos totales y positiva con el nivel nutricional de potasio en el año 2011, tal y como se ha descrito en el capítulo anterior. Los suelos clorosantes de la zona se caracterizan por tener un elevado contenido en carbonatos totales y un alto porcentaje de arcilla, lo que está relacionado a su vez con un nivel de $\mathrm{K}$ alto en el suelo. De hecho, en el apartado 4.3.1., se han observado relaciones negativas del contenido de carbonatos totales y positivas del $\mathrm{K}$ presente en el suelo con An, Fm, Fv, Fv/Fm y Fo/Fv en el cuajado.

La figura 4.24 muestra el primer plano factorial del análisis de componentes principales (ACP) realizado con los parámetros de la fluorescencia de la clorofila medidos en envero. Se representan las variables y las subzonas con peso de la madera de poda alto y bajo. 
En 2009, los ejes de los dos primeros componentes principales explican el $88,07 \%$ de la variación. La componente principal 1 (64,25\%) mostró una correlación negativa con $\mathrm{qP}, \mathrm{NPQ}$ y Fo/Fv y una correlación positiva con el resto de variables. La componente principal 2 mostró una correlación positiva con qP y ФPSII y una correlación negativa con Fo/Fv.

En 2010, las dos primeras componentes principales explicaron el $79,24 \%$ de la variación. La componente principal $1(51,17)$ se correlacionó positivamente con las variables de fluorescencia Fo, Fo/Fv, Fs/Fo, Fo', Fm', Fv', Fv'/Fm', Fs y ФPSIl y negativamente con el resto. La componente principal 2 mostró una correlación positiva con Fv/Fm y qP y negativa con Fo y Fo/Fv.

En 2011, los ejes de los dos primeros componentes principales explican el $77,09 \%$ de la variación. La componente principal 1 (56,31\%) mostró una correlación positiva con la mayoría de las variables de la fluorescencia y una correlación negativa con Fo, NPQ y Fo/Fv. La componente principal 2 mostró correlación positiva con qP y una correlación negativa con Fo y Fo/Fv.

En general, la componente principal 1 mostró una correlación negativa con qP, $\mathrm{NPQ}$ y Fo/Fv y una correlación positiva con el resto de variables. La componente principal 2 mostró una correlación positiva con qP y una correlación negativa con Fo/Fv en los tres años de estudio.

El análisis de componentes principales realizado a partir de los parámetros de fluorescencia de la clorofila medida en el envero, ha permitido, en el año 2011, una discriminación clara de grupos de observaciones en función del vigor (peso de la madera de poda) de los viñedos (figura 4.24). Sin embargo, los gráficos de 2009 y 2010 mostraron una alta dispersión, sin poder discriminarse grupos en función del rendimiento alto o bajo de los viñedos. Estos limitados resultados, se han dado probablemente por la poca variabilidad del peso de la madera de poda registrada en 2009 y principalmente en 2010, con valores anormalmente bajos. Estas oscilaciones interanuales en el peso de la madera de poda del viñedo se deberían, en gran medida, a la variabilidad de las condiciones meteorológicas en las tres campañas de estudio (apartado 3.2.3). En general, en el año 2011 se observaron unas precipitaciones y temperaturas más apropiadas para el desarrollo de las plantas que en las otras dos campañas, sin registrarse accidentes meteorológicos de ningún tipo. En el año 2011, el grupo de observaciones correspondientes a las subzonas con un vigor alto se distinguió por tener mayores niveles de Fo y Fo/Fv y menores de qP y NPQ. El grupo de observaciones correspondientes a las subzonas con un vigor bajo se distinguió por tener mayores niveles de Fm, Fv, Fv/Fm, ФPSII y ETR y menores de Fo', Fm', Fv', Fv'/Fm', Fs y Fs/Fo.

El estudio de las regresiones del peso de la madera de poda y sus componentes sobre los contenidos en pigmentos foliares y la asimilación neta medidos en cuajado y los parámetros de la fluorescencia de la clorofila medidos en condiciones de iluminación en cuajado y Fm y Fv en envero, nos permiten concluir que dichos parámetros pueden ser una buena herramienta para estimar el crecimiento de las plantas con diferente estado nutricional, siempre que exista una variabilidad suficiente. 

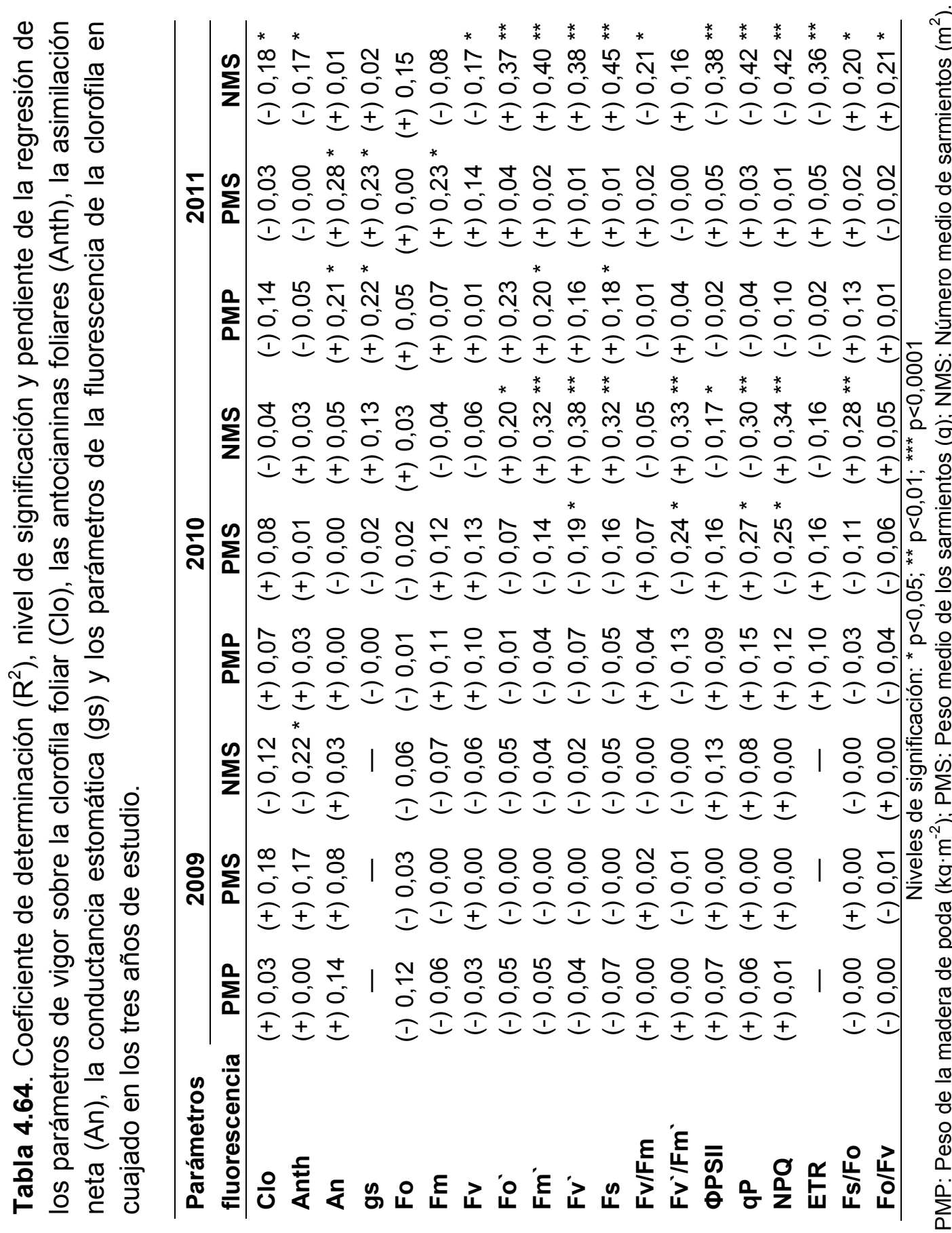


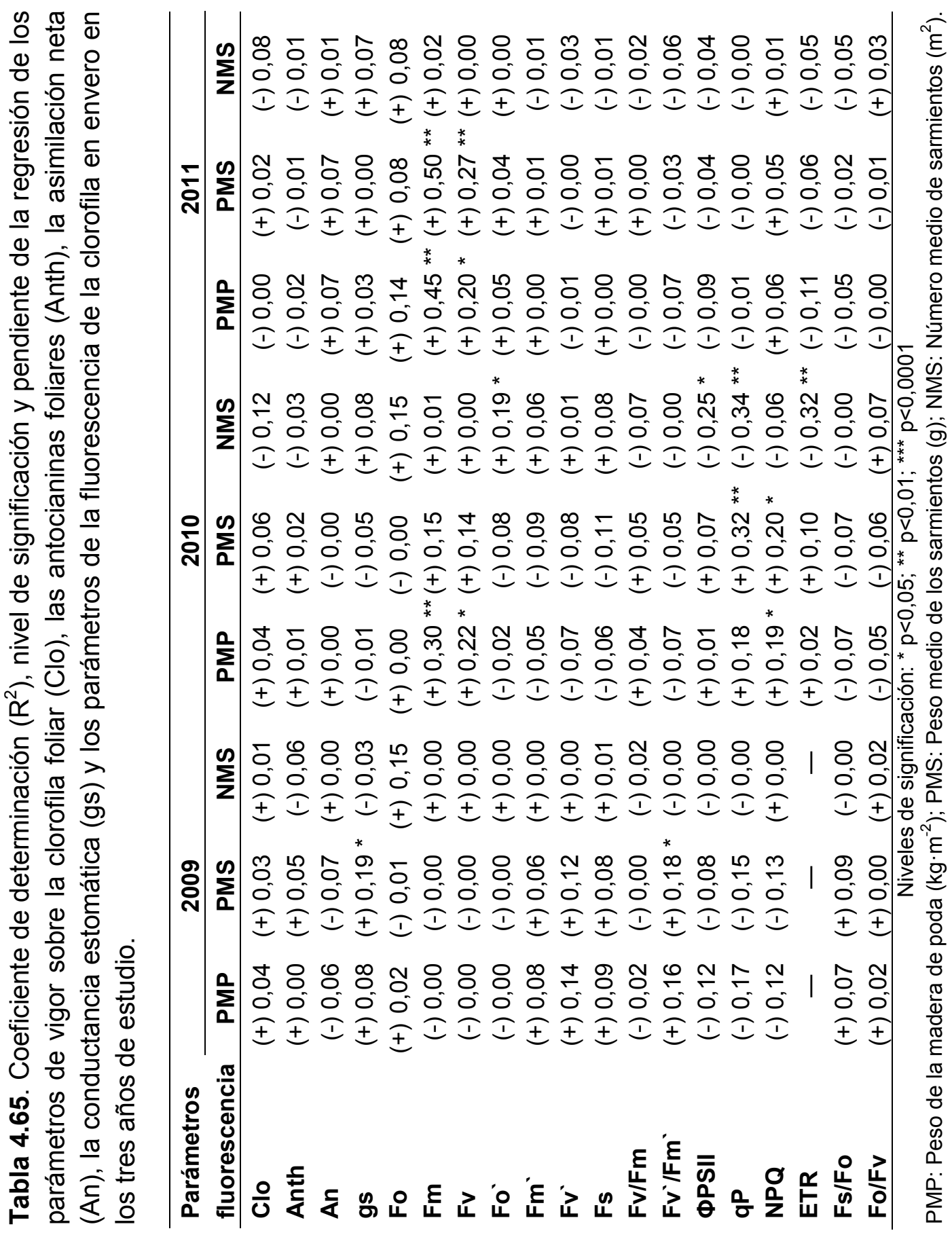



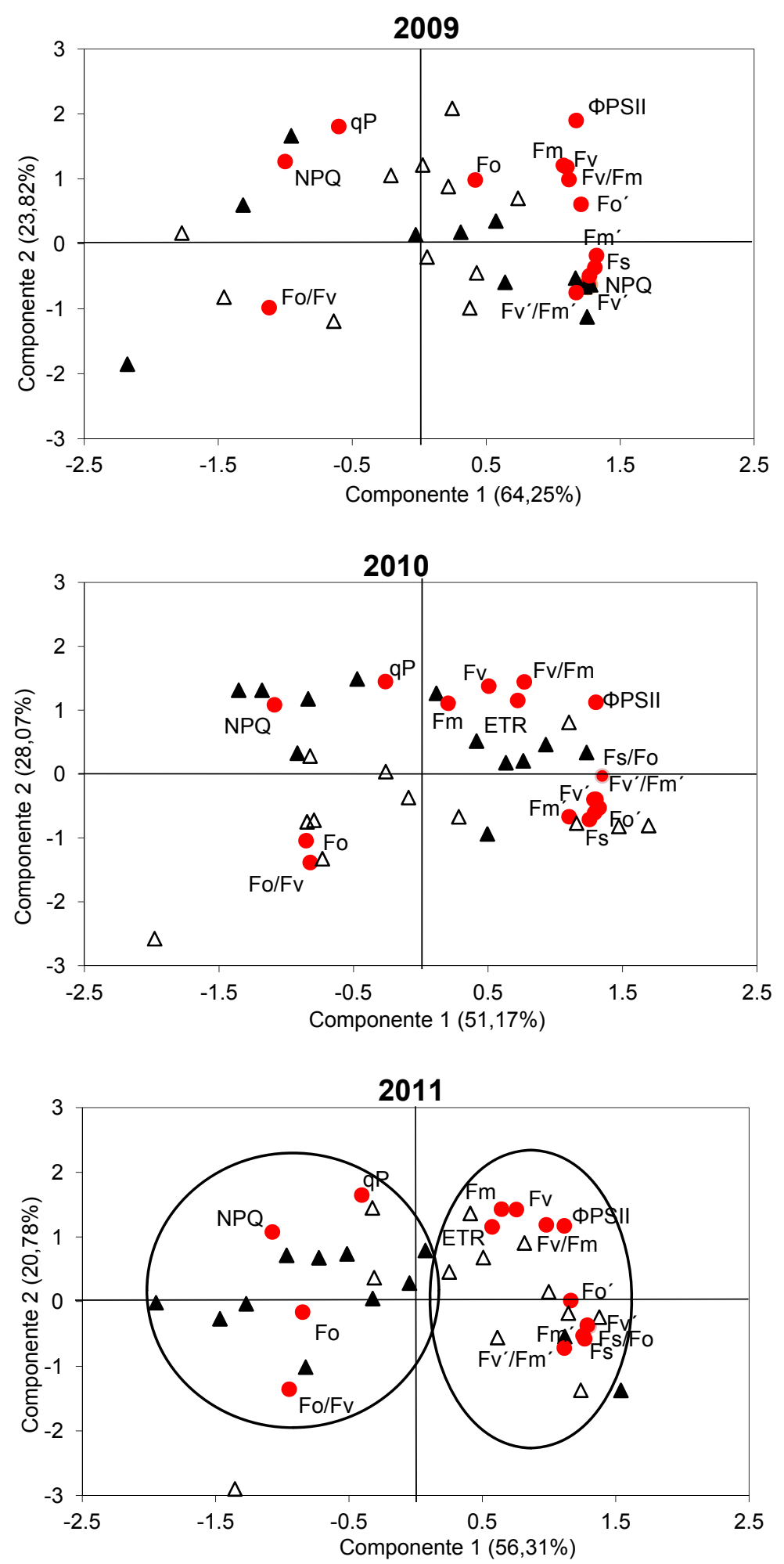

Figura 4.24. Primer plano factorial del análisis de componentes principales realizado con los datos de las variables de fluorescencia de la clorofila en el envero de los viñedos en el conjunto de las zonas de estudio en los tres años de seguimiento. Los círculos rojos representan los parámetros de fluorescencia de la clorofila en el envero, los triángulos negros representan las áreas de muestreo con alto crecimiento de madera de poda y los triángulos en blanco representan las áreas de muestreo con bajo crecimiento de madera de poda, utilizando la mediana como límite de peso. 


\subsection{2.- Parámetros de rendimiento}

Se ha relacionado de forma positiva el rendimiento con los contenidos foliares en clorofila y antocianinas en cuajado y en envero en el año 2011 (tablas 4.66 y 4.67). Además, se ha observado una regresión lineal positiva de PMR y P100 sobre el contenido en clorofila y antocianinas foliares en cuajado y envero de 2011. También se han encontrado relaciones significativas de la fertilidad de las yemas sobre la concentración foliar de antocianinas, pero no sobre la concentración de clorofila. Numerosos autores han observado reducciones importantes del rendimiento de viñedos asociada a la clorosis férrica (Gruber y Kosegarten, 2002; Bertamini y Nedunchezhian, 2005; Bavaresco y Poni, 2003; Bavaresco et al., 2006, 2010; Martín et al., 2008). Bavaresco et al. (2005)indicaron que la clorosis afecta negativamente la productividad, reduciendo el número de racimos por planta, el peso del racimo y el tamaño de la baya en comparación con las condiciones de crecimiento normales. El hecho de que solo en el año 2011 se hayan observado relaciones significativas se pueden deber, en gran medida, a la poca variabilidad los rendimientos en las otras dos campañas, donde estuvieron limitados básicamente por limitaciones en el régimen hídrico (apartado 3.2.3).

El rendimiento y sus componentes se relacionaron de forma negativa con An en el cuajado en el año 2009y con gs en el cuajado de 2010 (tabla 4.66). Sin embargo, el rendimiento en 2009, P100 en 2009 y 2011, y RPS en 2010 se relacionaron de manera positiva con An medida en envero (tabla 4.67). Es comúnmente aceptado que la disminución en el rendimiento de las plantas cultivadas en los suelos clorosantes (alto contenido en carbonatos) se puede explicar por la disminución de la capacidad fotosintética de las plantas debido a la carencia de hierro (Hurley et al., 1986; Bavaresco y Poni, 2003; Bertamini y Nedunchezhian, 2005; Bavaresco et al., 2006). Sin embargo, en este estudio, en el cuajado se ha producido el efecto contrario, aunque en el envero niveles mayores de asimilación neta han producido mayores rendimientos.

En cuanto a los parámetros de la fluorescencia de la clorofila, en el año 2009 el rendimiento se ha relacionado con ФPSIl en el cuajado y con Fm', Fv', Fs, Fv'/Fm', ФPSIl y qP en el envero. En el año 2011, el rendimiento se relacionó con Fo, Fv, Fm', Fs, qP, Fv/Fm y Fo/Fven el cuajado y Fo, Fv/Fm, Fv'/Fm', ФPSII, ETR y Fo/Fv en el envero (tablas 4.66 y 4.67). No se han encontrado regresiones significativas en el año 2010.

Como se ve en la tabla 4.66, P100 se ha relacionado significativamente con varios de los parámetros de la fluorescencia de la clorofila monitorizados en el cuajado los tres años de seguimiento, destacando Fo, Fv/Fm y Fo/Fv. Además, coincidiendo con la concentración de clorofila y antocianinas, es de destacar el gran número de regresiones lineales significativas de PMR, P100 y RPS sobre la mayoría de los parámetros de la fluorescencia en el año 2011. Resultados similares a los obtenidos en las medidas de cuajado se han obtenido para los parámetros de fluorescencia medidos en el envero para los años 2009 y 2011, no encontrando ninguna relación significativa en el año 2010 (tabla 4.67). Así, las relaciones significativas de las 
componentes del rendimiento fueron positivas con Fv/Fm, ФPSII, qP y ETR y negativas con Fo y Fo/Fv. Con los datos de 2011, los parámetros de la fluorescencia de la clorofila en cuajado Fo $\left(R^{2}=0,34 ; p<0,01\right)$, Fv/Fm $\left(R^{2}=0,38 ; p<0,01\right)$ y Fo/Fv $\left(R^{2}=0,36 ; \quad p<0,01\right)$ fueron mejores variables para estimar el rendimiento y sus componentes que el contenido foliar en clorofila $\left(R^{2}=0,21 ; p<0,05\right)$. Dichos parámetros de fluorescencia estiman mejor las componentes $P 100\left(R^{2}=0,55 ; p<0,01\right.$ para Fo; $R^{2}=0,41 ; p<0,01$ para $F v / F m ; R^{2}=0,42 ; p<0,01$ para Fo/Fv) y $P M R\left(R^{2}=0,51 ; p<0,01\right.$ para Fo; $R^{2}=0,58 ; p<0,01$ para $F v / F m ; R^{2}=0,56 ; p<0,01$ para $F o / F v$ ) que el rendimiento total $\left(R^{2}=0,34 ; p<0,01\right.$ para Fo; $R^{2}=0,38 ; p<0,01$ para $F v / F m ; R^{2}=0,36 ; p<0,01$ para Fo/Fv). Estos resultados confirman que las diferencias de productividad observadas entre subzonas se deben fundamentalmente al efecto de la clorosis férrica sobre el rendimiento del fotosistema II.

Como se ha descrito en el capítulo anterior, el rendimiento y sus componentes se han relacionado de forma positiva con el contenido de $\mathrm{K}$ y de $\mathrm{Mn}$ en el suelo y de forma negativa con la concentración de Mn peciolar. El contenido en potasio y el manganeso presente en el suelo y los peciolos se han relacionado significativamente con la concentración de clorofila de la hoja. La nutrición potásica afecta tanto a la absorción de la luz como a su aprovechamiento en el PSIl debido a que la concentración de clorofila foliar disminuye en respuesta a la limitación de $\mathrm{K}$ (Watson y Malmberg, 1996; Chen y Cheng, 2003). La intensidad de la clorosis férrica se manifiesta en la zona de estudio en una mayor acumulación de manganeso en los peciolos (Martín et al., 2008), siendo este un elemento que juega un papel importante en la fertilidad de las yemas y el cuajado de los frutos (Bavaresco et al., 2010b). Además, en el capítulo 4.3.1., se han establecido relaciones del $\mathrm{K}$ presente en el suelo con Fm, Fv, Fv/Fm, ФPSIl y qP y negativas con Fo y Fo/Fv y de la concentración de $\mathrm{Mn}$ en el suelo y en los peciolos con Fo, Fv/Fm y Fo/Fv. La fuerte influencia de ambos minerales en la afección de la carencia nutricional de hierro en los suelos clorosantes propios de la zona, hace que estos parámetros relacionados conel nivel de fluorescencia cuando $Q_{A}$ está oxidada al máximo (los centros de reacción del fotosistema II están abiertos, Fo), el nivel de la eficiencia máxima del fotosistema II (Fv/Fm),la eficiencia con la que la luz absorbida por las antenas del fotosistema II es convertida en energía química (ФPSII), el apagado fotoquímico (proporción de los centros de reacción del fotosistema II que están abiertos. Relaciona la máxima eficiencia del fotosistema II con la eficiencia a la que opera, qP) y la actividad del complejo de oxidación del agua en el donador de electrones del PSII (Fo/Fv) posean un gran potencial como medidas de estimación del rendimiento de las plantas.

El índice de Ravaz se relacionó significativamente con Fo, ФPSIl y qP en cuajado de 2009 y 2011, y con Fo, ФPSIl y ETR en envero de 2011.

La figura 4.25 muestra el primer plano factorial análisis de componentes principales (ACP) realizado con los parámetros de la fluorescencia de la clorofila medidos en envero. Se representan las variables y las subzonas con rendimiento alto y bajo. Se puede observar que con dos componentes principales se explica el $88 \%$ de la variación en 2009, el 79\% en 2010 y el $77 \%$ en 2011 . 
El ACP ha permitido en el año 2011 una discriminación clara de grupos de observaciones en función del rendimiento del viñedo (figura 4.25). Sin embargo, los gráficos de 2009 y 2010 mostraron una alta dispersión, sin poder discriminarse grupos en función del rendimiento. Estos resultados se han dado, probablemente, por la poca variabilidad del rendimiento en 2009 y 2010, con valores anormalmente bajos. En el año 2011, el grupo de observaciones correspondientes a las subzonas con rendimientos bajos se distinguió por tener mayores niveles de Fo y Fo/Fv y menores de $\mathrm{qP}$ y NPQ. El grupo de observaciones correspondientes a las subzonas con rendimientos altos se distinguió por tener mayores niveles de Fm, Fv, Fv/Fm, ФPSIl y ETR y menores de Fo', Fm', Fv', Fv'/Fm', Fs y Fs/Fo.

Como se ha descrito en el apartado 4.4.1., el rendimiento en las parcelas no afectadas por clorosis férrica en el año 2011 fue 1,9 veces mayor que en 2009 y 4,5 veces mayor que en 2010. Las relaciones entre parámetros de fluorescencia y rendimientos fueron más intensas en 2011 que en los otros dos años, cuando la capacidad productiva de las plantas estuvo más limitada por el déficit hídrico que por la incidencia de la clorosis férrica. Esto sugiere que en años donde haya suficiente variabilidad en el rendimiento, sin que existan otros factores limitantes, los parámetros $\mathrm{Fo}, \mathrm{Fv} / \mathrm{Fm}$ y $\mathrm{Fo} / \mathrm{Fv}$ podrían ser útiles en viticultura de precisión para hacer una estimación temprana del potencial productivo en viñedos afectados por clorosis férrica. 


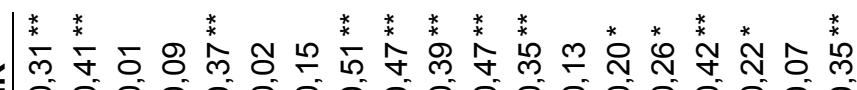

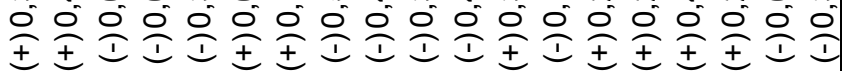

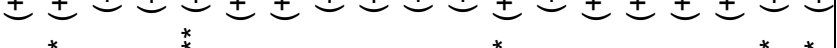

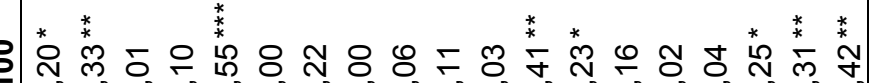

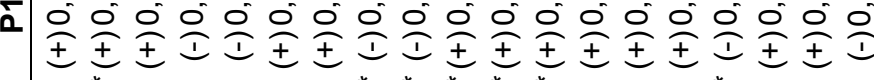
ก

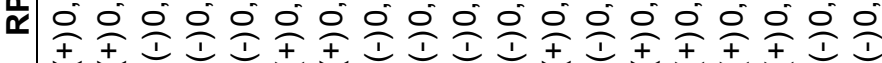

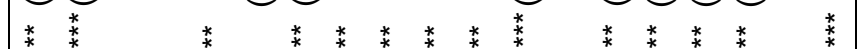

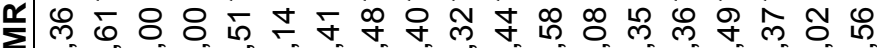

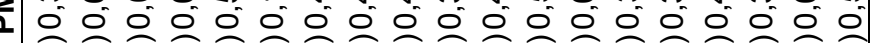

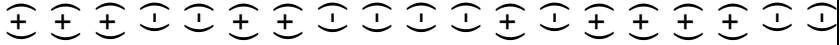

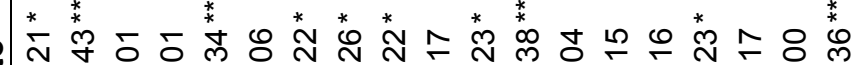

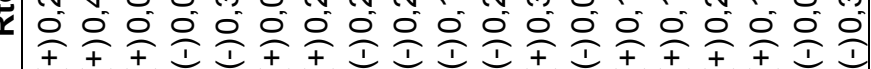

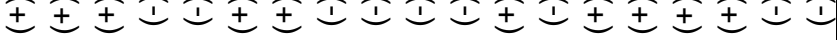
๓

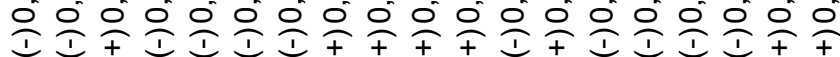

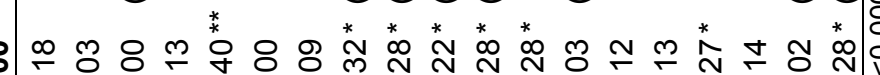

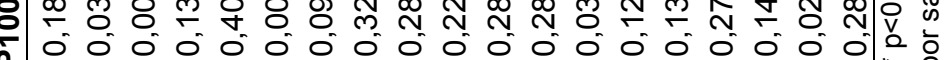

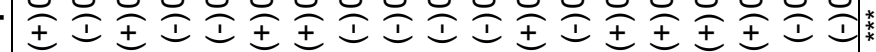

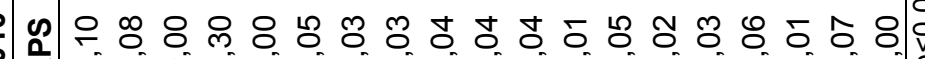

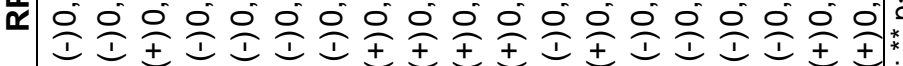

승 \& \&

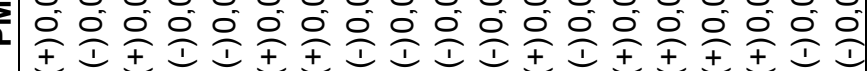

๑ రิ

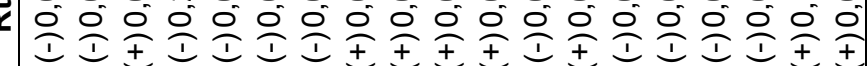
ธ

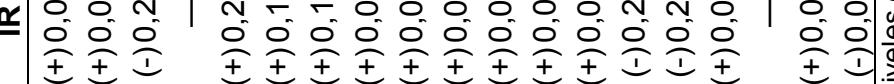

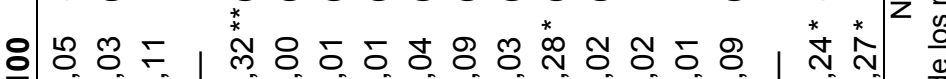

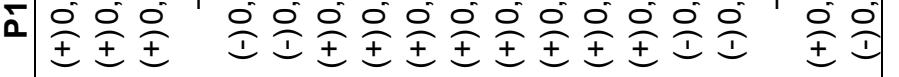

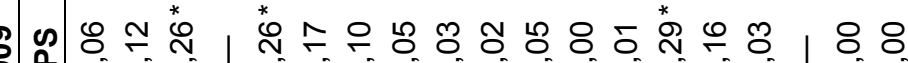

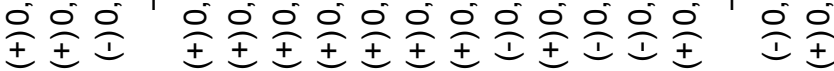
น ธ

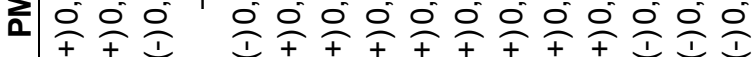

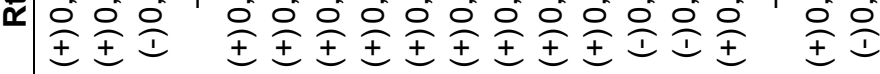

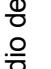
, 


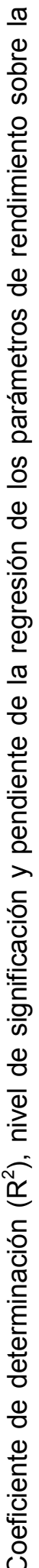

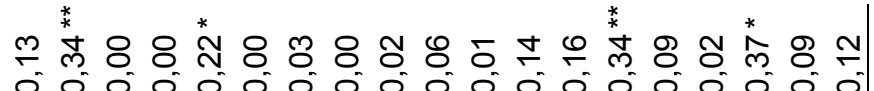

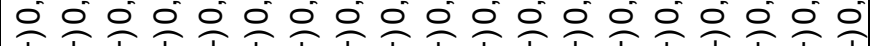

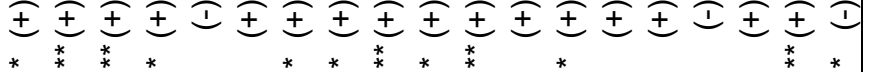

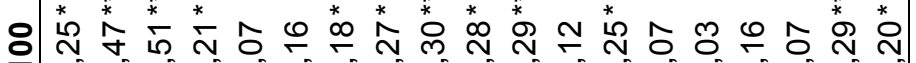

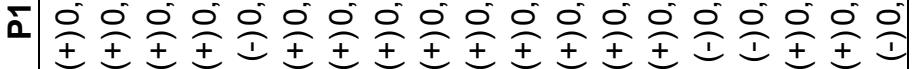

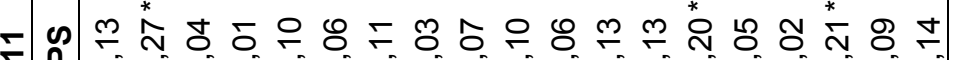

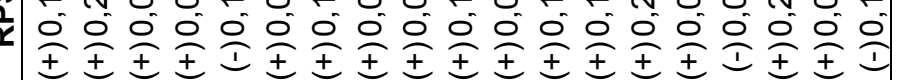
$\pm$

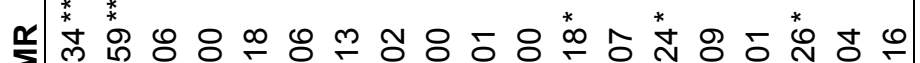

$\sum_{\mathbf{L}}$

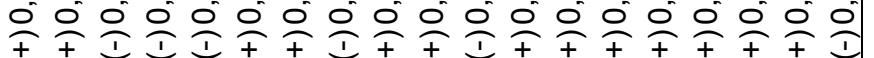
工*

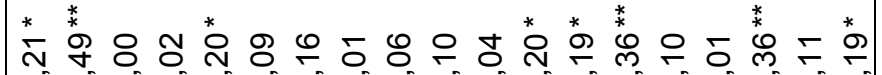

ฯ

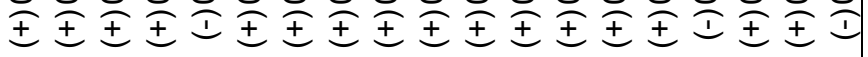

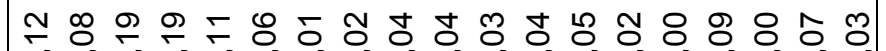

$\underline{\underline{x}}$

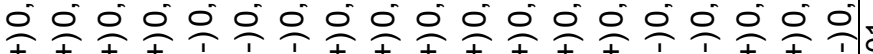

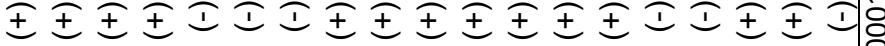

○ ผูก

¿

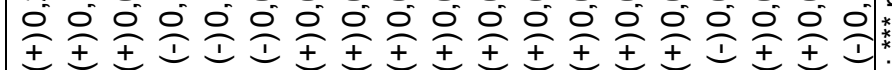
i-

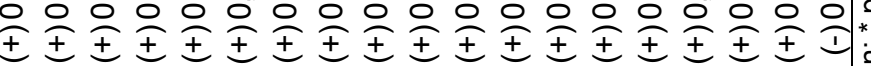

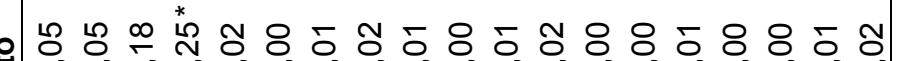

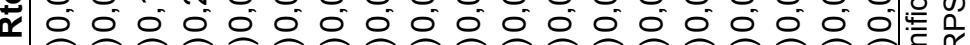

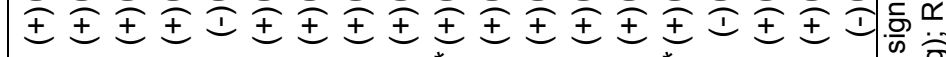

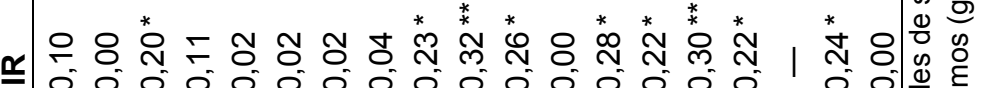

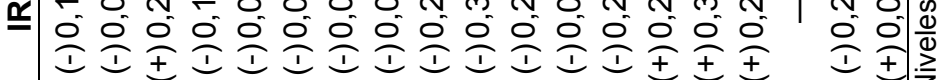

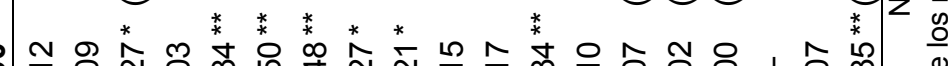

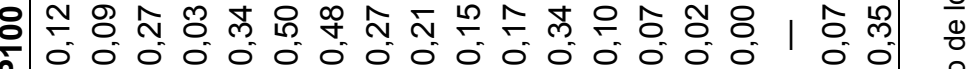

$\underline{1}$

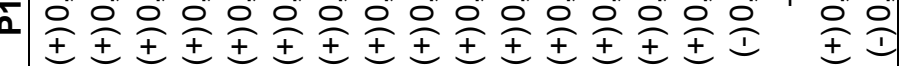

$\stackrel{0}{0}$

응 $\frac{-0}{\overline{0}}$

(⿻)

垔

$\underset{ \pm}{\frac{D}{\sigma}}$

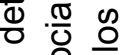

๑) 응

站

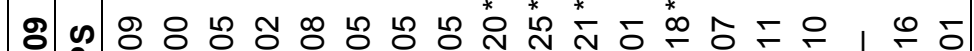

กิ

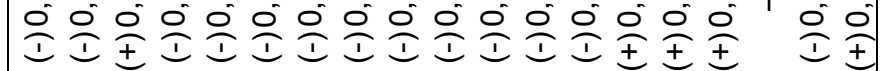

드 8 ㅇㅇㅇ \& 8 б

$\sum_{2}$

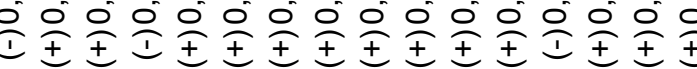

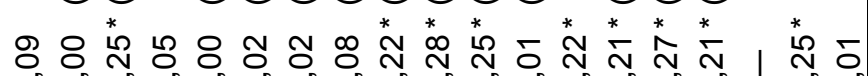

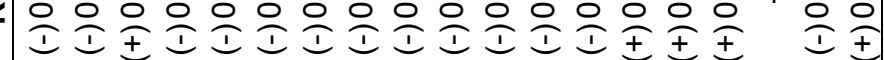

U

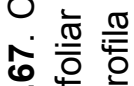

$\dot{+}$

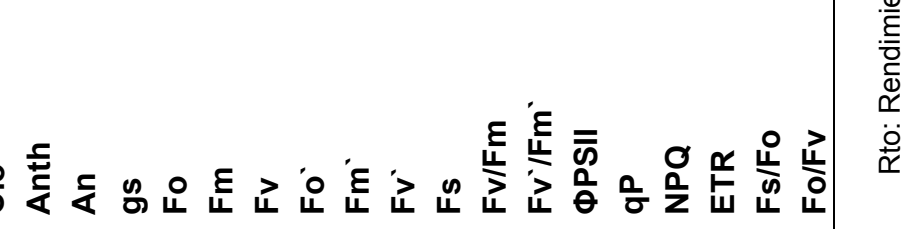



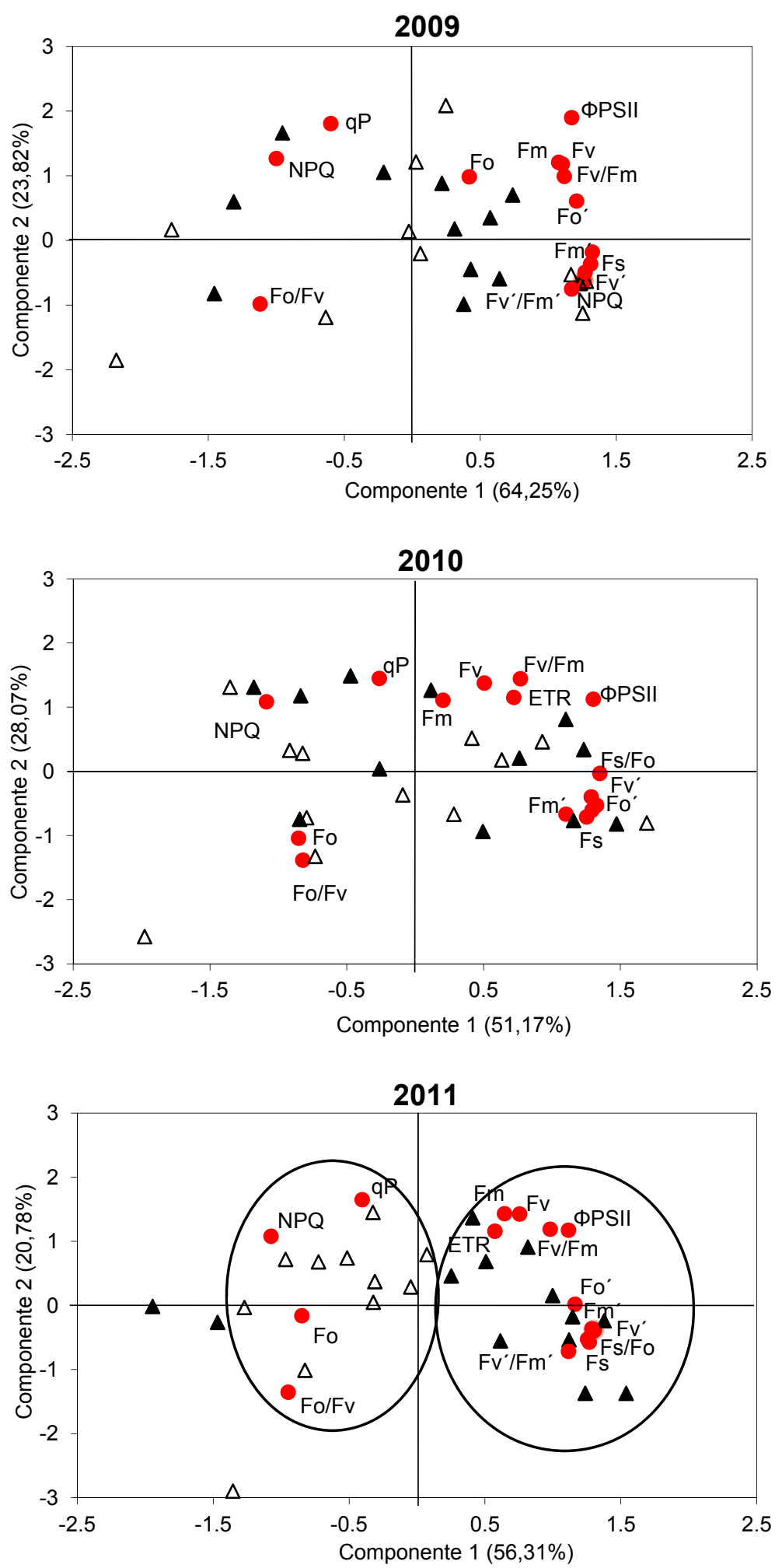

Figura 4.25. Primer plano factorial del análisis de componentes principales realizado con los datos de las variables de fluorescencia de la clorofila en el envero de los viñedos en el conjunto de las zonas de estudio en los tres años de seguimiento. Los círculos rojos representan los parámetros de fluorescencia de la clorofila en el envero, los triángulos negros representan las áreas de muestreo con alto rendimiento y los triángulos en blanco representan las áreas de muestreo con bajo rendimiento, utilizando la mediana como límite de peso. 


\subsection{3.- Composición del mosto}

La limitación en la producción y la dificultad en la maduración de las uvas en las plantas cloróticas, está provocada principalmente por una reducción en la capacidad asimiladora de la planta, a causa de la alteración de la estructura y las funciones del aparato fotosintético (Tagliavini y Rombolà, 2001; Pestana et al., 2003). Por esta razón es interesante el análisis de la relación de la composición del mosto con los contenidos en pigmentos foliares y los parámetros de la fluorescencia de la clorofila, que podrían ser medidas potencialmente interesantes para la estimación del potencial enológico de los viñedos.

En el año 2011, se han relacionado el IPT, pH, SST y el contenido de $\mathrm{K}$ de los mostos siempre de forma negativa con los contenidos foliares en clorofila y antocianinas en cuajado y en envero. Sin embargo, no se encontraron relaciones significativas en los años 2009 y 2010 (tablas 4.68 y 4.69), debido probablemente a la escasa variabilidad registrada a consecuencia de las condiciones generalizadas de estrés hídrico producidas en el área de estudio en estas dos campañas (apartado 3.2.3). Hay que tener en cuenta que en 2011 el rendimiento medio del conjunto de las subparcelas fue sensiblemente mayor que en los otros dos años, cuando la capacidad productiva de las plantas estuvo más limitada por el déficit hídrico que por la incidencia de la clorosis férrica.

AT se ha relacionado de forma positiva con gs medida en el envero de 2009 y de forma negativa con An en el envero de 2010. El IPT, pH y el contenido en $\mathrm{K}$ del mosto se relacionaron de forma positiva con gs, sólo en el cuajado de 2011 (tabla 4.81). Sin embargo, el IPT, $\mathrm{pH}$ y SST se han relacionado de manera negativa con An y gs medidas en envero de 2011 (tabla 4.69). Por el contrario, como se ha explicado en el apartado anterior, los parámetros de asimilación neta y conductancia estomática se han relacionado con el rendimiento y sus componentes de forma negativa en cuajado y de forma positiva en envero. En este estado fenológico, niveles mayores de An han producido mayor rendimiento y tamaño de la baya, lo que ha reducido la proporción hollejo/pulpa, y así la proporción en peso de polifenoles y contenido en K. La clorosis férrica al disminuir el tamaño de las bayas podría contribuir a incrementar su contenido fenólico, aunque la carencia afecta negativamente de algún modo a la biosíntesis de compuestos fenólicos (Bavaresco et al., 2005). Bavaresco y Poni (2003) observaron que los contenidos en sólidos solubles del mosto cv. Aurora se incrementaban en condiciones de estrés nutricional en suelos calizos.

Como se observa en las tablas 4.68 y 4.69 , apenas se encontraron regresiones lineales significativas de componentes del mosto analizados en 2009 y 2010 sobre los parámetros de la fluorescencia de la clorofila en cuajado y envero. En el año 2011, cabe destacar las relaciones significativas de IPT, SST y el contenido de $\mathrm{K}$ con Fo, Fv/Fm y Fo/Fv en cuajado, y el IPT, AT y SST con Fo', Fm', Fv', Fs, NPQ y Fs/Fo en envero (tablas 4.68 y 4.69). En la campaña de 2011, coincide el mayor número de regresiones significativas de las variables de composición del mosto sobre los parámetros de la fluorescencia de la clorofila con los mayores valores medios de SST e IPT de las tres campañas (tabla 4.46). 
Se observaron relaciones significativas de variables de composición del mosto con parámetros de fluorescencia medidos en hojas adaptadas a la oscuridad durante el cuajado, mientras que en envero, las relaciones más claras se dieron con los parámetros de fluorescencia medidos en hojas adaptadas a la luz. En este contexto, Bertamini et al. (2002), Bavaresco et al. (2006), Martín et al. (2007a), Catalina et al. (2010, 2011a) han relacionado el contenido foliar de clorofila en el cuajado del fruto, que reflejaría la presencia o no de síntomas iniciales de clorosis férrica, con las medidas de fluorescencia de la clorofila obtenidas en condiciones de oscuridad. Por otra parte, Flexas et al. (2002a, 2002b) y Catalina et al. (2011a) relacionaron el estado hídrico de las plantas con parámetros de la fluorescencia de la clorofila medidos en hojas adaptadas a la luz, y no con Fv/Fm. Según Baker y Rosenqvist (2004), el estrés hídrico no tiene gran impacto sobre la eficiencia del fotosistema II. Así pues, la clorosis férrica y el estrés hídrico afectan de forma diferente a los parámetros de fluorescencia, que podrían utilizarse para el seguimiento en campo de ambos tipos de estrés.

En definitiva, los parámetros que mejor estiman las variables de composición del mosto son los contenidos en clorofila y antocianinas foliares tanto en cuajado como en envero, Fo, Fv/Fm y Fo/Fv monitorizadas en cuajado y Fo', Fm', Fv', Fs, NPQ y Fs/Fo medidas en envero. Sin embargo, aún siendo en general similares los coeficientes de determinación $\left(R^{2}\right)$ de las regresiones, sobresale de todas ellas la relación observada entre las antocianinas foliares en envero con IPT $\left(R^{2}=0,66\right.$; $p<0,0001)$ y SST $\left(R^{2}=0,46 ; p<0,01\right)$ en 2011 , por lo que dicho parámetro podría ser la mejor herramienta para estimar el contenido fenólico y el contenido en sólidos solubles de los mostos. Meggio et al. (2010) sugirieron que el aumento del contenido de antocianinas en condiciones de sequía, altas temperaturas o deficiencias de micronutrientes es un buen indicador de las dificultades de maduración fenólica de la vid afectadas por clorosis férrica.

Como se ha descrito en el capítulo anterior, las variables IPT, $\mathrm{pH}$ y SST de los mostos se han relacionado de forma positiva con el contenido en carbonatos totales del suelo y la concentración de $\mathrm{Mn}$ peciolar, y de forma negativa con el contenido de $\mathrm{K}$ $\mathrm{y}$ de $\mathrm{Mn}$ en el suelo. El contenido en carbonatos totales, $\mathrm{K}$ y $\mathrm{Mn}$ presente en el suelo y la concentración de $\mathrm{Mn}$ de los peciolos se han relacionado significativamente con la concentración de clorofila de la hoja. En los suelos clorosantes propios de la zona (elevado contenido en carbonatos totales), la intensidad de la clorosis férrica se manifiesta en una mayor acumulación de Mn en los peciolos (Martín et al., 2008) Además, en el capítulo 4.3.1, se han establecido relaciones significativas del contenido en carbonatos totales y de la concentración de $\mathrm{Mn}$ en el suelo y en los peciolos con Fo, Fv/Fm y Fo/Fv monitorizadas en cuajado y con los parámetros de la fluorescencia en hojas adaptadas a la luz en los años 2009 y 2011.

En el análisis de componentes principales realizado a partir de los parámetros de fluorescencia de la clorofila medidos en el envero (figura 4.26) se puede observar que con dos componentes principales se explica el $88 \%$ en 2009 , el $79 \%$ en 2010 y el $77 \%$ en 2011 de la variación. Los gráficos mostraron una alta dispersión, sin poder discriminarse grupos de subzonas en función de los valores de SST del mosto de vendimia. 
Los resultados presentados en la campaña de 2011 nos permiten pensar que los parámetros de la fluorescencia de la clorofila pueden ser una buena herramienta para estimar variables de composición del mosto, en viñedos con diferente estado nutricional, en años donde la variabilidad entre subzonas no esté limitada por la incidencia de otros factores como el estrés hídrico. No obstante, el contenido foliar de antocianinas puede ser un mejor estimador que los parámetros de fluorescencia para el caso de IPT y SST del mosto. 


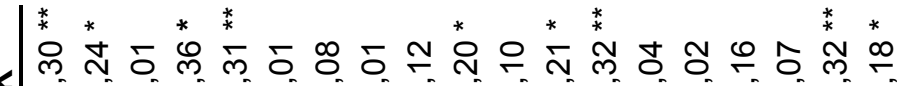

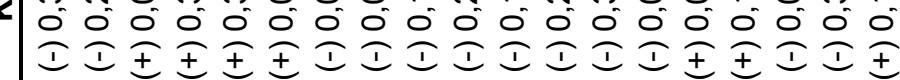

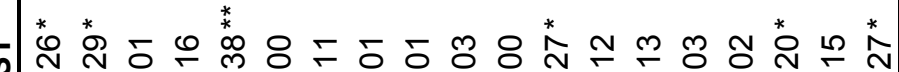

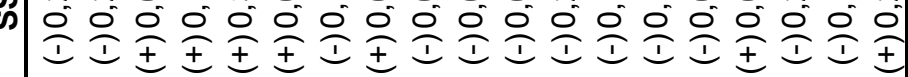
ㄷำ

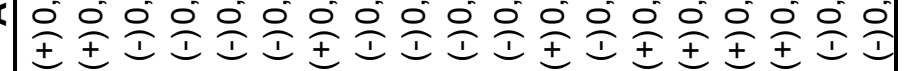

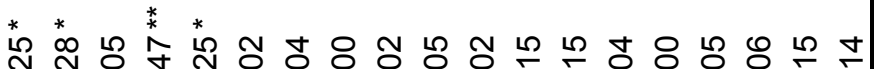

동

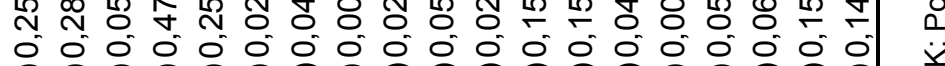

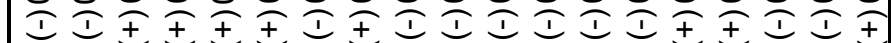
* * * * * * *

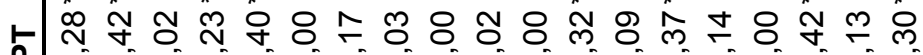

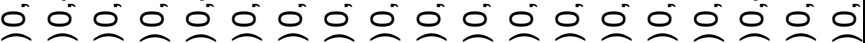

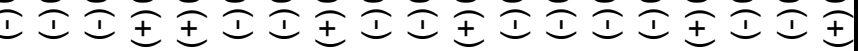

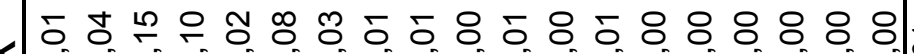

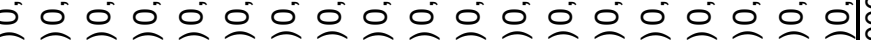

당ㅇㅇ

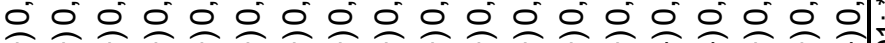

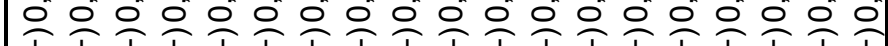

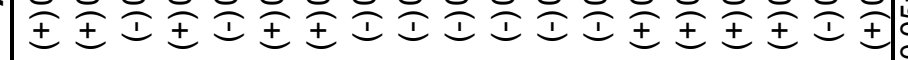

I

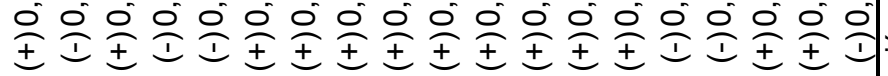

ำ น

0000000000000000000.

ป

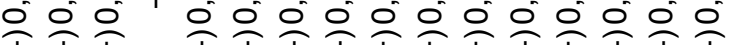

8 8 \% I กำก

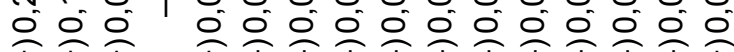

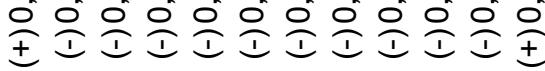

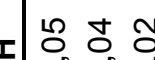




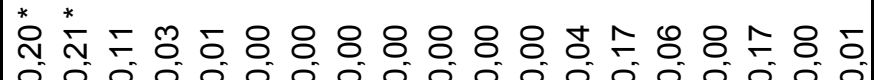

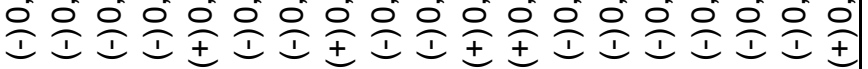

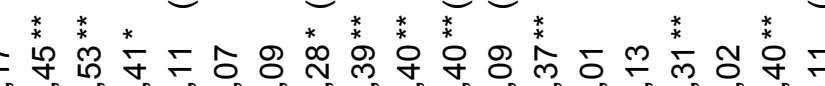

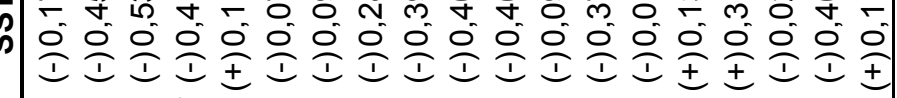

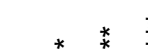

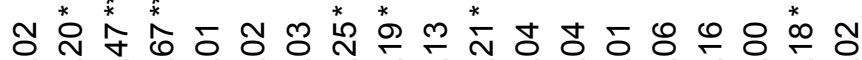

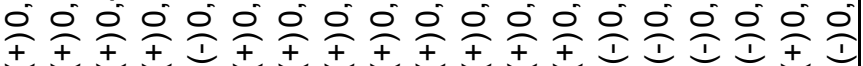
然

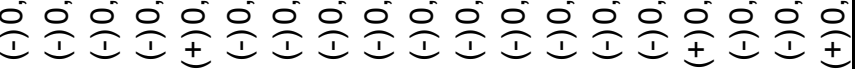
* * * *

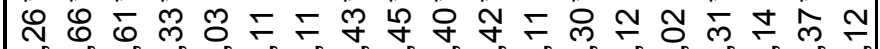

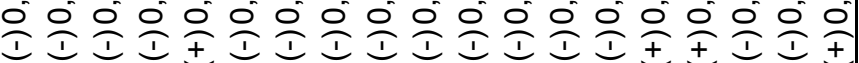
8 \&

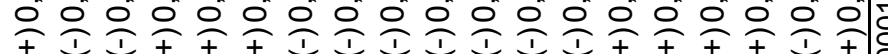

8 응 웡

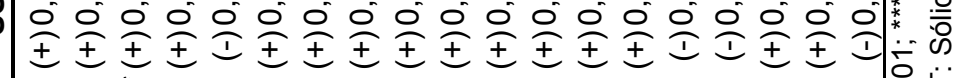

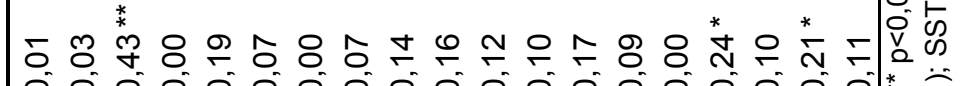

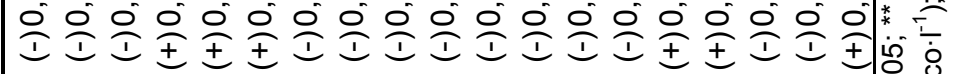
m O.

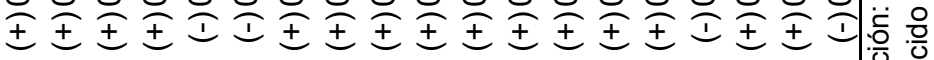

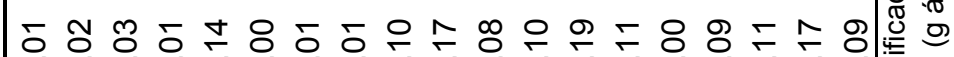

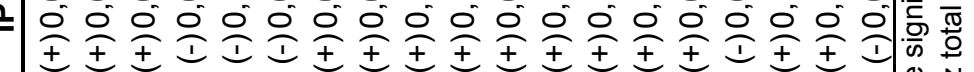

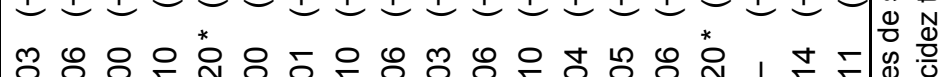
$x$ o

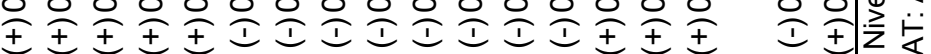

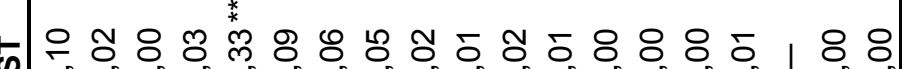

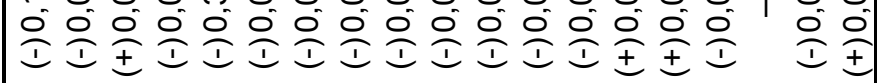

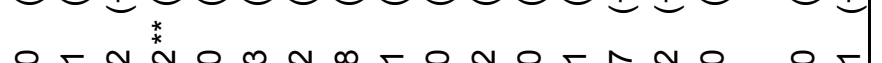
두 ำ

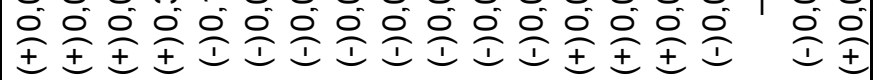

ธ 8 ○ 8 \&

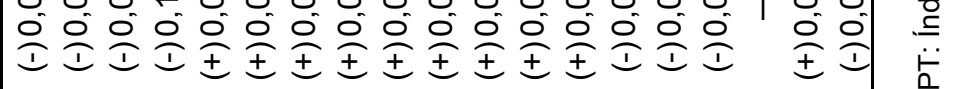
ชั

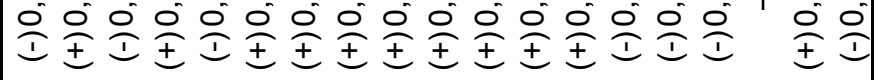
은 王定名 

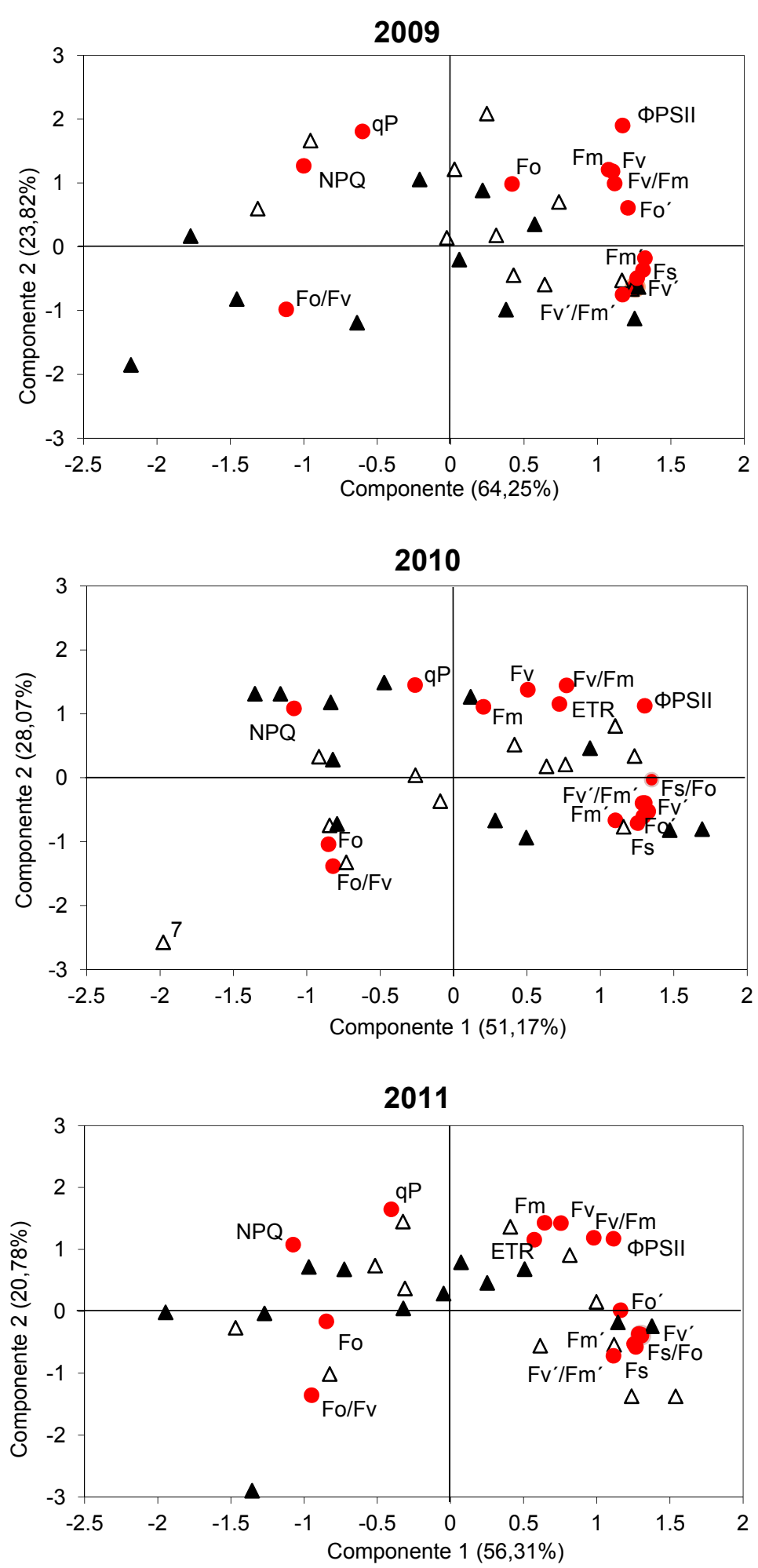

Figura 4.26. Primer plano factorial del análisis de componentes principales realizado con los datos de las variables de fluorescencia de la clorofila en el envero de los viñedos en el conjunto de las zonas de estudio en los tres años de seguimiento. Los círculos rojos representan los parámetros de fluorescencia de la clorofila en el envero, los triángulos negros representan las áreas de muestreo con alto SST y los triángulos en blanco representan las áreas de muestreo con bajo SST, utilizando la mediana como límite de medida. 


\subsection{4.- Características cromáticas del mosto}

En lo referente a los parámetros cromáticos del mosto, se han relacionado la luminosidad de forma positiva y la coordenada $a^{*}$ de forma negativa con los contenidos foliares en clorofila y antocianinas en cuajado y envero en el año 2011, no encontrándose relaciones significativas en los años 2009 y 2010 (tablas 4.70 y 4.71). Como se ha comentado en el apartado anterior, en los dos primeros años del estudio la variabilidad registrada de los parámetros cromáticos fue escasa a consecuencia de las condiciones generalizadas de estrés hídrico (ver epígrafe 3.2.3). En cuanto a las medidas de intercambio de gases, tanto An y gs en el envero se relacionaron significativamente con los parámetros cromáticos del mosto en2011 (tablas 4.70 y 4.71). Mayores niveles de An y gs en el cuajado aumentaron la luminosidad, el tono y la coordenada $b^{*}$ y disminuyeron la cromaticidad y la coordenada $a^{*}$. Estos resultados están de acuerdo con los de Martín et al. (2007a, 2007b) y Meggio et al. (2010), que han encontrado estrechas relaciones entre las características cromáticas de la uva y los niveles de clorofilas y otros pigmentos en hoja, en viñedos afectados por clorosis férrica.

Como se puede ver en las tablas 4.70 y 4.71 , apenas se encontraron regresiones lineales significativas de las componentes del color del mosto sobre los parámetros de la fluorescencia de la clorofila en los años 2009 y 2010. Sin embargo, en el año 2011 se dieron regresiones significativas de $L$ y $a^{*}$ sobre Fo, Fv, Fv/Fm, ФPSII, ETR y Fo/Fv monitorizadas en cuajado, y sobre Fo', Fm', Fv', Fs, NPQ y Fs/Fo medidas en envero. Estos resultados están de acuerdo con los presentados en el apartado anterior, ya que en cuajado las relaciones más destacadas se dieron con parámetros medidos en hojas adaptadas a la oscuridad, mientras que en envero las relaciones se dieron con los parámetros de la fluorescencia medida en hojas adaptadas a la luz. En este contexto, el estado nutricional y el estado hídrico de las plantas podrían afectar de forma diferente a los parámetros de fluorescencia de la clorofila, tal y como han sugerido diversos autores (Bertamini et al., 2002; Flexas et al., 2002a, 2002b; Baker y Rosenqvist 2004; Bavaresco et al., 2006; Martín et al., 2007a; Catalina et al., 2010, 2011a). Por lo tanto, los parámetros de fluorescencia podrían ser utilizados en campo para diferenciar zonas afectadas por uno u otro tipo de estrés.

A la vista de los resultados presentados, la luminosidad y la relación rojos/verdes son las variables cromáticas que mejor podrían ser estimadas por las medidas de fluorescencia, siempre que la variabilidad fuera suficiente De los parámetros monitorizados en el cuajado, Fo $\left(R^{2}=0,48\right.$; $p<0,01$ para $L$ y $R^{2}=0,36$; $p<0,01$ para $\left.a^{*}\right)$ y ETR $\left(R^{2}=0,45 ; p<0,01\right.$ para $L$ y $R^{2}=0,43 ; p<0,01$ para $\left.a^{*}\right)$ serían los más interesantes. De los parámetros fisiológicos monitorizados en el envero, el contenido foliar en antocianinas $\left(R^{2}=0,61 ; p<0,0001\right.$ para $L$ y $R^{2}=0,46 ; p<0,01$ para $\left.a^{*}\right)$ es el parámetro que mejor estima dichas variables cromáticas, de acuerdo con los resultados observados para el IPT del mosto presentados en el apartado anterior. 


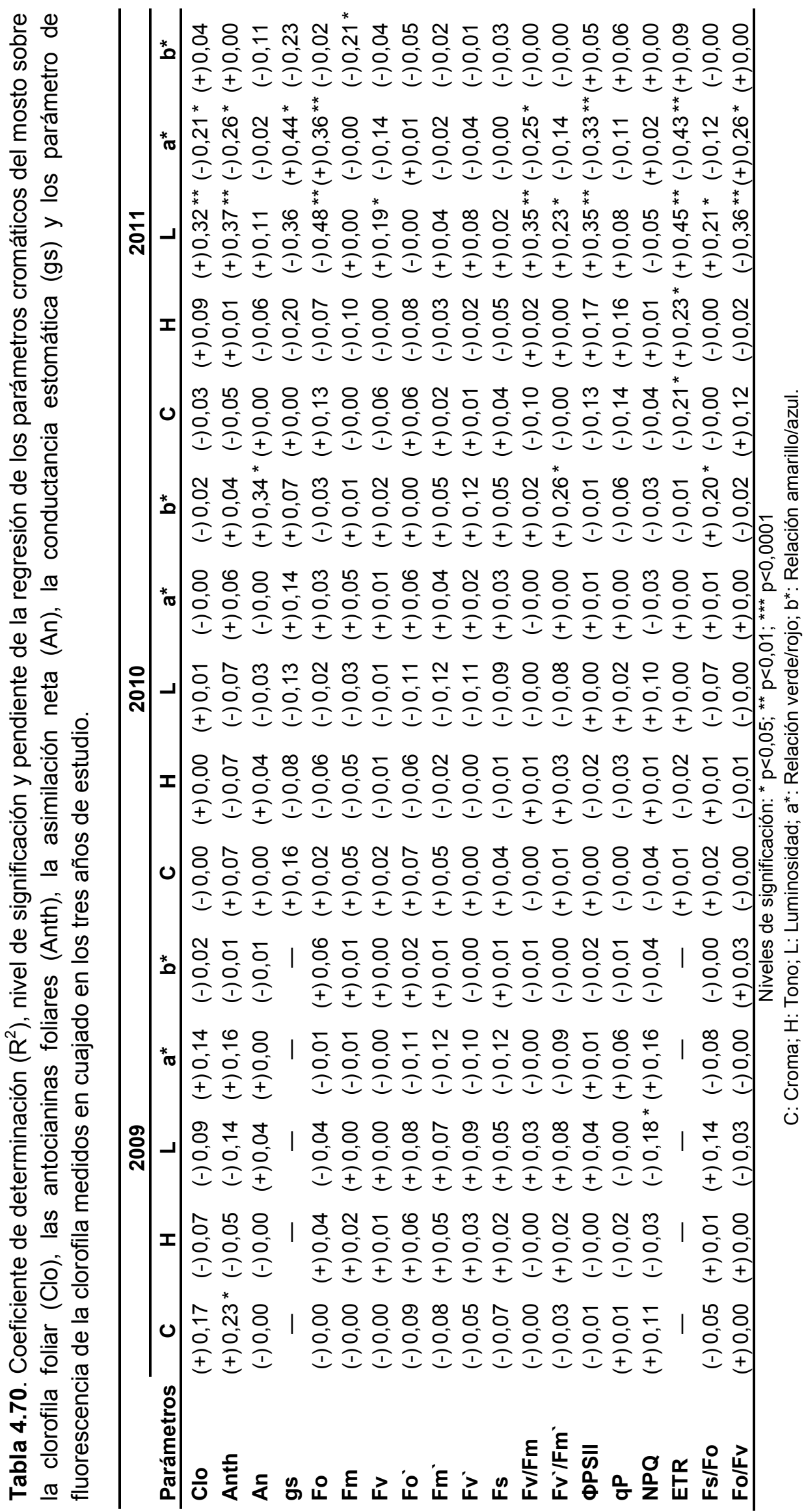




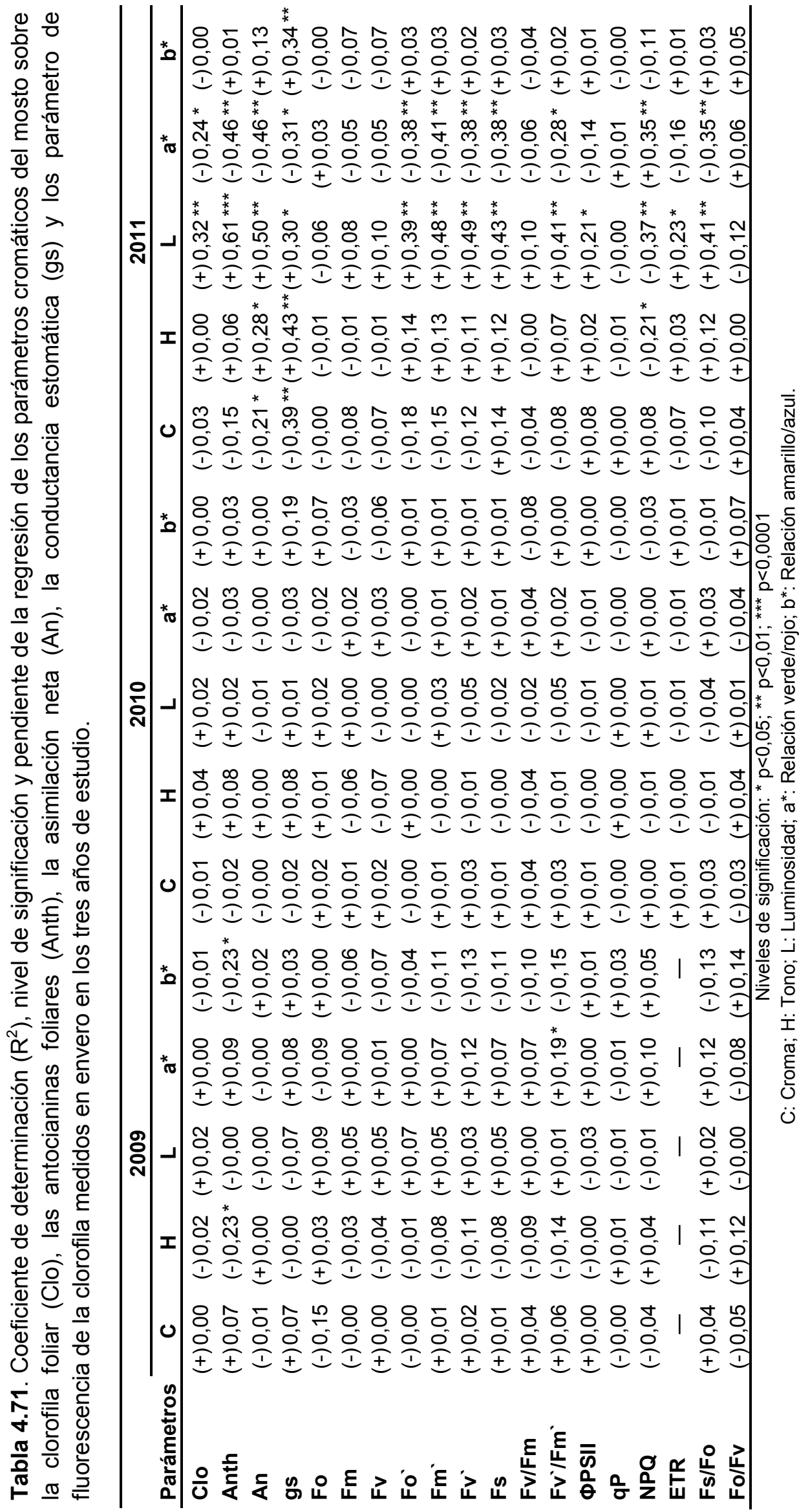




\subsection{5.- Madurez fenólica de las bayas.}

La síntesis y acumulación de los compuestos fenólicos en las uvas durante la maduración está muy influenciado por la capacidad fotosintética de la viña y la exposición a la radiación solar (Pirie y Mullins, 1980; Smart y Robinson, 1991). El contenido fenólico de las bayas es considerado como un parámetro fundamental para conocer la calidad final del vino, ya que es en gran medida responsable del color y las propiedades de astringencia de aquel (Agati et al., 2007). La composición y evolución de los compuestos fenólicos de la baya con la maduración dependen de la variedad de uva, prácticas vitícolas y los factores ambientales (Krstic, 2003; Downey et al, 2006). Las vides con estrés nutricional de hierro producen una mayor acumulación de polifenoles en las bayas (Bavaresco et al., 2005). Por esta razón es interesante el análisis de la relación de la madurez fenólica de las bayas con los contenidos en pigmentos foliares y los parámetros de la fluorescencia de la clorofila, que podrían ser medidas potencialmente interesantes para la estimación del potencial enológico de los viñedos.

El contenido en antocianos de la uva (ANT) y el índice de madurez celular (IMC) se han relacionado de forma positiva con el contenido en antocianinas foliares en cuajado y en envero en el año 2009 (tablas 4.72 y 4.73). Sin embargo, en el cuajado de 2011, el nivel de antocianos fácilmente extraíbles de la uva (AFE) se ha relacionado significativamente de forma negativa con la concentración foliar de clorofila y antocianinas. En 2011, el contenido fenólico total (CFT), AFE y ANT se relacionaron también negativamente con el nivel foliar de antocianinas en envero.

Del mismo modo que con las antocianinas foliares, CFT, AFE y ANT se relacionaron significativamente de manera negativa con An y gs medidas en el envero de 2011, no encontrándose relaciones significativas en los años 2009 y 2010 (tablas 4.72 y 4.73). Como se ha comentado anteriormente, en 2011 se ha relacionado de forma directa el rendimiento del viñedo con el nivel foliar de antocianinas y los valores de asimilación y conductancia estomática con el peso de 100 bayas (menor proporción hollejo/pulpa), y en consecuencia con la concentración en peso de compuestos fenólicos.

En relación a las medidas de fluorescencia tomadas en el cuajado del fruto, como se puede ver en la tabla 4.72, hubo una regresión lineal significativamente positiva de IMC sobre la relación Fv/Fm en 2009. En 2010 se observó una relación positiva de AFE, y negativa de IMC e IMP, sobre Fm. En el año 2011, se encontró una relación positiva de CFT, AFE y ANT con Fo y negativa con ФPSIl y ETR. Además, IMC se relacionó significativamente con varios de los parámetros de la fluorescencia medidos en condiciones de iluminación.

Considerando medias de fluorescencia en envero, AFE se relacionó significativamente de forma negativa, e IMC de forma positiva, con Fm, Fv, Fo', Fv/Fm y el ratio Fo/Fv en el año 2009. En 2010 se ha dado una regresión significativa del IMC sobre casi todos los parámetros de fluorescencia. En 2011 son de destacar las relaciones significativas de CFT, AFE y ANT con casi todos los parámetros de la fluorescencia de la clorofila medidos en condiciones de iluminación (tabla 4.73). 
Los resultados indican que el estado nutricional de las plantas, que afecta al rendimiento fotosintético, modifica en gran medida la maduración fenólica de las bayas. ANT se ha relacionado de forma negativa con la concentración de $\mathrm{Mn}$ en el suelo y AFE y ANT de forma positiva con el contenido de Mn peciolar, como se ha descrito en el capítulo 4.4.2.3. En los suelos clorosantes propios de la zona (alto contenido en carbonatos totales), la intensidad de la clorosis férrica se manifiesta en una mayor acumulación de manganeso en los peciolos (Martín et al., 2008). Fo', Fm', Fv' y Fs monitorizadas en el envero por su relación con el contenido en Mn en el suelo y en los peciolos podrían ser interesantes indicadores del potencial fenólico (especialmente en cuanto a concentración de materia colorante) de viñedos afectados por clorosis férrica.

Con los datos de 2011, al igual que para las variables cromáticas del mosto, de los parámetros de fluorescencia monitorizados en el cuajado que mejor estiman CFT, ANT y AFE han sido Fo $\left(R^{2}=0,26 ; p<0,05\right.$ para CFT; $R^{2}=0,34 ; p<0,01$ para ANT, $R^{2}=0,27 ; p<0,05$ para AFE) y ETR $\left(R^{2}=0,27 ; p<0,05\right.$ para CFT; $R^{2}=0,30 ; p<0,01$ para ANT, $R^{2}=0,50 ; p<0,01$ para AFE). Entre los parámetros fisiológicos monitorizados en el envero, el contenido foliar en antocianinas $\left(R^{2}=0,37 ; p<0,01\right.$ para CFT; $R^{2}=0,34$; $p<0,01$ para ANT, $R^{2}=0,36 ; p<0,01$ para AFE) es el que mejor ha estimado CFT, ANT y AFE de la uva.

Las relaciones de las variables de madurez fenólica de las bayas con los parámetros de la fluorescencia de la clorofila fueron diferentes según el estado fenológico en que estos se midieron, de modo similar a lo reflejado para las variables de composición del mosto y sus características cromáticas. En cuajado las relaciones más estrechas se dieron con parámetros medidos en hojas adaptadas a la oscuridad (relacionados con el rendimiento fotoquímico del PSII), mientras que en envero las relaciones se dieron mayoritariamente con los parámetros de la fluorescencia medidos en hojas adaptadas a la luz. Las medidas de cuajado podrían ser más interesantes para la detección y seguimiento de zonas afectadas por clorosis férrica, mientras que las medidas en hojas adaptadas a la luz en envero reflejarían más la variabilidad en el régimen hídrico de las parcelas. 


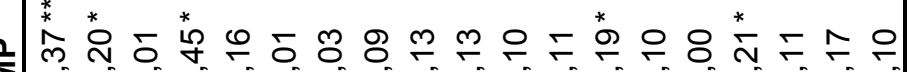

等

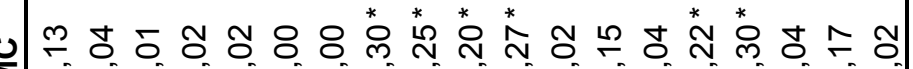

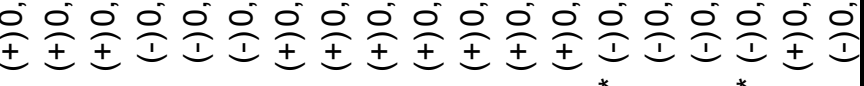

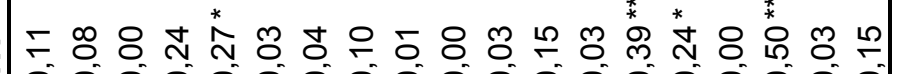

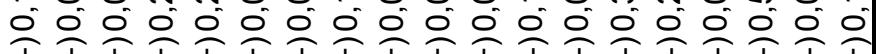

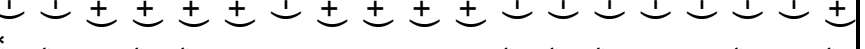

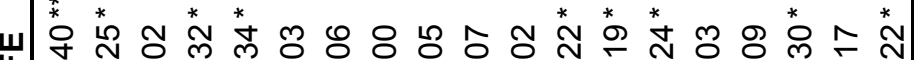

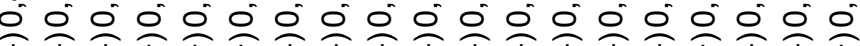

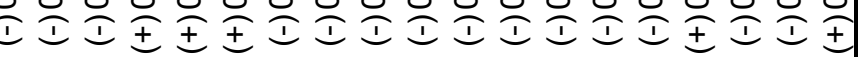

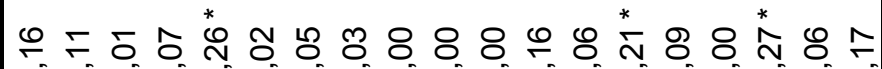

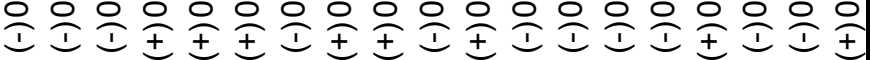

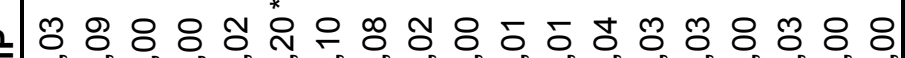

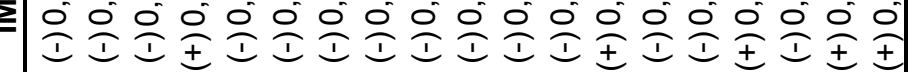
*

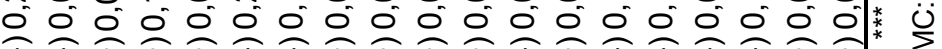

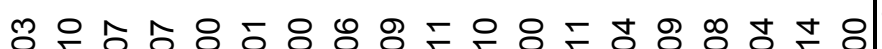

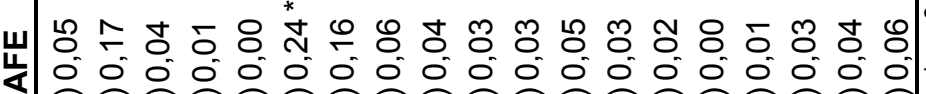

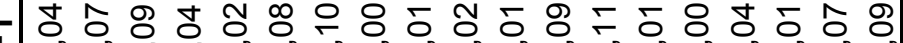

$\mathrm{U}$

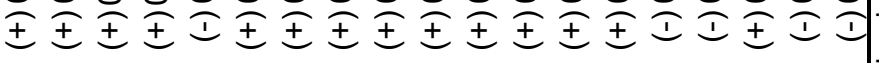

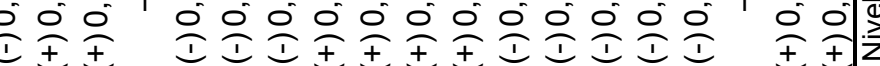

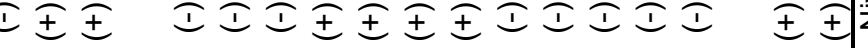

내에

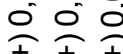

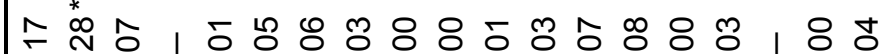

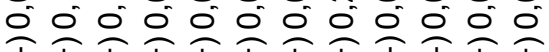

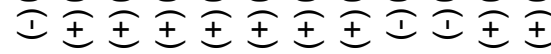
응ำ

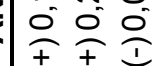
000

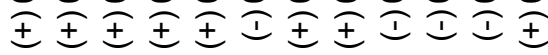
主产

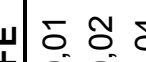

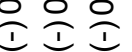

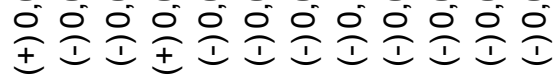




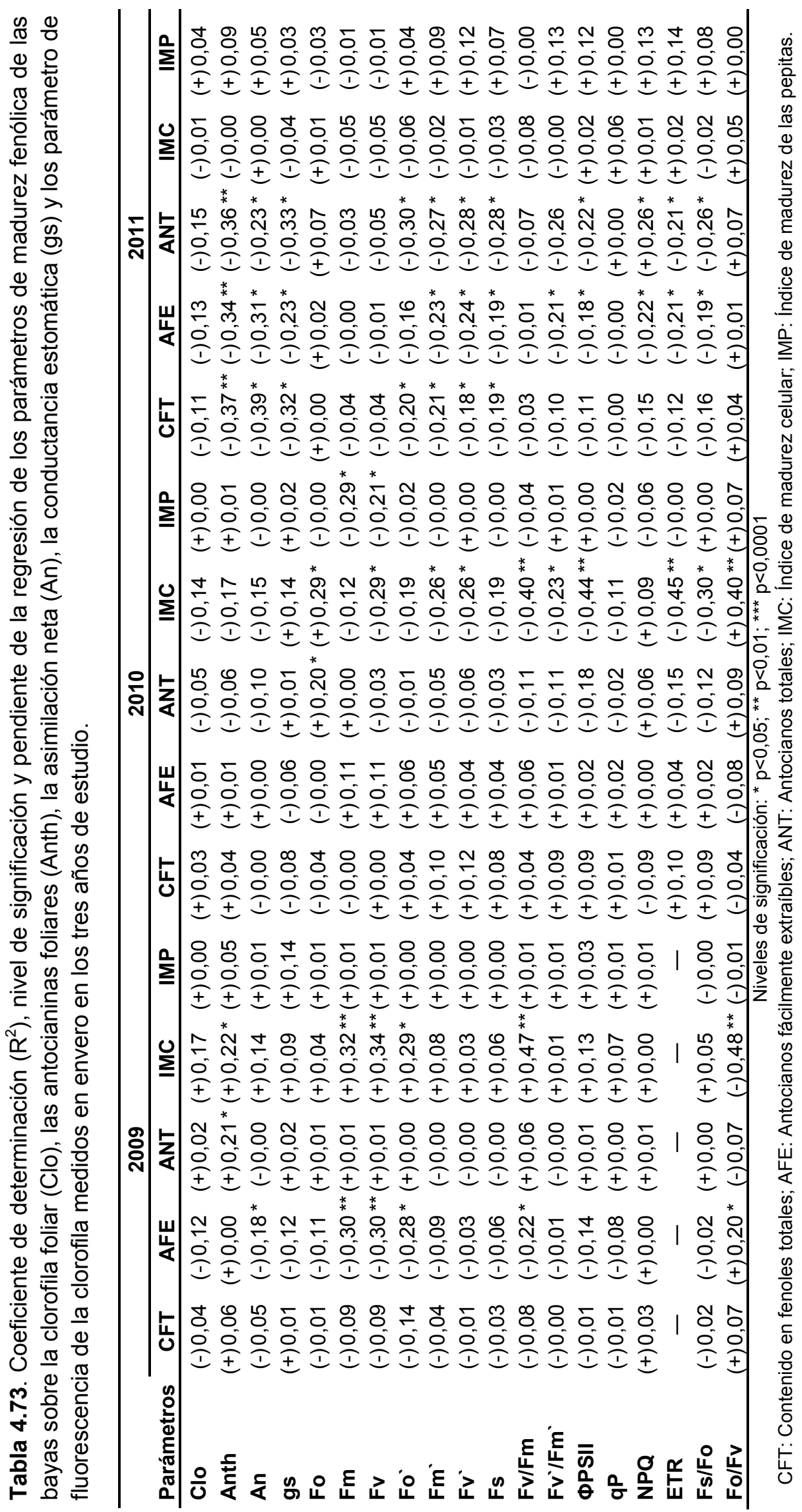





\section{CONCLUSIONES}




$$
\text { • }
$$




\section{5.- CONCLUSIONES}

A partir de los resultados obtenidos en este estudio se pueden extraer las siguientes conclusiones:

1. Se ha detectado una alta variabilidad en el porcentaje de arcilla, contenido en carbonatos totales y niveles de $\mathrm{P}, \mathrm{K}, \mathrm{Mg}, \mathrm{Zn}$ y Cu asimilables de los suelos de viñedo del área de estudio. La composición mineral de los peciolos recogidos en envero también ha mostrado una gran variación espacial para los mencionados nutrientes, con oscilaciones interanuales importantes en el caso de P, Cu y Mn.

2. Se ha podido comprobar que los niveles peciolares de Fe no son válidos para el diagnóstico de la clorosis férrica. La deficiencia en la zona de estudio está inducida por la interferencia de la caliza del suelo en la asimilación del hierro, ya que no se han detectado regresiones significativas de los niveles foliares de clorofila con los contenidos en Fe asimilable, pero si con los contenidos en carbonatos totales del suelo.

3. Los contenido en arcilla carbonatos de los suelos estuvieron altamente correlacionados, obteniéndose regresiones significativas de los niveles peciolares de $\mathrm{P}, \mathrm{Mg}$ y $\mathrm{Mn}$ con ambos parámetros. Los contenidos de $\mathrm{K}$ y $\mathrm{Mg}$ en el suelo se relacionaron directamente con sus respectivos niveles en los peciolos, constatándose un fuerte antagonismo entre ambos nutrientes. Los valores de la ratio $\mathrm{K} / \mathrm{Mg}$ en muchas de las subparcelas han estado por encima de los valores de referencia, dándose situaciones de carencia inducida de $\mathrm{Mg}$.

4. La concentración foliar de clorofilas, carotenoides y antocianinas se reduce con el incremento del contenido en carbonatos de los suelos del área de estudio, de forma más intensa en cuajado que en envero, por lo que las medidas del contenido en pigmentos después de floración podrían ser más interesantes para el seguimiento del estado nutricional del viñedo. Las elevadas concentraciones de carbonatos en el suelo han afectado más a los niveles de clorofila que a los de carotenoides, mientras que su efecto sobre los niveles de antocianinas ha sido variable en función del año de estudio.

5. Las relaciones entre niveles nutricionales y contenido foliar de pigmentos demuestran que la clorosis férrica se manifiesta en la zona de estudio en una mayor acumulación de $\mathrm{Mn}$ en los peciolos, y que una alta disponibilidad de $\mathrm{K}$ en el suelo disminuye el grado de afección de la fisiopatía.

6. La concentración foliar de clorofila, carotenoides y antocianinas en cuajado y envero no han mostrado relaciones significativas con la conductancia estomática y la asimilación neta, si bien los resultados reflejan que la clorosis férrica se traduce en un incremento de la fluorescencia mínima y disminuciones de la fluorescencia variable, de la eficiencia fotoquímica del 
fotosistema II y del transporte aparente de electrones. Parámetros de fluorescencia de la clorofila como Fo y Fv/Fm se han visto afectados, además de por el Fe, por la nutrición de $\mathrm{K}, \mathrm{Mg}$ y Mn. La ratio Fo/Fv ha presentado una gran sensibilidad para el seguimiento de los niveles nutricionales de Fe y $\mathrm{Mn}$ en el viñedo.

7. La clorosis férrica se ha traducido en el área de estudio en un menor vigor (medible tanto en el peso de madera de poda como en la superficie media de la hoja), y del rendimiento del viñedo (afectando principalmente al peso del racimo y al tamaño de la baya). Los mostos procedentes de subzonas afectadas han mostrado mayor concentración de azúcares y polifenoles, y menor acidez, que los de subzonas sanas, sin variaciones significativas en cuanto a pH. La mejora de los índices de madurez de la uva en los viñedos cloróticos es consecuencia, en las condiciones del estudio, de la reducción del rendimiento y del tamaño de la uva (efecto de concentración), lo que compensaría el impacto negativo del déficit de hierro sobre la actividad fotosintética de las plantas.

8. Las componentes de la expresión vegetativa del viñedo también se han visto modificadas por el nivel nutricional de otros elementos distintos al Fe. Así se ha apreciado que el nivel de $\mathrm{K}$ tiende a incrementar el vigor y rendimiento, reduciendo los contenidos en azúcares y polifenoles del mosto. En el conjunto de subparcelas, mayores niveles de nutrición magnésica dieron mostos con mayor índice de polifenoles totales. Debido a su interacción con el Fe, el nivel de $\mathrm{Mg}$ incrementó la concentración de sólidos solubles del mosto en las subparcelas afectadas por clorosis férrica, pero no en las sanas.

9. Las subzonas con déficit de $\mathrm{P}$ tuvieron un rendimiento y acidez total del mosto significativamente menor, y un contenido en azúcares, polifenoles, y antocianos totales y fácilmente extraíbles en la uva significativamente mayor que las subzonas con nutrición adecuada. En las áreas de estudio con déficit de $\mathrm{Cu}$, el índice de área foliar, la superficie media de la hoja, el rendimiento y sus componentes fueron menores que en las subzonas sanas, dando cosechas con mayor contenido en azúcares. El nivel nutricional de Zn se relacionó positivamente con los pesos de madera de poda y negativamente con el índice de polifenoles totales y la concentración de sólidos solubles totales del mosto. La concentración peciolar de $\mathrm{Mn}$ se ha relacionado de forma negativa con el rendimiento, y de forma positiva con el $\mathrm{pH}$ y los contenidos en azúcares y polifenoles del mosto.

10. Las relaciones detectadas entre concentración de pigmentos foliares, parámetros de fluorescencia de la clorofila y rendimiento del viñedo fueron más evidentes en 2011 que en los otros dos años de estudio, en los cuales la capacidad productiva de las plantas estuvo limitada a nivel general por el déficit hídrico. En viñedos donde exista suficiente variabilidad espacial en el rendimiento, los parámetros Fo, Fv/Fm y Fo/Fv monitorizados en cuajado y envero, (especialmente en cuajado) podrían ser útiles en viticultura de precisión para hacer una estimación temprana del potencial productivo en viñedos afectados por clorosis férrica. 
11. Se han observado relaciones significativas entre las variables de composición de la uva y las concentraciones foliares de clorofila y antocianinas en cuajado y envero, siendo las más destacadas las obtenidas con el nivel de antocianinas en envero. Siempre que la variación espacial fuera suficiente, esta variable podría ser una buena herramienta para estimar el contenido en azúcares, polifenoles y antocianos de la uva en vendimia.

12. Las relaciones entre las variables de composición de la uva y los parámetros de la fluorescencia de la clorofila fueron diferentes según el estado fenológico en que estos se registraron. En cuajado las relaciones más estrechas se dieron con medidas en hojas adaptadas a la oscuridad, relacionadas con el rendimiento fotoquímico del PSII, mientras que en envero las relaciones se dieron con mayor intensidad en parámetros medidos en hojas adaptadas a la luz, que reflejarían más la variabilidad en el régimen hídrico de las subparcelas. Las medidas de fluorescencia Fo, Fv/Fm, Fo/Fv y ETR, podrían ser útiles para la estimación del contenido en sólidos solubles, la luminosidad y la relación rojos/verdes del color de los mostos, el contenido fenólico total y la concentración de antocianos totales y fácilmente extraíbles de las bayas en viñedos afectados por clorosis férrica, para su aplicación en viticultura de precisión. 



\section{BIBLIOGRAFÍA}




$$
\text { • }
$$




\section{6.- BIBLIOGRAFÍA}

ABADÍA, J. 1992. Leaf responses to Fe deficiency: A review. J. Plant Nutr., 15: 1699-1713

ABADÍA, J., ÁlVAREZ-FERNÁNDEZ, A., ROMBOLÀ, A., SANZ, M., TAGLIAVINI, M. y ABADÍA, A. 2004. Technologies for the diagnosis and remediation of Fe deficiency. J. Plant Nutr. Soil Sci., 50(7): 965-971

ABAdíA, J., MORALES, F. y ABAdíA, A. 1999. Photosystem II efficiency in low chlorophyll, iron-deficient leaves. Plant Soil, 215: 183-192

ABADÍA, J., NISHIO, J. N., MONGE, E., MONTAÑÉS, L. y HERAS, L. 1985. Mineral composition of peach tree leaves affected by iron iosynth. J. Plant Nutr., 8: 697-708

ABADÍA, J., LÓPEZ-MILLÁN, A. F., ROMBOLÀ, A. y ABADÍA, A. 2002. Organic acids and iron deficiency: a review. Plant Soil, 241: 75-86

ABADÍA, J., SANZ, M., RIVAS, J. y ABADÍA, J. 1989. Photosynthetic pigments and mineral composition of Fe deficiency pear leaves. J. Plant Nutr., 12: 827-838

ABDEL-MAWGOUD, A.S., SADEK, S.A. MOUKHTAR, M.M. y ABDEL-AAL, A.I.N. 1998. Drainage in new reclaimed calcareous soils in relation to soil characteristics. In: The Seventh National Drainage Symposium, March, 8-10 ${ }^{\text {th }}$. Orlando, Florida.

ABDEL RAHMAN, A.A., SHALABY, A.F. y MONAYERI, M.O.E.I. 1971. Effect of moisture stress on metabolic products and ions accumulation. Plant soil, 34: 65

ADAMS III, W.W. y DEMMIG-ADAMS, B. 2004. Chlorophyll fluorescence as a tool to monitor plant response to the environment. In: Papageorgiou, GC, Govindjee, eds. Advances in photosynthesis and respiration, Vol. 19. Berlin: Springer, 583-604

ADAMS, M., NORWELL, A., PHILPOT, D. y PEVERLY, J. 2000. Spectral detection of micronutrient deficiency in "Bragg" soybean. Agron. J., 92: 261-268

ADILOGLU, S. 2006. The effect of increasing nitrogen and zinc doses on the iron, copper and manganese contents of maize plant in calcareous and zinc deficient soils. Asian J. Plant Sci., 5(3): 504-507

AEMET. 2013. Valores climatológicos normales [en línea]. Fecha de consulta: 05/06/2005. Disponible

en: http://www.aemet.es/es/elclima/datosclimatologicos/valoresclimatologicos. 
AGATI, G., MEYER, S., MATTEINI, P. y CEROVIC, Z.G. 2007. Assessment of Anthocyanins in Grape (Vitis vinifera L.) berries using a noninvasive chlorophyll fluorescence method. J. Agric. Food Chem., 55: 1053-1061

AHLAWAT, V.P. y YAMDAGNI, R. 1988a. Effects of various levels of nitrogen and potassium application on growth yield and petiole composition on grapes cv. Perlette. Prog Hort., 20(3): 190-196

AHLAWAT, V.P. y YAMDAGNI, R. 1988b. Effects of various levels of nitrogen and potassium application on berry set, berry drop and quality of grapes cultivar. Perlette. Prog Hort., 20 (1-2): 53-57

ALCÁNTARA, E., ROMERA, F.J., CANETE, M. y de la GUARDIA, M.D. 1994. Effects of heavy-metals on both induction and function of root Fe(III) reductase in Fe-deficient cucumber (Cucumis sativus L.) plants. J. Exp. Bot., 45:1893-1898

ALLAKHVERDIEV, S.I., SETLIKOVA, A, KLIMOV, V.V. y SETLIK, I. 1987. In photoinhibited photosystem II particles pheophytin photoreduction remains unimpaired, FEBS Lett., 226: 186-190

ALLEN, B.L. y HAJEK, B.F. 1989. Mineral occurrrence in soil environments. In: Dixon, J.B. y Weed, S B. eds. Mineral in soil environments. Soil Sci. Soc. of Am., Madison, Wis., pp. 228-231

ALLOWAY, B.J. 2004. Zinc in Soils and Crop Nutrition. International Zinc Association: Brussels, Belgium, pp. 30-35

ÁLVAREZ-FERNÁNDEZ, A.. 2000. Calidad y eficacia de los quelatos férricos (FeDDHA, FeEDDHMA, FeEDDHSA, FeEDDHCA) como fertilizantes. Tesis doctoral. Universidad Autónoma de Madrid

ÁLVAREZ-FERNÁNDEZ, A., ABADÍA, J. y ABADÍA, A. 2006. Iron deficiency, fruit yield and quality. In: Abadia J, Barton LL (eds). Iron Nutrition and Interactions in Plants. Springer, Dordrecht, pp. 85-101

ÁLVAREZ-FERNÁNDEZ, A., GARCÍA-MARCO, S. y LUCENA, J. 2005. Evaluation of synthetic iron (III) - chelates (EDDHA/Fe ${ }^{3+}, \mathrm{EDDHMA} / \mathrm{Fe}^{3+}$ ) and the novel EDDHSA $/ \mathrm{Fe}^{3+}$ ) to correct iron chlorosis. Eur. J. Agron., 22: 119-130

ÁLVAREZ-FERNÁNDEZ, A., SIERRA, M.A. y LUCENA, J.J. 2002. Reactivity of synthetic chelates with soils and soil components. Plant Soil, 241: 129-137

AMATI, A., PIVA, A., CASTELLARI, M. y ARFELLI, G. 1996. Preliminary studies on the effect of Oidium tuckeri on the phenolic composition of grapes and wine. Vitis, 35: 149-150

ANDERSON, W.B. 1982. Diagnosis and correction of iron deficiency in field crops -an overview-. J. Plant Nutr., 5: 785-795 
ANTER, F. 1984. Chemical and biological approach towards the definition of calcareous soils. III. Movement and distribution of $\mathrm{Fe}$ as related to the presence of $\mathrm{CaCO}_{3}$. J. Soil Sci., 24(2): 91-97

AREF, F. 2011. Influence of zinc and boron nutrition on copper, manganese and iron concentrations in maize leaf. Aust. J. Basic Appl. Sci., 5(7): 52-62

ARULANANTHAM, A.R., RAO, I.M. y TERRY, N. 1990. Limiting factors in photosynthesis. VI. Regeneration of ribulose 1,5-bisphosphate limits photosynthesis at low photochemical capacity. Plant Physiol., 93: 1466-1475

ASHOORI, M., LOLAEI, A., ZAMANI, S. y MOBASHERI, S. 2013. Effects of $\mathrm{N}$ and Zn on quantity and quality characters of grape vine (Vitis Viniferea). J. Agri. Crop. Sci., 5(3): 207-211

ASSIMAKOPOULOU, A. 2006. Effect of iron and nitrogen form on growth, nutritional status and ferric reducing activity of spinach in nutrient solution culture. Sci. Hortic., 110: $21-29$

BADIBANGA, B., PAGÉ, F., SAUVESTY, A. y ANSCEAU, C. 1992. Le système radiculaire dans les érablieres du Québec. 11. Le développement radiculaire relation avec le microrelief et la roche mère. The root system of sugar maple stands in Quebec. 11. Root development in relation to microtopagrahy and parent material. J. Can. For. Res., 22: 1568-1574

BAGGIOLINI, M. 1952. Les stades repères dans le développement annuel de la vigne et leur utilisation pratique. Revue romande d'Agriculture et d'Arboriculture, 8(1): 4-6

BAKER, N.R. 1996. Photosynthesis and the environment. Dordrecht: Kluwer Academic Press

BAKER, N.R. 2008. Chlorophyll fluorescence: a probe of photosynthesis in vivo. Annu. Rev. Plant Biol., 59: 89-113

BAKER, N.R. y ROSENQVIST, E. 2004. Applications of chlorophyll fluorescence can improve crop production strategies: an examination of future possibilities. J. Exp. Bot., 55: 1607-1621

BALAKRISHNAN, K., RAJENDRAN, C. y KULANDAIVELU, G. 2000. Differential responses of iron, magnesium, and zinc deficiency on pigment composition, nutrient content, and photosynthetic activity in tropical fruit crops. Photosynhetica, 38: $477-479$

BALAL, R., SHAHID, M.A., LIDON, V., GARCÍA, A.L., ABBAS, T., GARCÍA-SÁNCHEZ, F. y GHAZANFER, U. 2011. Effects of phosphorus fertilization on growth, leaf mineral concentration and xylem-phloem nutrient mobility in two rootstocks of prunus (Prunus persica $x$ Prunus amygdalus and Prunus insititia) in the Mediterranean. Aust. J. Crop Sci., 5: 1542-1549 
BALBA, A.M. 1987. Soil reclamation and Improvement. Alex., Egypt, pp. 189-218

BAR, Y. y KAFKAFI, U. 1992. Nitrate-induced iron-deficiency chlorosis in avocado (Persea Americana Mill.) rootstocks and its prevention by chloride. J. Plant Nutr., 15: 17391746

BARBAGALLO, R.P., OXBOROUGH, K., PALLETT, K.E. y BAKER, N. R. 2003. Rapid, noninvasive screening for perturbations of metabolism and plant growth using chlorophyll fluorescence imaging. Plant Physiol., 132: 485-493

BAVARESCO, L., BERTAMINI, M. y IACONO, F. 2006. Lime-induced chlorosis and physiological responses in grapevine (Vitis vinifera L. Cv. Pinot blanc) leaves. Vitis, 45: $45-46$

BAVARESCO, L., CIVARDI, S. PEZZUTTO, S. VEZZULLI, S. y FERRARI, F. 2005. Grape production, technological parameters, and stilbenic compounds as affected by limeinduced chlorosis. Vitis, 44: 63-65

BAVARESCO, L, GATTI, M. y FREGONI, M. 2010b. Nutritional deficiencies. In Methodologies and results in grapevine research; Springer: Berlin, Germany, pp. 165-191

BAVARESCO, L., GIACHINO, E. y COLLA, R. 1999. Iron chlorosis paradox in grapevine. J. Plant Nutr., 22: 1589-1 597

BAVARESCO, L., GIACHINO, E. y PEZZUTTO, S. 2003. Grapevine rootstock effects on lime-induced chlorosis, nutrient uptake, and source-sink relationships. J. Plant Nutr., 26: 1451-1465

BAVARESCO, L. y PONI, S. 2003. Effect of calcareous soil on photosynthesis rate, mineral nutrition, and source-Sink ratio of table grape. J. Plant Nutr., 26: 2123-2135

BAVARESCO, L., van ZELLER, M.I., CIVARDI, S., GATTI, M. y FERRARI, F. 2010a. Effects of traditional and new methods on overcoming lime-induced chlorosis of grapevine. Am. J. Enol. Vitic., 61: 186-190

BECKER, R., GRÜN, M. y SCHOLZ, G. 1992. Nicotinamine and the distribution of iron in the apoplasma and symplasm of tomato (Lycopersicon esculentum Mill). Planta, 187: $48-52$

BELKHODJA, R., MORALES, F., SANZ, M., ABADÍA, A. y ABADÍA, J. 1998. Iron deficiency in peach trees: effects on leaf chlorophyll and nutrient concentrations in flowers and leaves. Plant Soil, 203: 257-268

BELL, S. y ROBSON, A. 1999. Effect of nitrogen fertilization and growth, canopy density, and yield of Vitis vinifera L. Cv. Cabernet Sauvignon. Am. J. Enol. Vitic., 50(3): 351358 
BeNíTEZ, M.L., PEDRAJAS, V.M., del CAMPILLO, M.C. y TORRENT, J. 2002. Iron chlorosis in olive in relation to soil properties. Nutr. Cycl. Agroecosyst., 62: 47-52

BERGMANN, W. 1992. Nutritional disorders of plants. Development, visual and analytical diagnosis. Jena, Stuttgart, New York, Gustav Fischer

BERTAMINI, M., MUTHUCHELIAN, K. y NEDUNCHEZHIAN, N. 2002. Iron deficiency induced changes on the donor side of PS II in field grown grapevine (Vitis vinifera L. Cv. Pinot noir) leaves. Plant Sci, 162: 599-605

BERTAMINI, M. y NEDUNCHEZHIAN, N. 2005. Grapevine growth and physiological responses to iron deficiency. J. Plant Nutr., 28 (5): 737-749

BERTAMINI, M., NEDUNCHEZHIAN, N. y BORGHI, B. 2001. Effect of iron deficiency induced changes on photosynthetic pigments, ribulose-1,5-bisphosphate carboxylase, and photosystem activities in field grown grapevine (Vitis vinifera L. cv. Pinot noir) leaves. Photosynthetica, 39(1): 59-65

BHANDAL, J.S. y MALIK, C.P. 1988. Potassium estimation, uptake, and its role in the physiology and metabolism of flowering plants. Int Rev Cytol., 110: 205-254

BIENFAIT, H.F. 1985. Regulated redox processes at the plasmalemma of plant-root cells and their function in iron uptake. J. Bioenerg Biomembr., 17: 73-83

BIENFAIT, H.F., GARCÍA-MINA, J. y ZAMARENO, A.M. 2004. Distribution and secondary effects of EDDHA in some vegetable species. J. Plant Nutr. Soil Sci., 50: 11031110

BIGHAM, J.M., FITZPATRICK, R.W. y SCHULZE, D.G. 2002. Iron oxides. In: Dixon, J.B. y Schulze, D.G. (eds). Soil mineralogy with environmental applications. Madison, 323-366

BLOOM, P.R. 1981. Metal organic matter interactions in soil. In: Chemistry in the soil environment. Am. Soc. of Agron. Madison, WI, pp. 129-150

BOJOVIC, D.D., DUKIC, M., MAKSIMOVIC, V., SKOCAJIC, D. y SURUCIC, L. 2012. The effects of iron deficiency on lead accumulation in Alianthus altissima Mill. Swingle seedlings. J. Environ Qual., 41: 1517-1524

BORGGAARD, O.K. 1982. Selective extraction of the amorphous iron oxides by EDTA from selected silicates and mixtures of amorphous and crystalline iron oxides. Clay Miner, 17: 365-368

BORGGAARD, O.K. 1991. Effects of phosphate on iron-oxide dissolution in ethylenediamine-N, N, N', N'-tetraacetic acid and oxalate. Clay Miner, 39: 324-328

BOULTON, R. 1980. The general relationship between potassium, sodium and $\mathrm{pH}$ in grape juice and wine. Am. J. Enol. Vitic., 31: 182-186 
BOXMA, R. 1972. Bicarbonate as the most important soil factor in the lime induced chlorosis in Netherlands. Plant Soil, 37: 233-243

BRADY, N.C. y WEIL, R.R. 1999. The nature and properties of soils. 12th Edition. Prentice Hall, Upper Saddle River, New Jersey

BRAMELY, R.G.V. y LAMB, D.W. 2003. Making sense of vineyard variability in Australia. En: IX Congreso Latinoamericano de Viticultura y Enología. $24-28^{\text {th }}$ November. Santiago, Chile, pp. 35-54

BRAMELY, R.G.V., PEARSE, B. y CHAMBERLAIN, P. 2003. Being profitable precisely -a case study of precision viticulture from Margaret River. The Australian \& New Zealand Grapegrower \& Winemaker, 473: 84-87

BRAMELY, R.G.V. y HAMILTON, R.P. 2004. Understanding variability in winegrape production systems. 1. within vineyard variation in yield over several vintages. Aust. J. Grape Wine Res., 10: 32-45

BRAMELY, R.G.V. 2005. Understanding variability in winegrape production systems. 2. within vineyard variation in quality over several vintages. Aust. J. Grape Wine Res., 11: $33-42$

BRANCADORO, L., VALENTI, L., REINA, A. y SCIENZA, A. 1994. Potassium content of grapevine during the vegetative period: The role of the rootstock. J. Plant Nutr., 17(12): $2165-2175$

BRIANTAIS, J.M., VERNOTTE, C., KRAUSE, G.H. y WEIS, E. 1986. Chlorophyll fluorescence of higher plant chloroplasts and leaves. In: Govindjee, J.A.; fork, D.C., Eds. Light emission by plants and photosynthetic bacteria. Academic Press, New York. pp. 539-577

BROWN, J.C. 1960. An evaluation of bicarbonate-induced iron chlorosis. Soil Sci., 89: 246-247

BROWN, J.C. 1978. Mechanism of iron uptake by plant. Plant cell environ., 1: 249-257

BROWN, J.C., HOLMES, R.S. y SPECHT A.W. 1955. Iron, the limiting element in a chlorosis: part II. Copper - phosphorous induced chlorosis dependent upon plant species and varieties. Plant Physiol., 30: 457-462

BROWN, J.C., LUNT, O.R., HOLMES, R.S. y TIFFIN, L.O. 1959. The bicarbonate ion as an indirect cause of iron chlorosis. Soil Sci., 88: 260-266

BROWN, J.C. y OLSEN, R.A. 1980. Factors related to iron uptake by dicotyledonous and monocotyledonous plants III. Competition between root and external factors for Fe. J. Plant Nutr., 2: 661-682 
BRÜGGEMANN, W., MAAS-KANTEL, K. y MOOG, P.R. 1993. iron uptake by leaf mesophyll cells: The role of the plasma membrane-bound ferric-chelate reductase. Planta, 190: 151-155

BUCHANAN, B.B. 2000. Biochemistry and molecular biology of plants. Rockville, MD: American Society of Plant Physiologists, Vol. 40

BURGER, J. y EDWARDS, G.E. 1996. Photosynthetic efficiency, and photodamage by UV and visible radiation, in red versus green leaf Coleus varieties. Plant Cell Physiol., 37: 395-399

BURKHEAD, J.L., REYNOLDS, K.A., ABDEL-GHANY, S.E., COHU, C.M. y PILON, M. 2009. Copper homeostasis. New Phytol., 182: 799-816.

BYBORDI, A. y SHABANOV, J.A. 2010. Effects of the foliar application of magnesium and zinc on the yield and quality of three grape cultivars grown in the calcareous soils of Iran. Not. Sci. Biol., 2(1): 81-86

CALATAYUD, A., POMARES, F. y BARRENO, E. 2006. Interactions between nitrogen fertilization and ozone in watermelon cultivar Reina de Corazones in open-top chambers. Effects on chlorophyll a fluorescence, lipid peroxidation, and yield. Photosynthetica, 44: 193-201

CAMBROLLÉ, J., GARCÍA, J.L., FIGUEROA, M.E. y CANTOS, M. 2014. Physiological responses to soil lime in wild grapevine (Vitis vinifera ssp. sylvestris). Environ. Exper. Bot., 105: 25-31

CARREÑO, J., MARTíNEZ, A., ALMELA, L. y FERNÁNDEZ-LÓPEZ, J. A. 1995. Proposal of index for the objetive evaluation of colour of red table grapes. Foof. Research Int., 28: 27-34

CASTELLARIN, S.D., PFEIFFER, A., SIVILOTTI, P., DEGAN, M., PETERLUNGER, E. y Di GASPERO, G. 2007. Transcriptional regulation of anthocyanin biosynthesis in ripening fruits of grapevine under seasonal water deficit. Plant Cell Environ., 30: $1381-1399$

CASTILLO-MUÑOZ, N., GÓMEZ-ALONSO, S., GARCÍA-ROMERO, E. y HERMOSÍNGUTIÉRREZ, I. 2007. Flavonol profiles of Vitis vinifera red grapes and their singlecultivar wines. J. Agric. Food Chem., 55: 992-1002

CASTINO, M., UBIGLI, M., CORINO, L., LUZZATI, A., SIRAGUSA N. y NAPPI, P. 1987. Oenological effects of nutrient deficiencies on the grapes varity Barbera cultivated in Piedmont vineyards. Vignevini, Bologna, 14: 37-54

CATALINA, A., GONZÁLEZ, R., GONZÁLEZ, M.R. y MARTíN, P. 2010. Relationships between chlorophyll fluorescence, agronomic performance and grape quality in vineyards affected by iron deficiency chlorosis. In: XXVIII International Horticultural Congress. 22-27th August. ISHS, Eds. Lisboa (Portugal). 712-713. 
CATALINA, A., GONZÁLEZ, R., GONZÁLEZ, M.R. y MARTíN, P. 2012. Relaciones entre nivel de asimilación de nutrientes en el viñedo y composición fenólica de la uva en suelos calizos de la D.O. Ribera del Duero. reso: XIV Simposio Hispano-Luso de Nutrición mineral de las plantas. 23-26 Julio. Cantoblanco (Madrid).

CATALINA, A., GONZÁLEZ, R., GONZÁLEZ, M.R., ZARCO-TEJADA, P.J. y MARTÍN, P. 2011a. Iron and water stress differently affect vine photosynthetic efficiency and grape composition. In: XXXIV World Congress of Vine and Wine, 20-27th June, Oporto, Portugal.

CATAlinA, A., MATEI, P.M., GONZÁleZ, R., GONZÁleZ, M.R., MARTíN, P. 2011b. Relaciones entre niveles de asimilación de nutrientes y calidad de la uva en viñedos cv. Tempranillo afectados por clorosis férrica. IV Jornadas del Grupo de Fertilización de la Sociedad Española de Ciencias Hortícolas. Barcelona, noviembre de 2011

CELI, L., de LUCA, G. y BARBERIS, E. 2003. Effects of interaction of organic and inorganic $\mathrm{P}$ with ferrihydrite and kaolinite-iron oxide systems on iron release. Soil Sci., 168: 479-488

ÇELIK, H. y KATKAT, A.V. 2010. Comparison of various chemical extraction methods used for determination of the available iron amounts of calcareous soils. Commun. Soil Sci. Plant Anal., 41: 290-300

CESCO, S., RÖMHELD, V., VARANINI, Z. y PINTON, R. 2000. Solubilization of iron by water-extractable humic substances. J. Plant Nutr. Soil Sci., 163: 285-290

CHANEY, R.L., BROWN, J.C. y TIFFIN, L.O. 1972. Obligatory reduction of ferric chelates in iron uptake by soybeans. Plant Physiol., 50: 208-213

CHANEY, R.L. y COULUMBE, B.A. 1982. Effect of phosphate on regulation of Fe-stressresponse in soybean and peanut. J. Plant Nutr., 5: 469-487

CHANEY, R.L. 1984. Diagnostic practices to identify iron deficiency in higher plants. J. Plant Nutr., 7: 47-67

CHEFTEL, J.C. y CHEFTEL, H. 1992. Introducción a la bioquímica y tecnología de los alimentos. Zaragoza. Acribia. 1: 333

CHEN, Y. y BARAK, P. 1982. Iron nutrition of plants in calcareous soils. Adv. Agron., 35: 217-240

CHEN, L.S., CHENG, L.L. 2003. Both xanthophyll cycle-dependent thermal dissipation and the antioxidant system are up-regulated in grape (Vitis labrusca L. cv. Concord) leaves in response to $\mathrm{N}$ limitation. J. Exp. Bot., 54: 2165-2175

CHEN, Y., SHI J., TIAN, G., ZHENG, S. y LIN, Q. 2004b. Fe deficiency induces Cu uptake and accumulation in Commelina communis. Plant Sci., 166: 1371-1377 
CHEN, L.S., SMITH, B.R. y CHENG L.L. 2004a. $\mathrm{CO}_{2}$ assimilation, photosynthetic enzymes, and carbohydrates of 'Concord' grape leave in response to iron supply. J. Am. Soc. Hort. Sci., 129: 738-744

CHEN, W., WEI, W., YANG, J.L. y QUIN, C. 2010. Nitric oxide acts downstream of auxin to trigger root ferric-chelate reductase activity in response to iron deficiency in Arabidopsis. Plant Physiol., 154: 810-819

CHENG, L.L. y FUCHIGAMI, L.H. 2000. Rubisco activation state decreases with increasing nitrogen content in apple leaves. J. Exp. Bot., 51: 1687-1694

CHIERA, J., THOMAS, J. y RUFTY, T. 2002. Leaf initiation and development in soybean under phosphorus stress. J. Exp. Bot., 53(368): 473-481

CHIRA, K., PACELLA, N., JOURDES, M. y TEISSEDRE, P.L. 2011. Chemical and sensory evaluation of Bordeaux wines (Cabernet-Sauvignon and Merlot) and correlation with wine age. Food Chem., 126: 1971-1977

CHOMÉ, P.M, SOTÉS, V., BENAYAS, F., CAYUELA, M., HERNÁNDEZ, M., CABELLO, F., ORTIZ, J., RODRÍGUEZ, I. y CHAVES, J. 2003. Variedades de vid. Registro de variedades comerciales. M.A.P.A. Madrid (España)

CHRISTENSEN, P. 1984. Nutrient level comparisons of leaf petioles and blades in twentysix grape cultivars over three years (1979 through 1981). Am. J. Enol. Vitic., 35: 124-133

CIE, (1986): Colorimetry. (2ª edición). Publicación C.I.E. Viena, 152

CLARK, R.B., RÖMHELD, V. y MARSCHNER, H. 1988. Iron uptake and phytosiderophore release by roots of sorghum genotypes. J. Plant Nutr., 11: 663-676

CLEMENS, G. 1990. Charakterisierung und Melioration von Chlorosestandorten. Ph. D. Thesis, University of Hohenheim, Stuttgart

COHEN C.K., FOX, T.C., GARVIN, D.F. y KOCHIAN, L.V. 1998. The role of irondeficiency stress responses in stimulating heavy-metal transport in plants. Plant Physiol., 116: 1063-1072

COMISIÓN EUROPEA. 1990. Reglamento (CEE) no 2676/90 de 17 de septiembre de 1990 por el que se determinan los métodos oficiales de análisis de vinos, zumos y mostos de uva. Diario Oficial de las Comunidades Europeas L272 (3 de Octubre de 1990). Comisión Europea (Ed.) Bruselas, pp. 1-192

COMUZZO, P., TAT, L., TONIZZO, A. y BATTISTUTTA, F. 2006. Yeast derivates (extracts and autolysates) in winemaking: release of volatile compounds and effects on wine aroma volatility. Food Chem., 99: 217-230 
CONRADIE, W.J. 2001. Timing of nitrogen fertilization and the effects of poultry manure on the performance of grapevines on sandy soils. I. Soil analysis, grape yields and vegetative growth. S. Afr. J. Enol. Vitic., 22(2): 53-59

CONRADIE, W.J. y de WET, T.A. 1985. The effect of potassium fertilization of grapevines on yield and quality. In: Proceedings of the Potassium Symposium, Pretoria. Department of Agriculture and Water Supply, International Potash Institute and Fertilizer Society of South Africa, pp. 181-183

CONRADIE, W.J. y SAAYMAN, D. 1989a. Effects of long-term nitrogen, phosphorus, and potassium fertilization on Chenin blanc vines. I. Nutrient demand and vine performance. Am. J. Enol. Vitic. 40: 85-90

CONRADIE, W.J. y SAAYMAN, D. 1989b. Effects of long-term nitrogen, phosphorus, and potassium fertilization on Chenin blanc Vines. II. Leaf analyses and grape composition. Am. J. Enol. Vitic., 40(2): 91-98

CONSEJO D.O. RIBERA del DUERO. 2014. Superficie de viñedo inscrito en la Denominación de Origen Ribera del Duero [en línea]. Fecha de consulta: 04/04/2014. Disponible http://www.riberadelduero.es/web/saladeprensa/evolucion.htm

COOMBE, B.G. 1992. Research on development and ripening of the grape berry. Am. J. Enol. Vitic., 43: 101-110

COOMBE, B.G. y McCARTHY, M.G. 2000. Dynamics of grape berry growth and physiology of ripening. Aust. J. Grape Wine Res., 6: 131-135

COOPER, R.M. y WILLIAMS, J.S. 2004. Elemental sulphur as an induced antifungal substance in plant defense. J. Exp. Bot., 55(404): 1947-1953

CORNELL, R.M. y SCHWERTMANN, U. 2003. The iron oxides, 2nd edn. John Wiley \& Sons, Weinheim

CORTELL, J.M., HALBLEIB, M., GALLAGHER, A.V., RIGHETTI, T.L. y KENNEDY, J.A. 2005. Influence of vine vigor on grape (Vitis vinifera L.Cv. Pinot Noir) and wine proanthocyanidins. J. Agric. Food Chem., 53: 5798-5808

CORTELL, J.M., HALBLEIB, M., GALLAGHER, A.V., RIGHETTI, T.L. y KENNEDY, J.A. 2007. Influence of vine vigor on grape (Vitis vinifera L. cv. Pinot Noir) anthocyanins. 1. Anthocyanin concentration and composition in fruit. J. Agric. Food Chem., 55(16): 6575-6584

CORTELL, J.M. y KENNEDY, J.A. 2006. Effect of shading on accumulation of flavonoid compounds in (Vitis vinifera L.) Pinot Noir fruit and extraction in a model system. J. Agric. Food Chem., 54: 8510-8520

COULOMBE, B.A., CHANEY, R.L. y WICHOLD, W.J. 1984a. Use of bicarbonate in screening soybeans for resistance to iron chlorosis. J. Plant Nutr., 7: 411-425 
COULOMBE, B.A., CHANEY, R.L. y WICHOLD, W.J. 1984b. Bicarbonate directly induces iron chlorosis in susceptible soybean cultivars. Soil Sci. Soc. Am. J., 48: 1297-1301

COVARRUBIAS, J.I., PISI, A. y ROMBOLÀ, A.D. 2014. Evaluation of sustainable management techniques for preventing iron chlorosis in the grapevine. Aust. J. Grape Wine Res., 20: 149-159.

COVARRUBIAS, J.I. y ROMBOLÀ, A.D. 2013. Physiological and biochemical responses of the iron chlorosis tolerant grapevine rootstock 140 Ruggeri to iron deficiency and bicarbonate. Plant Soil, 370: 305-315

CROWLEY, D.E. 2001. Function of siderophores in the plant rhizosphere. In: Pinton, R., Varanini, Z. y Nannipieri, P. (eds). The Rhizosphere. Biochemistryand Organic Substances at the Soil-Plant Interface. Marcel Dekker, New York, 223-261

CUMBUS, I.P., HORNSEY, D.J. y ROBINSON, L.W. 1977. Influence of phosphorus, zinc and manganese on absorption and translocation of iron in watercress. Plant Soil, 48: $651-660$

CURRAN, M. 1999. Harvest systems and strategies to reduce soil and regeneration impacts (and costc). In McMorland, B. y Corradini, S. (eds). Impact of machine traffic on soil and regeneration. Proc. Mach. Traffic soil Interaction Workshop, February 1999, Edmonton, Alberta, pp. 75-111

DAVIES, D.D. 1986. The fine control of cytosolic pH. Physiol. Plant, 67: 702-706

DEDALDECHAMP, F., UHEL, C. y MACHEIX, J.J. 1995. Enhancement of anthocyanin synthesis and dihydroflavonol reductase (DFR) activity in response to phosphate deprivation in grape cell suspensions. Phytochem. 40:1357-1360

De kOCK, P.C. 1981. Iron nutrition under conditions of stress. J. Plant Nutr., 3: 513-521

De SANTIAGO, A., DÍAZ I., del CAMPILLO, M.C., TORRENT, J. y DELGADO, A. 2008. Predicting the incidence of iron deficiency chlorosis from hydroxylamine-extractable iron in soil. Soil Sci. Soc. Am. J., 72: 1493-1499

Del CAMPILLO, M.C., BARRÓN, V., TORRÈNT, J., IGLESIAS, I., DALMAU, R. y MARCÉ, X. 1998. Fertilisation with $\mathrm{Fe}(\mathrm{II})$-phosphate effectively prevents iron chlorosis in pear trees. In: XXV Int. Hortic. Congress, Part 1: Culture Techniques with Special Emphasis on Environmental Implications. 2-7 $7^{\text {th }}$ August. Brussels, Belgium, pp. 6572.

Del CAMPILLO, M.C. y TORRENT, J. 1992. Predicting the influence of iron chlorosis in calcareous soils of southern Spain. Commun. Soil Sci. Plan., 23: 399-416

DELGADO, R., MARTíN, P., ÁlAMO, M. y GONZÁLEZ, M.R. 2004. Changes in the phenolic composition of grape beries during ripening in relation to vineyard nitrogen and potassium fertilisation rates. J. Sci. Food Agr., 84: 623-630 
DEMMIG, B. y BJÖRKMAN, O. 1987. Comparison of the effect of excessive light on chlorophyll fluorescence $(77 \mathrm{~K})$ and photon yield of $\mathrm{O}_{2}$ evolution in leaves of higher plants. Planta, 171: 171-184

DEMIRER, T., MUFTÜOGLU, N.M., DARDENIZ, A. y ÖRS, T. 2007. Determination of the Nutrition Standard of Soil and Leaf Analysis of Bozcaada Çavusu Grape Variety Grown in Çanakkale, Turkey. Asian J. Chem., 19 (5): 3997-4006

DÍAZ, I., BARRÓN, V. del CAMPILLO, M.C. y TORRENT, J. 2009a. Vivianite (ferrous phosphate) alleviates iron chlorosis in grapevine. Vitis, 48: 107-113

DÍAZ, I., del CAMPILLO, M.C., BARRÓN, V. y TORRENT, J. 2010. Predicting the occurrence of Iron chlorosis in grapevine with tests based on soil iron forms. J. Int. Sci. Vigne Vin, 44: 77-85

DÍAZ, I., del CAMPILLO, M.C., CANTOS, M. y TORRENT, J. 2009b. Iron deficiency symptoms in grapevine as affected by the iron oxide and carbonate contents of model substrates. Plant Soil, 322: 293-302

DÍEZ-ALTARÉS, M. 1959. Fotodescomposición de clorofila en casos de deficiencia inducida de hierro. An. Estac. Exp. Aula Dei (Zaragoza), 6: 1-80

DINKELAKER, B., RÖMHELD, V. y MARSCHNER, H. 1989. Citric-acid excretion and precipitation of calcium citrate in the rhizosphere of white lupin (Lupinus albus L.) Plant Cell Environ., 12: 285-292

DOBROWSKI, S.Z., PUSHNIK, J.C., ZARCO-TEJADA, P.J. y USTIN, S.L. 2005. Simple reflectance indices track heat and water stress-induced changes in steady-state chlorophyll fluorescence at the canopy scale. Remote Sens. Environ., 97(3): 403414

DOWNEY, M.O., DOKOOZLIAN, N.K. y KRSTIC, M.P. 2006. Cultural practice and environmental impacts on the flavonoid composition of grapes and wine: A review of recent research. Am. J. Enol. Vitic., 57(3): 257-268

DOWNEY, M.O., HARVEY, J.S. y ROBINSON, S.P. 2004. The effect of bunch shading in berry development and flavonoid accumulation in Shiraz grapes. Aust. J. Grape Wine Res., 10: 55-73

DOWNTON, W.J.S. y HAWKER, J.S. 1980. Interaction of boron and chloride on growth and mineral composition of Cabernet Sauvignon vines. Am. J. Enol. Vitic., 31(3): 277-282

DROUINEAU, G. 1942. Dosage rapide du calcaire actif des sols. Nouvelles données sur la repartition et la nature des fractions calcaires. Annal Agron., 12: 441-450

DUCIC, T. y POLLE, A. 2005. Transport and detoxification of manganese and copper in plants. Braz. J. Plant Physiol., 17: 103-112 
DUNDON, C.G., SMART, R.E. y McCARTHY, M.G. 1984. The effects of potassium fertilizer on must and wine potassium levels of Shiraz grapevines. Am. J. Enol. Vitic., 35(4): 200-205

DURAES, F., GAMA, E., MAGALHAES, P., MARRIEL, I., CASELA, C., OLIVEIRA, A.C., LUCHIARI, A. y SHANAHAN, J.F. 2001. The usefulness of chlorophyll fluorescence in screening for disease resistance, water stress tolerance, aluminum toxicity tolerance, and $\mathrm{N}$ use efficiency in Maize. In 7. Proceedings of the Eastern and Southern Africa Regional Maize Conference. Nairobi (Kenya), pp. 356-360

ECKHARDT, U., MARQUES, A.M. y BUCKOUT, T.J. 2001. Two iron-regulated cation transporters from tomato complement metal uptake-deficient yeast mutants. Plant Mol. Biol., 45: 437-448

EIDE, D., BRODERIUS, M., FETT, J. y GUERINOT, M.L. 1996. A novel iron-regulated metal transporter from plants identified by functional expression in yeast. Proceedings of the National Academy of Sciences of the United States of America, 93: 5624-5628

ESCALONA, J.M., FLEXAS, J., y MEDRANO, H. 1999. Stomatal and non-stomatal limitations of photosynthesis under water stress in field-grown grapevines. Aust. J. Plant. Physiol., 26: 421-433

ESCUDERO, A., CAMPO, E., FARINA, L., CACHO, J. y FERREIRA, V. 2007. Analytical characterization of the aroma of five premium red wines. Insights into the role of odor families and the concept of fruitiness of wines. J. Agric. Food Chem., 55: $4501-4510$

ESTEBAN, M.A., VILLANUEVA, M.J. y LISSARRAGUE, J.R. 2001. Effect of irrigation on changes in the anthocyanin composition of the skin of cv Tempranillo (Vitis Vinifera L.) grape berries during ripening. J. Sci. Food Agric., 81: 409-420

ETCHEBARNE, F., OJEDA, H. y DELOIRE, A. 2009. Influence of water status on mineral composition of berries in 'Grenache Noir' (Vitis vinifera L.). Vitis, 48: 63-68

FARAGO, M.E. 1994. Plants and the chemical elements. Biochemistry, uptake, tolerance and toxicity. Weinheim, $\mathrm{VCH}$

FARGAŠOVÁ, A. y BEINROHR, E. 1998. Metal-metal interactions in accumulation of $\mathrm{V}^{5+}$, $\mathrm{Ni}^{2+}, \mathrm{Mo}^{6+}, \mathrm{Mn}^{2+}$ and $\mathrm{Cu}^{2+}$ in under-and above-ground parts of Sinapis alba.' Chemosphere, 36(6): 1305-1317

FERNÁNDEZ, V. y EBERT, G. 2005. Foliar iron fertilization: a critical review. J. Plant Nutr., 28: 2113-2124

FERNÁNDEZ, V., del RÍO, V., ABADÍA, J. y ABADÍA, A. 2006. Foliar iron fertilization of peach (prunus persica (L.) Batsch): effects of iron compounds, surfactants and other adjuvants. Plant Soil, 289: 239-252 
FILELLA, I., SERRANO, L., SERRA, J. y PEÑUELAS, J. 1995. Evaluating wheat nitrogen status with canopy reflectance indices and discriminant analysis. Crop Sci., 35: $1400-1405$

FLEXAS, J., BOTA, J., ESCALONA, J.M., SAMPOL, B. y MEDRANO, H. 2002a. Effects of drought on photosynthesis in grapevines under field conditions: an evaluation of stomatal and mesophyll limitations. Funct. Plant Biol., 29: 461-471

FLEXAS, J., BRIANTAIS, J.M., CEROVIC, Z., MEDRANO, H. y MOYA, I. 2000. Steadystate and maximum chlorophyll fluorescence responses to water stress in grapevine leaves: A new remote sensing system, Remote Sens. Environ., 73: 282297

FLEXAS, J., ESCALONA, J.M., EVAIN, S., GULÍAS, J., MOYA, I., OSMOND, C.B. y MEDRANO, H. 2002b. Steady-state chlorophyll fluorescence (Fs) measurements as a tool to follow variations of net $\mathrm{CO}_{2}$ assimilation and stomatal conductance during water-stress in C3 plants. Physiol. Plant, 114: 231-240

FLEXAS, J., ESCALONA, J.M. y MEDRANO, H. 1998. Down-regulation of photosynthesis by drought under field condition in grapevine leaves. Australian Aust. J. Plant. Physiol., 25: 893-900

FLEXAS, J., ESCALONA, J.M. y MEDRANO, H. 1999. Water stress induces different levels of photosynthesis and electron transport rate regulation in grapevines. Plant Cell Environ., 22: 39-48

FLEXAS, J. y MEDRANO, H., 2002. Drought-inhibition of photosynthesis in C3 plants: stomatal and non-stomatal limitation revisited. Annals of Botany, 89: 183-189

FOY, C.D., FARINA, M.P.W. y OAKES, A.J. 1998. Iron-manganese interactions among clones of nilegrass. J. Plant Nutr., 21(5): 987-1009

FREGONI, M. 1998. Viticoltura di Qualith. L'Informatore Agrario, pp. 515-534

FUENTES-YAGÜE, J.L. 2000. El suelo y los fertilizantes. Ed. Mundi-prensa. Madris, pp. $137-148$

FURBANK, R.T., von CAEMMERER, S., SHEEHY, J. y EDWARDS, G. 2009. C-4 rice: a challenge for plant phenomics. Funct. Plant Biol., 36: 845-856

GAITHER, L. A. y EIDE, D.J. 2001. Eukaryotic zinc transporters and their regulation. Biometals, 14: 251-270

GALLÉ, A. y FLEXAS, J. 2010. Gas-exchange and chlorophyll fluorescence measurements in grapevine leave in the field, In: S. Delrot et al. (eds.), Methodologies and Results in Grapevine Research, 8: 107-121

GÁLVEZ, N., BARRÓN, V. y TORRENT, J. 1999. Effect of phosphate on the crystallization of hematite, goethite and lepidocrocite from ferrihydrite. Clay Miner. 47: 304-311 
GARCÍA, M., DAVERADE, P., GALLEGO, P. y TOUMI, M. 1999. Effects of various potassium-calcium ratios on cation nutrition of grape grown hydroponically. J. Plant Nutr., 22: 417-425

GARCíA, M., GALlEGo, P., DAVERADE, C. y IBRAHIM, H. 2001. Effects of Three Rootstocks on Grape (Vitis vinifera L.) cv. Négrette, Grown Hydroponically. I. Potassium, Calcium and Magnesium Nutrition. S. Afr. J. Enol. Vitic., 22: 101-103

GARCÍA, M.J., GARCÍA-MATEO, M.J., LUCENA, C., ROMERA, F.J., ROJAS, C.L., ALCÁNTARA, E. y PÉREZ-VICENTE 2013. Hypoxia and bicarbonate could limit the expression of iron acquisition genes in Strategy I plants by affecting ethylene synthesis and signalling in different ways. Physiol. plantarum, 150: 95-106

GARCÍA, M.J., SUAREZ, V., ROMERA, F.J., ALCÁNTARA, E. y PÉREZ-VICENTE, R. 2011. A new model involving ethylene, nitric oxide and $\mathrm{Fe}$ to explain the regulation of Fe-acquisition genes in strategy I plants. Plant Physiol. Biochem., 49: 537-544

GARCÍA-BARCELÓ, J., 1990. "Compuestos fenólicos". En: Técnicas Analíticas para Vinos. G.A.B. (ed.). Moja-Olérdola. 8: 3-33

GARDE-CERDÁN, T., LOREZO, C., LARA, J.F., PARDO, F., ANCÍN-AZPILICUETA, C. y SALINAS, M.R. 2009. Study of the evolution of nitrogen compounds during grape ripening. Application to differentiate grape varieties and cultivated systems. J. Agric. Food Chem., 57: 2410-2419

GÄRTEL, W. 1993. Grapes. In W.F. BENNETT (Ed). Nutrient deficiencies and toxicities in crop plants. St. Paul, MN: APS Press, pp. 177-183

GEELHOED, J.S., Van RIEMSDIJK, W.H. y FINDENEGG, G.R. 1999. Simulation of the effect of citrate exudation from roots on the plant availability of phosphate adsorbed on goethite. Eur. J. Soil Sci., 50: 379-390

GENTY, B., BRIANTAIS, J.M. y BAKER N.R. 1989. The relationship between the quantum yield photosynthetic electron transport and quenching of chlorophyll fluorescence. Biochimica et Biophysica Acta, 990: 87-92

GLORIES, Y. y AUGUSTIN, M. 1993. Maturité phénolique du raisin, conséquences technologiques: application aux millésimes 1991 et 1992. In: Compte Rendu Colloque Journée Technique CIVB. Bordeaux, France, pp. 56-61

GLUHIĆ, D., HERAK-ĆUSTIĆ, M., PETEK, M., ČOGA, L., SLUNISKI, S. y SINČIĆ, M. 2009. The content of $\mathrm{Mg}, \mathrm{K}$ and $\mathrm{Ca}$ ions in vine leaf under foliar application of magnesium on calcareous soils. Agriculturae Conspectus Scientificus (ACS), 74(2): 81-84

GODDE, D. y HEFER, M. 1994. Photoinhibition and light-dependent turnover of the D1 reaction-centre polypeptide of photosystem II are enhanced by mineral-stress conditions. Planta, 193: 290-299 
GOLDEN, D.C., TURNER, F.T., SITTERTZ-BHATKAR, H. y DIXON, J.B. 1997. Seasonally precipitated iron oxides in a Vertisol of Southeast Texas. Soil Sci. Soc. Am. J. 61: 958-964

GOMEZ-MIGUEL, V. 2009. Inventarios del recurso suelo de las D.O. de Castilla y León: II D.O. Ribera del Duero. Innovación y tecnología alimentaria, 2: 99-112

GONZÁLEZ, M.R y MARTíN, P. 2005. Valores de referencia para el diagnóstico nutricional del viñedo cv. Tempranillo en la Ribera del Duero. La Semana Vitivinícola, 3073: 2198-2202

GONZÁLEZ, M.R y MARTíN, P. 2006. Prevención y tratamiento de la clorosis férrica del viñedo. Vida Rural, 226: 30-33

GONZÁLEZ, M.R., NÚÑEZ, L.C., GONZÁLEZ, R., ZARCO-TEJADA, P.J., MARTíN, P. 2005b. Diagnóstico foliar de la clorosis férrica del viñedo en la D.O. "Ribera del Duero". Viticultura/Enología Profesional, 101: 53-58

GONZÁLEZ, M.R., NÚÑEZ, L.C., GONZÁLEZ, R., ZARCO-TEJADA, P.J. y MARTÍN, P. 2006. Efectos de la clorosis férrica sobre la acumulación de antocianos en la uva cv. Tempranillo durante la maduración. In: Nutrición Mineral. Aspectos fisiológicos y ambientales. Vol II. Lamsfus. C. y otros. Eds. Universidad Pública de Navarra. Pamplona. 493-498.

GONZÁLEZ, M.S., PERALES, V.H. y SALCEDO, A.M. 2008. La fluorescencia de la clorofila a como herramienta en la investigación de efectos tóxicos en el aparato fotosintético de plantas y algas. Rev. Educación Bioquímica, 27(4): 119-129

GONZÁLEZ, R., NUÑEZ, L. C., MARTíN, P., BERJÓN, A. y ZARCO-TEJADA, P.J. 2005a. Estimación de la absorbancia de radiación PAR en hojas de vid a partir de su contenido en clorofila. V In: Congreso Ibérico de Ciencias Hortícolas, Actas Portuguesas de Horticultura, Vol. 2, Asociación Portuguesa de CC. Hortícolas (Ed.), Lisboa. 22-27 Mayo. Oporto. Portugal, pp. 384-389

GONZÁLEZ-NEVES, G., FERRER, M., GIL, G., CHARAMELO, D., BALADO, J., BOCHICCHIO, R., GATTO, G. y TESSORE, A. 2010. Estudio plurianual del potencial polifenólico de uvas Tannat en el sur de Uruguay. Agrociencia, 14(2): 1021

GONZÁLEZ-NEVES, G., GIL, G. y FERRER, M. 2002. Effect of different vineyard treatments on the phenolic contents in Tannat (Vitis vinifera L.) grapes and their respective wines. Food Sci. Tech. Int., 8: 315-321

GONZÁLEZ-VALLEJO, E.B., ABADÍA, A., GONZÁLEZ-REYES, J. A., LUCENA, J.J. y ABADÍA, J. 1999. Reduction of ferric chelates by leaf plasma membranes from Fedeficient by Fe deficient and Fe-sufficiency, assay buffer sugar beet. Aust. J. Plant Physiol., 26: 601-611 
GonZÁleZ-VALLEJO, E. B., MORALES, F., CISTUÉ, L., ABADÍA, A. y ABADÍA, J. 2000. Iron deficiency decreases the $\mathrm{Fe}(\mathrm{III})$-chelate reducing activity of leaf protoplasts. Plant Physiol., 122: 337-344

GONZÁLEZ-VALLEJO, E.B., SUSIN, S., ABADÍA, A. y ABADÍA, J. 1998. Changes in sugar beet leaf plasma membrane $\mathrm{Fe}(\mathrm{III})$-chelate reductase activities mediated by Fe deficiency, assay buffer composition, anaerobiosis and the presence of flavins. Protoplasma, 205: 163-168

GOULD, K.S., NEILL, S.O. y VOGELMANN, T.C. 2002. A unified explanation for anthocyanins in leaves? Advances in Botanical Research, 37: 167-192

GOVINDJEE, 1995. Sixty-three years since Kautsky: chlorophyll a fluorescence. Aust. J. Plant Physiol., 22: 131-160

GOVINDJEE, 2004. Chlorophyll a fluorescence: a bit of basics and history. In: Papageorgiou, G., Govindjee (Eds.), Chlorophyll a fluorescence: a signature of photosynthesis. Springer, Ordrecht, pp. 1-42

GRANT, R.S. y MATTHEWS, M.A. 1996a. The influence of phosphorous availability, scion, and rootstock on grapevines shoot growth, leaf area and petiole phosphorous concentration. Am. J. Enol. Vitic., 47(2): 217-224

GREENE, R.M., GEIDER, R.J. y FALKOWSKI, P.G. 1991. Effect of iron limitation on photosynthesis in a marine diatom. Limnol. Oceanogr., 36: 1772-1782

GREENE, R.M., GEIDER, R.J., KOLBER, Z. y FALKOWSKI, P.G. 1992. Iron induced changes in light harvesting and photochemical energy conversion processes in eucaryotic marine algae. Plant Physiol., 100: 565-575

GRIS, E. 1844. Nouvelles experiences sur l'action des composes ferrugineux solubles, et de la debilite des plantes. C. R. Acad. Sci., 19: 1118-1119

GRIS, E. 1847. Addition y une precedente. Note concernant des experiences sur Tapplication des seis de fer a la vegetation, et specialement au traitement des plantes chlorosees, languissantes et menacees deune mort prochaine. C. R. Acad. Sci., 25: 276

GROVER, A., SABAT, S.C. y MOHANTY, P. 1986. Effect of temperature on photosynthetic Activities of Senescing detached wheat leaves. Plant Cell Physiol., 27: $117-126$

GRUBER, B. y KOSEGARTEN, H. 2002. Depressed growth of non-chlorotic vine grown in calcareous soil is an iron deficiency symptom prior lo leaf chlorosis. J. Plant Nutr. Soil Sci., 165: 111-117

GUIDONI, S., FERRANDINO, A. y NOVELLO, V. 2008. Effects of seasonal and agronomical practices on skin anthocyanin profile of Nebbiolo grapes. Am. J. Enol. Vitic., 59: 22-29 
GUIKEMA, J.A. 1985. Fluorescence induction characteristics of Anacystis nidulans during recovery from iron deficiency. J. Plant Nutr., 8: 891-908

GUIKEMA, J.A. y SHERMAN, L.A. 1983. Organization and function of chlorophyll in membranes of cyanobacteria during iron starvation. Plant Physiol., 73: 250-256

GUO, Y y TAN, J. 2015. Recent Advances in the Application of Chlorophyll a Fluorescence from Photosystem II. J. Photochem. Photobiol., 91: 1-14

HAESELER, C.W., SMITH, C.B., KARDOS, L.T. y FLEMING, H.K. 1980. Response of mature vines of Vitis Labrusca L. cv Concord to application of phosphorous and potassium over an eight-year span in Pennsylvania. Am. J. Enol. Vitic., 31(3): 237244

HAGIN, J. y TUCKER, B. 1982. Fertilization of dryland and irrigated soils. Springer Verlag, New York

HAILEMICHAEL, G., CATALINA, A., UZQUIZA, L., GONZÁLEZ, M.R. y MARTÍN, P. 2014. Efectos del estado nutricional sobre la eficiencia fotosintética y el comportamiento agronómico de viñedos cv. Tempranillo en Ribera del Duero. I Jornadas del Grupo de Viticultura y Enología de la SECCHH.

HALL, G.E.M., VAIVE, J.E., BEER, R. y HOASHI, M. 1996. Selective leaches revisited, with emphasis on the amorphous Fe oxyhydroxide phase extraction. J. Geochem Explor., 56: 59-78

HANNAM, R.J., GRAHAM, R.D. y RIGGS, J.L. 1985. Diagnosis and prognosis of manganese deficiency in Lupinus augustifolius L. J. Agric. Res., 36: 765-777

HARTWIG, R.C. y LOEPPERT, R.H. 1991 Pretreatment effect on dispersion of carbonates in calcareous soils. Soil Sci. Soc. Am. J., 55: 19-25

HASELGROVE, L., BOTTING, D., van HEESWIJCK, R., HOJ, P.B., DRY, P.R., FORD, C. y ILAND, P.G. 2000. Canopy microclimate and berry composition: The effect of bunch exposure on the phenolic composition of Vitis vinifera L. cv Shiraz grape berries. Aust. J. Grape Wine Res., 6: 141-149

HÄUSSLING, M., RÖMHELD, V., MARSCHNER, H. 1985. Bezihungen zwischen Chlorosegrad, Eisengehalten und Blattwachstum von Weinreben auf vershie denen Standorten. Vitis, 24: 158-168

HAVLIN, J.L. y WESTFALL, D.G.1985. Potassium release kinetics and plant response in calcareous soils. Soil Sci. Soc. Am. J., 49: 366-370

HAYNES, R.J. y NAIDU, R. 1998. Influence of lime, fertilizer and manure applications on soil organic matter content and soil physical conditions: a review. Nutr. Cycl. Agroecosyst., 51: 123-213 
HE, Z.L., YANG, X.E. y STOFFELLA, P.J. 2005. Trace elements in agroecosystems and impacts on the environment. J. Trace Elem. Med. Biol., 19: 125-140

HEENAN, D.P. y CANPBELL, L.C. 1981. Influence of potassium and manganese on growth and uptake of magnesium by soybean varieties. Plant Soil, 61: 447-456

HENRIQUES, F.S. 2003. Gas exchange, chlorophyll a fluorescence kinetics and lipid peroxidation of pecan leaves with varying manganese concentrations. Plant Sci., 165: 239-244

HERMANS, C., JOHNSON, G.N., STRASSER, R.J. y VERBRUGGEN, N. 2004. Physiological characterisation of magnesium deficiency in sugar beet: acclimation to low magnesium differentially affects photosystems I and II. Planta, 220: 344-355

HERNÁNDEZ-ORTE, P., CACHO, J.F. y FERREIRA, V. 2002. Relationship between varietal amino acid profile of grapes and wine aromatic composition. Experiments with model solutions and chemometric study. J. Agric. Food Chem., 50: 2891-2899

HIDALGO, L. 1999. Tratado de viticultura general. Ediciones Mundiprensa. Madrid.

HILAL, H.M., ANTER, F. y El-DAMATY, H. 1973. A chemical and biological approach towards the definition of $P$ in soils as affected by percentage and particle size of calcium carbonate fixation. Plant Soil, 39: 469-478

HILBERT, G., SOYER, J.P., MOLOT, C., GIRAUDON, J., MILIN, S. y GAUDILLERE, J.P. 2003. Effects of nitrogen supply on must quality and anthocyanin accumulation in berries of $\mathrm{cv}$. Merlot. Vitis, 42: 69-76

HINSINGER, P., PLASSARD, C., TANG, C.X. y JAILLARD, B. 2003. Origins of rootmediated $\mathrm{pH}$ changes in the rhizosphere and their responses to environmental constraints: A review. Plant Soil, 248: 43-59

HIRADATE, S. y INOUE, K. 1998. Interaction of mugineic acid with iron (hydr)oxides sulphate and phosphate influences. Soil Sci. Soc. Am. J., 62: 159-165

HIRSCH, J., MARIN, E., FLORIANI, M., CHIARENZA, S., RICHAUD, P., NUSSAUME, L. y THIBAUD, M.C. 2006. Phosphate deficiency promotes modification of iron distribution in Arabidopsis plants. Biochimiestry, 88: 1767-1771

HOBERG, E., MARSCHNER, P. y LIEBEREI, R. 2005. Organic acid exudation and pH changes by Gordonia sp and Pseudomonas fluorescens grown with $\mathrm{P}$ adsorbed to goethite. Microbiol Res., 160: 177-187

HOLT, H.E., FRANCIS, I.L., FIELD, J., HERDERICH, M.J. y ILAND, P.G. 2008. Relationships between wine phenolic composition and wine sensory properties for Cabernet Sauvignon (Vitis vinifera L.). Aust. J. Grape Wine Res., 14: 162-176

HOPKINS, B.G., JOLLEY, V.D. y BROWN, J.C. 1992. Plant utilization of iron solubilized by oat phytosiderophore. J. Plant Nutr., 15: 1599-1612 
HORNECK, D.A., SULLIVAN, D.M., OWEN, J.S. y HART, J.M. 2011. Soil test interpretation guide. [Corvallis, Or.]: Oregon State University, Extension Service.

HRADZINA, G., PARSONS, G.F. y MATTICK, L.R. 1984. Physiological and biochemical events during development and maturation of grape berries. Am. J. Enol. Vitic., 35: 220-227

HU, Y. y SCHMIDHALTER, U. 2005. Drought and salinity: A comparison of their effects on mineral nutrition of plants J. Plant Nutr. Soil Sci., 168: 541-549

HUANG, Z.A., JIANG, D.A., YANG, Y., SUN, J.W. y JIN, S.H. 2004. Effects of nitrogen deficiency on gas exchange, chlorophyll fluorescence, and antioxidant enzymes in leaves of rice plants. Photosynthetica, 42: 357-364

HUGHES, D.F., JOLLEY, V.D. y BROWN, J.C. 1990. Differential response of dicotyledonous plants to potassium-deficiency stress-iron-stress response mechanism. J. Plant Nutr., 13:405-1417

HUGHES, D.F., JOLLEY, V.D. y BROWN, J.C. 1992. Roles for potassium in the ironstress response mechanisms of strategy-I and strategy-II plants. J. Plant Nutr., 15: 1821-1839

HUGHES, N.M., NEUFELD, H.S. y BURKEY, K.O. 2005. Functional role of anthocyanins in high-light winter leaves of the evergreen herb Galax urceolata. New Phytologist., 168: $575-587$

HUNT, C.B. 1972. Geology of soils: their evolution, classification and uses. W.H. Freeman, San Francisco, California.

HURLEY, A.K., WALSER, R.H., DAVIS, T.D., y BARNEY, D.L. 1986. Net photosynthesis and chlorophyll, and foliar iron in apple trees after injection with ferrous sulphate. HortSci., 21: 1029-1031

IACONO, F. y SOMMER, K.J. 1999. The measurement of chlorophyll fluorescence as a tool to evaluate the photosynthetic performance of grapevine leaves. Acta Horticulturae, 493: 31-44

INFORIEGO. 2013. Datos meteorológicos de la estación meteorológica de Valbuena de Duero (VA-07) [En línea]. Fecha de consulta: 04/02/2013. Disponible en: http://www.inforiego.org/opencms/opencms/info_meteo/construir/index.html

INSKEEP, W.P. y BLOOM P.R. 1986. Effects of soil moisture on pCO2, soil solution bicarbonate, and iron chlorosis in soybeans. Soil Sci. Soc. Am. J., 50: 946-952

IZAGUIRRE-MAYORAL, M.L. y SINCLAIR, T.R. 2005. Soybean genotypic difference in growth, nutrient accumulation and ultrastructure in response to manganese and iron supply in solution culture. Ann. Bot., 96(1): 149-158

JACKSON, M.L. 1958. Soil Chemical Analysis. Prentice-Hall, New York. 
JACKSON, D.I. y LOMBARD, P.B. 1993. Environmental and management practices affecting grape composition and wine quality-A review. Am. J. Enol. Vitic., 44: 409430

JAULMES, P. 1966. Tables de correspondance entre les diverses tables Alcoo- métriques. Société Pharmacie Montpellier, 26(2): 111-141

JEONG, S.T., GOTO-YAMAMOTO, N., KOBAYASHI, S. y ESAKA, M. 2004. Effects of plant hormones and shading on the accumulation of anthocyanins and the expression of anthocyanin biosynthetic genes in grape berry skins. Plant Sci., 167: 247-252

JIMÉNEZ, S., GOGORCENA, Y., HEVIN, C., ROMBOLÀ, A.D. y OLLAT, N. 2007. Nitrogen nutrition influences some biochemical responses to iron deficiency in tolerant and sensitive genotypes of Vitis. Plant Soil, 290: 343-355

JOLLEY, V.D., HANSEN, N.C. y SHIFFLER, A.K. 2004. Nutritional and management related interactions with iron-deficiency stress response mechanisms. Soil Sci. Plant Nutr., 50: 973-981

JONES, D.L. 1998. Organic acids in the rhizosphere-a critical review. Plant Soil, 205: 2544

JONES, D.L., DARRAH, P.R. y KOCHIAN, L.V. 1996. Critical-evaluation of organic-acid mediated iron dissolution in the rhizosphere and its potential role in root iron uptake. Plant Soil, 180: 57-66

JONES, D.L., DENNIS, P.G., OWEN, A.G. y van HEES, P.A.W. 2003. Organic acid behavior in soils - misconceptions and knowledge gaps. Plant Soil, 248: 31-41

JONES, J.B. y WALLACE, A. 1992. Sample preparation and determination of iron in plants tissue samples. J. Plants Nutr., 15(10): 2085-2108

JUAREZ-SANZ, M., CERDAN-SALA, M.D.M. y SANCHEZ-SANCHEZ, A. 2007. Hierro en el sistema suelo-planta. Química del Sistema Suelo Planta.

JUSTE, C. y POUGET, R. 1972. Appréciation du poivoir chlorosant des sols par un nouvel indice faisant intervener le calcaire actif et le ferrihydrite facilement extractaible: Application au choix des porte-greffes de la vigne. Compt. Rend. Acad. Agric., 58: 352-357

KAISER, B.N., GRIDLEY, K.L., BRADY, J.N., PHILLIPS, T. y TYERMAN, S.D. 2005. The role of molybdenum in agricultural plant production. Ann. Bot., 96(5): 745-754

KAKEGAWA, K., SUDA, J., SUGIYAMA, M., y KOMAMINE, A. 1995. Regulation of anthocyanin biosynthesis in cell suspension cultures of Vitis in relation to cell division. Physiol. Plant, 94: 661-666 
KALAJI, H.M., BOSA, K., KOSCIELNIAK, J. y ŻUK-GOLASZEWSKA, K. 2011. Effects of salt stress on photosystem II efficiency and $\mathrm{CO}_{2}$ assimilation of two Syrian barley landraces. Environ. Exper. Bot., 73: 64-72

KAWAI, S., TAKAGI, S.I. y SATO, Y. 1988. Mugineic acid-family phytosiderophores in root-secretions of barley, corn and sorghum varieties. J. Plant Nutr., 11: 633-642

KELLER, M. 2005. Deficit irrigation and vine mineral nutrition. Am. J. Enol. Vitic., 56: 267283

KELLER, M. 2010. The science of grapevines: anatomy and physiology. Burlington, MA: Academic Press, pp. 243-274

KELLER, M., ARNINK, K.J. y HRAZDINA, G. 1998. Interaction of nitrogen availability during bloom and light intensity during veraison. I. Effects in grapevine growth, fruit development, and ripening. American Journal of Enolology and Viticulture, 49(3): 333-340

KELLER, M., KUMMER, M., y VASCONCELOS, M.C. 2001a. Reproductive growth of grapevines in response to nitrogen supply and rootstock. Australian Journal of Grape and Wine Research, 7: 12-18

KELLER, M., KUMMER, M., y VASCONCELOS, M.C. 2001b. Soil nitrogen utilization for growth and gas exchange by grapevines in response to nitrogen supply and rootstock. Aust. J. Grape Wine Res., 7: 2-11

KENNEDY, J.A., MATTHEW, M.A. y WATERHOUSE, A.L. 2002. Effect of maturity and vine water status on grape skin and wine flavonoids. Am. J. Enol. Vitic., 53: 268274

KO, M.P., JUANG, P.Y., HUANG, J.S. y BARKER, K.R. 1987. The occurrence of phytoferritin and its relationship to effectiveness of soybean nodules. Plant Physiol., 83: 299-305

KOBAYASHI, T., YOSHIHARA, T., JIANG, T.B., GOTO, F., NAKANISHI, H., MORI, S. y NISHIZAWA, N.K. 2003. Combined deficiency of iron and other divalent cations mitigates the symptoms of iron deficiency in tobacco plants. Physiol. Plantarum, 119: $400-408$

KOCHIAN, L.V. 1991. Mechanisms of micronutrient uptake and translocation in plants. In: Mortvedt, J.J., Cox, F.R., Shuman, L.M. y Welch, R.M. (eds) Micronutrients in agriculture, $2^{\text {nd }}$ ed. Soil Science Society of America, Madison, Wis., pp. 229-296

KOCHIAN, L., HOEKENGA, O. y PINEROS, M. 2004. How do crops plants tolerate acid soils? Mechanisms of aluminum tolerance and phosphorus efficiency. Annu. Rev. Plant Biolog., 55: 459-493 
KOLESCH, H., HÖFNER, W. y SCHALLER, K. 1987a. Effect of bicarbonate and phosphate on iron chlorosis of grape-vines with special regard to the susceptibility of two rootstocks. I. Field experiments. J. Plant Nutr., 10: 207-230

KOLESCH, H., HÖFNER, W. y SCHALLER, K. 1987b. Effect of bicarbonate and phosphate on iron chlorosis of grape-vines with special regard to the susceptibility of two rootstocks. II. Pot experiments. J. Plant Nutr., 10: 231-249

KOPRIVA, S. 2006. Regulation of sulfate assimilation in Arabidopsis and beyond. Ann. Bot., 97(4): 479-495

KORCAK, R.F. 1987. Iron deficiency chlorosis. Hort. Rev., 9: 133-186

KORSHUNOVA, Y.O., EIDE, D., CLARK, W.G., GUERINOT, M.L. y PAKRASI, H.B. 1999. The IRT1 protein from Arabidopsis thaliana is a metal transporter with a broad substrate range. Plant Mol. Biol., 40: 37-44

KOSEgARTEN, H., HOFFMANN, B. y MENGEL, K. 1999. Apoplastic pH and $\mathrm{Fe}^{3+}$ Reduction in intact sunflower leaves. Plant Physiol., 121: 1069-1079

KOSEGARTEN, H., HOFFMANN, B. y MENGEL, K. 2001. The paramount influence of nitrate in increasing apoplastic $\mathrm{pH}$ of young sunflower leaf to induce $\mathrm{Fe}$ deficiency chlorosis, and the re-greening effect brought about acid foliar sprays. J. Plant Nutr. Soil Sci., 164: 155-163

KOSEGARTEN, H., WILSON, G.H. y ESCH, A. 1998. The effect of nitrate nutrition on iron chlorosis and leaf growth in sunflower (Helianthus annuus L.). Eur. J. Agr., 8: 283292

KRAEMER, S.M., CROWLEY, D.E. y KRETZSCHMAR, R. 2006. Geochemical aspects of phytosiderophore-promoted iron acquisition by plants. Adv. Agron., 91: 1-46

KRÄMER, U. y CLEMENS, S. 2006. Functions and homeostasis of zinc, copper, and nickel in plants. In Molecular Biology of Metal Homeostasis and Detoxification; Springer: Berlin, Germany, pp. 215-271

KRAUSE, G.H. y WEIS, E. 1991. Chlorophyll fluorescence and photosynthesis-the basics. Annu. Rev. Plant. Physiol. Plant Mol. Biol.. 42, 313-349

KRIEDEMANN, P.E., GRAHAM, R.D. y WISKICH, J.T. 1985. Photosynthetic dysfunction and in vivo changes in chlorophyll a fluorescence from manganese-deficient wheat leaves. Aust. J. Agric. Res., 36: 157-169

KRISHNAMURTI, G.S.R., VIOLANTE, A. y HUANG, P.M. 1998. Influence of montmorillonite on Fe(II) oxidation products. Clay Miner, 33: 205-212

KRSTIC, M., MOULDS, G., PANAGIOTOPOULOS, B. y WEST, S. 2003. Growing Quality Grapes to Winery Specifications: Quality Measurement and Management Options for Grapegrowers; Winetitles: Adelaide, Australia. 
LADOUCEUR, A., TOZAWA, S., ALAM, S., KAMEI, S. y KAWAI, S. 2006. Effect of low phosphorus and iron-deficient conditions on phytosiderophore release and mineral nutrition in barley. Soil Sci. Plant Nutr., 52: 203-210

LAIBARRA, I.R., RUEDA, I.M., IÑIGO, I.L., OLIVERAS, C.G., RUBIO, M.T.V., LLARÍA, D. L. y DOMÍNGUEZ, E.G.E. 2004. Diagnóstico nutricional de" vitis vinifera" L cv Tempranillo en la DO Ca. Rioja: Niveles Críticos Preliminares. Zubía, 16: 41-57

LARBI, A., ABADÍA, A., ABADÍA, J. y MORALES, F. 2006. Down co-regulation of light absorption, photochemistry, and carboxylation in Fe-deficient plants growing in different environments. Photosynth. Res., 89: 113-126

LEE, D.W., O'KEEFE, J., HOLBROOK, N.M. y FEILD, T.S. 2003. Pigment dynamics and autumn leaf senescence in a New England deciduous forest, eastern USA. Ecological Research, 18: 677-694

LEGAZ, F., SERNA, M.D., FERRER P., CEBOLLA V. y PRIMO-MILLO E. 1995. Análisis de hojas, suelos y aguas de riego para el diagnóstico nutricional de plantaciones de cítricos. Procedimiento de toma de muestras. Servicio de Transferencia de Tecnología Agraria. Dirección General de Investigación y Tecnología Agraria. Consellería de Agricultura, Pesca i Alimentació. Generalitat Valenciana, pp 26

LEI, Y., KORPELAINEN, H. y LI, C. 2007. Physiological and biochemical responses to high $\mathrm{Mn}$ concentrations in two contrasting Populus cathayana populations. Chemosphere, 68: 686-694

LEONHARDT, A. 1987. Stiellähmebekämpfung im markgräflerland aufgrund der prognose nach theiler. Mitt. Klosterneuburg, 37: 130-134

LEWIS, T. 1991. Developing timber harvesting prescriptions to minimize site degradation. B.C. Minist. For., For Sci. Res. Branch, Victoria, British Columbia. Land Manage. Rep. 62

LI, S.C., HU, C.H., GONG, J., DONG, S.T. y DONG, Z.X. 2004. Effects of low phosphorus stress on the chlorophyll fluorescence of different phosphorus use efficient maize (Zea mays L.). Acta Agron. Sin., 30: 365-370

LI-COR Biosciences, Inc. 2003. Using the LI-6400. Portable Photosynthesis System. Lincoln, EEUU. Book, 1: 2-6

LICHTENTHALER, H.K. 1987. Chlorophylls and carotenoids: Pigments of photosynthetic biomembranes. Methods Enzymol., 148: 350-382

LICHTENTHALER, H.K. 2003. El estrés y la medida del estrés en las plantas. La Ecofisiología Vegetal: una ciencia de síntesis. Ed. Thomson, pp. 59-111

LILLO, C., LEA, U.S. y RUOFF, P. 2008. Nutrient depletion as a key factor for manipulating gene expression and product formation in different branches of the flavonoid pathway. Plant Cell Environ., 31(5): 587-601 
LIN, C.H. y STOCKING, C.R. 1978. Influence of leaf age, light, dark and iron deficiency on polyribosome levels in maize leaves, Plant Cell Physiol., 19: 461-470

LINDSAY, W.L. 1972. Inorganic phase equilibria of micronutrients in soils. In: J.J. Mortvedt et al. (ed.). Micronutrients in Agriculture. Soil Science Society of America, Inc., Madison, WI. pp. 41-57

LINDSAY, W.L. 1979. Chemical equilibria in soils. John Wiley \& Sons, New York

LINDSAY, W.L. 1984. Soil plant relationship associated with iron deficiency with emphasis on nutrient interactions. J. Plant Nutr., 7: 489-500

LINDSAY, W.L. 1991. Iron oxide solubilization by organic matter and its effect on iron availability. pp.: 29-36. En: Iron Nutrition and In teractions in Plants. CHEN, Y. y HADAR, Y. (eds). Kluwer Academic Publishers: Holanda

LINDSAY, W.L. y NORVELL, W.A. 1978. Development of a DPTA soil test for zinc, iron, manganese and copper. Soil Sci. Soc. Am. J., 42: 421-428

LINDSAY, W.L. y SCHWAB, A.P. 1982. The chemistry of iron in soils and its availability to plants. J. Plant Nutr., 5: 821-840

LING, Q., HUANG, W. y JARVIS, P. 2011. Use of a SPAD-502 meter to measure leaf chlorophyll concentration in Arabidopsis thaliana, Photosynth. Res., 107: 209-214

LOBREAUX, S. y BRIAT, J.F. 1991. Ferritin accumulation and degradation in different organs of pea (Pisum sativum) during development. Biochem. J., 274: 601-606

LOEPPERT, R.H. 1986. Reaction of iron and carbonates in calcareous soils. J. Plant Nutr., 9: 195-215

LOEPPERT, R.H., GEIGER, S.C., HARTWIG, R.C. y MORRIS, D.R. 1988. A comparison of indigenous soil factors influencing the Fe-deficiency chlorosis of sorghum and soybean in calcareous soils. J. Plant Nutr., 11: 1481-1492

LOEPPERT, R.H. y HALLMARK, C.T. 1985. Indigenous soil properties influencing the availability of iron in calcareous soils. Soil Sci. Soc. Am. J., 49: 597-603

LOEPPERT, R.H HALLMARK, C.T. y KOSHY, M.M. 1984. Routine procedure for rapid determination of soil carbonates. Soil Sci. Soc. Am. J., 48: 1030-1033

LOEPPERT, R.H. y SUAREZ, D.L. 1996. Carbonate and gypsum, In: D.L. Sparks, A.L. Page, P.A. Helmke, R.H. Loeppert, P.N. Soltanpour, M.A. Tabatabai, C.T. Johnson and M.E. Sumner (eds.). Methods of Soil Analysis Part 3 Chemical Methods. SSSA Special Publication No 5. Madison, WI., pp. 437-474

LOEPPERT, R.H, WEI, L.C. y OCUMPAUGH, W.R. 1994. Soil factors influencing the mobilization of iron in calcareous soils. In: Manthey, J.A., Crowley, D.E. y Luster, 
D.G. (eds). Biochemestry of metal micronutrients in the rhizosphere. CRC Press, Florida, pp 343-360

LOGAN, B.A., ADAMS, W.W. y DEMMIG-ADAMS, B. 2007. Viewpoint: avoiding common pitfalls of chlorophyll fluorescence analysis under field conditions. Funct. Plant Biol., 34: 853-859

LONGBOTTOM, M., DRY, P. y SEDGLEY, M. 2005. Molybdenum and fruitset of Merlot. Transforming Flowers to Fruit. Proceedings of a seminar held in Mildura, Victoria. Australian Society of Viticulture and Oenology, pp. 25-26

LÓPEZ-MILLÁN, A. F., MORALES, F., ABADÍA, A. y ABADÍA, J. 2001. Changes induced by $\mathrm{Fe}$ deficiency and $\mathrm{Fe}$ resupply in the organic acid metabolism of sugar beet (Beta vulgaris) leaves. Physiol. Plantarum, 112: 31-38

LÓPEZ-BUCIO, J., CRUZ-RAMÍREZ, A. y HERRERA-ESTRELLA, L. 2003. The role of nutrient availability in regulating root architecture. Current opinion in plant biology, 6(3): $280-287$

LOUE, A. 1988. Microelementos en agricultura. Mundiprensa, Madrid, España. pp. 354

LUCENA, J.J. 2000. Effect of bicarbonate, nitrate and other environmental factors on iron deficiency chlorosis. A review. J. Plant Nutr., 23:1 591-1606

LUCENA, J.J., GARATE, A., y CARPENA, O. 1987. Iron-chelates evaluation in a calcareous soil. Plant Soil, 103: 134-138

LUCENA, C., ROMERA, F.J., ROJAS, C.L., GARCÍA, M. y ALCÁNTARA, E. 2007. Bicarbonate blocks the expression of several genes envolved in the physiological responses to Fe deficiency of Strategy I plants. Funct. Plant Biol., 34: 1002-1009

MÁJER, J. 2004. Magnesium supply of the vineyards in the balaton-highlands. Proceedings of the 1st International Society of Grapevine, Acta Horticulturae, 652: 175-182

MALAKOUTI, M.J. 2006. Nutritional disorders in fruit trees on the calcareous soils of Iran. In:18th World Congress of Soil Science: Frontiers of Soil science Technology and the Information Age. $19-25^{\text {th }}$ July. Philadelphia, Pennsylvania, USA

MALDONADO-TORRES, R., ETCHEVERS-BARRA, J.D., ALCÁNTAR-GONZÁLEZ, G., RODRÍGUEZ-ALCÁZAR, J. y COLINAS-LEÓN, M.T. 2006. Morphological changes in leaves of Mexican lime affected by iron chlorosis. J. Plant Nutr., 29: 615-628

MALLICKA, N. y MOHN, F.H. 2003. Use of chlorophyll fluorescence in metal-stress research: a case study with the green microalga Scenedesmus. Ecotoxicol. Environ. Saf., 55: 64-69 
MANETAS, Y., DRINIA, A. y PETROPOULOU, Y. 2002. High contents of anthocyanins in young leaves are correlated with low pools of xanthophylls cycle components and low risk of photoinhibition. Photosynthetica, 40: 349-354

MANETAS, Y., PETROPOULOU, Y., PSARAS, G.K. y DRINIA, A. 2003. Exposed red (anthocyanic) leaves of Quercus coccifera display shade characteristics. Funct. Plant Biol., 30: 265-270

MARION, G.M., van CLEVE, K., DYRNESS, C.T. y BLACK, C.T. 1993. The soil chemical environment along a forest primary successional sequence along the Tanana River floodplain, interior Alaska. Can. J. For. Res., 23: 914-922

MARSCHNER, H. 1995. Marschner's mineral nutrition of higher plants. P. Marschner (Ed.). Academic Press, San Diego, CA.

MARSCHNER, H. y RÖMHELD, V. 1994. Strategies of plants for acquisition or iron. Plant Soil, 165: 261-274

MARSCHNER, H., RÖMHELD, V. y KISSEL, M. 1986. Different strategies in higher plants in mobilization and uptake of iron. J. Plant Nutr., 9: 695-713

MARSCHNER, H., RÖMHELD, V. y KISSEL, M. 1987. Localization of phytosiderophore release and of iron uptake along intact barley roots. Physiol. Plantarum, 71: 157162

MARSCHNER, H., TREBY, M. y RÖMHELD. 1989. Role of rootinduced changes in the rhizosphere for iron acquisition in higher plants. J. Plant Nutr. Soil Sci., 152: 197204

MARTíN, P., ÁlVAREZ, I. y del ALAMO, M. 1999. Nutrición Mineral y Fertilización de la Viña. Agrícola vergel: Fruticultura, horticultura, floricultura, 206: 83-86

MARTíN, P., DELGADO, R., GONZÁLEZ, M.R., y GALLEGOS, J.I. 2004. Colour of 'Tempranillo' grapes as affected by different nitrogen and potassium fertilization rates. Acta Horticulturae, 652: 153-159

MARTÍN, P., GONZÁLEZ, M.R., NÚÑEZ, L.C, GONZÁLEZ, R. y ZARCO-TEJADA, P.J., 2007b. Influencia de la clorosis férrica sobre el rendimiento fotosintético del viñedo cv. Tempranillo. In: Actas de las IX Jornadas de los Grupos de Investigación Enológica. GIENOL, Ed. Badajoz. 437-439

MARTíN, P., ZARCO-TEJADA, P.J., GONZÁLEZ, M.R. y BERJÓN, A. 2007a. Using hyperspectral remote sensing to map grape quality in "Tempranillo" vineyard affected by iron deficiency chlorosis. Vitis, 46: 7-14

MARTÍN, P., ZARCO-TEJADA, P.J., GONZÁLEZ, R. y GONZÁLEZ, M.R. 2008. Diagnóstico nutricional y recomendaciones de abonado en suelos calizos de la Ribera del Duero. Vida Rural, 270: 26-32 
MARTÍN-CALVARRO, L., de SANTIAGO-MARTÍN, A, QUIRÓS-GÓMEZ, J., GONZÁLEZHUECAS, C., QUINTANA, J.R., VÁZQUEZ, A., LAFUENTE, A.L., RODRÍGUEZFERNÁNDEZ, T.M., RAMÍREZ-VERA, R. 2014. Biological activity in metalcontaminated calcareous agricultural soils: The role of the organic matter composition and the particle size distribution. Environ. Sci. Pollut. Res., 21: 61766187

MARTÍNEZ-PEÑALVER, A., REIGOSA, M.J. y SÁNCHEZ-MOREIRAS, A.M. 2011. Imaging chlorophyll a fluorescence reveals specific spatial distributions under different stress conditions. Flora, 206: 836-844

MASALHA, J., KOSERGARTEN, H., ELMACI, Ö. y MENGEL, K. 2000. The central role of microbial activity for iron acquisition in maize and sunflower. Biol. Fertil. Soils, 30: 433-439

MASNEUF, I. y DUBOURDIEU, D. 1999. L’azote asimilable: intéret de son dosage par formoltitration; étude de quelques paramétres á l'origine des variations de sa teneur dans les mouts. Rev. Oenol., 93: 31-32

MATTIVI, F., GUZZON, R., VRHOVSEK, U., STEFANINI, M. y VELASCO, R. 2006. Metabolite profiling of grape: flavonols and anthocyanins. J. Agric. Food Chem., 54: 7692-7702

MATUS-PICERO, J.T. 2008. Effect of post-veraison sun light exposure on the transcriptional regulation of flavonoid synthesis in grape berry skin (Vitis vinifera L., cv. Cabernet Sauvignon).Tesis doctoral en Ciencias de la Agricultura. Santiago, Chile, pp. 214

MAUREL, C., VERDOUCQ, L., LUU, D.T. y SANTONI, V. 2008. Plant aquaporins: membrane channels with multiple integrated functions. Annu. Rev. Plant Biol., 59: 595-624

MAXWELL, K. y JONSON, G.N. 2000. Chlorophyll fluorescence - a practical guide. J. Exp. Bot., 51: 659-668

MEGGIO F., ZARCO-TEJADAP.J., MILLER J.R., MARTÍN P., GONZÁLEZ M.R., BERJÓN A. 2008. Row Orientation and Viewing Geometry Effects on Rowstructured Crops for Chlorophyll Content Estimation. Can. J. Remote Sens., 34(3): 220-234

MEGGIO, F., ZARCO-TEJADA, P.J., NÚÑEZ, L.C., SEPULCRE-CANTÓ, G., GONZÁLEZ, M.R. y MARTíN, P. 2010. Grape quality assessment in vineyards affected by iron deficiency chlorosis using narrow-band physiological remote sensing indices. Remote Sens. Environ., 114: 1968-1986

MENGEL, K. 1994. Iron availability in plant tissues-iron chlorosis on calcareous soils. Plant Soil, 165: 275-283

MENGEL, K., BREINIGER, M.T. y BULB, W. 1984. Bicarbonate, the most important factor inducing ironchlorosis in vine grapes on calcareous soils. Plant Soil, 81: 333-344 
MENGEL, K. y BÜBL, W. 1983. Verteilung von Eisen in Blättern von Weinreben mit $\mathrm{HCO}^{3-}$ induzierter Chlorose. Z. Pflanzenernähr. Bodenk, 146: 560-571

MENGEL, K. y GEURTZEN, G. 1986. Iron chlorosis on calcareous soils - Alkaline nutritional conditions as the cause for the chlorosis. J. Plant Nutr., 9: 161-173

MENGEL, K. y KIRKBY, E.A. 2001. Principles of plant nutrition, 5th ed. Kluwer Academic Publishers, Dordrecht

MENGEL, K. y MALISSIOVAS, N. 1982. Light dependent proton excretion by roots of entire vine plants (Vitis vinifera L.). Z. Pflanzenernähr. Bodenk, 145: 261-267

MENGEL, K. y SCHUBERT, S. 1985: Active extrusion of protons into deionized water by roots of intact maize plants. Plant Physiol., 79: 344-348

MENGEL, K., SCHERER, H.W. y MALISSIOVAS, N. 1979. Die chlorose aus der sicht der bodenchemie und rebenernahrung. Mitt Klosterneuburg, 29: 151-156

MENZEL, C.M., SIMPSON, D.R. y DOWLING, A.J. 1986. Water relations in passionfruit: effect of moisture stress on growth, flowering and nutrient uptake. Scien. Hort., 29: 239-249

METWALLY, A.A. 1969. Soil of the Mediterranean coastal littoral, gneiss, and classification of the soils of Daba area .PhD. Thesis, Fac. Agric. Shams. Univ.Egypt.

MILLALEO, R., REYES-DÍAZ M., IVANOV, A.G., MORA, M.L. y ALBERDI, M. 2010. Manganese as essential and toxic element for plants: transport, accumulation and resistance mechanisms. J. Soil Sci. Plant Nutr., 10: 470-481

MILLER, G.W., PUSHNIK, J.C. y WELKIE, G.W. 1984. Iron chlorosis, a worldwide problem: the relation of chlorophyll biosynthesis to iron. J. Plant Nutr., 7: 1-22

MINOLTA Camera Co., Ltd. 1989. Manual for chlorophyll meter SPAD 502. Minolta, Radiometric Instruments Div., Osaka, Japan

MIRANDA, V., BAKER, N.R. y LONG, S.P. 1981. Limitations of photosynthesis in different regions of the Zea mays leaf. New Phytol., 89: 179-190

MLIKOTA-GABLER, F., MANSOUR, F.M., SMILANICK, L.J. y HASHIM-BUCKEY, J. 2009. Influence of cluster-directed applications of potassium and calcium solutions and plant bioregulators before harvest on the quality of table grapes. In: $32^{\text {nd }}$ World Congress of Vine and Wine. $7^{\text {th }}$ General Assembly of the OIV, June $28^{\text {th }}-$ July $3^{\text {rd }}$. Zagreb, Croatia.

MOLASSIOTIS, A., TANOU, G., DIAMANTIDIS, G., PATAKAS, A. y THERIOS, I. 2006. Effects of 4-month $\mathrm{Fe}$ deficiency exposure on $\mathrm{Fe}$ reduction mechanism, photosynthetic gas exchange, chlorophyll fluorescence and antioxidant defense in 
two peach rootstocks differing in Fe deficiency tolerance. J. Plant Physiol., 163: 176-185

MOLTZ, E. 1907. Untersuchungen über die chlorose von reben, Ph.D.Thesis. University of Jena

MONGE, E., PÉREZ, C., PEQUERUL, P., MADERO, P. y VAL, J. 1993. Effect of iron chlorosis on mineral nutrition and lipid composition of thylakoid biomembrane in Prunus persica (L.) Bastch. Plant Soil, 154: 97-102

MONTES, J.M., MELCHINGER, A.E. y REIF, J.C. 2007. Novel throughput phenotyping platforms in plant genetic studies. Trends Plant Sci., 12: 433-436

MORALES, F., ABADÍA, A. y ABADÍA, J. 1990. Characterization of the xanthophyll cycle and other photosynthetic pigment changes induced by iron deficiency in sugar beet (Beta vulgaris L.). Plant Physiol., 94: 607-613

MORALES, F., ABADÍA, A. y ABADÍA, J. 1991. Chlorophyll fluorescence and photon yield of oxygen evolution in iron-deficient sugar beet (Beta vulgaris L.) leaves. Plant Physiol., 97(3), 886-893

MORALES, F., ABADÍA, A., y ABADÍA, J. 1998a. Photosynthesis, quenching of chlorophyll fluorescence and thermal energy dissipation in iron-deficient sugar beet leaves. Aust. J. Plant Physiol., 25: 403-41

MORALES, F., ABADÍA, A., BELKHODJA, R. y ABADÍA, J. 1994. Iron deficiency-induced changes in the photosynthetic pigment composition of field-grown pear (Pyrus cornrnunis L.) leaves. Plant Cell Environ., 17: 1153-1160

MORALES, F., BELKHODJA, R., ABADÍA, A. y ABAdÍA, J. 2000. Photosystem ॥ efficiency and mechanisms of energy dissipation in iron-deficient, field-grown pear trees (Pyrus communis L.). Photosynth. Res., 63: 9-21

MORALES, F., GRASA, R., ABADÍA, A. y ABADÍA, J. 1998b. Iron chlorosis paradox in fruit trees. J. Plant Nutr., 21: 815-825

MORALES, F., MOISE, N., QUÍLEZ, R., ABADÍA, A., ABADÍA, J. y Moya, I. 2001. Iron deficiency interrupts energy transfer from a disconnected part of the antenna to the rest of photosystem II. Photosynth. Res., 70(2): 207-220

MORRIS, J.B. y CAWTHON, D.L. 1982. Effects of irrigation, fruit load, and potassium fertilization on yield, quality, and petiole analysis of Concord (Vitis labrusca L.) grapes. Am. J. Enol. Vitic., 33: 145-148

MORRIS, J.B., CAWTHON, D.L. y FLEMING J.W. 1980. Effects of high rates of potassium fertilization on raw product quality and changes in $\mathrm{pH}$ and acidity during storage of Concord grape juice. Am. J. Enol. Vitic., 31:323-328 
MOYA, I., CAMENEN, L., EVAIN, S., GOULAS, Y., CEROVIC, Z.G., LATOUCHE, G., FLEXAS, J. y OUNIS, A. 2004. A new measurement for passive remote sensing. 1. Measurements of sunlight-induced chlorophyll fluorescence. Remote Sens. Environ., 91: 186-197

MPELASOKA, B.S., SCHACHTMAN, D.P., TREEBY, M.T. y THOMAS, M.R. 2003. A review of potassium nutrition in grapevines with special emphasis on berry accumulation. Aust. J. Grape Wine Res., 9(3): 154-168

MURAKAMI, T., ISE, K., HAYAKAWA, M., KAMEI, S. y TAKAGI, S.I. 1989. Stabilities of metal-complexes of mugineic acids and their specific affinities for iron (III). Chem. Lett., 12: 2137-2140

MURCHIE, E. H. y LAWSON, T. 2013. Chlorophyll fluorescence analysis: a guide to good practice and understanding some new applications. J. Exp. Bot., 64(13): 3983-3998

MUSTAFA, A., ELSHAZLY, A.S.A., EISSA, A.M. y ZAHRAN, M.A. 1986. Effect of foliar applications of chelated $\mathrm{Fe}, \mathrm{Zn}$ and $\mathrm{Mn}$ on leaf mineral content, yield and fruit quality of Roumi Red grape-vines. Ann. Agric. Sci., 31: 623- 635

NEDBAL, L., SOUKUPOVA, J., WHITMARSH, J. y TRTILEK, M. 2000. Post harvest imaging of chlorophyll fluorescence from lemons can be used to predict fruit quality. Photosynthetica, 38: 571-579

NEDBAL, L. y WHITMARSH, J. 2004. Chlorophyll Fluorescence Imaging of Leaves and Fruits. En Chlorophyll a Fluorescence a Signature of Photosynthesis, G. Papaqeorgiou y Govindjee, eds. Springer, Dordrecht, Netherlands, pp. 389-407

NEDUNCHEZHIAN, N., MORALES, F., ABADÍA, A. y ABADÍA, J. 1997. Decline in photosynthetic electrón transport activity and changes in thylakoid protein pattern in field grown iron deficient Peach (Prunus persica L.). Plant Sci., 129: 29-38

NETTO, A.T., CAMPOSTRINI, E., de OLIVEIRA, J.G. y BRESSAN-SMITH, R.E. 2005. Photosynthetic pigments, nitrogen, chlorophyll a fluorescence and SPAD-502 readings in coffee leaves Scientia Horticulturae, 104: 199-209

NEUMANN, G. y RÖMHELD, V. 2001. The release of root exudates as affected by the plant's physiological status. In: PINTON, R., VARANINI, Z. y NANNIPIERI, P. (eds) The rhizosphere: Biochemistry and organic substances at the soilplant interface. Marcel Dekker, New York, pp. 41-94

NIKOLIC, M. 1998. The role of the redox systems in uptake and translocation of iron by higher plants. Lugoslav. Physiol Pharmacol. Acta, 34: 479-489

NIKOLIC, M. y KASTORI, R. 2000. Effect of bicarbonate and Fe supply on Fe nutrition of grapevine. J. Plant Nutr., 23: 1619-1627

NIKOLIC, M. y RÖMHELD, V. 1999. Mechanism of Fe uptake by the leaf symplast: Is Fe inactivation in leaf a cause of Fe deficiency chlorosis? Plant Soil, 215: 229-237 
NIKOLIC, M. y RÖMHELD, V. 2002. Does high bicarbonate supply to roots change availability of iron in the leaf apoplast? Plant Soil, 241: 67-74

NIKOLIC, M. y RÖMHELD, V. 2003. Nitrate does not result in iron inactivation in the apoplast of sunflower leaves. Plant Physiol., 132: 1303-1314

NOCTOR, G. y FOYER, C.H. 1998. Ascorbate and glutathione: keeping active oxygen under control. Annu. Rev. Plant Biol., 49(1): 249-279

NÚÑEZ, V., MONAGAS, M., GÓMEZ-CORDOBÉS, M.C. y BARTOLOMÉ, B. 2004. Vitis viniferaL. cv. Graciano grapes characterized by its anthocyanin profile. Postharvest Biol. Technol., 31: 69-79

O.I.V. (1996). Résolution VITI 4/95. Diagnostic foliare une métode harmonisée. Bull O.I.V. París, 69: 779-780

OBENLAND, D., FELIZIANI, E., ZHU, S., ZHAO, X., MARGSAN, D.A., MLIKOTAGABLER, F., VAN ZYLC, S., ROMANAZZIB, G., SMILANICKA, J.L., BENOMOUALEME, D., KAPLUNOVE, T. y LICHTER, A. 2015. Potassium application to table grape clusters after veraison increases soluble solids by enhancing berry water loss. Scientia Horticulturae, 187, 58-64.

OBREZA, T.A., ALVA, A.K. y CALVERT. D.V. 1993. Citrus fertilizer management on calcareous soils. Circular 1127, Soil and Water Science Department, Florida Cooperative Extension Service, Institute of Food and Agricultural Sciences, University of Florida.

OJEDA, H., ANDARA, C., KRAEVA, E., CARBONNEAU, A. y DELOIRE, A. 2002. Influence of pre- and postveraison water deficit on synthesis and concentration of skin phenolic compounds during berry growth of Vitis vinifera cv. Syrah. Am. J. Enol. Vitic., 53: 261-267

OLSEN, R.A., CLARK, R.B. y BENNETT. J.H. 1981. The enhancement of soil fertility by plants roots. Am. Sci., 69: 378

OMARA, M.A. 1993. An evaluation of the use of synthetic enveloped materials for subsurface drains in western Delta soils. Ph.D. Thesis, Fac. Agric. Ain. Shams. Univ. Egypt

ONYEZILI, F.N. y ROSS, J.D. 1993. Iron-deficiency stress responses of 5 gramineous monocots. J. Plant Nutr., 16: 953-974

ORTEGA-REGULES, A., ROMERO-CASCALES, I., ROS, J., LÓPEZ, J. y GÓMEZ, E. 2006. A first approach towards the relationship between grape skin cell-wall composition and anthocyanin extractability. Analytica Chimica Acta, 563: 26-32

OTTENEDER, H., MARX, R. y ZIMMER, M. 2004. Analysis of the anthocyanin composition of Cabernet Sauvignon and Portugieser wines provides an objective assessment of the grape varieties. Aust. J. Grape Wine Res., 10: 3-7 
OXBOROUGH, K. 2004. Imaginig of chlorophyll a fluorescence: theoretical and practical aspects an emerging technique for the monitoring of photosynthetic performance. J. Exp. Bot., 55: 1195-1205

PARKER, D., KENNAN, R.A., MYERS, G.S., PAULSEN, I.T. y ROOD, J.I. 2005. Identification of a Dichelobacter nodosus ferric uptake regulator and determination of its regulatory targets. J. Bacteriol, 187: 366-375

PARRA, M.A., FERNÁNDEZ-ESCOBAR, R., NAVARRO, C. y ARQUERO, O. 2003. Los suelos y la fertilización del olivar cultivado en zonas calcáreas. Ed. Mundi-Prensa. Madrid, pp. 37-38

PEARCE, R.C., LI, Y. y BUSH, L.P.1999. Calcium and bicarbonate effects on the growth and nutrient uptake of burley tobacco seedlings: hydroponic culture. J. Plant Nutr. 22: 1069-1078

PEARSON, R.C. y GOHEEN, A.C. 1998. Compendium of grape diseases. 4th Edition. The American Phytopathological Society, USA

PEÑA-NEIRA, A., DUEÑAS, M., DUARTE, A., HERNÁNDEZ, T., ESTRELLA, I. y LOYOLA, E. 2004. Effects of ripening stages and of plant vegetative vigor on the phenolic composition of grapes (Vitis vinifera L.) cv. Cabernet Sauvignon in the Maipo Valley (Chile). Vitis, 43: 51-57

PEÑUELAS, J. y FILELLA, I. 1998. Visible and near-infrared reflectance techniques for diagnosing plant physiological status. Trends Plant Sci., 3: 151-156

PERYEA, F. y KAMMERECK, R. 1997. Use of SPAD meter to quantify the effectiveness of mid- summer trunk injection of iron on iron deficient pear trees. Acta Horticulturae, 448: 359-360.

PESTANA, M., VARENNES, A., ABADÍA, J. y FARIA, E. A. 2005. Differential tolerance to iron deficiency of citrus rootstocks grown in nutrient solution. Scientia Horticulturae, 104: $25-36$

PESTANA, M., VARENNES, A. y ARAUJO-FARIA, E. 2003. Diagnosis and correction of iron chlorosis in fruti trees: a review. J. Food Agric. Environ., (1): 46-51

PEUKE, A.D. 2009. Nutrient composition of leaves and fruit juice as affected by soil and foliar fertilization. Journal of Plant Nutrition and Soil Science, 172: 557- 564

PINKERTON, A. y SIMPSON, J.R. 1986. Interactions of surface drying and subsurface nutrients affecting plant-growth on acidic soil profiles from an old pasture. Aust. J. Exp. Agric., 26: 681-689

PINTON, R., CESCO, S., SANTI, S., AGNOLON, F. y VARANINI, Z. 1999. Waterextractable humic substances enhance iron deficiency responses by Fe-deficient cucumber plants. Plant Soil, 210: 145-157 
PIRIE, A.J.G. y MULLINS, M.G. 1980. Concentration of phenolics in the skin of grape berries during fruit development and ripening. Am. J. Enol. Vitic., 31(1): 34-36

PITTMAN, J. 2005. Managing the manganese: molecular mechanisms of manganese transport and homeostasis. New Phytol., 167: 733-742

PLATT-ALOIA, K.A., THOMSON, W.W. y TERRY, N. 1983. Changes in plastid ultrastructure during iron-mediated chloroplast development, Protoplasma, 114: 8592

PONI, S., QUARTIERI, M. y TAGLIAVINI, M. 2003. Potassium nutrition of Cabernet Sauvignon grapevines (Vitis vinifera L.) as affected by shoot trimming. Plant Soil, 253: $341-351$

PONI, S., BERNIZZONI, F., CIVARDI, S. y LIBELLI, N. 2009. Effects of pre-bloom leaf removal on growth of berry tissues and must composition in two red Vitis vinifera $L$. cultivars. Aust. J. Grape Wine Res., 15: 185-193

PONTIGGIA, A., DE NISI, P. y ZOCCHI, G. 2003. Effect of iron deficiency on RNA and protein synthesis in cucumber roots. J. Plant Nutr., 26: 2177-2186

RAATH, P.J. 2012. Effect of varying levels of nitrogen, potassium and calcium nutrition on table grape vine physiology and berry quality (Doctoral dissertation, Stellenbosch: Stellenbosch University)

RABOTTI, G., DE NISI, P. y ZOCCHI, G. 1995. Metabolic implications in the biochemical responses to iron deficiency in cucumber (Cucumis sativus L.) roots. Plant Physiol., 107: 1195-1199

RABOTTI, G. y ZOCCHI, G. 1994. Plasma membrana-bound $\mathrm{H}^{+}$-ATPase and reductase activities in Fe-deficient cucumber roots. Physiol. Plantarum, 90: 779-785

RAESE, J.T., PARISH, C.L. y STAIFF, D.C. 1986. Nutrition of apple and pear trees with foliar sprays, trunk injections or soil applications of iron compounds. J. Plant Nutr., 9: $987-999$

RANIERI, A., CASIAGNA, A., BALDAN, B., SEBASTIANI, L. y SOLDATINI, G.F. 2003. $\mathrm{H}_{2} \mathrm{O}_{2}$ accumulation in sunflower leaves as a consequence of iron deprivation. J. Plant Nutr., 26: 2187-2196

RAZAVI, F., POLLET, K., STEPPE y Van LABEKE, M.C. 2008. Chlorophyll fluorescence as a tool for evaluation of drought stress in strawberry. Photosynthetica, 46: 631633

REEVE, J.R., CARPENTER-BOGGS, L., REGANOLD, J.P., YORK, A.L., McGOURTY, G. y McCLOSKEY, L.P. 2005. Soil and winegrape quality in biodynamically and organically managed vineyards. Am. J. Enol. Vitic., 56: 367-376 
REICHMAN, S.M. y PARKER, D.R. 2007. Probing the effects of light and temperature on diurnal rhythms of phytosiderophore release in wheat. New Phytol., 174: 101-108

RENGELI, Z. 2000. Uptake and transport of manganese in plants. In: A. Sigel, H. Sigel (eds.). Metal lons in Biological Systems. New York, Marcel Dekker, pp. 57-87

REYES, J.M., del CAMPILLO, M.C. y TORRENT, J. 2006. Soil properties influencing iron chlorosis in grapevines in the Montilla-Moriles area, Southern Spain. Commun Soil Sci. Plan., 37: 1723-1729

REYES, I. y TORRENT, J. 1997. Citrate-ascorbate as a highly selective extractant for poorly crystalline iron oxides. Soil Sci. Soc. Am. J., 61: 1647-1654

REYNOLDS, A.G., PEARSON, E.G., De SAVIGNY, C., COVENTRY, J. y STROMMER, J. 2007. Interactions of vine age and reflective mulch upon berry, must, and wine composition of five Vitis vinifera cultivars. Int. J. Fruit Sci., 7: 85-119

RIBÉREAU-GAYON, P., DUBOURDIEU, D., DONĖCHE, B. y LONVAUD, A. 2006. Handbook of enology. The microbiology of wine and vinifications. $2^{\text {nd }}$ ed. West Sussex. England, John Wiley \& Sons Ltd

RIBÉREAU-GAYON, P. y GLORIES, Y. 1987. Phenolics in grapes and wine. In Proceedings of the sixth Australian wine industry technical conference, Terry Lee, Adelaide, South Australia, 14-17 July, pp. 247-256

ROBINSON, J.B. 1995. Grapevine Nutrition. In: Coombe, B.G. y Dry, P.R. (eds.) Viticulture Vol. 2 Practices. Winetitiles, Adelaide, pp. 178-208

ROBINSON, N.J., PROCTER, C.M., CONNOLLY, E.L. y GUERINOT, M.L. 1999. A ferricchelate reductase for iron uptake from soils. Nature, 397: 694-697

ROBY, G., HARBERTSON, J.F., ADAMS, D.O. y MATTHEWS, M.A. 2004. Berry size and vine water deficits as factors in winegrape composition: anthocyanins and tannins. Aust. J. Grape Wine Res., 10: 100-107

ROBY, G. y MATTHEWS, M.A. 2004. Relative proportions of seed, skin and flesh in ripe berries from Cabernet Sauvignon grapevines grown in a vineyard either well irrigated or under water deficit. Aust. J. Grape Wine Res., 10: 74-82

RODECAP, K.D., TINGEY, D.T. y LEE, E.H. 1994. Iron nutrition influence on cadmium accumulation by Arabidopsis thaliana (L.) Heynh. J. Environ Qual, 23: 239-246

ROGIERS, S.Y., GREER, D.H., HATFIELD, J.M., ORCHARD, B.A. y KELLER, M. 2006. Mineral sinks within ripening grape berries (Vitis vinifera L.). Vitis, 45(3): 115-123

ROLDÁN, R., BARRÓN, V. y TORRENT, J. 2002. Experimental alteration of vivianite to lepidocrocite in a calcareous medium. Clay Miner, 37: 709-718 
ROMBOLÀ, A. D., BRÜGGEMANN, W., TAGLIAVINI, M., MARANGONI, B. y MOOG, P. R. 2000. Iron source affects iron reduction and re-greening of kiwifruit (Actinidia deliciosa) leaves. J. Plant Nutr., 23: 1751-1765

ROMBOLÀ, A.D. y TAGLIAVINI, M. 2006. Iron nutrition of fruit tree crops. In: ABADÍA, J. y BARTON, L.L. (eds). Iron Nutrition and Interactions in Plants. Springer, Dordrecht, pp 61-83

ROMERA, F.J. y ALCÁNTARA, E. y de la GUARDIA, M.D. 1991. Characterization of tolerance to iron chlorosis in different peach rootstocks grown in nutrient solution. Effect of bicarbonate and phosphate. Plant Soil, 130: 121-125

ROMERA, F.J. y ALCÁNTARA, E. y de la GUARDIA, M.D. 1992. Effects of bicarbonate, phosphate and high $\mathrm{pH}$ on the reducing capacity of Fe-deficient sunflower and cucumber plants. J. Plant Nutr., 15: 1519-1530

ROMERA, F.J. y ALCÁNTARA, E. 2004. Ethylene involvement in the regulation of Fedeficiency stress responses by Strategy I plants. Funct. Plant Biol., 31: 315-328

ROMERO-CASCALES, I., ORTEGA-REGULES, A., LÓPEZ-ROCA, J., FERNÁNDEZFERNÁNDEZ, J. y GÓMEZ-PLAZA, E. 2005. Differences in anthocyanin extractability from grapes to wines according to variety. Am. J. Enol. Vitic., 56(3): 212-219

RÖMHELD, V. 1991. The role of phytosiderophores in acquisition of iron and other micronutrients in gramineous species-an ecological approach. Plant Soil, 130: 127134

RÖMHELD, V. 1997. The chlorosis paradox: Fe inactivation in leaves as a secondary event in Fe deficiency chlorosis. In: Abstracts 9th International Symposium on iron Nutrition and Interactions in Plants. Hohenheim, Stuttgart, Germany, pp. 10

RÖMHELD, V. 2000. The chlorosis paradox: Fe inactivation as a secondary event in chlorotic leaves of grapevine. J. Plant Nutr., 23: 1629-164

RÖMHELD, V. y KRAMER, D. 1983. Relationship between proton efflux and rhizodermal transfer cells induced by iron-deficiency. Zeitschrift fur pflanzenphysiologie, 113: 73-83

RÖMHELD, V. y MARSCHNER, H. 1986. Evidence for specific uptake system for iron phytosiderophores in roots of grasses. Plant Physiol., 80: 175-180

RÖMHELD, V. y MARSCHNER, H. 1990. Genotypical differences among gramineous species in release of phytosiderophores and uptake of iron phytosiderophores. Plant Soil, 123: 147-153

RÖMHELD, V. y NIKOLIC, M. 2007. Iron. In: Baker, A.V. y Pilbeam, D.J. (eds) Handbook of Plant Nutrition. Taylor \& Francis Group, Boca Raton, pp. 329-350 
ROUSE, J.W., HAAS, R.H., SCHELL, J.A., DEERING, D.W. 1973. Monitoring vegetation systems in the great plains with ERTS. Proc. Third ERTS Symp. NASA, 351(1): 309-317

RUHL, E.H., FUDA, A.P. y TREEBY, M.T. 1992. Effect of potassium, magnesium and nitrogen supply on grape juice composition of Riesling, Chardonnay and Cabernet Sauvignon vines. Aust. J. Exp. Agric., 32: 645-649

RUSSO, M.A., SAMBUCO, F. y BELLIGNO, A. 2010. The response to iron deficiency of two sensitive grapevine cultivars grafted on a tolerant rootstock. Afr. J. Biochem. Res., 4: 33-42

SABIR, A., BILIR-EKBIC, H., ERDEM, H. y TANGOLAR, S. 2010. Response of four grapevine (Vitis spp.) genotypes to direct or bicarbonate-induced iron deficiency. Span. J. Agric. Res., 8: 823-829

SACCHI, K.L., BISSON, L.F. y ADAMS, D.O. 2005. A Review of the effect of winemaking techniques on phenolic extraction in red wines. Am. J. Enol. Vitic., 56: 197-206

SÁENZ-NAVAJAS, M., CAMPO, E., FERNÁNDEZ-ZURBANO, P., VALENTIN, D. y FERREIRA, V. 2010a. An assessment of the effects of wine volatiles on the perception of taste and astringency in wine. Food Chem., 121: 1139-1149

SÁENZ-NAVAJAS, M., FERREIRA, V., DIZY, M. y FERNÁNDEZ-ZURBANO, P. 2010b. Characterization of taste-active fractions in red wine combining HPLC fractionation, sensory analysis and ultra performance liquid chromatography coupled with mass spectrometry detection. Anal. Chim. Acta, 673: 151-159

SAFFORD, L.O. 1975. Effect of manganese level in nutrient solution on growth and magnesium content of Pinus radiata seedlings. Plant Soil, 42: 293-295.

SAINT-CRIQ, N., VIVAS, N. y GLORIES, Y. 1998. Maturation phenolique des raisins rouges. Relation avec la quelite des vins. Comparison des cepages Merlot et Tempranillo. Prog. Agric. Vitic., 115(13): 306-318

SAKAGUCHI, T., NISHIZAWA, N.K., NAKANISHI, H., YOSHIMURA, E. y MORI, S. 1999. The role of potassium in the secretion of mugineic acids family phytosiderophores from iron-deficient barley roots. Plant Soil, 215: 221-227

SALISBURY, F.B. y ROSS, C.W. 1992. Plant Physiology 4th Edition. Wadsworth Publishing Company, USA

SÁNCHEZ-ALCALÁ I., BELLÓN, F., del CAMPILLO, M.C., BARRON, V. y TORRENT J. 2012. Application of synthetic siderite $\left(\mathrm{FeCO}_{3}\right)$ to the soil is capable of alleviating iron chlorosis in olive trees. Sci Hortic, 138: 17-23

SÁNCHEZ-de MIGUEL, P., BAEZA, P., JUNQUERA, P. y LISSARRAGUE, J.R. 2010. Vegetative development: Total leaf area and surface area indexes. In: 
Methodologies and results in grapevine research (Delrot S., Medrano H., Or E., Bavaresco L., Grando S., eds). Springer, Dordrecht. pp. 31-44

SÁNCHEZ-RODRÍGUEZ, A.R., del CAMPILLO, M.C. y TORRENT, J. 2014. The severity of iron chlorosis in sensitive plants is related to soil phosphorus levels. J. Sci. Food Agric., 94(13): 2766-2773

SANTESTEBAN, L.G., MIRANDA, C., JIMÉNEZ, C., FUENTEMILLA, M., URRETAVIZCAYA, I. y TISSEYRE, B. 2010. Evaluación del interés del índice NDVI para la delimitación de unidades de manejo diferenciado en una explotación vitícola. Revista de Teledetección, 33: 11-16

SANZ, M., CAVERO, J. y ABADÍA, J. 1992. Iron chlorosis in the Ebro river basin. Span. J. Plant Nutr., 15: 1971-1981

SANZ-ENCINAS, M. y MONTAÑÉS L. 1997. Diagnóstico visual de la clorosis férrica. ITEA, 93: 7-22

SAMAR, S.M., SHAHABIAN, M., FALLAHI, E., DAVOODI, M.H., BAGHERI, Y.R. y NOORGHOLIPOOR, F. 2007. Iron deficiency of apple tree as affected by increasing soil available phosphorus. J. Plant Nutr., 30: 1-7

SAS INSTITUTE. 2004. SAS Procedure Guide, Version 9.1.3. SAS Institute Inc. Cary (Estados Unidos).

SAYED, O.H. 1998. Analysis of photosynthetic responses and adaptation to nitrogen starvation in Chlorella using in vivo chlorophyll fluorescence. Photosynthetica, 35: 611-619

SCHACHTMAN, D.P. y SHIN, R. 2007. Nutrient sensing and signaling: NPKS. Annu. Rev. Plant Biol., 58: 47-69

SCHENKEVELD, W.D.C., DIJCKER, R., REICHWEIN, A.M., TEMMINGHOFF, E.J.M. y van RIEMSDIJK, W.H. 2008. The effectiveness of soil-applied FeEDDHA treatments in preventing iron chlorosis in soybean as a function of the $0,0-$ FeEDDHA content. Plant Soil, 303: 161-176

SCHLEE, D., REINBOTHE, D. y FRITSCHE, W. 1968. Der Einfluss von eisen auf den purinstoffwechsel und die riboflavinbildung von Canadida guilliermondii (cast). Lang et G. Allg. Mikrobiol, 8: 127-138

SCHMIDT, W. 2003. Iron solutions: acquisition strategies and signaling pathways in plants. Trends Plant Sci., 8: 188-193

SCHMIDT, W. 2006. Iron stress responses in roots of strategy I plants. In Iron nutrition in plants and rhizospheric microorganisms. Barton, L.L. y Abadía, J. (eds). Springer. Netherlands. 229-250 
SCHMIDT, W. y BARTELS, M. 1997. Topography of the NADH-linked feric chelate (turbo) reductase in plasma membrane from Plantago roots. In: IX International Symposium on iron nutrition and interactions in plants. University of Hoheneim. Stuttgart. Germany

SCHMIDT, W. y SCHUCK, C. 1996. Pyridine nucleotide pool size changes in iron-deficient plantago lanceolata roots during reduction of external oxidants. Physiol. Plantarum, 98: $215-221$

SCHÖNER, S. y KRAUSE, G.H. 1990. Protective systems against active oxygen species in spinach: response to cold acclimation in excess light. Planta, 180: 383-389

SCHREINER, R.P., LEE, J. y SKINKIS, P.A. 2013. N, P, and K Supply to Pinot noir Grapevines: Impact on Vine Nutrient Status, Growth, Physiology, and Yield. Am. J. Enol. Vitic, 64(1): 26-38

SCHREINER, R.P., SCAGEL, C.F. y BAHAM, J. 2006. Nutrient uptake and distribution in a mature "Pinot noir" vineyard. HortScience, 41(2): 336-345

SCHREINER, R.P., SCAGEL, C.F. y LEE, J. 2014. N, P, and K supply to Pinot noir grapevines: Impact on berry phenolics and free amino acids. American Journal of Enology and Viticulture, 65(1), 43-49

SCHWARZ, G. y MENDEL, R.R. 2006. Molybdenum cofactor biosynthesis and molybdenum enzymes. Annu. Rev. Plant Biol., 57: 623-647

SCHWERTMANN, U. 1964. Differenzierung der eisenoxide des bodens durch extraktion mit ammoniumoxalatlösung. Z Flanzenähr. Düng Bodenk, 105: 194-202

SCHWERTMANN, U. 1991. Solubility and dissolution of iron oxides. In: CHEN, Y. y HADAR, Y. (eds). Iron nutrition and interactions in plants. Kluwer Academic Publishers, The Netherlands, pp. 3-27

SCHWERTMANN, U. y TAYLOR, R.M. 1989. Iron oxides. In: DIXON, B. y WEED, S.B. (eds). Minerals in soil environments, $2^{\text {nd }}$ ed. Soil Sci. Soc. Am. Madison, Wisconsin, pp. 379-438

SENI, A. y MARSHED, A.1998. Hydroulic condectivity of calcareous soils as affected by salinity and sodicity. Commun..Soil Sci. Plant Anal, 31: 69-80

SETLIK, I., ALLAKHVERDIEV, S.I., NEDBAL, L., SETLIKOVA, E. y KLIMOV, V.V. 1990. Three types of photosystem II photoinactivation. 1. Damaging processes on the acceptor side. Photosynth. Res., 23: 39-48

SHANMUGAM, V., LO, J.C., WU, C.L., WANG, S.L., LAI, C.C., CONNOLLY, E.L., HUANG, J.L. y YEH, K.C. 2011. Differential expression and regulation of ironregulated metal transporters in Arabidopsis halleri and Arabidopsis thaliana - the role in zinc tolerance. New Phytol., 190: 125-137 
SHEHATA, A.A. 1975. Physicochemical and micromorphological studies on Egyptian calcareous soil. PhD. Thesis, Fac. Agric. Cairo Univ. Egypt

SHI, W.M., CHINO, M., YOUSSEF, R.A., MORI, S. y TAKAGI, S. 1988. The occurrence of mugineic acid in the rhizosphere soil of barley plant. Soil Sci. Plant Nutr., 34: 585592

SHMIDTS-EIBERGER, M., HAEFS, R y NOGA, G., 2002. Enhancing biological efficacy and rainfastness of foliar applied calcium chloride solutions by addition of rapeseed oil surfactants. J. Plant Nutr. Soil Sci., 165(5): 634-639

SIEBNER-FREIBACH, H., HADAR, Y. y CHEN, Y. 2003. Siderophores sorbed on Camontmorillonite as an iron source for plants. Plant Soil, 251: 115-121

SIJMONS, P.C., KOLATTUKUDY, P.E. y BIENFAIT, H.F. 1985. Iron deficiency decreases suberization in bean roots through a decrease in suberin-specific peroxidase activity. Plant Physiol., 78: 115-120

SIMS, J.T. y JOHNSON, G.V. 1991. Micronutrient soil tests. In J. J. Mortvedt et al. (ed.). Micronutrients in agriculture. 2nd. Edition. Book series No. 4. SSSA. Madison, Wisconsin, EE.UU

SINGH, A.L., CHAUDHARI, V., KORADIA, V.G. y ZALA, P.V. 1995. Effect of excess irrigation and iron and sulphur fertilizers on the chlorosis, dry matter production, yield and nutrients uptake by groundnut in calcareous soil. Agrochimica, 39: 184198

SINGH, B. 2002. Effects of macro and micro nutrient spray on fruit yield and quality of grapes (Visit vinifera L.) cv. Perlette. Acta Hort., 594: 197-202

SKINNER, P.W. y MATTHEWS, M.A. 1989. Reproductive Development in Grape (Vitis vinifera L.) under Phosphorous-Limited Conditions. Scientia Horticulturae, 38: 4960

SKINNER, P.W. y MATTHEWS, M.A. 1990. A Novel interaction of magnesium translocation with the supply of phosphorous to root of grapevine (Vitis vinifera L.). Plant Cell Environ., 13: 821-826

SMART, R.E. y ROBINSON, M. 1991. Sunlight into the Wine: A Handbook for Winegrape Canopy Management. Winetitles, Adelaide, pp. 88

SMITH, B.R. Y CHENG, L.L. 2006. Fe-EDDHA alleviates chlorosis in "Concord" grapevines grown at high $\mathrm{pH}$. HortSci., 41: 1498-1501

SMOLARZ, K y MERCIK, S. 1997. Growth and yield of grape in response to long term (since 1923) different mineral fertilization. Acta Horticulturae, 448: 42-432. 
SOLFANELLI, C., POGGI, A., LORETI, E., ALPI, A. y PERATA, P. 2006. Sucrose-specific induction of the anthocyanin biosynthetic pathway in Arabidopsis. Plant Physiol., 140: 637-646.

SONG, C.Z., LIU, M.Y., MENG, J.F., CHI, M., XI, Z.M. y ZHANG, Z.W. 2015. Promoting effect of foliage sprayed Zinc Sulfate on accumulation of sugar and phenolics in berries of Vitis vinifera cv. Merlot growing on Zinc deficient soil. Molecules, 20: 2536-2554

SPÁČILOVÁ, V. y ŠAFRÁNKOVÁ, I. 2011. Potential of chlorophyll fluorescence and VIS/NIR spectroscopy measurement use for the detection of nitrogen content and disease infection of apple leaves. Acta Universitatis Agriculturae Et Silviculturae Mendelianae Brunensis, 59: 39

SPAYD, S.E., TARARA, J.M., MEE, D.L. y FERGUSON, J.C. 2002. Separation of sunlight and temperature effects on the composition of Vitis vinifera cv. Merlot berries. Am. J. Enol. Vitic., 53: 171-182

SPILLER, S.C. y TERRY, N. 1980. Limiting factors in photosynthesis. II. Iron stress diminishes photochemical capacity by reducing the number of photosynthetic units. Plant Physiol., 65: 121-125

SRIVASTAVA, A.K. y SINGH, S. 2009. Zinc nutrition in "Nagpur" mandarin on haplustert. J. Plant Nutr., 32: 1065-1081

STARK, Z., NIEMYSKA, B., BOGDAN, J. y TAWALBEH, R.N. 2000. Response of Tomato Plants to Chilling Stress in Association with Nutrient or Phosphorus Starvation. Plant Soil, 226: 99-106

STEELE, M., GITELSON, A., RUNDQUIST, D. y MERZLYAK, M. 2009. Nondestructive estimation of anthocyanin content in grapevine leaves. Am. J. Enol. Vitic., 60(1): 87-92

STEPHAN, U.W. y SCHOLZ, G. 1993. Nicotinamine: mediator of transport of iron and heavy metals in the phloem? Physiol. Plant, 88: 522-529

STEPHAN, U.W. 2002. Intra- and intercellular iron trafficking and subcellular compartmentation withn roots. Plant Soil. 241: 19-25

STEYN, W.J., WAND, S.J.E., HOLCROFT, D.M. y G. JACOBS. 2002. Anthocyanins in vegetative tissues: a proposed unified function in photoprotection. New Phytologist, 155: $349-361$

SUSÍN, S., ABADÍA, A., GONZÁLEZ-REYES, J.A., LUCENA, J.J. y ABADÍA, J. 1996. The $\mathrm{pH}$ requirement for in vivo activity of the iron-deficiency-induced "Turbo" ferric chelate reductase. A comparison of the iron-deficiency-induced iron reductase activities of intact plants and isolated plasma membrane fractions insugar beet. Plant Physiol., 110: 111- 123 
TAGLIAVINI, M. y ROMBOLÀ, A.D. 2001. Iron deficiency and chlorosis in orchard and vineyard ecosystems. Eur. J. Agron., 15: 71-92

TAIZ, L. y ZEIGER, E. 2002. Plant Physiology, 3rd edition, Sinauer Associates, Sunderland, Massachusetts, USA.

TAKAGI, S.I. 1976. Naturally occurring iron-chelating compounds in oat-root and rice-root washings. 1. Activity measurement and preliminary characterization. Soil Sci. Plant Nutr., 22: 423-433

TAKAGI, S.I., KAMEI, S. y YU, M.H. 1988. Efficiency of iron extraction from soil by mugineic acid family phytosiderophores. J. Plant Nutr., 11: 643-651

TAKAGI, S.I., NOMOTO, K. y TAKEMOTO, T. 1984. Physiological aspect of mugineic acid, a possible phytosiderophore of graminaceous plants. J. Plant Nutr., 7: 469477

TALIBUDEEN, O. 1981. Precipitation. In D.J. Greenland and M.H.B. Hayes, edc. The chemistry of soil processes. John Wiley and Sons, New York, New York, pp. 81114

TANG, Y., WEN, X., LU, Q., YANG, Z., CHENG, Z. y LU C. 2007. Heat stress induces an aggregation of the light-harvesting complex of photosystem II in spinach plants. Plant Physiol., 143: 629-638

TARDAGUILA, J., BALUJA, J., ARPON, L., BALDA, P. y OLIVEIRA, M.T. 2011. Variations of soil properties affect the vegetative growth and yield components of Tempranillo grapevines. Precision Agriculture, 12: 762-773

TAVARES, S., VESENTINI, D., FERNANDES, J.C., FERREIRA, R.B., LAUREANO, O., RICARDO-Da SILVA, J.M. y AMÂNCIO, S. 2013. Vitis vinifera secondary metabolism as affected by sulfate depletion: Diagnosis through phenylpropanoid pathway genes and metabolites. Plant Physiol. Biochem., 66: 118-126

TEIXEIRA, A., EIRAS-DIAS, J., CASTELLARIN, S.D. y GERÓS, H. 2013. Berry phenolics of grapevine under challenging environments. Int. J. Mol. Sci., 14: 1811-18739

TERRY, N. 1980. Limiting factors in photosynthesis I. Use of iron stress to control photochemical capacity in vivo. Plant Physiol., 65: 114-120

TERRY, N. y ABADÍA, J. 1986. Function of iron in chloroplasts. J. Plant Nutr., 9: 609-646

TERRY, N. y LOW, G. 1982. Leaf chlorophyll content and its relation to the intracellular localization of iron. J. Plant Nutr., 5: 301-310

TERRY, N. y ZAYED, A. M. 1995. Physiology and biochemistry of leaves under iron deficiency. In Iron Nutrtion in Soils and Plants. Kluwer Academic Publishers. Dordrecht, pp. 283-294 
THEIL, E.C. 1987. Ferritin: structure, gene regulation, and cellular function in animals, plants and microorganisms. Annu. Rev. Biochem., 56: 289-315

TIFFIN, L.O. 1966. Iron translocation I. Plant culture, exudate sampling, iron citrate analysis. Plant Physiol., 41: 1051-1060

TIFFIN, L.O. 1970. Translocation of iron citrate and phosphorous in xylem exudate of soybeans. Plant Physiol., 45: 280-283

TINUS, R.W. 1987. Modification of seed covering material yields more and larger pine seedlings. Tree Planter's Notes, 38: 11-13

TISSEYRE, B., MAZZONI, C. y FONTA, H. 2008. Within-field temporal stability of some parameters in viticulture: Potential toward a site specific management. Journal International des Sciences de la Vigne et du Vin, 42(1): 27-39

TOPALOVIC A., SLATNAR, A., STAMPAR, F., KNEZEVIC, M. y VEBERIC, R. 2011. Influence of foliar fertilization with $\mathrm{P}$ and $\mathrm{K}$ on chemical constituents of grape cv. "Cardinal". J. Agr. Food Chem., 59: 10303-10310

TORRENT, J. 1987 Rapid and slow phosphate sorption by Mediterranean soils. Effects of iron-oxides. Soil Sci. Soc. Am. J., 51: 78-82

TORRENT, J. 1995. Genesis and properties of the soils of the Mediterranean regions. Università degli Studi di Napoli Federico II, Dipartimento di Scienze ChimicoAgrarie, Naples, Italy

TOSELLI, M., MARANGONI, B. y TAGLIAVINI, M. 2000. Iron content in vegetative and reproductive organs of nectarin trees in calcareous soils during the development of chlorosis. Europ. J. Agronomy, 13: 279-286

TOULON, V., SENTENAC, H., THIBAUD, J.B., DAVIDIAN, J.C., MOULINEAU, C. y GRIGNON, C. 1992. Role of apoplast acidification by the $\mathrm{H}^{+}$pump. Effect on the sensitivity of $\mathrm{pH}$ and $\mathrm{CO}_{2}$ of iron reduction by roots of brassica napus L. Planta, 186: $212-218$

TREEBY, M. 2005. Manipulating grapevine annual shoot growth, yield and composition of grapes using fertigation. In: Imas, P. y Price, M. R. (eds.) International Symposium on Fertigation. Beijing: International Potash Institute. Vol. 20, pp. 89

TROLOVE, S.N., WHEELER, S. y SPIERS, A. 2008. A comparison of three methods of magnesium application to grapes. Agronomy New Zealand, 38: 69-76

TROUGHT, M.C.T. y BRAMLEY, R.G.V. 2011. Vineyard variability in Marlborough, New Zealand: Characterising spatial and temporal changes in fruit composition and juice quality in the vineyard. Aust. J. Grape Wine Res., 17: 72-81 
URRETAVIZCAYA, I., SANTESTEBAN, L.G., TISSEYRE, B., GUILLAUME, S., MIRANDA, C. y ROYO, J.B. 2014. Oenological significance of vineyard management zones delineated using early grape sampling. Precision Agriculture, 15: 111-129

U.S.D.A. 2006. Keys to soil taxonomy. Soil survey staff. Natural resources conservation service. Washington, D.C. (Estados Unidos)

USHA, K. y SINGH, B. 2002. Effects of macro and micro-nutrients spray on fruit yield quality of grape (Vitis vinifera L.) cV. Perlette. Proceedings of the International Society on Foliar Nutrition, 594: 197-202

UTZIG, G. y HERRING, L. 1975. Forest harvesting impacts at high elevations: five case studies. B.C. Minist. For., Victoria, British Columbia, pp. 72

VAL, J., MONGE, E., HERAS, L. y ABADÍA, J. 1987. Changes in photosynthetic pigment composition in higher plants as affected by iron nutrition status. J. Plant Nutr., 10: 995-1001

VALDÉS, M.E., MORENO, D., GAMERO, E., URIARTE, D., PRIETO, M.H., MANZANO, R., PICON, J. y INTRIGLIOLO, D.S. 2009. Effects of cluster thinning and irrigation amount on water relations, growth, yield and fruit and wine composition of Tempranillo grapes in Extremadura (Spain). J. Int. Sci. Vigne Vin, 43: 67-76

VELÁZQUEZ, M., del CAMPILLO, M.C. y TORRENT, J. 2004. Temporary flooding increases iron phytoavailability in calcareous Vertisols and Inceptisols. Plant Soil, 266: 195-203

VEILKSAR, S.G., TOMA, S.I. y KREIDMAN, J. 2005. Effect of Fe-containing compounds on the chlorosis manifestation and grape quality. Proc. Int. Workshop Adv. Grapevine Wine Res., Venosa, Italy

VEMPATI, R.K. y LOEPPERT, R.H. 1986. Chemistry and mineralogy of Fe-containing oxides and layer silicates in relation to plant available iron. J. Plant Nutr., 11: 15571572

VIAN, M.A., TOMAO, V., COULOMB, P.O., LACOMBE, J.M. y DANGLES, O. 2006. Comparison of the anthocyanin composition during ripening of Syrah grapes grown using organic or conventional agricultural practices. J. Agric. Food Chem., 54: $5230-5235$

VIETS, F.G. 1972. Water déficits and nutrient availability. In: KOZOLOWSKI, T.T. (ed.). Water deficits and plant growth. Vol 13. New York: Academic Press, pp 217

VOLSCHENK, C.G., HUNTER, J.J. y WATTS, J.E. 1996. The effects of different zinc levels on the growth of grapevines. J. Plant Nutr., 19(6): 827-837

VOSE, P. 1982. Iron nutrition in plants: A world overview. J. Plant Nutr., 5: 233-249 
WALKER, E.L y CONNOLLY, E.L. 2008. Time to pump: iron-deficiency signaling mechanism of higher plants. Deparment of Biology, University of Masachusetts, 11: $530-535$

WALLACE, A. 1983. The third decade of synthetic chelating agents in plant nutrition. J. Plant Nutr., 6: 425-562

WALTER-SHEA, E.A., NORMAN, J.M., BLAD, B.L. y ROBINSON, B.F. 1991. Leaf reflectance and transmittance in soybean and corn. Agron. J., 83: 631-636

WANG, H. y JIN, J.Y. 2005. Photosynthetic rate, chlorophyll fluorescence parameters, and lipid peroxidation of maize leaves as affected by zinc deficiency. Photosynthetica, 43(4): 591-596

WATERS, B.M., BLEVINS, D.G. y EIDE, D.J. 2002. Characterization of FRO1, a pea ferricchelate reductase involved in root iron acquisition. Plant Physiol., 129: 85-94

WATSON, M.B. y MALMBERG, R.L. 1996. Regulation of Arabidopsis thaliana (L.) Heynh arginine decarboxylase by potassium deficiency stress. Plant Physiol., 111: 10771083

WEI, L.C., LOEPPERT, R.H. y OCUMPAUGH, W.R. 1997. Fe-deficiency stress response in Fe-deficiency resistant and susceptible subterranean clover: importance of induced $\mathrm{H}^{+}$release. J. Exp. Bot., 48: 239-246

WELCH, R.M. y NORWELL, W.A. 1993. Growth and nutrient uptake by barley (Hordeum vulgare L. cv Herta): studies using an N-(2-hydroxyethyl)ethylenedinitrilotriacetic acid-buffered nutrient solution technique. II. Role of zinc in the uptake and root leakage of mineral nutrients. Plant Physiol., 101: 627-631

WELCH, R. M., NORWELL, W.A., SCHAEFER, S.C., SHAFT, J.E. y KOCHIAN, L.V. 1993. Induction of iron(III) and copper(II) reduction in pea (Pisum satirum L.) roots by Fe and Cu status: Does the root-cell plasmalemma Fe(III)-chelate reductase perform a general role in regulating cation uptake? Planta, 190: 555-561

WELCH, R. M. 1995. Micronutrient nutrition of plants. Plant Sci., 14: 49-82

WELKIE, G.W. y MILLER, G.W. 1993. Plant iron uptake physiology by nonsiderophore system. pp 345-369. En: Iron Chelation in Plants and Soil Microorganisms. Academic Press. San Diego, CA, USA

WENG, X.Y., ZHENG, C.J., XU, H.X. y SUN, J.Y. 2007. Characteristics of photosynthesis and functions of the water-water cycle in rice (Oryza sativa) leaves in response to potassium deficiency. Physiol. Plantarum, 131: 614-621

WHITE, P.J. 1998. Calcium channels in the plasma membrane of root cells. Ann. Bot., 81: 173-183 
WIERSMA, J.V. 2010. Nirate-induced iron deficiency in soybean varieties with varying iron-stress responses. Agron. J., 102: 1738-1744

WITTE, C.P., ROSSO, M.G. y ROMEIS, T. 2005. Identification of three urease accessory proteins that are required for urease activation in Arabidopsis. Plant physiol., 139(3): 1155-1162

WOLF, T.K., HEASELER, C.W. y BERGMAN, E.L. 1983. Growth and foliar elemental composition of seyvel blanc grapevines as affected by four nutrient solution concentration of nitrogen, potassium and magnesium. Am. J. Enol. Vitic., 34: 271277

YANGÜAS, R, del CAMPILLO, M.C. y TORRENT, J. 1997. Predicción de la clorosis férrica en melocotonero cultivado en suelos calcáreos. Agrochimica, 41: 120-129

YAÑEZ, J. 1989. Análisis de suelos y su interpretación. Horticultura, 49: 75-84

YI, Y. y GUERINOT, M.L. 1996. Genetic evidence that induction of root Fe(III) chelate reductase activity is necessary for iron uptake under iron deficiency. Plant J., 10: 835-844

ZAHARIEVA, T.B. y ABADÍA, J. 2003. Iron deficiency enhances the levels of ascorbate, glutathione, and related enzimes in sugar beet roots. Protoplasma, 221: 269-275

ZAHARIEVA, T.B., GOGORCENA, Y. y ABADÍA, J. 2004. Dynamics of metabolic responses to iron deficiency in sugar beet roots. Plant Science, 166: 1045-1050

ZAHARIEVA, T.B. y RÖMHELD, V. 2000. Specific $\mathrm{Fe}^{2+}$ uptake system in strategy I plant inducible under Fe deficiency. J. Plant Nutr., 23: 1733-1744

ZARCO-TEJADA, P.J., BERJÓN, A., LÓPEZ-LOZANO, R., MILLER, J.R., MARTÍN, P., CACHORRO, V., GONZÁLEZ, M.R. y FRUTOS, A. 2005. Assessing vineyard condition with hyperspectral indices: Leaf and canopy reflectance simulation in a row-structured discontinuous canopy. Remote Sens. Environ., 99: 271-287

ZARCO-TEJADA, P.J., CATALINA, A., GONZÁLEZ, M.R. y MARTíN, P. 2013a. Relationships between net photosynthesis and steady-state chlorophyll fluorescence retrieved from airborne hyperspectral imagery. Remote Sens. Environ., 136: 247-258

ZARCO-TEJADA, P.J., GONZÁLEZ DUGO, V., y BERNI, J.A.J. 2012. Fluorescence, temperature and narrowband indices acquired from a UAV platform for water stress detection using a micro-hyperspectral imager and a thermal camera. Remote Sens. Environ. t, 117: 322-337

ZARCO-TEJADA, P.J, GUILLÉN-CLIMENT, M.L., HERNÁNDEZ-CLEMENTE, R., CATALINA, A., GONZÁLEZ, M.R. y MARTÍN, P. 2013b. Estimating leaf carotenoid content in vineyards using high resolution hyperspectral imagery acquired from an unmanned aerial vehicle (UAV). Agricultural and Forest Meteorology, 171: 281-294 
ZATLOUKALOVÁ, A., LOŠÁK, T., HLUŠEK, J., PAVLOUŠEK, P., SEDLÁČEK, M. y FILIPČíK, R. 2014. The effect of soil and foliar applications of magnesium fertilisers on yields and quality of vine (Vitis vinifera, L.) grapes. Acta universitatis agriculturae et silviculturae mendelianae brunensis, 59(3): 221-226.

ZERIHUN, A. y TREEBY, M.T. 2002. Biomass distribution and nitrate assimilation in response to $\mathrm{N}$ supply for Vitis vinifera L. cv. Cabernet Sauvignon on five Vitis rootstock genotypes. Aust. J. Grape Wine Res., 8:157-162

ZHAO, H. y EIDE, D. 1996. The yeast ZRT1 gene encodes the zinc transporter protein of a high-affinity uptake system induced by zinc limitation. Proceedings of the National Academy of Sciences of the United States of America, 93: 2454-2458

ZHAO, H., WU, L., CHAI, T., ZHANG, Y., TAN, J. y MA, S. 2012. The effects of copper, manganese and zinc on plant growth and elemental accumulation in the manganese-hyperaccumulator Phytolacca americana. J. plant physiol., 169(13), $1243-1252$

ZHENG, S., HE, Y., ARAKAWA, Y., MASAOKA, Y. y TANG, C. 2005. A copper-deficiency -induced root reductase is different from the iron-deficiency-induced one in red clover (Trifolium pratenseL.). Plant Soil, 273: 69-76

ZHENG, L., HUANG, F. y NARSAI, R., WU, J., GIRAUD, E., HE, F., CHENG, L., WANG, F., WU, P., WHELAN, J. y SHOU, H. 2009. Physiological and transcriptome analysis of iron and phosphorus interaction in rice seedlings. Plant Physiol., 151: 262-274

ZOCCHI, G. y COCUCCI, S. 1990. Fe uptake mechanism in Fe-efficient cucumber roots. Plant physiol., 92: 908-911

ZUO, Y. y ZHANG, F. 2008. Effect of peanut mixed cropping with gramineous species on micronutrient concentrations and iron chlorosis of peanut plants grown in a calcareous soil. Plant Soil, 306: 23-36 